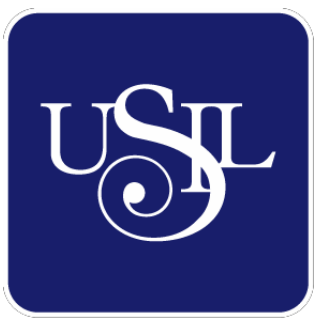

UNIVERSIDAD

SAN IGNACIO

DE LOYOLA

ESCUELA DE POSTGRADO

\title{
PLAN DE NEGOCIO: PRODUCCIÓN GASTRONÓMICA SALUDABLE E IMPLEMENTACIÓN DEL SERVICIO DE DELIVERY DIRIGIDO A CONSUMIDORES FINALES EN LA CIUDAD DE AREQUIPA
}

Trabajo de investigación para optar el grado de:

MABEL KATHERINE RIVEROS APAZA

Maestro en Ciencias Empresariales con Mención en Gestión de Proyectos

BRUNELLA TALLEDO MONROY

Maestro en Ciencias Empresariales con Mención en Gestión de Proyectos

Asesor:

Dr. Edmundo Casavilca Maldonado

Lima - Perú

2019 


\section{DEDICATORIAS}

A mi madre y mi abuela, quienes son mi ejemplo y motivación. Ellas me enseñaron lo que es la fortaleza y que, aun siendo mujeres pudieron con gran esfuerzo y trabajo superar todos los obstáculos que la vida les puso en el camino y lograr lo que se propusieron. Las amo y admiro!

Mabel Riveros Apaza

Este es el momento perfecto para decir una vez más:

¡Gracias Dios Mío!

A mis padres, Rossana y Coco; por su apoyo constante e incondicional, siendo en mi vida fuente de amor infinito.

A mi abuelo, mi motivación más grande día a día; ahora sí, hasta donde estés: ¡promesa cumplida viejito lindo!

Brunella Talledo Monroy 


\section{RESUMEN EJECUTIVO}

Este plan de negocios, surge de la necesidad que presenta actualmente el mercado gastronómico saludable Arequipeño; enfocándonos en generar una propuesta de valor para el cliente, que nos permita satisfacer sus requerimientos alimenticios y saludables.

Es relevante mencionar, que esta idea de negocio también tiene como eje principal la tendencia actual sobre el cuidado en la alimentación de las personas quienes buscan mejorar su calidad de vida y prevenir problemas de salud como consecuencia de la obesidad y el sobrepeso.

FIT FOOD, 100\% Fit; está dirigido a mujeres que buscan cuidar su salud y alimentarse de forma balanceada y adecuada, pero que no tienen el tiempo ni el conocimiento suficiente para lograrlo; es así que nuestra propuesta contará con asesoría nutricional para lograr este objetivo, sin que resulte monótono, brindando variedad de opciones y productos saludables para su alimentación diaria; a su vez, desarrollaremos el servicio de delivery hacia el lugar solicitado, satisfaciendo así una de las mayores necesidades actuales: alimentarse de forma saludable, la que por falta de tiempo ha sido descuidada.

La inversión total para la realización del proyecto es de S/ 79,128.16, la cual será financiada por aportes propios. Dentro de la viabilidad económica FIT FOOD, 100\% Fit, presenta un VAN de S/ $12,246.91$ y una TIR de $23.89 \%$, lo que hace que nos indica que es un proyecto rentable.

FIT FOOD, 100\% Fit, tendrá como insignia en sus colaboradores la calidad en el trabajo, el servicio al cliente y la puntualidad; usando estos principios como una alianza sólida para lograr la satisfacción del cliente con relación a la marca. 


\section{Índice}

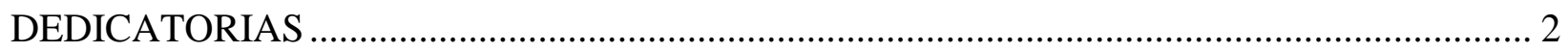

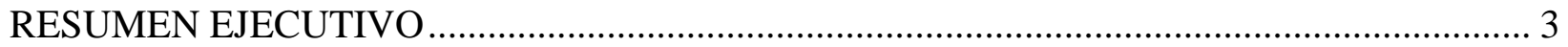

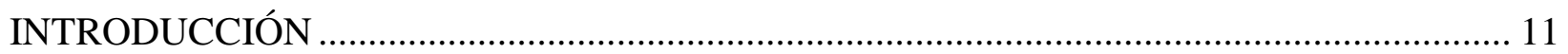

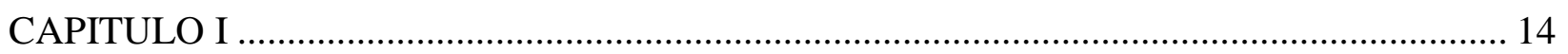

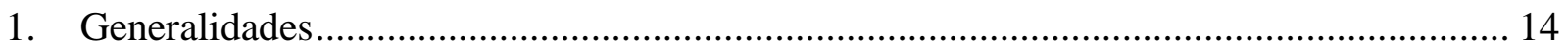

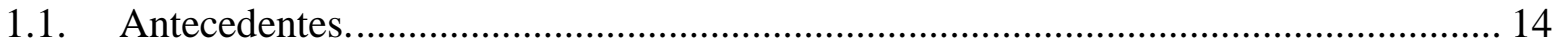

1.1.1. Sobrepeso y Obesidad ............................................................................. 15

1.1.2. Datos sobre el sobrepeso y la obesidad ........................................................... 15

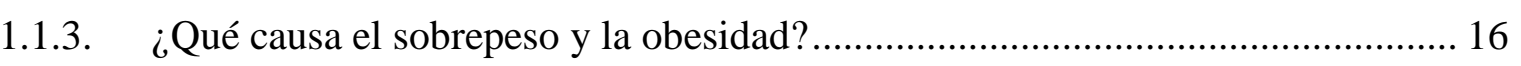

1.1.4. ¿Cómo pueden reducirse el sobrepeso y la obesidad? ....................................... 17

1.1.5. Índices de obesidad en el mundo....................................................................... 18

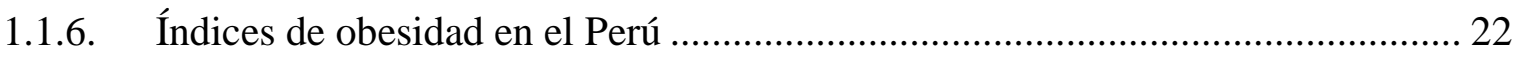

1.1.7. Indicadores nutricionales en Arequipa ......................................................... 25

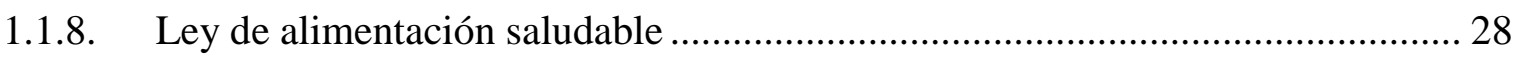

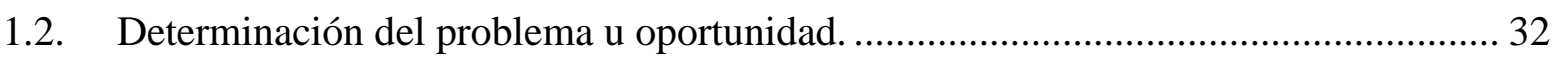

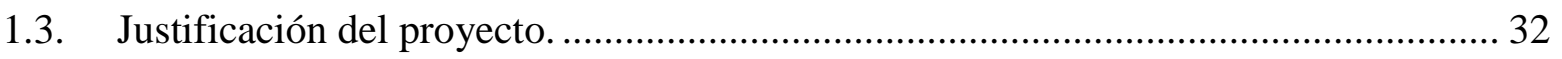

1.4. Objetivos generales y específicos....................................................................... 33

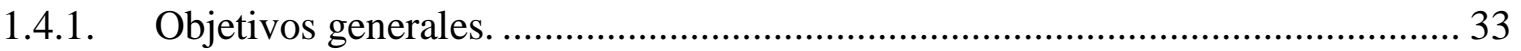

1.4.2. Objetivos específicos................................................................................. 33

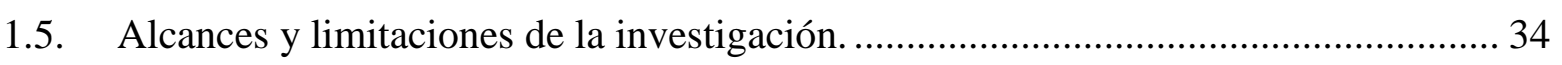

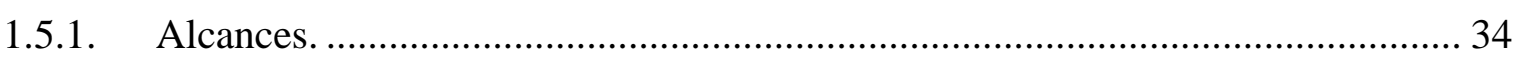

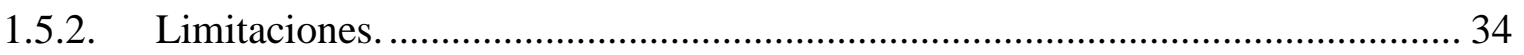

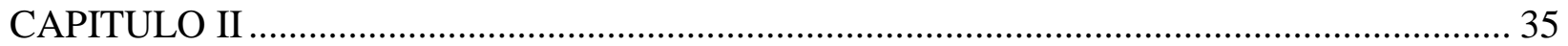

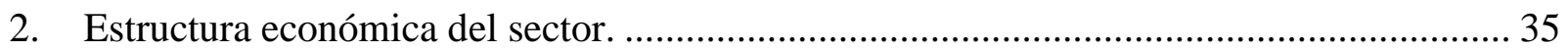

2.1. Descripción del Estado Actual de la Industria Peruana................................................. 35

2.1.1. Segmentación de la industria........................................................................ 44

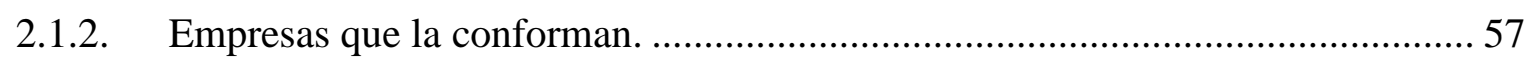

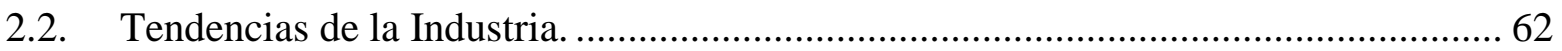

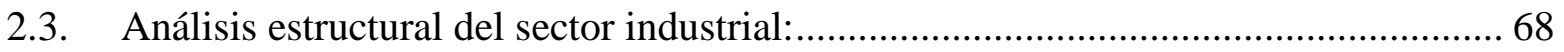

2.3.1. Desarrollo de las fuerzas competitivas de Porter: ............................................... 71 


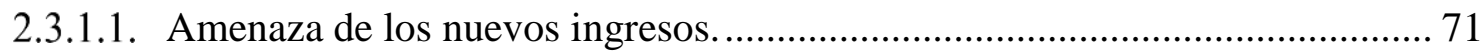

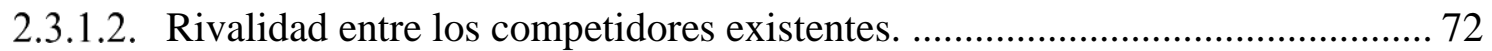

2.3.1.3. Amenaza de servicios o productos sustitutos. ............................................. 74

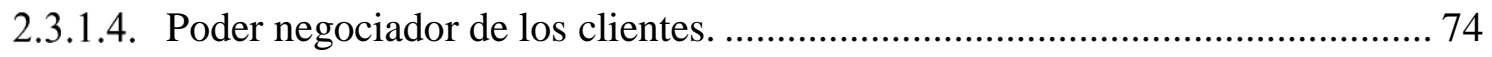

2.3.1.5. Poder negociador de los proveedores..................................................... 75

2.3.1.6. Atractividad del mercado según las cinco fuerzas de Porter........................... 76

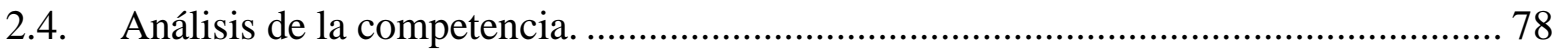

2.4.1. Caracterización de los competidores que ofrecen productos o servicios similares. 81

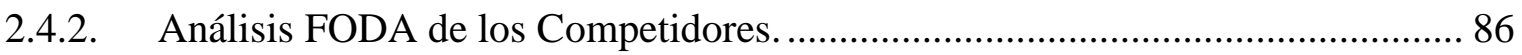

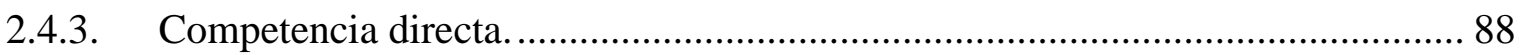

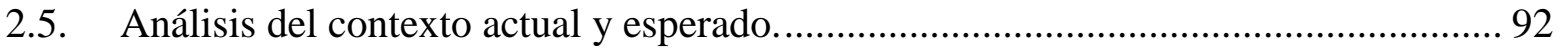

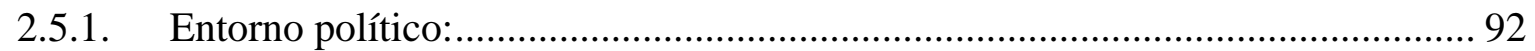

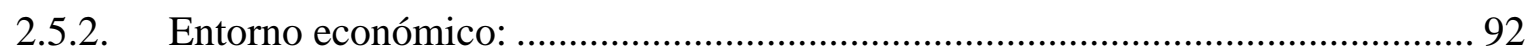

2.5.3. Entorno social - demográfico: .............................................................. 93

2.5.4. Entorno cultural:.............................................................................. 93

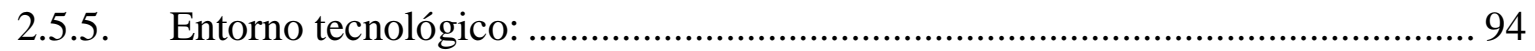

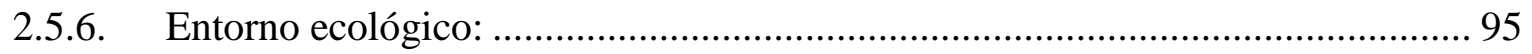

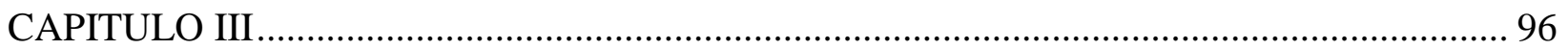

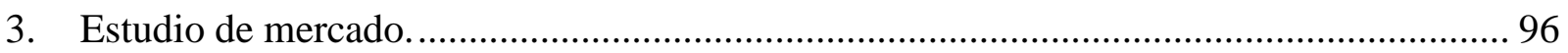

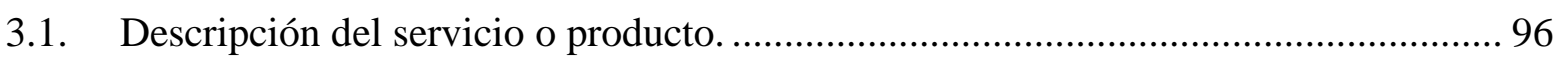

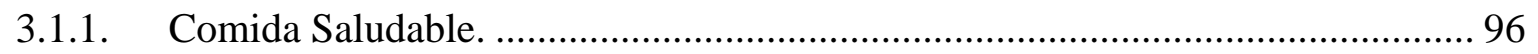

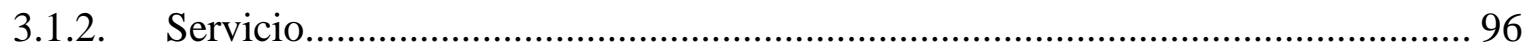

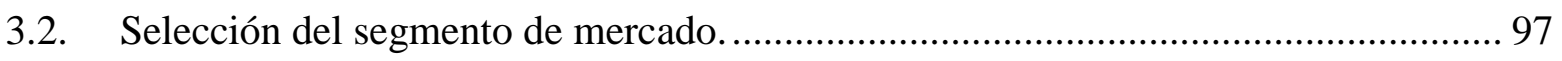

3.3. Investigación Cuantitativa. ................................................................................. 100

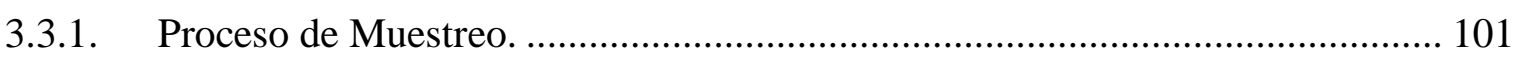

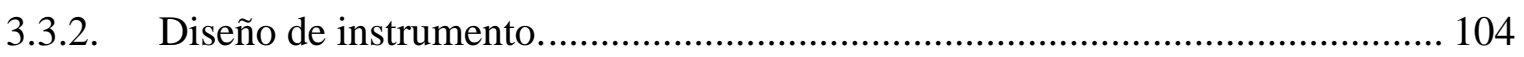

3.3.3. Análisis y procesamiento de datos. .................................................................. 104

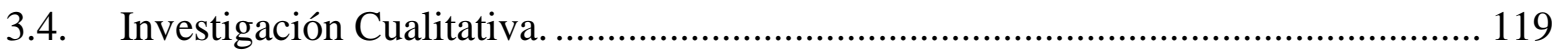

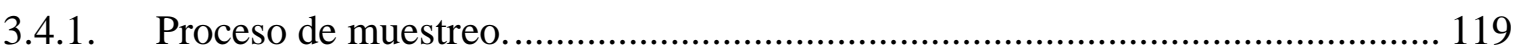

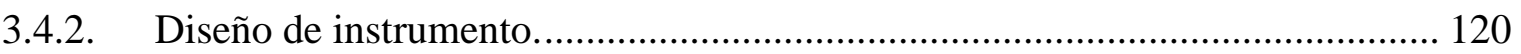

3.4.3. Análisis y procesamiento de datos. ......................................................... 120

3.5. Conclusiones y recomendaciones del Estudio Cualitativo y Cuantitativo. .............. 122 
3.6. Perfil del consumidor tipo y sus variantes........................................................... 123

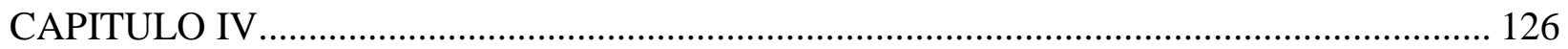

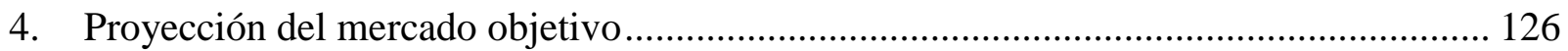

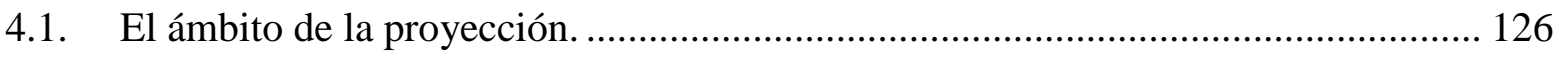

4.2. Selección del método de proyección. …………………......................................... 126

4.2.1. Mercado potencial..................................................................................... 126

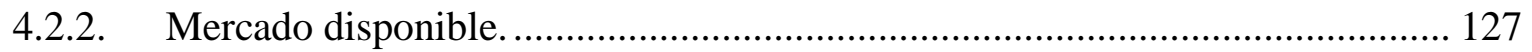

4.2.3. Mercado efectivo................................................................................ 128

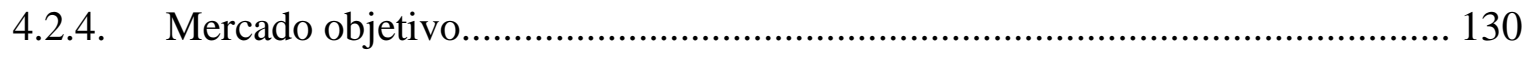

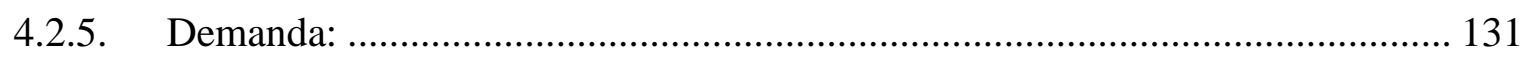

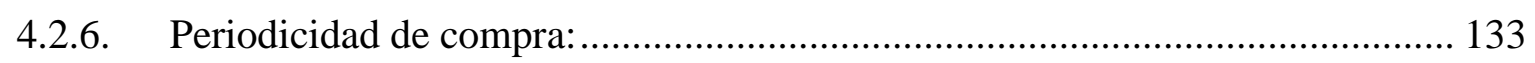

4.2.7. Proyección de Ventas según demanda diaria ..................................................... 134

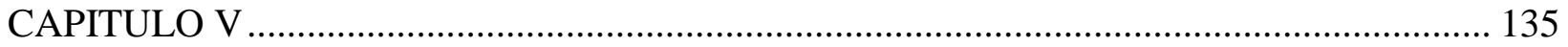

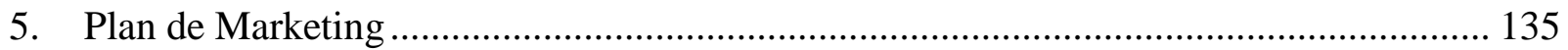

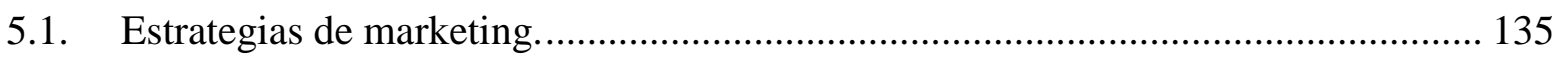

5.1.1. Estrategia de producto.............................................................................. 135

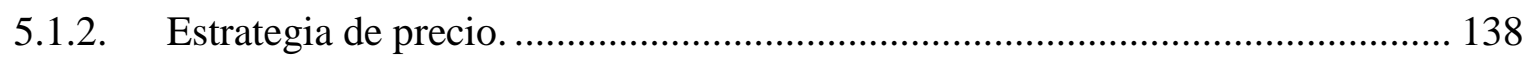

5.1.3. Estrategia de plaza y distribución.................................................................... 140

5.1.4. Estrategia de promoción y publicidad............................................................. 143

5.1.4.1. Estrategia de promoción ............................................................................... 143

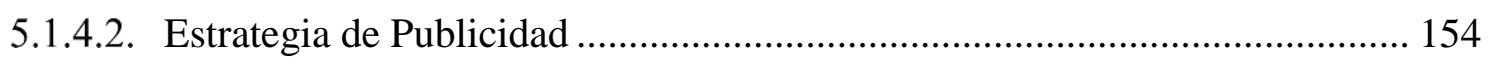

5.1.5. Estrategia de persona.................................................................................. 160

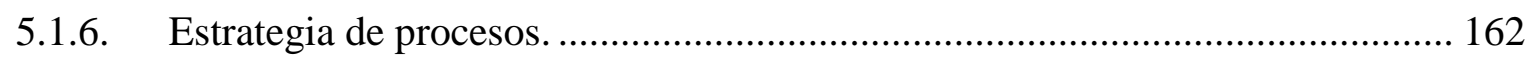

5.1.7. Estrategia de presencia Física. ……………………………………........... 165

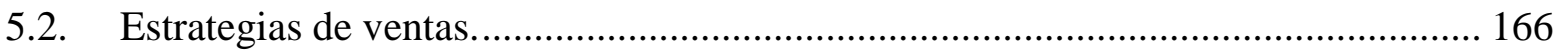

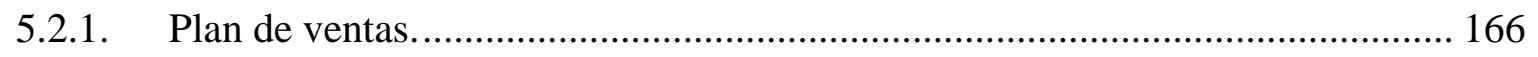

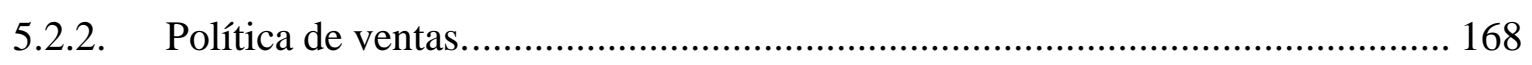

5.2.3. Política de servicios y garantías. ........................................................................ 169

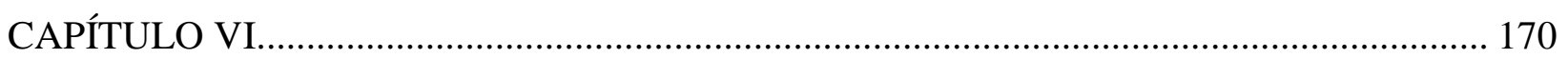

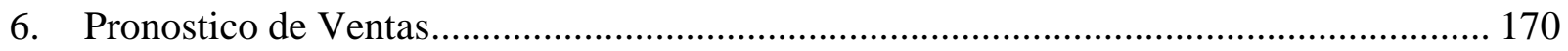

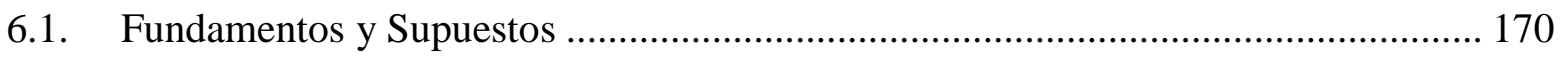

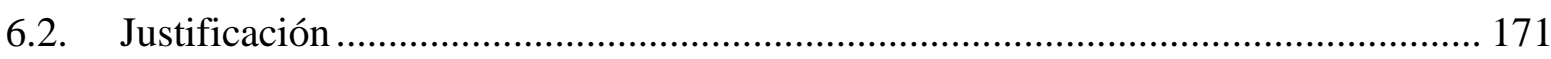


6.3. Análisis de los riesgos y aspectos críticos que impactan en el pronóstico 172

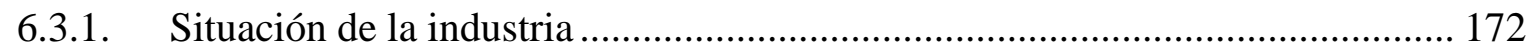

6.3.2. Aparición de nuevos competidores ............................................................ 172

6.3.3. Deficiencia en la calidad de servicio........................................................ 172

6.3.4. Variabilidad en las ventas .................................................................... 173

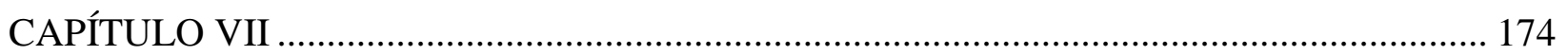

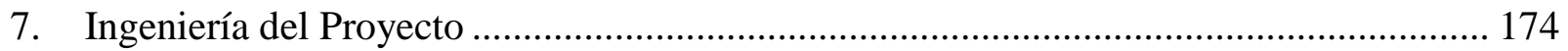

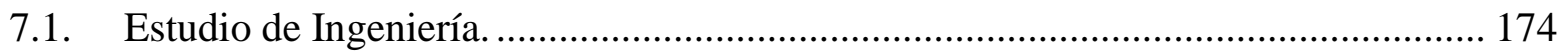

7.1.1. Modelamiento y selección de procesos productivos.................................... 181

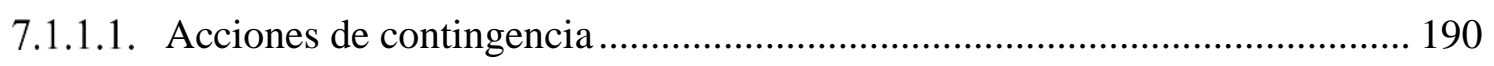

7.1.2. Selección de equipamiento.................................................................... 191

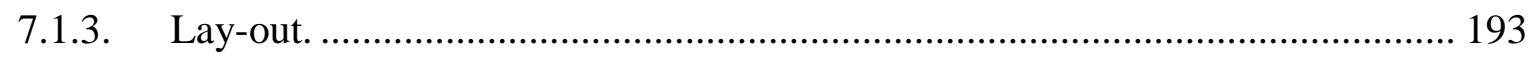

7.2. Distribución de equipos y maquinarias. ............................................................. 196

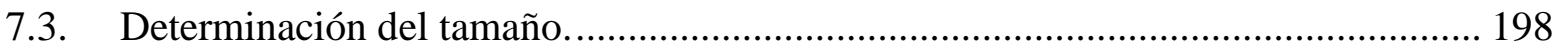

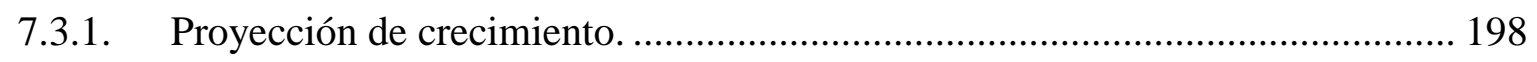

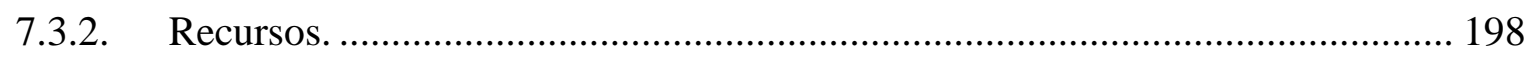

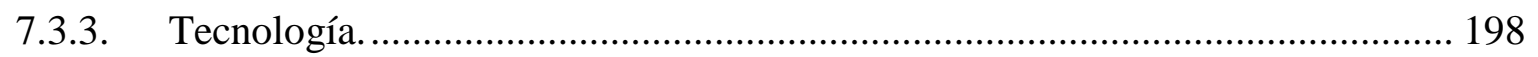

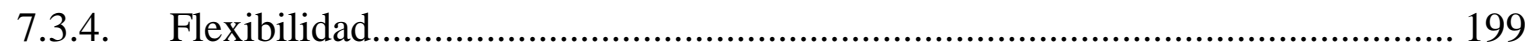

7.3.5. Selección de tamaño ideal. ........................................................................ 199

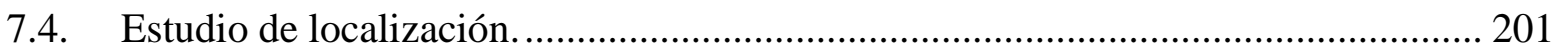

7.4.1. Definición de factores de localización. ...................................................... 202

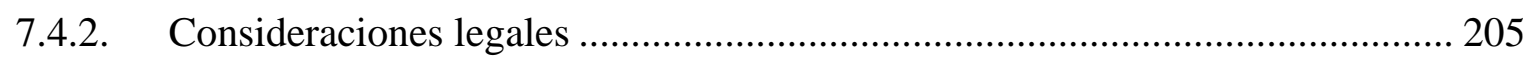

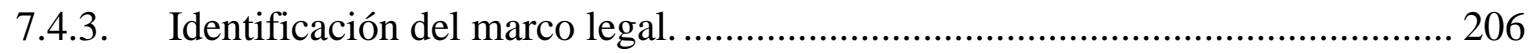

7.4.4. Ordenamiento jurídico de la empresa............................................................ 206

7.5. Determinación de la localización óptima. ........................................................ 218

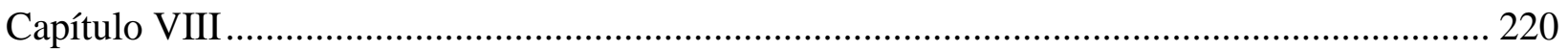

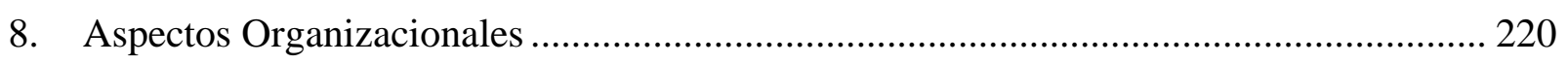

8.1. Caracterización de la cultura organizacional deseada. ........................................... 220

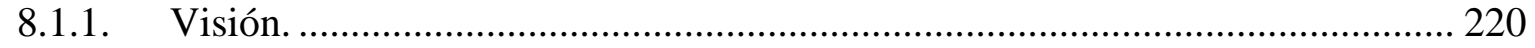

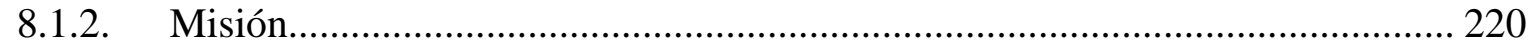

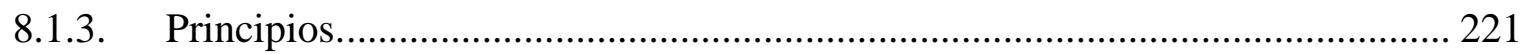

8.2. Formulación de estrategias del negocio......................................................... 222 
8.3. Determinación de las ventajas competitivas críticas......................................... 224

8.4. Diseño de la estructura organizacional deseada............................................ 225

8.5. Diseño de los perfiles de puestos claves............................................................ 226

8.6. Remuneraciones, compensaciones e incentivos........................................... 232

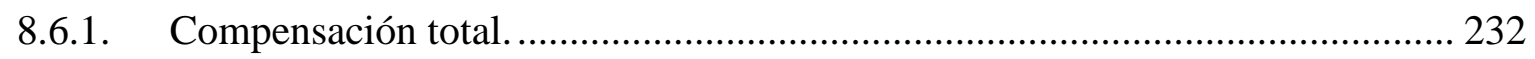

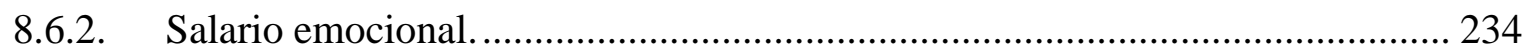

8.6.3. Remuneración del personal ................................................................. 235

8.7. Política de Recursos Humanos ............................................................................ 243

8.7.1. Políticas de integración ............................................................................ 244

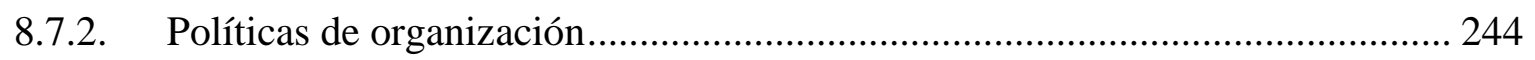

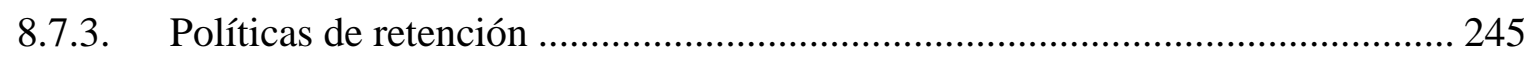

8.7.4. Políticas de desarrollo ............................................................................... 245

8.7.5. Políticas de auditoria .......................................................................... 246

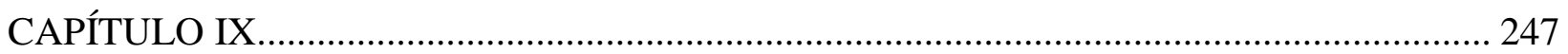

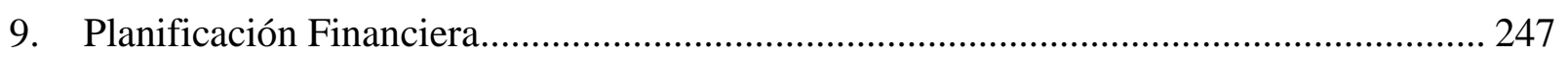

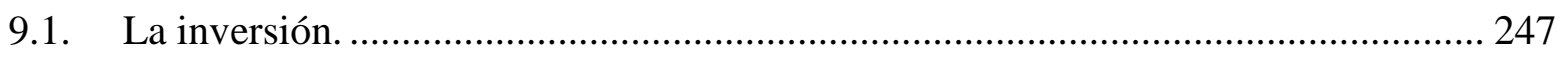

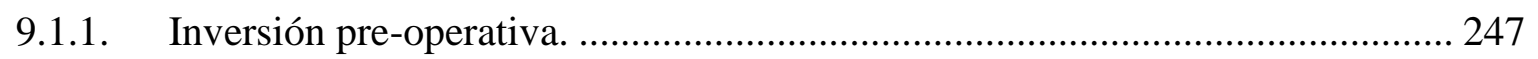

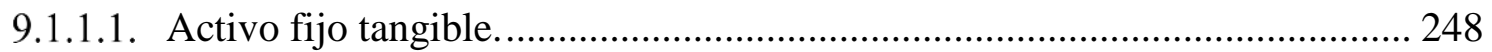

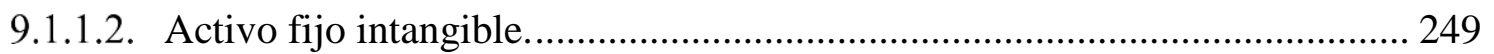

9.1.2. Inversión en capital de trabajo. ............................................................. 250

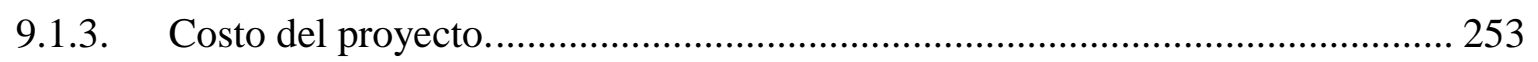

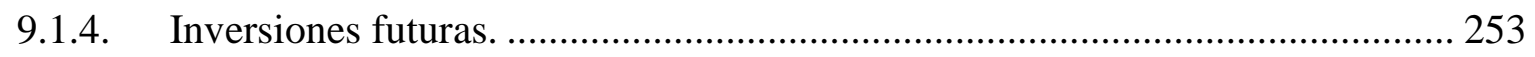

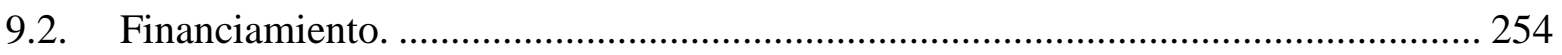

9.2.1. Capital y costo de oportunidad.................................................................... 255

9.3. Presupuesto base............................................................................................ 264

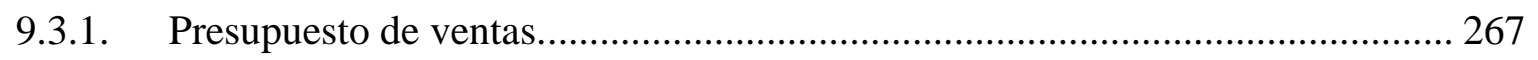

9.3.2. Presupuesto de costo de producción............................................................. 272

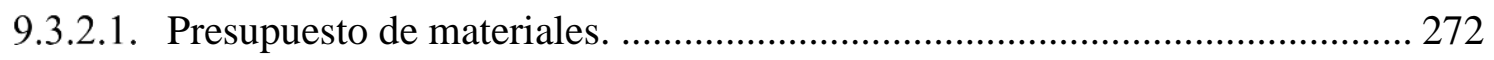

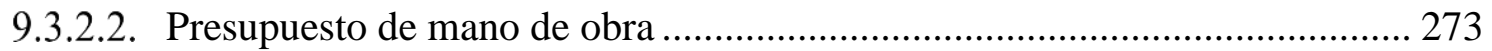

9.3.2.3. Presupuesto de gastos indirectos de fabricación. ...................................... 275

9.3.3. Presupuesto del costo de ventas. ............................................................. 276

9.3.4. Presupuesto de gastos administrativos..................................................... 277 
9.3.5. Presupuesto de marketing y ventas ............................................................. 280

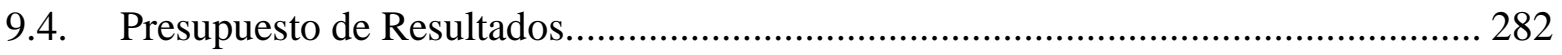

9.4.1. Estado de ganancias y pérdidas proyectado.................................................... 282

9.4.2. Balance general proyectado .................................................................... 283

9.4.3. Flujo de caja proyectado. ……………………...................................... 286

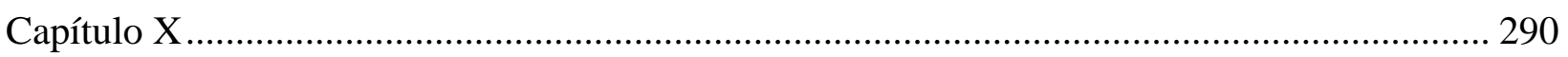

10. Evaluación Económica Financiera........................................................................... 290

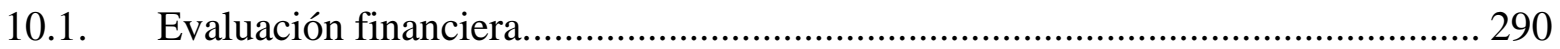

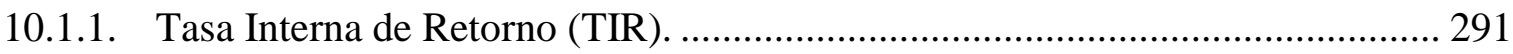

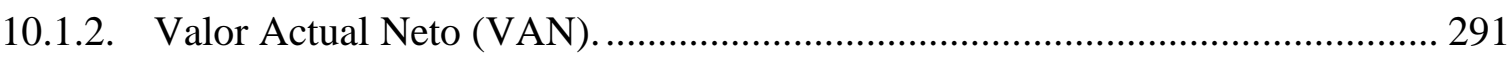

10.1.3. Retorno sobre el patrimonio (ROE), ............................................................ 292

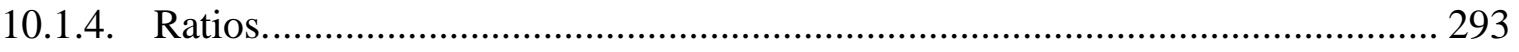

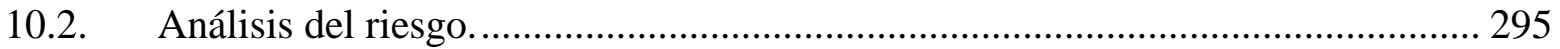

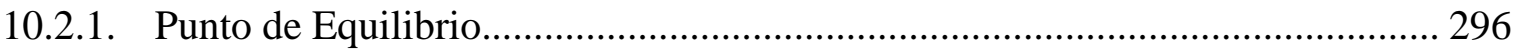

10.2.2. Análisis de sensibilidad................................................................................ 297

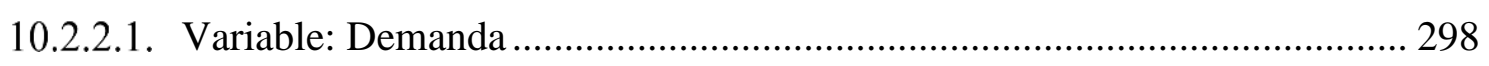

10.2.2.2. Variable: Costo Materia Prima (expresado en soles), ……………….......... 299

10.2.2.3. Variable: costo mano de obra ..................................................................... 299

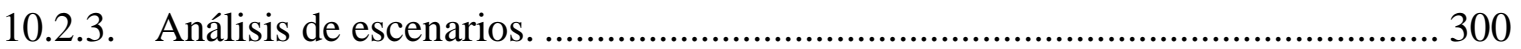

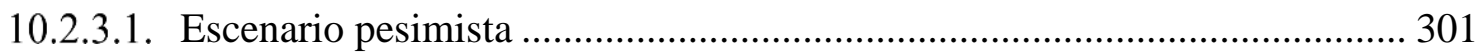

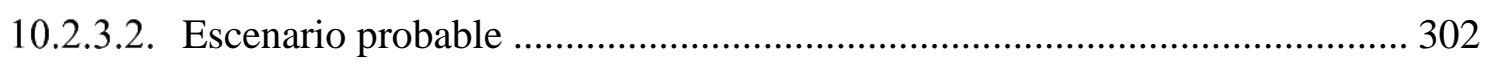

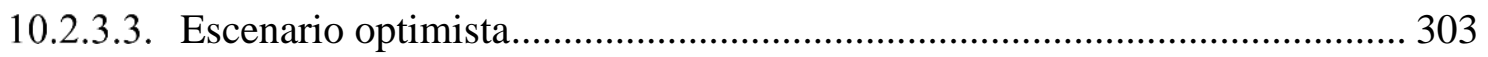

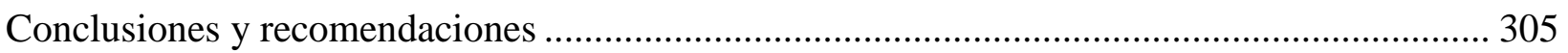

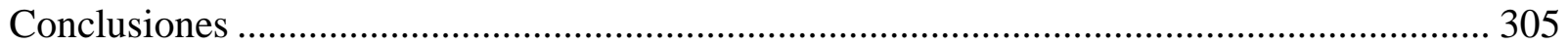

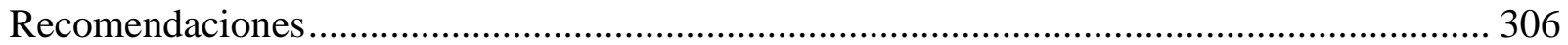

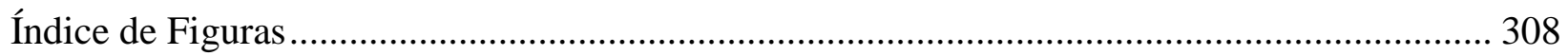

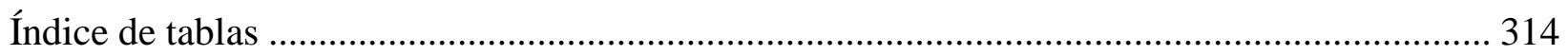

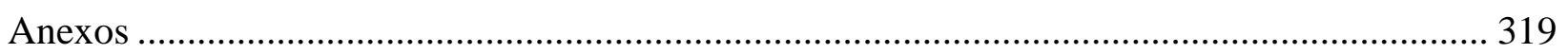

Anexo I Resultados datos socioeconómicos APEIM - NSE 2018 ………………………...... 319

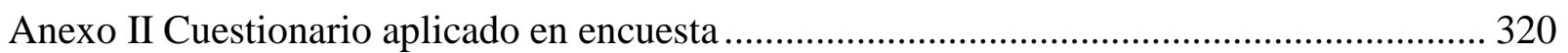

Anexo III Guía de preguntas Focus Group - comida saludable ............................................ 325

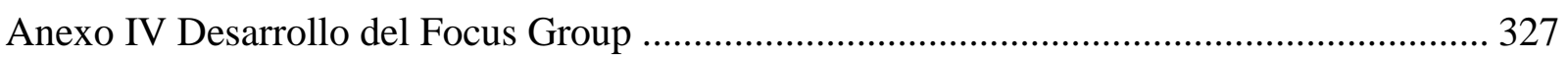


Anexo V Elementos y fotos del desarrollo del Focus Group ........................................... 344

Anexo VI Detalle de la inversión en activo fijo tangible ................................................... 347

Anexo VII Costeo de materia prima y materiales varios para un menú saludable ................. 348

Anexo VIII Diseños de envases ecológicos QAYA........................................................ 350

Anexo IX Rentabilidad del bono de Estados Unidos 5 años............................................. 351

Anexo X Rendimiento promedio de la industria DJI......................................................... 353

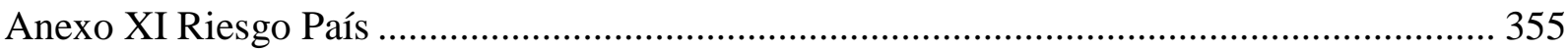

Anexo XII Inflación promedio anual de Estados Unidos y Perú .......................................... 356

Anexo XIII Betas promedio por sector ....................................................................... 357

Anexo XIV Valores nutricionales de opciones de entradas para el menú saludable. ............ 358

Anexo XV Valores nutricionales de opciones de platos de fondo para el menú saludable. ... 359

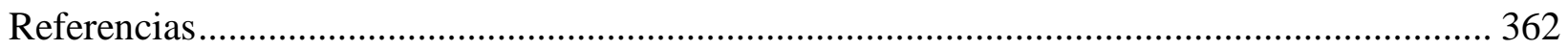




\section{INTRODUCCIÓN}

El presente trabajo de investigación es un plan de negocios sobre producción gastronómica saludable e implementación del servicio de delivery en la ciudad de Arequipa; este proyecto estará dedicado a ofrecer al mercado una variedad de comidas balanceadas y saludables, que a su vez da la facilidad de hacer una entrega personalizada del pedido a sus clientes.

Siendo una opción de alimentación saludable en un mercado lleno de comidas al paso (comida chatarra) y bebidas artificiales, que son dañinas para la salud. Esta idea de negocio nace a raíz de la preocupación por la realidad actual alimenticia en la ciudad de Arequipa, por los altos índices de obesidad y sobrepeso, el sedentarismo y las enfermedades que esto conlleva.

Es así como, sin perder el buen sabor, y las diferentes propiedades de los insumos a utilizar, brindaremos al consumidor un producto de calidad para mejorar su estilo de vida y su salud.

El presente trabajo a desarrollar consta de diez capítulos, en los cuales iremos realizando el estudio de investigación de la siguiente manera:

- El capítulo I: Generalidades, conoceremos la necesidad del problema actual y lo

justificaremos como una oportunidad de negocio, enfocándonos en los objetivos del proyecto $\mathrm{y}$ teniendo en cuenta sus alcances y limitaciones.

- El capítulo II: Estructura económica del sector, realizaremos la descripción del estado actual de la industria gastronómica en Arequipa, analizaremos las tendencias y las empresas competidoras en el rubro; así como la determinación de la cuota de mercado a través de la elaboración de la Matriz de Perfil Competitivo, teniendo como resultado el análisis del contexto actual y el esperado para nuestro negocio. 
- El capítulo III: Estudio de mercado, se hará la descripción de nuestro servicio, y conoceremos nuestro segmento de mercado, el cuál será sometido a una investigación cualitativa y cuantitativa; para determinar el nivel de aceptabilidad de nuestro proyecto.

- El capítulo IV: Proyección del mercado, nos permitirá conocer la dimensión del mercado y el método de proyección que usaremos, definiendo nuestro mercado objetivo, potencial, disponible y efectivo.

- El capítulo V: Plan de marketing, aquí enfocaremos nuestras diferentes estrategias a utilizar, basándonos en el precio, el producto, la plaza, la distribución, la publicidad, los procesos, las ventas, y las políticas que aplicaremos a nuestro servicio y las garantías del mismo.

- El capítulo VI: Pronóstico de ventas, justificaremos nuestros fundamentos y realizaremos el análisis de riesgo que podría impactar sobre nuestros pronósticos.

- El capítulo VII: Ingeniería del proyecto, realizaremos todo un estudio de ingeniería enfocado a nuestro negocio, el cual nos permitirá cubrir todos los requerimientos a través del uso de recursos y tecnologías, así mismo en este capítulo veremos la distribución de los equipos y maquinarias a utilizar; y finalmente el estudio de localización adecuada para el negocio, y todas las consideraciones legales a tener en cuenta para el mismo.

- El capítulo VIII: Aspectos organizacionales, nos permitirá determinar la cultura organizacional deseada nuestro negocio, así como establecer nuestra misión, visión y los principios con los cuáles regiremos nuestro proyecto y de esta manera realizaremos el diseño de los perfiles de puestos existentes y la política de recursos humanos.

- El capítulo IX: Planificación financiera, en este capítulo desarrollaremos todos nuestros presupuestos y los costos que tendrá el proyecto, así como determinar la inversión del mismo; 
y finalmente obtendremos un estado de ganancias y pérdidas que vendrá acompañado del balance proyectado.

- El capítulo X: Evaluación económico financiera, aquí realizaremos las diferentes evaluaciones financieras y los análisis correspondientes, tales como: punto de equilibrio, sensibilidad y análisis de escenarios.

Finalmente, este estudio de investigación nos indicará las conclusiones y las recomendaciones a tener en cuenta para el desarrollo de este proyecto. 


\section{CAPITULO I}

\section{Generalidades}

\subsection{Antecedentes.}

En la ciudad de Arequipa existe un porcentaje de población, en continuo ascenso; que se preocupa por tener una vida saludable, enfocándose en mejorar su alimentación y en el incremento de la actividad física diaria. Muchas veces el tiempo se convierte en un obstáculo para lograr su objetivo, particularmente el de la alimentación, es por esto que buscan en la calle opciones de comida saludables para ahorrar tiempo sin sacrificar sus objetivos.

Es así como nos encontramos frente a una tendencia creciente hacia la comida saludable y rápida, que sea rica en nutrientes y en las proporciones adecuadas según los requerimientos de nuestro organismo. De este modo en la ciudad de Arequipa se vienen desarrollando negocios relacionados a la gastronomía y servicios afines, que ofrecen comida balanceada, saludable, natural e inclusive personalizada según las necesidades nutricionales de cada persona.

En el mercado actual, vemos que se está introduciendo el servicio de Delivery; ya que se hacen entregas de comidas y meriendas a centros de trabajo, gimnasios, universidades y hogares en los cuales la mayoría de sus integrantes no permanecen en casa y requieren satisfacer sus necesidades de alimentación adecuada.

Así mismo, podemos decir que la mayoría de servicios Delivery's enfocados en temas de nutrición se desarrollan desde internet, usando plataformas tales como: Whatsapp, Instagram, Facebook. 


\subsubsection{Sobrepeso y Obesidad}

Según la OMS el sobrepeso y la obesidad pueden definirse como una acumulación de grasa en el organismo en niveles fuera de lo normal, o hasta excesivos que podrían perjudicar la salud.

El índice de masa corporal (IMC) es un indicador que se obtienen de relacionar el peso y la talla, es de utilidad para identificar cuando un adulto se encuentra con sobrepeso u obesidad. Para su cálculo dividimos el peso en kilos por el cuadrado de la talla en metros $\left(\mathrm{kg} / \mathrm{m}^{2}\right)$.

Para los adultos, la OMS delimita el sobrepeso cuando el IMC de la persona es igual o superior a 25 y la obesidad cuando el IMC es igual o superior a 30.

El IMC es el indicador más útil para determinar el sobrepeso y la obesidad en la población, pues no varía según el sexo ni la edad, sin embargo se puede aplicar solo en adultos. Para los niños, la talla y el peso no es suficiente es necesario incluir también la edad para establecer de forma correcta si hay sobrepeso u obesidad

\subsubsection{Datos sobre el sobrepeso y la obesidad}

La OMS afirma que:

- $\quad$ En el año 2016, más de 1,900 millones de personas en edad adulta a partir de los 18 años sufrían problemas de sobrepeso, y de ellos, se consideraban obesos un número mayor a 650 millones.

- $\quad$ En 2016, el 39\% de los adultos a partir de 18 años, en similar porcentaje de hombres y mujeres, $39 \%$ y $40 \%$ respectivamente, sufrían de sobrepeso. 
- Un $13 \%$ de la población adulta en el año 2016, $11 \%$ de hombres y $15 \%$ mujeres, eran obesos.

- Las cifras de obesidad y sobrepeso en la población han llegado casi a triplicarse entre 1975 y 2006.

A nivel mundial, son el sobrepeso y la obesidad lo que causan mayor cantidad de muertes que la desnutrición. Actualmente, encontramos mayor cantidad de personas obesas que con peso inferior al normal, siendo esto una realidad que se da en todos los países del mundo, excepto en territorios de Asia y África subsahariana.

\subsection{3. ¿Qué causa el sobrepeso y la obesidad?}

Llevar una vida equilibrada implica gastar más calorías de las que consumimos o en similar cantidad, en promedio; sin embargo, el desequilibrio causado por un escenario inverso al ideal, es la principal causa del sobrepeso y la obesidad. Mundialmente tenemos los siguientes escenarios:

1. Incremento en la ingesta de alimentos de alto contenido calórico que son ricos en grasa; y

2. Disminución de la actividad física debido a la vida sedentaria que está adoptando cada vez más la población, ya sea por falta de tiempo o comodidad.

Es de suponerse que estos cambios en la alimentación y actividad física son resultado de los cambios ambientales y sociales relacionados al desarrollo y la falta de políticas de salud, agricultura, transporte, medio ambiente, educación, comercialización de alimentos y planificación urbana. 


\subsection{4. ¿Cómo pueden reducirse el sobrepeso y la obesidad?}

Cuando hablamos de sobrepeso y obesidad no nos referimos a enfermedades irreversibles sino a males que se pueden prevenir en un porcentaje considerable de casos. Sin embargo, es fundamental que el entorno influya en las elecciones de las personas, de forma que la opción más accesible o disponibles, sea la más saludable tanto en alimentación como en actividad física y poder, conjuntamente, prevenir el sobrepeso y obesidad.

Individualmente las personas pueden optar por:

- reducir o limitar el consumo de alimentos con contenido elevado de grasa, azúcar y sodio;

- mejorar la combinación de macronutrientes del día y en cada comida;

- aumentar el consumo de legumbres, cereales integrales y frutos secos; sin dejar de lado las frutas y verduras;

- realizar periódicamente actividad física

La industria alimentaria también cumple un rol importante en la disminución de estos índices alarmantes:

- reduciendo el contenido de grasa, azúcar y sodio de los alimentos procesados;

- asegurando que existan en el mercado opciones saludables y nutritivas que estén disponibles y sean asequibles para todos los consumidores;

- limitando la venta de productos alimenticios altos en azúcar, sodio y grasas, sobre todo aquellos destinados a los niños y los adolescentes; y 
En la Declaración política de la "Reunión de Alto Nivel de la Asamblea General de las Naciones Unidas sobre la Prevención y el Control de las Enfermedades No Transmisibles", de septiembre de 2011, se identifica y se acepta la importancia de reducir el consumo de alimentos perjudiciales e incrementar la inactividad física. En dicha Declaración se asume el compromiso de promover la aplicación de la "Estrategia Mundial OMS sobre Régimen Alimentario, Actividad Física y Salud", entre otros medios, según proceda, introduciendo políticas y medidas encaminadas a promover dietas sanas y a aumentar la actividad física de toda la población (Organización Mundial de la Salud, 2018).

\subsection{5. Índices de obesidad en el mundo}

En la actualidad y ya desde hace algunos años, gran porcentaje de la población vive tan pendiente de cosas materiales que descuido completamente aspectos simples, y tan complejos a la vez, como lo es su salud y bienestar. El mundo se enfrente a una epidemia mortal: la obesidad, y las tendencias actuales indican que sólo va a empeorar.

Un estudio reciente determinó que más de 2.000 millones de adultos y niños alrededor del mundo sufren de sobrepeso u obesidad causándoles problemas de salud, escenario recurrente en los últimos años (CNN, 2017).

El Imperial College de Londres, Reino Unido realizo un estudio publicado en la revista científica The Lancet, titulado "Tendencias en el índice de masa corporal en adultos en 200 países de 1975 a 2014: un análisis conjunto de 1698 estudios de medición basados en la población con 19,2 millones de participantes", en el que se hace referencia al cambio que se ha dado en cuanto a índices de obesidad en el 
mundo desde 1975 al 2014, en el que hemos pasado de vivir en un mundo en el que el número de personas con bajo peso duplicaba a la de obesos, a uno en el que el número de personas en situación de obesidad supera enormemente a aquellas con delgadez extrema.

En este estudio se analizaron el IMC de más de 19,2 millones de adultos (9,9 millones de hombres y 9,3 millones de mujeres) en 186 países. Según los resultados obtenidos, el número de hombres obesos se había triplicado, mientras que el de mujeres era más del doble.

\section{Las naciones con más hombres obesos}

1 China

\section{Estados Unidos}

3 Brasil

4 Rusia

5 India

6 México
Las naciones con más mujeres obesas

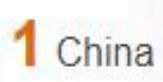

2 Estados Unidos

3 India

4 Rusia

5 Brasil

6 México

Figura 1 Naciones con más hombres y mujeres obesos. Información tomada de los resultados del estudio publicado en la revista The Lancet en el 2016 Recuperado de https://www.bbc.com/

Los datos obtenidos en el estudio revelan que, en 40 años, la cifra mundial de obesos se incrementó de 105 millones en 1975 a 641 millones de personas en 2014 (266 millones de hombres y 375 millones de mujeres). 
Muestran también que la cifra en hombres se disparó del 3,2\% al 10,8\%, en las mujeres se duplicó, aunque sigue siendo superior que los hombres, de un 6,4\% en 1975 a un $14,9 \%$ en 2014.

"Si la obesidad sigue aumentando a este ritmo, para 2025 un quinto de los hombres (18\%) y de las mujeres (21\%) serán obesos; la obesidad severa superará el $6 \%$ en hombres y el $9 \%$ en mujeres, en general la obesidad ha alcanzado un punto crítico", advirtió Ezzati.

La obesidad es uno de los grandes desafíos que afronta hoy la salud en el mundo, además de otros males como el envejecimiento y enfermedades tan importantes como el cáncer o los trastornos neurodegenerativos.

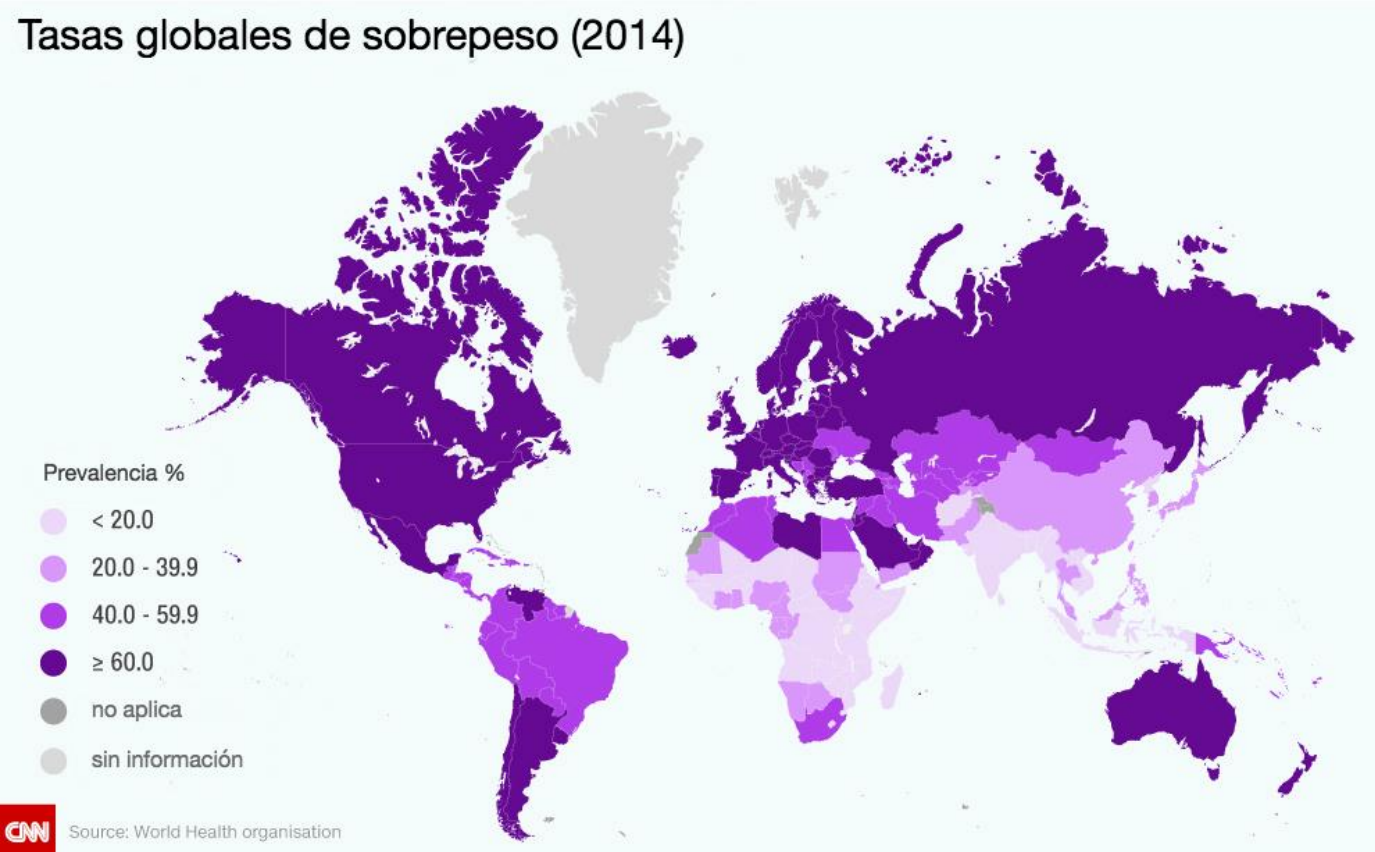

Figura 2 Tasas globales de sobrepeso al 2014. Según estudios realizados por la Organización Mundial de la Salud. Recuperado de https://cnnespanol.cnn.com/ 


\section{Tasas globales de obesidad (2014)}

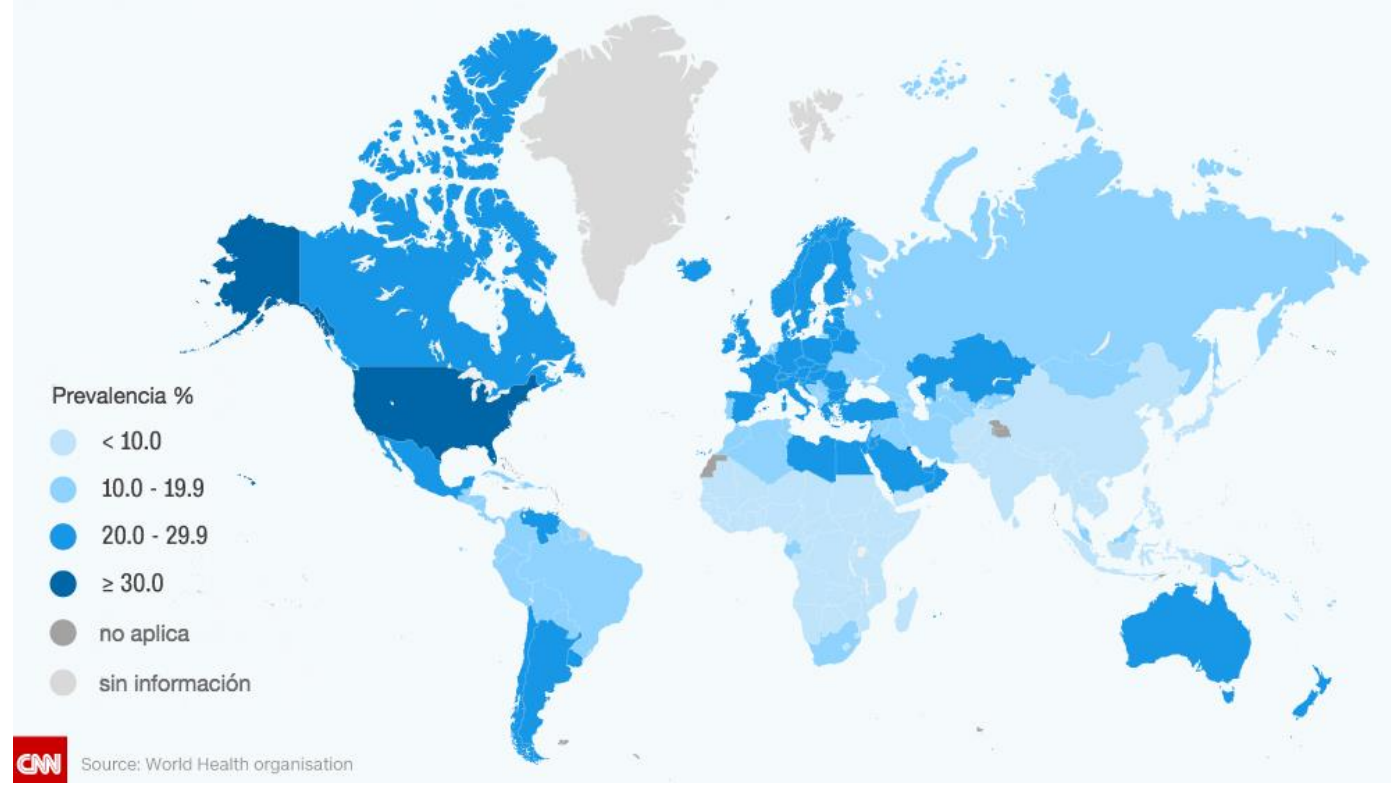

Figura 3 Tasas globales de obesidad al 2014. Según estudios realizados por la Organización Mundial de la Salud. Recuperado de https://cnnespanol.cnn.com/

Se encuentra como factores determinantes a la dieta y la actividad física, es decir, dietas pobres y poca o nula actividad física. Sin embargo, no son los únicos, existen pequeños factores que también ejercen influencia y necesitan ser identificados y abordados de forma adecuada para poder tratar el problema.

La obesidad no es exclusiva de solo algunos países, sino que ataca a la mayoría ellos y una de cada tres personas en el mundo tiene afecciones derivadas del sobrepeso. Según la Organización Mundial de la Salud, las islas del Pacífico, Oriente Medio y el continente americano presentan las tasas de obesidad más elevadas, en comparación a las demás regiones. En 2014, casi el 50\% de la población de las Islas Cook fue clasificada como obesa, con un índice de masa corporal (IMC) que sobrepasa el 32. Qatar fue el líder en Oriente Medio con un 34\%, seguido de cerca por Estados Unidos con 33\%. Estados Unidos es el país occidental con mayor 
cantidad de población acercándose a la obesidad, con una media de 29,1 (la obesidad se considera a partir de 30).

Ningún país europeo está libre del sobrepeso, situación a la que se llega cuando el índice medio de masa corporal supera el 25, siendo Irlanda, Grecia o Reino Unido, los países que muestran el valor más alto, con un 27,5. Aunque lo valores no llegan a los de obesidad, se puede decir que toda Europa supera este valor referencial de 25, que marca la diferencia entre el peso ideal y el sobrepeso.

Según los estudios en 2014, la población que sufría de problemas de obesidad se concentraba en 10 países, entre ellos México, Estados Unidos, China, Brasil y Alemania.

La Organización para la Cooperación y el Desarrollo Económicos (OCDE), a la que pertenecen por 35 países, practicó un estudio relacionado a la obesidad, siendo Estados Unidos el país tiene un 38,2\% de su población mayor de 15 años con obesidad, encabezando la lista.

\subsection{6. Índices de obesidad en el Perú}

En la 35a Conferencia Regional para América Latina y el Caribe de la Organización de las Naciones Unidas para la Alimentación y la Agricultura (FAO), que se le desarrollo en Jamaica la primera semana de marzo de 2018, se informó que el Perú estaba posicionado en el tercer lugar en relación a sobrepeso y obesidad en la región, siendo México y Chile los países que lo superan (El Comercio, 2018).

Es en este marco de preocupación por reducir estos niveles de sobrepeso y obesidad que, en el Congreso se desarrolló el debate por el reglamento de la Ley de 
Promoción de la Alimentación Saludable, en el que el punto de mayor desacuerdo está relacionado al etiquetado de los productos, buscando regular los porcentajes de azúcares, sal, grasas y otros componentes que resultan dañinos para la salud..

De acuerdo con datos oficiales del Ministerio de Salud (MINSA), tanto el sobrepeso como la obesidad se han incrementado en el Perú de forma significativa en los últimos años. Se observa que, en personas mayores de 15 años, el sobrepeso aumentó de 33,8\% en el 2013 a 35,5\% en el 2016. Otro valor que es necesario resaltar es que, la obesidad llegó a afectar al 18,3\% de la población durante ese mismo período. Si sumamos las cifras de gordura y súper gordura de los peruanos, se tiene que en el 2016 el 53,6\% cae en esa categoría; es decir, más de la mitad de los peruanos somos gordos o súper gordos (El Comercio, 2018).

El MINSA resalta que la alternativa de etiquetado octogonal podrá indicar a los ciudadanos la cantidad de azúcar, sodio, grasas saturadas o las denominadas grasas trans en cada producto, de una forma más clara y sencilla, contribuyendo al objetivo de la reducción de los índices de sobrepeso y obesidad. Asimismo, advierte que este problema de salud no tiene un solo origen, sino que, es agravado poca o escasa actividad física en forma regular.

El informe "Perú: Enfermedades No transmisibles y transmisibles", elaborado por el Centro Nacional de Alimentación y Nutrición del MINSA, indica entre otras cosas que las cifras de población con exceso de peso en el Perú se incrementaron de 52.1\% en el 2013, a 53.8\% en el 2016. Siendo las regiones de Tacna, Callao, Ica, Lima, Moquegua, Madre de Dios, Lambayeque, Arequipa, Tumbes, La Libertad y Piura, las que albergaron la mayor cantidad de personas con este problema. 
Por otro lado, el informe muestra que la mayor cantidad de persona con sobrepeso y obesidad en el país, son parte de la población femenina, con 57.7\%, es decir, tres de cada cinco mujeres padecen esta enfermedad. En el caso de los varones alcanzan el 49.8\%, es decir, uno de cada dos tiene grasa corporal en exceso.

En el análisis territorial de los resultados, se observa que Lima Metropolitana es la región que concentra casi al $40 \%$ de la población con obesidad. Tres de cada cinco habitantes de la costa, incluyendo Lima, presentan sobrepeso y obesidad (64.3\%), en la selva uno de cada dos habitantes tienen este problema de salud (45.6\%) y en la sierra se reduce a dos de cada cinco $(43.2 \%)$.

Dicho estudio se hizo también por nivel educacional y nos muestra que tres de cada cinco personas con nivel de estudio superior en el país tienen una acumulación excesiva de grasa corporal $(62,8 \%)$. Asimismo, se observa que la obesidad se presenta en uno de cada dos personas con educación primaria y/o secundaria (El Comercio, 2018).

Un estudio de la Organización Mundial de la Salud (OMS) indica que en el Perú se incrementó en 107\% el consumo de bebidas y alimentos ultra-procesados entre los años 2000 y 2013

En referencia al consumo de comida rápida, la OMS advierte que, en comparación a otros países de la región, el Perú experimentó el mayor crecimiento, con 265\%. En cifras esto se refleja como que en el 2000 una persona compraba este tipo de comidas 8.7 veces al año, cantidad que se elevó hasta 31.8 en el 2013. 
Frente a esta situación y con valores poco estrictos para definir ciertos productos como comida chatarra, los especialistas son escépticos sobre los beneficios del reglamento, ya que, si las tendencias mostradas se mantienen en la población, las consecuencias podrían ser mayores y terminar afectando todo el sistema de salud (La República, 2017).

\subsubsection{Indicadores nutricionales en Arequipa}

Las afecciones causadas por el sobrepeso pueden ser diversas, cardiopatías, diabetes y artritis son algunas de las enfermedades que pueden sufrir tres de cada diez arequipeños a causa de este mal, según informe del Club Médico Deportivo Bodytech. Según la nutricionista Cecilia Luza, "5 de cada 12 arequipeños entre 30 y 59 años, así como 3 de cada 9 mayores de 60 años, sufren de sobrepeso; siendo factores recurrentes el desequilibrio entre las calorías ingeridas y las utilizadas, el sedentarismo" (Diario Sin Fronteras, 2016).

Sabemos que el sedentarismo y los hábitos poco saludables de alimentación son las causas principales de que las personas se enfrenten a enfermedades como obesidad, hipertensión, diabetes, influyendo inclusive en una autoestima baja y falta de motivación. Esto llega a afectar no solo el sistema de salud, sino también tiene cierto efecto en la productividad que pueda tener una persona en su trabajo.

Según el último informe ejecutivo de la situación nutricional de Arequipa del año 2013, los resultados de la aplicación de indicadores que van desde delgadez severa hasta obesidad por diferentes etapas de vida son los siguientes: 
Tabla 1

Resultados de indicadores: grupo etario de 5 a 9 años

\begin{tabular}{ccc}
\hline Indicador & \multicolumn{2}{c}{5 a 9 años } \\
\cline { 2 - 3 } & Perú & Arequipa \\
\hline Delgadez Severa & 0.5 & 0.4 \\
\hline Delgadez & 0.6 & 0.4 \\
\hline Normal & 74.5 & 66.4 \\
\hline Sobrepeso & 15.5 & 22.1 \\
\hline Obesidad & 8.9 & 10.8
\end{tabular}

Fuente: Centro Nacional de Alimentación y Nutrición-MINSA

En el grupo etario de 5 a 9 años la delgadez severa y normal en Arequipa es menor a la proporción nacional; sin embargo, el sobrepeso y la obesidad superan las proporciones nacionales, así mismo, el indicador de normalidad es menor respecto al nacional. El exceso de peso afecta a 1 de cada 3 niños de este grupo etario.

Tabla 2

Resultados de indicadores: grupo etario de 10 a 19 años

\begin{tabular}{ccc}
\hline Indicador & \multicolumn{2}{c}{ 10 a 19 años } \\
\cline { 2 - 3 } Delgadez Severa & Perú & Arequipa \\
\hline Delgadez & 0.2 & 0.2 \\
\hline Normal & 0.9 & 0.9 \\
\hline Sobrepeso & 11.0 & 75.2 \\
\hline Obesidad & 3.3 & 18.2 \\
\hline
\end{tabular}

Fuente: Centro Nacional de Alimentación y Nutrición-MINSA

En el grupo etario de adolescentes de 10 a 19 años, los resultados nos muestran que los indicadores de delgadez se igualan con la proporción nacional. La tendencia al sobrepeso y obesidad disminuye respecto al grupo anterior (5 a 9 años), 
incrementándose el indicador de normalidad. Sin embargo, el sobrepeso y obesidad continúan con valores superiores a la proporción nacional, de esta forma el exceso de peso afecta a casi 1 de cada 4 adolescentes.

Tabla 3

Resultados de indicadores: grupos etarios de 20 a 29 años y 30 a 59 años

\begin{tabular}{ccccc}
\hline \multirow{2}{*}{ Indicador } & \multicolumn{2}{c}{ 20 a 29 años } & \multicolumn{2}{c}{ 30 a 59 años } \\
\cline { 2 - 5 } & Perú & Arequipa & Perú & Arequipa \\
\hline Adelgazado & 2.1 & 2.6 & 0.6 & 0.9 \\
\hline Normal & 58.2 & 60.0 & 37.1 & 31.2 \\
\hline Sobrepeso & 30.9 & 30.4 & 42.5 & 42.9 \\
\hline Obesidad & 8.7 & 7.0 & 19.8 & 25.0 \\
\hline
\end{tabular}

Fuente: Centro Nacional de Alimentación y Nutrición-MINSA

En el grupo de 20 a 29 años considerados adultos jóvenes el sobrepeso y la obesidad aumentaron en comparación al grupo etario anterior, en desmedro del indicador de normalidad, y el exceso de peso afecta a 3 de cada 8 adultos jóvenes, sin embargo, se observa que en este grupo las proporciones nacionales superan en casi dos puntos al de la región.

En el grupo de adultos de 30 a 59 años, permanece la tendencia al aumento de las cifras de sobrepeso y obesidad, superando, igual que los anteriores grupos, a las proporciones nacionales y aquejando a 2 de cada 3 personas adultas. La obesidad aqueja a 1 de cada 4 adultos, cifra que está muy por encima de los adultos jóvenes. La delgadez disminuyo y no llega ni al 1\%, sin embargo, aquellos que se encuentran en el indicador normal son casi 1 de cada 3 individuos, el más bajo entre los grupos etarios evaluados. 
Tabla 4

Resultados de indicadores: grupo etarios mayor de 60 años

\begin{tabular}{ccc}
\hline Indicador & \multicolumn{2}{c}{$\geq \mathbf{6 0}$ años } \\
\cline { 2 - 3 } & Perú & Arequipa \\
\hline Adelgazado & 26.8 & 17.8 \\
\hline Normal & 40.8 & 43.8 \\
\hline Sobrepeso & 21.7 & 26.5 \\
\hline Obesidad & 10.6 & 11.8
\end{tabular}

Fuente: Centro Nacional de Alimentación y Nutrición-MINSA

En el grupo de 60 años, el sobrepeso no causa tanta alarma como si lo hace el incremento de la delgadez, que afecta a los adulos mayores en una relación de 1 de cada 6 adultos mayores. Los valores de sobrepeso y obesidad hay disminuido, pero sigue siendo superiores a los nacionales, afectando a 1 de cada 3 adultos mayores.

\subsubsection{Ley de alimentación saludable}

La alimentación es una de las necesidades fundamentales del ser humano. Todos tenemos el derecho de informarnos acerca de lo que comemos y no comemos, consideramos que es información vital para cuidar nuestro bienestar. La existencia de una ley que obligue a las empresas de alimentos a brindarnos dicha información de forma clara y entendible es realmente necesaria.

El 10 de mayo de 2013 el Congreso de la República de nuestro país aprobó la Ley 30021, Ley de promoción de la alimentación saludable para niños, niñas y adolescentes, la que fue promulgada el 16 de mayo de 2013 y publicada en el diario Oficial El Peruano el 17 de mayo de 2013, dependiendo su aplicación de la aprobación del reglamento. Esta ley tiene como principal objeto la protección y 
promoción del derecho a la salud pública, de los niños, niñas y adolescentes para lograr la reducción y eliminación de enfermedades que son consecuencia directa o indirecta de las altas tasas de sobrepeso, obesidad y enfermedades crónicas no transmisibles. (Congreso de la República, 2013)

Después de más de cuatro años sin promulgar el reglamento para esta ley, en el 2017 se aprueba el reglamento de la Ley de Alimentación Saludable. Este documento señala los ámbitos de aplicación de la ley, los parámetros relativos al contenido de azúcar, sodio, grasa saturada, grasa trans en los alimentos procesados, y disposiciones referidas a la publicidad, y etiquetado de los productos.

Adicionalmente se establece que el Ministerio de Salud será el encargado de elaborar el Manual de Advertencias Publicitaras para las etiquetas: alto en sodio, alto en azúcar, alto en grasas, alto en grasas saturadas o contiene grasas trans. El 17 de agosto del año pasado el MINSA prepublicó un documento estableciendo su propuesta para el sistema de advertencia y etiquetado (El Comercio, 2018).
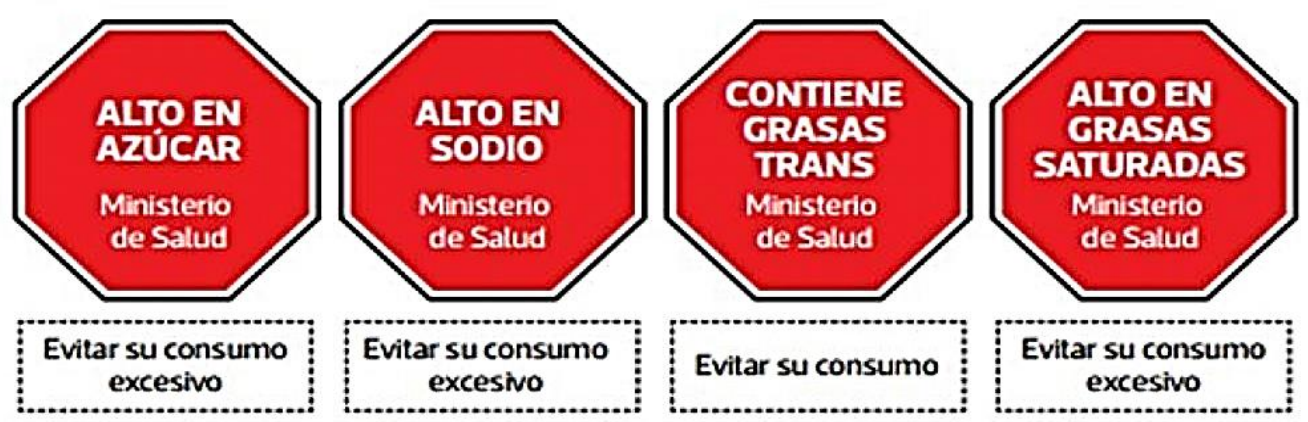

Los productos con exceso de grasas trans deberán contener el mensaje "evitar su consumo". ya que se consideran totalmente dañinas, como el tabaco.

Figura 4 Etiquetado propuesto por el MINSA. Octágonos de color rojo con marco negro y blanco, advierten sobre el contenido de azúcar, sodio, grasas saturadas y grasas trans. Recuperado de https://elcomercio.pe/ 
Posteriormente el Congreso presentó un proyecto, como sugerencia, para que se incluyan los porcentajes del contenido de azúcar, grasa y sodio en alimentos procesados, mostrando esta información en forma de un gráfico de barras de colores rojo (contenido alto), amarillo (contenido medio) y verde: el semáforo nutricional, el cual fue aprobado el 16 de mayo de 2018

\section{SEMÁFORO NUTRICIONAL APROBADO EN EL CONGRESO}

- El semáforo se ubicará en la parte superior izquierda de la parte frontal del etiquetado del producto.

- Está sustentado en los valores diarios de referencia que elabora el Ministerio de Salud con recomendaciones de ta OMS y la FAO.

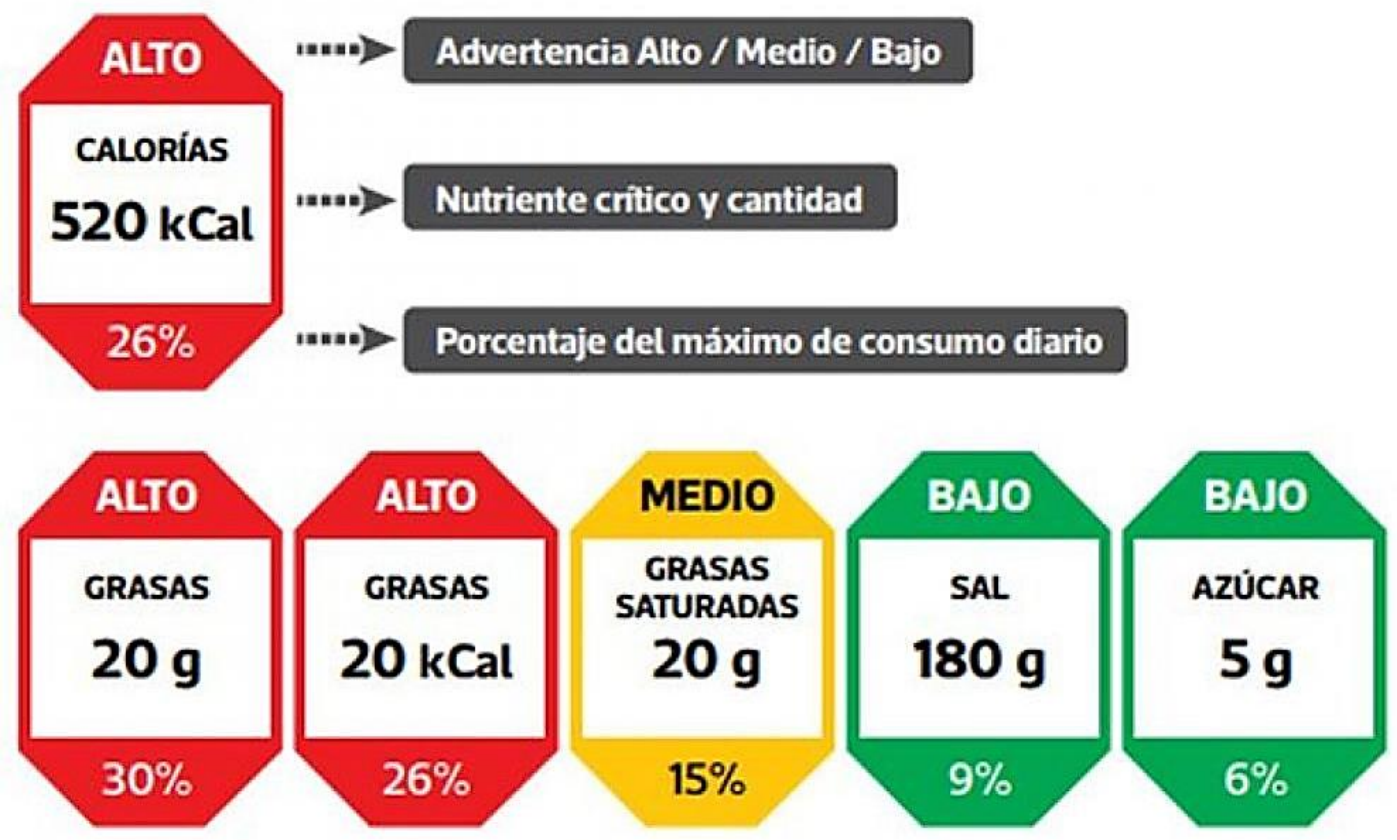

EVITAR SU CONSUMO EXCESIVO

Figura 5 Etiquetado propuesto y aprobado por el Congreso. Semáforo nutricional. Recuperado de https://elcomercio.pe/

Este nuevo modelo planteado se orienta en tres aspectos: un modelo de etiquetado que muestre en colores (rojo, amarillo y verde) los porcentajes de cada componente considerado dañino, un plan de educación nutricional que incluya a escolares, 
profesores y padres de familia y la creación de un Observatorio de Nutrición y del Estudio de Sobrepeso y Obesidad que desarrolle no solo alternativas para vencer la enfermedad, sino que promueva una cultura de prevención.

El debate originado por esta ley no solo se relaciona a cuando entrara en vigencia el nuevo etiquetado, sino la opción de etiquetado a elegir, los octógonos o el semáforo nutricional.

Según diversas opiniones de expertos el sistema de semáforo nutricional no es muy claro y no presenta de forma adecuada y entendible la información que se quiere dar a conocer del producto, por lo tanto, no se estaría logrando el objetivo de la ley.

A inicios de Julio el Gobierno consideró que el modelo de los octágonos tendría un mayor impacto. Si bien la ley es aceptada en todos los sectores socioeconómicos, toma mayor importancia para los peruanos de clase alta y media. Según la encuesta de Pulso Perú del mes de julio, elaborada por Datum, un $89 \%$ del NSE C y $87.9 \%$ del NSE A/B creen que el aporte de la ley será favorable. Además, la mayoría de jóvenes, casi un 83\%, entre 18 y 24 años tiene la misma percepción (Gestión, 2018).

Dentro de los encuestados, un 64\% afirmó que la información que le puedan brindar los octógonos en los productos considerados en esta ley, tendría influencia en su decisión de compra. Se observó que tendrá mayor impacto en la decisión de compra en el NSE A/B (67.2\%) y C (66.8\%). También se da principalmente entre los peruanos de 35 a 44 años (65\%) Gestión, 2018). 


\subsection{Determinación del problema u oportunidad.}

Arequipa es una ciudad que se encuentra en crecimiento constante, considerándose la segunda ciudad económica del Perú, y a la que muchos jóvenes se dirigen por mejores oportunidades trabajo y/o estudio. Esta porción de la población que tiene gran porcentaje de su tiempo ocupado en los estudios, trabajo o en muchos casos ambos, carecen de tiempo para cuidar de su alimentación (prepararla, escoger los insumos adecuados para hacerlo y sobre todo cuidar que sea a la misma hora), lo que los empuja a consumir comidas rápidas con escasos nutrientes y "a la hora que tengan tiempo" o incluso saltarse comidas. Estas son prácticas que dañan la salud y a la larga traerán consecuencias realmente negativas.

Es a partir de este análisis que identificamos una necesidad que no está siendo cubierta de forma adecuada, por lo que nuestro emprendimiento busca ayudar a aquellas personas que necesitan comer algo nutritivo, apropiado a sus necesidades, variado y delicioso.

\subsection{Justificación del proyecto.}

Actualmente nos encontramos ante una sociedad que quiere mejorar su calidad de vida y para lograrlo busca corregir o agregar nuevas prácticas a sus rutinas diarias, es entonces que adoptan algunas actividades, como: ejercitarse diariamente, dormir mejor, relajarse y corregir sus hábitos alimenticios. Sin embargo, debido al poco tiempo del que disponemos para poder preparar personalmente nuestras comidas, la alimentación es lo que más descuidamos, tanto su calidad como tiempo dedicado a ello. Así mismo, estamos experimentando una gran influencia de la cultura fitness en el mundo, y en Arequipa se ha visto reflejada con la aparición y crecimiento de tres cadenas de gimnasios locales muy bien posicionadas en el mercado, lo que aunque es considerada como una moda que pasará 
en cualquier momento, esperamos cale en la población como un estilo de vida, y sea un primer paso para mejorar el estado general de la salud.

\subsection{Objetivos generales y específicos.}

\subsubsection{Objetivos generales.}

Demostrar la viabilidad comercial, técnica y financiera de la producción y delivery de comida saludable en la ciudad de Arequipa, tomando ventaja de la creciente tendencia al consumo de alimentos saludables, satisfaciendo sus necesidades y superando sus expectativas; así mismo, posicionarnos como la mejor alternativa de comida saludable.

\subsubsection{Objetivos específicos.}

- Definir claramente el servicio y diseñar los procesos técnicos para brindar a nuestro público objetivo un servicio diferenciado.

- Determinar el mercado objetivo para el negocio de comida saludable e identificar a la competencia, proveedores, precios, productos y clientes potenciales que nos permitan posicionarnos en el mercado.

- Determinar estrategias de marketing que nos permitan obtener la mayor cuota de mercado y posicionarnos como la mejor alternativa.

- Determinar los costos y presupuestos del proyecto según el pronóstico de ventas planteado en base a nuestro estudio de mercado.

- Formular una estrategia financiera adecuada que permita maximizar la rentabilidad de la empresa. 


\subsection{Alcances y limitaciones de la investigación.}

\subsubsection{Alcances.}

Este plan de negocios abarca la producción de alimentos saludables e implementación del servicio de delivery en la ciudad de Arequipa, el que se centrara en la creación de planes alimenticios balanceados según reglas generales y personalizados según las necesidades del cliente, con la asesoría de especialistas en nutrición, es decir brindar las herramientas necesarias para que cliente cumpla su objetivo. Nuestro mercado objetivo es la población de la ciudad de Arequipa que no cuenta con el tiempo ni conocimientos suficientes para hacerse cargo de una alimentación balanceada y saludable

Además, se contempla la implementación de un sistema logístico eficiente que abarque toda la ciudad de Arequipa.

\subsubsection{Limitaciones.}

- La cultura tradicional de la región hace que el consumidor no acepte fácilmente un concepto diferente de alimentación.

- Los recursos económicos disponibles se limitan a los ingresos de los dos participantes del proyecto.

- Escaso conocimiento del consumidor con respecto a una alimentación saludable.

- Poca información secundaria con respecto a este tipo de idea de negocio por ser recientemente puesta en marcha en el mercado Arequipeño.

- Poca información con respecto al nivel socioeconómico de los encuestados.

- Información escasa acerca de la competencia al ser poco conocidas en el mercado. 


\section{CAPITULO II}

\section{Estructura económica del sector.}

\subsection{Descripción del Estado Actual de la Industria Peruana}

El Perú se ha convertido en uno de los países más importantes de Latinoamérica. La economía peruana, ha mejorado considerablemente en su desempeño, sus tasas de PBI han crecido y su deuda y niveles de inflación se han conservado en niveles bajos; al mismo tiempo ha logrado mantener tasas de cambio constantes. Podemos identificar una gran variedad de climas, una enorme extensión territorial, importantes recursos naturales, personas de gran capacidad y con alto nivel académico, además de sólidos antecedentes económicos e industriales, características que le dan esa calificación.

Actualmente, de acuerdo al Fondo Monetario Internacional (FMI), el Perú es una "estrella en ascenso", que está surgiendo y pasando a formar parte de mercados líderes, acompañado de un sólido crecimiento y baja inseguridad. De la misma forma en el 2014, el FMI ha señalado que el Perú tendrá una década casi asegurada de amplio crecimiento, destacando los buenos resultados de las políticas macroeconómicas que se vienen implementando, asegurando que permiten al país lograr un desarrollo impulsivo y estabilidad económica; así mismo, aconsejan se sigan poniendo en práctica medidas similares orientadas aspecto monetario, fiscal y de infraestructura (EY Perú, 2016, p.22).

Según datos de ProInversión en el período 2008 - 2016 el PBI creció a una tasa promedio de 4.8\%, llegando a alcanzar en el 2016 un valor superior a US\$190,000 millones. Asimismo, el Banco Central de Reserva anunció que se estima un crecimiento de 4.2\% para los años 2018 y 2019. De esta forma, la economía peruana está experimentando 
un periodo de 16 años de crecimiento consecutivo, a tasas que superan el promedio de los países de su región, es necesario destacar también la actitud de su población, que con un gran rendimiento e ideas de emprendimiento, han convertido al Perú en un destino rentable para invertir (ProInversión, 2017).

Para describir el estado actual de la industria utilizaremos el PBI como indicador principal y descomposición por sectores.

Primero una definición. El PBI (Producto Bruto Interno) es la unidad de medida monetaria de todos los bienes y servicios finales que la economía de un país produce en un periodo determinado. Es entonces, la sumatoria de los valores monetarios del consumo, inversión bruta privada, compra de bienes y servicios por parte del estado, la inversión bruta estatal y las exportaciones menos las importaciones.

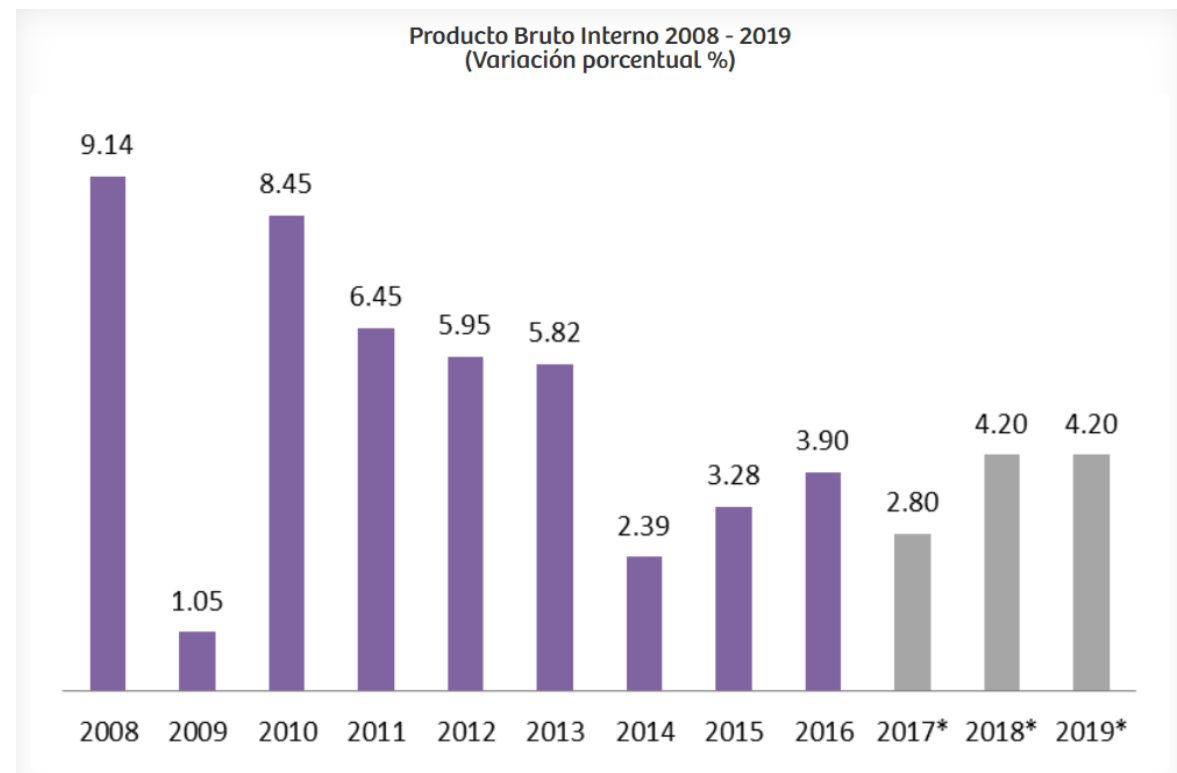

Figura 6 Producto Bruto Interno 2008-2019. Datos tomados del Banco Central de Reserva del Perú y elaborado por ProInversión. (*) Cifras estimadas. 
Diversos indicadores, como el incremento del consumo privado y nuevos proyectos de inversión privada y pública; así como, perspectivas económicas favorables para el Perú, son el resultado de la continuidad que se ha dado, al aplicar medidas de política juiciosas y políticas macroeconómicas prudentes, en diferentes gobiernos.

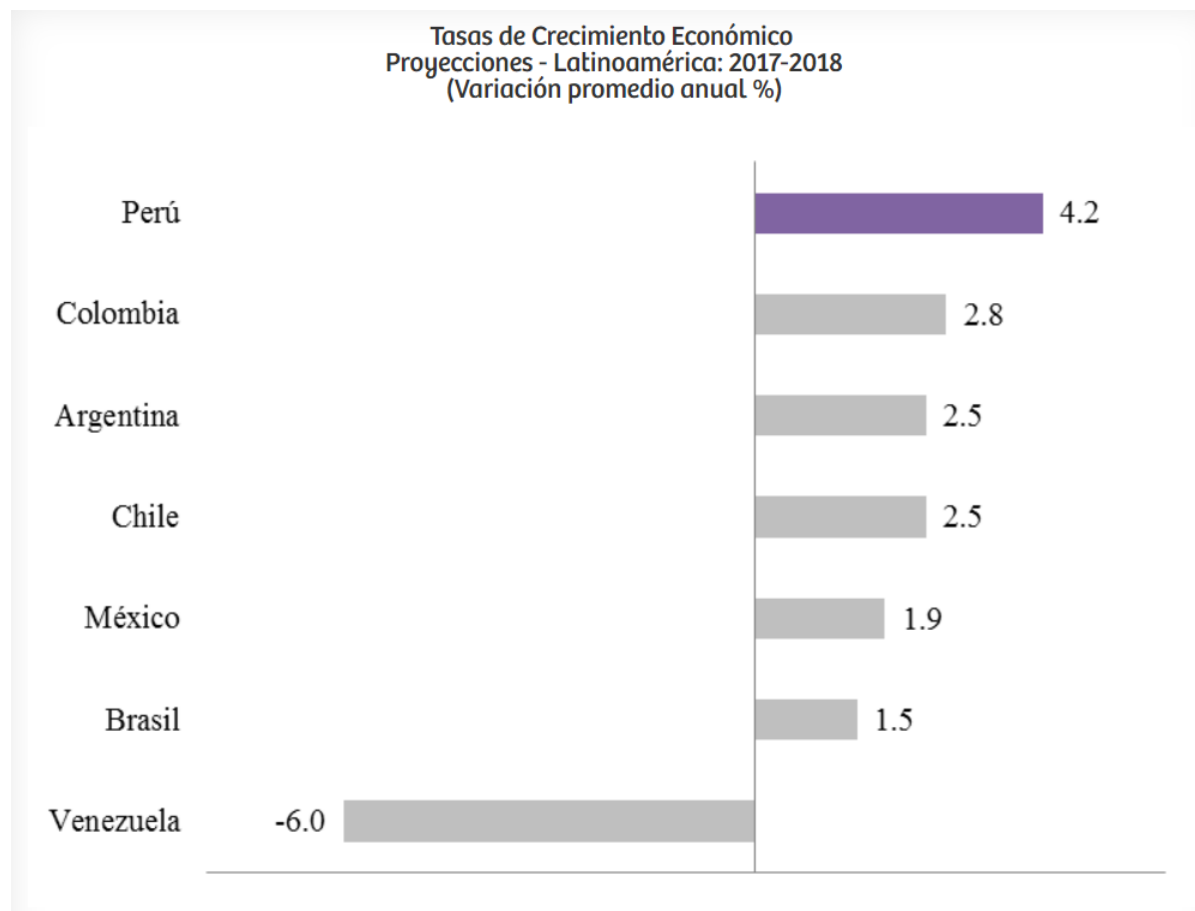

Figura 7 Tasas de Crecimiento Económico: Proyecciones Latinoamérica 2017-2018. Datos tomados del Banco Central de Reserva para Perú y Fondo Monetario Internacional el resto de países latinoamericanos. Elaborado por ProInversión.

El año 2017 se vio afectado por diversos acontecimientos en el ámbito político, económico y social. Los daños ocasionados por El Niño Costero, la solicitud de vacancia contra el entonces presidente Pedro Pablo Kuczynski y los cambios en el gabinete de ministros fueron algunos acontecimientos que marcaron el año. 
En el siguiente cuadro se muestran los principales acontecimientos que pudieron influenciar en la variación del PBI proyectado para el año 2017.

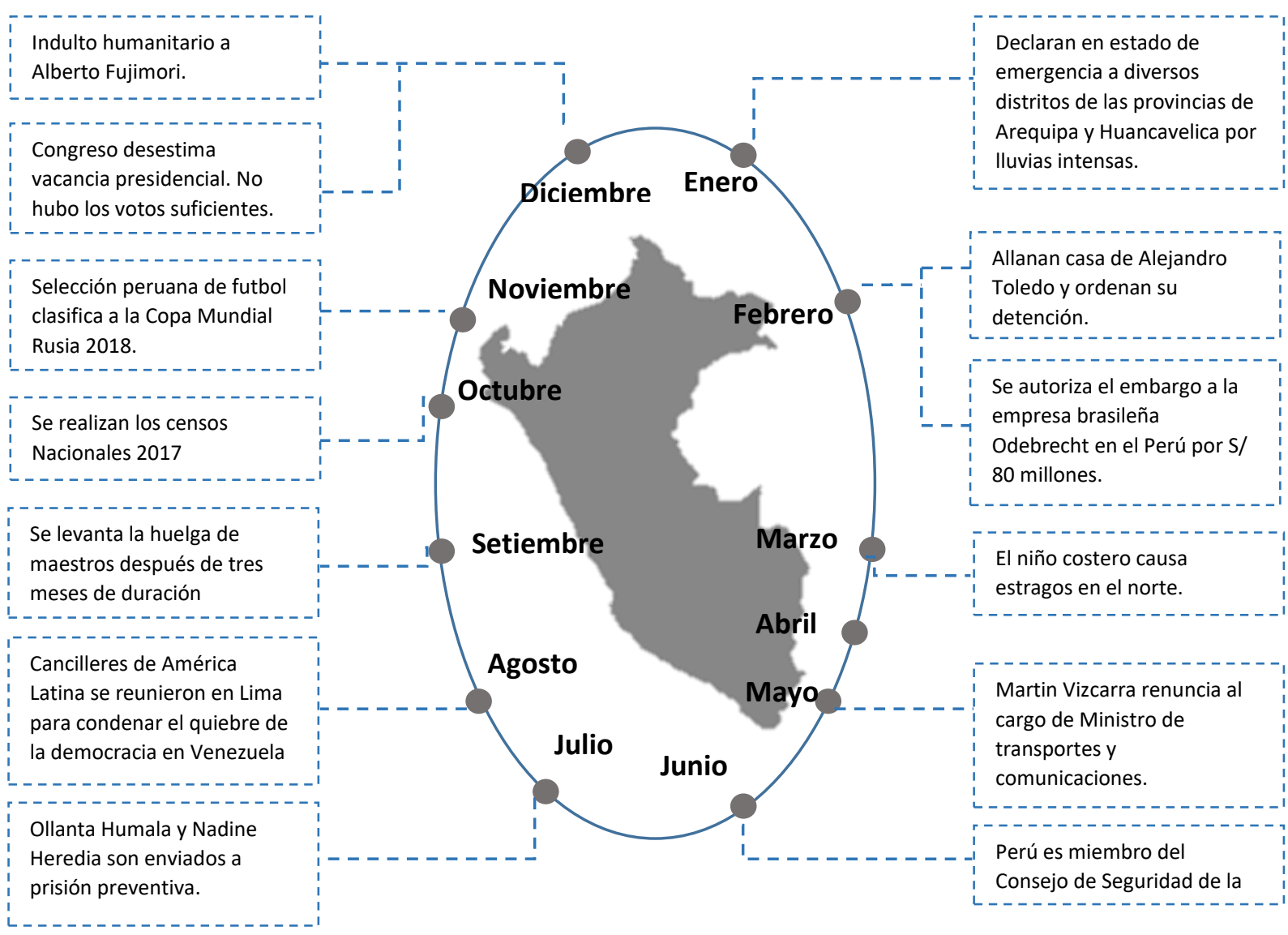

Figura 8 Acontecimiento que influenciaron en la economía 2017. Datos tomados de Andina y otras fuentes.

En el año 2017, ciertas zonas geográficas del Perú mostraron mayor desarrollo que otras, siendo la zona orientes y la zona sur las que alcanzaron un crecimiento de $3.3 \%$, gracias a que es en estas regiones donde la actividad minera, de construcción y agropecuaria tiene mayor dinamismo 
El PBI de Arequipa ha evolucionado favorablemente en los últimos años, alcanzando en el año 2017 los S/ 30,917 millones en soles constantes desde 2007, siendo el sector minero y el de construcción los que más contribuyen al crecimiento.

Región Arequipa: evolución del PBI real, 2000-2016

(soles constantes de 2007)

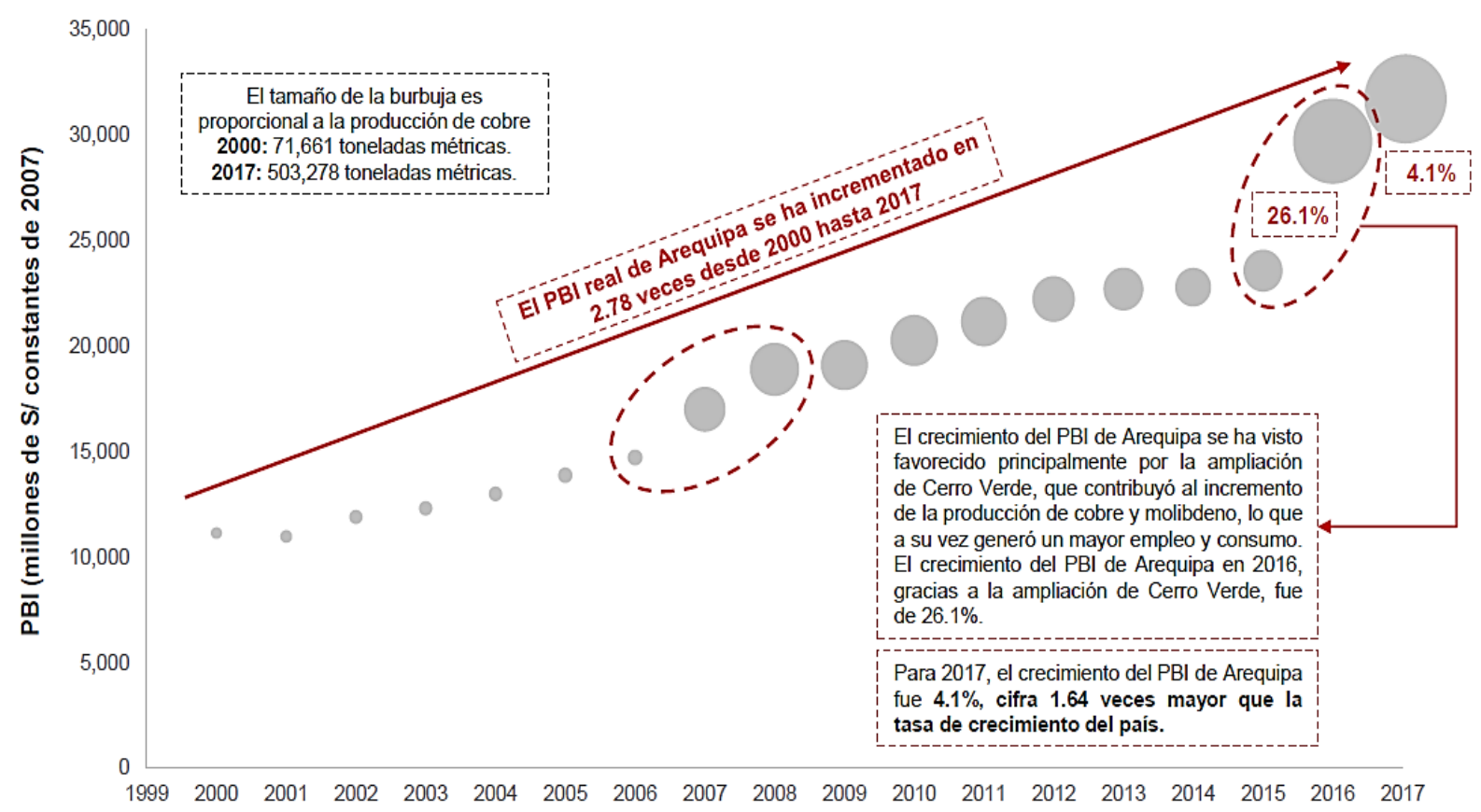

Figura 9 Región Arequipa: evolución del PBI real 2000-2016. Datos tomados de Instituto Nacional de Estadística e Informática (INEI), Ministerio de Energía y Minas (MINEM). Elaborado por Aurum Consultoría y Mercado.

En el periodo 2010-2016, el gasto del hogar promedio en Arequipa se ha incrementado en diversas categorías, especialmente en el rubro de alimentación, en el que se ha incrementado en un $4.11 \%$, y el promedio de su gasto es mayor que el nacional en ciertos rubros como alimentos, vestido y calzado, transportes y comunicaciones y esparcimiento. 
Región Arequipa: evolución promedio anual del gasto mensual del hogar, 2010-2016,

CAGR (soles)

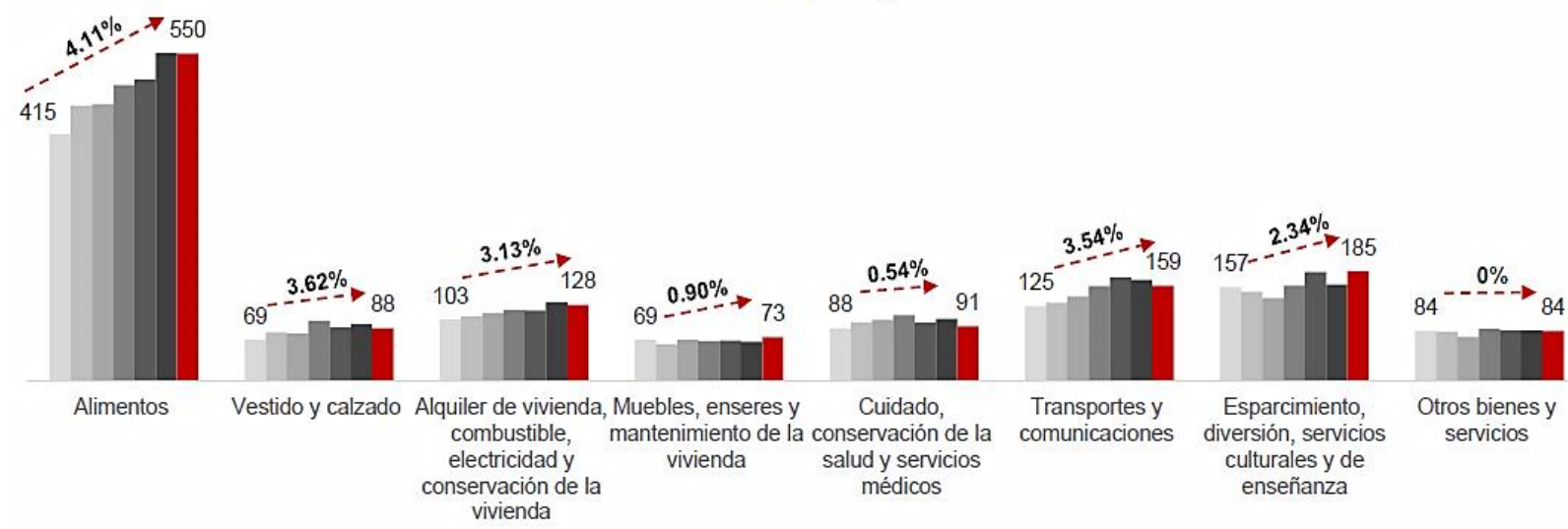

Otras regiones: gasto promedio mensual del hogar, 2010 vs. 2016

(soles)

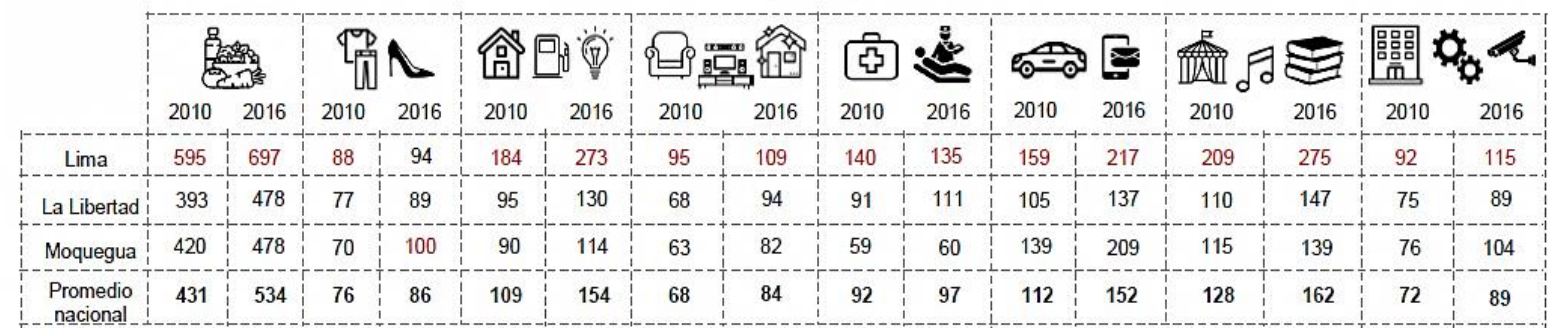

Figura 10 Región Arequipa: evolución promedio anual del gasto mensual del hogar 2010-2016. Datos tomados de la Encuesta Nacional de Hogares Enaho-INEI. Elaborado por Aurum Consultoría y Mercado.

Según la Cámara de Comercio de Arequipa, en el año 2017 la inflación acumulada en Arequipa alcanzó el 2.67\%, superando el porcentaje de la inflación a nivel nacional y la inflación de Lima Metropolitana.

A fines del 2017, la inflación acumulada en Arequipa, alcanzó el 2.67\%, superando las tasas de inflación a nivel nacional y de Lima Metropolitana, quienes alcanzaron el 1.5\% y $1.36 \%$ respectivamente. Ciertamente, es un poco elevado en comparación al porcentaje nacional, sin embargo, estuvo dentro del rango meta establecido por el Banco Central de Reserva del Perú, entre 1\% y 3\%. Según el Informe Técnico №1 (2018) del Instituto 
Nacional de Estadística e Informática, de las principales ciudades del país, 11 de ellas tuvieron una mayor inflación al promedio nacional, y dentro de ellas, estaría Arequipa.

En el 2017, el país en general experimento algunos eventos que ocasionaron que los precios de algunos productos se elevaran. El caso del limón es el más representativo ya que su precio sufrió un incremento de hasta $147 \%$, a causa de los daños ocasionados por el Niño Costero en el norte del país. En el mes de julio, un sismo fuerte en la provincia de Acarí ocasionó daños en la carretera, ocasionando problemas en el ingreso y salida de productos de Arequipa, lo que ocasiono un incremento de precios en algunos productos.

Los rubros que se vieron más afectados por la variación de precios en Arequipa, fueron Transportes y Comunicaciones (7.78\%), Esparcimiento, diversión, servicios de cultura y enseñanza (4.48\%), Muebles, enseres y mantenimiento de vivienda (3.43\%); y Alquiler de vivienda, combustible y electricidad (3.27\%). Otros rubros que se vieron afectados, pero en una mejor magnitud fueron: Vestido y Calzado (1.54\%); Otros bienes y Servicios (1.50\%); Alimentos y Bebidas (0.57\%); así como Cuidado y Conservación de la salud y servicios médicos $(0.20 \%)$. Es necesario mencionar que, aunque la variación del rubro Alimentos y Bebidas fue una de las menos afectadas porcentualmente, el impacto que produce un incremento de precios es mayor por tener una mayor ponderación en las divisiones de consumo (Cámara de Comercio e Industria Arequipa, 2018). 


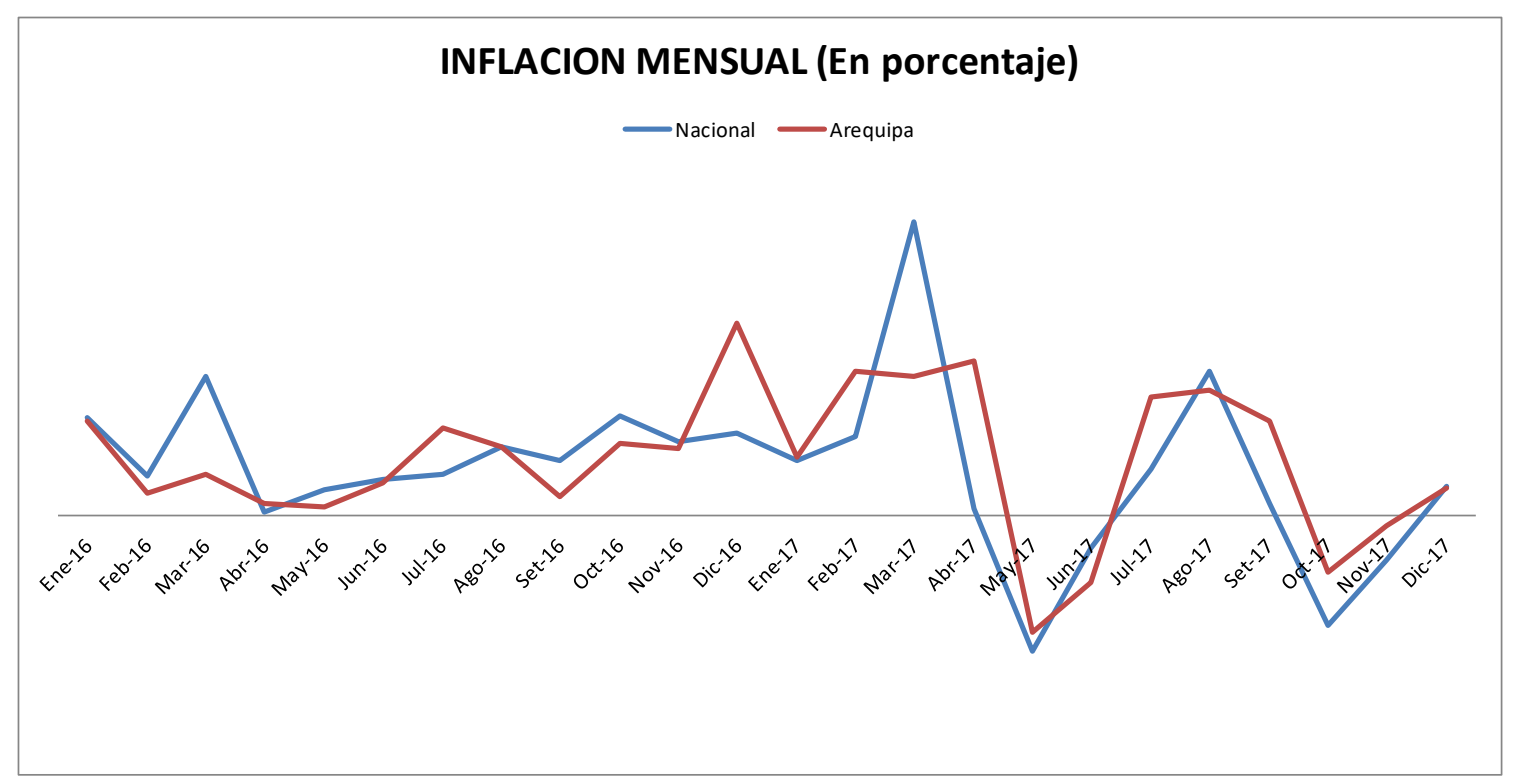

\begin{tabular}{|c|c|c|c|c|c|c|c|c|c|c|c|c|c|c|c|c|c|c|c|c|c|c|c|c|}
\hline & Ene- & Feb- & Mar- & Abr- & May- & Jun- & Jul- & & Set- & Oct- & Nov & Dic- & Ene- & eb- & Mar & & May & & Jul- & Ago & Set- & Oct- & Nov- & \\
\hline & 16 & 16 & 16 & 16 & 16 & 16 & 16 & 16 & 16 & 16 & 16 & 16 & 17 & 17 & 17 & 17 & 17 & 17 & 17 & 17 & 17 & 17 & 17 & 17 \\
\hline & 0.42 & 0.17 & 0.60 & 0.02 & 0.11 & 0.16 & 0.18 & 0.30 & 0.24 & 0.43 & 0.32 & 0.36 & 0.24 & 0.34 & 1.27 & 0.03 & $3-0.58$ & $8-0.14$ & 0.20 & 0.62 & & $5-0.47$ & $7-0.19$ & 0.13 \\
\hline ipa & 0.41 & 0.10 & 0.18 & 0.05 & 0.04 & 0.14 & 0.38 & 0.30 & 0.08 & 0.31 & 0.29 & 0.83 & 0.25 & 0.62 & 0.60 & $\begin{array}{ll}0 & 0.67\end{array}$ & $7-0.50$ & $0-0.29$ & 0.51 & 0.54 & & $1-0.24$ & $4-0.04$ & 0.1 \\
\hline
\end{tabular}

Figura 11 Inflación Mensual (Nacional-Arequipa) Datos tomados del Instituto Nacional de Estadística e Informática-INEI.

A febrero del 2018, la inflación acumulada de Arequipa era de 0.46\%, superando a la tasa de inflación a nivel nacional que fue de $0.48 \%$, mientras que la de Lima Metropolitana fue de $0.38 \%$. Según el Instituto Nacional de Estadística e Informática, a nivel nacional, los rubros que conforman el sector de consumo Alojamiento, Agua, Electricidad, Gas y Otros Combustibles presentó un alza de $1.25 \%$, debido principalmente al alza de la tarifa de energía eléctrica. 

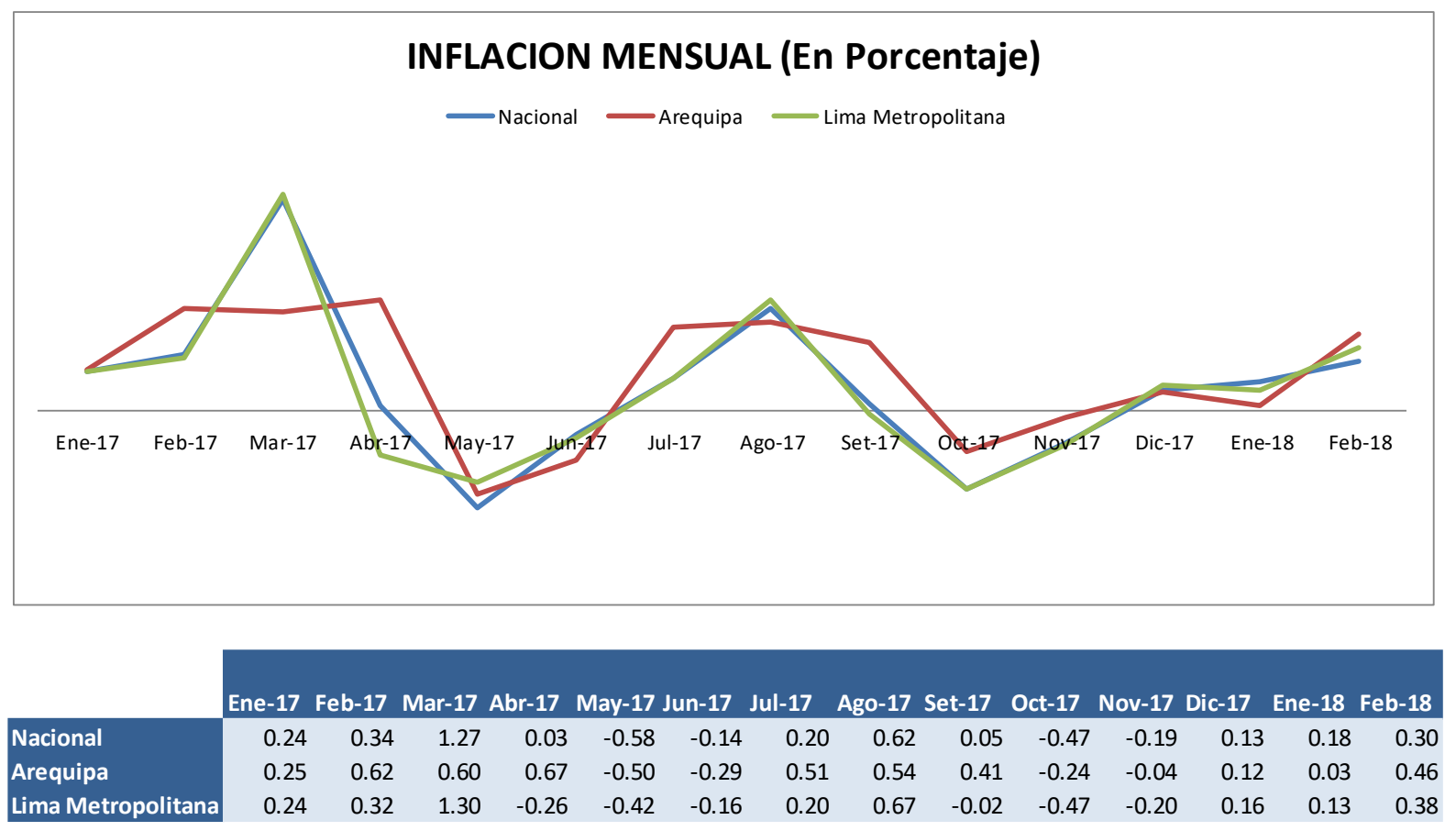

Figura 12 Inflación mensual (Nacional-Arequipa-Lima Metropolitana) Datos tomados del Instituto Nacional de Estadística e Informática-INEI.

\section{SECTOR GASTRONÓMICO.}

El sector gastronómico en el Perú ha tenido un gran crecimiento en estos últimos años en comparación a otros sectores de consumo. El 2009 se considera como el año en el que la gastronomía inicio su crecimiento y promoción, llegando a significar el 6\% del PBI anual

Según datos del Centro de Desarrollo de Franquicias de la Cámara de Comercio de Lima, existen en el mercado un total de 470 franquicias donde el $48 \%$ son nacionales, y la mayoría de éstas son del sector gastronómico.

Lima es considerada la ciudad que más proyectos gastronómicos ha lanzado, seguida de Cusco y luego Arequipa, se destaca también que los negocios relacionados con comida dan empleo a 60 mil personas, en alrededor de 20 mil comercios. 
Según Daniel Tejada, miembro del subcomité de Gastronomía de la Cámara de Comercio, en los últimos años innovar se ha convertido en un patrón para los emprendedores y cuando hablamos de vender productos saludables se convierte en un paso seguro para crear una tendencia. El año anterior tres de cada diez empleados decidieron mejorar sus hábitos alimenticios; de estos tres, uno de ellos ha convertido este hábito en parte de su vida diaria, los otros dos no mantienen un menú exclusivamente saludable, pero lo combinan.

El crecimiento del sector de la población que pertenece a la clase media ha contribuido al impulso de esta tendencia; según opiniones de expertos, el consumidor promedio en la ciudad de Lima está dispuesto a gastar entre S/ 25.00 y S/ 35.00 diariamente en su alimentación, mientras que en la ciudad de Arequipa este rango varía entre S/ 15.00 y S/ 20.00 .

\subsubsection{Segmentación de la industria.}

Las actividades económicas del Perú son diversas debido a la riqueza geográfica, ubicación y recursos naturales de los que goza el país, logrando ser considerado como un país de ingresos medio-altos. Sin embargo, siempre se enfrentará a dificultades de tipo social como la informalidad, inequidad y violencia, lo que va en contraste a sus avances económicos.

Se consideran actividades económicas a aquellos procesos identificados por la economía y por los cuales la el Perú obtiene gran parte de los ingresos que les permiten a sus ciudadanos subsistir. A su vez estas actividades están agrupadas por sectores: 


\section{El sector primario}

El sector primario está compuesto por todas las actividades que se refieren a la explotación y extracción de recursos naturales. Como sucede en casi toda Latinoamérica, y el Perú no es una excepción, este sector concentra gran parte de los esfuerzos en materia económica.

La agricultura, la ganadería, la silvicultura, la pesca, la minería y los hidrocarburos son las principales actividades que la conforman.

\section{El sector secundario}

El sector secundario es considerado en cierta forma como el siguiente paso después de las actividades del sector primario, está conformado por las actividades industriales y de manufactura, que le agregaran valor a la materia prima obtenida en el sector primario. Representa aproximadamente el 35\% del PBI nacional, aunque se han realizado esfuerzos para su crecimiento, no se ven grandes resultados debido a los costos elevados y que depende de materias primas que es necesario importar y de algunas que en su mayoría son exportados.

Las actividades que más resaltan son la manufactura, construcción, industria textil, la producción de alimentos, productos químicos y farmacéuticos, y la siderurgia.

\section{El sector terciario}

El sector servicios denominado también sector de servicios, al igual que en la mayoría de países, resulta ser el más grande de la economía, impulsando en gran 
medida el crecimiento económico del país, alcanzando el 70\% de este. Los principales sectores de estas actividades son el comercio, turismo, banca, servicios financieros, educación, salud, transporte, entretenimiento, seguridad, restaurantes, hotelería y comunicaciones.

Considerando que nuestro proyecto se encuentra en el sector terciario, dentro de la industria de Alojamiento y Restaurantes, y subsector restaurantes, específicamente en la alimentación saludable, procederemos a analizar dicha industria con mayor detenimiento.

Según el Informe de Coyuntura del Panorama Actual de marzo de 2018 de la Cámara de Comercio de Arequipa, el 46.8\% de las empresas se encuentran ubicadas en la Provincia de Lima y en la Provincia Constitucional del Callao, lo cual reafirma la gran concentración empresarial en estos ámbitos geográficos. Siendo Arequipa y La Libertad con $5,6 \%$ y 5,2\%, respectivamente, las otras ciudades que tienen mayor concentración, pero podemos observar que la diferencia es considerable. Por otro lado, según estudios del INEI, entre las principales actividades económicas durante el 2016, el 45,3\% de empresas están vinculadas a actividades comerciales; el 14.8\% a otros servicios; el $10.5 \%$ a servicios profesionales, técnicos y de apoyo profesional; el $8.2 \%$ a industrias manufactureras; y el $7.6 \%$ a actividades de servicios de comidas y bebidas (Cámara de Comercio e Industria, 2018). 


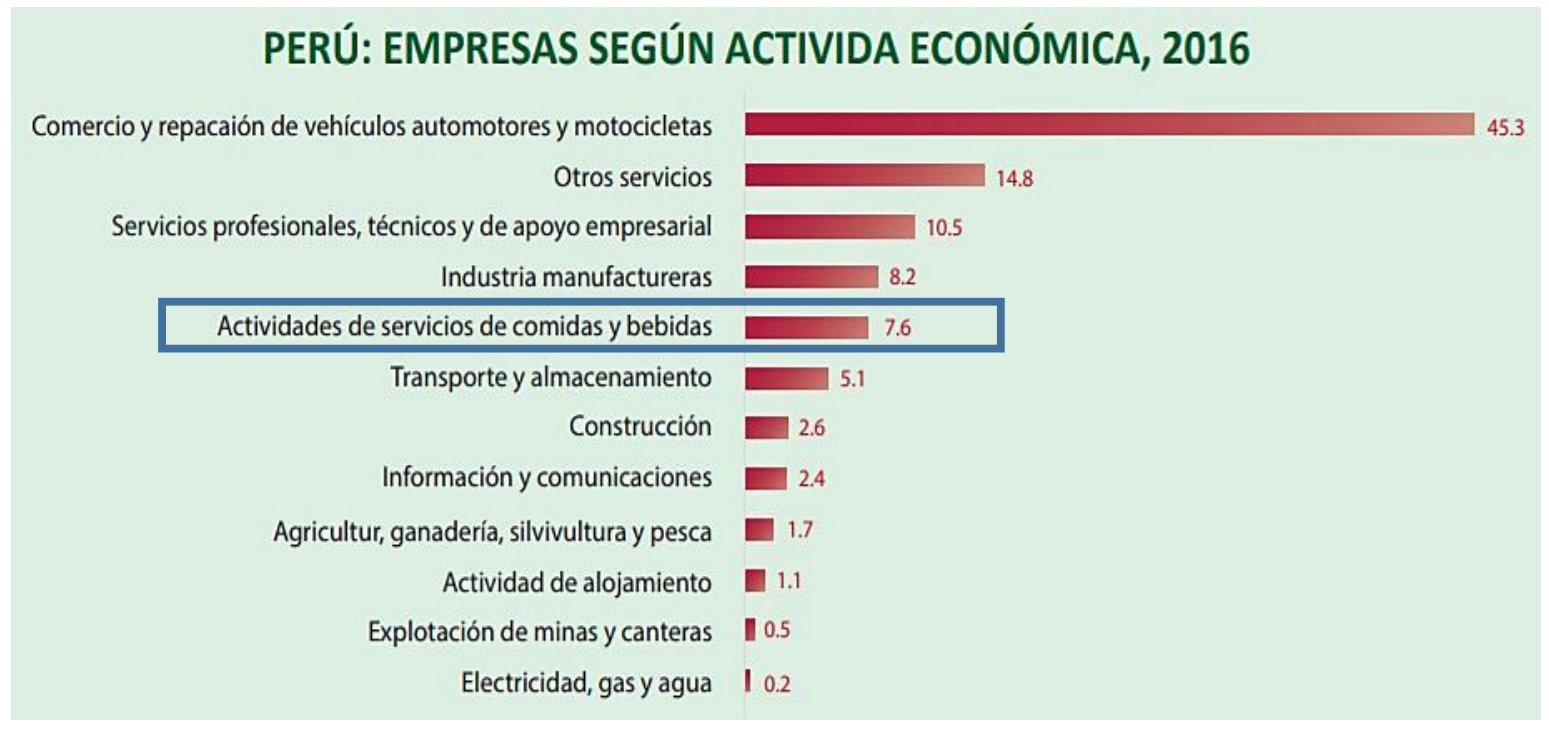

Figura 13 Perú: Empresas según actividad económica 2016. Datos tomados del Instituto Nacional de Estadística e Informática-INEI y elaborado por el Dpto. de Estudios Económicos de la Cámara de Comercio e Industria de Arequipa.

En promedio durante el año 2017, el sector alojamiento y restaurantes presentó un incremento de 1,24\%, apoyado principalmente en el crecimiento de la actividad de restaurantes en $1,18 \%$ y de alojamiento en $1,62 \%$; sin embargo, en diciembre del mismo año el sector alojamiento y restaurantes registró un aumento de 2,21\%, por el avance del subsector restaurantes en 1,94\% y del subsector alojamiento en 4,19\%.

Tabla 5

Variaciones del sector alojamiento y restaurantes: diciembre 2017 (Año base 2007)

\begin{tabular}{l|r|r|r}
\hline \multirow{2}{*}{ Sector } & \multirow{2}{*}{$\begin{array}{l}\text { Ponde- } \\
\text { ración }\end{array}$} & \multicolumn{3}{|c}{$\begin{array}{c}\text { Variación porcentual } \\
\text { 2017/2016 }\end{array}$} \\
\cline { 3 - 5 } & & Diciembre & Enero-Diciembre \\
\hline Alojamientos y Restaurantes & 100,00 & $\mathbf{2 , 2 1}$ & $\mathbf{1 , 2 4}$ \\
Alojamiento & 13,60 & 4,19 & 1,62 \\
Restaurantes & 86,40 & 1,94 & 1,18 \\
\hline
\end{tabular}

Fuente: INEI - Encuesta mensual de restaurantes, MINCETUR 
Durante el 2017, en general los restaurantes crecieron en un $0,94 \%$, impulsados por la actividad en los negocios de comidas rápidas, pollerías, restaurantes, comida criolla y sandwicherías.

En diciembre del 2017 el grupo de restaurantes presentó un avance de 1,84\%, de la misma forma otras actividades de servicio de comidas crecieron $2,29 \%$, debido a la actividades y celebraciones corporativas de fin de año, renovación y ampliación de contratos en los que se ofrece menú ejecutivo, económico y dieta, garantizando estándares de calidad y seguridad alimentaria (INEI, 2018).

En mayo 2018, el sector restaurantes (servicios de comidas y bebidas) creció en $3.11 \%$, sostenido por el resultado positivo de la actividad de restaurantes que varió en $3,12 \%$, otras actividades de servicio de comidas en 3,82\%. En tanto, decrecieron las actividades de suministro de comida por encargo en $-2.77 \%$. El índice del sector restaurantes registró una variación acumulada de 2.93\%, según datos obtenidos de la Encuesta Mensual de Restaurantes que considera una muestra de 1 mil 105 empresas. (INEI, 2018). 


\section{EVOLUCION ACTUAL DE LA ACTIVIDAD DE RESTAURANTES: 2016-2018}

Variación \% respecto a similar periodo del año anterior

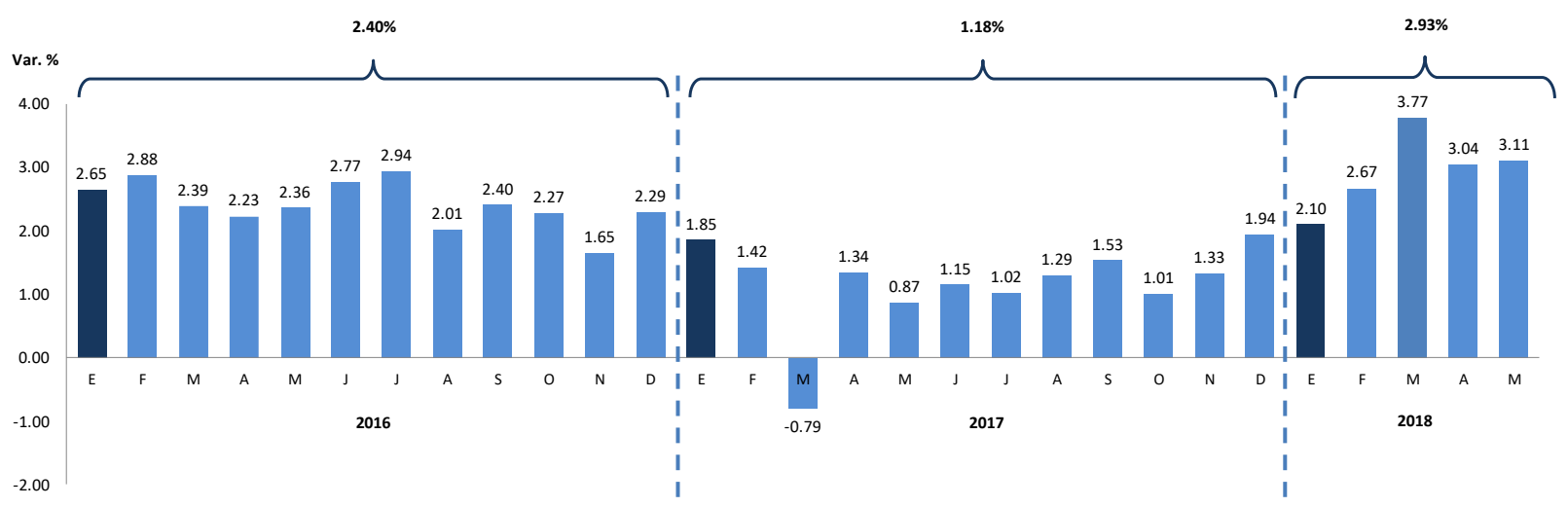

Figura 14 Evolución actual de la actividad de restaurantes: 2016-2018. Datos tomados del Instituto Nacional de Estadística e Informática - INEI Encuesta Mensual de Restaurantes.

Por tipo de negocio, en la actividad restaurantes y servicio móvil de comida, destacaron los rubros de comidas criollas, pizzerías, sandwicherías, comidas rápidas, heladerías y restaurantes principalmente, sin dejar de lado el servicio delivery de comida saludable que en el 2016 tuvo un incremento del 30\% en comparación al año anterior, porcentaje que va en constante crecimiento, y se ve reflejado en todo el Perú. En el caso de la ciudad de Lima, los distritos que más demandaron este servicio fueron Miraflores con el 51\%, San Isidro con el 26\%, La Molina con 11\%, y Santiago de Surco con $6 \%$.

Según un reporte de la compañía Hellofood Perú, el público objetivo al que una empresa de comida saludable debe apuntar va en un rango de entre los 25 y 45 años de edad, ya que representan el 57\% del consumo de esta comida, mientras que los jóvenes entre 18 y 24 años representan un $25 \%$ del total de la demanda. Si bien la opción de ofrecer delivery de comida saludable es interesante pues minimiza los 
costos de alquiler, dos aspectos importantes que deben cuidarse es el los envases y la higiene.

\section{SUBSECTOR RESTAURANTES \\ (Servicios de comidas y bebidas) \\ Mayo 2018: 3.11\%}

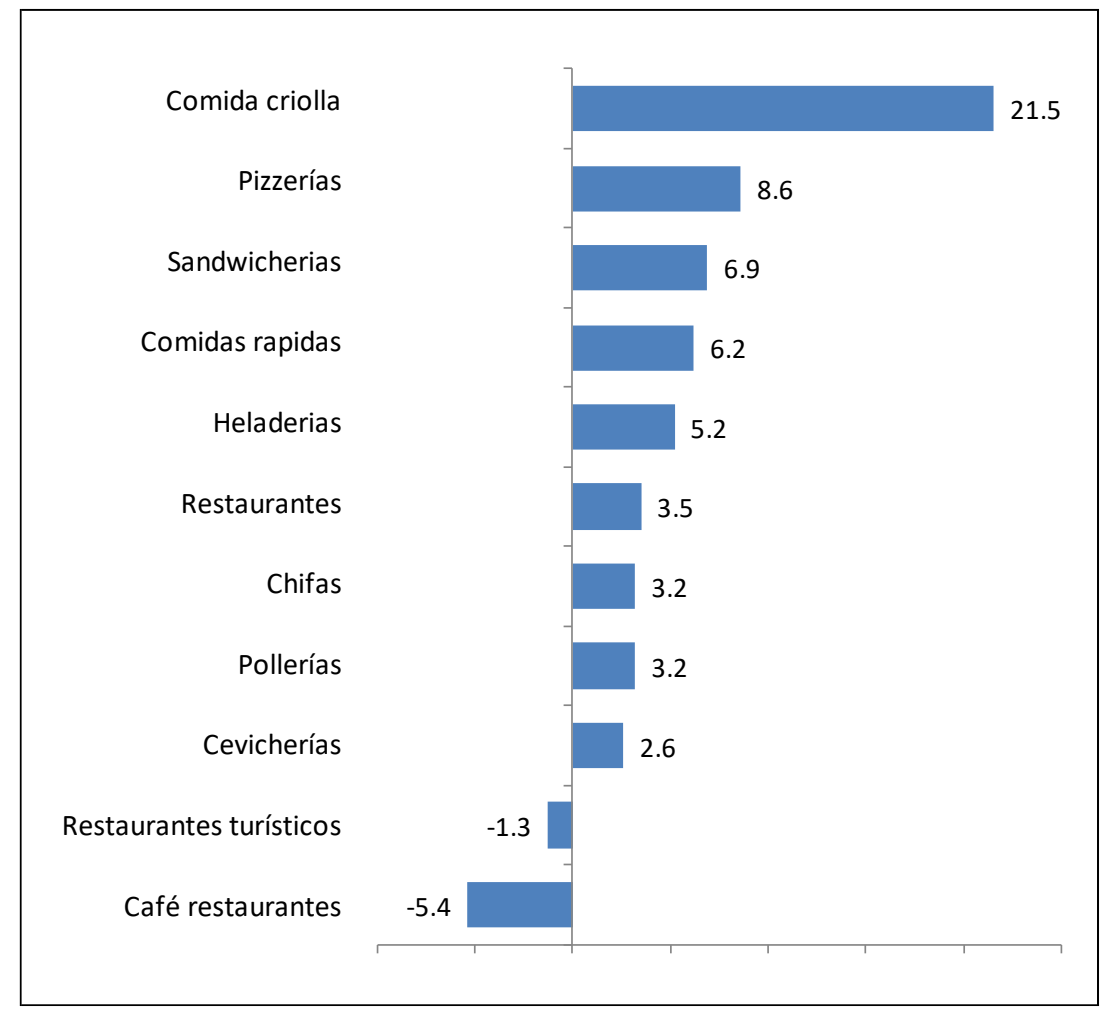

Figura 15 Variación en el sector restaurantes por tipo de comida. Datos tomados del Instituto Nacional de Estadística e Informática - INEI Encuesta Mensual de Restaurantes

Con respecto a los establecimientos de servicios en funcionamiento registrados en las municipalidades, los de mayor frecuencia son: restaurantes (54 mil 518), oficinas administrativas (29 mil 729), establecimientos de hospedaje (17 mil 809), peluquerías y salones spa (13 mil 871) y actividades profesionales (10 mil 280). 
PERU: PRINCIPALES ESTABLECIMIENTOS DE SERVICIOS REGISTRADOS EN LA

MUNICIPALIDAD

AL 31 DE DICIEMBRE DE 2015

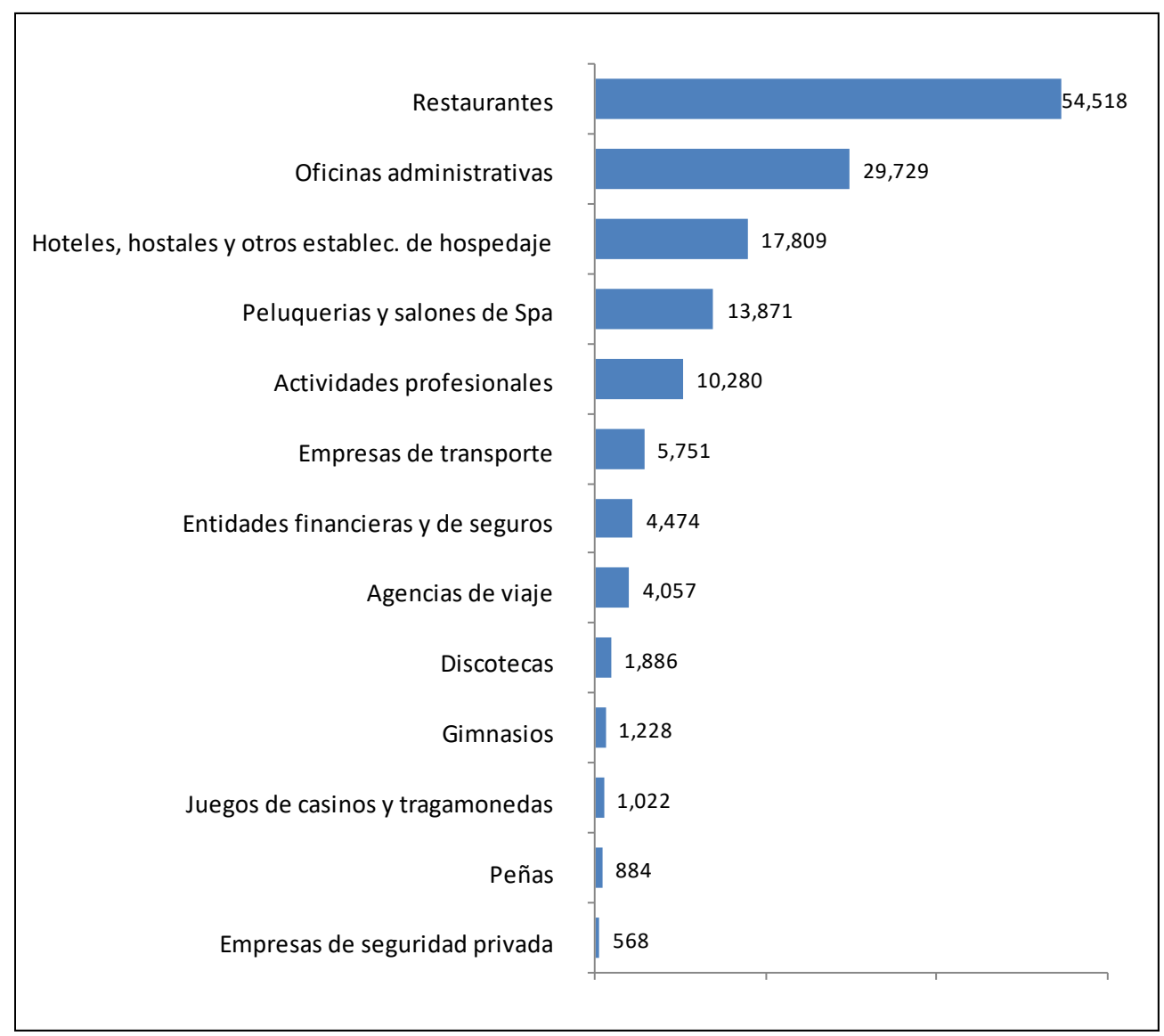

Figura 16 Principales establecimientos registrados en las municipalidades al 2015. Datos tomados del Instituto Nacional de Estadística e InformáticaINEI Y Registro Nacional de Municipalidades del 2016

\section{ALIMENTACION SALUDABLE}

Lo saludable se ha puesto de moda, y la tendencia va en aumento. Según datos del estudio sobre Salud y Etiquetado de Kantar Worldpanel (KWP), el 54\% de hogares peruanos se considera "saludable" o "muy saludable", este porcentaje de población es cada vez más consciente de lo que ellos y sus familias consumen, buscando un balance, una alimentación más sana y leen la información en las etiquetas de los productos, aspecto que ya ha sido reglamentado con la Ley del Etiquetado. Para la 
gran mayoría de peruanos el termino saludable está relacionado con "comer sano" (68\%), "hacer deporte" (58\%) lo cual estaría relacionado con salud física y "pasar tiempo con la familia" (56\%) que podría estar relacionado con la salud afectivaemocional.

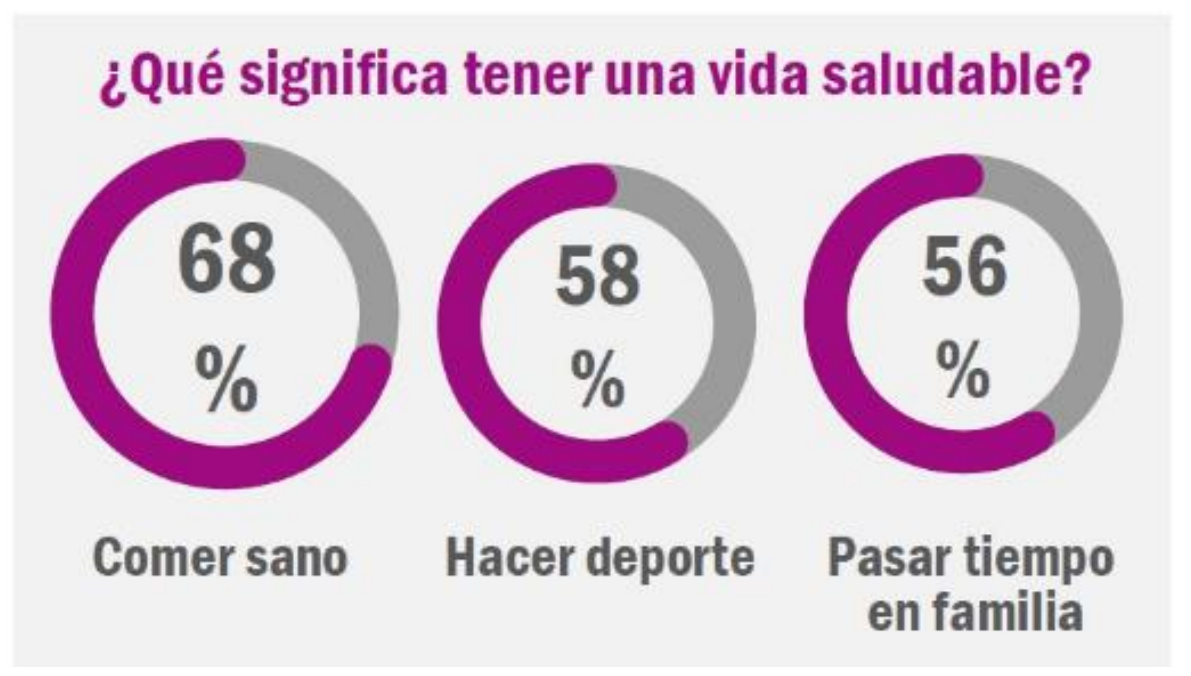

Figura 17 ¿Qué significa tener una vida saludable? Datos tomados de Estudio de Vida Saludable a nivel nacional dirigido por Gustavo Yrala - DATUM. Recuperado de https://www.mercadonegro.pe/datumpresenta-estudio-sobre-vida-saludable/

A pesar de que llevar un estilo de vida saludable debería ser un objetivo importante para la mayoría de la población, el 75\% considera que es difícil hacerlo porque implica mayor gasto o dinero (25\%), no cuentan con el tiempo necesario (19\%), y además, porque la comida chatarra es más accesible (12\%). 


\section{¿Por qué es difícil llevar una vida saludable?

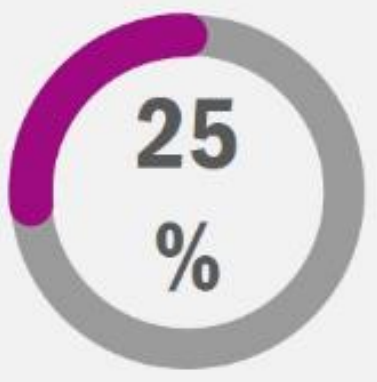 \\ Se gasta mucho

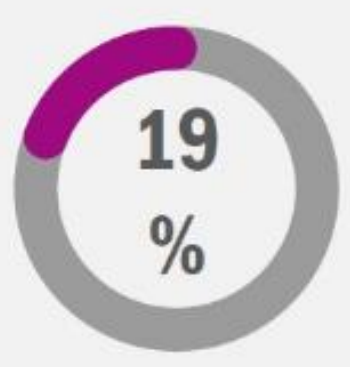 \\ Falta tiempo

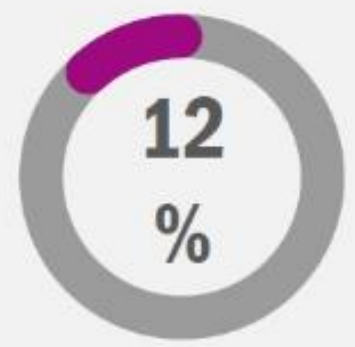 \\ La chatarra es más accesible}

Figura 18 ¿Por qué es difícil llevar una vida saludable? Datos tomados de Estudio de Vida Saludable a nivel nacional dirigido por Gustavo Yrala - DATUM. Recuperado de https://www.mercadonegro.pe/datumpresenta-estudio-sobre-vida-saludable/

Aquellos que califican su alimentación como saludable, se muestran dispuestos a mejorar de manera radical (11\%) y parcial (74\%) su alimentación; así mismo, aquellos que no se alimentan de manera saludable, el 36\% está dispuesto a mejorar sus hábitos alimenticios de forma radical y el 59\% de forma parcial.

La gran mayoría no hace dieta (87\%), lo hacen principalmente las mujeres y personas del nivel socioeconómico A/B. La mitad de los que hacen dieta deciden ellos mismos lo que comen, mientras que para el resto, es un especialista el que les indica la dieta que deben seguir. 


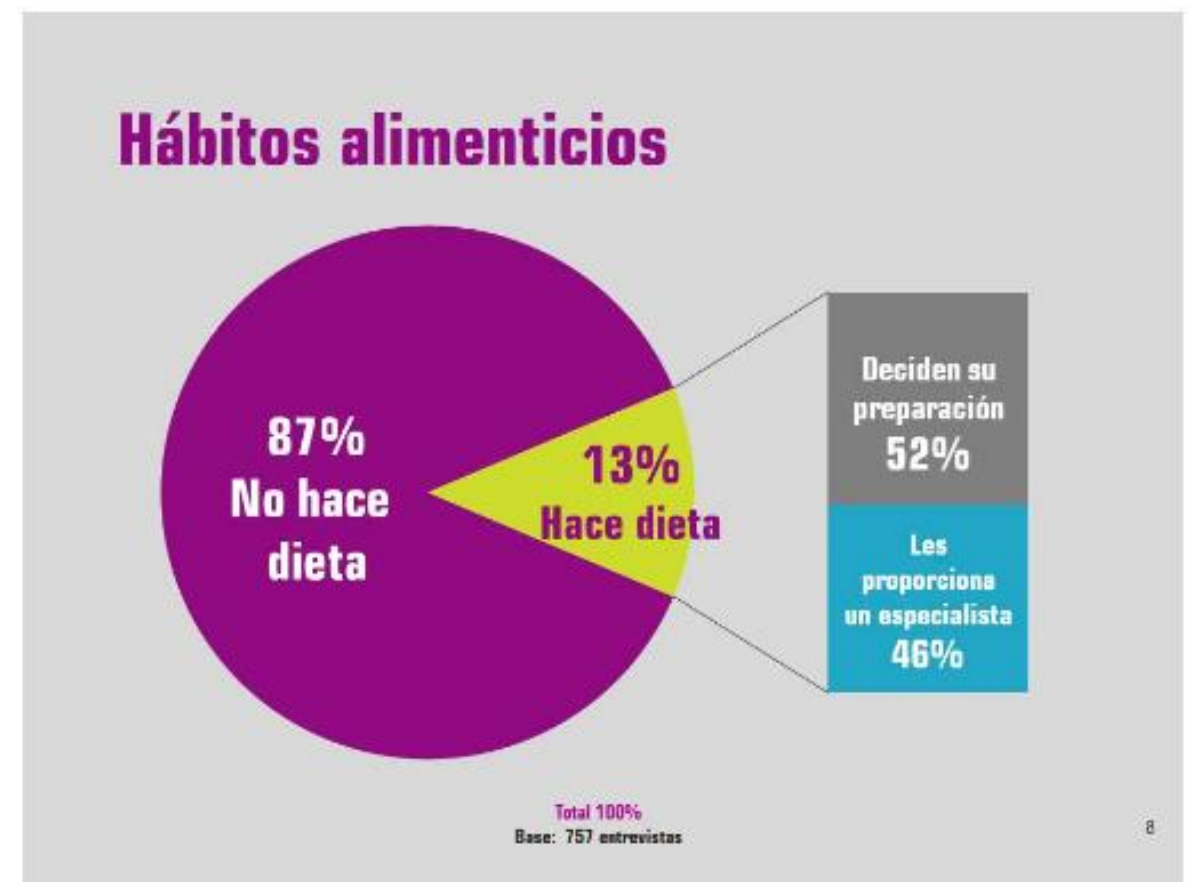

Figura 19 Hábitos alimenticios. Datos tomados de Estudio de Vida Saludable a nivel nacional dirigido por Gustavo Yrala - DATUM. Recuperado de https://www.mercadonegro.pe/datum-presenta-estudiosobre-vida-saludable/

Se observa que 4 de cada 10 peruanos considera que esta en el peso ideal; no obstante, analizando la relación talla peso indicado, un porcentaje importante se encontraría con sobrepeso. Por otra parte casi la mitad de la población evaluada ha consultado con médicos sobre temas de peso, siendo las mujeres de niveles socioeconómicos más altos las preocupadas por el tema.

Según un estudio realizado por la consultora internacional Nielsen en la ciudad de Lima, evidenció que el $90 \%$ de personas entrevistadas desean comer saludable, pero no encuentran un lugar cercano a sus oficinas o casas (El Comercio, 2017). 
Víctor Hugo de la Cruz, gerente general de Pickadeli, fast food que aspira a eliminar la idea de que comida rápida es igual a comida chatarra, asegura que los peruanos están dispuestos a pagar hasta 50\% extra por comida saludable.

De la Cruz calcula que el sector saludable, en general, creció $6 \%$ en el último año, y en el rubro de restaurantes, el crecimiento se amplía a 9\%

aproximadamente. Tomando en cuenta que la oferta de pollos a la brasa creció solo 3\%, podemos observar una clara tendencia fitness (Gestión, 2018). El mercado que demanda estos productos aún no es muy grandes pero existe y crece rápidamente.

Es importante mencionar que, el interés por el cuidado de la alimentación saludable va en constante crecimiento; según informo Fernando Cruz, representante de HelloFood (Aplicación móvil de comida delivery), el servicio delivery de comida saludable experimentó un crecimiento del 75\% en sus ventas en la ciudad de Lima, señala también que estamos siendo testigos de la expansión del delivery de comida saludable en el Perú y el incremento de estas cifras dependerá de la cantidad de empresas que adopten el delivery como alternativa de venta.

\section{OFERTA DEL SECTOR}

En el II Congreso Internacional de Gastronomía organizado por APEGA, se habló de la comida saludable como un negocio rentable y sostenible. Alexia Cook, dueña de Quinoa, primera cadena peruana de comida saludable, afirma que uno de los retos es eliminar el concepto equivocado de que la comida saludable no es rica, e introducir la idea que comer saludable es un placer. La nutricionista Miyaray Benavente propone promover alimentos peruanos sanos y agradables, tal como lo dice el lema de APEGA de la campaña Come Peruano: "Come rico, come sano, 
come peruano"; así mismo, tomar nuestros platos típicos peruanos, que contienen gran cantidad de carbohidratos, y hacerlos más saludables y balanceados, cuidando las porciones de arroz y papa y combinándolos con vegetales, de modo que puedan formar parte de nuestra alimentación diaria.

Al Perú están ingresando franquicias internacionales de comida saludable, tal como Freshii, cadena canadiense que ingreso a nuestro mercado en el año 2018 con un plan de expansión de diez locales durante los siguientes tres años. Ofrece una carta ligera que permite alimentarse de forma saludable y a un precio razonable, se puede decir que uno de los factores que contribuyen a su éxito es que los productos ofrecidos son elaborados estrictamente por nutricionistas con el fin de no solo alimentar al cliente sino proveer la energía "On the go".

En el caso de Arequipa, las empresas que brindan el servicio delivery de comida saludable exclusivamente son tres: Fit lunch, Santé y Mansana, siendo Fit Lunch, según el estudio realizado, el que tiene la mayor cuota de mercado (Ver Figura 27)

\section{TENDENCIAS DE CONSUMO}

Flavia Maggi, Vicepresidenta de Ipsos, destaco que entre las tendencias de consumo para el 2018 se encuentran el crecimiento significativo del retail, el consumo inteligente y principalmente que el cliente moderno apostará por una oferta más saludable, aun cuando este tipo de productos (bebidas o alimentos) pueden costar hasta tres veces más, el consumidor prioriza su bienestar y salud (Gestión, 2018).

Según el último estudio de Kantar Worldpanel, "Empoderamiento femenino”, “consumo saludable", "provincias" y "búsqueda de experiencias" son las tendencias 
que definirán el consumo de los hogares peruanos en el 2019 (Mercado Negro, 2018).

- Empoderamiento femenino, actualmente 7 de cada 10 mujeres peruanas contribuyen con la economía de sus hogares según una encuesta realizada por Kantar Worldpanel en septiembre del 2018, porcentaje que se incrementó en 12 por ciento en comparación al mismo mes del 2017. En tal sentido, ahorrar tiempo y la cercanía, son factores que impulsarán el consumo de las mujeres en Perú, por lo que la planificación de compras será determinante.

- Consumo saludable, se mantendrá como una tendencia con gran influencia en el consumo Según el último estudio de Kantar Worldpanel: el 87\% de hogares peruanos requieren productos más nutritivos; frente al 53\% que prefiere productos más económicos; el $21 \%$ que pide productos más prácticos; y el $11 \%$ mayor variedad en colores, sabores y aromas. Asimismo, cuando se consultó a cerca del cambio de hábitos de consumo hoy respecto a hace 3 años, se encontró que el $66 \%$ incrementó en su dieta las frutas y verduras, el $27 \%$ los productos integrales, y el $18 \%$ los productos light, disminuyendo en gran porcentaje el consumo de snacks, gaseosas, chocolates y galletas dulces.

\subsubsection{Empresas que la conforman.}

Las empresas que brindan el servicio de delivery de comida saludable en Arequipa son pocas y no son conocidas, hemos realizado un estudio de cada una identificando las características y servicios de las tres empresas encontradas. A continuación, presentamos la información obtenida: 
Tabla 6

Análisis de las características del servicio de FIT LUNCH.

FIT LUNCH

SERVICIO

\section{DESCRIPCION}

Ofrecen el servicio de delivery gratis de: menú ejecutivo (entrada, plato de fondo y refresco) y alimentación completa (desayuno, merienda mañana, almuerzo, merienda tarde y cena), planes diarios, semanales y mensuales.

El contacto con el cliente es solo a través de mensajes.

Brinda servicio de nutricionista si es que el cliente lo solicita, costo aparte.

Ofrecen solo una opción de entrada y plato de fondo diario.

Reciben pedidos hasta las 10 de la noche del día anterior.

PRESENTACION En el caso de los almuerzos, están empacados en envases de plástico con tapa dentro de una bolsa de papel. Se aprecia limpieza, sin embargo, a veces algo desordenado. Porciones suficientes y a veces grandes.

En el caso de la alimentación completa, igualmente son empacados en envases de plásticos, cambian la bolsa de papel por una caja más resistente al peso.

HORARIOS Y

FORMA DE

REPARTO
Se puede deducir que los horarios de reparto varían según los pedidos que tengan y el lugar de reparto. Pueden entregarlo durante la mañana, al medio día o hasta las dos de la tarde (se hicieron pedidos, diferentes días al mismo lugar).

El medio de transporte que utilizan es un automóvil.

CALIDAD Su servicio es de calidad óptima y buen sabor.

EMPLEADOS Dos personas (Una pareja de esposos) y un ayudante. 
Tabla 7

Análisis de las características del servicio de MANSANA.

\section{MANSANA DESCRIPCION}

SERVICIO Ofrecen el servicio de delivery gratis de: menú ejecutivo (entrada, plato de fondo, postre y refresco) solo pedidos diarios.

El primer contacto con el cliente, si es que se les envió un mensaje por cualquier medio, se comunican telefónicamente para brindar información del servicio.

Brinda servicio de nutricionista si es que el cliente lo solicita, el cual tiene un costo aparte.

Ofrecen solo una opción de entrada y plato de fondo diario.

Confirman pedidos hasta las 9 de la mañana del día de reparto.

Delivery gratis

PRESENTACION Los almuerzos, están empacados en envases de plástico con tapa dentro de una bolsa de papel. Se aprecia limpieza, sin embargo, desordenado a primera vista, porciones pequeñas no bien distribuidas en el envase.

HORARIOS Y Al hacer el pedido preguntan la hora de almuerzo, para no dejarlo muy FORMA DE temprano ni muy tarde y conserve su temperatura hasta el momento de REPARTO ser consumido.

El medio de transporte que utilizan es una bicicleta.

CALIDAD Su servicio es de calidad media y no tan buen sabor.

EMPLEADOS Dos personas (Hermanos) y un repartidor.


Tabla 8

Análisis de las características del servicio de SANTÉ.

\section{SANTÉ DESCRIPCION}

SERVICIO Restaurante que ofrece desayunos y almuerzos en su establecimiento

ubicado en Yanahuara.

Ofrecen el servicio de delivery, gratis para ocho cuadras a la redonda o con un cargo extra fuera de este perímetro, de: menú ejecutivo (entrada y plato de fondo, postre opcional con cargo extra) y menú especial (plato de fondo, postre y refresco) solo pedidos diarios.

El contacto con el cliente es a través de llamadas telefónicas.

Brinda servicio de nutricionista, si es que el cliente lo solicita, solo una consulta gratis.

Ofrecen dos opciones de entrada y plato de fondo diario, El pedido se hace durante el día.

PRESENTACION Los almuerzos, están empacados en envases de plástico algunos sin tapa, dentro de una bolsa de plástico. Se aprecia limpieza, pero desorden.

HORARIOS Y Al hacer el pedido preguntan la hora de almuerzo, para no dejarlo muy FORMA DE temprano ni muy tarde y conserve su temperatura hasta el momento de REPARTO ser consumido.

El medio de transporte que utilizan es una bicicleta.

CALIDAD Su servicio es de calidad media y buen sabor.

EMPLEADOS En el restaurante hay dos personas en la cocina, dos mozos y un repartidor. 


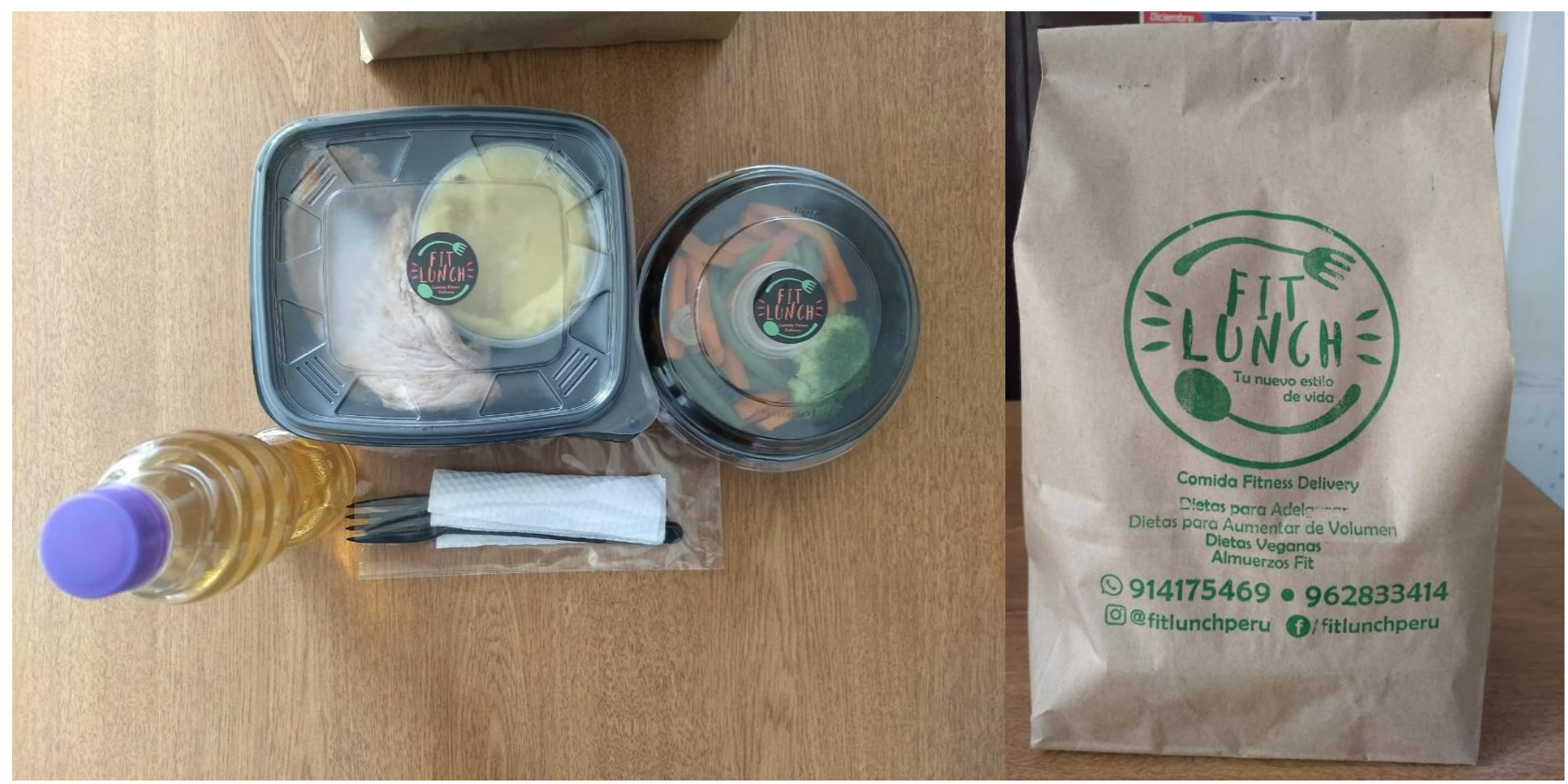

Figura 20 Presentación y empaque del producto ofrecido por la empresa FIT LUNCH.

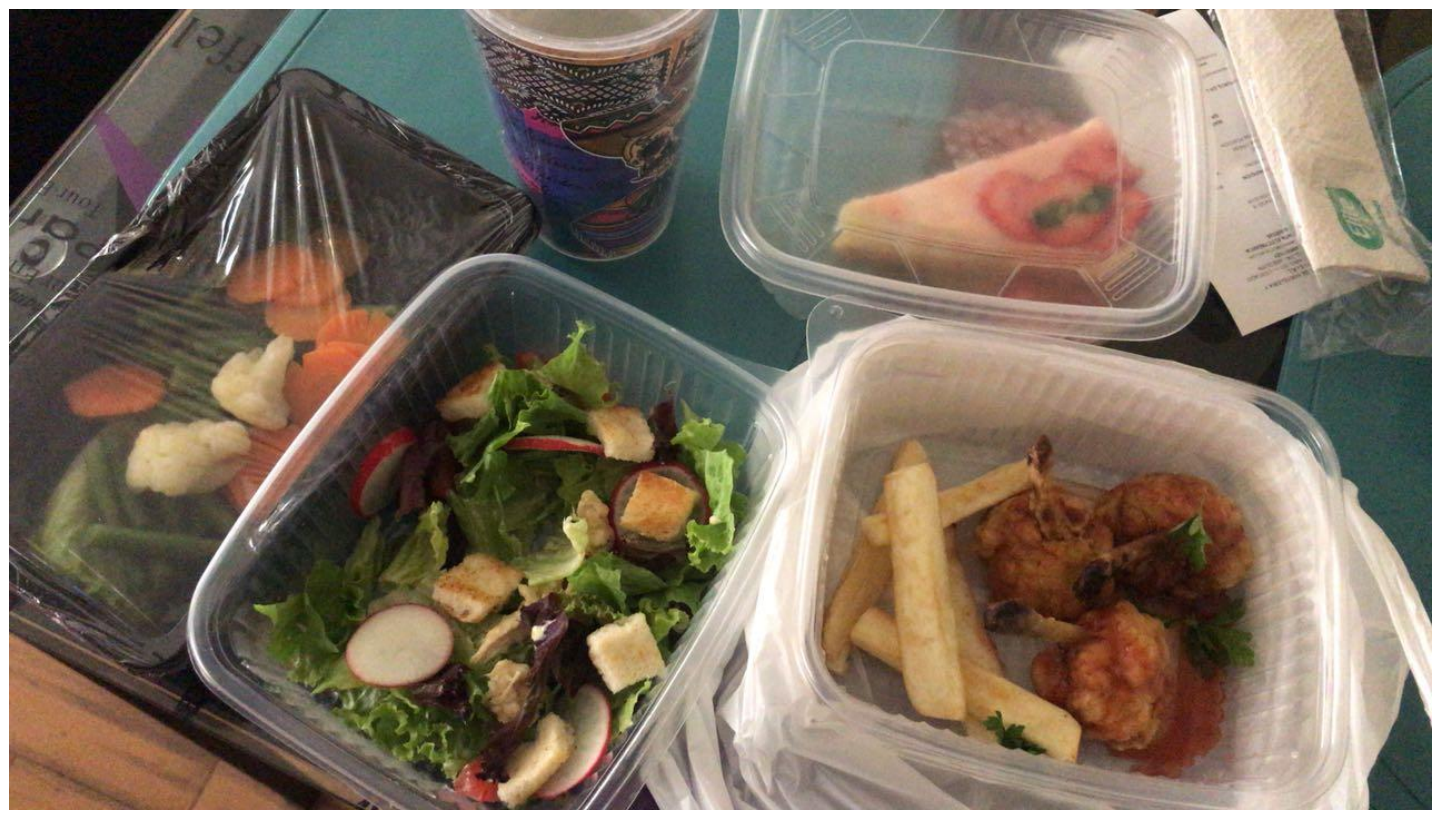

Figura 21 Presentación y empaque del producto ofrecido por la empresa SANTE. 


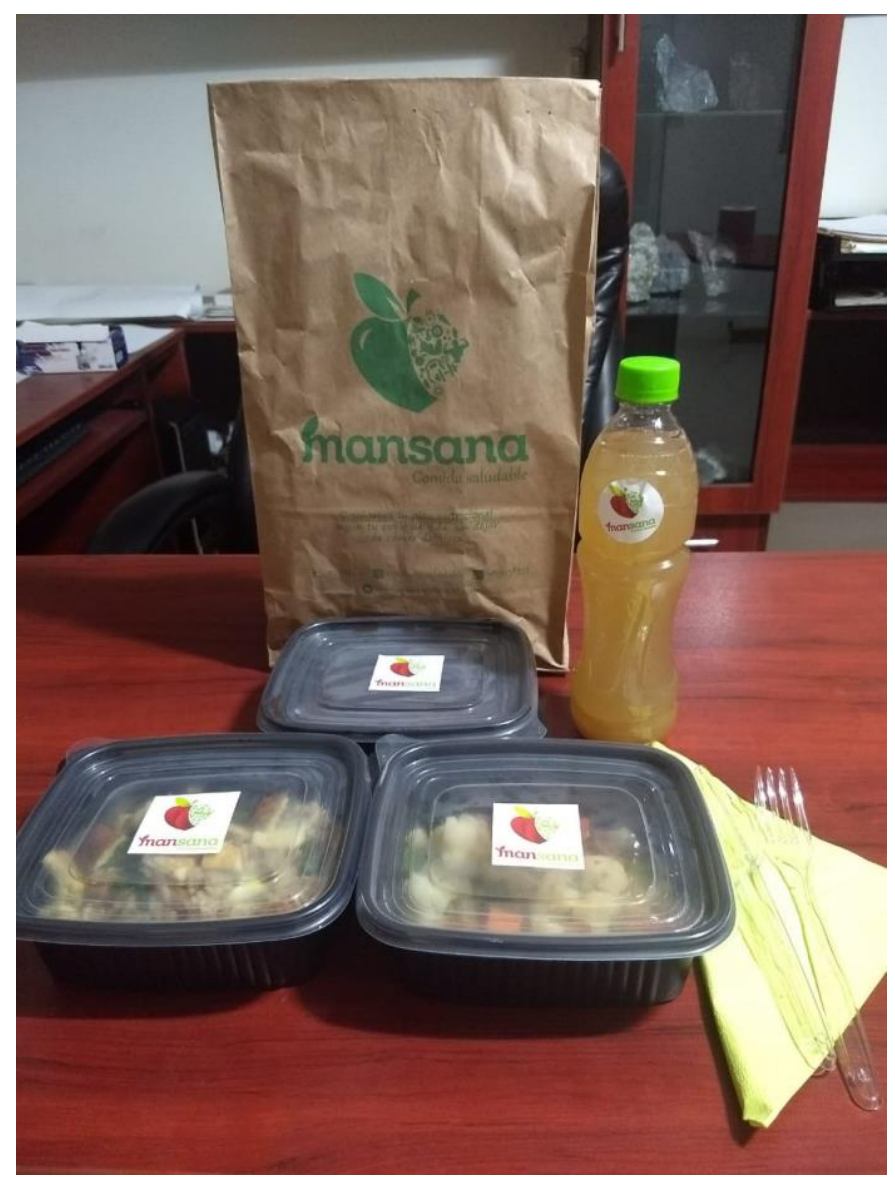

Figura 22 Presentación y empaque del producto ofrecido por la empresa MANSANA.

\subsection{Tendencias de la Industria.}

Según los resultados de las últimas encuestas nacionales de hogares, nos muestra que en el Perú se está experimentando un rápido crecimiento en la tendencia de sobrepeso y obesidad. Resaltando las cifras que se obtuvieron para el grupo de niños de 5 a 9 años, la que nos revela que el porcentaje de aquellos que se encuentran en sobrepeso creció de $19.4 \%$ a $32.3 \%$; tomando en cuenta estos resultados, es imprescindible planificar y desarrollar campañas que eduquen a nuestra población en hábitos de alimentación saludable, con información verídica, términos sencillos y sin caer en ningún tipo de demagogia (El Peruano, 2017). 
Un primer paso hacia la alimentación saludable es tomar conciencia de que una buena salud se basa en una alimentación adecuada. "Somos lo que comemos" parece una frase muy trillada, pero nada más cierto que esto, ya que es a través de lo que comemos que nuestro organismo forma sus células, se regenera y obtiene los nutrientes necesarios para un buen funcionamiento, desarrollo y autoprotección. La tendencia mundial hacia una vida más saludable y una adecuada nutrición está en crecimiento constante y el Perú no es ajeno a ello, indiferentemente del nivel socioeconómico o género. Si bien en un inicio era considerado una moda enfocada en mejorar el aspecto físico, con la información disponible y las campañas realizadas por diversas organizaciones se intenta redireccionar este interés por los hábitos saludables hacia un estilo de vida.

Debido al incremento en la demanda de productos sanos y naturales, las grandes industrias se han visto obligadas a adaptar sus productos a formatos más saludables y en algunos casos a crear nuevas líneas de negocio para satisfacer este mercado en crecimiento. Así mismo, han surgido empresas especializadas en productos naturales y/o orgánicos que ofrecen productos especializados y dirigidos a aquellos que buscan cuidar su alimentación.

Giselle Huanqui encargada de marketing del biomarket La Sanahoria, considera que la labor más importante que cumplen este tipo de tiendas es educar a sus consumidores y clientes sobre cómo elegir los productos según los nutrientes que su organismo requiera (El Comercio, 2017).

Esta preocupación por saber lo que estamos consumiendo, obliga a los consumidores a aprender a interpretar las etiquetas con información nutricional y leerlas con detenimiento, buscando productos novedosos, sanos y nutritivos. A partir de esto podemos identificar la clasificación de productos en orgánicos, integrales, funcionales y ligth. 
1. Orgánicos: productos que se cultivan, crían y procesan utilizando únicamente métodos naturales. No contienen aditivos químicos ni ningún tipo de compuesto sintético.

2. Integrales: conservan el grano del cereal íntegro, procurando que el producto contenga más fibra, vitaminas y minerales. La función de la fibra es mantener el tracto gastrointestinal funcionando correctamente y las vitaminas y minerales desarrollan defensas naturales en nuestro cuerpo.

3. Funcionales: buscan potenciar la salud, añadiendo nutrientes que tienen efectos positivos en el organismo, como el omega 3, el DHA, el ácido fólico, entre otros.

4. Light: productos que contienen cerca del $50 \%$ menos de un nutriente específico (azúcar, grasa o sodio) en comparación a su versión regular. Aunque permiten que el consumidor controles la ingesta de uno de estos componentes, generalmente, reducen un componente y aumentan otro. Es recomendable, en el caso de estos productos, revisar los valores nutricionales para no caer en un error.

Hoy en día es muy fácil para las empresas conocer las preferencias, necesidades y hábitos de consumo del mercado, y deberán usar esta información para crear o adaptar sus productos actuales para responder mejor a la demanda y necesidades de sus consumidores.

La plataforma ComeBien.pe identifica 4 factores que demuestran el empoderamiento del consumidor en la actualidad:

1. Mayores exigencias del consumidor. - Si bien en términos generales en el mercado se ofrecen productos o servicios que satisfagan las necesidades del consumidor, es en la industria alimentaria, donde se refleja claramente que las marcas están al servicio del consumidor. En este sentido, se han identificado grupos insatisfechos con los productos 
que se ofrecen en el mercado, que requieren diferentes alimentos, ricos en nutrientes o según los requerimientos de su organismo y las empresas responden con acciones concretas.

2. Productos más naturales y sanos. - Últimamente es común que los consumidores tengan preferencia por productos que sean beneficiosos para su salud, aun cuando paguen más por ellos. Vemos, por esta razón, que surgen nuevas marcas de productos orgánicos, naturales, y libres de aditivos químicos, teniendo gran acogida en el público.

3. Menor cantidad de azucar- Es común escuchar críticas acerca del consumo elevado de azúcar, como consecuencia se buscan alternativas saludables pero que no altere el sabor del producto. Así mismo, procuran que el consumidor se detenga a leer el contenido nutricional de cada producto y regular la proporción de nutrientes consumidos a lo largo del día y según su actividad física.

4. Mayor información de lo que compran - Contrario a lo que la mayoría de personas piensan, cada vez son más los consumidores que se preocupan en leer y entender las etiquetas de los productos. De acuerdo a la última encuesta de CPI (Compañía Peruana de Investigación de Mercados), el $87 \%$ de peruanos lee las etiquetas de los alimentos y bebidas procesadas, indicando que en los últimos 30 días han leído por lo menos una etiqueta.

$\underline{\text { La penetración de las comidas ultra procesadas en provincias }}$

Las tendencias, sin embargo, parecen ir hacia un agravamiento de la malnutrición que termina en sobrepeso y obesidad. La cantidad de malls, que ineludiblemente cuentan con «patios de comida» y supermercados, incrementan cada vez más, no solo en los distritos de 
Lima, sino también en varias ciudades del interior, llevando propuestas de consumo de alimentos y bebidas diferentes a los de la región, con conservantes, con exceso en azúcar, grasas, sodio y otros elementos de las comidas insanas.

Podríamos decir que la aparición de estos centros comerciales, cuyo número cada vez es mayor, contribuye al incremento del sobrepeso y la obesidad en las provincias. Según analistas de mercado, en el Perú los supermercados aún tienen espacio para crecer, pues mientras que en otros países como Chile o México la proporción entre área de supermercados y habitantes es casi 5 veces mayor que en Perú. De todos modos, ya hay en el país más de 40 malls en alrededor de 20 provincias, y otros tantos en Lima (Eguren, 2015).

Otra tendencia que crece continuamente y algo en lo que coinciden los medios especializados, es que en 2018 el veganismo continuará en imparable ascenso. La demanda crece y, como consecuencia, la oferta va aumentando mejora, y empieza a especializarse, no cabe duda que llegue a la alta cocina.

En el 2015 nació la primera comunidad saludable en el Perú, Lima Orgánica propuso un nuevo modelo de comida sana, una alternativa no tan conocida ni comercial en el mercado peruano. La tendencia se dirigía hacia productos saludables y hoy en día el 78\% de peruanos busca tener alternativas orgánicas y naturales en sus comidas, ocupando uno de los niveles más altos niveles de la región. Siempre habrá alternativas para comer de forma saludable y según las necesidades de cada uno.

Lucho Carbajal, actual director de Lima Orgánica, afirma que el mercado de comida saludable ha ido evolucionado de una forma realmente optimista y la cantidad de locales 
que ofrecen comida saludable va en aumento, ya sea en centro comerciales como en zonas de bastante concurrencia. Un factor importante es que la gente demanda este tipo de alimentos.

Lima Orgánica ha ido creciendo poco a poco en la plataforma digital, iniciando con 12 marcas entre restaurantes y tiendas, para actualmente contar con más de 100 marcas en diversas categorías. Llevar un estilo de vida saludable no solo se refiere a la alimentación, sino que agrupa otras categorías como belleza, cuidado personal, artículos del hogar y todo aquello que fomente una cultura saludable en la sociedad (Gestión, 2017)

\section{$\underline{\text { Educación sobre alimentos }}$}

Como se mencionó anteriormente, el consumidor se encuentra cada vez más empoderado, es así que, a la hora de comer no solo buscan alternativas saludables, sino que éstas tengan el mismo sabor atractivo que el de una comida tradicional.

En esta tendencia de mantener una vida saludable, los millenials son los más exigentes, ya que no solo buscan insumos naturales, de procedencia conocida y que tenga un sabor agradable, sino que prepararlos no tome mucho tiempo, exigen cosas simples por su apresurada vida.

La industria alimentaria y la gastronomía juegan un papel importante al buscar insumos que cumplan con todos los requerimientos, bajos en sodio y grasa, reducidos en calorías y azúcares, enriquecidos con minerales y fibras serán los preferidos. Sería favorable tener en las cartas permanentemente opciones que cumplan con estas condiciones. La falta de tiempo hace que sea imposible preparar nuestras comidas personalmente, por lo que se buscan opciones saludables fuera de casa. 
La posibilidad de un menú delivery que brinde el servicio de desayunos, almuerzos y cenas saludables y adicionalmente ofrezca alternativas variadas de menú, que vayan más allá de ensaladas y fruta, sin tornarse aburrido, es una de las características más atrayentes de la tendencia. Como valor agregado, se puede ofrecer el servicio de evaluación y asesoría nutricional a cargo de un especialista, en la que deberá respetar las indicaciones de la dieta con gramajes y medidas exactas (Rengifo, 2017).

Aunque esta tendencia está tomando fuerza hace poco tiempo, no es apresurado decir que se ha instalado para quedarse. Los consumidores buscan lo mejor para su cuerpo, alma y mente. Debemos tener claro que no es una moda pasajera como muchas otras, sino que se ha tomado conciencia y se quiere vivir mejor.

\subsection{Análisis estructural del sector industrial:}

La comida rápida, o fast food, llegó al Perú en la década de 1980. Actualmente, es uno de los negocios que se está expandiendo con mayor fuerza y rapidez en nuestro país y no solo en la modalidad de alimentos altos en calorías, azúcar, sal y grasas saturadas; sino que, están surgiendo opciones de fast food de comida saludable, llamada también "fast good", como Pickadeli que cuenta ya con dos locales en Lima. Esta alternativa surge como consecuencia de satisfacer las necesidades de aquellas personas con un estilo de vida agitado, convirtiéndose en cadenas y restaurantes que se caracterizan por: tener los alimentos listos, atención rápida y precios razonables.

De la mayoría de ciudadanos, su vida diaria transcurre en el trabajo, tenido poco tiempo para pasar con su familia y/o poder preparar sus alimentos, es por ello que muchas personas acuden a establecimientos de comida rápida, restaurantes o solicitan un servicio de delivery; siendo la hora del almuerzo el momento de mayor concurrencia. 
Es de suponerse que Lima concentra el mayor porcentaje de consumo, siendo el 65\% del total del país. Según un estudio realizado por Mapcity.com, empresa especializada en geobusiness intelligence para Latinoamérica, en el 2017 identificó a 557 locales de comida rápida en el Perú de los cuales 419 se encuentras repartidos entre Lima y Callao y 138 en provincias, siendo los departamentos de Arequipa y La Libertad aquellos en los que se encuentran un mayor número, 55 y 33 locales respectivamente.

Para el 2017 se estimó que los fast food en el Perú iban a tener una rentabilidad del 20\% con ventas de US\$700 millones según estimaciones de Front Consulting. Según Luis Kiser, presidente de dicha consultora, una persona consume el valor de $\mathrm{S} / 25$ en promedio cada vez que visita este tipo de establecimientos.

La tendencia actual es que, las personas se preocupen cada vez más por su salud y alimentación. Aunque los establecimientos de comida rápida tradicional están respondiendo de forma positiva a esta preocupación, con acciones como: incluir alternativas saludables entre sus opciones y brindar información nutricional y de los ingredientes que contienen sus menús, en poco tiempo esto no será suficiente, ya que el consumidor será más exigente con respecto a tener una alimentación saludable y sobre todo buscará variedad de opciones y no solo ensaladas.

Para poder tener una estrategia competitiva óptima se deberá conocer bien el entorno de la competencia, la cual está conformada por empresas que brindan el servicio de delivery de comidas saludable; diferenciándonos de estas por prestar un servicio de calidad superior, ofreciendo un menú variado, balanceado, una presentación agradable a la vista y entrega en horario oportuno según las necesidades de cada cliente 
A continuación, realizaremos el estudio de las cinco fuerzas competitivas según Porter en el sector restaurantes:

1. Amenaza de los nuevos ingresos.

2. Rivalidad entre los competidores existentes.

3. Amenaza de productos o servicios sustitutos.

4. Poder negociador de los clientes.

5. Poder negociador de los proveedores.

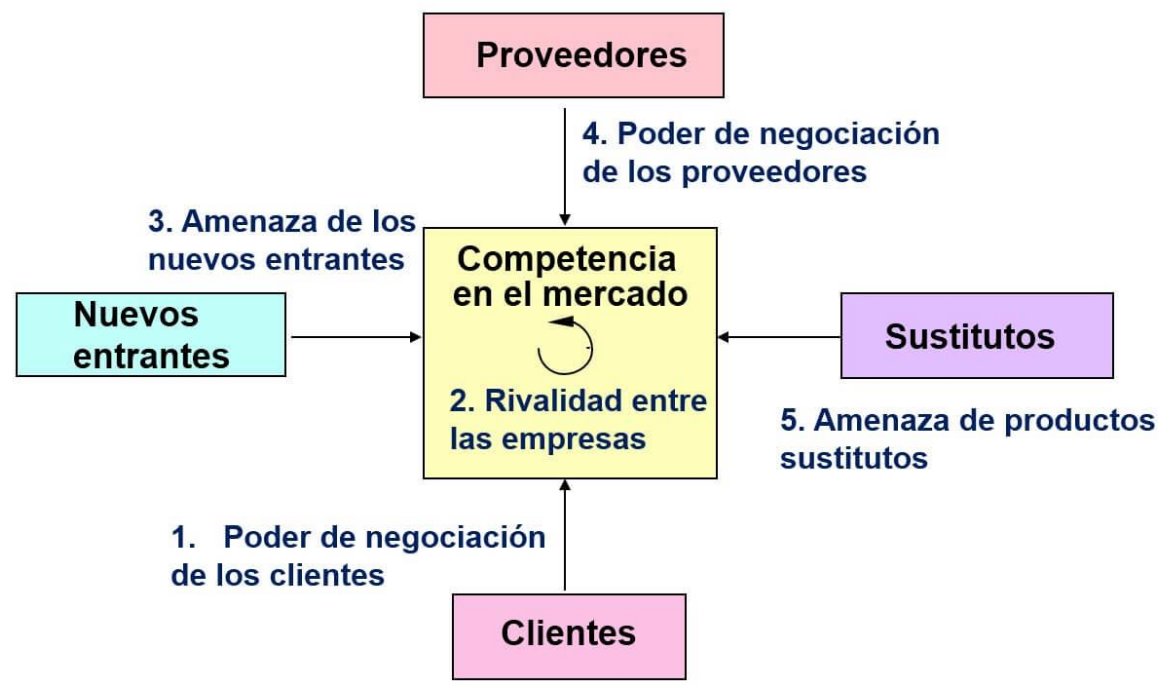

Figura 23 Diagrama de las cinco fuerzas de Porter - Clave para el éxito de una empresa. Tomado de http://www.5fuerzasdeporter.com/

Al ser una empresa nueva lo que se buscará a través de este análisis será, identificar aquellos aspectos externos que nos ayudaran a conocer la estructura del sector al que pretendemos ingresar, para poder posicionarnos en el mercado. 


\subsubsection{Desarrollo de las fuerzas competitivas de Porter:}

\subsubsection{Amenaza de los nuevos ingresos.}

En general en el sector restaurantes esta amenaza puede ser determinante, ya que es común el ingreso de nuevas empresas al mercado y esto puede afectar los resultados que tenga el negocio.

Para poder evitar una situación de inestabilidad en el rubro específico, que nos conlleve a bajar precios, e inflar costos, deberemos tener las barreras de ingresos al negocio bien identificadas, dentro de ellas encontramos las siguientes:

- Diferenciación del producto: Nuestro objetivo será posicionarnos en el mercado, por nuestra calidad, desarrollando la lealtad del cliente con ayuda de una buena publicidad y la buena atención al cliente (generando satisfacción en relación al precio-calidad brindada en nuestro producto). Esta barrera nos ayudará a que, la posible competencia que planee ingresar al mercado tenga cierta dificultad al intentar posicionarse y obtener una cuota de mercado aceptable.

- Requisitos de capital: Para poder ingresar a un nuevo mercado a competir, se genera una nueva barrera de ingreso que será la escasez de recursos financieros para poder invertir (capital de inversión), teniendo en cuenta que hay inversiones que se hacen en este tipo de negocio y son irrecuperables en su naturaleza, tales como: inventarios, publicidad agresiva, desarrollo e investigación del mercado. 
- Costos cambiantes: Esta es una barrera que surge en este tipo de negocio, por la inestabilidad de los precios de nuestros insumos, ya que hay precios que varían según temporadas en frutas y verduras, generando así una barrera para los nuevos ingresantes en el mercado.

- Economías de escala: Para esta industria no existen grandes requerimientos de economías de escala, dado que en general no es necesario lotes grandes de producción para una empresa que recién ingresa al mercado a competir.

- Curva de aprendizaje o experiencia: Esta será una de las barreras más difíciles que afrontaremos como negocio, sin embargo, tendremos que aprovechar nuestra etapa de desarrollo de mercado, para ganar la experiencia necesaria que nos ayude a ser sostenibles en el tiempo, minimizando nuestras debilidades como negocio novato en el rubro.

Las barreras de ingresos van cambiando según las condiciones dadas por el mercado; sin embargo, en ocasiones también cambian por la administración del negocio y por el impacto que pueden generan las decisiones estratégicas.

\subsubsection{Rivalidad entre los competidores existentes.}

En este tipo de mercado las empresas que compiten son mutuamente dependientes, generando competencia directa, que permite usar estrategias enfocadas en competencia de precios, las famosas batallas de publicidad, mejora del servicio al cliente y la introducción de nuevos productos. En nuestro caso en particular la competencia existente, aparentemente, no posee una 
estrategia de marketing fuerte ni competitiva, son opciones que se están dando a conocer poco a poco y que aún no están posicionadas en el mercado.

La rivalidad es el resultado de diferentes factores estructurales:

- Cuando encontramos numerosas empresas en el mercado.

Gran número de competidores:
Crecimiento lento en el sector industrial:

- Un crecimiento lento origina que la competencia se convierta en un juego por alcanzar una mayor participación en el mercado.
Costos fijos elevados o de almacenamiento:
- Estos costos fijos elevados crean fuertes presiones para que las empresas operen a plena capacidad.
- Cuando en el mercado se percibe al producto casi sin diferencia, la elección de los clientes esta basada por el precio y da como resultado lacompetencia.

\section{Falta de
diferenciación:}

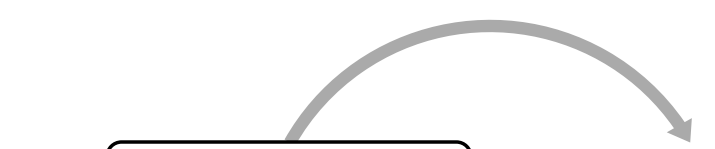

\section{Competidores} diversos:

- Los competidores poseen distintas estrategias y tienen diferentes objetivos sobre la forma de competir, generando enfrentamiento.
- Son factores económicos, estratégicos y emocionales qye mantienen a empresas compitiendo aun cuando tengan rendimientos bajos o incluso negativos sobre la inversión.

Fuertes barreras de salida:

Figura 24 Factores que generan la rivalidad entre competidores. 


\subsubsection{Amenaza de servicios o productos sustitutos.}

Esta amenaza de alguna manera repercutirá en establecer el precio del producto brindado en el mercado, ya que los productos sustitutos limitan los rendimientos potenciales de un sector industrial, estableciendo un límite en los precios que las empresas manejan dentro del rubro y que les generan rentabilidad.

La identificación de los productos sustitutos se basa en la búsqueda de otros productos que puedan desempeñar la misma función; en nuestro caso, la alimentación saludable de los consumidores no tiene gran competencia en el mercado, solo podría ser sustituida por comida vegetariana, nikkei, salad bar y cafeterías que tengan opciones saludables en su carta.

Es casi improbable que alguien que busque alimentación saludable opte por consumir alimentos con alto contenido de grasa, sal o azúcar.

\subsubsection{Poder negociador de los clientes.}

Los clientes son la base de todo negocio, y por ende también del nuestro. Ellos compiten entre sí forzando, indirectamente, a los negocios del rubro a mejorar la calidad sin que exista una gran diferencia en precios, generando así la competencia entre las empresas que están en el mercado.

Nuestro proyecto está orientado a personas que ya consumen alimentos saludables o tienen interés en hacerlo, que viven y/o trabajan en la zona, pero que no disponen de mucho tiempo para buscarlo o prepararlo y desean un servicio puntual y rápido, sin embargo, actualmente no existen empresas que brinden un servicio con dichas características. 
Como empresa competitiva, tendremos que desarrollar la lealtad del cliente satisfaciendo sus necesidades, para poder concentrar volúmenes de ventas a través de nuestro producto diferenciado en la industria.

\subsubsection{Poder negociador de los proveedores.}

Esta fuerza de Porter, también juega un papel protagónico en todos los negocios, ya que de alguna manera amenaza con determinar los precios del producto, y coloca en una posición vulnerable al negocio, ya que al no existir un buen poder de negociación con el proveedor estamos vulnerables a la elevación de los costos y la reducción en la calidad del producto brindado en el mercado.

Para el mercado de alimentos en general, el poder de los proveedores es medio-bajo, dada la cantidad de oferentes que existen de los insumos tipo alimenticio que se utiliza, tales como fruta fresca, carne, verduras frescas, pescado, pollo, etc. Sin embargo, para ciertas empresas, como la nuestra, un insumo importante y diferenciador en el mercado de alimentos delivery, es el envase que contendrá la orden solicitada, ya que estos cuentan con características principales de diseño, forma y utilidad (especialmente hechos para ser calentados en el microondas). Nuestro proyecto está optando por envases ecológicos, ya que al fomentar la vida saludable debemos también reflejarlo en nuestra imagen, actualmente los proveedores de estos envases son pocos, lo que nos condicionara un poco a ciertos proveedores. 
Para poder afrontar esta negociación se aplicarán estrategias de integración que nos ayudarán a disminuir las amenazas que hay en el entorno industrial y nos ayuden a obtener un mayor control.

\subsubsection{Atractividad del mercado según las cinco fuerzas de Porter.}

Según la información analizada para cada una de las fuerzas de Porter, procederemos a presentar la matriz de atractividad de la industria, en la que evaluaremos cada ítem, calificando su atractividad con valores que van del 1 al 5, donde 1 es menos atractivo y 5 muy atractivo. A las 5 fuerzas de Porter se les ha asignado un peso, sumando en total 1.

Tabla 9

Matriz de atractividad del mercado

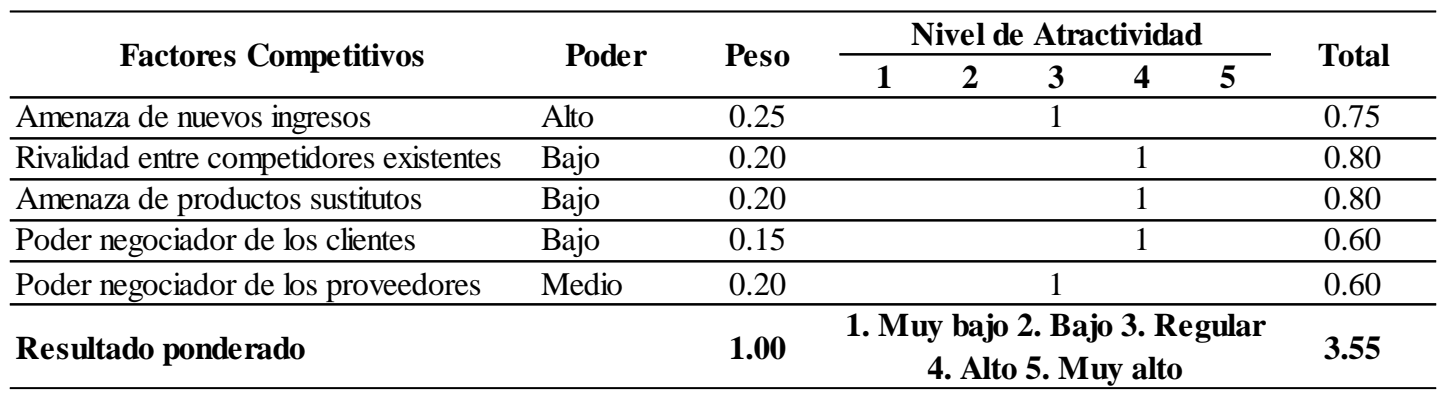

Elaboración propia

Según los resultados de nuestra matriz podemos concluir que:

a. La amenaza de ingreso de nuevos competidores es ALTA, las barreras de entrada no significan una gran dificultad para ingresar al sector. La inversión inicial no es muy alta, el costo de implementación no es elevado ya que no se necesita un lugar físico para la venta del producto y los costos que ello implica; si bien el mercado de lo saludable en general es una de las tendencias más fuertes de consumo, el mercado de la 
alimentación saludable aún no es muy grande pero va creciendo rápidamente, el producto se hace cada vez más conocido y requerido; los procesos de elaboración no son difíciles y no es necesaria gran tecnología, sin embargo, la presencia de un especialista en nutrición es sumamente necesaria.

b. La rivalidad entre competidores existentes es BAJA, actualmente existen pocas empresas que brindan este servicio, en un entorno en donde la tendencia por la alimentación saludable es creciente, añadido a que presentamos una propuesta diferente y mejorada. Nos daremos a conocer a través de publicidad en la zona de influencia, ofreciendo un servicio diferenciado que logre llegar a la mayor cantidad de público objetivo desde antes de iniciar actividades; logrando, con el tiempo, convertirnos en la primera opción de los clientes.

c. La amenaza de productos sustitutos es BAJA, existen una cantidad considerable de opciones de alimentación en la zona de influencia, sin embargo, no desempeña la función principal que brinda nuestro producto, que es la alimentación saludable, es por esto que nuestra estrategia de diferenciación tiene un papel importante.

d. El poder negociador de los clientes es BAJO, en la industria gastronómica tenemos una gran cantidad de posibles clientes que representan la mayor proporción del éxito del negocio; es por ello, que debemos definir al cliente como aquella persona que busca comprar en el mercado a un precio más favorable y con la mejor calidad, por lo que 
su decisión se vuelve más selectiva y define el éxito o fracaso del negocio. Sin embargo, debemos tomar en cuenta que actualmente existe una mayor proporción de clientes interesados en la alimentación saludable y las opciones delivery en la zona son pocas lo que ocasiona que los clientes no tengan opción de negociación, añadido a esto que sus productos no son variados.

e. El poder negociador de los proveedores es MEDIO, si bien es cierto que en este rubro hay gran cantidad de proveedores, la calidad de los insumos es relevante, es importante contar con los proveedores adecuados que nos brinden el soporte necesario para lograr nuestros objetivos de calidad del producto y esto puede verse reflejado en el precio que nos ofrezcan lo que al mismo tiempo influye en la rentabilidad. Así mismo, buscamos que el envase utilizado para el transporte sea un elemento diferenciador por lo que se optara por envases ecológicos, actualmente existen pocos proveedores de este tipo de envases, ya que recién están entrando al mercado.

\subsection{Análisis de la competencia.}

En la ciudad de Arequipa, se puede observar actualmente que es complicado hacerse espacio en un mercado determinado, dejando de lado la importancia de la pequeña, mediana o gran empresa. El acecho de la competencia se torna más fuerte en el tiempo, ya que los clientes se fidelizan a las empresas según el grado de calidad de las mismas, y eso obliga a estar a la vanguardia de los subsistentes cambios que implica el desarrollo de calidad del producto con relación al tiempo en el mercado. 
Esto permite a las nuevas empresas y/o negocios en el mercado formas de diferenciarse de sus competidores, buscando así la innovación para darse a conocer y afianzarse en el mercado.

Para lograr esta diferenciación debemos primero, enfocarnos en conocer a los competidores y analizar su forma de trabajo, observando sus estrategias de marketing y poder determinar quiénes son sus clientes. Esto nos dará como resultado una visión global del negocio y sobre todo del mercado al cual pretendemos incorporarnos.

Al realizar un análisis de la competencia de manera adecuada, también nos permitirá generar una amplia lista de fortalezas y debilidades de nuestra competencia directa e indirecta que, a través del conocimiento de las mismas, nos apoyaremos en la formulación de las estrategias de marketing que usaremos para poder introducirnos y afianzarnos en el mercado; y finalmente obtener la lealtad de nuestros consumidores finales; teniendo siempre como premisa la calidad de nuestro producto.

Para poder generar el plan de negocios exacto, deberemos considerar todas aquellas empresas que representan de alguna manera ser nuestra competencia en el mercado, buscando las similitudes de sus productos con el nuestro.

Hoy en día, en la ciudad de Arequipa, existen varias opciones que proporcionan alimentación saludable al público y que no necesariamente están en el mismo rubro gastronómico, es por ese motivo que para realizar el análisis correspondiente, decidimos agrupar estas empresas y/o negocios según su rubro, y consideramos los siguientes:

- Comida vegana.

- Comida nikkei. 
- Salad bar.

- Cafeterías/ snack.

Dentro de los cuatro rubros anteriormente mencionados, encontramos opciones saludables que se brindan como alternativa de alimentación en el mercado; y que podríamos considerar competencia indirecta, ya que no ofrecen exactamente el mismo producto de nuestro negocio, pero sí podría ser considerados productos sustitutos, que en algunos casos también realizan el servicio de delivery.

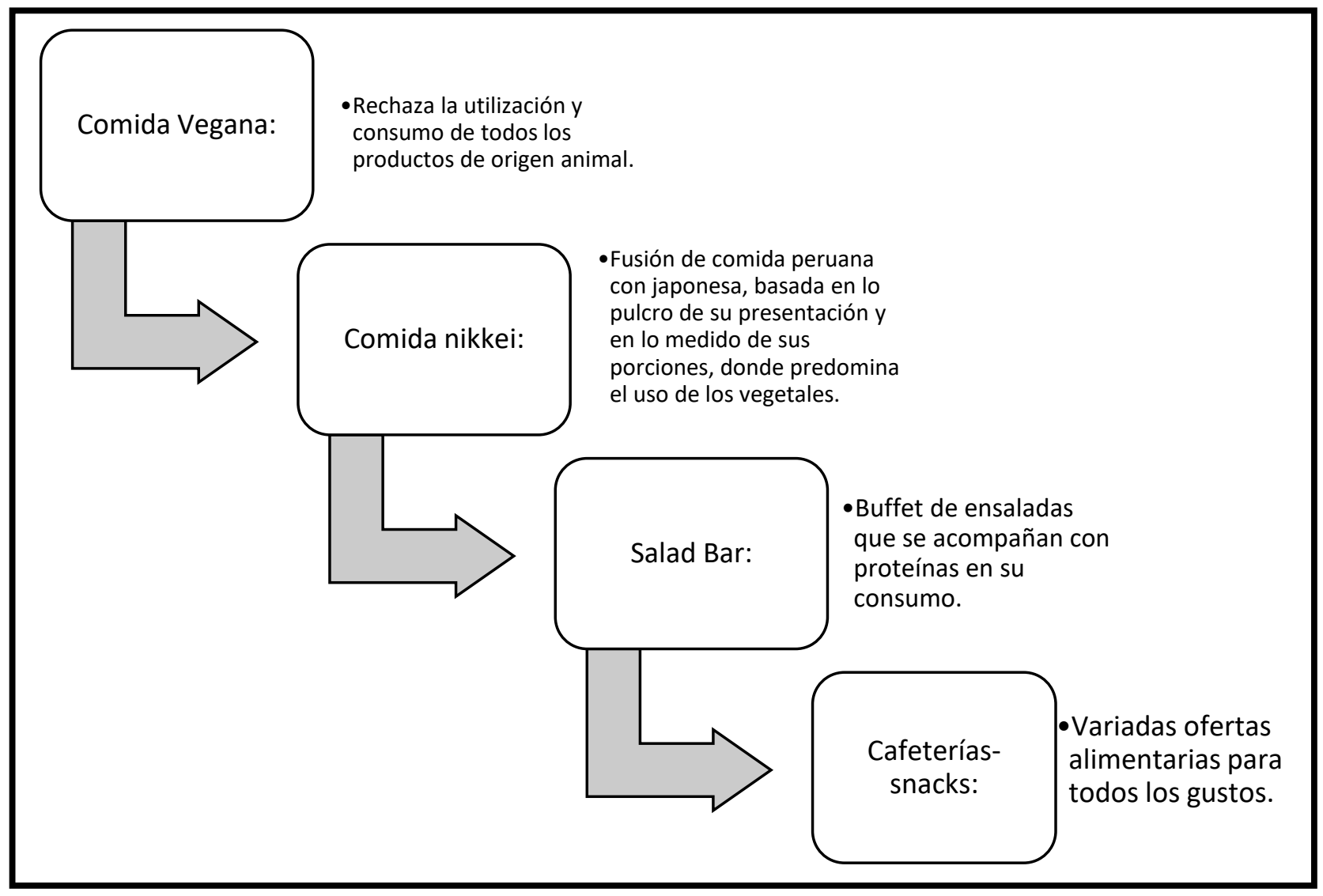

Figura 25 Alternativas de comida saludable en la ciudad de Arequipa. 


\subsubsection{Caracterización de los competidores que ofrecen productos o servicios similares.}

Plasmaremos los puntos determinantes del análisis realizado a la competencia, en la siguiente tabla:

Tabla 10

Análisis de características de competidores indirectos.

\begin{tabular}{|c|c|c|c|c|}
\hline ÍTEMS: & $\begin{array}{c}\text { COMIDA } \\
\text { VEGETARIANA: }\end{array}$ & COMIDA NIKKEI: & SALAD BAR: & $\begin{array}{c}\text { CAFETERÍAS Y } \\
\text { SNACKS: }\end{array}$ \\
\hline $\begin{array}{c}\text { Servicio } \\
\text { Principal. }\end{array}$ & $\begin{array}{l}\text { Brindar comidas, } \\
\text { meriendas, postres, jugos, } \\
\text { aguas detox con la } \\
\text { filosofía de ser "sanas y } \\
\text { amigables" para el } \\
\text { consumidor. }\end{array}$ & $\begin{array}{l}\text { Brindar una nueva } \\
\text { alternativa de } \\
\text { alimentación en el } \\
\text { mercado, enfocada en la } \\
\text { combinación de comida } \\
\text { peruano-japonesa, } \\
\text { identificando el tamaño de } \\
\text { las porciones. }\end{array}$ & $\begin{array}{l}\text { Brindar una amplia } \\
\text { combinación de ensaladas } \\
\text { al consumidor. }\end{array}$ & $\begin{array}{l}\text { Brindar satisfacción } \\
\text { inmediata al consumidor, } \\
\text { a través de productos de } \\
\text { elaboración simple. }\end{array}$ \\
\hline $\begin{array}{l}\text { Estilo, Calidad } \\
\text { y Presentación } \\
\text { de Platos. }\end{array}$ & $\begin{array}{l}\text { Amplia carta de platos y } \\
\text { bebidas, cubriendo los } \\
\text { requerimientos } \\
\text { nutricionales de los } \\
\text { insumos de origen animal } \\
\text { con productos alternativos }\end{array}$ & $\begin{array}{l}\text { Brinda al mercado una } \\
\text { carta de platos con } \\
\text { nombres temáticos, sus } \\
\text { preparaciones son } \\
\text { sofisticadas y se destacan } \\
\text { por el tamaño de sus }\end{array}$ & $\begin{array}{l}\text { Cocina simple } \\
\text { (sancochados en su } \\
\text { mayoría) pero con amplia } \\
\text { variedad de ensaladas } \\
\text { constituidas por } \\
\text { legumbres y verduras, que }\end{array}$ & $\begin{array}{l}\text { Básico la hora del } \\
\text { almuerzo, brindando al } \\
\text { mercado meriendas } \\
\text { rápidas de preparar, } \\
\text { consideradas como } \\
\text { "productos al paso", }\end{array}$ \\
\hline
\end{tabular}




\begin{tabular}{|c|c|c|c|c|}
\hline & $\begin{array}{l}\text { de origen vegetal. } \\
\text { Buscando la innovación } \\
\text { de sus productos } \\
\text { constantemente. }\end{array}$ & $\begin{array}{l}\text { porciones y la buena } \\
\text { calidad de su materia } \\
\text { prima principal: } \\
\text { preparaciones a base de } \\
\text { pescados y/o atún, } \\
\text { fusionándola con } \\
\text { vegetales. }\end{array}$ & $\begin{array}{l}\text { a su vez son acompañadas } \\
\text { con proteínas, teniendo la } \\
\text { facilidad de hacer } \\
\text { diferentes combinaciones } \\
\text { y eso hace divertida su } \\
\text { carta de productos en el } \\
\text { mercado. }\end{array}$ & $\begin{array}{l}\text { destacando en las } \\
\text { cafeterías la incorporación } \\
\text { de ensaladas acompañadas } \\
\text { con porciones de } \\
\text { proteínas, y el consumo } \\
\text { de jugos naturales. }\end{array}$ \\
\hline $\begin{array}{c}\text { Tiempo de } \\
\text { servicio y } \\
\text { profesionalismo } \\
\text { en la atención. }\end{array}$ & $\begin{array}{l}\text { Atención medianamente } \\
\text { lenta, estando } \\
\text { condicionada al tiempo de } \\
\text { entrega de los platos a } \\
\text { ordenar, personal con } \\
\text { conocimiento general } \\
\text { sobre los platos y de perfil } \\
\text { joven. }\end{array}$ & $\begin{array}{l}\text { Atención medianamente } \\
\text { lenta, también } \\
\text { condicionada al tiempo de } \\
\text { entrega de los platos, } \\
\text { personal con poco } \\
\text { conocimiento en la carta. } \\
\text { Se presenta bastante } \\
\text { rotación de personal en } \\
\text { este tipo de industria } \\
\text { gastronómica. }\end{array}$ & $\begin{array}{l}\text { Atención súper rápida, } \\
\text { demora lo que el } \\
\text { consumidor invierte de } \\
\text { tiempo en generar las } \\
\text { combinaciones que } \\
\text { requiere para su } \\
\text { alimentación. Se observa } \\
\text { auto atención en este tipo } \\
\text { de servicio. }\end{array}$ & $\begin{array}{l}\text { Atención efectivamente } \\
\text { rápida, personal con } \\
\text { conocimiento general } \\
\text { sobre la elaboración de la } \\
\text { carta brindada al mercado. }\end{array}$ \\
\hline $\begin{array}{c}\text { Horarios de } \\
\text { atención. }\end{array}$ & $\begin{array}{l}\text { En su mayoría abren a } \\
\text { partir del mediodía en } \\
\text { adelante, en promedio } \\
\text { (12:00pm- 9:00pm). }\end{array}$ & $\begin{array}{l}\text { En su mayoría abren a } \\
\text { partir del mediodía en } \\
\text { adelante, en promedio } \\
(12: 00 \mathrm{pm}-11: 00 \mathrm{pm}) .\end{array}$ & $\begin{array}{l}\text { En su mayoría abren a } \\
\text { partir del mediodía en } \\
\text { adelante, en promedio } \\
\text { (11:00am- 9:00pm). }\end{array}$ & $\begin{array}{l}\text { En su mayoría las } \\
\text { cafeterías y/o Snacks } \\
\text { abren desde la mañana } \\
\text { hasta la noche, en }\end{array}$ \\
\hline
\end{tabular}




\begin{tabular}{|c|c|c|c|c|}
\hline & & & & $\begin{array}{l}\text { promedio (9:00am - } \\
\text { 10:00pm). }\end{array}$ \\
\hline Ubicación. & $\begin{array}{l}\text { Se encuentran ubicados } \\
\text { dispersos dentro de la } \\
\text { ciudad, algunos incluso no } \\
\text { son tan conocidos. }\end{array}$ & $\begin{array}{l}\text { Se encuentran en lugares } \\
\text { céntricos y fáciles de } \\
\text { llegar, inclusos algunos } \\
\text { están dentro de los } \\
\text { grandes centros } \\
\text { comerciales denominados } \\
\text { malls. }\end{array}$ & $\begin{array}{l}\text { Se encuentran en zonas } \\
\text { relativamente transitadas } \\
\text { y fáciles de llegar en } \\
\text { medio de transporte } \\
\text { propio o público. }\end{array}$ & $\begin{array}{l}\text { Se encuentran en su } \\
\text { mayoría ubicados en } \\
\text { lugares céntricos y fáciles } \\
\text { para llegar en medio de } \\
\text { transporte propio o } \\
\text { sistemas de transportes } \\
\text { públicos. }\end{array}$ \\
\hline $\begin{array}{c}\text { Formas de } \\
\text { pago. }\end{array}$ & $\begin{array}{l}\text { En su mayoría se aceptan } \\
\text { todo tipo de pago } \\
\text { (efectivo y tarjetas de } \\
\text { crédito). }\end{array}$ & $\begin{array}{l}\text { En su mayoría se aceptan } \\
\text { todo tipo de pago } \\
\text { (efectivo y tarjetas de } \\
\text { crédito). }\end{array}$ & $\begin{array}{l}\text { En su mayoría se aceptan } \\
\text { todo tipo de pago } \\
\text { (efectivo y tarjetas de } \\
\text { crédito). }\end{array}$ & $\begin{array}{l}\text { En su mayoría se aceptan } \\
\text { todo tipo de pago } \\
\text { (efectivo y tarjetas de } \\
\text { crédito). }\end{array}$ \\
\hline $\begin{array}{c}\text { Servicios } \\
\text { adicionales. }\end{array}$ & $\begin{array}{l}\text { Muy pocos } \\
\text { establecimientos cuentan } \\
\text { con el servicio de } \\
\text { delivery. }\end{array}$ & $\begin{array}{l}\text { Algunos establecimientos } \\
\text { cuentan con servicio de } \\
\text { delivery pero son muy } \\
\text { deficientes con el tiempo } \\
\text { de entrega. }\end{array}$ & & $\begin{array}{l}\text { En algunos } \\
\text { establecimientos se realiza } \\
\text { el servicio de delivery a } \\
\text { través del uso de taxis. }\end{array}$ \\
\hline
\end{tabular}

Elaboración propia 
En el análisis de la competencia realizado, debemos considerar que es frecuente encontrar clientes asociados a la materialización del proyecto gastronómico, explicado en el siguiente esquema:

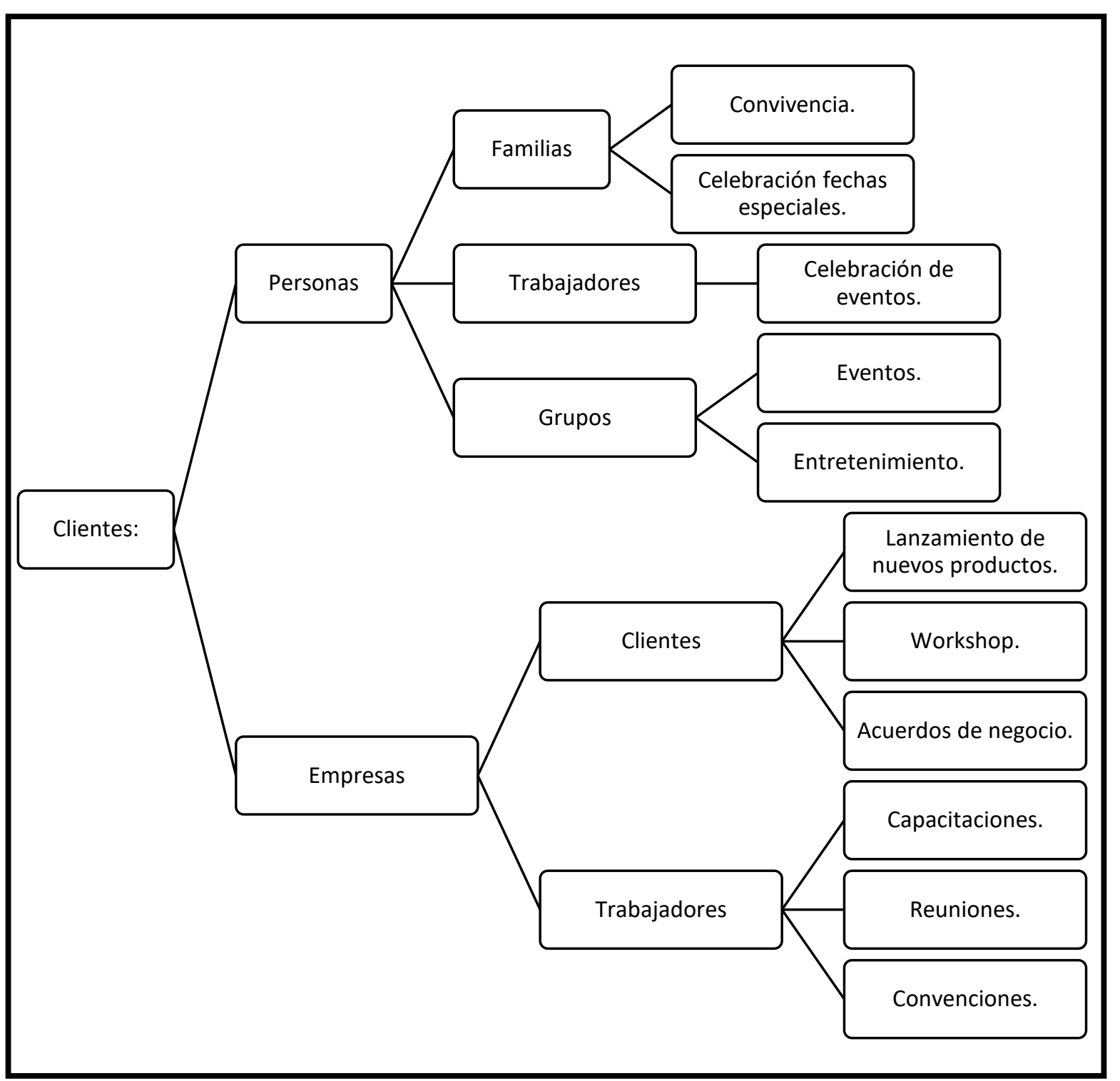

Figura 26 Esquema de generación de contactos.

El esquema de generación de contactos, es básicamente la red mediante la cual es altamente probable generar clientes. Como se puede observar en el esquema, los clientes pueden llegar a nuestro negocio a través de personas naturales o empresas: 
Personas: Podemos atraer a sus diferentes allegados, según las recomendaciones y opiniones que puedan dar los clientes de nuestro servicio.

- Familias: podrían recomendarnos con familiares para que opten por nuestro servicio, ya sea el servicio de almuerzos personal o si desean para alguna celebración o fecha especial

- Trabajadores: nos podrían recomendar con sus compañeros de trabajo ya sea para el consumo diario o algún evento que puedan tener.

- Grupos: básicamente son amigos, y nos podrían contactar para satisfacer sus necesidades de alimentación diaria, o para reuniones, cumpleaños, o similares

Empresas: Podemos atraer a sus clientes como también a sus trabajadores.

- Clientes: Podemos generar acuerdos promocionales para captar nuevos clientes, así mismo podemos participar en los diferentes workshops.

- Trabajadores: nos podrían contactar para ofrecerles los almuerzos diarios opcionalmente o también brindar nuestros servicios gastronómicos en sus capacitaciones, reuniones y convenciones que puedan tener eventualmente.

Cabe mencionar, que esta forma de generación de contactos es a través del "boca a boca", según cuan satisfecho se pueda sentir nuestro cliente y lo transmita a su círculo, es por ello que es importante mantener la calidad en nuestro servicio, para que la opinión de nuestro cliente sea positiva y así nos permita incrementar nuestra red de clientes. 


\subsubsection{Análisis FODA de los Competidores.}

Tabla 11

Análisis FODA de los competidores

\begin{tabular}{|c|c|c|c|c|}
\hline \multicolumn{5}{|c|}{ FODA de la competencia por empresa: } \\
\hline Empresa: & Fortalezas: & Oportunidades: & Debilidades: & Amenazas: \\
\hline FIT LUNCH & $\begin{array}{l}\text { - Posee un buen } \\
\text { canal de } \\
\text { ventas on line. } \\
\text { - Mantiene una } \\
\text { estructura de } \\
\text { bajo costo. } \\
\text { - Mejor } \\
\text { desempeño } \\
\text { del producto, } \\
\text { comparado } \\
\text { con los } \\
\text { competidores. }\end{array}$ & $\begin{array}{l}\text { - Se generarán } \\
\text { buenos } \\
\text { márgenes de } \\
\text { ganancia. } \\
\text { - Baja } \\
\text { competencia. } \\
\text { - Mayor } \\
\text { reconocimient } \\
\text { o de la marca } \\
\text { en el mercado. }\end{array}$ & $\begin{array}{l}\text { - Fragilidad } \\
\text { ante nuevos } \\
\text { competidores. } \\
\text { - Deficiencia en } \\
\text { el servicio al } \\
\text { consumidor. } \\
\text { - Carencias en } \\
\text { su canal de } \\
\text { distribución } \\
\text { del producto. }\end{array}$ & $\begin{array}{l}\text { - Consumidores } \\
\text { poco fieles. } \\
\text { - Ingreso de } \\
\text { nuevos } \\
\text { competidores } \\
\text { en la industria. } \\
\text { - Existencia de } \\
\text { productos } \\
\text { sustitutos. }\end{array}$ \\
\hline MANSANA & $\begin{array}{l}\text { - Excelente } \\
\text { manejo de las } \\
\text { ventas on line. } \\
\text { - Incremento de } \\
\text { clientes en su } \\
\text { zona de } \\
\text { operaciones. }\end{array}$ & $\begin{array}{l}\text { - Mayor uso de } \\
\text { las redes } \\
\text { sociales para } \\
\text { su negocio. } \\
\text { - Desarrollo de } \\
\text { nuevos } \\
\text { productos. }\end{array}$ & $\begin{array}{l}\text { - Poco } \\
\text { reconocimien } \\
\text { to de la marca } \\
\text { en el } \\
\text { mercado. } \\
\text { - Bajo nivel de } \\
\text { participación } \\
\text { del mercado } \\
\text { por su mal } \\
\text { canal de } \\
\text { distribución. }\end{array}$ & $\begin{array}{l}\text { - Ingreso de } \\
\text { nuevos } \\
\text { competidores } \\
\text { en la industria. } \\
\text { - Inestabilidad } \\
\text { de sus clientes. }\end{array}$ \\
\hline SANTÉ & $\begin{array}{l}\text { - Mayor } \\
\text { cantidad de } \\
\text { promociones } \\
\text { en sus } \\
\text { productos. } \\
\text { - Mayor } \\
\text { retención de } \\
\text { clientes. } \\
\text { - Buen servicio } \\
\text { al cliente. } \\
\text { - Uso adecuado } \\
\text { de redes } \\
\text { sociales para } \\
\text { espacios } \\
\text { publicitarios. }\end{array}$ & $\begin{array}{l}\text { - Desarrollo de } \\
\text { nuevos } \\
\text { productos. } \\
\text { - Aumento en el } \\
\text { porcentaje de } \\
\text { ventas. } \\
\text { - Participación } \\
\text { en ferias de } \\
\text { alimentación. }\end{array}$ & $\begin{array}{l}\text { - Dependencia } \\
\text { del } \\
\text { consumidor. } \\
\text { - Dependencia } \\
\text { con algunos } \\
\text { proveedores. }\end{array}$ & $\begin{array}{l}\text { - Existencia de } \\
\text { empresas con } \\
\text { mayor } \\
\text { presencia en el } \\
\text { mercado. } \\
\text { - Costos } \\
\text { unitarios no } \\
\text { muy } \\
\text { competitivos. }\end{array}$ \\
\hline
\end{tabular}




\section{$\underline{\text { Participación de mercado }}$}

El mercado relacionado a la alimentación saludable, aún se encuentra en estado de exploración y desarrollo en la ciudad de Arequipa, las empresas que funcionan actualmente no cuentan con la formalidad necesaria.

Al tratarse de un mercado informal, no se cuenta con cifras exactas de su participación de mercado, sin embargo, a través de nuestro estudio de mercado pudimos obtener cifras referenciales.

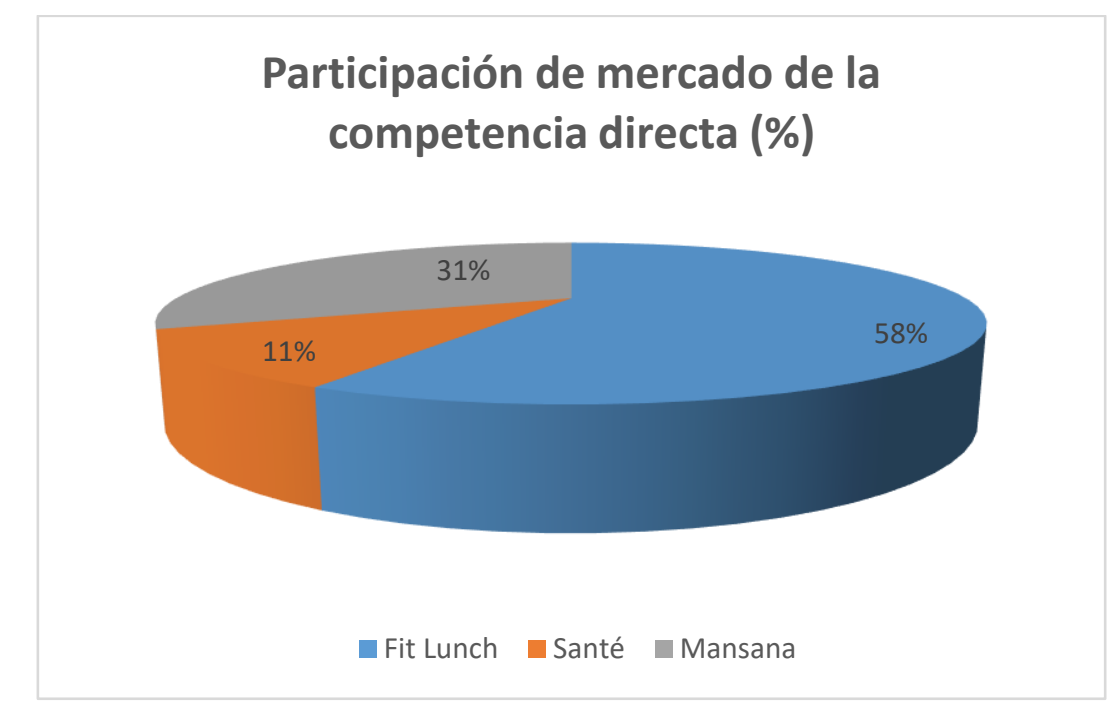

Figura 27 Participación de mercado de la competencia.

Datos obtenidos de la encuesta

En el gráfico anterior estamos considerando solo a aquellos que ya consumen comida saludable a través de delivery, sin embargo, nuestra pregunta estuvo dirigida a aquellos que consumen tanto en restaurantes como en deliverys. Del universo que consumen comida saludable, encontramos dentro de la competencia directa (servicios delivery): Fit Lunch con un 22\% de participación en el mercado, Mansana con un 
12\% de participación en el mercado, Santé con un $6 \%$ de participación en el mercado; la competencia no directa (no ofrecen servicio delivery), pero en su carta se presentan opciones saludables: Capriccio con un 36\% de participación en el mercado, Pura fruta con un 21\% de participación en el mercado y Veggie con un 3\% de participación en el mercado.

Dentro de las opiniones del mercado, se realizó un análisis general sobre fortalezas y debilidades, y se encontraron las siguientes:

Tabla 12

Fortalezas y debilidades de la competencia.

\begin{tabular}{|c|l|l|}
\hline \multirow{4}{*}{$\begin{array}{c}\text { Fortalezas y } \\
\text { Debilidades de la } \\
\text { Competencia }\end{array}$} & Fortalezas & Debilidades \\
\cline { 2 - 3 } & Precios razonbles dentro & $\begin{array}{l}\text { Desconfianza al pedir } \\
\text { delivery }\end{array}$ \\
\cline { 2 - 3 } & Buen sabor en el producto & $\begin{array}{l}\text { Difícil de acceder a un } \\
\text { restaurante dentro del } \\
\text { horario de oficina }\end{array}$ \\
\cline { 2 - 3 } & $\begin{array}{l}\text { Buena interacción en } \\
\text { redes sociales }\end{array}$ & $\begin{array}{l}\text { No conocen los beneficios } \\
\text { de la Comida Saludable }\end{array}$ \\
\hline
\end{tabular}

Elaboración propia

\subsubsection{Competencia directa.}

En cuestiones de mercadotecnia es importante conocer ampliamente a toda nuestra competencia en general para poder fijar nuestras posturas comerciales y promocionales, independientemente del tamaño de nuestro competidor, todo influye en las decisiones que se tomen como empresa.

Es por ello que hemos determinado como competencia directa a todos aquellos negocios/ empresas que venden un producto igual o casi igual al nuestro y que lo comercializan en el mismo mercado en el cuál pretendemos ingresar, es decir consideran a nuestros clientes para venderles lo mismo. 
Enfocándonos directamente en nuestro rubro de negocio, podemos encontrar dentro de comidas saludables que aplican el servicio de delivery, las siguientes marcas en el mercado Arequipeño:

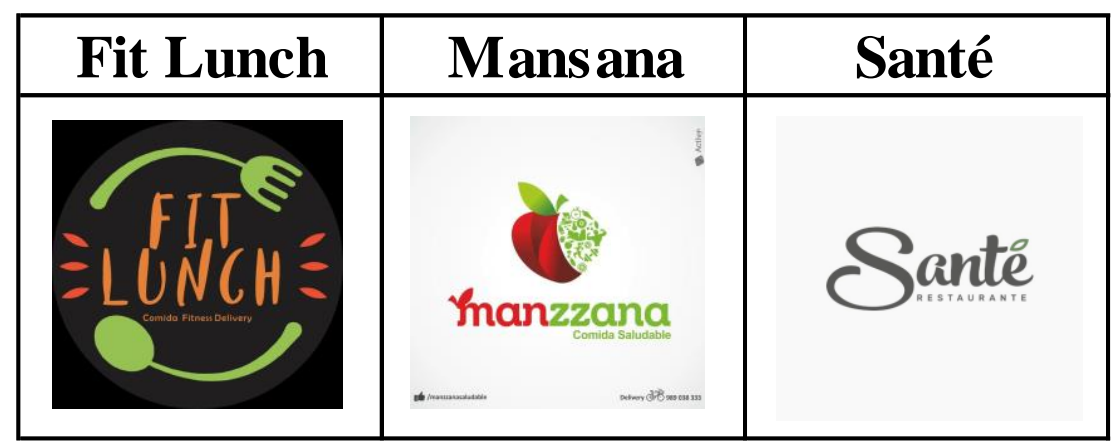

Figura 28 Marcas de competidores directos en el mercado local.

Estas tres marcas vienen a ser nuestra competencia directa dentro del mercado, ya que brindan un producto de alimentación saludable y realizan el servicio delivery.

Para poder efectuar un estudio de la competencia directa, desarrollaremos la Matriz de Perfil Competitivo (MPC), así podremos comparar todas las marcas y evaluar sus fortalezas y debilidades en el mercado; esto nos permitirá conocer mejor el entorno externo y la competencia que tiene la industria.

En del desarrollo de la matriz de perfil competitivo MPC, son 10 los factores considerados como críticos en la industria de restaurantes, según opiniones de expertos se clasificó los factores de la siguiente manera: 


\begin{tabular}{|c|c|}
\hline \multirow{5}{*}{$\begin{array}{l}\text { Factores con mayor } \\
\text { criticidad }\end{array}$} & Participación del mercado \\
\hline & Reconocimiento de la marca \\
\hline & Servicio al consumidor \\
\hline & Retención de clientes \\
\hline & Promociones \\
\hline \multirow{5}{*}{$\begin{array}{l}\text { Factores con menor } \\
\text { criticidad }\end{array}$} & Diseño del Producto \\
\hline & Estructura de Bajo costo \\
\hline & Ventas on line \\
\hline & Buen canal de distribución \\
\hline & Variedad de productos \\
\hline
\end{tabular}

Figura 29 Factores de criticidad en la industria de los restaurantes.

Para el desarrollo eficiente de esta matriz MPC, los factores de criticidad evaluados van acompañados de pesos, para posteriormente arrojar puntajes y totales que nos permitan jerarquizar a las empresas comparadas en dicha matriz.

Los pesos en su totalidad tienen que sumar la unidad (1); al ser 10 factores los evaluados, se ponderaron decimales en cada uno de los factores, para cumplir la regla de la suma total igual a 1.00, estos pesos se asignaron de acuerdo a la estructura de criticidad, puesto que a mayor criticidad habrá mayor peso a evaluar dentro de la MPC.

Posteriormente se realiza la operación de puntajes, que se recrea en base a la multiplicación del peso por la Calificación*.

La Calificación*, posee valores que van de 4 a 1; donde 4 representa una gran fortaleza, 3 una fuerza menor, 2 una debilidad y 1 una gran debilidad. 
Tabla 13

Análisis MPC de la Industria.

\begin{tabular}{|c|c|c|c|c|c|c|c|}
\hline \multicolumn{8}{|c|}{ ANÁLISIS MPC DE LA INDUSTRIA } \\
\hline \multirow[b]{2}{*}{ Factores Críticos de Riesgo: } & \multirow[b]{2}{*}{ Peso } & \multicolumn{2}{|c|}{ Fit Lunch } & \multicolumn{2}{|c|}{ Mansana } & \multicolumn{2}{|c|}{ Santé } \\
\hline & & Calif. & Puntaje & Calif. & Puntaje & Calif. & Puntaje \\
\hline Reconocimiento de la marca & 0.15 & 3 & 0.45 & 2 & 0.30 & 2 & 0.30 \\
\hline Variedad de productos & 0.06 & 3 & 0.18 & 3 & 0.18 & 2 & 0.12 \\
\hline Participación del mercado & 0.16 & 3 & 0.48 & 2 & 0.32 & 2 & 0.32 \\
\hline Estructura de bajo costo & 0.08 & 4 & 0.32 & 3 & 0.24 & 3 & 0.24 \\
\hline Ventas on line & 0.07 & 4 & 0.28 & 4 & 0.28 & 4 & 0.28 \\
\hline Promociones & 0.09 & 3 & 0.27 & 3 & 0.27 & 3 & 0.27 \\
\hline Retención de clientes & 0.12 & 2 & 0.24 & 3 & 0.36 & 3 & 0.36 \\
\hline Buen canal de distribución & 0.06 & 2 & 0.12 & 2 & 0.12 & 3 & 0.18 \\
\hline Diseño del producto & 0.08 & 3 & 0.24 & 3 & 0.24 & 2 & 0.16 \\
\hline Servicio al consumidor & 0.13 & 1 & 0.13 & 3 & 0.39 & 3 & 0.39 \\
\hline TOTAL & 1.00 & & 2.71 & & 2.70 & & 2.62 \\
\hline
\end{tabular}

Elaboración Propia.

Dentro de los factores críticos que evaluamos, le damos un peso a cada uno de éstos, este valor es relativo y oscila entre 0,0 (factor crítico de poca importancia) y 1,0 (factor crítico de alta importancia), la suma de dichos factores a evaluar debe hacer un total de 1,00. Siguiendo con el desarrollo de esta matriz, se genera la ponderación de la calificación de cada marca a evaluar, estos valores van de 4 a 1; donde 4 representa una gran fortaleza, 3 una fuerza menor, 2 una debilidad y 1 una gran debilidad. Y por último en la columna de puntaje, tenemos simplemente la multiplicación del rating por el peso de cada factor crítico a evaluar, y de esta manera cada marca recibe una puntuación en cada factor.

La marca que recibe una mayor puntuación total es relativamente más fuerte que sus competidores, esto significa que la marca Fit Lunch tiene un mejor desempeño en el mercado, seguida de Mansana y luego Santé.

Realizamos esta matriz, poniendo como factores claves a evaluar: 
- La participación del mercado de cada marca, tomando como referencia el número de seguidores en redes sociales que tiene cada marca a evaluar.

- El reconocimiento de la marca por parte la población.

- El servicio al consumidor que brinda cada marca, en relación a feed backs, o reclamos relacionados con el producto.

- La retención de clientes, que determinará la cuota de mercado y el crecimiento del mismo.

\subsection{Análisis del contexto actual y esperado.}

\subsubsection{Entorno político:}

Se buscará siempre cumplir con las normas y leyes gubernamentales de la ciudad, con respecto a licencias y permisos por tratarse de manipulación de alimentos, respetando y pagando los que correspondan a la actividad de la empresa y los relacionados a sus empleados. Además, si es posible la empresa estará dispuesta a colaborar en proyectos o eventos organizados por la municipalidad, que promuevan la cultura saludable, de esta forma mantener buenas relaciones.

\subsubsection{Entorno económico:}

Como región estamos experimentando un continuo crecimiento; sin embargo, según datos de la Gerencia Regional de trabajo se observa que durante los últimos 5 años el crecimiento del empleo en empresas privadas formales de 10 a más trabajadores en la ciudad de Arequipa se ha mantenido en cifras positivas, pero con menor aceleración. 
La tasa de ocupación en Arequipa es del 95.6\%, conformada en un 44\% por mujeres y en un $56 \%$ por hombres, del total el $18.7 \%$ va de 14 a 24 años, $48.2 \%$ entre $\operatorname{los} 25$ y 44 años y $33.2 \%$ de 45 a más.

La remuneración promedio mensual por grupo ocupacional es: Gerentes y directivos S/ 8,667.00, Profesionales S/ 2,024.00, Técnicos S/ 2,666.00, Empleados $\mathrm{S} / 1,457.00$ y trabajadores de servicios personales $\mathrm{S} / 929.00$

\subsubsection{Entorno social - demográfico:}

En la última década se ha generado un incremento considerable en el consumo de comida rápida, debido a una serie de factores dentro de los cuales resaltan los cambios de hábitos del consumidor, el incremento de jornada laboral, entrada de la mujer al mercado laboral y sobre todo con las obligaciones y contratiempos de la vida moderna, que han originado la necesidad de optimizar el tiempo.

Sin embargo, estamos experimentado una fuerte tendencia social hacia un estilo de vida cada vez más sano provocando una búsqueda de nuevos hábitos alimenticios, que se refleja en el desinterés de la comida rápida tradicional hacia una alimentación más saludable, la que también es etiquetada como "casual food" y una creciente preocupación por el culto al cuerpo.

\subsubsection{Entorno cultural:}

Dentro de este análisis, consideraremos que, en la ciudad de Arequipa, existe en la actualidad un fenómeno cultural en el tipo de alimentación de las personas y en el cuidado que tienen día a día con su imagen personal. 
Es importante mencionar, que en la ciudad de Arequipa actualmente hay la presencia de muchas personas migrantes, lo que genera que existan muchas sub culturas y pensamientos o ideologías distintas, las mismas que reflejan un punto importante y determinante en el mercado.

Nos enfocaremos en exhibir nuestro producto- servicio, dando a conocer sus ventajas para de esta manera, poder introducirnos en el mercado, y que al conocer las ventajas de la práctica de "comer saludable" se transforme en una costumbre, y que nos permita como negocio, ser sostenibles en el tiempo.

\subsubsection{Entorno tecnológico:}

En la actualidad, en la ciudad de Arequipa se está viviendo una revolución con la aparición de nuevas tecnologías que se han integrado en la vida cotidiana del entorno familiar y empresarial, han generado un mayor flujo de información; sin generar mucho costo y en tiempos sumamente cortos.

Hoy en día acceder al internet y redes sociales es muy fácil; todas las personas poseen un ordenador o un equipo Smartphone, lo cual les permite estar conectados todo el tiempo a las redes sociales y así, buscar una interacción con perfiles de personas y/o empresas que hacen negocios; es la causa por la cual nos enfocamos a una plataforma digital, ya que por medio de una página web y redes sociales estaríamos informando y promocionando nuestros servicios a todo nuestro público.

De esta forma, podremos captar más cuota de mercado; ya que nuestros clientes interactuarán con nuestra plataforma virtual, conociendo nuestro producto- servicio. 


\subsubsection{Entorno ecológico:}

Durante décadas, la actividad empresarial ha supuesto el principal agente de contaminación ambiental; sin embargo, hoy en día la mayoría de empresas son más responsables y son conscientes de su importante papel en el cuidado y conservación del medio ambiente y de la capacidad que tienen cada una para reducir el impacto ambiental negativo.

De esta manera, la incorporación del medio ambiente en la empresa es una de las principales ventajas competitivas, relacionadas con:

- Reducción del consumo de recursos.

- Generación de residuos.

- Optimización de procesos productivos.

Esto a su vez, nos conlleva a la minimización de gastos y el incremento de los beneficios.

Nosotros como empresa nueva e innovadora, generaremos en nuestros consumidores una concientización ecológica, que se verá manifestada en la cultura que tendremos al momento de usar empaques para los alimentos, así como también en la materia prima a utilizar. Usando normas protectoras del medio ambiente y normas vigentes sobre la correcta manipulación de los alimentos. 


\section{CAPITULO III}

\section{Estudio de mercado.}

\subsection{Descripción del servicio o producto.}

\subsubsection{Comida Saludable.}

Comida balanceada recomendada por un nutricionista, basada en estilo de vida.

\subsubsection{Servicio.}

Servicio de delivery de comida saludable que satisface las necesidades nutricionales de mujeres en los distritos de Yanahuara, Cayma y Cercado de Arequipa.

El segmento recibirá la comida, con la información nutricional de lo que está comiendo e información de otros platos que podría seleccionar y que contienen valores nutricionales similares. El pedido se realiza el día anterior por teléfono o WhatsApp.

Se utilizarán insumos naturales y frescos, preparados por especialistas, con la supervisión y asesoría de un nutricionista. Se utilizarán envases de plástico y/o ecoamigables, inofensivos para la salud y herméticos. Además, el servicio cuenta con estándares de calidad para asegurar la calidad del producto.

El precio estará en el rango de 13 a 16 soles.

La publicidad se realizará por redes sociales Facebook, Instagram y alianzas estratégicas B2B (empresas relacionadas con el segmento). 
En redes sociales utilizaremos un tono de comunicación informativo y una personalidad de marca "aliada" en tu alimentación "saludable".

El centro de operaciones estará ubicado en el distrito de Yanahuara, para no tener problemas en la cobertura al momento de realizar el delivery. La competencia no cumple con los tiempos de entrega, por lo cual nuestra promesa de servicio es entregas en el tiempo pactado.

\subsection{Selección del segmento de mercado.}

La "segmentación del mercado" es el proceso de análisis e identificación de grupos de consumidores en un mercado donde comparten características parecidas y también necesidades muy similares.

Para nuestro proyecto de comida saludable y servicio de delivery, se realizó la siguiente segmentación para lograr definir nuestro mercado:

- $\quad$ Edad y sexo:

Muchos productos se dirigen directamente a grupos de cierta edad; esta segmentación es muy útil para determinar los medios de comunicación para captarlos. Se consideró mujeres de 21-44 años de edad.

- Ingresos:

Conocer la renta disponible de los consumidores es importante para determinar la calidad o nivel del producto que pueda atraer a un consumidor o grupo de ellos. Se filtró el nivel de ingresos de los encuestados en el cuestionario realizado.

- $\quad$ Clase social o nivel socioeconómico: 
Es una medida total económica y sociológica que combina datos relacionados con la preparación laboral de una persona, posición económica y social individual o familiar en relación a otras personas, basada en sus ingresos, educación y empleo. Se clasifica por lo general en tres categorías: Alto (A/B), Medio (C) y Bajo (D y E), en las cuales una familia puede ser ubicada. Según Rolando Arellano en su libro "Mucho más que tener: Latir" (2017), define las características que identifican y diferencian a cada nivel socioeconómico y son: dinero o ingresos (92.5\%), educación (50.7\%), distrito en que vive (49.3\%), profesión u ocupación (43.2\%), tipo de casa (27.4\%), apellido (27.4\%), ropa y vestimenta $(5.5 \%)$ y raza $(2.7 \%)$, entonces podemos afirmar que el ingreso es un factor determinante para identificar el sector socioeconómico en el que se encuentra el individuo, es por ello que se decidió tomar en cuenta esta información para nuestra evaluación de mercado. Las distintas clases sociales a que pertenecen los consumidores podrán afectar sus intereses, actitudes y formas de gastar el dinero. Se determinó considerar los niveles A/B y C y se identificó esta condición con la pregunta correspondiente al Nivel de Ingresos.

- $\quad$ Situación geográfica:

El lugar donde vive o labora el consumidor, al norte o sur del país, en una ciudad o en el campo, es importantes para ciertos tipos de productos o servicios. Para nuestro proyecto se delimitaron 3 distritos de la ciudad de Arequipa: distrito de Yanahuara, distrito de Cayma y Cercado de Arequipa.

- Preferencias:

Otras formas de segmentación más orientadas al producto es la diferencia entre usuarios: exigentes o poco exigentes. Consideramos a las personas que consumen comida saludable o en su defecto estén interesadas en ello. 
Esta segmentación nos permitirá ver con claridad la finalidad y objetivos que perseguimos, implementando estrategias de marketing eficaces.

Segmento: Mujeres de 24 a 44 años que viven y/o laboran en los distritos de Yanahuara, Cayma y Cercado de Arequipa, que se encuentren en un nivel socio-económico A, B y C, con necesidad de alimentarse con comida saludable (supervisado por un nutricionista y/o especialista).

Escogimos este sector de mercado porque corresponde a personas en edad de trabajar, y que pueden potenciar el desarrollo económico de la ciudad y el país; demográficamente, como se mencionó anteriormente, según opiniones de expertos en el rubro, el público objetivo en el que una empresa de este tipo debe enfocarse va en un rango de entre los 25 y 45 años de edad, ya que constituyen el 57\% de los consumidores de esta comida, mientras que los jóvenes entre 18 y 24 años constituyen un $25 \%$ del total de la demanda, socioeconómicamente, según APEIM (2018), del total de la población del área urbana del departamento de Arequipa en el 2017, un 58.6\% se encuentran en los niveles socioeconómicos $\mathrm{A} / \mathrm{B}$ y $\mathrm{C}$. 


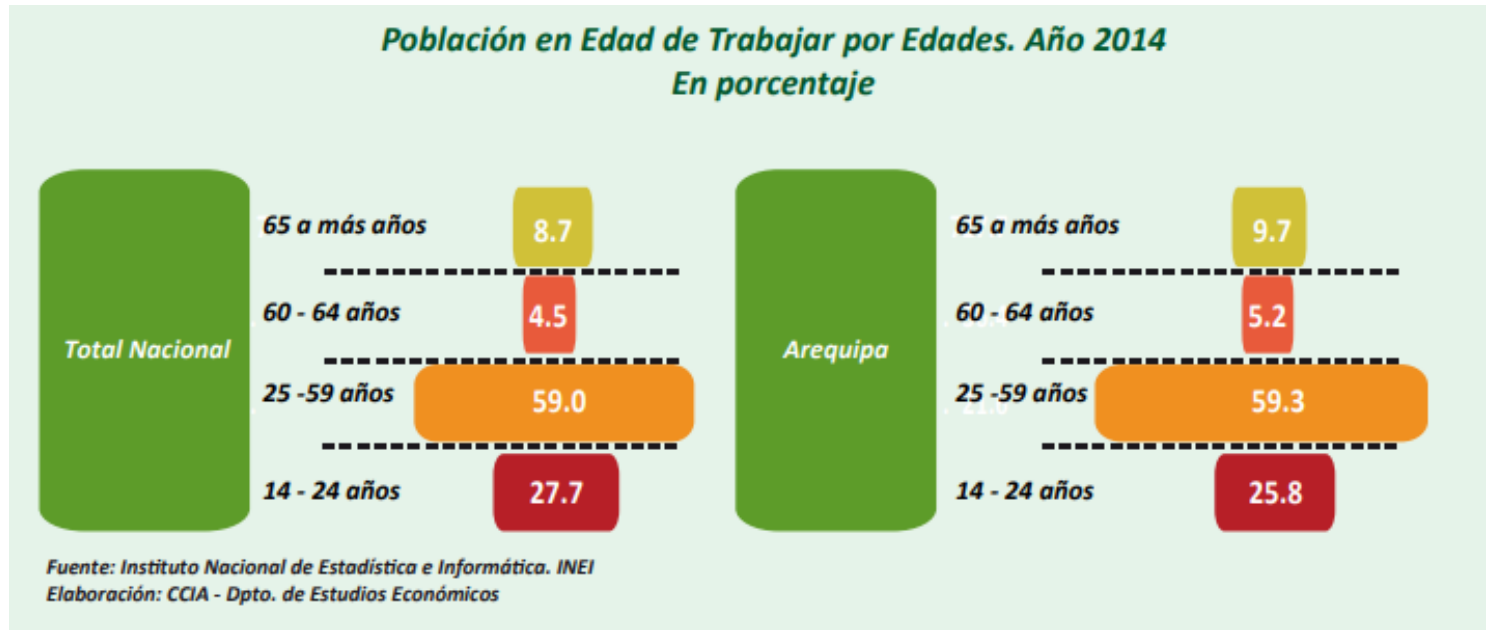

Figura 30 Población en edad de trabajar segmentado por edades. Información tomada del Instituto Nacional de Estadística e Informática INEI y elaborado por el Dpto. de Estudios Económicos de la CCIA.

Seleccionamos la porción que refleja el porcentaje más alto de las personas aptas para trabajar en Arequipa siendo el 59.3\%.

\subsection{Investigación Cuantitativa.}

Para la elaboración del diseño muestral se tomó como base los resultados definitivos publicados por INEI sobre la Población Económicamente Activa del departamento de Arequipa de los Censos Nacionales 2017: XII de Población, VII de Vivienda y III de Comunidades Indígenas, la cual nos brindan información discriminada acerca de la PEA ocupada, por sexo, distrito, ocupación y otras variables; sin embargo, los rangos de edad tomados van de 14-29, 30-44, 45-64 y 65 a más años. Consultando a expertos de la Cámara de Comercio de Arequipa, nos indican que según datos que ellos mantienen el porcentaje de mujeres que laboran de entre 14 y 20 años es mínimo, por lo que tomar el número total no influiría en el tamaño de la muestra. 
Así mismo, para identificar el nivel socioeconómico se recurrió a los datos de la Asociación Peruana de Empresas de Investigación de Mercados (APEIM), Niveles socioeconómicos 2018 (data ENAHO 2017).

Tabla 14

Ficha técnica de la encuesta.

\section{Objetivo de la}

encuesta
Determinar la cantidad de consumidores que estarían dispuestos a contratar el servicio de comida saludable delivery en los distritos de Cayma, Yanahuara y cercado de Arequipa.

Mujeres de entre 21 y 44 años de edad, de los niveles socioeconómicos A/B y C, que viven o laboran en las zonas

Universo urbanas de los distritos Cayma, Yanahuara y Cercado de Arequipa.

Tamaño de muestra Conformado por 287 personas.

Técnica Encuesta personal, cara a cara, en puntos que se concentra nuestro público objetivo.

\begin{tabular}{ll}
\hline Tipo de muestreo & Muestreo no probabilístico por conveniencia \\
\hline Margen de error & $+/-5.75 \%$ \\
\hline Nivel de confianza & $95 \%$ \\
\hline Población Objetivo & 27,150
\end{tabular}

Fecha de aplicación Del 30 de marzo al 02 de Abril de 2019

Elaboración propia

\subsubsection{Proceso de Muestreo.}

TECNICA DE MUESTREO

La investigación cuantitativa en nuestro proyecto, contempló el uso legítimo y efectivo del muestreo no probabilístico, ya que los costos y problemas para desarrollar un marco de muestreo son eliminados. Hablamos de muestreo no probabilístico cuando no tenemos acceso a una lista completa de los individuos que 
forman la población (marco muestral) y, por lo tanto, no conocemos la probabilidad de que cada individuo sea seleccionado para la muestra.

Consiste en seleccionar una muestra de la población por el hecho de que sea accesible. Es decir, los individuos empleados en la investigación se seleccionan porque están fácilmente disponibles, no porque hayan sido seleccionados mediante un criterio estadístico. Se desarrolló el muestreo por conveniencia, para poder obtener información en forma rápida y sin costo.

El procedimiento consistió sencillamente en contactar unidades de muestreo convenientes -en nuestro caso-, fueron mujeres entrevistadas de forma aleatoria, en puntos estratégicos de concentración del público que se encuentra dentro de la ubicación geográfica donde se desarrollará el proyecto, en un día en particular, usando como herramienta un cuestionario de 22 preguntas.

\section{POBLACION OBJETIVO}

Mujeres de entre 21 y 44 años de edad, de los niveles socioeconómicos A/B y C, que viven o laboran en las zonas urbanas de los distritos Cayma, Yanahuara y Cercado de Arequipa que consumen comida saludable o están interesadas en ello.

\section{TAMAÑO DE LA MUESTRA}

Para determinar el tamaño de la muestra se utilizó información del número de Mujeres que laboran en el área urbana de los distritos de Arequipa, Yanahuara y Cayma al 2017. 


\section{Tabla 15}

Cantidad de mujeres de entre 14 y 44 años que trabajan en la zona urbana de los distritos de Arequipa, Cayma y Yanahuara al 2017.

\begin{tabular}{cccc}
\hline Edad & $\mathbf{1 4 - 2 9}$ & $\mathbf{3 0 - 4 4}$ & TOTAL \\
\hline Arequipa & 2,945 & 4,323 & 7,268 \\
Cayma & 6,112 & 7,788 & 13,900 \\
Yanahuara & 3,181 & 2,801 & 5,982 \\
\hline TOTAL & $\mathbf{1 2 , 2 3 8}$ & $\mathbf{1 4 , 9 1 2}$ & $\mathbf{2 7 , 1 5 0}$ \\
\hline
\end{tabular}

Fuente: Resultados definitivos Población económicamente activa - Arequipa 2017

$$
n=\frac{k^{\wedge} 2 * p^{*} q^{*} N}{\left(e^{\wedge} 2 *(N-1)\right)+k^{\wedge} 2 * p^{*} q}
$$

Dónde:

$\mathrm{n}=$ muestra $\mathrm{a}$ determinar

$\mathrm{N}=$ universo

$\mathrm{K}=$ nivel de confianza

$\mathrm{p}=$ probabilidad de éxito

$\mathrm{q}=$ probabilidad de fracaso

$\mathrm{e}=$ error de muestra

Nivel de confianza $95 \%$

Margen de error (e) utilizado en cada distrito:

e- Cayma $=0.099$

e- Yanahuara $=0.099$

e- Arequipa $=0.09989$ 
Tabla 16

Tamaño de muestra.

\begin{tabular}{lc}
\hline Distrito & Muestra (n) \\
\hline Arequipa & 95 \\
Cayma & 96 \\
Yanahuara & 96 \\
\hline TOTAL & $\mathbf{2 8 7}$ \\
\hline
\end{tabular}

Elaboración propia

\subsubsection{Diseño de instrumento.}

Se trabajó la encuesta con 22 preguntas, utilizando un cuestionario como herramienta (Anexo II). Se utilizó las variables de nivel de ingresos, estilo de vida del consumidor y atributos más valorados por los clientes como precio, características del servicio, contenido de un almuerzo saludable y presentación.

\subsubsection{Análisis y procesamiento de datos.}

La encuesta se realizó en la esquina de la Av. Ejército con Av. Lima, esquina calle Mercaderes y Jerusalen, esquina calle Tronchadero con Avenida Ejército (Banco BBVA) y puente peatonal Av. Ejército (Telefónica).

Luego de realizar la encuesta se obtuvieron los siguientes resultados: 


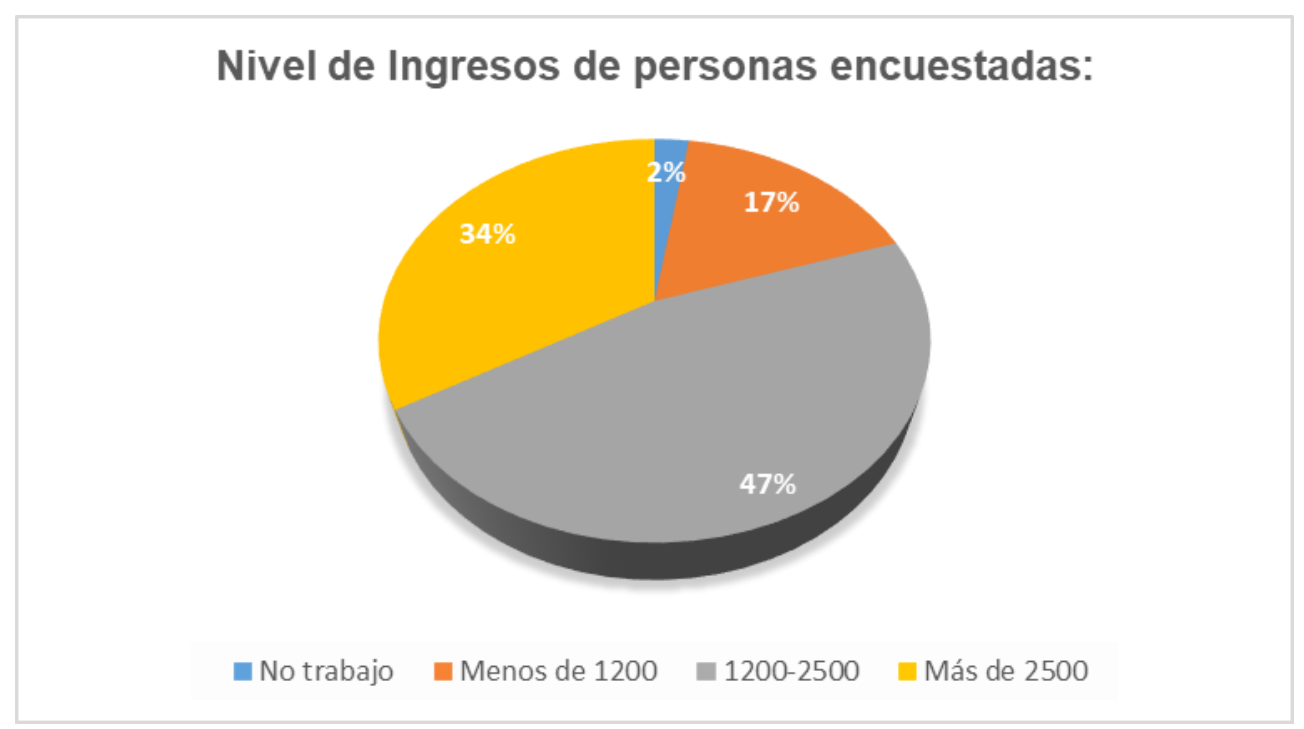

Figura 31 Resultados de Nivel de Ingresos de las personas encuestadas. Datos tomados de las encuestas realizadas.

Considerando que nuestro público objetivo se encuentra entre los niveles socioeconómicos A y C, un $81 \%$ de los encuestados está dentro de nuestro target, ya que tienen ingresos que van desde los S/ 1,200.00 y más de S/. 2,500.00, lo que lo haría una persona con ingresos que pueden contratar servicios diferenciados de alimentación. 


\section{P1:¿Consumes Comida Saludable?}

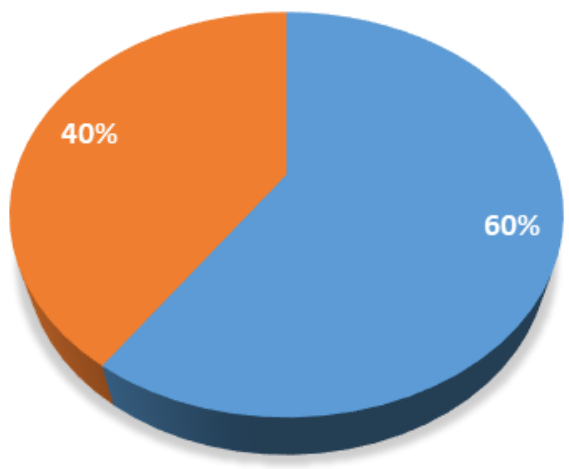

$\square \mathrm{SI} \square \mathrm{NO}$

Figura 32 Resultados de pregunta 1 ¿Consumes comida saludable? Datos tomados de las encuestas realizadas.

Un mayor porcentaje de los encuestados (60\%) ya consume comida saludable, por lo que pasa a formar parte de nuestro mercado disponible, lo que no significa que la porción de la muestra restante no lo vaya a consumir nunca.

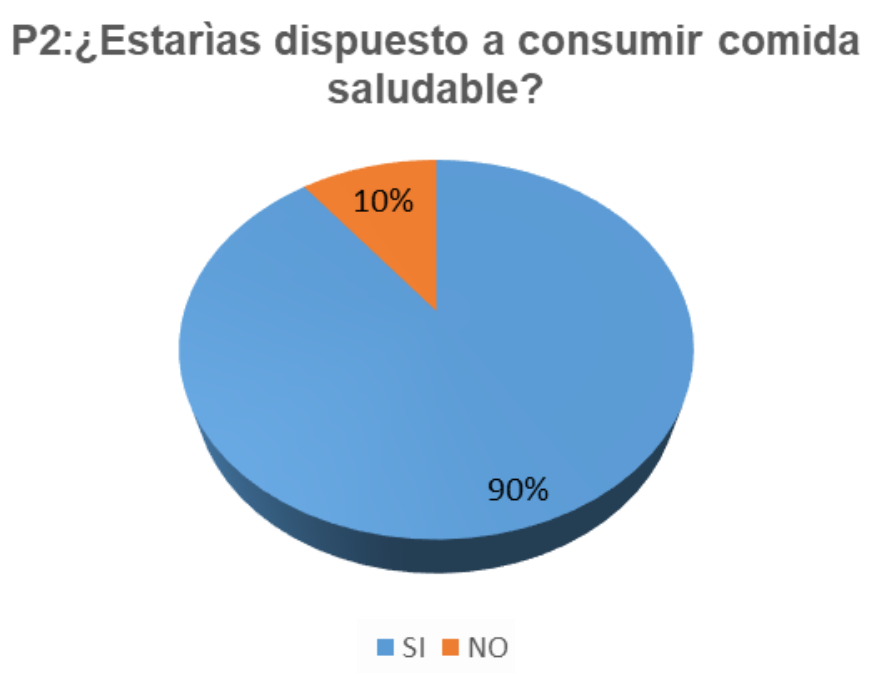

Figura 33 Resultados de pregunta 2 ¿Estarías dispuesto a consumir comida saludable? Datos tomados de las encuestas realizadas. 
Del $40 \%$ de encuestados que no consume comida saludable, un $10 \%$ no desea consumirla en un futuro, sin embargo, un $90 \%$ nos dice que si le gustaría consumirla.

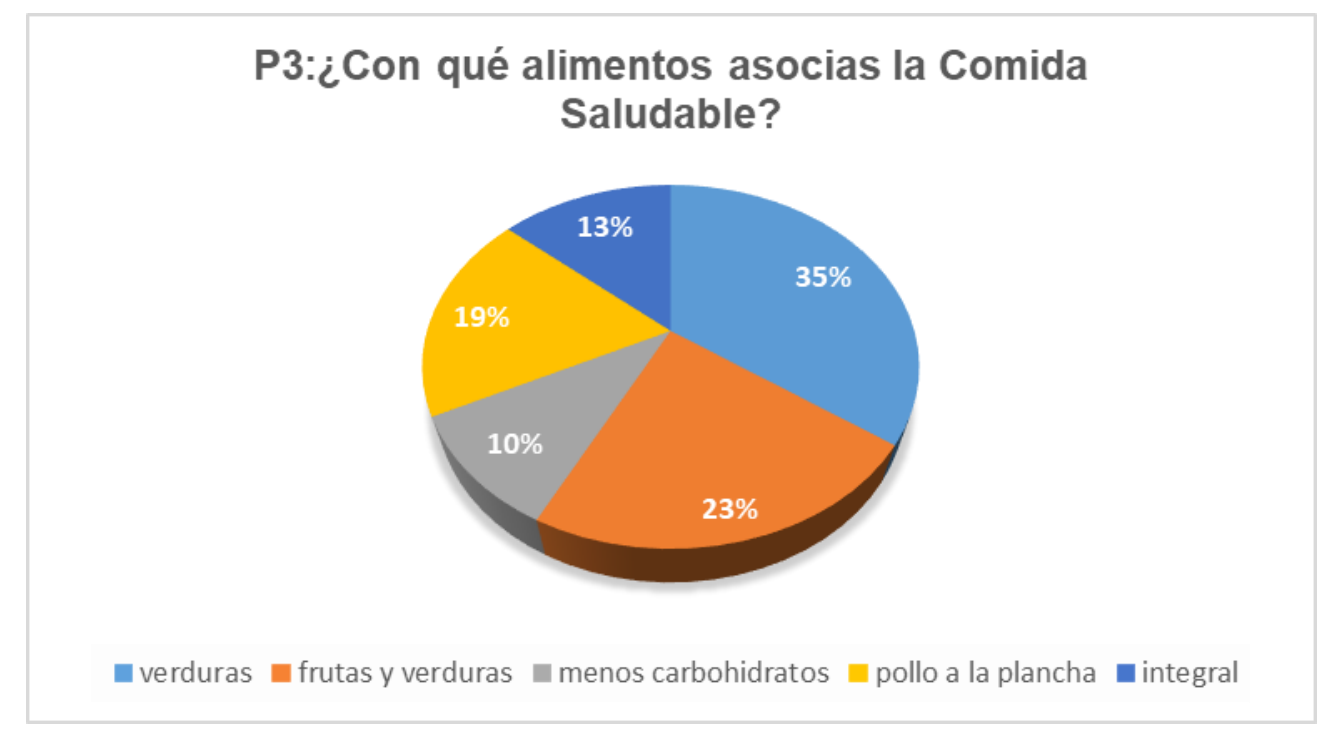

Figura 34 Resultados de pregunta 3 ¿Con qué elementos asocias la comida saludable? Datos tomados de las encuestas realizadas.

Un total del 58\% de los encuestados asocia la comida saludable a frutas y verduras, si bien es una idea no muy acertada de lo que significa comer saludable, podemos inferir que la población tiene una asociación muy fuerte de lo saludable con las frutas y verduras. 


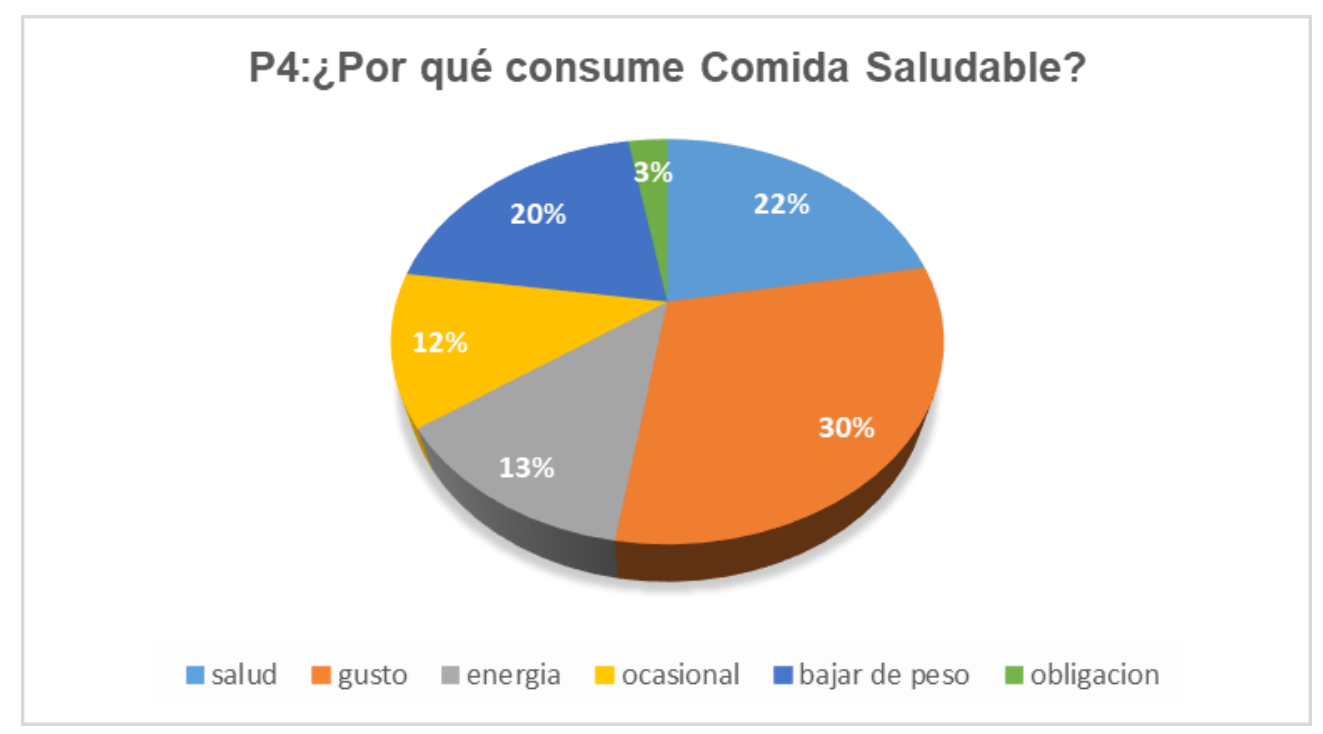

Figura 35 Resultados de pregunta 4 ¿Por qué consume comida saludable? Datos tomados de las encuestas realizadas.

La mayor parte de nuestra muestra referencial (30\%) consume comida saludable porque le gusta y es el público que debemos fidelizar porque ponto se convertirá en un hábito, el otro $42 \%$ que lo hace por salud o bajar de peso, que son conceptos similares, esta menos convencido y es probable que cuando logre su objetivo lo deje de lado.

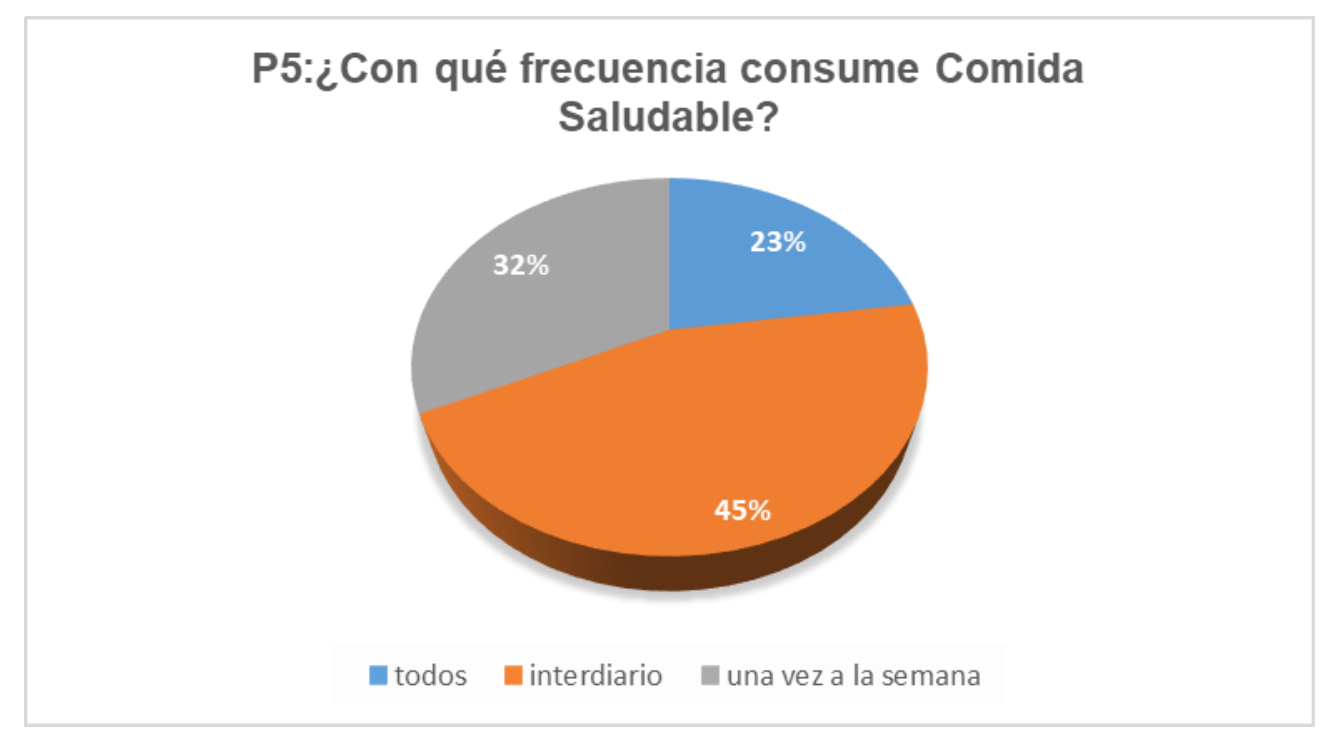

Figura 36 Resultados de pregunta 5 ¿Con qué frecuencia consume comida saludable? Datos tomados de las encuestas realizadas. 
La mayor parte de nuestro público objetivo $(45 \%)$ consume comida saludable con frecuencia interdiaria, seguido de otro porcentaje que lo consume una vez a la semana. Lo cual nos indica que podemos desarrollar un plan de fidelización de los clientes que ya consumen interdiario para que con el tiempo lo hagan diariamente.

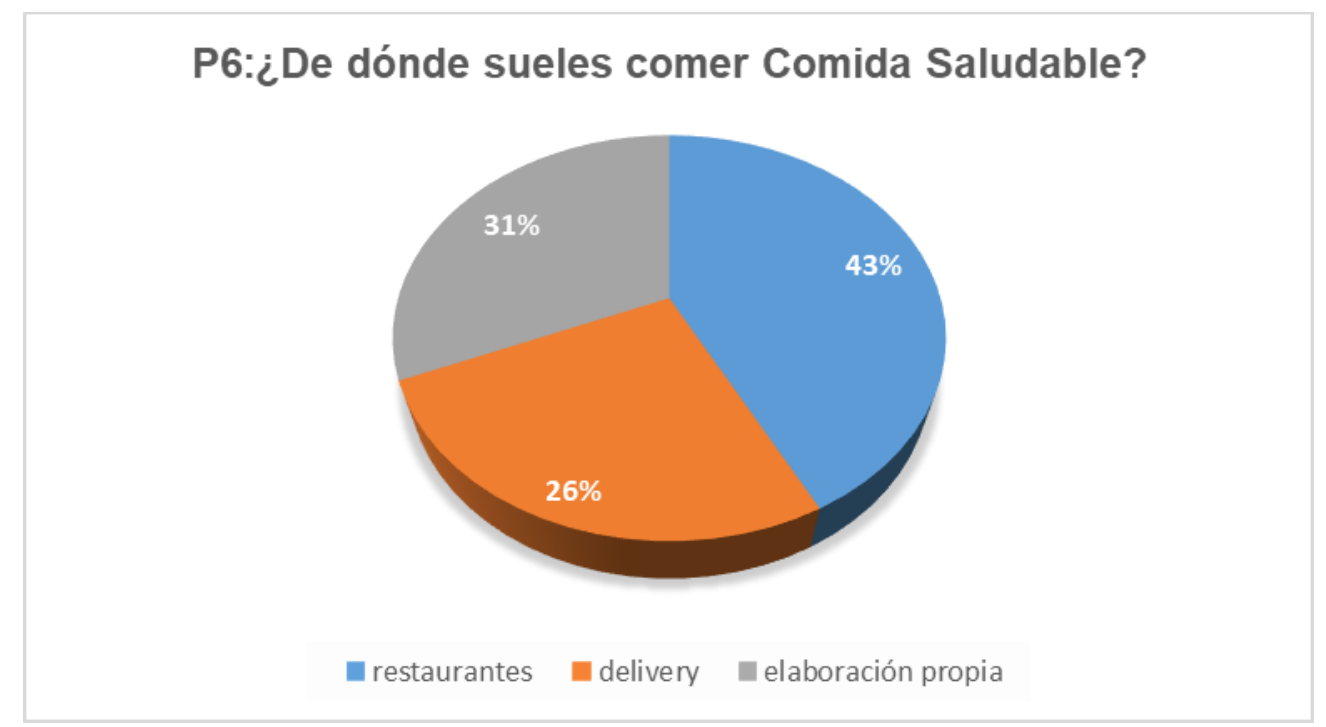

Figura 37 Resultados de pregunta 6 ¿De dónde suele comer comida saludable? Datos tomados de las encuestas realizadas.

De la proporción que consume comida saludable la mayor parte lo hacen en restaurantes, un porcentaje menor prefiere elaborarlos en casa y un $28 \%$ lo hace en la modalidad que nosotros proponemos: delivery. 


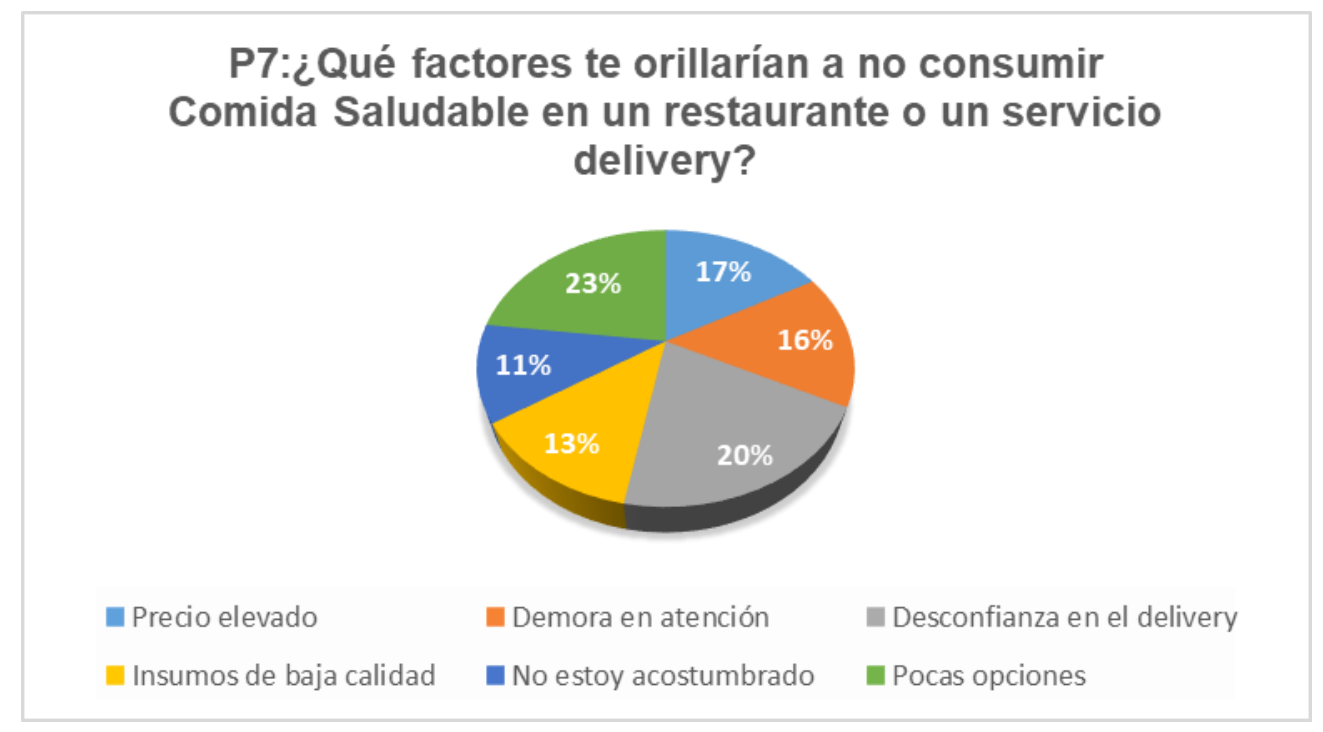

Figura 38 Resultados de pregunta 7 ¿Qué factores te orillarían a no consumir comida saludable en un restaurante o un servicio delivery? Datos tomados de las encuestas realizadas.

Una mayor proporción (23\%) en comparación a las demás nos dice que las opciones de comida saludable en restaurantes y servicios de delivery son muy pocas, por lo que la comida se torna repetitiva y un $20 \%$ aún tiene desconfianza en este tipo de servicio, estos serían puntos determinantes en los que debemos trabajar para que nuestro servicio sea mucho más atractivo. Los demás motivos están más dispersos entre los encuestados. 


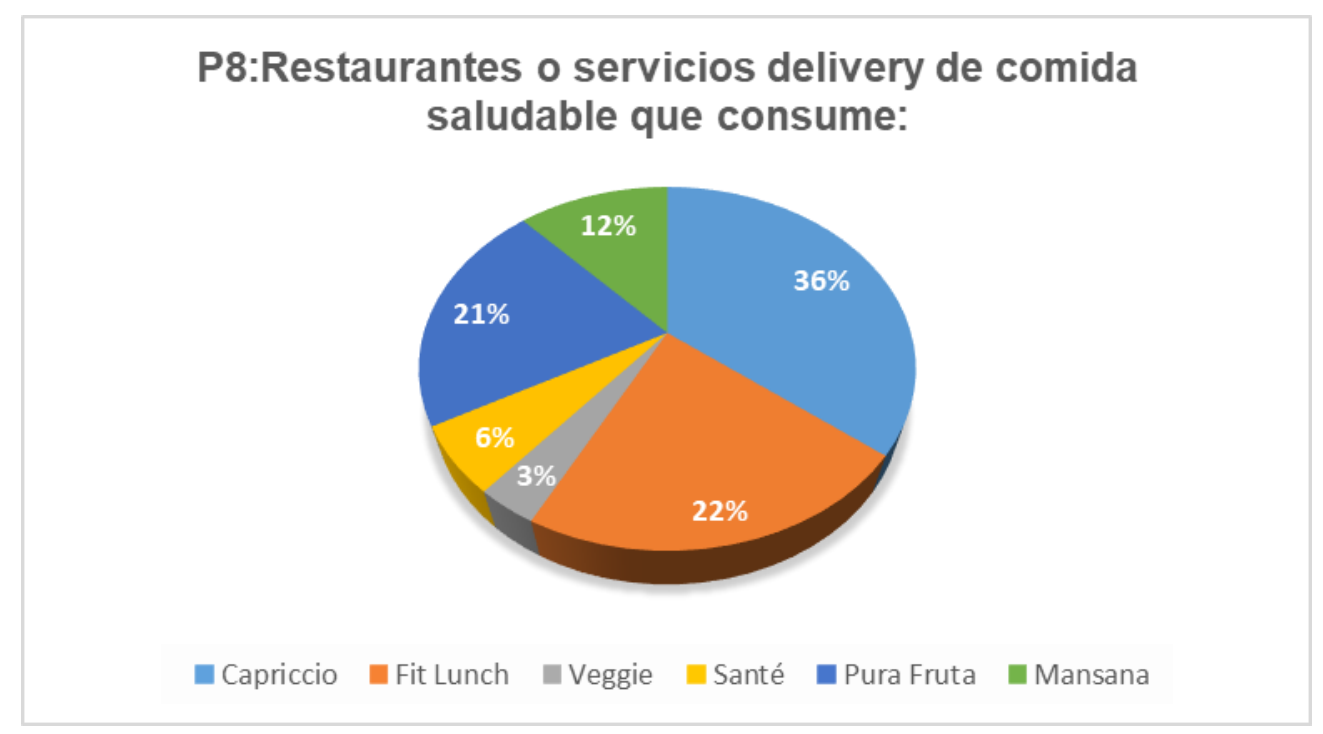

Figura 39 Resultados de pregunta 8 Restaurantes o servicios delivery de comida saludable que consume. Datos tomados de las encuestas realizadas.

Del porcentaje de encuestados que consume comida saludable en la modalidad de delivery un $22 \%$ lo hace de fit lunch, siendo esta empresa la que tiene mayor cuota de mercado en la zona, seguido de Mansana y con un porcentaje mucho menor de Santé. Debemos observar que hay dos restaurantes en las zonas de influencia que tienen mayor preferencia. Esto puede convertirse en una oportunidad para tomar ese porcentaje de población que no consume de los deliverys existentes y opten por el nuestro. 


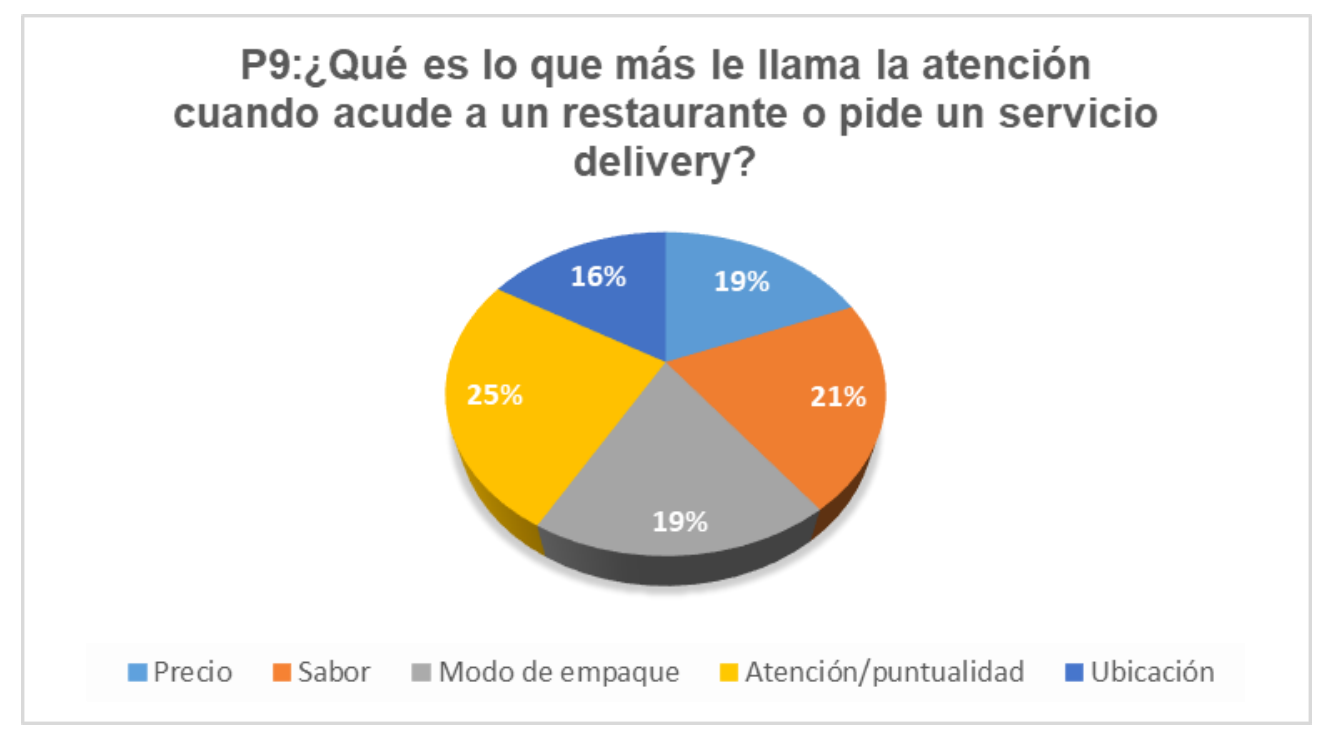

Figura 40 Resultados de pregunta 9 ¿Qué es lo que más le llama la atención cuando acude a un restaurante o pide un servicio delivery. Datos tomados de las encuestas realizadas.

Lo que más les atrae a los encuestados acerca de los restaurantes y servicios delivery es la atención y/o puntualidad en el servicio, seguido del sabor, modo de empaque y precio. Podemos aprovechar esta información para idear estrategias que trabajen en mejorar estos aspectos que para el público son importantes.

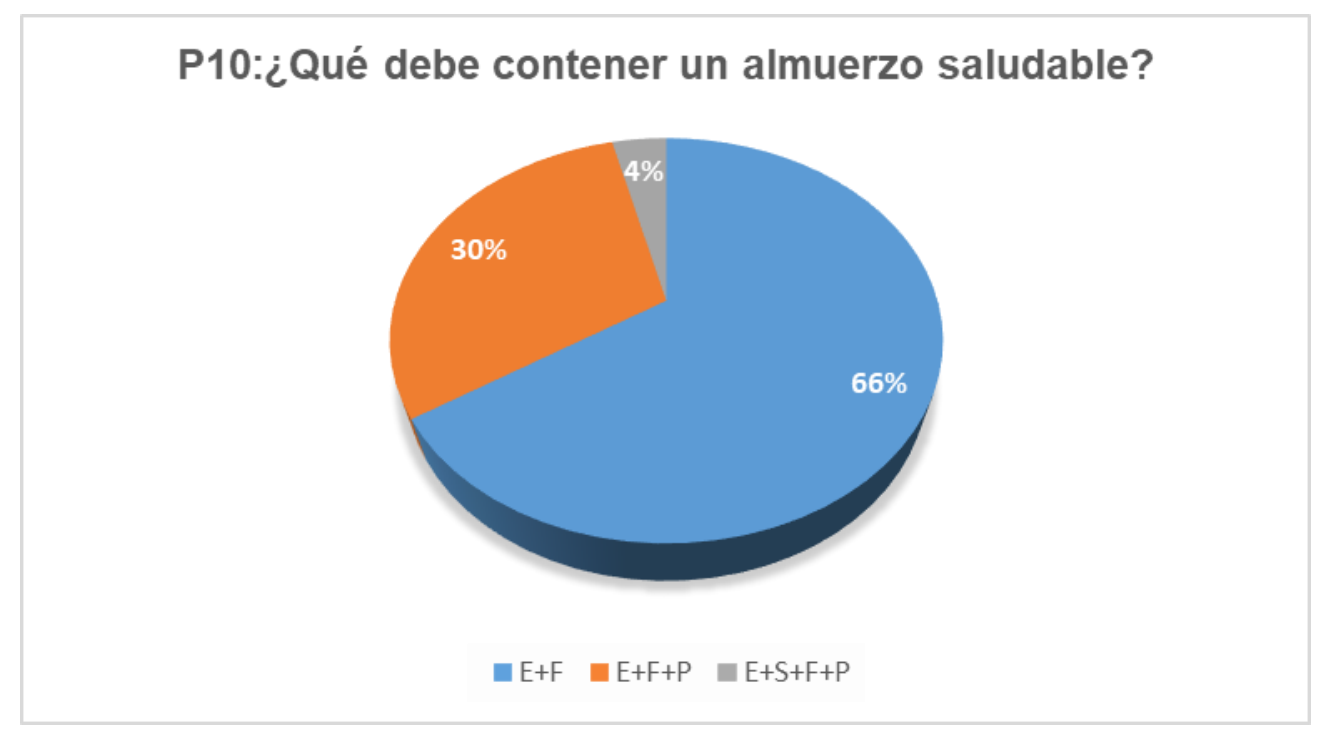

Figura 41 Resultados de pregunta 10. ¿Qué debe contener un almuerzo saludable? Datos tomados de las encuestas realizadas. 
La mayoría de personas de nuestro segmento suelen comer entrada y plato de fondo, por lo cual podemos disminuir nuestro producto sólo a dos componentes y el refresco.

\section{P11:¿Cuánto pagaría Ud. por un almuerzo saludable?}

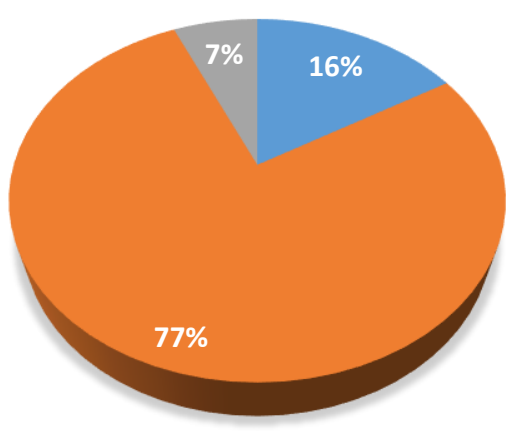

-9 a $12 \square 13$ a $16 \square 17$ a 20

Figura 42 Resultados de pregunta 11 ¿Cuánto pagaría usted por un menú de comida saludable? Datos tomados de las encuestas realizadas.

La mayor parte de nuestro público puede pagar entre 13 y 16 soles por un menú de comida saludable, lo cual concuerda con nuestro precio final. 


\section{P12:¿A qué hora suele almorzar?}

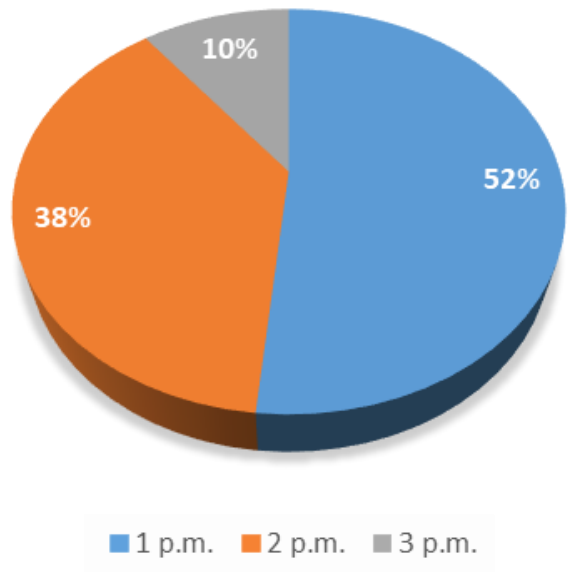

Figura 43 Resultados de pregunta 12 ¿A qué hora suele almorzar? Datos tomados de las encuestas realizadas.

Nuestra hora pico de reparto será entre $12 \mathrm{~m}$ y $1 \mathrm{pm}$, puesto que la mayor parte de nuestro segmento suele almorzar entre la $1 \mathrm{pm}$ y $2 \mathrm{pm}$.

\section{P13:¿Es importante que los productos muestren información nutricional y valores calóricos?}

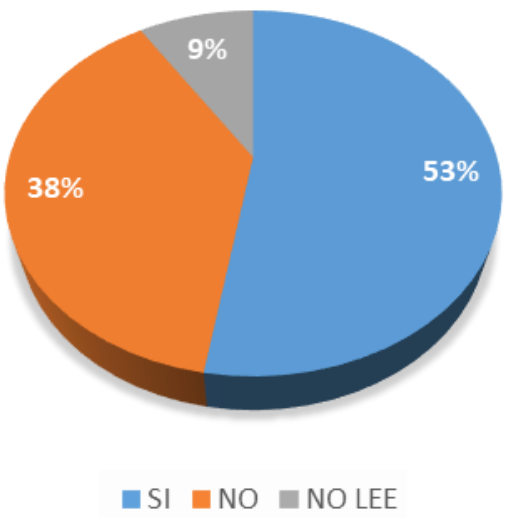

Figura 44 Resultados de pregunta 13 ¿Es importante que los productos muestren información nutricional y valores calóricos? Datos tomados de las encuestas realizadas. 
Existe una tendencia de nuestro segmento a informarse sobre lo que consume, se preocupa por la información nutricional y valores calóricos, por ello se tendrá que elaborar publicidad informativa en redes sociales.

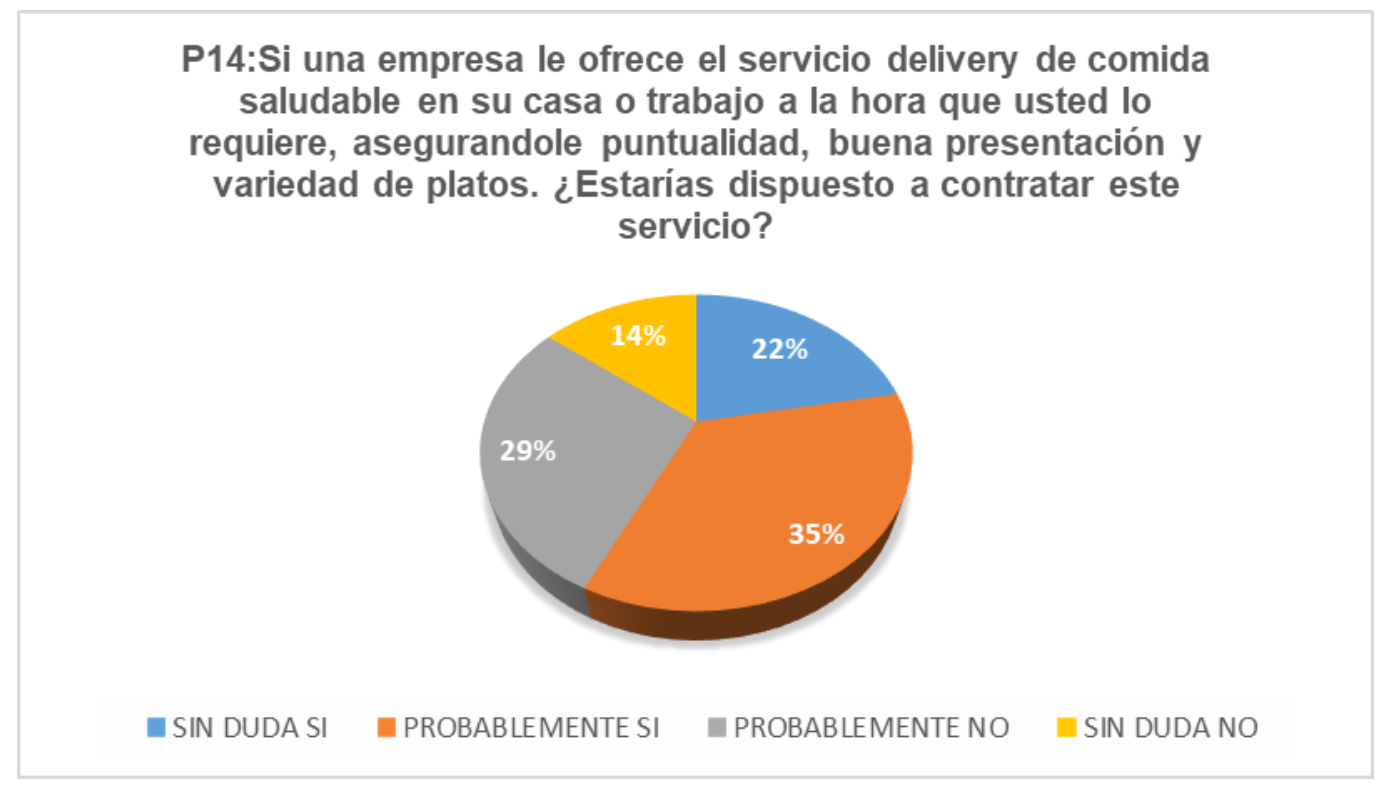

Figura 45 Resultados de pregunta 14 Si una empresa le ofrece el servicio delivery de comida saludable en su casa o trabajo a la hora que usted lo requiere, asegurándole puntualidad, buena presentación y variedad de platos. ¿Estarías dispuesto a contratar este servicio? Datos tomados de las encuestas realizadas.

Alrededor de un $57 \%$ de los encuestados estaría dispuesto a contratar nuestro servicio. Un $29 \%$ no muestra ni interés, ni desinterés; mientras que un $14 \%$ se niega rotundamente. 


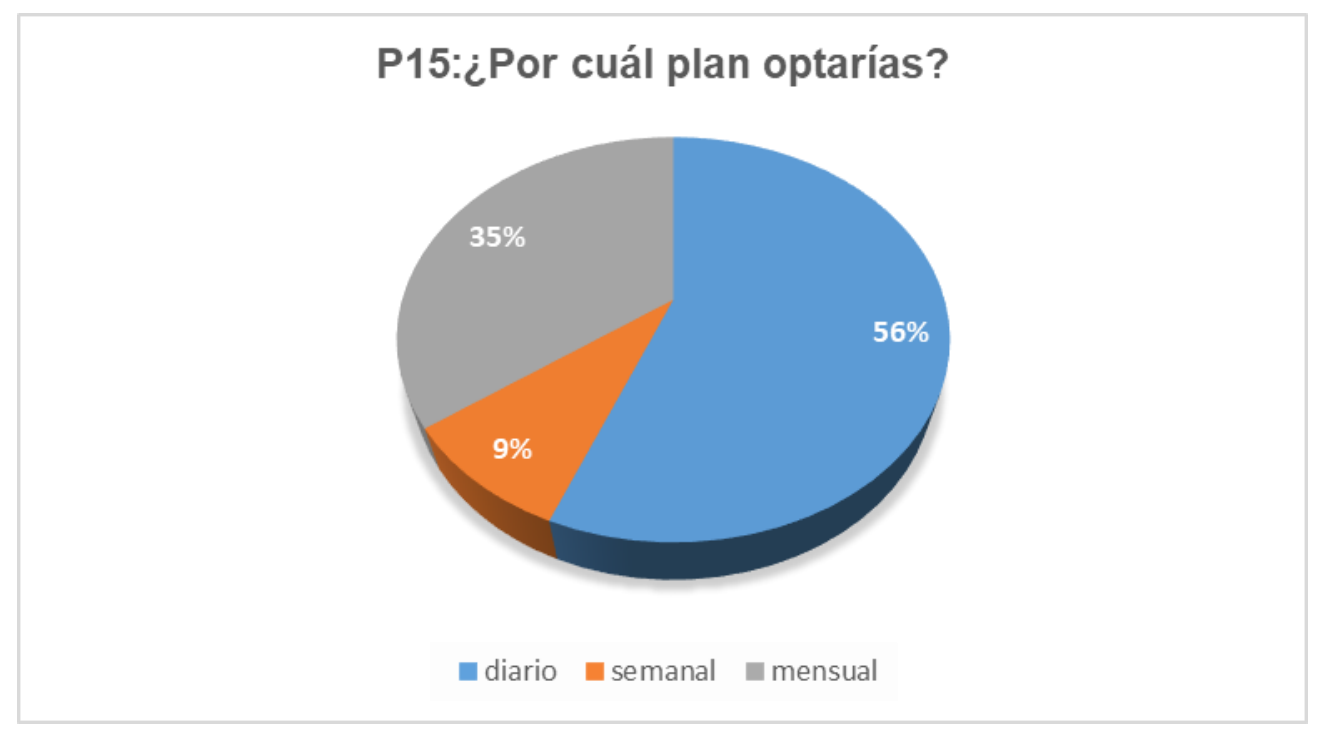

Figura 46 Resultados de pregunta 15 ¿Qué tipo de planes recomiendas? Datos tomados de las encuestas realizadas.

Los planes que debemos considerar para poder vender nuestro producto son los diarios y mensuales, podemos observar que lo planes semanales no tendrían mucha acogida.

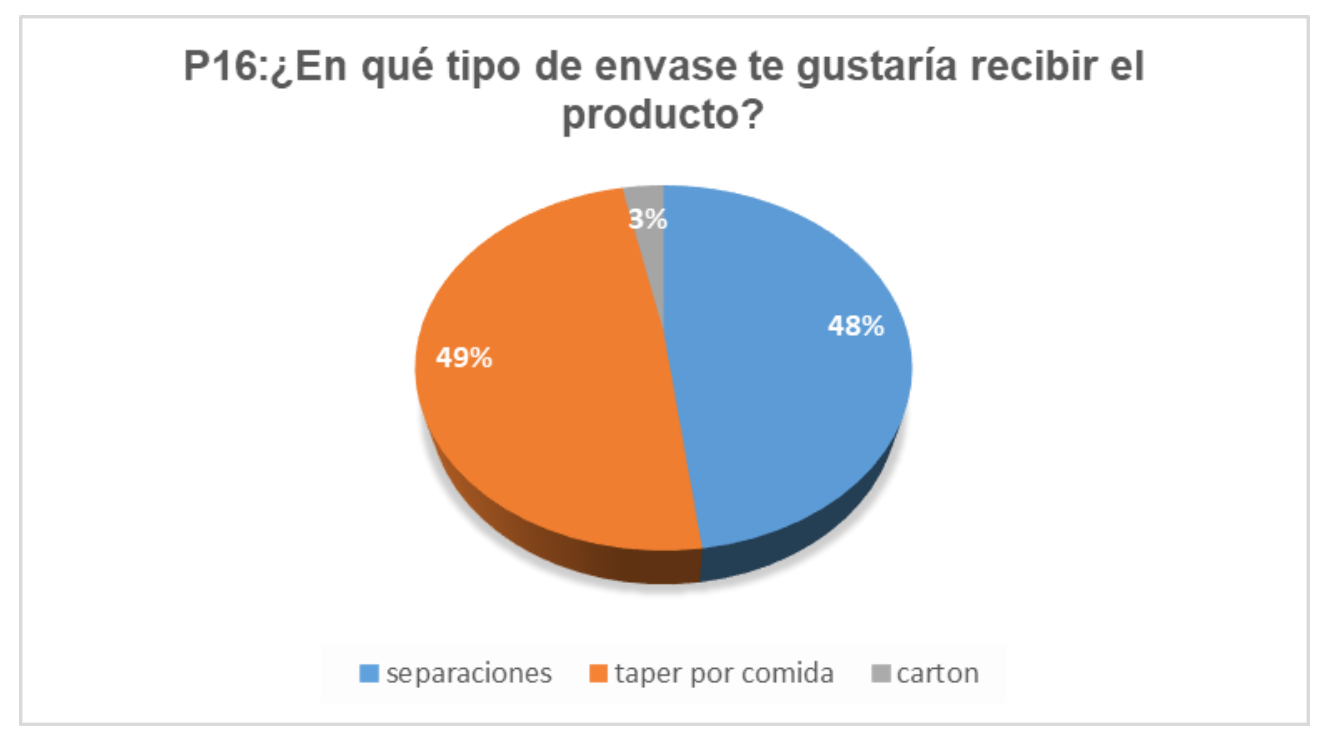

Figura 47 Resultados de pregunta 16 ¿En qué tipo de envase te gustaría recibir el producto ? Datos tomados de las encuestas realizadas. 
Nuestro target no se preocupa mucho por el envase, puede ser con separaciones o uno por comida, sin embargo, por estrategia de diferenciación utilizaremos envases eco-amigables.

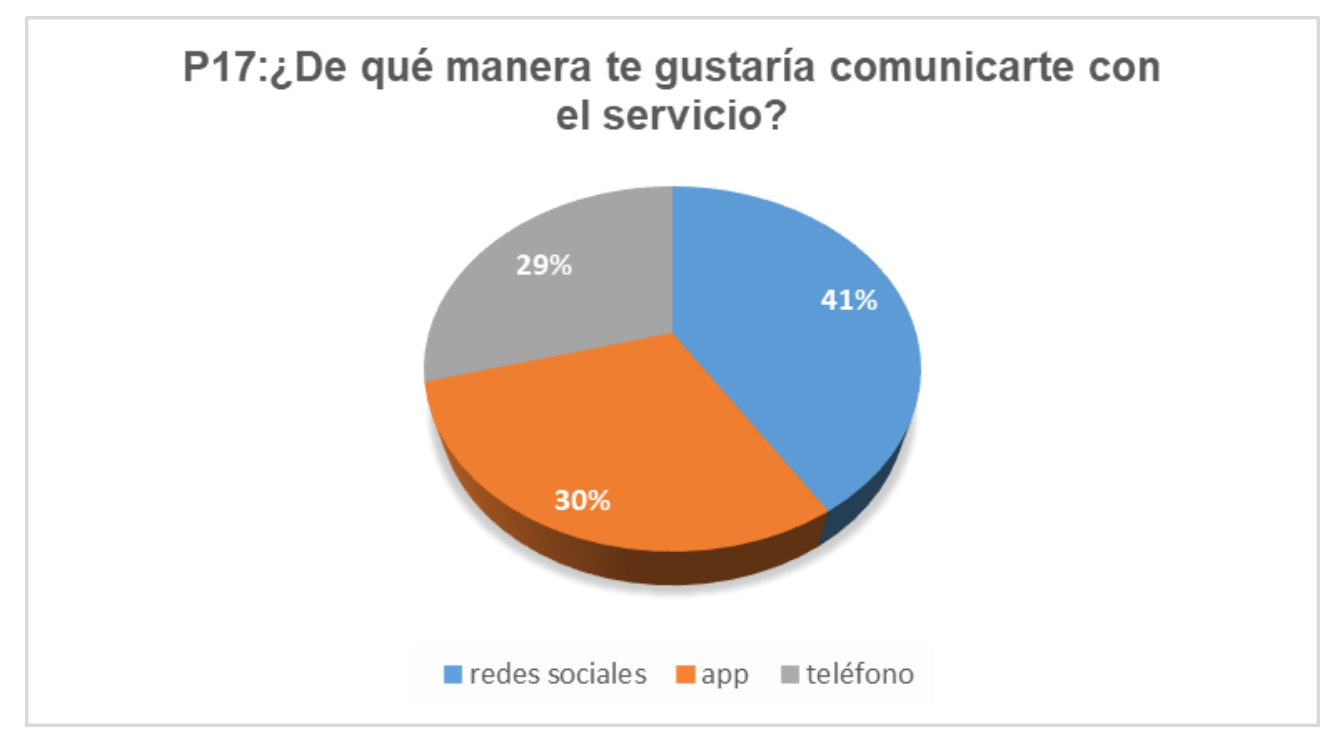

Figura 48 Resultados de pregunta 17 ¿De qué manera te gustaría comunicarte con el servicio? Datos tomados de las encuestas realizadas.

Si bien la mayoría de personas preferirían hacerlo a través de redes sociales, hay un porcentaje casi igual de personas que preferirían hacerlo a través de una app y teléfono. Esto nos indica que, si bien debemos empezar con una fuerte estrategia a través de redes sociales, en el futuro podríamos desarrollar una app amigable a través de la cual nos permita comunicarnos con nuestros clientes. Mencionar también que el uso del teléfono es imprescindible. 


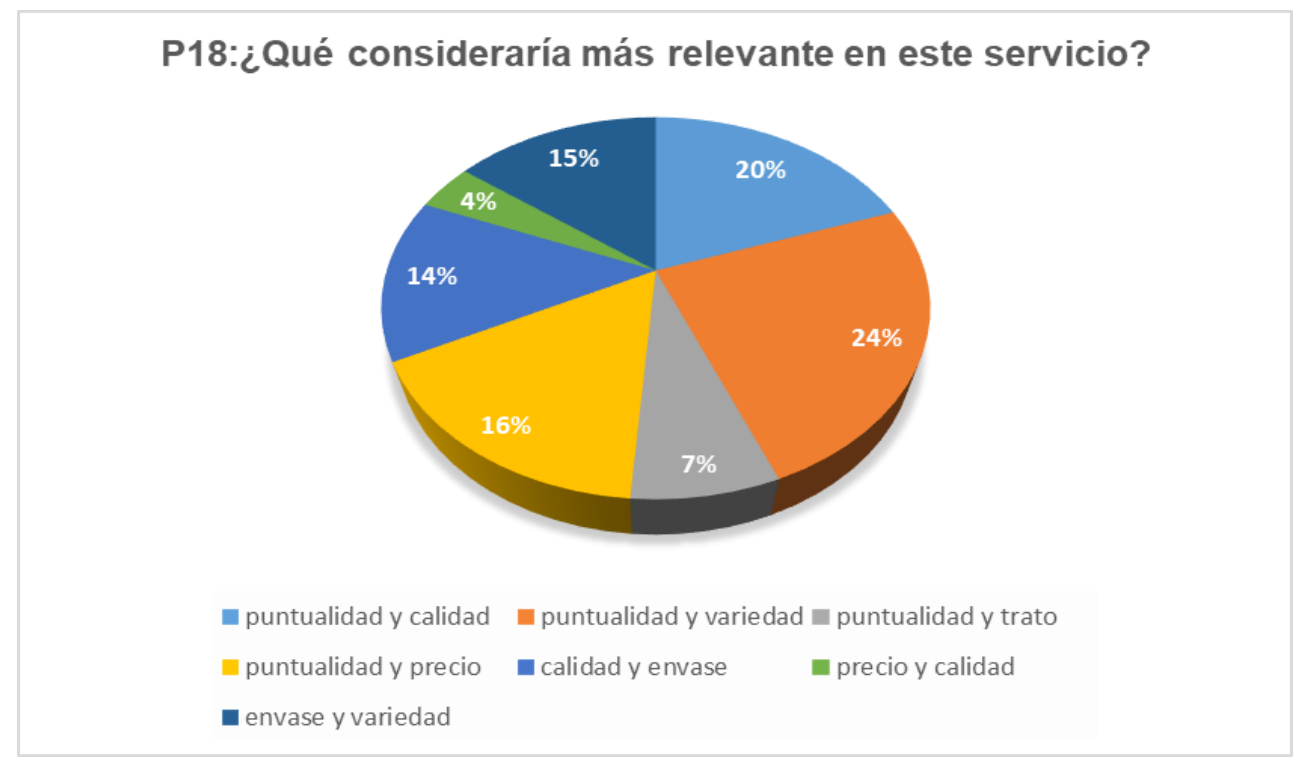

Figura 49 Resultados de pregunta 18 ¿Qué consideras más relevante en este servicio? Datos tomados de las encuestas realizadas.

Podemos observar una vez más que el público exige puntualidad como característica principal, ya que se repite en varias de las opciones, así mismo, le dan importancia también a la calidad seguida del precio y variedad de opciones.

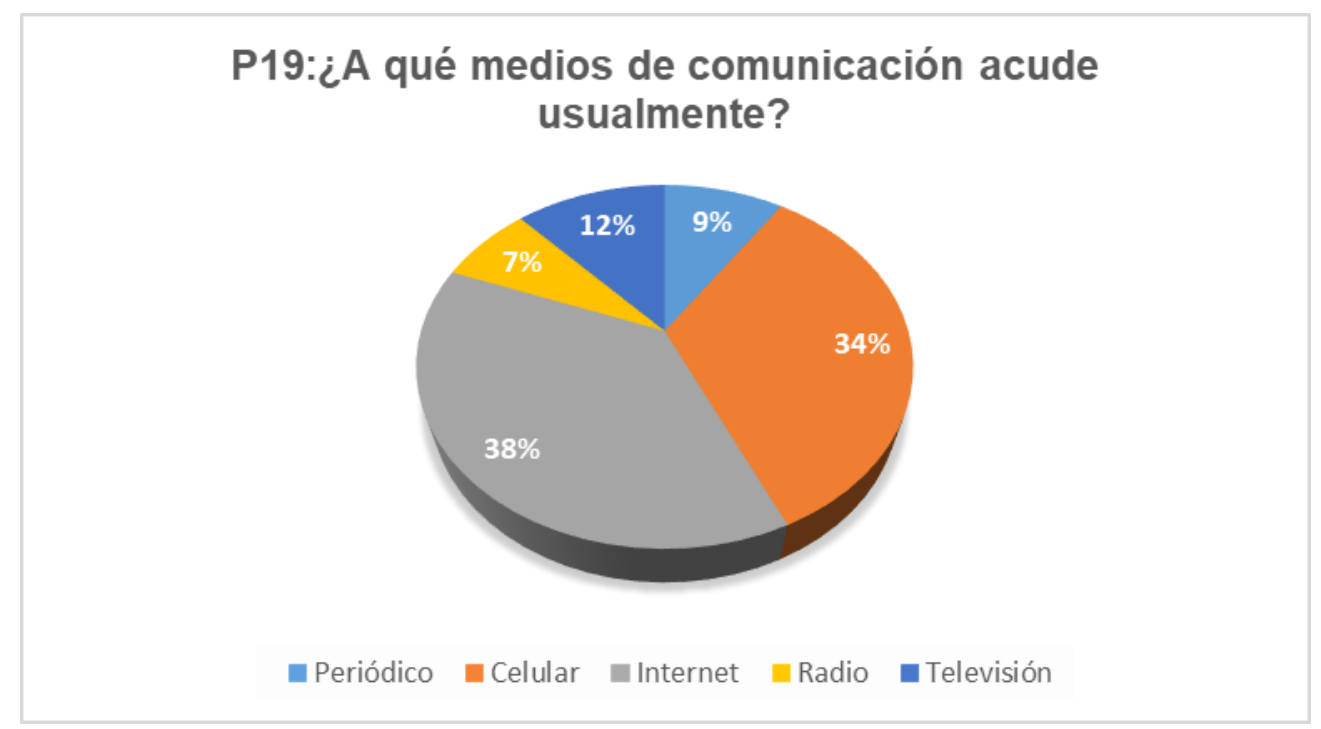

Figura 50 Resultados de pregunta 19 ¿A qué medio de comunicación acude usualmente? Datos tomados de las encuestas realizadas. 
En general los encuestados tienen mayor preferencia por medios como el celular y la internet, es por ellos que debemos centrarnos en este tipo de medios para realizar nuestras estrategias de promoción y publicidad.

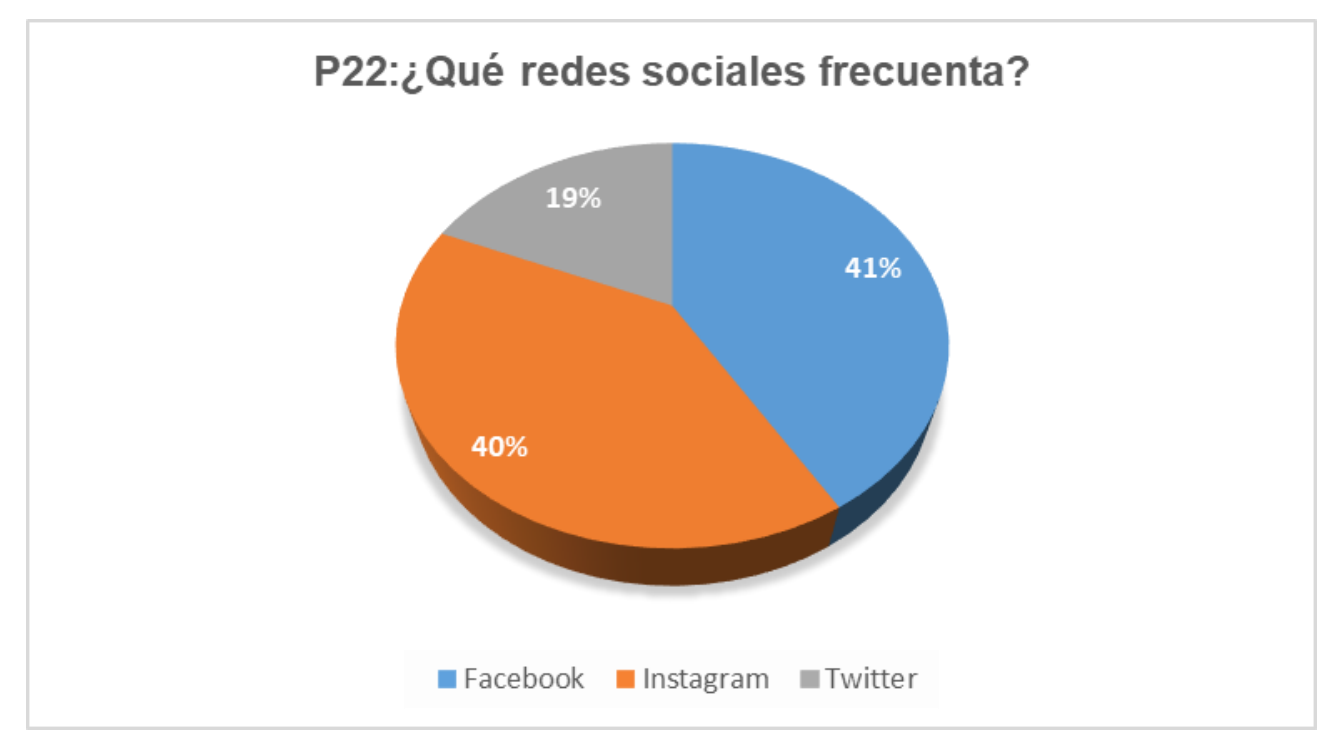

Figura 51 Resultados de pregunta 20 ¿Qué redes sociales frecuenta? Datos tomados de las encuestas realizadas.

Las redes sociales más usadas por los encuestados son Facebook e Instagram y es en estas donde debemos colocar mayor publicidad.

\subsection{Investigación Cualitativa.}

\subsubsection{Proceso de muestreo.}

Se buscó información específica sobre el segmento, el negocio de comida saludable ofrece solamente delivery se enfoca en una primera etapa en los distritos de Cayma, Yanahuara y Cercado.

La muestra para el focus group fue de 8 personas, considerando en especial características del estilo de vida y geografía de la muestra. Además, también se consultó a especialistas tanto en Publicidad y Medios. 


\section{Información clave}

La composición del grupo es la siguiente:

- Número de participantes: 8 (todas mujeres)

- Edad: comprendida entre 25 y 39

- Variable: Mujeres que consumen comida saludable o que tengan la necesidad de consumirla y no tengan tiempo de prepararla o no sepan hacerla.

- Distrito donde viven y/o trabajan: Yanahuara, Cayma, Cercado.

\section{Consulta a Especialistas:}

Dos especialistas, un publicista de la UCSM y una docente de Publicidad del Instituto Unitek.

\subsubsection{Diseño de instrumento.}

Se elaboró una guía de preguntas (20), la mayoría abiertas, para poder conocer insights, pensamientos y gustos del público objetivo (Anexo II).

Consulta a Especialistas:

Se desarrolló una guía de preguntas breve.

\subsubsection{Análisis y procesamiento de datos.}

Objetivo general:

Determinar los factores más importantes relacionados con las necesidades que tiene el segmento. Encontrar insights en el segmento para la propuesta de imagen y el servicio.

Objetivos específicos: 
- Identificar necesidades del segmento conforme al servicio propuesto.

- Determinar la percepción de los clientes en cuanto al servicio que brindan.

- Identificar problemática de la competencia.

- Conseguir los recursos para realizar las actividades.

- Elaborar las muestras del producto para cada participante

- Conseguir cámara y grabadoras de audio.

- Elaborar diseños de identidad corporativa (Logo) para mostrar en la investigación cualitativa.

- Elaborar el cuestionario para repartir al final del focus group.

Análisis de resultados

Percepción del segmento conforme a la comida saludable.

- El target está bien informado sobre lo que es comida saludable, tiene idea sobre lo que debe contener un menú de comida saludable.

"La comida saludable de contener más ensalada, proteína y menos carbohidratos"

Conocimiento que tiene el target sobre mercado el rubro de comida saludable.

- El target no conoce la existencia de otras marcas de comida saludable, a pesar de la existencia de por lo menos 7 marcas en la ciudad.

"En Arequipa no hay marcas de comida saludable, sólo en Lima"

Como el target percibe el servicio de delivery en general.

- El 80\% de participantes calificaron como malo el servicio de delivery en general.

"Te llevan a casa en contendores donde la comida llega en mal estado."

Consulta a especialistas: 
- "La representación gráfica de la marca, ya sea un logotipo, isotipo, imagotipo, o isologo debe tener pocos elementos. "Menos es más"

- "Un mensaje debe ser claro, preciso. Mientras la comunicación sea más dispersa, la publicidad que harás no será efectiva.”

- "Si utilizas muchos elementos y beneficios, no logras posicionamiento. Para posicionarse en un segmento de mercado, debes apuntar a un beneficio principal."

\subsection{Conclusiones y recomendaciones del Estudio Cualitativo y Cuantitativo.}

- El público objetivo está interesado en comer sano, sin embargo, en promedio come sano de manera interdiaria, lo cual nos indica que el mercado potencial es grande.

- El target tiene un insight marcado de relacionar el término saludable con fruta y verduras o sólo verduras.

- El target sugiere la identidad visual 3 (Anexo V) como representación gráfica de la empresa, haciendo algunas variaciones en cuanto a los elementos que la conforman.

- La hora ideal para repartir almuerzos es de 12 a 1 pm.

- El menú saludable de contener comida balanceada.

- El target sugiere que el producto de comida saludable debe ser supervisado por un médico o un nutricionista.

- En cuanto a la presentación, el menú saludable podría darse en un tupper con separaciones o un tupper por comida, sin preferencia marcada por ninguno de los dos.

- El target se muestra interesado en saber qué es lo que está comiendo (información de valores nutricionales).

- En cuanto a cantidad el target considera que se sentiría satisfecho si sólo se incluye entrada y plato de fondo. 
- El target considera que se debe pagar entre 13 y 16 soles por un menú de comida saludable incluido el delivery.

\subsection{Perfil del consumidor tipo y sus variantes.}

La consultora de marketing Arellano marketing tipifica al consumidor peruano en 6 estilos de vida.

Tabla 17

Cuadro de participación de cada estilo de vida LATIR en distintos países de América Latina.

PARTICIPACIÓN DE CADA ESTILO DE VIDA LATIR EN DISTINTOS PAÍSES DE AMÉRICA LATINA

$$
\text { Total País (share \%) }
$$

\begin{tabular}{|c|c|c|c|c|c|c|}
\hline & $\begin{array}{l}\text { Perú } \\
2011\end{array}$ & $\begin{array}{c}\text { Colombia } \\
2010\end{array}$ & $\begin{array}{l}\text { Chile } \\
2009\end{array}$ & $\begin{array}{l}\text { Brasil } \\
2009\end{array}$ & $\begin{array}{c}\text { México } \\
2010\end{array}$ & $\begin{array}{c}\text { Costa Rica } \\
2009\end{array}$ \\
\hline Sofisticados & 5 & 8 & 10 & 5 & 8 & 4 \\
\hline Progresistas & 25 & 27 & 19 & 18 & 16 & 18 \\
\hline Modernas & 21 & 27 & 21 & 32 & 23 & 25 \\
\hline Formalistas & 18 & 16 & 20 & 23 & 26 & 27 \\
\hline Conservadoras & 24 & 16 & 18 & 13 & 21 & 18 \\
\hline Austeros & 7 & 6 & 12 & 9 & 6 & 8 \\
\hline
\end{tabular}

Fuente: Arellano (2017) “LATIR: Los Estilos de Vida de la Nueva Sociedad Peruana y Latinoamericana".

- Dos son exclusivamente conformados por hombres: los Progresistas y los Formalistas.

- Dos son solo mujeres: las Modernas y las Conservadoras.

- Los últimos dos son mixtos: los Sofisticados y los Austeros.

Los Estilos de Vida nos ayudarán a entender al consumidor y cubrir mejor sus necesidades. 
Estos estudios mostraron la existencia de 6 estilos de vida Perú con dos grandes ejes: el nivel de ingreso y el de modernidad-tradición, altamente correlacionado con una variable de tendencia y resistencia al cambio. Paralelamente se encontró que la variable sexo también era importante para la clasificación de algunos grupos.

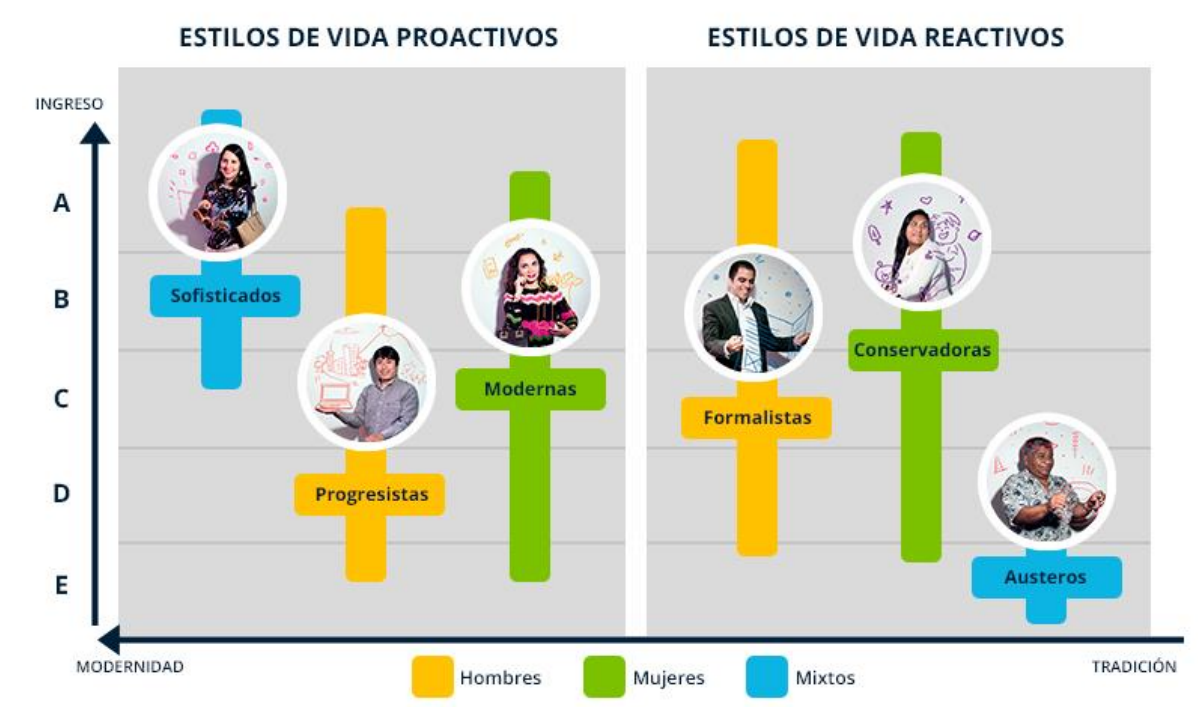

Figura 52 : Estilos de vida proactivo y reactivo. Tomada de Arellano (2017) "LATIR: Los Estilos de Vida de la Nueva Sociedad Peruana y Latinoamericana".

Al hacer el análisis de nuestro target, se segmentaron estilos de vida proactivos, considerando niveles de ingresos $\mathrm{A} / \mathrm{B}$ y $\mathrm{C} ; \mathrm{y}$ tomando como eje de desarrollo de proyecto los estilos de vida Sofisticados (mixto) y Modernos (mujeres).

Modernas que trabajan, pero a la vez también dedican parte de su tiempo a realizar quehaceres del hogar.

Sofisticadas que se dedica sólo a trabajar y como prioriza el tiempo tiene la necesidad de comer fuera.

Estos dos tipos de consumidores según el estudio valoran mucho el tiempo y la promesa de marca. Están dispuestos a pagar más de un menú estándar por un buen servicio que 
cumpla lo que promete. Además, necesitan información de lo que están comiendo. Y como plus sugieren que sea una comida supervisada por un especialista. 


\section{CAPITULO IV}

\section{Proyección del mercado objetivo}

\subsection{El ámbito de la proyección.}

El ámbito del proyecto comprende una investigación de mercados cuantitativa y cualitativa.

\subsection{Selección del método de proyección.}

Se aplicaron dos métodos para poder predecir comportamientos futuros:

- Consulta a Expertos

- Investigación de Mercados

\subsubsection{Mercado potencial.}

Definición: Es el conjunto de consumidores al que puede llegar nuestro producto o servicio. Son aquellos que “podrían necesitar” el producto o servicio que queremos ofrecer.

Está formada por las personas que consumen y no consumen el producto general que queremos ofrecer.

Para nuestro proyecto de comida saludable y servicio de delivery, el mercado potencial son todas las personas que viven o laboran en el distrito de Yanahuara, Cayma y Cercado de Arequipa, que tienen entre 21-44 años de edad, pertenecen al nivel socioeconómico A/B y C y tienen el estilo de vida saludable o están interesados en ello. 
Tabla 18

Mercado potencial: Cantidad de mujeres de entre 14 y 44 años que trabajan en la zona urbana de los distritos de Arequipa, Cayma y Yanahuara al 2017.

\begin{tabular}{cccc}
\hline Edad & $\mathbf{1 4 - 2 9}$ & $\mathbf{3 0 - 4 4}$ & TOTAL \\
\hline Arequipa & 2,945 & 4,323 & 7,268 \\
Cayma & 6,112 & 7,788 & 13,900 \\
Yanahuara & 3,181 & 2,801 & 5,982 \\
\hline TOTAL & $\mathbf{1 2 , 2 3 8}$ & $\mathbf{1 4 , 9 1 2}$ & $\mathbf{2 7 , 1 5 0}$ \\
\hline
\end{tabular}

Fuente: Resultados definitivos Población económicamente activa - Arequipa 2017

*Se tomó en cuenta el total ponderado en el rango 14-29, a pesar que nuestro target va desde los 21; ya que según expertos el porcentaje de 14-21 no genera mucho impacto de variación, al no ser muy representativo.

En la tabla se presenta la cantidad de personas con estas características, las cuales arrojan un total de 27,150 personas.

\subsubsection{Mercado disponible.}

Definición: Es una parte del mercado potencial y está formada por el conjunto de consumidores que tienen la "necesidad específica" de comprar el producto o servicio que ofrece el nuevo negocio. Esto no quiere decir que todas estas personas compraran el producto que ofrecerá el nuevo negocio. De este total, una parte podría comprar al nuevo negocio y otro no, por diferentes razones.

Para determinar el mercado disponible se utiliza el cuestionario de encuesta, e incluimos una pregunta para ello. 
Para nuestro proyecto de comida saludable y servicio de delivery, en el cuestionario de encuesta se considera una pregunta que dice: ¿Consume usted alimentos saludables? Esta pregunta se refiere a la comida saludable en general, no se refiere al tipo de comida saludable del nuevo negocio.

Tabla 19

Mercado disponible ¿Consumes comida saludable?

\begin{tabular}{cc}
\hline ¿Consumes comida saludable? \\
\hline Respuestas & $\%$ \\
SI & $59.93 \%$ \\
NO & $40.07 \%$ \\
\hline Total & $\mathbf{1 0 0 . 0 0 \%}$ \\
\hline
\end{tabular}

Elaboración propia

Para el cálculo del mercado disponible utilizamos el resultado de la respuesta SI. El mercado disponible es $=$ Mercado Potencial $\times \%$ Respuesta SI $=27,150 \times 59.93 \%$ $=16,271$ personas.

\subsubsection{Mercado efectivo.}

Definición: Es una parte del mercado disponible y está formado por el conjunto de consumidores que además de la necesidad específica, "tienen la intención de comprar" el bien y/o servicio que ofrece el nuevo negocio. Aquí si se refiere a la comida saludable variada, de buen sabor y con excelente servicio de delivery que se ofrecerá.

Este mercado también es definido a través de una pregunta en el cuestionario de encuesta. 
Para nuestro proyecto de comida saludable y servicio de delivery, en el cuestionario de encuesta se considera una pregunta que dice:

Si una empresa le ofrece el servicio delivery de comida saludable en su casa o trabajo a la hora que usted lo requiere, asegurándole puntualidad, buena presentación y variedad de platos. ¿Estarías dispuesto a contratar este servicio?

Tabla 20

Mercado efectivo: Intención de compra del producto o servicio

\begin{tabular}{lcc}
\hline Interés de Compra & Rptas & \% \\
\hline Sin duda Si & 63 & $21.95 \%$ \\
Probablemente $\mathrm{Si}$ & 101 & $35.19 \%$ \\
Probablemente No & 82 & $28.57 \%$ \\
Sin duda No & 41 & $14.29 \%$ \\
\hline Total & $\mathbf{2 8 7}$ & $\mathbf{1 0 0 . 0 0 \%}$ \\
\hline
\end{tabular}

\section{Elaboración propia}

Para calcular el mercado efectivo trabajamos con la respuesta "Sin duda si", porque es la que nos indica aquellas personas más interesadas o con quienes existe una alta probabilidad que consumirán el producto de este nuevo negocio.

Por lo tanto, el mercado efectivo es: mercado disponible por $\%$ Sin duda si $=$ $16,271 \times 21.95 \%=3,572$ personas.

Se debe señalar que esta cantidad de 3,572 personas $(21.95 \%)$ no debemos considerarlo como algo absoluto, pero si un valor que nos da una idea de la cantidad de personas que con cierta seguridad comprarían nuestro producto y/o servicio. 


\subsubsection{Mercado objetivo.}

Definición: Es una parte del mercado efectivo que el negocio espera atender; es decir, al realizar los esfuerzos y acciones de marketing de la empresa se espera captar a esta cantidad de personas.

Nuestro mercado objetivo ha sido calculado en base a los resultados de la pregunta de intención de compra, para ellos tomamos la pregunta 14: Si una empresa le ofrece el servicio delivery de comida saludable en su casa o trabajo a la hora que usted lo requiere, asegurándole puntualidad, buena presentación y variedad de platos. ¿Estarías dispuesto a contratar este servicio?

Tabla 21

Intención de compra del producto o servicio.

\begin{tabular}{lcc}
\hline Interés de Compra & Rptas & \% \\
\hline Sin duda Si & 63 & $21.95 \%$ \\
Probablemente Si & 101 & $35.19 \%$ \\
Probablemente No & 82 & $28.57 \%$ \\
Sin duda No & 41 & $14.29 \%$ \\
\hline Total & $\mathbf{2 8 7}$ & $\mathbf{1 0 0 . 0 0 \%}$ \\
\hline
\end{tabular}

Elaboración propia

Según los resultados, aproximadamente un 57\% de los encuestados estarían dispuestos a contratar nuestro servicio, sin embargo, para tener un cálculo más razonable y conservador aplicaremos la escala de intención de compra de Carl McDaniel (2016) que consiste en calcular un 70\% de los que "sin duda comprarán", $35 \%$ de los que "probablemente comprarán", $10 \%$ de los que "probablemente no comprarán" y cero por ciento de los que “sin duda no comprarán”. Aplicando este principio nuestro mercado objetivo asciende 1,300 personas, que representa un $30.54 \%$ de nuestro mercado efectivo. 
Tabla 22

Calculo de mercado objetivo aplicando principio McDaniel.

\begin{tabular}{lrr}
\hline Mercado Obje tivo & & \\
\hline \hline Sin Duda SI & Encuesta & McDaniel \\
\hline Probablemente si & $21.95 \%$ & $70 \%$ \\
& 785 & 550 \\
\hline Probablemente no & $35.19 \%$ & $35 \%$ \\
& 1258 & 440 \\
\hline Sin duda No & $28.57 \%$ & $10 \%$ \\
& 1022 & 102 \\
\hline TOTAL & $14.29 \%$ & $0 \%$ \\
\hline
\end{tabular}

Elaboración propia

Aplicando este principio nuestro mercado objetivo resulta ser 1,092 personas, que representan un $30.54 \%$ de nuestro mercado efectivo.

\subsubsection{Demanda:}

Se considera que existe una mayor demanda del servicio de lunes a viernes, ya que las oficinas y demás centros de labores en la zona de influencia no trabajan los días sábados, es por ello que el servicio solo se brindará de lunes a viernes, no incluyendo sábados, domingos ni feriados.

Demanda de menús saludables según frecuencia:

Tabla 23

Frecuencia con la que se compra un menú saludable

\begin{tabular}{lc}
\hline Frecuencia con la que compran un menú saludable \\
\hline Diario & $21.95 \%$ \\
\hline Interdiario & $45.35 \%$ \\
\hline Una vez a la semana & $31.98 \%$ \\
\hline Elaboración propia &
\end{tabular}


- Cálculo de la demanda diaria según frecuencia de una vez a la semana:

Según nuestro estudio de mercado la mayoría de personas consumiría un menú saludable una vez a la semana: el $23.84 \%$

$1,092 * 31.98 \%=348.78=349$ personas

310 personas consumirían mensualmente un menú saludable una vez a la semana.

Si todas estas personas deciden comprar nuestro menú al menos una vez a la semana y el mismo día, la demanda sería de

349/22 días = 16 menús con frecuencia semanal

Cabe resaltar que estos clientes son ocasionales, su grado de fidelidad es muy bajo. Comen un menú saludable semanal para variar su rutina.

- Cálculo de la demanda diaria según frecuencia interdiaria:

Según nuestro estudio de mercado la cantidad de personas que consumiría un menú saludable interdiario sería el $45.35 \%$

$1,092 * 45.35 \%=494.64=495$ personas

695 personas consumirían mensualmente un menú saludable con frecuencia interdiaria.

495/22 = 23 menús con frecuencia interdiaria

Estos clientes poseen un nivel de fidelidad mayor que un cliente que consume una vez a la semana, y debemos crear estrategias que los convenzan de consumirlo diariamente. 
- Cálculo de la demanda diaria según frecuencia diaria:

Según nuestro estudio de mercado la cantidad de personas que consumiría un menú saludable de forma diaria es el $22.67 \%$.

$1,092 * 22.67 \%=247.32=247$ personas

295 personas durante el mes consumirían un menú saludable con frecuencia diaria.

$247 / 22$ = 11 menús con frecuencia diaria

Los clientes que consumen el menú diariamente tienen más relevancia y debemos trabajar su grado de fidelización, así como, de los clientes que consumen el producto con frecuencia interdiaria, es por esto que nuestras estrategias deben estar más enfocadas a ellos.

Tabla 24

Número de menús saludables al día.

\begin{tabular}{lc}
\hline \multicolumn{2}{c}{ Números de menús saludables al día } \\
\hline Frecuencia diaria & 11 \\
\hline Frecuencia interdiaria & 23 \\
\hline Frecuencia ocasional (una vez a la semana) & 16 \\
\hline \multicolumn{1}{c}{ TOTAL } & $\mathbf{5 0}$
\end{tabular}

Elaboración propia

\subsubsection{Periodicidad de compra:}

Según los estudios, la periodicidad de compra sería como sigue: 
Tabla 25

Periodicidad de compra.

\begin{tabular}{lcc}
\hline \multicolumn{3}{c}{ Periodicidad de compra } \\
\hline Diaria & $22.67 \%$ & 11 personas \\
\hline Interdiario & $45.35 \%$ & 22 personas \\
\hline Una vez a la semana & $31.98 \%$ & 16 personas \\
\hline Elaboración propia & &
\end{tabular}

\subsubsection{Proyección de Ventas según demanda diaria}

La proyección de ventas de acuerdo a los resultados del estudio realizado si logramos captar la atención de incluso aquellos que la consumen ocasionalmente, sería como sigue:

Tabla 26

Proyección de ventas según demanda diaria.

\begin{tabular}{lccccc}
\hline \multicolumn{5}{c}{ Proyección de Ventas } \\
\hline Descripción & $\begin{array}{c}\text { Demanda } \\
\text { Diaria en } \\
\text { menús }\end{array}$ & $\begin{array}{c}\text { Demanda } \\
\text { diaria en soles }\end{array}$ & $\begin{array}{c}\text { Venta } \\
\text { Semanal }\end{array}$ & $\begin{array}{c}\text { Venta } \\
\text { Mensual }\end{array}$ & $\begin{array}{c}\text { Venta } \\
\text { Anual }\end{array}$ \\
\hline Diaria & 11 & 159.50 & $\mathrm{~S} / .797 .50$ & $\mathrm{~S} / .3,509.00$ & $\mathrm{~S} / .42,108.00$ \\
Interdiario & 22 & 319.00 & $\mathrm{~S} / .957 .00$ & $\mathrm{~S} / .5,104.00$ & $\mathrm{~S} / .61,248.00$ \\
Una vez a la & 16 & 232.00 & $\mathrm{~S} / .232 .00$ & $\mathrm{~S} / .928 .00$ & $\mathrm{~S} / .11,136.00$ \\
semana & 16 & & &
\end{tabular}

Elaboración propia

*Precio de menú: 14.50 soles. 


\section{CAPITULO V}

\section{Plan de Marketing}

\subsection{Estrategias de marketing.}

\subsubsection{Estrategia de producto.}

Nuestro servicio busca satisfacer las necesidades de alimentación saludable a la hora del almuerzo en los distritos de Yanahuara, Cayma y Cercado de Arequipa, dirigido a mujeres que se encuentran entre los 21 y 44 años de edad, dentro de los niveles socioeconómicos A, B y C.

\section{Niveles del producto:}

Primero debemos tener en claro que, según el Comité de Definiciones de la Asociación Americana de Marketing, producto es definido como "cualquier cosa que pueda ofrecerse a la atención del mercado para su adquisición, uso o consumo, que pueda satisfacer un deseo o una necesidad; incluye objetos físicos, servicios, personas, lugares, organizaciones e ideas". Entonces, todo producto antes de ser puesto en el mercado, debe ser analizado de diversas formas para que su comercialización este bien dirigida y tenga una buena aceptación por parte del público.

Desde el punto de vista funcional se desglosan del producto ciertos niveles para así conocer su grado de utilidad, diseño y bondades. Esto permitirá conocer el valor que aporta el producto a las personas. 


\section{a. Producto básico:}

Hace referencia a la utilidad que tiene el producto y las necesidades básicas que satisface.

El producto básico que ofrece FitFood es:

- Almuerzos preparados con insumos de calidad, frescos y bajo las indicaciones de un nutricionista que satisfacen la necesidad de almuerzos saludable

- Servicio de delivery de almuerzo saludable que le ahorra tiempo al cliente, al recibir el producto en su centro de trabajo, evitando gastar tiempo en movilizarse o preparándolo por su cuenta.

\section{b. Producto real:}

Tiene que ver con la forma como se presenta el producto al público y que características lo diferencian de la competencia.

El producto real que ofrece FitFood es:

- Almuerzos saludables presentados de forma ordenada en envases ecoamigables, contribuyendo de esta forma con el cuidado del ambiente.

- Menú diario con más de una opción de entrada y plato de fondo, para que el cliente tenga la libertad de escoger aquellos que más le agrade, así mismo, variedad de platos a lo largo del mes.

- Servicio delivery que asegura puntualidad en la entrega del producto, según las necesidades de cada cliente (hora de almuerzo).

\section{c. Producto aumentado:}

Este nivel se identifica por darle prioridad a la atención al cliente o el servicio que se le ofrece al público al momento de adquirir el producto. 
El producto aumentado que ofrece FitFood es:

- Servicio de atención al cliente a través de Whatsapp y/o redes sociales verificando el estado y la hora de llegada de los pedidos.

- Finalizando el servicio, se realizarán preguntas de control al cliente por el servicio brindado y se recibirán sugerencias para poder tener una mejora continua del servicio.

\section{Oferta de valor del producto:}

\section{a. ¿Cómo satisfacemos las necesidades de nuestros clientes?}

- Servicio de delivery puntual según las necesidades e indicaciones de nuestros clientes.

- Menús saludables armados por un nutricionista y preparados con insumos de calidad.

- Variedad de opciones para los menús diarios y semanales.

\section{b. ¿Qué ventajas of rece FitFood?}

- Alimentación balanceada y variada, supervisada por un nutricionista cuidando la presencia de macronutrientes en las porciones necesarias.

- Tiempo libre para realizar otras actividades o para almorzar con más calma.

- Entrega del almuerzo en el momento oportuno.

- Comunicación constante con el cliente.

\section{c. ¿Cuáles son las características diferenciales de Fit Food?}

- Producto elaborado con insumos de buena calidad.

- Más de una opción de almuerzo en el menú diario y variedad de opciones para el mes. 
- Entrega puntual y efectiva del producto ofrecido según los requerimientos del cliente.

- Presentación ordenada y en envases ecológicos de la marca Qaya (marca de eco-envases), que están hechos de material renovable como fibras vegetales, harina de maíz, PLA / Bio-plástico, papel ecológico, entre otros, dándole un valor agregado a nuestro producto.

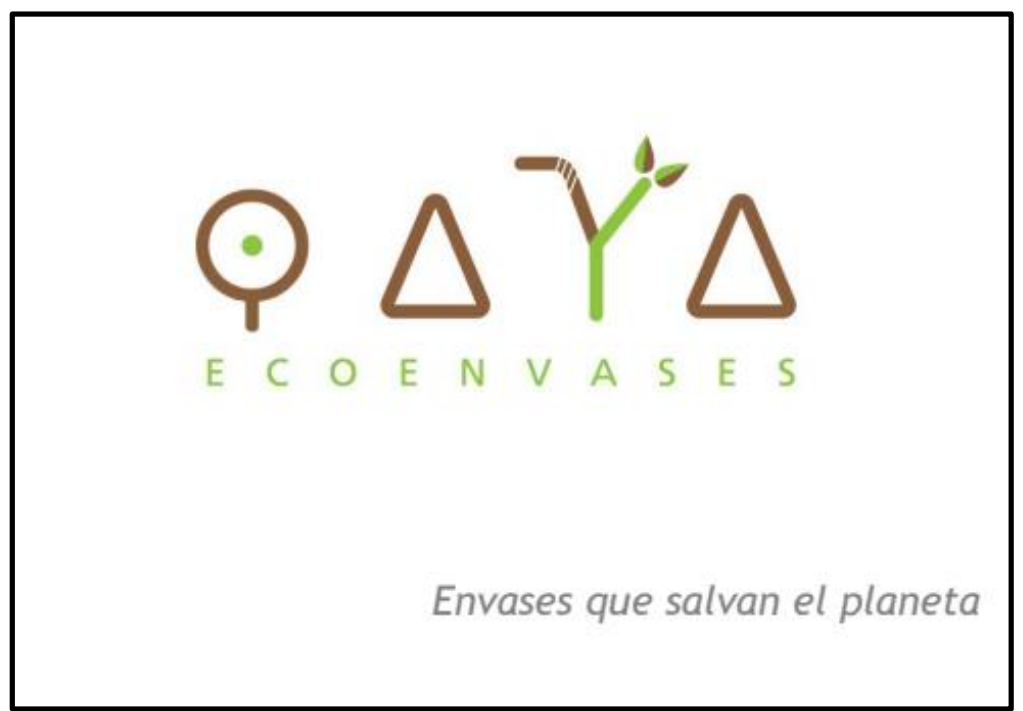

Figura 53 Marca de envases ecológicos QAYA. Tomada de catálogo enviado por empresa.

\subsubsection{Estrategia de precio.}

La estrategia de precios que se ha considerado para el proyecto es la de Precios Orientados a la Competencia, la que consiste en basarnos en los precios que ofrece la competencia. Según Esteban Agueda (1997), se pueden distinguir diferentes acciones:

- Equipararse con los precios de los competidores

- Diferenciarse de los competidores con precios superiores 
- Diferenciarse de los competidores con precios inferiores

- Mantenimiento de precios frente a la competencia

Nosotros optaremos por mantener precios similares frente a la competencia, de modo que el cliente no sienta un desbalance con respecto al precio de otra marca u opción de almuerzo. Según la encuesta nuestro público objetivo pagaría entre 13 y 16 soles, comparado con nuestros competidores que sus precios oscilan entre 12 y 15 soles el menú.

Para la investigación del precio se procedió de las siguientes maneras:

- Primero, indagamos el precio de la competencia directa, actuando nosotras mismas como clientas de las 3 marcas que actualmente se desarrollan en el mercado de la ciudad de Arequipa. Esto también fue un determinante para probar la calidad de su producto, así como las condiciones de entrega del mismo (hora de entrega, presentación final del menú, características propias tales como temperatura, buen sabor, calidad en insumos, etc).

- Posteriormente, al realizar la investigación cuantitativa, se hizo uso de un cuestionario en el cuál una pregunta definía rangos de precios, esto nos permitió conocer el precio que los "posibles clientes" estarían de acuerdo a pagar por un menú saludable; arrojando datos que están relacionados con los precios que maneja actualmente la competencia.

- Finalmente, en la investigación cualitativa, se realizó un focus group que también nos permitió conocer el precio que estaría dispuesto a pagar el cliente por el producto/servicio mostrado en esa dinámica. 
Estos insights nos permitieron plasmar el precio final de nuestro menú saludable y servicio de delivery; argumentando también el análisis de costos que se hizo para poder determinar el precio, tomando en cuenta la mano de obra, la materia prima y los materiales utilizados para la elaboración y empaque del producto.

Nuestro precio es congruente con nuestros costos ya que se realizó un análisis de costos previo a la fijación del precio de nuestro servicio.

Tabla 27

Estructura de costos (expresado en soles)

\begin{tabular}{|c|c|c|c|c|c|}
\hline Componentes del costo & AÑO 1 & AÑO 2 & AÑO 3 & Ã̃O 4 & Ã̃O 5 \\
\hline Materia Prima & 4.661 & 4.857 & 5.061 & 5.274 & 5.495 \\
\hline Mano de Obra & 1.801 & 1.877 & 1.956 & 2.038 & 2.123 \\
\hline Materiales & 1.600 & 1.667 & 1.737 & 1.810 & 1.886 \\
\hline COSTO UNITARIO & 8.063 & 8.401 & 8.754 & 9.122 & 9.505 \\
\hline
\end{tabular}

Elaboración propia

Tabla 28

Precio almuerzo FIT FOOD

(expresado en soles)

\begin{tabular}{cc}
\hline Producto & \multicolumn{2}{c}{ Precio } \\
\hline Almuerzo saludable & S/ $\quad \mathbf{1 4 . 5 0}$ \\
\hline
\end{tabular}

Elaboración propia

\subsubsection{Estrategia de plaza y distribución.}

La forma de distribución del producto es muy importante en cualquier negocio, y de forma especial en el nuestro, los almuerzos serán distribuidos en las mejores condiciones, acondicionando una caja especial de delivery a las motos que se encarguen de hacer los repartos y de forma que el producto llegue en buen estado. 
La ubicación de nuestro mercado meta es en los distritos de Cayma, Yanahuara y cercado de Arequipa por lo que nuestro centro de operaciones se ubicara en Yanahuara, siendo un punto casi céntrico de la zona de influencia. Con las ubicaciones de nuestros clientes y los horarios de entrega deberá prepararse una hoja de ruta, teniendo en cuenta las vías más descongestionadas para evitar demoras. En un primer momento se contará con un repartidor motorizado para cubrir los pedidos y que se cumpla con la característica diferenciadora de puntualidad en la entrega del producto; posteriormente a medida que vaya incrementándose la demanda se implementarán repartidores adicionales.

Hemos podido identificar que nuestra competencia realiza las entregas en horarios que no son los adecuados para el cliente, ya sea muy temprano en la mañana o muy tarde, algunas veces el producto no tiene la mejor presentación por el movimiento del vehículo en el que lo transportan, estos son puntos en los que trabajaremos para diferenciarnos.

Nuestra estrategia de venta será Multicanal, según el estudio de mercado y la información de APEIM (2018), aquellas personas que se encuentran dentro de los sectores socioeconómicos A, B y C, utilizan más la internet y el teléfono como medio de comunicación, es por ellos que ofreceremos nuestros productos a través de los siguientes canales:

\section{- Venta Online}

La venta online se realizará a través de las redes sociales como Instagram, y Facebook, y a través de nuestra página web donde se publicarán los menús diariamente y podrán hacerse los pedidos. 
Según la encuesta aplicada, más del $40 \%$ de encuestados prefiere comunicarse con nosotros a través de redes sociales y en su gran mayoría usan con mayor frecuencia Instagram y Facebook

El proyecto contará con una página web aparte de su presencia en redes, el administrador se encargará de atender y hacer la confirmación de los pedidos y demás consultas que se puedan generar

De acuerdo al análisis realizado a la competencia y el estudio de mercado se ha identificado la importancia de mantener un contacto continuo con el cliente a través de redes sociales, ya sea para promocionar la marca, realizar los pedidos, confirmarlos y obtener un feedback sobre el servicio brindado. Podemos observar también que, si bien nuestra competencia hace uso de redes sociales, no logra obtener el máximo provecho en beneficio del negocio, utilizándolo solo para la recepción de pedidos.

Contar con una página web amigable y vistosa, ayudará a nuestros clientes a navegar en ella de forma rápida, hacer sus pedidos, pagar y realizar consultas sin problemas.

\section{- Venta Telefónica}

La venta telefónica se realizará a través del aplicativo WhatsApp y de llamadas telefónicas. En un inicio será el administrador quien se encargue de ello, planeamos actualizar constantemente una lista de contactos a quienes enviaremos diariamente el menú del día.

Considerando el análisis realizado, el cliente prefiere un trato más personalizado, si bien las redes sociales son un excelente medio para comunicarnos, realizar la 
promoción diaria directamente con cada uno de ellos, servirá para fidelizarlos y hacerles notar su importancia para la empresa y estar presentes en su vida diaria.

\subsubsection{Estrategia de promoción y publicidad.}

\subsubsection{Estrategia de promoción}

Según el libro Fundamentos de Marketing, se manejan dos tipos de estrategias: promoción de empujar (push) y promoción de jalar (pull). Según las características de nuestro proyecto optaremos por la estrategia de jalar, en la cual se invierte en promoción y publicidad para inducir a los consumidores finales a adquirir el producto (Kotler y Armstrong, 2013).

Después del estudio cualitativo y cuantitativo el nombre que el segmento sugiere es FIT FOOD.

Como resultado de los estudios cualitativos y cuantitativos podemos darnos cuenta que hay una asociación muy fuerte en los consumidores de relacionar saludable con verduras, lo que define la identidad corporativa; así mismo, del Estudio sobre salud y etiquetado realizado por KWP (Kantar Worldpanel), se desprende que la característica más importante de una alimentación saludable para un $62 \%$ de los peruanos es "comer frutas y verduras" casi todos los días (El Comercio, 2019), lo que confirma la idea preconcebida que tenemos acerca de lo que es comida saludable. Además, decidimos cambiar el nombre de Green Power a Fit Food porque el target lo relaciona más con el servicio. 


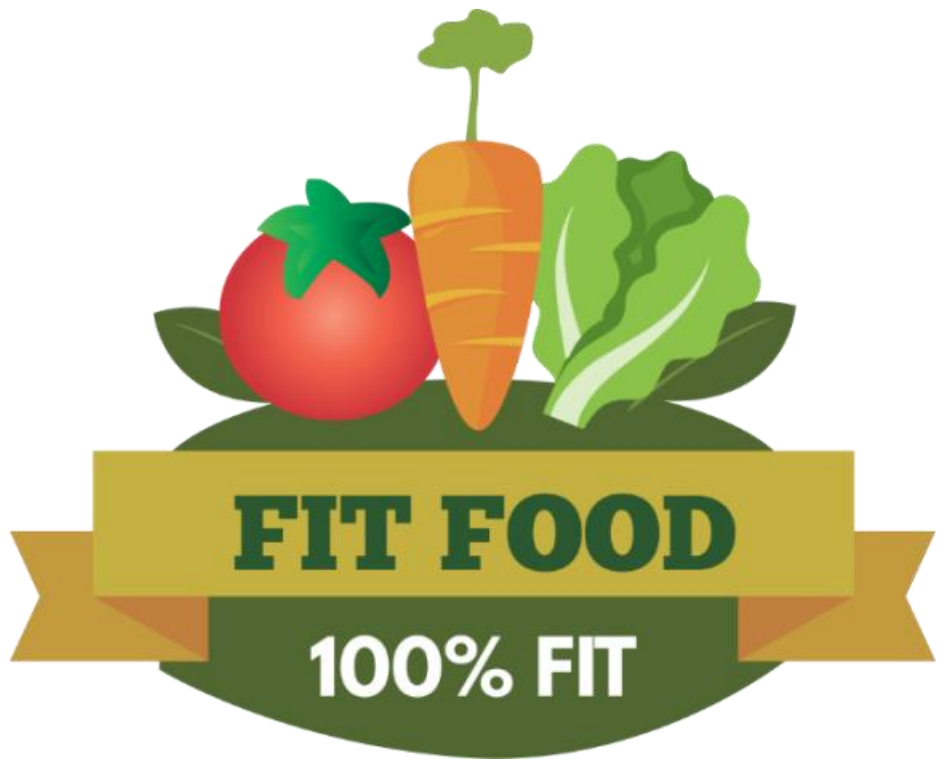

Figura 54 Imagotipo elegido para el proyecto de comida saludable.

Teniendo la identidad visual corporativa definida, procederemos a elegir nuestra estrategia de promoción.

\section{- Redes sociales}

Es una de las herramientas más utilizadas en la actualidad debido a su bajo costo y facilidad de manejo. Se crearán perfiles en dos redes sociales:

Instagram y Facebook donde no solo publicaremos información acerca de nuestro producto o servicio sino imágenes y textos atractivos para nuestros seguidores y que les brinden información relacionada a temas saludables, así como enlaces con información a mayor detalle que los lleven a nuestra página y de esta forma darla a conocer. 


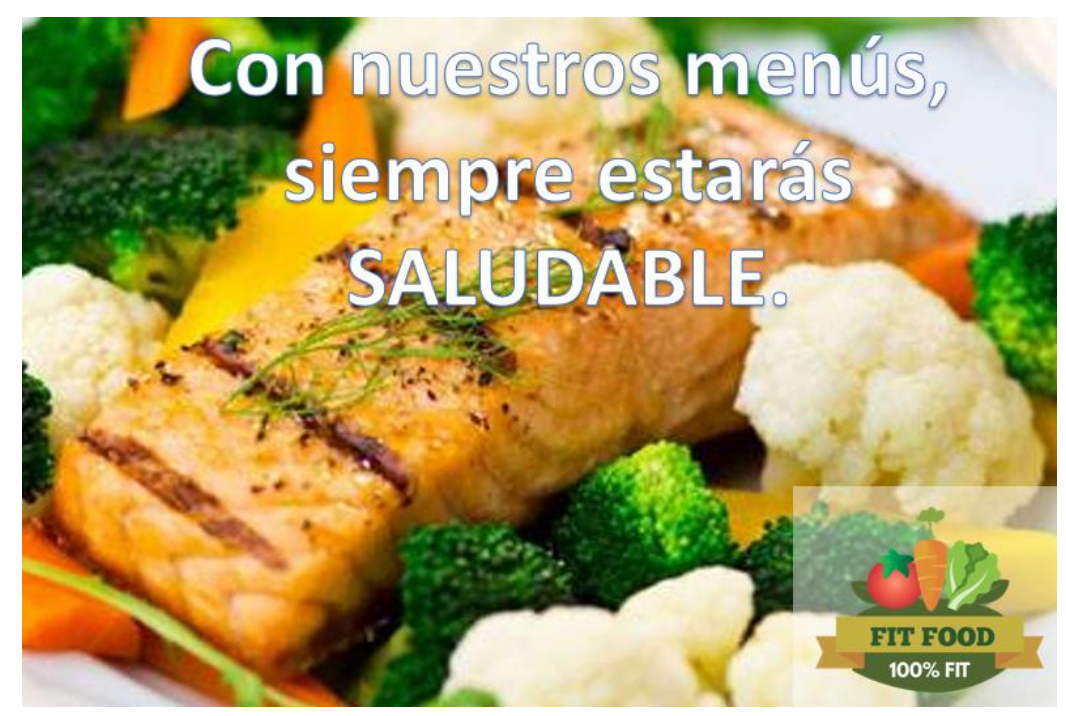

Figura 55 Modelo 1 de imagen informativa.

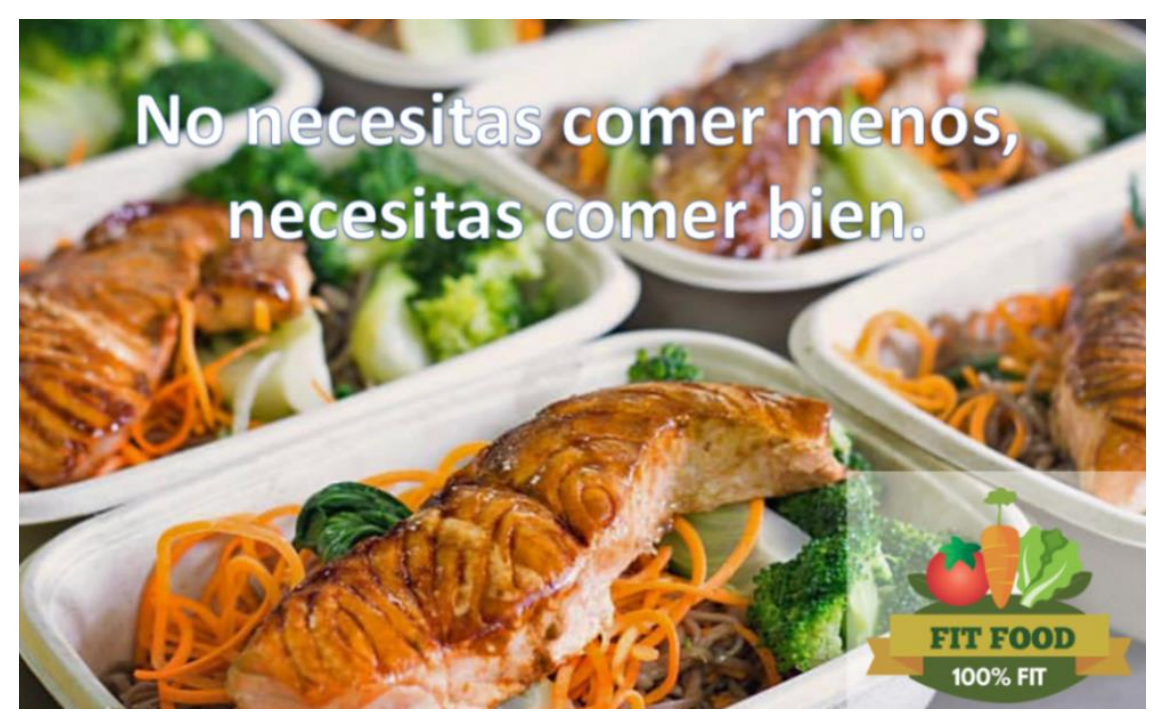

Figura 56 Modelo 2 de imagen informativa.

Revisar las redes sociales será de suma importancia ya que no basta solo con publicar información sino contestar siempre a las preguntas y comentarios que nos dejen cada uno de nuestros seguidores.

Además, utilizaremos publicaciones informativas sobre el contenido de nuestro menú del día y sus opciones 


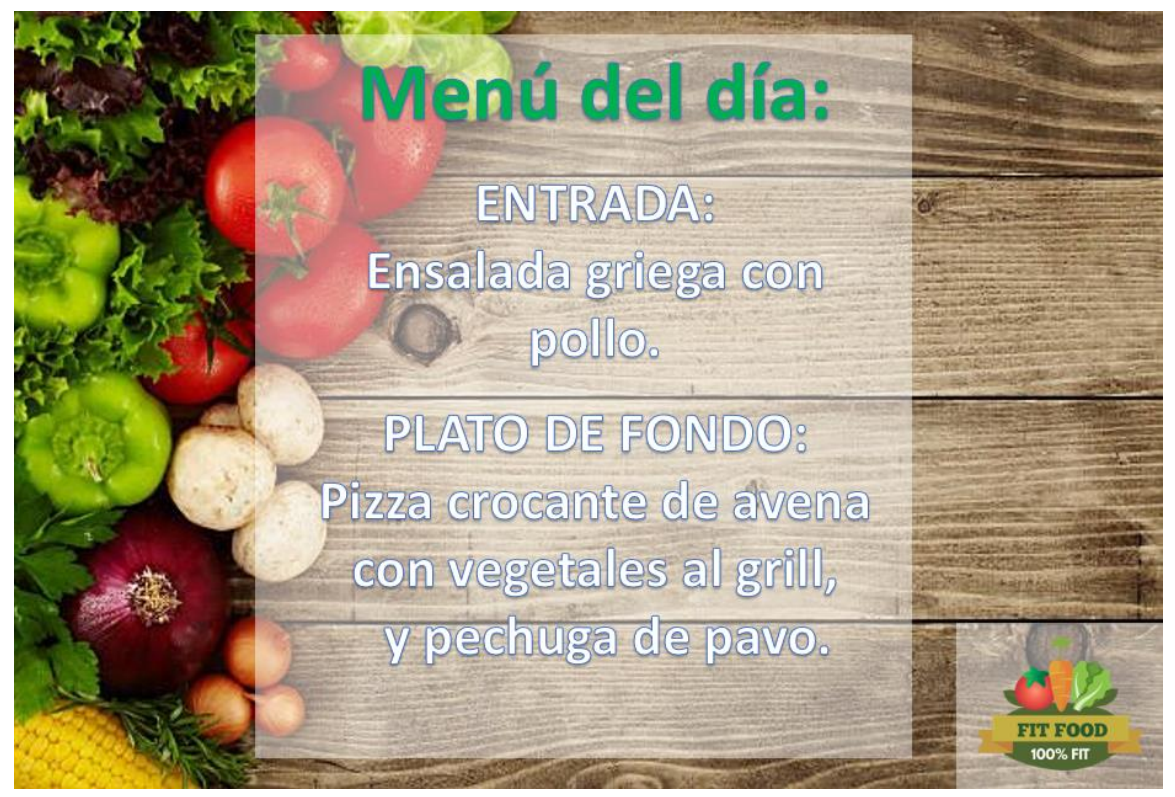

Figura 57 Publicidad para enviar diariamente el menú

Frases motivadoras acorde a los beneficios de FIT FOOD.

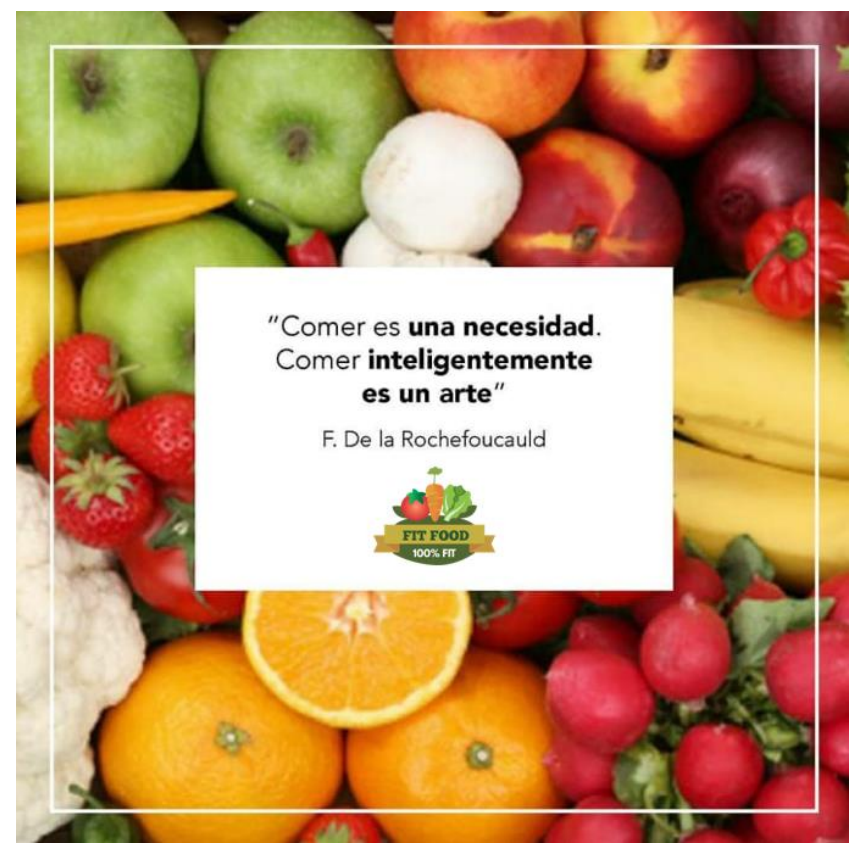

Figura 58 Modelo 3 de imagen informativa.

\section{- Crear concursos}

Crear concursos en los que todos nuestros seguidores puedan interactuar y dar a conocer nuestras redes sociales, los premios consistirán en almuerzos 
saludables gratis. Por ejemplo: "Etiqueta en nuestra foto de perfil a 3 amigos, publícala y asegúrate de que todos nos sigan en nuestras redes sociales", de esta forma obtenemos más seguidores, más personas que nos conocen y posibles clientes.

\section{- Enviar nuestro producto a bloggers}

Es un método que está siendo muy utilizado tanto por grandes como por pequeñas empresas y los resultados suelen ser muy buenos y cuestan poco dinero. Nos contactaremos con bloggers de la ciudad relacionados con la vida saludable para enviarles nuestro producto y que lo den a conocer.

\section{- Buscar colaborar con otros emprendedores}

Buscar negocios relacionados con productos saludables, que no formen parte de nuestra competencia directa, pero que compartamos un perfil similar de clientes y proponerles taggearnos en publicaciones, de forma que podamos darnos a conocer mutuamente y conseguir mayor cantidad de seguidores. Por

ejemplo, podemos buscar colaborar con Meraki, tienda online de mantequillas de frutos secos.

\subsection{Creación de marca (branding), registro y desarrollo de la marca (brand equity).}

\section{- Creación de la marca (Branding)}

Consideraremos un presupuesto de creación de marca, conocido como "Branding"; definiéndolo como una gestión inteligente, estratégica y creativa de todos aquellos elementos diferenciadores de la identidad de una marca (ya sean tangibles o intangibles); esto nos permitirá construir 
una experiencia de marca distintiva, relevante, completa y sostenible en el tiempo.

Utilizaremos la técnica de Branding Corporative, desarrollando un Branding enfocado a nuestra marca empresarial. Para ello, se contará con el siguiente presupuesto:

\section{Tabla 29}

Presupuesto de creación de marca: Branding (expresado en soles)

\begin{tabular}{c}
\hline $\begin{array}{c}\text { Presupuesto de Creación de Marca: } \\
\text { BRANDING }\end{array}$ \\
\hline Identidad visual \\
Manual de marca \\
Aplicaciones de marca \\
\hline Total $\quad$ S/ 7, 000.00 \\
\hline Elaboración propia
\end{tabular}

Lo que buscamos como empresa al implementar el Branding, es trasladar nuestros objetivos reales al desarrollo de nuestra marca; de esta manera lograremos:

- Establecer nuestra propuesta de valor o ventaja competitiva, la cual está determinada en construir una experiencia de deleite gastronómico saludable y de calidad, a través de la variedad de opciones de platos nutricionalmente balanceados, ofrecidos diariamente a nuestros clientes; así mismo, ofrecer puntualidad en la entrega de nuestros productos según los requerimientos de cada cliente, servicio casi personalizado según sus necesidades y en envases adecuados y amigables con el medio ambiente, generando satisfacción al cliente. 
- Diseñar una estrategia de marca competitiva, orientada al mercado y que vaya en línea con las estrategias de marketing que contempla el proyecto, tales como: estrategia de producto, estrategia de precio, estrategia de plaza y distribución, estrategia de promoción, estrategia de publicidad, estrategia de personas, estrategia de procesos y estrategia de ventas. Esto con el fin de posicionar la marca en el mapa competitivo actual.

- Configurar la personalidad de la marca; dotándola de atributos y valores, que nos permitan trabajar bajo las dimensiones propias del proyecto, sin olvidar que el objetivo final del Branding no es otro que la marca venda más a través de su posicionamiento en el mercado.

Para nuestro proyecto de comida saludable y servicio de delivery, se plasmó el desarrollo del mismo, netamente en plataformas virtuales; entonces dentro de las principales ventajas de implementar el Branding en nuestras estrategias de marketing on line encontramos: 


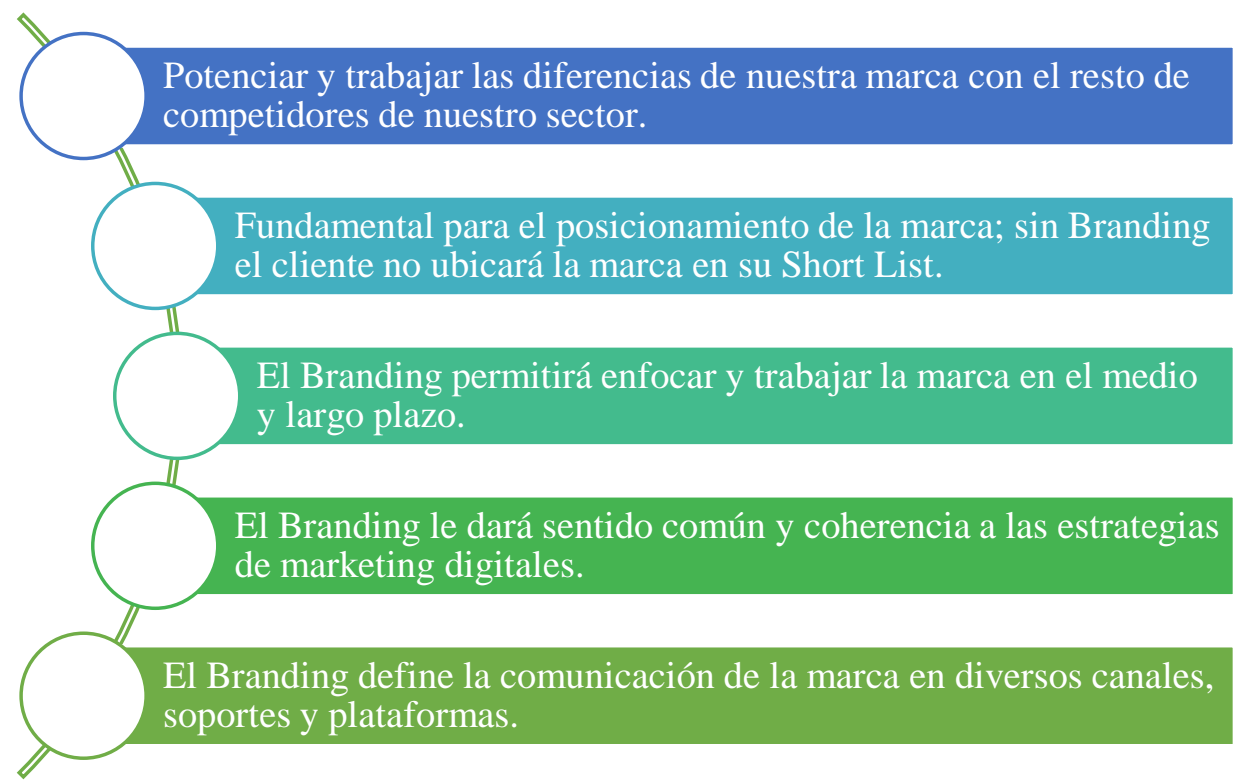

Figura 59 Ventajas de implementar el Branding.

\section{- Desarrollo de la marca (Brand Equity)}

De la mano del Branding; también encontramos el desarrollo del "Brand Equity", que refleja el valor que tiene una marca al vender debido a su notoriedad. El nivel de Brand Equity se determina por la elección que hace el cliente al escoger una marca sobre las demás, gracias a que la reconoció inmediatamente.

Como producto/servicio nuevo, para nuestra marca proponemos no solo el hecho de medir el valor generado por nuestras probables ventas, sino también consideraremos factores tales como las "experiencias de los clientes" y la "proyección de nuestra imagen" como marca. Para ello trabajaremos en base a 4 factores claves del Brand Equity: 

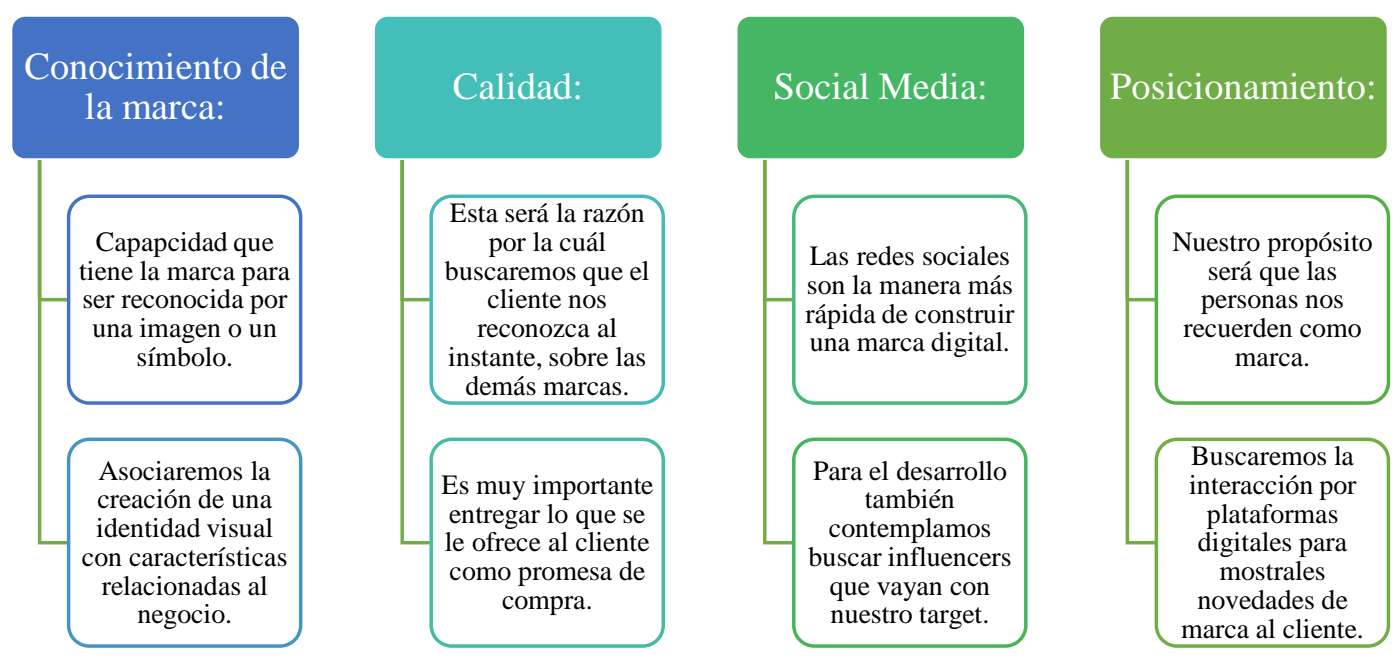

Figura 60 Cuatro factores clave del Brand Equity.

Entonces podemos concluir, con que el hecho de implementar el

Brand Equity en nuestro proyecto es un elemento muy importante, ya que nos ayudará a potenciar las estrategias de marketing que se desarrollan en el Branding, permitiéndonos generar mayores ingresos y medir el éxito del valor del proyecto en base a la dedicación que se le dará a la marca.

\section{- Registro de la marca.}

Una vez desarrollado el Branding, al obtener la identidad visual y el nombre elegido para el proyecto, se procederá a realizar formalmente el registro de la marca ante Indecopi, para protegerla, y así evitar que otras personas puedan utilizarla y se beneficien de su éxito.

$\mathrm{Al}$ registrar una marca ante el Indecopi, tenemos el derecho a usarla de manera exclusiva, a nivel nacional, durante 10 años. Pasado este plazo se puede renovar el registro, con lo cual la marca seguirá resguardada. Este registro brinda protección jurídica al titular y da derecho a denunciar a 
quien use la marca sin autorización. Además, asegura que otras personas no puedan comercializar productos iguales o similares con la marca o con una parecida, porque puede confundir a los consumidores.

Para ello, primero estableceremos la ubicación de nuestro negocio, según la Clasificación Internacional de Productos y Servicios, guiándonos de la Clasificación de NIZA, $11^{\circ}$ Edición, versión 2017; en la cual tenemos la siguiente ubicación:

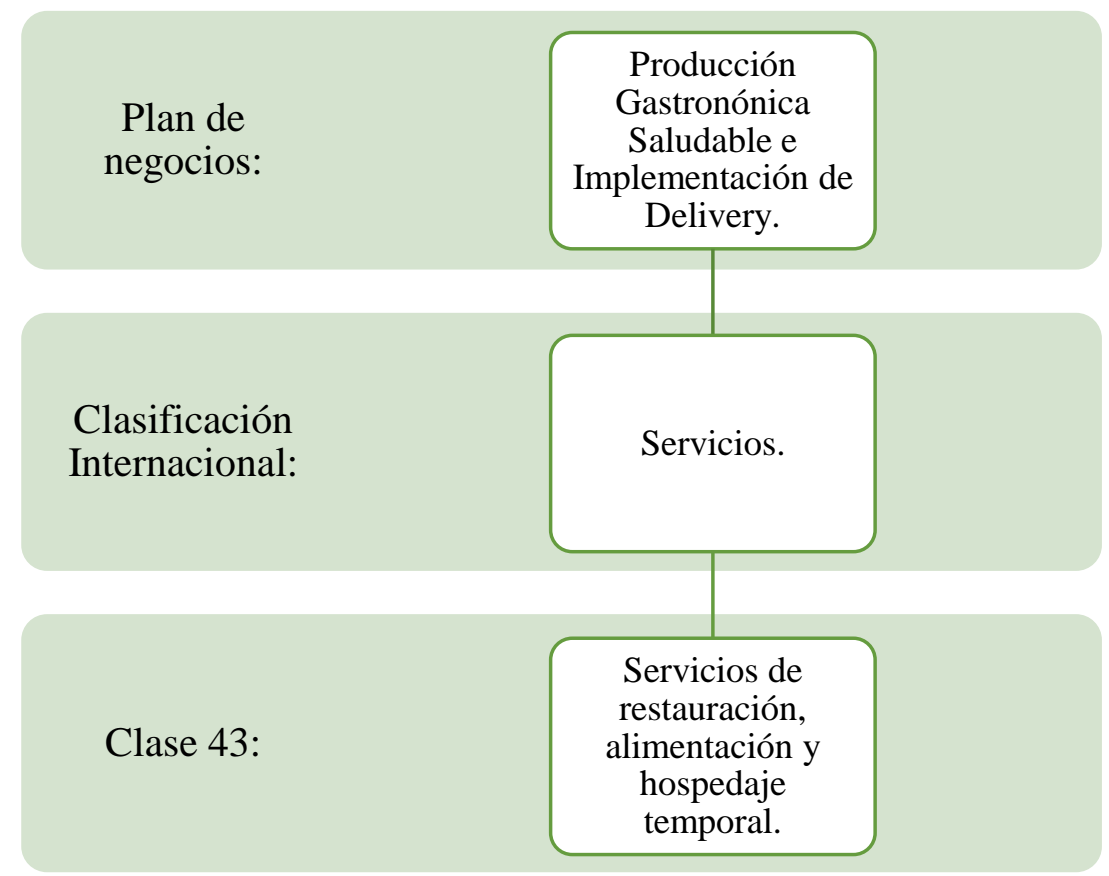

Figura 61 Ubicación del proyecto según la Clasificación Internacional de Productos y Servicios.

Seguidamente, los pasos a efectuar para generar el registro de marca son los siguientes:

- Llevar a cabo la búsqueda de antecedentes por marca, respecto a la clase y al nombre que se estableció al proyecto; esto con el fin de buscar 
la legitimidad de los datos de la marca, según los registros de Indecopi a nivel nacional. Para este proceso, se tendrá que realizar un pago de derecho de búsqueda con un importe de S/. 38.00.

- Posteriormente, una vez que tengamos liberado el nombre de la marca propuesta para nuestro negocio, procedemos a presentar una Solicitud de Registro de Marca, la cuál va acompañada de un pago de tasa del registro de marca ante el Indecopi por un importe de S/. 535.00.

- En simultáneo, al momento de ser aceptada la Solicitud de Registro de será publicada de manera gratuita en la Gaceta Electrónica de Propiedad Industrial del Indecopi, la publicación tiene el objetivo de que otras personas o empresas que tengan marcas registradas o en trámite presenten oposición, si consideran que la marca es parecida a la suya y podría generar confusión en el consumidor.

- Así mismo, se procederá hacer la publicación de la marca en el diario oficial El Peruano, bajo un importe de S/. 270.00, esto con el fin de hacer público el trámite y darle valor legal con el hecho de haber tenido un periodo de publicación circular masiva y no se manifestó ninguna oposición al nombre de la patente, lo cual otorgaría el derecho pleno de la marca.

- Seguidamente, si nadie se opone al registro de tu marca, la Dirección de Signos Distintivos del Indecopi procederá a evaluar la solicitud. 
- Finalmente, Indecopi manifiesta la resolución que otorga la marca, recibiendo un certificado de registro y quedando protegido bajo los parámetros legales.

Para el proceso de registro de marca ante Indecopi, consideraremos el siguiente presupuesto:

Tabla 30

Presupuesto registro de marca en Indecopi.

\begin{tabular}{|c|c|c|}
\hline \multicolumn{3}{|c|}{ Registro de Marca en INDECOPI } \\
\hline Busqueda de antecedentes & & 38.00 \\
\hline Tasa de registro de marca & & 535.00 \\
\hline Publicación de marca & & 270.00 \\
\hline TOTAL & $\mathbf{S} /$ & 843.00 \\
\hline
\end{tabular}

Elaboración propia

El proceso de registro de marca en Indecopi dura aproximadamente un periodo de tres meses.

\subsubsection{Estrategia de Publicidad}

Para desarrollar un programa de publicidad deberán tomarse cuatro decisiones importantes: formulación de objetivos publicitarios, establecer el presupuesto de publicidad, desarrollo de la estrategia de publicidad y evaluación de campañas publicitarias (Kotler y Armstrong, 2013).

Un objetivo publicitario, se trata de una misión de comunicación específica, hacia un segmento de mercado específico durante un periodo específico, según su finalidad pueden ser: informar, persuadir y recordar.

Para establecer el presupuesto de publicidad, se conocen cuatro métodos: costeable, porcentaje de ventas, paridad competitiva y de objetivo y tarea. 
La estrategia de publicidad, consta de dos elementos principales:

- Crear mensajes publicitarios: no importa cuán grande sea el presupuesto, sino que los anuncios capten la atención del público y comuniquen lo que en realidad quieren comunicar. Plantearnos cuál es la estrategia del mensaje, el objetivo de la publicidad es que el público se quede pensando en el producto y esto solo se logrará si nuestro mensaje comienza identificando los beneficios del producto para el cliente y el cliente se convenza de que se beneficiara con ello.

- Seleccionar medios de publicidad. Debemos asegurarnos de determinar el alcance, la frecuencia y el impacto, elegir entre los principales tipos de medios, seleccionar los vehículos de medios específicos y decidir sobre la programación de los medios.

El objetivo de nuestra estrategia publicitaria será informar y persuadir, vamos a crear una imagen de marca y empresa, vamos a contarle al mercado acerca de un nuevo producto, describir el servicio y beneficios; y convencer al consumidor de elegir esta marca, de esta forma impulsar nuestras ventas.

La estrategia del mensaje será racional y emocional, primero llamaremos la atención del cliente con un mensaje emotivo, posteriormente cuando éste haya considerado la posibilidad de consumirlo, le daremos las razones consistentes para que perciba su decisión como lógica.

- Emocional: Se resaltará que: a. ofrecemos la experiencia de comer saludable sin necesidad de movilizarse hacia lugares apartados de su trabajo, b. la posibilidad de descansar durante más tiempo ya que no 
tendrá que preparar sus alimentos, c. están comiendo lo que su organismo requiere.

- Racional: Se comunicará los beneficios de nuestro servicio, los que buscan satisfacer necesidades no cubiertas por la oferta actual.

$\checkmark$ Puntualidad: Ni antes ni después, sino cuando lo requieras.

$\checkmark$ Calidad: Constante supervisión de los insumos.

$\checkmark$ Variedad: Comer saludable nunca más será aburrido.

$\checkmark$ Presentación: Es tan bueno como se ve.

Nuestro presupuesto será establecido bajo el método de objetivo y tarea, el que consiste en establecer un presupuesto basándonos en los objetivos que se quiere lograr con la promoción; este método implica: definición de objetivos de promoción específicos, determinación de las tareas necesarias para alcanzar estos objetivos y la estimación de los costos de realizar estas tareas.

Par seleccionar los canales de comunicación de los que haremos uso debemos tener claro a quién nos dirigimos y cuáles son sus preferencias en cuanto a comunicación, en este proyecto se seleccionaron según el estudio de mercado realizado, en el que la mayoría de personas usan come medio de comunicación el internet y el celular o teléfono. Adicionalmente se utilizarán canales masivos, como la publicidad exterior para dar a conocer nuestro producto.

- Masivo: Publicidad exterior, se trata de un impacto visual importante que está colocado a la vista del consumidor las 24 horas de día y los 7 días de la semana. En campaña de lanzamiento y en los meses de noviembre, 
diciembre y enero contrataremos los tótems publicitarios de la avenida ejército, ya que es una de las vías más transitadas y vía casi obligatoria para nuestro público objetivo. Se contratará también una empresa publicitaria para que se encargue de realizar publicidad móvil en bicicleta (bicivallas) en las zonas de influencia, que principalmente son el centro de la ciudad, Av. Ejército y Av. Trinidad Morán. El servicio que nos brindan es de 4 horas diarias, se encargaran de entregar volantes y dar a conocer el servicio, llamando la atención y generando impacto visual. No brindaran información a profundidad.

- Personal: En este caso se realizará envío de publicidad, promociones y mensajes a través de e-mail y whatsapp a aquellas personas que se hayan registrado en el newsletter de nuestra página web o que ya sean nuestros clientes. Así mismo, de contratará publicidad en redes sociales como Facebook e Instagram.

Tabla 31

Presupuesto de estrategias publicitarias (expresado en soles).

\begin{tabular}{lrrrrrrrrr}
\hline \multicolumn{1}{c}{ PLAN PRESUPUESTARIO PUBLICIDAD } & & & \\
\hline \multicolumn{1}{c}{ DETALLE } & $\begin{array}{c}\text { Costo } \\
\text { Unitario }\end{array}$ & $\begin{array}{c}\text { Inversión } \\
\text { Inicial }\end{array}$ & $\begin{array}{c}\text { Valor } \\
\text { mensual }\end{array}$ & Año 1 & Año 2 & Año 3 & Año 4 & Año 5 \\
\hline TOTEM Publicitario & 330.00 & 660.00 & 660.00 & $1,980.00$ & $2,750.88$ & $2,866.42$ & $2,986.81$ & $3,112.25$ \\
Bicivallas & 300.00 & 900.00 & 300.00 & $1,500.00$ & & & & & \\
Página Web & & $3,000.00$ & & - & & & & & \\
Dominio y Hosting & 150.00 & 150.00 & 150.00 & - & 156.30 & 162.86 & 169.70 & 176.83 \\
Publicidad en facebook & & 100.00 & 50.00 & 600.00 & 625.20 & 651.46 & 678.82 & 707.33 \\
Publicidad en instagram & & 90.00 & 45.00 & 540.00 & 562.68 & 586.31 & 610.94 & 636.60 \\
\hline SUBTOTAL & & S/ 4,900.00 & S/ $\mathbf{1 , 2 0 5 . 0 0}$ & S/ 4,620.00 & S/ 4,095.06 & S/ 4,267.05 & S/ 4,446.27 & S/ 4,633.01 \\
\hline
\end{tabular}

Elaboración propia 


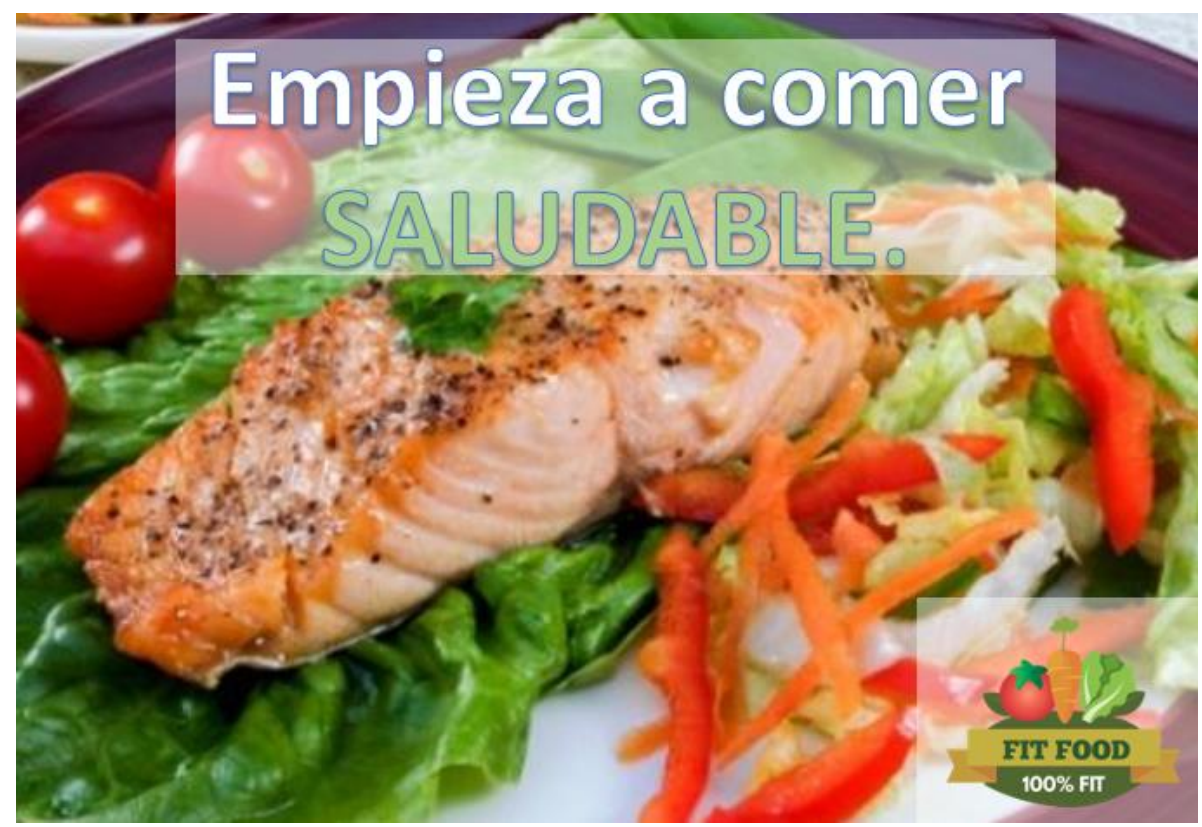

Figura 62 Modelo 1 de afiche de publicidad.

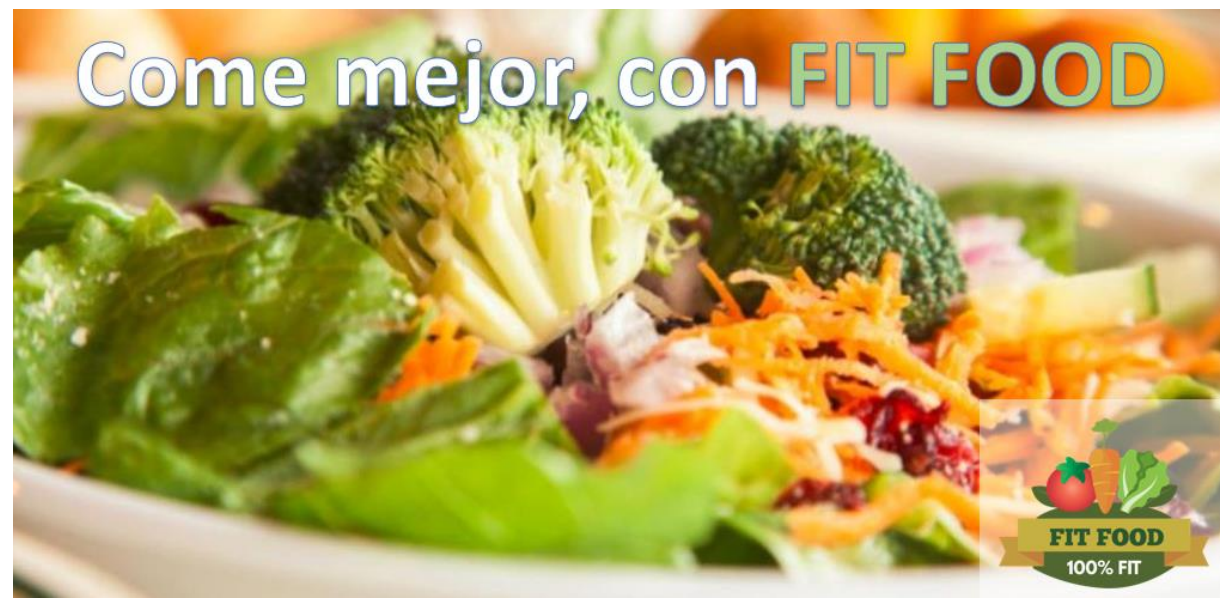

Figura 63 Modelo 2 de afiche de publicidad. 


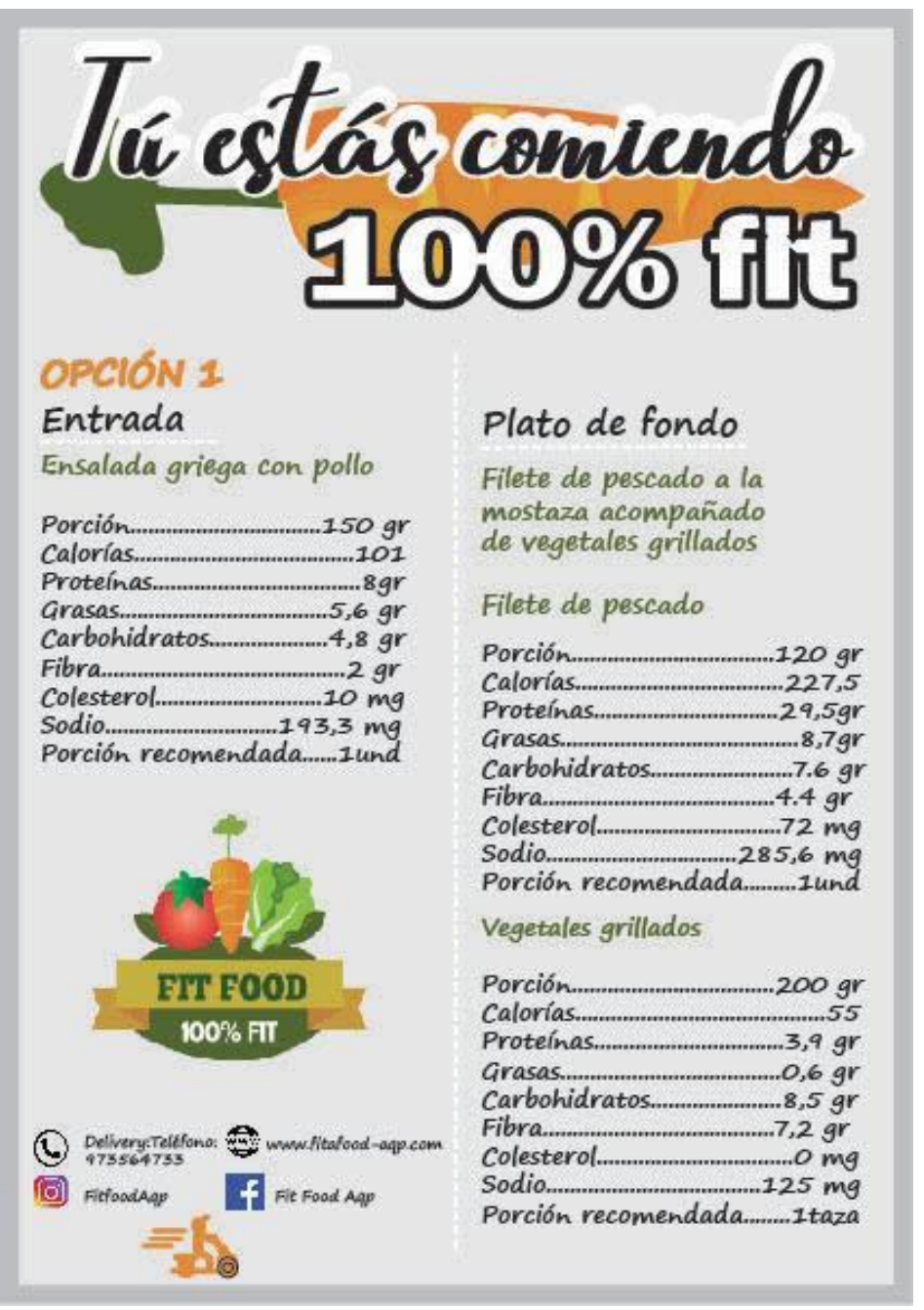

Figura 64 Modelo cartilla de información nutricional de opción 1. 


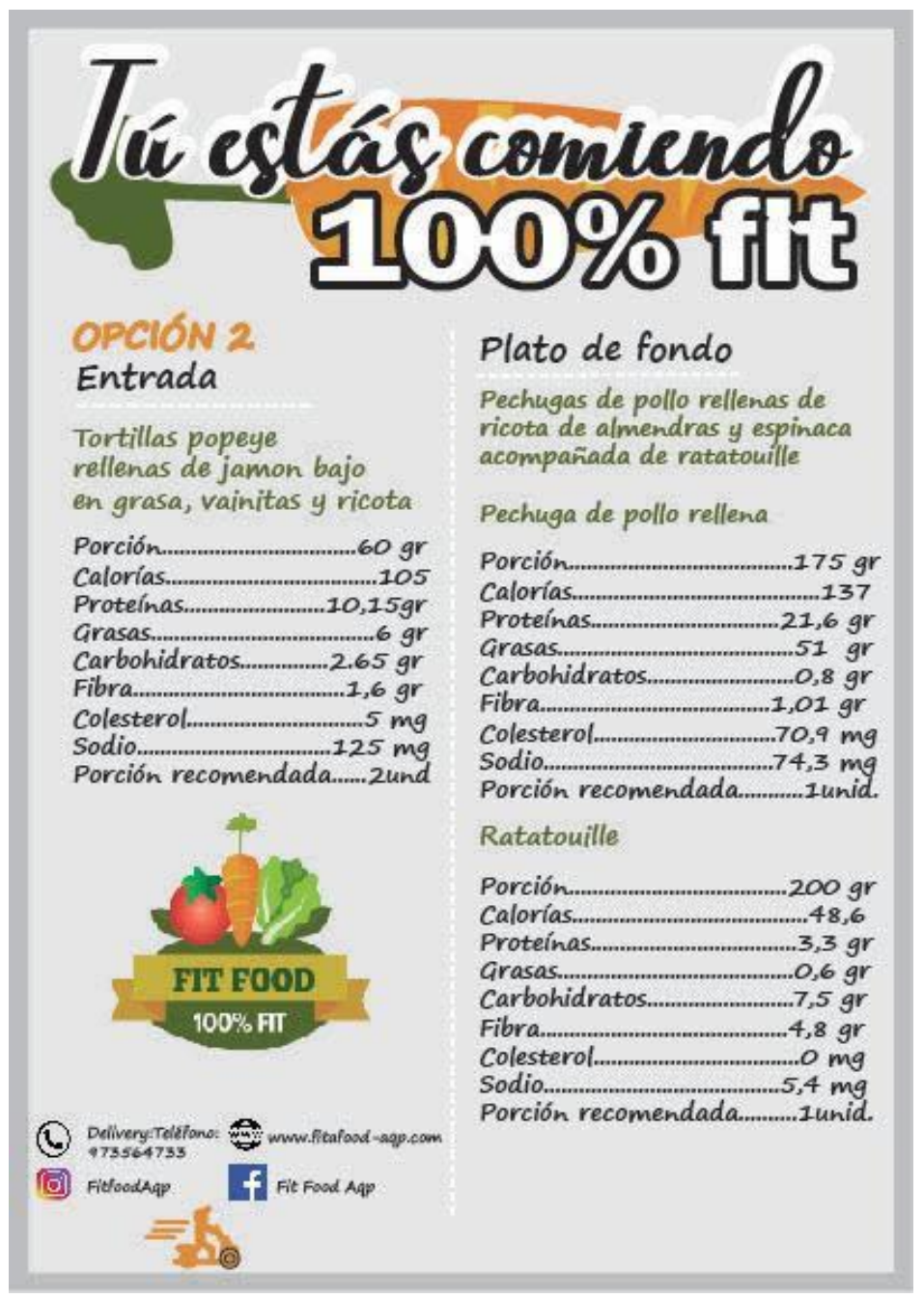

Figura 65 Modelo de cartilla información nutricional de opción 2

\subsubsection{Estrategia de persona.}

Se debe tener en cuenta a la persona no solo cuando se trata de ventas en establecimientos físicos sino también cuando se trata de ventas online. Un aspecto importante para tener éxito es que más allá de vender un producto se venda una experiencia, ya que toda persona que entre en contacto con el cliente, proveedores o entre los mismos compañeros siempre dejan una huella, una imagen positiva o de lo contrario negativa, difícil de cambiar. 
La empresa no solo debe enfocarse en vender el producto sino en hacer sentir especial a sus clientes y potenciales clientes, para ellos debemos desarrollar en todos los miembros del equipo la identidad con la marca, que la sientan suya y convencerlos de que son la imagen de la misma.

Se desarrollará la marca personal de cada uno de los miembros del equipo alineándola con los principios de la empresa, de esta forma los colaboradores desarrollarán un sentido de pertenencia con la empresa que los hará sentir confianza en la marca, seguros y motivados para proyectar su mejor imagen y potenciar la de la empresa.

Es común que los consumidores asocien la marca, ya sea un producto o un servicio, a la persona que lo brinda, a su actitud, comportamiento y es realmente difícil separar estos conceptos. Esto nos demuestra la importancia de las personas en el éxito del proyecto.

Se plantean algunas actividades para desarrollar dicha estrategia:

Actividades motivacionales:

- Reconocimientos por su desempeño

- Reuniones de confraternidad en diferentes fechas

- Saludos personales en fechas especiales

- Reuniones semanales para evaluar nuestro progreso, tomar las opiniones y sugerencias de los colaboradores.

- Comunicarles oportunamente cambios y/o decisiones, haciéndolos sentir parte de estos.

Aplicación de test de clima laboral y evaluaciones de desempeño 
- Se realizarán periódicamente, por lo menos 4 veces al año.

- Tomar acciones inmediatas según los resultados obtenidos de las evaluaciones y test de clima laboral.

- Se evaluarán puntos clave como respeto, puntualidad e integridad.

- Tomar en cuenta y discutir sus sugerencias.

Plan de capacitación

Pensado para que nuestro personal adquiera nuevos conocimientos que sean aplicados en nuestra empresa, y replicado al personal.

Estas capacitaciones, que se realizarán principalmente antes de iniciar operaciones, es decir en nuestro año 0 serán las siguientes:

Tabla 32

Plan de Capacitación (expresado en soles).

\begin{tabular}{lllr}
\hline \multicolumn{1}{c}{ Puesto } & \multicolumn{1}{c}{ Área a capacitar } & Lugar & \multicolumn{1}{c}{ Costo } \\
\hline Cocinero & Curso Comida Saludable & ISUR & 350.00 \\
Asistente de cocina & Curso Comida Saludable & ISUR & 350.00 \\
Administrador & Taller Atención al cliente & ISUR & 260.00 \\
Repartidor 1 & Taller Atención al cliente & ISUR & 260.00 \\
\hline & & TOTAL & S/ $\mathbf{1 , 2 2 0 . 0 0}$ \\
\hline
\end{tabular}

Elaboración Propia

Posteriormente el personal capacitado se encargará de replicar los conocimientos adquiridos al personal nuevo, se planea realizar estas capacitaciones al personal nuevo una vez al año.

\subsubsection{Estrategia de procesos.}

Los procesos se relacionan con el método con el que el cliente es atendido, se den tener cuenta tiempos de espera para ser atendidos, que información se les brinda y el 
trato que se les da. A los clientes no les interesa cómo funciona el negocio por dentro, sino que el proceso funcione y que ellos terminen satisfechos. Se dice que los procesos muchas veces fallan porque están planeados según las necesidades de la empresa y no para satisfacer las necesidades de sus clientes.

Como parte del talento humano contaremos con un jefe de cocina que se encargara de gestionar todas las actividades que comprenden el área de cocina, un cocinero que se encargara de la preparación adecuada de los alimentos según los estándares requeridos, un asistente de cocina que auxiliara al cocinero en las actividades de preparación y distribución de los alimentos, así como la limpieza y orden del área de cocina, finalmente un repartidos que se encargara del transporte y distribución de los pedidos en buenas condiciones así como el cobro de ser el caso.

Adicionalmente, se contará con la asesoría externa de un nutricionista quien elaborará los planes de alimentación saludable semanalmente, cuidando una alimentación equilibrada y nutritiva.

En el área administrativa contaremos con los servicios de un gerente quien se encargará supervisar y controlar que todas las actividades planificadas se lleven a cabo en forma y tiempo, así como responder de forma adecuada los pedidos y requerimientos de nuestros clientes.

Para lo cual aplicaremos la Estrategia de Enfoque repetitivo, haciendo una línea de producción diaria:

1. Recepción de pedidos (día anterior).

2. Reposición MP e insumos específicos. 
3. Preparación de los menús.

3.1 Procesar los insumos.

3.2 Cocción de los insumos y preparación del menú.

3.3 Emplatar los menús de acuerdo a los pedidos.

3.4 Empaquetar menús.

4. Delivery

4.1 Revisar área geográfica a cubrir.

4.2 Establecer el camino más corto para llegar a tiempo.

4.3 Revisar si los pedidos están completos, antes de partir.

4.4 Entrega de pedido y cobro en caso de compra contra-entrega

5. Servicio al cliente

5.1 Escribir mensajes al Whatsapp de los clientes, verificando la hora de llegada de los pedidos.

5.2 Preguntar sobre la calidad del servicio, para poder tener una mejora continua del servicio.

Dentro de la estrategia de procesos, guardamos un enfoque estándar de los mismos, ya que al ser un servicio gastronómico tenemos tareas que son repetitivas, al igual que cualquier otra empresa, para poder generar nuestro producto final.

Sin embargo, para lograr la diferenciación con la competencia, brindaremos un servicio al cliente con mayor eficiencia y detalle; verificaremos uno a uno los 
pedidos entregados a los clientes en comunicación directa por WhatsApp o llamada telefónica, de igual manera pediremos un feedback sobre el producto y servicio recibido, así podremos captar la percepción que guarda el cliente en cuanto a calidad de servicio en general y de esta manera poder monitorear e implementar mejoras para las posibles deficiencias.

\subsubsection{Estrategia de presencia Física.}

No utilizaremos instalaciones físicas abiertas al público porque no somos un restaurante con presencia física, sino un servicio delivery de comida saludable; sin embargo, algunos autores afirman que, dadas las condiciones actuales del mercado, se considera presencia física a las páginas web y espacios de servicio virtual.

Nuestra marca contará con una página web y estará presente en medios digitales como Facebook, Instagram y WhatsApp, donde publicaremos información que mantenga cautivo a nuestro segmento:

- Información de nuestros planes mensuales, y menús diarios.

- Publicaciones acerca de nuevos productos y promociones que se lancen al mercado.

- Información nutricional de nuestros menús.

- Información nutricional de la comida no saludable.

- Publicar un boletín informativo acerca de alimentación saludable.

- Información de contacto para servicios especiales y/o corporativos. 


\subsection{Estrategias de ventas.}

\subsubsection{Plan de ventas.}

Nuestro plan de ventas fue realizado en función a los resultados de la información obtenida en el estudio de mercado y a las estrategias de marketing formuladas para el proyecto, con el objetivo de maximizar las ventas y como consecuencia la rentabilidad.

\section{a. Definición del negocio}

Fit Food se encuentra en el rubro de la comida saludable y se encargará de dar el servicio de delivery de almuerzos saludables.

\section{b. Perfil del cliente}

Mujeres de 20 a 44 años que viven y/o laboran en los distritos de Yanahuara, Cayma y Cercado de Arequipa, que tengan un poder adquisitivo medio-alto, que tengan la necesidad de alimentarse con comida saludable

\section{c. Propuesta de valor}

La Propuesta de Valor debe comunicar aquello que la empresa espera hacer mejor o de manera diferente que la competencia para sus clientes. En nuestro proyecto lo que buscamos con la propuesta de valor ofrecida es dar solución a los problemas de consumidores saludables y satisfacer sus necesidades. Nuestra propuesta de valor es la siguiente:

“Constituir una experiencia de deleite gastronómico saludable y de calidad, a través de la variedad de opciones de platos nutricionalmente balanceados, ofrecidos diariamente a nuestros clientes; así mismo, ofrecer puntualidad en la entrega de nuestros productos según los requerimientos de cada cliente, 
servicio casi personalizado según sus necesidades y en envases adecuados y amigables con el medio ambiente, generando satisfacción en el cliente".

Dentro de las propuestas de valor por segmentos, encontramos:

- Precio:

Ofrecemos un valor superior en el mercado actual, por un precio justo, que se mantenga en el rango aceptable dentro del mercado, para alcanzar clientes sensibles al precio.

- Novedad:

Creamos variedad de productos saludables, para poder satisfacer necesidades que los clientes no tenían identificadas explícitamente; ya que en la competencia directa no se ve mucha variedad.

- Calidad:

Estamos orientados a entregar un nivel de calidad superior a los competidores, por los insumos o materiales utilizados en la producción del menú saludable y entrega de servicio al cliente.

- Conveniencia:

Nos enfocamos en "facilitar la vida" al cliente, optimizando su tiempo, implementando el servicio de delivery.

- Marca / Status:

Lanzamos al mercado productos asociados a la pertenencia a un cierto grupo, en este caso consideramos el género y la edad como determinante de pertenencia de grupo; también nos asociamos a la moda, queriendo aprovechar la influencia fitness y la tendencia del desarrollo delivery.

- Desempeño: 
Garantizamos un desempeño superior a los productos/servicios de los competidores directos, ya que nos preocuparemos en entregar los alimentos a la hora necesaria y en un empaque determinado, que nos permita llegar al cliente en óptimas condiciones, ya sean de temperatura y/o presentación.

- Reducción de riesgos:

Nos enfocamos en minimizar el riesgo que el cliente incurre al comprar el producto y/o servicio; ya que avalamos el desarrollo de la compra segura y a la vez implantamos una política de garantía de venta, en la cual se ofrecen recompensas, cambios, etc.

- Diseño:

Enfatizamos el diseño cómo elemento diferenciador de la oferta del proyecto, brindándole al cliente un empaque con divisiones que nos permita mantener la presentación final del menú y a la vez sea amigable con el medio ambiente.

\section{d. Competidores}

Según el estudio realizado, la competencia es escaza y no ofrece un servicio adecuado, el mercado objetivo no está siendo atendido por la competencia.

\subsubsection{Política de ventas.}

Si bien nuestro objetivo es vender nuestros productos a mujeres que trabajan en la zona de influencia, se establecerán política de ventas corporativas en gimnasios, clubes de deporte, oficinas y retails que se encuentran en dicha zona.

Ventas corporativas: 
- Centros de trabajo cercanos a nuestro punto de distribución. Ofreciendo planes mensuales a la cantidad de trabajadores que estén en la organización, con ciertos beneficios y/o descuentos.

- Realizar demostraciones en los gimnasios, activaciones al momento de establecer la venta con la empresa aliada. (un set de regalo al momento de la inscripción)

Ventas unitarias:

- Trato personalizado, con consulta de nutricionista.

- Dar obsequios a los clientes fieles. (Un almuerzo gratis para un amigo al que llego a ser fiel por un mes, tarjetas de fidelidad para clientes frecuentes)

\subsubsection{Política de servicios y garantías.}

- Se ofrecerá garantía al momento de la puntualidad, si no llega el pedido a su hora, el menú es gratis.

- Si hubo algún inconveniente con el pedido recibirá una recompensa en su próximo pedido.

- Sólo se acepta cobertura de áreas cercanas: distritos de Cayma, Yanahuara y Arequipa (cercado).

- Para cerrar ventas corporativas deben ser de 5 a más personas. 


\section{CAPÍTULO VI}

\section{Pronostico de Ventas}

Para poder determinar nuestro pronóstico de ventas, haremos el desarrollo de los puntos más relevantes a analizar.

\subsection{Fundamentos y Supuestos}

Dentro de nuestro pronóstico de ventas del proyecto, desarrollaremos los siguientes supuestos:

- En nuestro primer año de operaciones: las ventas durante el primer mes estarán basadas en el dato arrojado en nuestro estudio de mercado, diferenciando las ventas diarias de las ventas interdiarias, las mismas que a partir del tercer mes experimentaran un incremento del 10\%, el cual será constante hasta el cierre del primer año.

- En el segundo año: mantendremos los 3 primeros meses la cantidad con la que cerramos nuestro primer año de operaciones, de esta forma, buscaremos la expansión de la demanda en los próximos meses, generando un incremento de $5 \%$ en los meses 4, 7, 10, acumulando un crecimiento del $15 \%$ anual.

- En los años tres, cuatro y cinco: apuntaremos a un crecimiento de $3.75 \%$ en los meses 1 , 4, 7 y 10 respectivamente, que nos ayude y permita fidelizar a los clientes con nuestra marca.

- No se están tomando en cuenta para las proyecciones el servicio de una vez a la semana, ya que no son ventas seguras y podrían desviar el resultado. 
- Así mismo, se tomará como objetivo un incremento del $40 \%$ en la demanda diaria para efectuar el pronóstico de ventas en mercados cerrados, las mismas que tendrán un incremento constante a medida que crece la demanda.

Estos supuestos de pronósticos de ventas e incrementos de las mismas según periodos, nos ayudarán a determinar diferentes aspectos dentro del negocio, ya que regulariza la variación en el precio, contrataciones de personal y la determinación de la demanda para hacer de nuestro proyecto un negocio rentable.

Es relevante mencionar que debemos estar atentos a las modificaciones que se puedan presentar en relación al negocio con el tiempo, tratando de evitar el hecho de limitar la capacidad de desarrollo del proyecto dentro de un contexto tan dinámico como es nuestra propuesta en el mercado.

\subsection{Justificación}

La justificación principal para determinar los porcentajes de crecimiento de nuestras ventas, es que nos encontramos en un mercado que está en pleno desarrollo, y no hay presencia de muchos competidores, permitiendo fidelizar a nuestros clientes y lograr el conocimiento de nuestra marca en el mercado; ayudando así a captar nuevos clientes.

A ese hecho, hay que sumarle; que hoy en día en la ciudad de Arequipa, al igual que en todo nuestro país, hay una gran preocupación por el estilo y/o forma de vida que llevan las personas y la orientación que se le da al cuidado de la salud.

Esto origina también apuntar a un mercado mayor, que vaya en un crecimiento constante a través de cambios culturales enfocados en la salud de las personas; creando en ellos costumbres sanas y equilibradas de alimentación. 


\subsection{Análisis de los riesgos y aspectos críticos que impactan en el pronóstico}

Dentro de los aspectos críticos que probablemente puedan impactar en nuestro pronóstico, encontramos riesgos internos y externos en el mercado.

\subsubsection{Situación de la industria}

Es relevante hacer monitoreos periódicos del desarrollo de la industria, eso nos ayudará a medir las nuevas tendencias que se presentan en el mercado, generando estrategias que nos permitan como marca innovar según las necesidades del cliente y así ampliar nuestra cartera de clientes.

\subsubsection{Aparición de nuevos competidores}

A medida que se va desarrollando el mercado en el cual competimos y se vuelva más sólido, también será fácil que aparezcan nuevos competidores de la industria, teniendo en cuenta que las barreras de ingreso para nuestro mercado no son muy altas; y hay muchas marcas con características similares a las nuestras en otras ciudades (Lima, con mayor presencia) que puedan atreverse a introducirse a un mercado nuevo como es el de la ciudad de Arequipa.

\subsubsection{Deficiencia en la calidad de servicio}

Una de nuestras estrategias de diferenciación del producto es la calidad de nuestro servicio, esto significa que será un eje principal de nuestro negocio con relación a la competencia, ya que nos definirá como marca; de esta manera debemos ser constantes en la búsqueda de la calidad día a día en nuestro producto, así como también en nuestro sistema de post venta y las relaciones con nuestros clientes (Feed Back). 


\subsubsection{Variabilidad en las ventas}

El grado de variabilidad en las ventas, se originará cuando se presente estacionalidad en la demanda de nuestro producto; teniendo en cuenta que nuestro público son mujeres que trabajan y/o estudian, en los meses de enero y febrero son considerados meses bajos, puesto que la mayoría de personas están de vacaciones y este factor puede impactar en el pronóstico de nuestras ventas. 


\section{CAPÍTULO VII}

\section{Ingeniería del Proyecto}

\subsection{Estudio de Ingeniería.}

La ingeniería de proyectos es aquella etapa en la que se definen los recursos necesarios para la ejecución de las tareas: máquinas y equipos, lugar de implantación, tareas para el suministro de insumos, manejo de recursos humanos, entre otros.

El cálculo de la capacidad instalada de los equipos por porción se desarrolla en base al tiempo de demora en la cocción de cada porción.

Tabla 33

Tiempo de demora en cocción por porción.

\begin{tabular}{|c|c|c|c|c|c|c|c|}
\hline TIPO & NOMBRE PLATO & PORCIONES & $\begin{array}{c}\text { TIEMPO } \\
\text { COCCION (min) }\end{array}$ & $\begin{array}{c}\text { TIEMPO } \\
\text { COCCION POR } \\
\text { PORCION (min) } \\
\end{array}$ & $\begin{array}{l}\text { EQUIPO } \\
\text { UTILIZADO }\end{array}$ & CAPACIDAD & $\begin{array}{c}\text { TIEMPO } \\
\text { ESTIMADO } \\
\text { POR PORCION }\end{array}$ \\
\hline \multicolumn{8}{|l|}{ OPCION 1} \\
\hline Entrada & $\begin{array}{l}\text { Tortillas rellenas con jamon bajo } \\
\text { en grasas, esparragos y ricota }\end{array}$ & 3 & 6.00 & 2.00 & Sarten/wok & 2.00 & 1.000 \\
\hline Plato de fondo & Croquetas de pollo con avena & 1 & 6.00 & 6.00 & Horno & 4.00 & 1.500 \\
\hline Plato de fondo & Quinoa graneada & 6 & 15.00 & 2.50 & Olla & 2.00 & 1.250 \\
\hline \multirow[t]{2}{*}{ Refresco } & Jugo de pera & 4 & 10.00 & 2.50 & Olla & 3.00 & 0.833 \\
\hline & & & & 13.00 & & & 4.583 \\
\hline \multicolumn{8}{|l|}{ OPCION 2} \\
\hline Entrada & Ensalada griega con pollo & 5 & 10.00 & 2.00 & Sarten/wok & 2.00 & 1.000 \\
\hline Plato de fondo & $\begin{array}{l}\text { Pollo horneado en costra de } \\
\text { especias }\end{array}$ & 5 & 40.00 & 8.00 & Horno & 4.00 & 2.000 \\
\hline Plato de fondo & Cama de quinoa & 7 & 18.00 & 2.57 & Olla & 2.00 & 1.286 \\
\hline \multirow[t]{3}{*}{ Refresco } & Agua de Piña & 4 & 10.00 & 2.50 & Olla & 3.00 & 0.833 \\
\hline & & & & 15.07 & & & 5.119 \\
\hline & & & & & & PROMEDIO & 4.851 \\
\hline
\end{tabular}

Elaboración propia 
Tabla 34

Capacidad instalada de equipos principales

\begin{tabular}{|c|c|c|c|c|}
\hline DETALLE & $\begin{array}{c}\text { ESPECIFIC } \\
\text { CAPACIDAD }\end{array}$ & $\begin{array}{l}\text { NUMERO DE HORAS } \\
\text { DE PRODUCCIÒN DE } \\
\text { EQUIPOS DE COCINA }\end{array}$ & $\begin{array}{c}\text { PROMEDIO DE } \\
\text { HORAS DE DEMORA } \\
\text { DE COCCIÒN POR } \\
\text { PORCIÒN }\end{array}$ & $\begin{array}{c}\text { CAPACIDAD } \\
\text { PRODUCCION } \\
\text { POR PORCION } \\
\text { DE } 15 \text { PLATOS }\end{array}$ \\
\hline COCINA 4 HORNILLAS & 3.00 & 5 & 0.080853175 & 185.5214724 \\
\hline HORNO 4 BANDEJAS & 4.00 & 5 & 0.080853175 & 247.3619632 \\
\hline OLLAS 5 UNID & 3.00 & 5 & 0.080853175 & 185.5214724 \\
\hline
\end{tabular}

Elaboración propia

El cálculo del costo de mano de obra se realizara en base al tiempo de demora en la preparación de cada porción o almuerzo completo en un día de trabajo considerando que se manejan dos opciones de menú, y la cantidad ya está definida por los pedidos realizados el día anterior, lo que reduce el riesgo de productos sobrantes o no vendidos.

Tabla 35

Tiempo estimado de demora por porción.

\begin{tabular}{|c|c|c|c|c|c|c|c|c|}
\hline TIPO & NOMBRE PLATO & PORCIONES & $\begin{array}{c}\text { TIEMPO } \\
\text { PREPARAC } \\
\text { POR RECETA } \\
\text { (min) }\end{array}$ & $\begin{array}{c}\text { TIEMPO } \\
\text { PREPARAC POR } \\
\text { PORCION } \\
\text { SEGÚN RECETA } \\
(\text { min) }\end{array}$ & $\begin{array}{c}\text { PORCIONES } \\
\text { PREPARAD } \\
\text { AS POR VEZ } \\
\text { (min) }\end{array}$ & $\begin{array}{c}\text { TIEMPO } \\
\text { PREPARAC } \\
\text { POR } \\
\text { PORCION } \\
(\text { min }) \\
\end{array}$ & $\begin{array}{c}\text { TIEMPO } \\
\text { COCCION POR } \\
\text { PORCION (min) }\end{array}$ & $\begin{array}{c}\text { TIEMPO TOTAL } \\
\text { POR PORCION } \\
\text { (min) }\end{array}$ \\
\hline \multicolumn{9}{|l|}{ OPCION 1} \\
\hline Entrada & $\begin{array}{l}\text { Tortillas rellenas con jamon bajo } \\
\text { en grasas, esparragos y ricota }\end{array}$ & 3 & 7.00 & 2.33 & 4.00 & 0.58 & 1.00 & 1.58 \\
\hline Plato de fondo & Croquetas de pollo con avena & 1 & 4.00 & 4.00 & 4.00 & 1.00 & 1.50 & 2.50 \\
\hline Plato de fondo & Quinoa graneada & 6 & 2.00 & 0.33 & 4.00 & 0.08 & 1.25 & 1.33 \\
\hline \multirow[t]{2}{*}{ Refresco } & Jugo de pera & 4 & 4.00 & 1.00 & 4.00 & 0.25 & 0.83 & 1.08 \\
\hline & & & 17.00 & 7.67 & & 1.92 & 4.58 & 6.50 \\
\hline \multicolumn{9}{|l|}{ OPCION 2} \\
\hline Entrada & Ensalada griega con pollo & 9 & 11.00 & 1.22 & 4.00 & 0.31 & 1.00 & 1.31 \\
\hline Plato de fondo & Pollo horneado en costra de espe & 5 & 9.00 & 1.80 & 4.00 & 0.45 & 2.00 & 2.45 \\
\hline Plato de fondo & Cama de quinoa & 7 & 4.00 & 0.57 & 4.00 & 0.14 & 1.29 & 1.43 \\
\hline \multirow[t]{4}{*}{ Refresco } & Agua de Piña & 4 & 4.00 & 1.00 & 4.00 & 0.25 & 0.83 & 1.08 \\
\hline & & & 28.00 & 4.59 & \multirow{2}{*}{\multicolumn{2}{|c|}{$\begin{array}{lr} & 1.15 \\
\text { PROM EN MIN } & \end{array}$}} & 5.12 & 6.27 \\
\hline & & & & & & & 4.8512 & 6.3837 \\
\hline & & & & & \multicolumn{2}{|c|}{ PROM EN HORAS } & 0.0809 & 0.1064 \\
\hline
\end{tabular}

Elaboración propia 
Tabla 36

Capacidad de producción por porción.

\begin{tabular}{lccccr}
\hline \multicolumn{1}{c}{ DETALLE } & $\begin{array}{c}\text { REMUN } \\
\text { MENSUAL }\end{array}$ & HORAS & $\begin{array}{c}\text { REMUN POR } \\
\text { HORA }\end{array}$ & $\begin{array}{c}\text { COSTO } \\
\text { UNIT POR } \\
\text { PORCION }\end{array}$ & $\begin{array}{c}\text { CAPACIDAD } \\
\text { PRODUCCION } \\
\text { POR PORCION }\end{array}$ \\
\hline Cocinero & $1,398.63$ & 5 & 9.082043651 & 0.966288599 & 46.99446758 \\
Asistente de cocina & $1,208.45$ & 5 & 7.847100469 & 0.834896199 & 46.99446758 \\
\hline & & & TOTAL & $\mathbf{1 . 8 0 1 1 8 4 7 9 8}$ & $\mathbf{9 3 . 9 8 8 9 3 5 1 7}$ \\
\hline
\end{tabular}

Elaboración propia

Así mismo, se consideró en el proyecto el coste de la materia prima, y de los insumos ocupados por menú para poder determinar el costo variable de cada uno, y la productividad de los materiales a usar, agregando también a detalle los empaques en los cuales se entregará el producto. Esta información se encuentra a detalle en el Anexo VII - Costeo de insumos para un menú saludable.

Por otro lado, consideramos en el primer mes, la contratación de un motorizado para reparto de los menús. Se planea realizar el reparto del producto al cliente en dos viajes según la hora que requiera recibir su pedido, a aquellos que su hora de almuerzo es de $12 \mathrm{~m}$ a 1.30 pm será de 11.30 am a $1 \mathrm{pm}$ y a los que su hora de almuerzo es pasada la $1.30 \mathrm{pm}$ a 3 pm será de 1.30 pm a 3 pm, teniendo en total una capacidad de reparto de 32 almuerzos por caja delivery en dos viajes.

Tabla 37

Capacidad instalada de cajas de reparto.

\begin{tabular}{cccc}
\hline DETALLE & $\begin{array}{c}\text { CAPACIDAD } \\
\text { POR VIAJE }\end{array}$ & $\begin{array}{c}\text { VIAJES POR } \\
\text { DIA }\end{array}$ & $\begin{array}{c}\text { CAPACIDAD DE } \\
\text { REPARTO POR } \\
\text { DIA }\end{array}$ \\
\hline CAJA DELIVERY 1 UNID & 16 & 2 & 32 \\
\hline
\end{tabular}

Elaboración propia 
Se plantea en promedio generar 5.43 min por reparto de menú (considerando tiempos de distancias y entregas del producto al cliente), lo cual da como resultado 84 min, restando un tiempo de 6 min como respaldo para algún inconveniente de tráfico que pueda darse en el camino.

En cuanto al tiempo promedio de 5.43 minutos por pedido repartido. Se realizó un estudio de actividades y/o tareas que se programan, las mismas que se ponderarán con un tiempo medido por distancias y se hallará el promedio correspondiente para llegar al tiempo establecido.

Para ello, hemos simulado la estructura de pedido de 1 día de trabajo en el proyecto, el cual contempla 16 pedidos de almuerzos saludables por delivery.

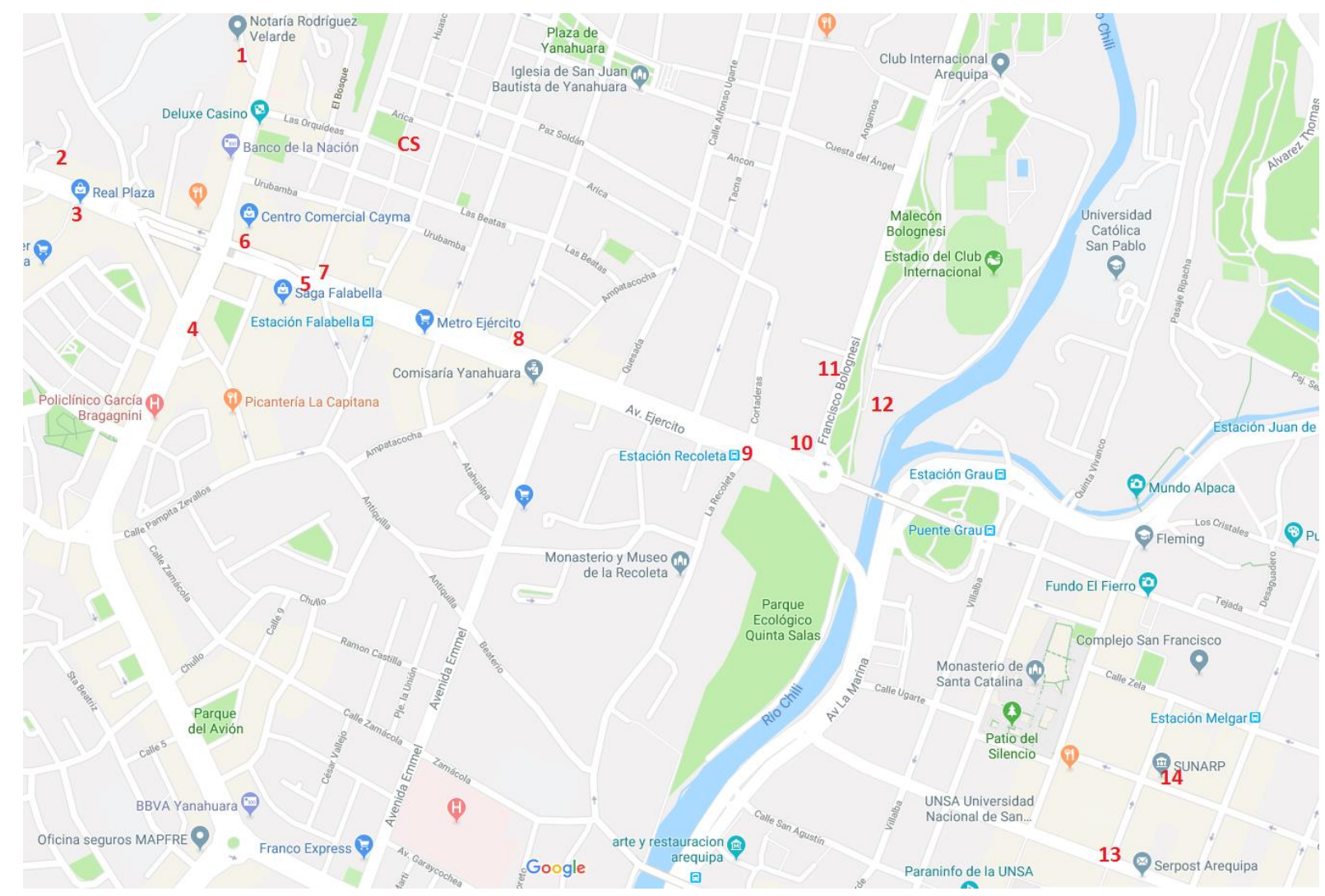

Figura 66 Mapa de ubicación de pedidos. 
En el mapa adjuntado podemos apreciar, la distancia que hay entre pedidos por medio de la simulación realizada, teniendo en cuenta los 3 distritos que abarcaremos en el proyecto: distrito de Yanahuara, distrito de Cayma y Cercado de Arequipa.

Tabla 38

Ubicación exacta de pedidos para analizar.

\begin{tabular}{cllc}
\hline Nro. & \multicolumn{1}{c}{ Puntos de entrega } & \multicolumn{1}{c}{ Dirección exacta } & $\begin{array}{c}\text { Cantidad } \\
\text { de pedidos }\end{array}$ \\
\hline 1 & Notaria Rodriguez Velarde & Urb. Señorial A-3, Cayma & 1 \\
2 & Clínica San Juan de Dios & Av. Ejército 1020, Cayma & 1 \\
3 & Real Plaza & Av. Ejército 1009, Cayma & 1 \\
& Clinica Braganini & Trinidad Morán, J - 2 Urb. León XIII, & \\
4 & & Cayma & 1 \\
5 & Mall Plaza & Av. Ejército 795, Cayma & 2 \\
& CC Cayma & Esq Av. Cayma con Av. Ejercito S/N & \\
6 & & Cayma & 1 \\
7 & Edificio El Peral & Av. Ejército 701, Yanahuara & 2 \\
8 & Edificio Nasya II & Av. Lima 100, Yanahuara & 1 \\
9 & Edificio Nasya I & Av. Ejército 101, Yanahuara & 1 \\
& Clínica Arequipa & Esq Puente Grau con Bolognesi S/N & 1 \\
10 & Ylínica SANNA & Yanahuara & 1 \\
11 & Bolognesi 134, Yanahuara & 1 \\
12 & Club Internacional & Av. Bolognesi s/n Cercado & 1 \\
13 & Crediscotia & Calle San Francisco 201, Cercado & 1 \\
14 & SUNARP & Calle Ugarte 119, Cercado & $\mathbf{1 6}$ \\
\hline & & & TOTAL
\end{tabular}

Elaboración propia

Se realizó el análisis de actividades y/o tareas y nos arrojó las siguientes cifras: 
Tabla 39

Control de tiempos de reparto.

\begin{tabular}{|c|c|c|c|c|c|}
\hline Punto de entrega & $\begin{array}{c}\text { Distancia de } \\
\text { un pedido a } \\
\text { otro (min) }\end{array}$ & $\begin{array}{c}\text { Entrega } \\
\text { del pedido } \\
\text { (min) }\end{array}$ & $\begin{array}{l}\text { Cobro del pedido } \\
\text { / acomodar caja } \\
\text { de reparto (min) }\end{array}$ & $\begin{array}{l}\text { Total de } \\
\text { minutos }\end{array}$ & $\begin{array}{l}\text { Promedio de } \\
\text { entrega por } \\
\text { pedido (min) }\end{array}$ \\
\hline Notaria Rodriguez Velarde & 4 & 1 & 1 & 6 & \multirow{15}{*}{5.43} \\
\hline Clínica San Juan de Dios & 5 & 1 & 1 & 7 & \\
\hline Real Plaza & 3 & 1 & 1 & 5 & \\
\hline Clinica Braganini & 3 & 1 & 1 & 5 & \\
\hline Mall Plaza & 3 & 1 & 2 & 6 & \\
\hline CC Cayma & 3 & 1 & 1 & 5 & \\
\hline Edificio El Peral & 2 & 1 & 2 & 5 & \\
\hline Edificio Nasya II & 4 & 1 & 1 & 6 & \\
\hline Edificio Nasya I & 3 & 1 & 1 & 5 & \\
\hline Clínica Arequipa & 3 & 1 & 1 & 5 & \\
\hline Clínica SANNA & 2 & 1 & 1 & 4 & \\
\hline Club Internacional & 2 & 1 & 1 & 4 & \\
\hline Crediscotia & 7 & 1 & 1 & 9 & \\
\hline SUNARP & 2 & 1 & 1 & 4 & \\
\hline \multirow[t]{2}{*}{ Centro de servicio } & 8 & & & 8 & \\
\hline & & & TOTAL (min) & 84 & \\
\hline
\end{tabular}

Elaboración propia

Los datos de cálculo de tiempo en minutos, se obtuvieron gracias a una simulación en tiempo real en la misma zona, puesto que utilizamos el aplicativo Waze, que nos permite ver mapas y navegación en vivo, ayudándonos de esta manera a establecer tiempos de entrega, tomando en cuenta factores como: existencia de policía, presencia de semáforos, accidentes, peligros viales y embotellamientos, así como también rutas de evacuación en el caso que así se amerite.

Posteriormente consideramos un tiempo bajo el concepto de entrega del pedido, tomando en cuenta que en caso de ser edificio o centro comercial el pedido será entregado en la puerta del mismo. 
También consideramos otro ítem en la matriz, bajo la razón de cobro de pedido, ya que es una opción que brindamos al cliente, el cual puede cancelar el pedido al momento de la recepción del mismo; a su vez, en el mismo ítem integramos la actividad que tiene el repartidor de acomodar los demás pedidos en la caja/cooler en el cual los transporta, con el fin de salvaguardar los productos y que estos lleguen en buenas condiciones a su próximo punto de entrega.

Como se puede observar en el mapa, hay distancias más amplias que otras, por lo cual arrojan diferentes valores en la celda de total de tiempo de entrega, por esa razón decidimos trabajar en base a un promedio, el mismo que nos genera 5.43 min por reparto de pedido satisfactoriamente al cliente.

En cuanto a los proveedores, se realizó un análisis comparativo entre un mercado y un super mercado:

Tabla 40

Cuadro comparativo de análisis de proveedores.

\begin{tabular}{|l|l|}
\hline \multicolumn{1}{|c|}{ Mercado } & \multicolumn{1}{|c|}{ Super mercado } \\
\hline $\begin{array}{l}\text { Maneja precios mas } \\
\text { baratos }\end{array}$ & $\begin{array}{l}\text { Maneja precios mas } \\
\text { caros }\end{array}$ \\
\hline $\begin{array}{l}\text { Se encuentran más } \\
\text { alejados de la zona } \\
\text { del negocio }\end{array}$ & $\begin{array}{l}\text { Se encuentran con } \\
\text { mayor facilidad }\end{array}$ \\
\hline No entregan factura & Si entregan factura \\
\hline $\begin{array}{l}\text { Variedad de } \\
\text { productos }\end{array}$ & $\begin{array}{l}\text { Productos de mejor } \\
\text { calidad }\end{array}$ \\
\hline $\begin{array}{l}\text { Productos más } \\
\text { frescos }\end{array}$ & $\begin{array}{l}\text { Productos } \\
\text { almacenados/ } \\
\text { guardados }\end{array}$ \\
\hline $\begin{array}{l}\text { No existen ofertas } \\
\text { en cuanto a precios }\end{array}$ & $\begin{array}{l}\text { Si se generan } \\
\text { ofertas en cuanto a } \\
\text { precios }\end{array}$ \\
\hline
\end{tabular}

Elaboración propia 
Al ser un proyecto con demanda variable diaria, y en un inicio tener menor cantidad de clientes podríamos optar por comprar en super mercados, ya que las condiciones de venta no varían mucho; puesto que no se dará compras por grandes volúmenes, la compra realizada sería -in situ- por lo que no tendríamos los beneficios de lugar de entrega y la entrega de comprobantes en un mercado es menos frecuente, adicionalmente tendríamos que sumarle el costo de movilidad. Posteriormente, conforme las ventas se incrementen consideramos contactar a un proveedor formal de mercados principales para obtener beneficios en cuanto a precios, entrega en el centro de servicios y comprobantes de pago.

Dentro de los super mercados con los cuales podríamos interactuar debido a la cercanía del proyecto, encontramos los siguientes: Plaza Vea, Metro, Franco, Tottus.

Conoceremos a detalle los procesos productivos que tendrá el negocio, y por ende los requerimientos y necesidades a cubrir, teniendo como objetivo:

- Un diseño de producción que permita optimizar nuestros recursos para lograr el producto final.

- Demostrar la factibilidad de nuestro proyecto, y dar validez a la asignación de recursos por proceso.

- Optimización de la estructura física y del equipamiento del proyecto, basada en especificaciones técnicas requeridas.

\subsubsection{Modelamiento y selección de procesos productivos.}

Bajo el concepto de la descripción de nuestro proceso productivo, podemos definir que nuestro servicio a brindar en el mercado dividido, sin embargo, a su vez es complementario, ya que es $50 \%$ tangible y $50 \%$ intangible. 
Dentro del modelamiento de los procesos productivos, encontramos los siguientes diagramas de flujos que determinarán las actividades que realizaremos en el proyecto y la definición de nuestro servicio a brindar:

- $\quad$ DOP - Flujo general del Servicio.

- DOP - Elaboración del menú.

- $\quad$ DOP - Ventas.

- $\quad$ DOP - Abastecimiento de materia prima e insumos.

- $\quad$ DOP - Servicio al cliente.

- $\quad$ DOP - Manejo de residuos.

- $\quad$ DOP - Preparación del menú.

- DOP - Delivery del producto 


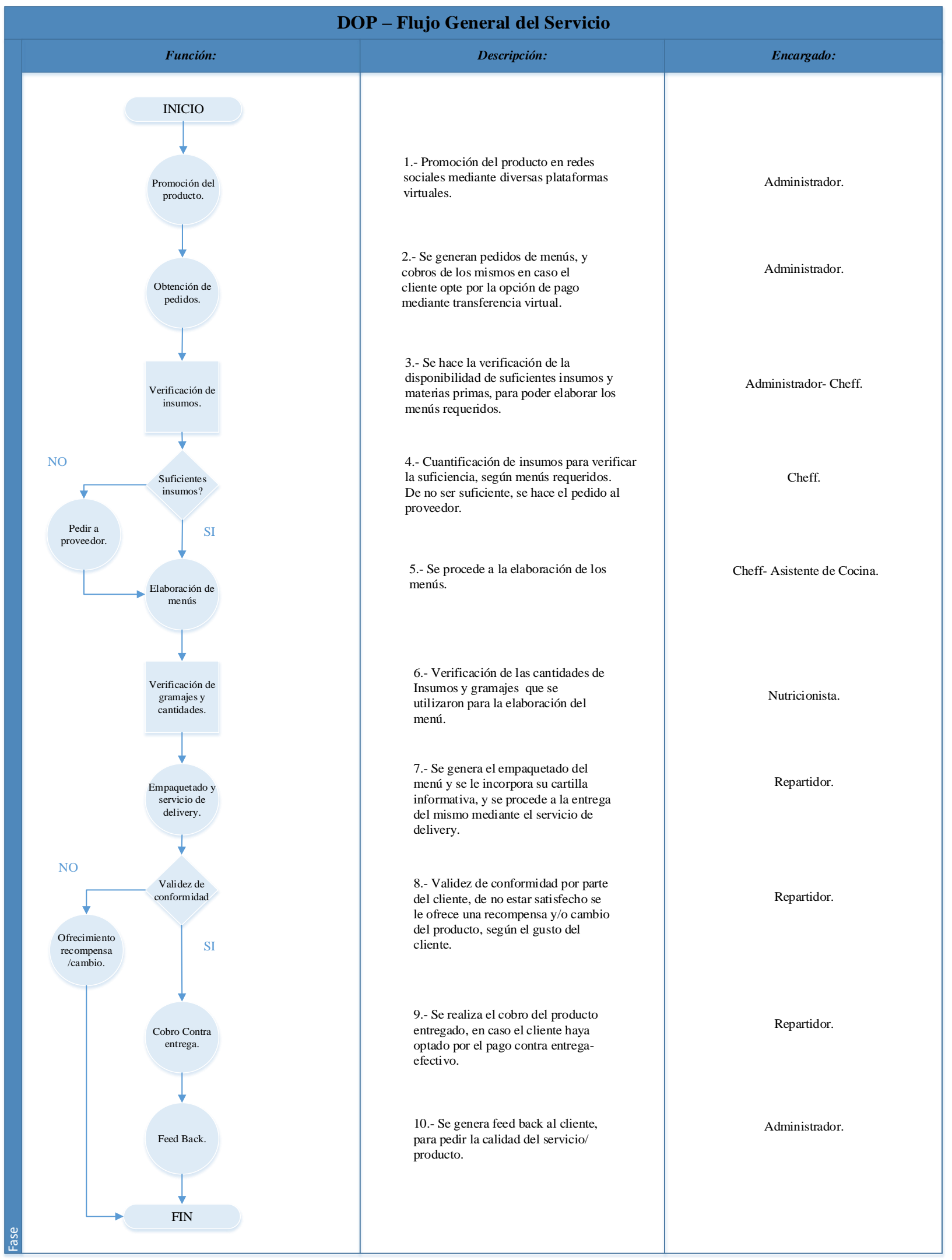

Figura 67 DOP-Flujo general del servicio. 


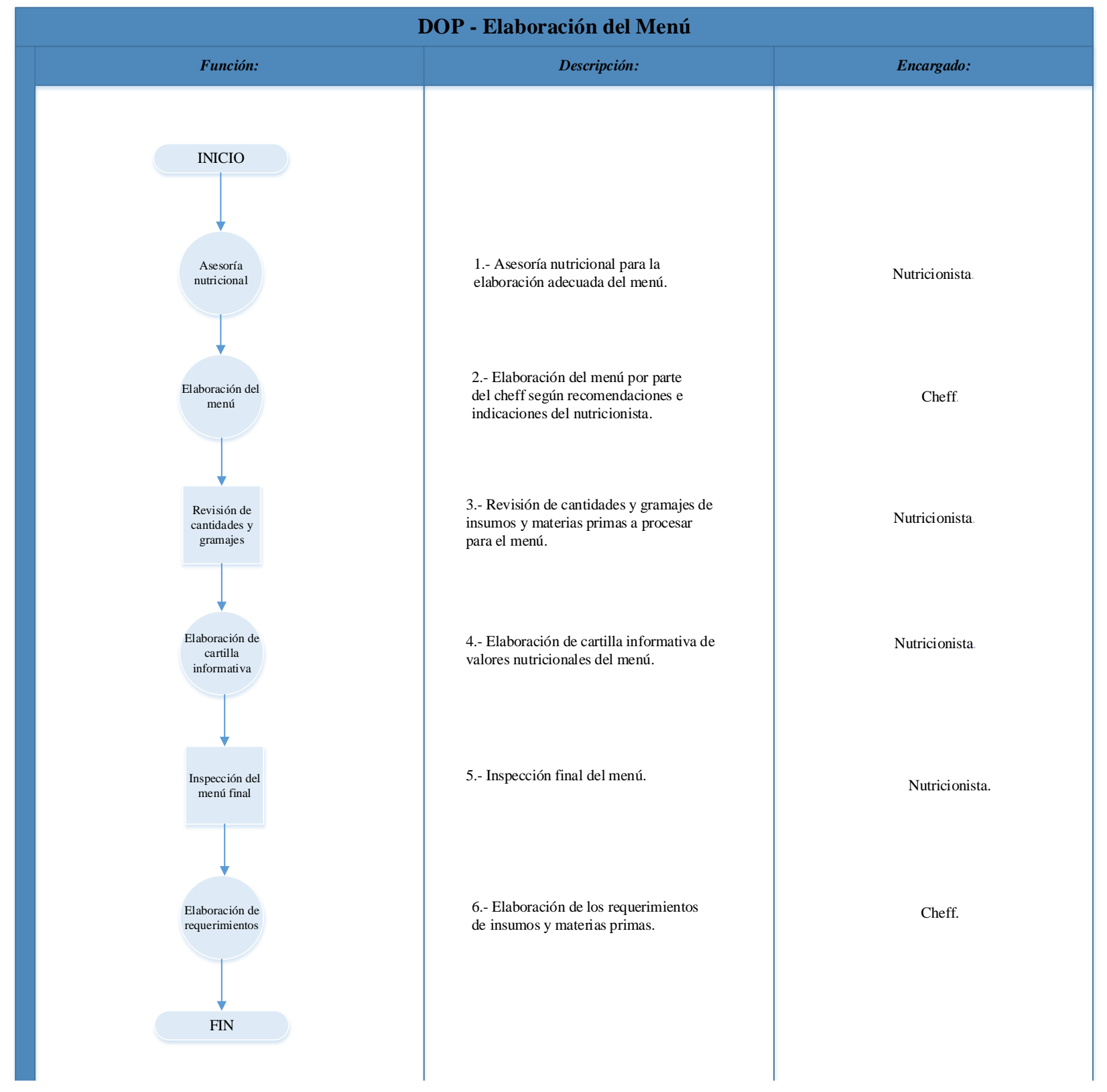

Figura 68 DOP-Elaboración del menú. 


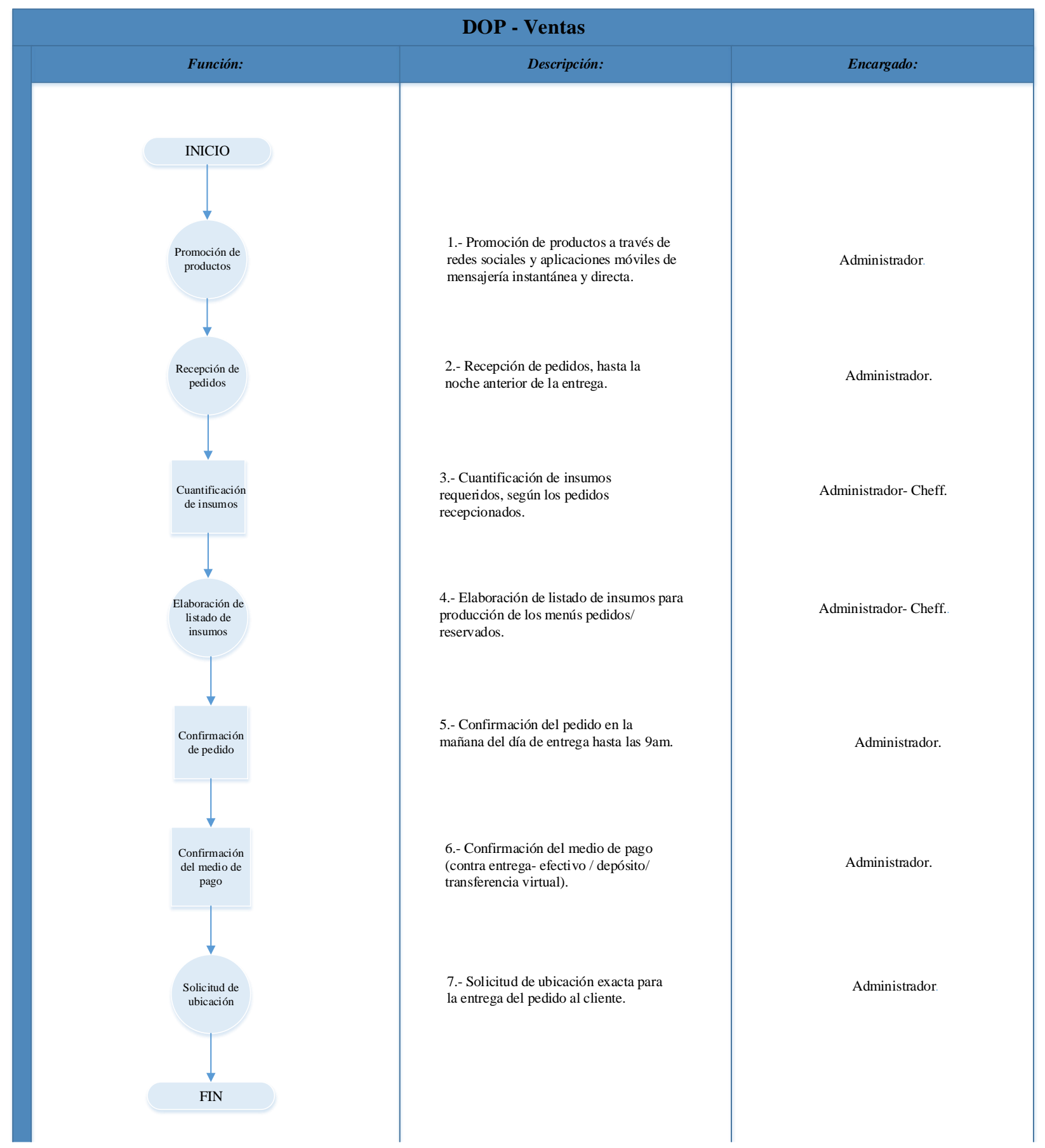

Figura 69 DOP-Ventas. 


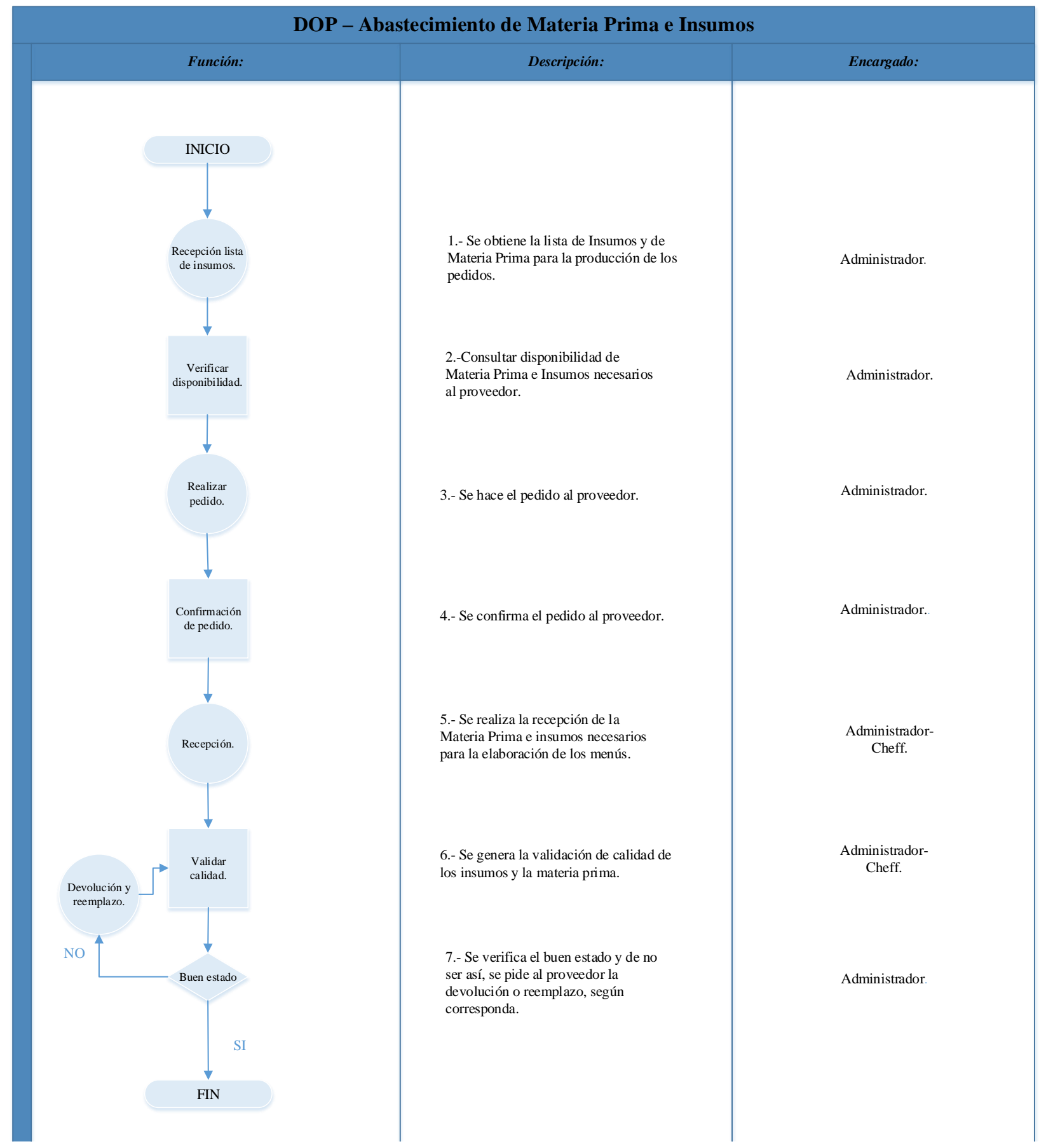

Figura 70 DOP-Abastecimiento de materia prima e insumos. 


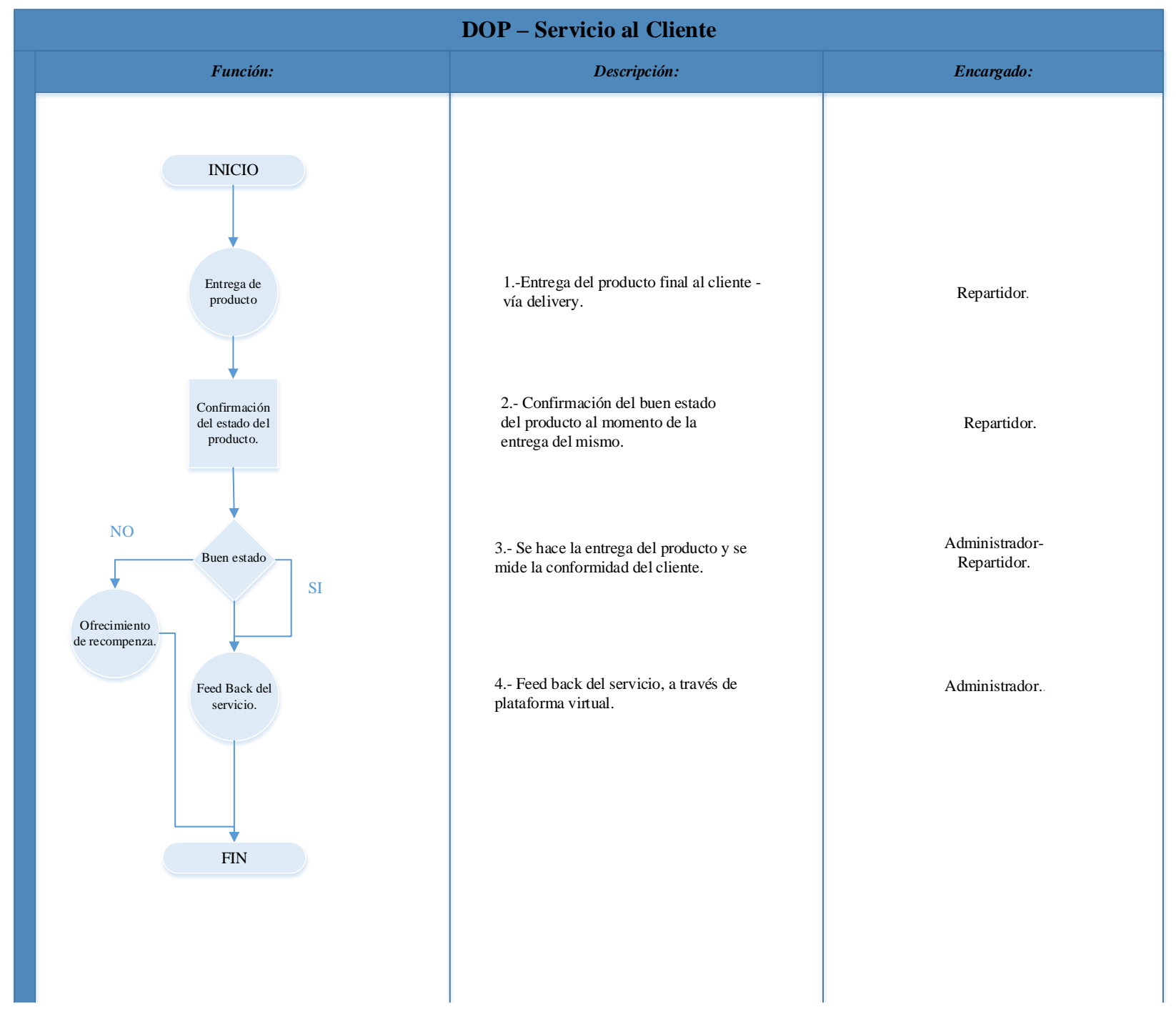

Figura 71 DOP-Servicio al cliente. 


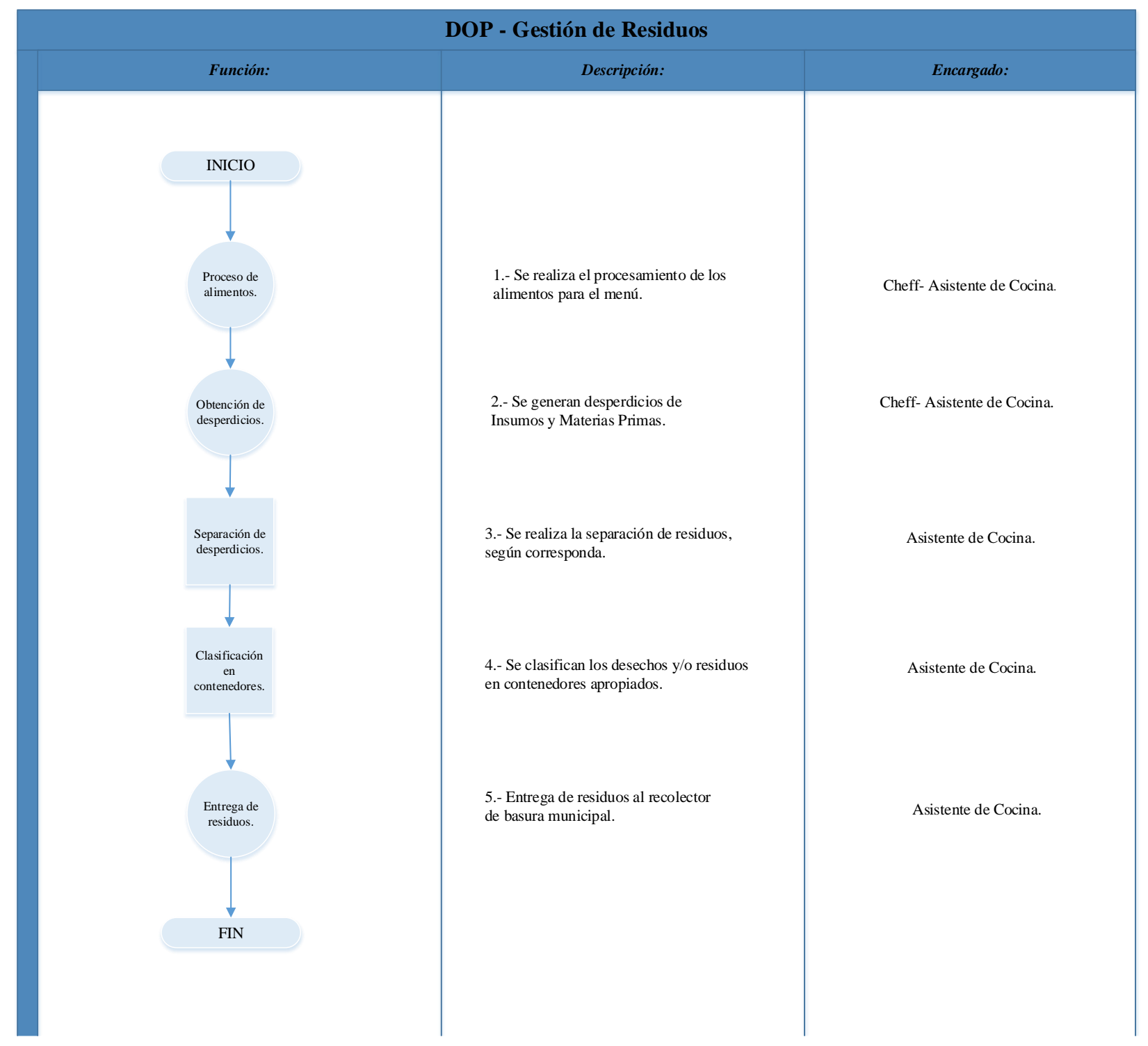

Figura 72 DOP-Gestión de residuos. 


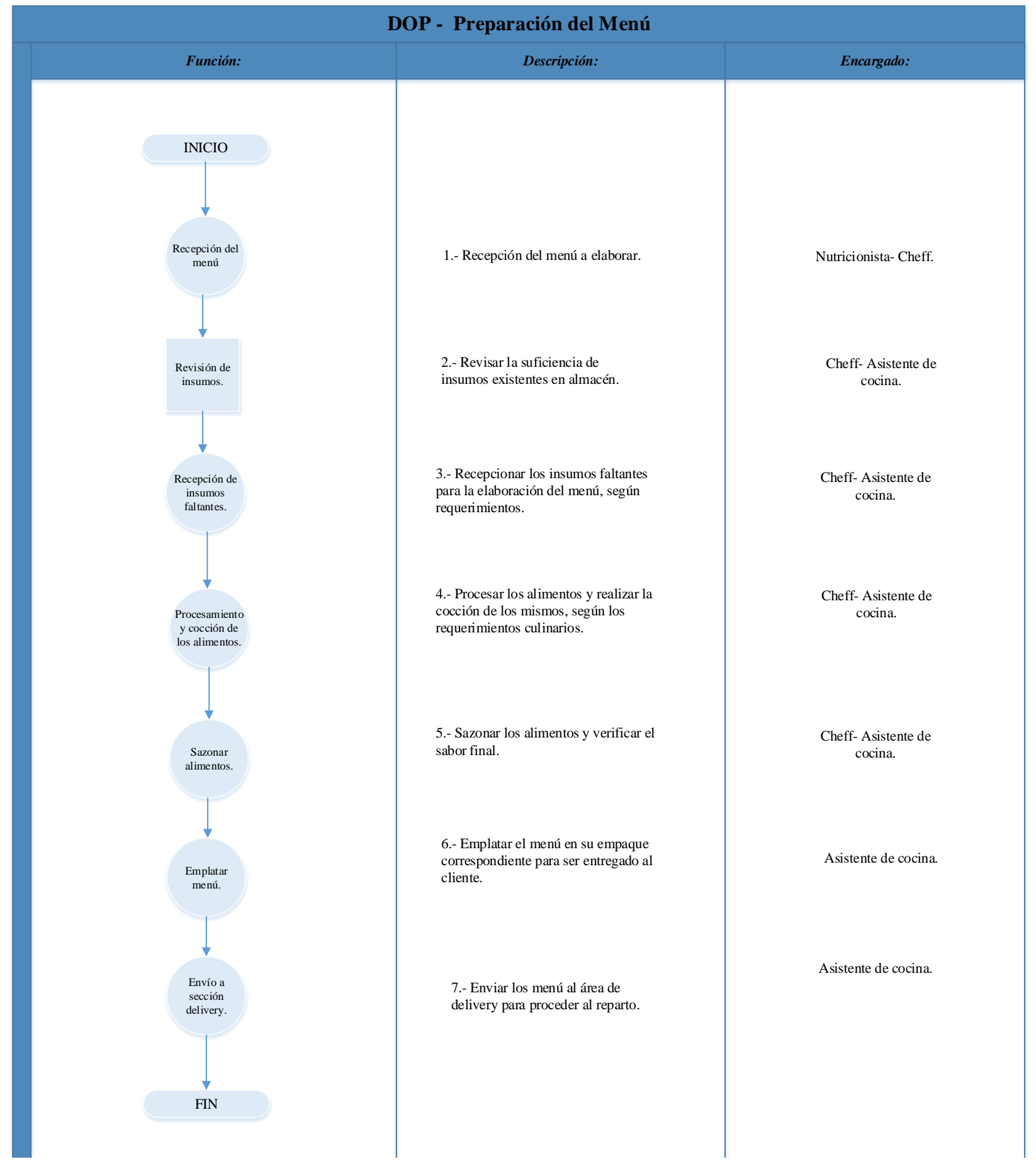

Figura 73 Preparación del menú. 


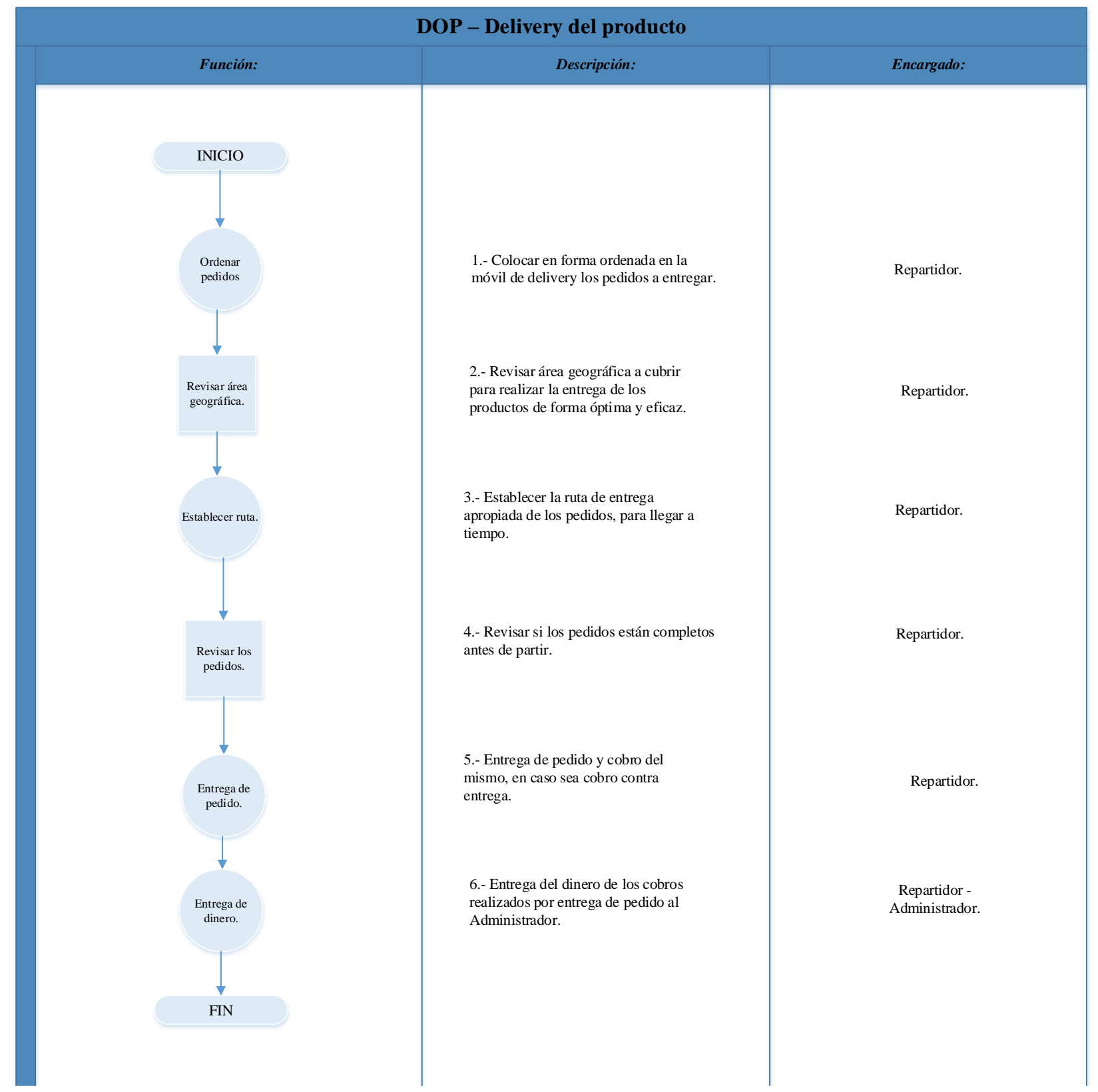

Figura 74 DOP-Delivery del producto.

\subsubsection{Acciones de contingencia}

Como es natural, existe el riesgo que surjan inconvenientes por factores externos a la planificación y procesos planteados, y la forma de reducir el efecto del mismo es mitigarlo con planes de contingencia. En el caso del proyecto planteado un riesgo latente es el referente a la demora o ausencia de 
los repartidores afectando directamente el servicio brindado y la satisfacción del cliente.

Las acciones que se tomaran como parte del plan de contingencia serían:

- Adquisición de una moto como parte de la inversión en activos del proyecto para que en caso de ausencia del repartidos y/o inconvenientes con su vehículo, pueda ser usada para el reparto de los productos, así mismo, inconvenientes en cuanto a tiempos a causa del tráfico.

- Tener un colchón de 6 minutos por probables demoras en el recorrido, no podemos manejar tiempos exactos ya que la afluencia del tráfico no puede ser planificada completamente, se convierten en factores que escapan a nuestro control.

- Contratar personal con conocimiento de manejo de moto, para que en caso sea necesario pueda sustituir a un conductor sin afectar el proceso productivo de la cocina.

\subsubsection{Selección de equipamiento.}

Para poder satisfacer las necesidades que representa nuestro proyecto, tenemos que seleccionar y definir los equipos y maquinas que serán indispensables para el proceso de preparación de alimentos y el empaque de los mismos: 


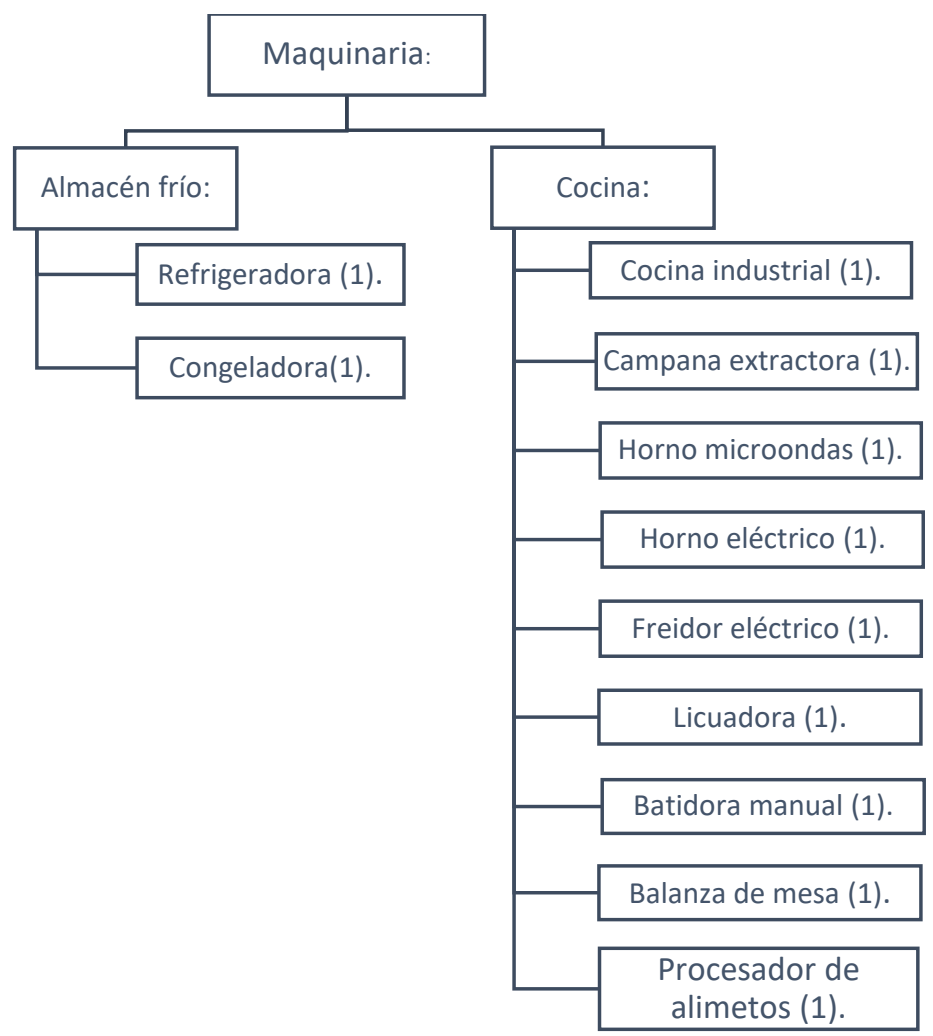

Figura 75 Relación de maquinaria necesaria para la puesta en marcha. 


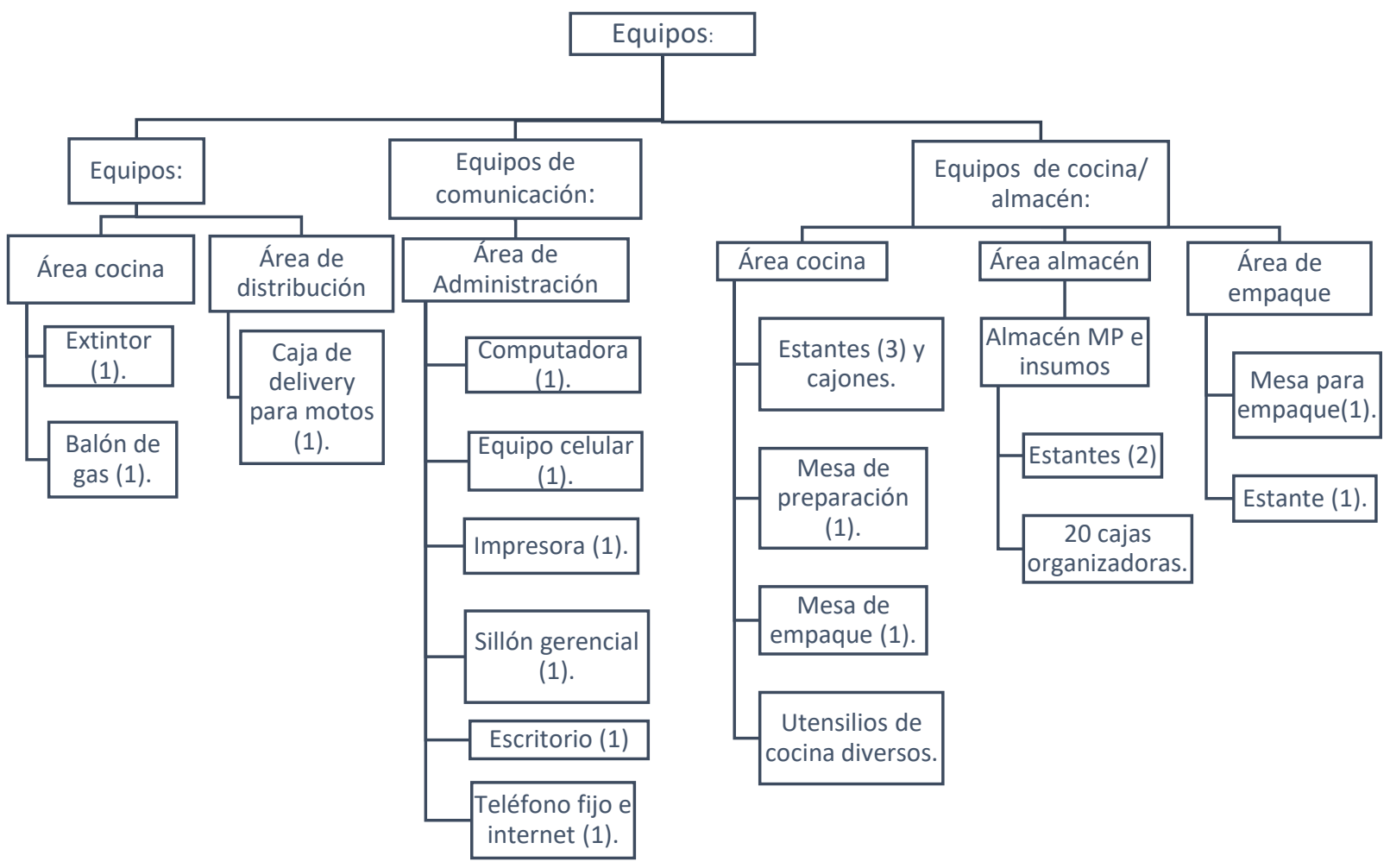

Figura 76 Relación de equipos necesarios para la puesta en marcha.

\subsubsection{Lay-out.}

Dentro de nuestro proyecto, tendremos que desarrollar el diseño y la distribución

física, para lo cual hemos definido los siguientes espacios: 


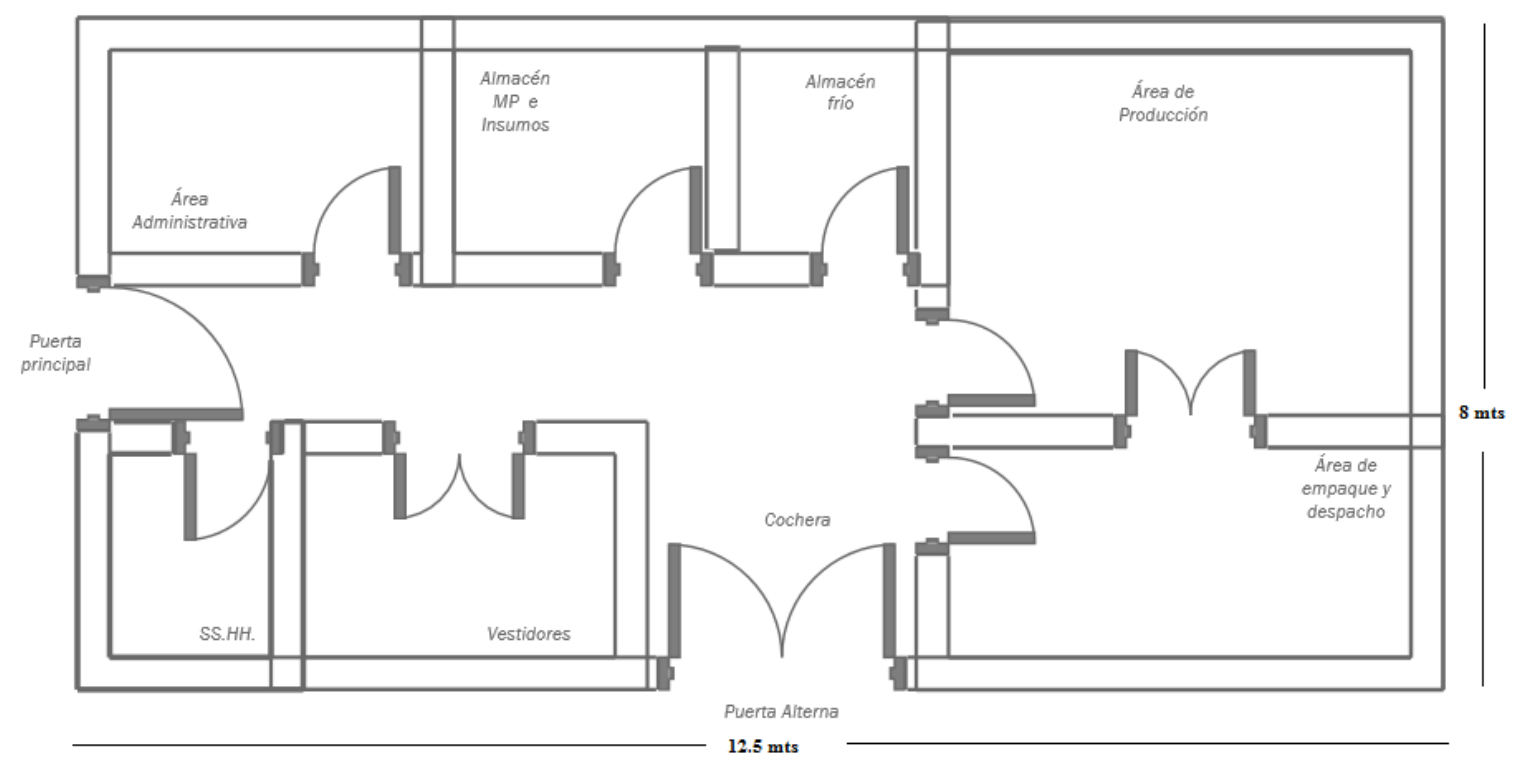

Figura 77 Lay-out simple de planta.

\section{Área administrativa.}

Aquí encontraremos la zona en la cual se desempañará el administrador del proyecto, y se encargará de las negociaciones con los clientes (ventas a realizar) y los proveedores (compras a realizar), y realizará actividades de logística, RR.HH. y finanzas.

\section{Área de producción.}

El centro de producción gastronómica, será el eje principal de nuestro negocio, ya que es parte fundamental de las actividades de logística y producción, dentro de él encontraremos las diferentes actividades que implica el servicio de producción gastronómica: procesar alimentos, cocción de alimentos.

\section{Área de empaque y despacho.}

Será el área determinada para generar los despachos de menús hacia el público (servicio de delivery). 


\section{Almacén de materia prima e insumos.}

Dentro del área de almacén, se realizará la revisión del inventario de materia prima e insumos; así como la inspección de calidad de los mismos.

\section{Almacén frío.}

Se considera un almacén frío de productos que requieren congelamiento, para poder garantizar su calidad.

\section{Área de vestidores y SS.HH.}

El proyecto considerará el área de vestidores para los trabajadores que participen dentro del negocio, así como los SS.HH. que se regirán según las normativas legales actuales.

\section{Cochera.}

Este será el espacio requerido para poder guardar las unidades móviles asignadas para el servicio de delivery del proyecto. 


\subsection{Distribución de equipos y maquinarias.}

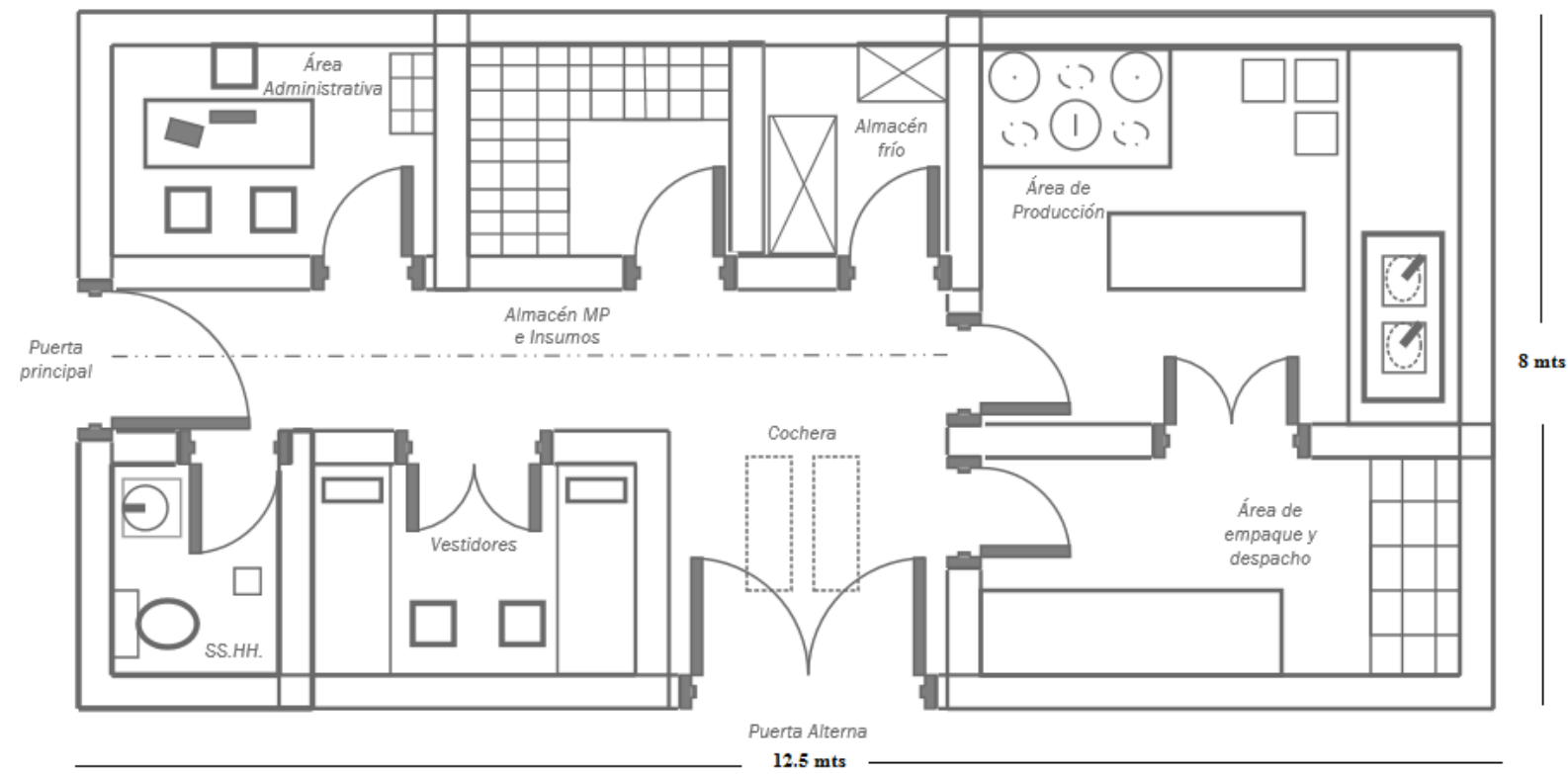

Figura 78 Lay-out estructurado de planta.

Dentro de la distribución de equipos y maquinarias tenemos los siguientes:

Área administrativa.

En el área administrativa tendremos un estante, un escritorio, un sillón gerencial y dos sillas, para las reuniones de trabajo.

\section{Almacén de Materia Prima e insumos.}

Contaremos con dos estantes y 20 cajas organizadoras, que nos permitirán almacenar de forma adecuada los insumos.

\section{Almacén frío.}

Contará con una congeladora y una refrigeradora.

\section{Área de Producción.}


Estará constituida por una cocina industrial con campana extractora, una mesa para procesar alimentos, dos lavaderos especiales de cocina, un horno microondas, un horno eléctrico, un freidor eléctrico, una licuadora, una batidora manual, una balanza de mesa, un procesador de alimentos, tres estantes.

\section{Área de empaque y despacho.}

Contaremos con una mesa especial para despacho y un estante para almacenar productos para envase y embalaje.

\section{Cochera.}

Tendremos un área para guardar la moto de delivery, la misma que será suficientemente amplia para en un futuro que incremente la demanda pueda almacenar una unidad más.

\section{Vestidores.}

Contará con dos estantes, dos sillas y una mesa, para los colaboradores del negocio.

\section{SS.HH.}

Contaremos con SS.HH. básicos, los cuáles serán habilitados como manda la norma, según la cantidad de colaboradores que tendrá el proyecto. 


\subsection{Determinación del tamaño.}

\subsubsection{Proyección de crecimiento.}

Dentro de la proyección de crecimiento se considera un incremento de $10 \%$ en los meses 2 y 3, $15 \%$ del mes 4 al 7 y $20 \%$ hasta culminar el primer año de operaciones.

\subsubsection{Recursos.}

Dentro de los recursos del proyecto, encontramos dos recursos primordiales:

\section{Recursos Humanos:}

Se entiende que el capital humano es la clave del éxito para todo proyecto, es por eso que son parte importante para nuestra implementación; el proceso de selección y reclutamiento estará a cargo del Gerente General - Administrador, y se regirá al perfil establecido en el diseño de puestos claves, teniendo en cuenta las habilidades, experiencia, grado de instrucción, entre otros. Así mismo se establecerán horarios de trabajo y responsabilidades de cada colaborador del proyecto.

\section{Recursos financieros:}

Para poder implementar el proyecto, se debe de tener en cuenta la inversión, siendo esta un factor relevante en el cuál consideraremos todos los gastos preoperativos y nuestro capital de trabajo necesario para poner el proyecto en marcha.

\subsubsection{Tecnología.}

El uso de la tecnología será un elemento clave para nuestro proyecto, en aquellos cambios que se puedan enfrentar con relación a la sostenibilidad en el tiempo; ya sean el ingreso de nuevos competidores, la capacidad de nuestro punto de 
operaciones, cambios en el tamaño del mercado, cambios en el diseño de nuestro producto, nuevas herramientas y/o plataformas digitales; esto nos permitirá adecuar las estrategias para poder mitigar cualquier cambio.

\subsubsection{Flexibilidad.}

Fundamentaremos la flexibilidad de nuestro proyecto, en los cambios que se puedan enfrentar con relación a la sostenibilidad en el tiempo; ya sean el ingreso de nuevos competidores, la capacidad de nuestro punto de operaciones, cambios en el tamaño del mercado, cambios en el diseño de nuestro producto, nuevas herramientas y/o plataformas digitales; esto nos permitirá el ajuste de las estrategias para poder mitigar cualquier cambio.

\subsubsection{Selección de tamaño ideal.}

Para lograr determinar el tamaño de planta, hemos considerado las siguientes capacidades de producción:

\section{Capacidad de diseño:}

La capacidad de diseño se consideró en base a la mayor demanda diaria del proyecto durante los dos primeros años proyectados, aumentada en un $15 \%$ ya que este porcentaje representa el incremento en promedio que afecta a la demanda anualmente.

Se escogió esta capacidad puesto que la planta, dentro de 5 años deberá estar en condición de satisfacer una demanda mayor; ya que el proyecto contempla incrementos secuenciales en función al tiempo. 


\section{Capacidad real:}

Esta capacidad se verá reflejada en el promedio de las demandas diarias consideradas para los 5 años, ya que de esta manera nos permitirá asumir para este cálculo una estrategia de capacidad del tipo intermedia; por ende, la capacidad cubrirá una porción intermedia de las demandas diarias proyectadas dentro del horizonte.

\section{Capacidad máxima:}

La capacidad máxima del proyecto será igual a la mayor demanda diaria dada en las proyecciones, ya que esta demanda significará la cantidad máxima a producir dentro del periodo de 5 años.

Después de este análisis consideramos alquilar un local de $100 \mathrm{~m}^{2},(8 \mathrm{~m} \times 12.5 \mathrm{~m})$, dentro del cual podamos establecer las áreas y/o procesos que interactúan en este proyecto.

Como se puede apreciar en el lay out plano o de piso, se cuenta con un área administrativa, área de almacén de MP e insumos como el almacén frío, área de producción, área de empaque y despacho, los vestidores y SS.HH. para los colaboradores del proyecto y la cochera para el motorizado.

Es relevante mencionar, que la mayoría de locales en alquiler (como contempla este proyecto) son de áreas similares a la planteada, y por ser un negocio de emprendimiento, es recomendable alquilar un establecimiento y adecuarlo para poder operar nuestro proyecto, ya que comprarlo y diseñarlo tal cual las necesidades, incrementaría nuestra inversión. 
En el lay out a detalle, podemos apreciar el equipamiento del mismo, el cual también se encuentra descrito a detalle en el cuadro de maquinarias y equipos, y muebles y enseres que se requerirán en este proyecto.

\subsection{Estudio de localización.}

En el estudio de localización analizaremos la ubicación apropiada para nuestro proyecto.

Para poder determinar este estudio, se deberá tener en cuenta la macro localización y la micro localización.

- En la macro localización de nuestro negocio, se decidió desde un principio ubicarlo en la ciudad de Arequipa, ya que hay la necesidad de plantear un negocio con estas características para poder satisfacer el mercado local, así mismo; es importante mencionar que la ciudad de Arequipa presenta factores favorables para efectuar este proyecto, tales como: disponibilidad de materias primas e insumos, contando con varias fuentes de abastecimiento en la zona por existencia de proveedores locales y así garantizar la disponibilidad de este factor y los recursos de mano de obra de calidad, que hace posible la transformación de la materia prima e insumos para llegar a la elaboración del producto terminado que se brindará al mercado.

- En la micro localización de nuestro negocio, nos basaremos en un conjunto de evaluaciones que se realizarán dentro de la zona de operaciones del proyecto, para determinar el lugar exacto donde se ubicará nuestra propuesta. 


\subsubsection{Definición de factores de localización.}

Dentro de los factores de localización para el análisis de implementación de nuestro punto de operaciones del negocio, consideraremos los siguientes:

\section{Cercanía al mercado objetivo:}

Dentro del mercado objetivo del proyecto, tenemos los siguientes distritos: Cayma, Yanahuara y Cercado de Arequipa; considerando que en dicha zona existe un mayor porcentaje de oficinas.

Se considera que, por un tema de cercanía y centralidad nuestro punto de operaciones se desarrollará en el distrito de Yanahuara.

\section{Demanda - cantidad de oficinas (centros de trabajo y esparcimiento):}

Tomamos como un factor de localización la demanda o nicho de mercado a explotar, ya que como se mencionó en el factor anterior, en los distritos en los cuales estará dirigido nuestro proyecto hay mayor cantidad de centros de labores, esparcimientos (malls) y gimnasios, y aplican estilos de vida a los cuales estamos enfocando el negocio.

\section{Lugares en alquiler disponibles:}

Para poder establecer este factor, se tendrá que comparar la disponibilidad de metros cuadrados existentes en estado de alquiler, que a la vez los mismos cuenten con las características que presentan los requerimientos de este proyecto.

\section{Disponibilidad de servicios básicos:}

Con frecuencia, un punto clave que influye para determinar la ubicación para todo tipo de negocio (sobre todo actividades con procesos de alimentos), es que la zona 
disponga de servicios básicos, tales como: energía eléctrica, agua potable, y desagüe, ya que son indispensables para realizar las actividades que demanda el proyecto.

A continuación, mostramos el plan de delimitación por sectores de la provincia de Arequipa, para poder ubicar los distritos donde llevaremos a cabo el negocio. 


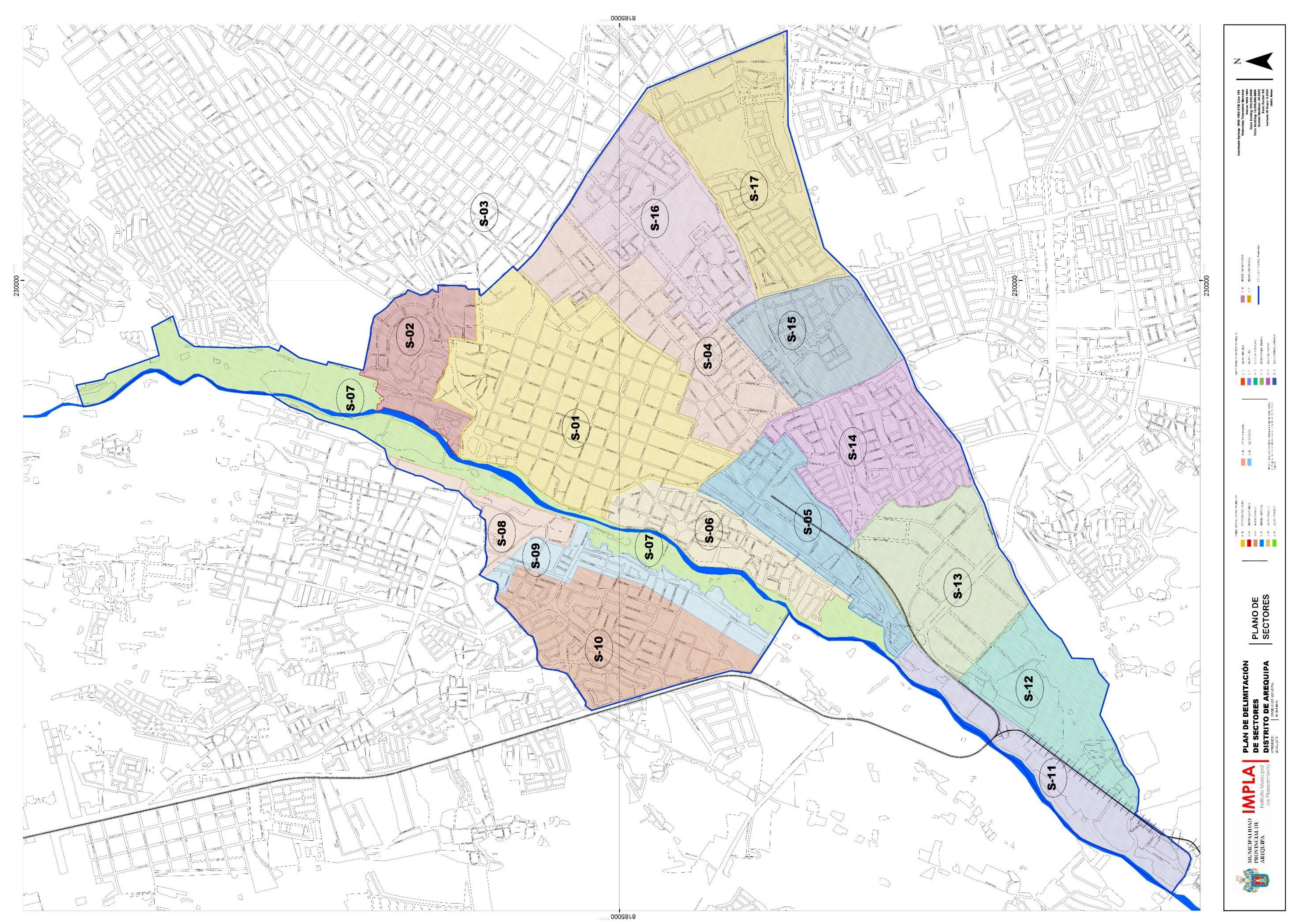

Figura 79 Plan de delimitación de sectores - Distrito de Arequipa. Tomado de la Municipalidad Provincial de Arequipa. 


\subsubsection{Consideraciones legales}

Las consideraciones legales que se tendrán en cuenta estarán basadas en el desarrollo de los reglamentos fiscales y legales.

Para poder analizar este factor, realizaremos una tabla de comparación de los requisitos, tiempo de entrega y los costos que amerita tener una licencia de funcionamiento en los distintos distritos de la zona a evaluar.

Tabla 41

Tabla comparativa de requisitos, tiempos y costo de licencias de funcionamiento en los distritos de Arequipa, Cayma y Yanahuara.

\begin{tabular}{|c|c|c|c|c|}
\hline Distrito & Ente de Control & Requisitos & $\begin{array}{l}\text { Tiempo de } \\
\text { Entrega }\end{array}$ & $\begin{array}{c}\text { Costo en Soles } \\
\text { S/. }\end{array}$ \\
\hline $\begin{array}{l}\text { Cercado de } \\
\text { Arequipa }\end{array}$ & $\begin{array}{l}\text { Municipalidad } \\
\text { Provincial de } \\
\text { Arequipa }\end{array}$ & $\begin{array}{l}\text { Formato Solicitud- Declaración Jurada para el } \\
\text { trámite de Licencia de Funcionamiento. } \\
\text { Copia de vigencia de poder de representante legal } \\
\text { en caso de personas jurídicas u entes colectivos. } \\
\text { Comprobante de pago de derechos. } \\
\text { Declaración jurada de observancia de } \\
\text { condiciones de seguridad. } \\
\text { Copia de autorización sectorial, según el giro. }\end{array}$ & 15 días & S/. 289.60 \\
\hline Cayma & $\begin{array}{c}\text { Municipalidad } \\
\text { Distrital de Cayma }\end{array}$ & $\begin{array}{l}\text { Solicitud con carácter de declaración jurada para } \\
\text { obtener licencia de Funcionamiento. } \\
\text { Declaración jurada de condiciones básicas de } \\
\text { seguridad. } \\
\text { Llenado de formularios. }\end{array}$ & 15 días & $\begin{array}{c}2.97 \% \text { del UIT } \\
(3600)=S / .96 .12\end{array}$ \\
\hline Yanahuara & $\begin{array}{l}\text { Municipalidad } \\
\text { Distrital de } \\
\text { Yanahuara }\end{array}$ & $\begin{array}{l}\text { Declaración jurada, según proyecto. } \\
\text { Carta poder vigente del representante legal. } \\
\text { Declaración jurada de observancia de } \\
\text { condiciones de seguridad de defensa civil. } \\
\text { Copia simple de la autorización sectorial } \\
\text { respectiva, según el giro de la actividad. } \\
\text { Pago total de derechos. }\end{array}$ & 15 días & $\begin{array}{c}7.003 \% \text { del UIT } \\
(3850)= \\
\text { S } / .269 .61\end{array}$ \\
\hline
\end{tabular}

Elaboración Propia 


\subsubsection{Identificación del marco legal.}

Dentro del marco legal encontramos las siguientes ordenanzas:

- Ley Marco de Licencia de Funcionamiento Ley Nº 28976.

- Reglamento de inspecciones Técnicas de Seguridad D.S. No 058-2014 PCM.

- T.U.P.A. Municipalidad Provincial de Arequipa, Compendio normativo.

- Índice de usos para la ubicación de actividades en Arequipa, Ordenanza municipal No 994-2016.

- $\quad$ Ley General de Sociedades.

- HACCP- Análisis de Peligros y Puntos Críticos de Control.

- $\quad$ Reglamento de Restaurantes D.S. No 025-2004- MINCETUR.

- Norma Sanitaria para Restaurantes y servicios afines, Resolución Ministerial № 516-2016 -MINSA.

- $\quad$ Ley de Inocuidad de los Alimentos D.L. No 1062-2008.

- Código de protección y defensa del consumidor, Ley N²9571-2010.

- Reglamento sobre Vigilancia y Control Sanitario de alimentos y bebidas D.S. No007-98-SA.

\subsubsection{Ordenamiento jurídico de la empresa.}

Teniendo conocimiento de la base legal que norma la constitución de una empresa en el Perú, independientemente del tamaño de ésta, se tendrá en cuenta la normativa vigente en relación a trámites necesarios previos al inicio de actividades de la empresa y posterior a esta, siguiendo todos los requisitos de ley. 
La forma de organización elegida será la de persona jurídica. Entendemos por persona jurídica una organización formada por personas naturales o jurídicas; a diferencia de la persona natural, no tiene existencia física, y puede ser representada judicial y extrajudicialmente por una o más personas naturales o jurídicas.

\section{$\underline{\text { Sociedades en el Perú }}$}

Toda sociedad tiene la naturaleza de persona jurídica, compuesta por personas naturales o jurídicas, quienes han decidido realizar un aporte para desarrollar negocios o actividades en común. La Ley General de Sociedades es el órgano legal que reglamenta la existencia de las sociedades en el Perú y ha establecido un total de 11 tipos diferentes.

La Sociedad Anónima, S.A. Tiene dos formas en nuestro país: la sociedad anónima cerrada y la sociedad anónima abierta. En cualquiera de ambas figuras, los socios tienen responsabilidad limitada, es decir, no tienen la obligación de responder solidariamente por las deudas que mantenga la sociedad.

Sociedad Anónima Cerrada, S.A.C. El capital social se inscribe en forma de acciones. Para poder elegir esta figura social, la sociedad no podrá tener más de 20 socios y no deberá inscribir sus acciones en el Registro Público de Mercado de Valores, de esta manera no son públicas y no podrán ser adquiridas en el mercado, solo los socios pueden hacerlo, pueden acogerse pequeñas y medianas empresas. La formación de un directorio no es necesaria pero tampoco prohibida.

Sociedad Anónima Abierta, S.A.A. Las acciones deberán estár inscritas en el Registro Público del Mercado de Valores para que pueden ser compradas por 
cualquier persona. Debe estar conformada mínimo por 750 socios y tienen responsabilidad limitada.

Sociedad Comercial de Responsabilidad Limitada, S.C.R.L. En este tipo de sociedad la cantidad de socios no puede exceder de 20 personas, el capital social está dividido en partes iguales, llamadas participaciones y su responsabilidad es limitada, es decir, los socios responden solo por lo aportado en caso de que la persona jurídica tenga deudas impagas.

Empresa Individual de Responsabilidad Limitada, E.I.R.L. Solo puede ser constituida por una persona natural y esta misma será el titular. El patrimonio inicial de la Empresa estará determinado por el capital aportado de la persona que la constituye. En la EIRL la persona natural puede limitar su responsabilidad por los bienes aportados a la persona jurídica y su patrimonio no es el mismo que el del titular.

Además, tenemos aquellos tipos de sociedad menos comunes como: sociedad en comandita simple, sociedad en comandita por acciones, sociedad civil, sociedad civil ordinaria, sociedad civil de responsabilidad limitada y sociedad colectiva.

\section{Principales tributos de ámbito nacional}

Los impuestos más importantes a los que se encuentran afecto son:

Impuesto a la Renta:

Todas las rentas que provengan ya sea del capital, de la actividad o de la conjunción de ambos factores están gravadas por el impuesto a la renta. 
Las rentas de fuente peruana están afectas al impuesto y se dividen en cinco categorías, existiendo una normativa especial para las rentas percibidas de fuente extranjera. Los ingresos de nuestro negocio pertenecen a la tercera categoría: ingresos de actividades comerciales, industriales, servicios o negocios.

En el Perú tenemos cuatro regímenes tributarios de tercera categoría a los cuales se pueden acoger según los ingresos y actividad que realicen:

Régimen Especial (RER): Se acogen a este régimen cualquier persona natural o jurídicas domiciliada en el Perú y que genere rentas de tercera categoría; es decir, rentas que provengan de la actividad empresarial ya sea por compra y venta de vienen, producción y/o la prestación de servicios.

Antes de acogerse se debe tener en cuenta las actividades no comprendidas en este régimen, como actividades de construcción, los que realizan venta de inmuebles, agencias de viaje, propaganda, entre otros. Es requisito fundamental que, los ingresos netos anuales o el valor de las compras anuales no superen los $\mathrm{S} / 525,000$.

El valor de los activos fijos, con excepción de predios y vehículos, no debe superar los S/ 126,000. Así mismo, no pueden superar la cantidad de 10 trabajadores por turno.

Aquellas personas naturales o jurídicas que estén en este régimen solo están obligadas a presentar declaraciones mensuales y pagar el $1.5 \%$ de los ingresos netos más el IGV resultante, no están obligados a llevar contabilidad completa, solo registro de compras y ventas. 
Régimen General (RG): Todas las personas con negocios y personas jurídicas que desarrollan algún tipo de actividad empresarial pueden acogerse a este régimen. No existe ningún tope de ingresos ni límites en compras. Están obligados al pago anual del $29.5 \%$ de la utilidad resultante de las actividades comerciales. Se realizan pagos a cuenta mensuales, teniendo como base imponible el total de los ingresos del mes y aplicando dos tipos de sistemas:

- Sistema A o de coeficientes, para contribuyentes que en el ejercicio anterior hayan registrado utilidad, su cálculo se hace en base al impuesto anual e ingresos netos del ejercicio anterior.

- Sistema B, para contribuyentes, que hayan iniciado operaciones en el periodo corriente o que hayan obtenido perdida tributaria, se calcula el $1.5 \%$ sobre los ingresos netos

En caso, el cálculo del 1.5\% resulte mayor que el coeficiente se aplica el sistema $\mathrm{B}$, es decir siempre se aplicará el porcentaje que resulte mayor.

Para la regularización del pago anual del 29.5\% sobre la utilidad, se deducen los pagos a cuenta realizados durante el año. En este régimen se lleva contabilidad completa, es decir compras, ventas, diario, mayor, inventarios y balances y cualquier otro que se aplique según la actividad.

Régimen MYPE Tributario (RMT): Enfocado en la micro y pequeña empresa que realicen cualquier tipo de actividad. Se ha establecido un tope de ingresos de 1700 UIT. En el caso de las compras no existe límites y puede emitir todo tipo de comprobante de pago. 
Al igual que los demás regímenes están obligados a pagar mensualmente renta e IGV. Para el pago mensual de renta el cálculo es en función a sus ingresos: hasta 300 UIT se aplicará el 1\% de los ingresos netos, cuando supera esta cifra, se aplicará a los ingresos el porcentaje que resulte mayor entre un coeficiente o el $1.5 \%$.

En este régimen también se realiza la declaración anual del impuesto a la renta, sin embargo, el cálculo difiere en algunos aspectos del régimen general, siendo de la siguiente forma:

Para las primeras 15 UIT de la renta neta, la tasa que se aplica es de $10 \%$ y para la parte que supera esta cifra, se aplica el $29.5 \%$. De la misma forma, los pagos mensuales se pueden deducir del impuesto anual resultante. En este régimen es obligatorio llevar libro de compras, ventas y diario simplificado.

Nuevo RUS (NRUS): Para negocios pequeños cuyos principales clientes son consumidores finales. En este régimen no se llevan registros contables solo se efectúa un pago único mensual en función a las dos categorías existentes actualmente. La primera categoría es para aquellos negocios en los que sus ingresos y egresos no superan los S/ 5,000, se paga S/ 20; la segunda categoría, re realiza un pago único de $\mathrm{S} / 50$ mientras sus egresos e ingresos no superen los $\mathrm{S} / 8,000$. Solo se pueden emitir boletas de venta o tickets.

$\underline{\text { Impuesto General a las Ventas: }}$

El Impuesto General a las Ventas, su objetivo es gravar las diferentes etapas del ciclo de producción y distribución; normalmente se encuentra en el precio de compra de cualquier adquisición por lo que se puede afirmar que su objetivo es ser asumido 
por el consumidor final. La tasa aplicable es del $16 \%$ en todas las operaciones gravadas con el IGV,

Para el pago mensual se aplica el criterio de impuesto contra impuesto o débito contra crédito, se calcula de la diferencia del impuesto resultante del valor de las ventas, y el impuesto que gravo la compra de productos relacionados con el giro del negocio.

Impuesto de Promoción Municipal:

Su aplicación es la misma que el Impuesto General a las Ventas, con una tasa de $2 \%$, por lo tanto, es un agregado de dicho Impuesto.

En la práctica, al impuesto general a las ventas se le agrega el impuesto de promoción municipal, es por esto que se observa que el porcentaje aplicado por IGV es $18 \%$.

\section{Régimen Laboral para la Micro y Pequeña Empresa (REMYPE)}

El Régimen laboral aplicable a las Micro y pequeñas empresas se encuentra regulado por Decreto Legislativo $\mathrm{N}^{\circ} 1086$ y los Decretos Supremos $\mathrm{N}^{\circ}$ s. 007-2008TR y 008-2008-TR, Texto Único Ordenado de la Ley de Promoción de la Competitividad, Formalización y Desarrollo de la Micro y Pequeña Empresa y del Acceso al empleo Decente - Ley MYPE y su respectivo reglamento, los que están vigentes actualmente.

Los requisitos que deben cumplir las empresas que desean acogerse al Régimen MYPES son los siguientes: 
Tabla 42

Requisitos para la inscripción al Régimen MYPE.

\begin{tabular}{|c|c|c|}
\hline TIPO & TRABAJADORES & VENTAS ANUALES \\
\hline Microempresa & $\begin{array}{c}\text { De } 1 \text { a } 10 \\
\text { trabajadores }\end{array}$ & Máximo de 150 UIT's \\
\hline Pequeña Empresa & $\begin{array}{c}\text { De } 1 \text { a } 100 \\
\text { trabajadores }\end{array}$ & Máximo de 1,700 UIT's \\
\hline
\end{tabular}

Elaboración propia

Aunque la norma plantea un Régimen Laboral Especial para los trabajadores y las MYPES, las condiciones pueden ser negociadas por ambas partes para mejorarlas. Su permanencia en este régimen laboral depende de que la empresa no pase los límites de ingresos durante dos años seguidos

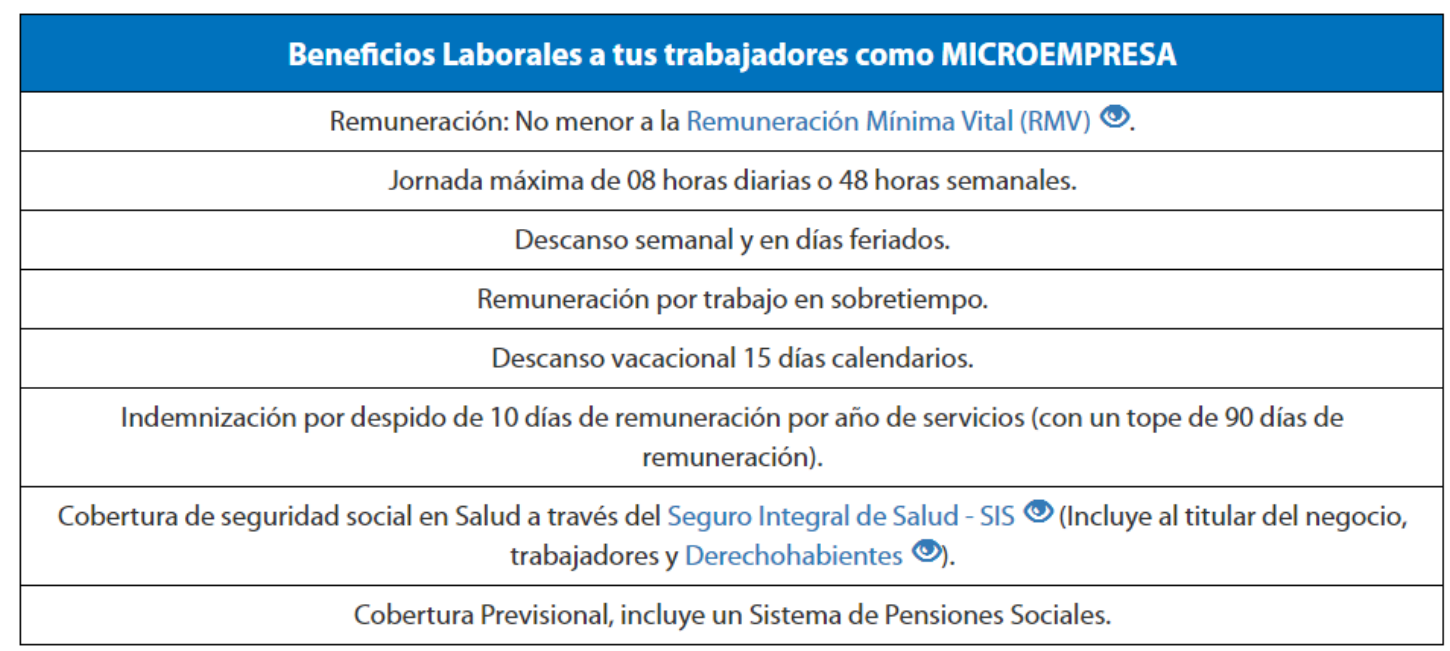

Figura 80 Beneficios laborales de los trabajadores de una MICROEMPRESA. Datos tomados de la Ley MYPE. Recuperado de http://emprender.sunat.gob.pe/si-tengotrabajadores-que-obligaciones-y-beneficios-laborales-existen 


\section{Beneficios Laborales a tus trabajadores como PEQUEÑA EMPRESA}

Remuneración: No menor a la Remuneración Mínima Vital (RMV).

Jornada máxima de 08 horas diarias o 48 horas semanales.

Descanso semanal y en días feriados.

Remuneración por trabajo en sobretiempo.

Descanso vacacional 15 días calendarios.

Indemnización por despido de 20 días de remuneración por año de servicios (con un tope de 120 días de remuneración).

Cobertura de seguridad social en salud a través del ESSALUD.

Cobertura Previsional ().

Cobertura de Seguro de Vida y Seguro Complementario de Trabajo de Riesgo (SCTR).

Derecho a percibir 2 gratificaciones al año de 1/2 sueldo (Fiestas Patrias y Navidad).

Derecho a participar en las utilidades () de la empresa.

Derecho a la Compensación por Tiempo de Servicios (CTS) C equivalente a 15 días de remuneración por año de servicio con tope de 90 días de remuneración.

Derechos colectivos según las normas del Régimen General de la actividad privada.

Figura 81 Beneficios laborales de los trabajadores de una PEQUEÑA EMPRESA. Datos tomados de la Ley MYPE. Recuperado de http://emprender.sunat.gob.pe/sitengo-trabajadores-que-obligaciones-y-beneficios-laborales-existen

\section{Constitución de la empresa}

Para constituir la empresa y poder iniciar actividades deberemos seguir pasos ya estipulados.

1. Elaborar la minuta de Constitución: Para la constitución o creación de una empresa, es requisito fundamental contar con una minuta de constitución, documento redactado por un abogado y en el que se declara la voluntad de dar nacimiento a una empresa, es en este documento donde se plasman por escrito todos los acuerdos referentes a la empresa. Debe presentarse ante un notario para su elevación ante escritura pública, para esto es necesario algunos pasos e información previa que debemos detallar, como: 
- Búsqueda y reserva del nombre o razón social, que decidimos colocar a la empresa, en Registros Púbicos (SUNARP), para comprobar que no existen otras empresas con nombre similar ó igual inscritas en el registro. A) Búsqueda de índices. B) Reserva de preferencia.

- Definir la modalidad o tipo de sociedad,

- Datos personales de los socios, si es que fueran casados sin división de patrimonio deberán incluir los datos de sus esposos.

- El giro del negocio, cuáles serán las actividades a las que se dedicará.

- Dónde va a funcionar o cual será su domicilio fiscal.

- El tiempo de duración de la sociedad (plazo fijo o indeterminado).

- Nombre del representante legal y facultades que se le asignaran.

- Lo estatutos de la sociedad, son pautas o normas que marcan el régimen interno de la empresa a nivel legal, que están obligados a cumplir todos los socios. Se regulan cuestiones como el funcionamiento, aspectos que puedan plantear conflictos en el futuro entre los socios, cuál va a ser el órgano de administración, duración, retribución, facultades y demás aspectos que se consideren importantes.

- Los aportes de cada socio. Los cuales pueden ser:

- Bienes dinerarios: dinero u otros medios bancarizados como cheques, letras, pagares, etc..

- Bienes no dinerarios: inmuebles o muebles tales como escritorios, mesas, computadoras, herramientas, maquinaria, etc.

Una vez redactada la minuta, debe ser llevada a un notario público, para que la revise y la eleve a escritura pública.

Los documentos que debe llevar junto con la minuta son: 
- La constancia o el comprobante de depósito del capital aportado en una cuenta bancaria a nombre de la empresa.

- Un inventario detallado y valorizado de los bienes no dinerarios.

Una vez elevada la minuta, ya no podrá tener modificaciones. Al final, se genera la Escritura Pública, o Constitución Social, que es el documento que da fe de que la minuta es legal, la cual debe estar firmada y sellada por el notario.

2. Inscribir la Escritura Publica en Registros Públicos (SUNARP), ya que solo se considera que la empresa existe a partir de su inscripción en SUNARP.

3. Se procede a registrar la empresa en SUNAT en el Registro Único de Contribuyentes (padrón que contiene la información de todos los contribuyentes domiciliados en el país, obligados a tributar según la normativa vigente,

4. padrón en el que deben registrarse los contribuyentes respecto de los tributos que administra la SUNAT, funge también como base de datos, manteniéndose actualizada constantemente por los contribuyentes y por la misma SUNAT). Al inscribir a la empresa se obtiene un RUC, código único de 11 dígitos y que en adelante será el número de identificación de la empresa para cualquier trámite ante diferentes instituciones del Estado peruano. Los requisitos que solicitan son el DNI del Representante legal, copia literal certificada de la constitución en Registros Públicos y recibo de servicios del domicilio fiscal el cual será verificado posteriormente por SUNAT. Debemos tener en cuenta que cualquier modificación en la empresa debe ser comunicada a SUNAT para la actualización de datos. 
5. Debemos optar por el régimen de renta que más se acomode a nuestra actividad y modalidad de empresa.

6. Para los libros contables tenemos dos opciones: Físicos y electrónicos, en el caso de libros físicos debemos legalizarlos antes del inicio de actividades, y llenarlos mensualmente; para los libros electrónicos debemos enviarlos mensualmente a SUNAT, en el caso de compras y ventas tener en cuenta el cronograma ya establecido según el último digito del RUC, para diario y mayor o diario simplificado se enviará mensualmente con un atraso no mayor a tres meses.

7. Los comprobantes de pago según la normativa vigente deben ser electrónicos, tenemos dos opciones: se generan por el sistema de SUNAT o compramos un sistema que nos permita emitir comprobantes electrónicos y sean aceptados por SUNAT.

8. Solicitar la licencia de funcionamiento a la municipalidad correspondiente.

9. Realizar los contratos respectivos al personal contratado e inscribirlo en el TRegistro a través de CLAVE SOL-SUNAT, dentro de los primeros cinco días después de su ingreso.

10. Registrarse en el Regimen MYPE para acogernos al tratamiento laboral de pequeña empresa.

Habiendo cumplido con todos los pasos necesarios, recién podemos iniciar actividades y cumplir con las obligaciones jurídicas y tributarias a las que estamos sujetos. 


\subsection{Determinación de la localización óptima.}

Para concluir con la determinación óptima para la localización, realizaremos un cuadro en el cual se hará el sustento técnico, analizando cada uno de los atributos que posee las alternativas de localización:

\section{Alternativas de localización:}

- Cercado de Arequipa.

- $\quad$ Distrito de Cayma.

- Distrito de Yanahuara.

\section{Atributos a evaluar:}

- Cercanía a proveedores de Materias Primas e Insumos.

- Costo de Mano de Obra.

- Afluencia de tráfico.

- Costo de Servicios Básicos de agua y luz.

- Costo de Alquiler local.

- Permisos y Ordenanzas Municipales.

En el cuadro a continuación se ponderarán los atributos, comparando alternativas para determinar la localización más óptima y hacer el sustento técnico correspondiente: 
Tabla 43

Análisis MPC de las posibles ubicaciones de la planta de producción.

\begin{tabular}{|c|c|c|c|c|c|c|c|}
\hline \multirow{2}{*}{ Atributos a evaluar } & \multirow{2}{*}{ Peso } & \multicolumn{2}{|c|}{ Cercado de Arequipa } & \multicolumn{2}{|c|}{ Distrito de Cayma } & \multicolumn{2}{|c|}{ Distrito de Yanahuara } \\
\hline & & Calificación & Ponderación & Calificación & Ponderación & Calificación & Ponderación \\
\hline Cercanía a proveedores & 0.15 & 1 & 0.15 & 2 & 0.30 & 2 & 0.30 \\
\hline Costo de Mano de Obra. & 0.05 & 2 & 0.10 & 2 & 0.10 & 2 & 0.10 \\
\hline Afluencia de tráfico & 0.30 & 3 & 0.90 & 2 & 0.60 & 1 & 0.30 \\
\hline $\begin{array}{c}\text { Costos de Servicios } \\
\text { Básicos }\end{array}$ & 0.20 & 2 & 0.40 & 2 & 0.40 & 2 & 0.40 \\
\hline Costo Alquiler Local & 0.20 & 3 & 0.60 & 3 & 0.60 & 2 & 0.40 \\
\hline $\begin{array}{l}\text { Costos de Permisos y } \\
\text { Ordenanzas Municipales }\end{array}$ & 0.10 & 3 & 0.30 & 1 & 0.10 & 2 & 0.20 \\
\hline TOTAL: & 1.00 & & 2.45 & & 2.1 & & 1.7 \\
\hline
\end{tabular}

Elaboración Propia

Siendo los valores de Calificación tomados en cuenta, los siguientes:

\begin{tabular}{|c|c|}
\hline Alto & 3 \\
\hline Medio & 2 \\
\hline Bajo & 1 \\
\hline
\end{tabular}

Según el cuadro evaluador, la mejor zona para ubicar el proyecto es el Distrito de

Yanahuara, las razones son:

- En dicha zona encontramos menor afluencia de tráfico para realizar el servicio de delivery.

- Los costos de permisos y ordenanzas municipales y los costos de alquiler son menores a comparación de las otras alternativas evaluadas.

- Existe una mayor cercanía a los proveedores.

Esta ubicación, será la más apropiada considerando también, que estamos optando por instalar el punto de operaciones dentro de la zona del mercado objetivo del negocio. 


\section{Capítulo VIII}

\section{Aspectos Organizacionales}

\subsection{Caracterización de la cultura organizacional deseada.}

Nuestro proyecto considera sumamente importante el capital humano y la cultura organizacional existente, ya que esto nos permitirá canalizar el comportamiento de nuestros colaboradores y así poder dirigir los esfuerzos adecuadamente.

Las empresas más exitosas de las diferentes industrias, están comprometidas con una cultura organizacional sólida, la cual se desarrolla dentro de los parámetros de sus principios organizacionales, su visión y su misión.

\subsubsection{Visión.}

Es importante que la declaración de visión responda fundamentalmente a la pegunta: ¿En qué queremos convertirnos? Establecer una visión que sea compartida por toda la organización nos lleva a trabajar en comunión y entrar a un mundo diferente en el que habrá oportunidades y desafíos (David, 2013).

“Ser una empresa líder en delivery de alimentos saludables en Arequipa, satisfaciendo las necesidades de nuestros clientes a través del uso de insumos naturales y de calidad".

\subsubsection{Misión.}

La declaración de misión responde a la pregunta: “¿cuál es nuestro negocio?”. Es considerada la expresión que diferencia a una organización de otras similares y expresa en una frase su razón de ser. Una misión establecida de forma apropiada 
tiene como resultado fijar objetivos reales y formular estrategias de manera efectiva; así mismo, pone en claro lo que una organización quiere ser y a quien quiere servir (David, 2013).

"Satisfacemos las necesidades alimenticias de aquellas personas que se encuentran en los distritos de Cayma, Yanahuara y cercado de Arequipa, ofreciendo servicio de delivery de comida saludable con insumos naturales y de calidad, garantizando la puntualidad del servicio y contribuyendo al mismo tiempo con la salud de la población arequipeña”.

\subsubsection{Principios.}

Los principios de toda empresa tienen que demostrar las creencias y/o hábitos que deben de tener todos los colaboradores, para poder alcanzar los objetivos y conseguir las metas deseadas; usando mejor los recursos que se tienen a disposición.

Para que nuestro proyecto tenga éxito, se eligieron los siguientes valores organizacionales, los cuales deben ser manifestados día a día en las actividades de los colaboradores y se reflejaran en los logros de los diferentes objetivos:

\section{- Orientación al Cliente:}

Enfocaremos todos nuestros esfuerzos como empresa para generar un valor superior para el cliente, y que giren alrededor del cliente nuestras acciones para poder lograr su satisfacción; será también uno de nuestros puntos relevantes para adquirir la fidelización.

\section{- Trabajo en Equipo:}


Pensamos que la fuerza que integra el equipo y su cohesión, serán el eje principal para expresar un buen trabajo, fomentando un ambiente de armonía y un clima laboral óptimo que obtenga resultados beneficiosos para la empresa y para el cliente.

\section{- Planificación:}

Este valor nos permitirá como empresa cumplir con nuestros compromisos con el cliente, ya que trabajaremos metódicamente en el desarrollo de cada tarea de nuestros procesos para poder desarrollar de forma óptima nuestro servicio.

\section{- Puntualidad:}

Al ser un servicio de delivery, estableceremos este valor como la base para crear una relación sólida con el cliente, ya que generaremos confianza a través de los tiempos de entrega del servicio.

\section{- Calidad del trabajo:}

Estamos seguros, que teniendo como valor la calidad de nuestro trabajo, lograremos una ventaja competitiva superior, que incentivará a los colaboradores a generar mejores prácticas en las actividades que realicen, las mismas que se verán reflejadas en nuestro producto- servicio final que llegará al cliente.

\subsection{Formulación de estrategias del negocio.}

Como empresa debemos establecer una estrategia competitiva para posicionarnos en la industria y obtener el mejor rendimiento posible sobre la inversión. La mejor estrategia que puede tomar una empresa en cualquier industria será aquella que refleje sus características particulares, ayudándonos a lograr una posición estable a lo largo del tiempo y superar a nuestros competidores (Porter, 2008). 
Michael E. Porter definió tres estrategias genéricas para lograr un mejor desempeño que los rivales en la industria:

- Liderazgo global en costos

- Diferenciación

- Enfoque o concentración

La estrategia general de FIT FOOD es la DIFERENCIACIÓN. Desarrollaremos un producto gastronómico saludable y variado, al mismo tiempo, brindaremos un servicio de delivery según los requerimientos de nuestros clientes, que nos haga únicos en la industria, esto nos posiciona por delante de nuestra competencia ya que nuestros clientes desarrollaran lealtad hacia nuestra marca y la sensibilidad al precio será menor. La fijación en la reducción de costos disminuirá porque buscamos calidad para nuestro producto y esto aumenta las barreras de ingreso al rubro, nos da mayor poder frente a los proveedores y el poder de negociación del cliente disminuye ya que no tendrán opciones similares a su alcance. El cliente debe sentir que, de estar recibiendo un buen producto pasará a recibir el mejor producto.

A continuación, presentamos un cuadro comparativo de nuestros aspectos diferenciadores en relación a la competencia: 
Tabla 44

Cuadro comparativo de aspectos diferenciadores en relación a nuestra competencia.

\begin{tabular}{|c|c|c|c|c|}
\hline \multicolumn{5}{|c|}{ DIFERENCIACIÓN CON LA COMPETENCIA } \\
\hline \multirow{2}{*}{$\begin{array}{l}\text { Criterios a } \\
\text { Comparar }\end{array}$} & \multirow{2}{*}{ FIT FOOD } & \multicolumn{3}{|c|}{\begin{tabular}{|c|} 
Competencia \\
\end{tabular}} \\
\hline & & FIT LUNCH & MANSANA & SANTÉ \\
\hline $\begin{array}{l}\text { Variedad de } \\
\text { opciones }\end{array}$ & $\begin{array}{l}\text { Ofreceremos variedad de } \\
\text { productos en la carta, que } \\
\text { satisfaceran al cliente y no } \\
\text { generarán la monotonía de } \\
\text { su consumo. }\end{array}$ & $\begin{array}{l}\text { Sólo cuenta con una } \\
\text { opción de almuerzo para } \\
\text { ofrecer al mercado. }\end{array}$ & $\begin{array}{l}\text { Sólo cuenta con una } \\
\text { opción de almuerzo para } \\
\text { ofrecer al mercado. }\end{array}$ & $\begin{array}{l}\text { Sólo cuenta con una } \\
\text { opción de almuerzo para } \\
\text { ofrecer al mercado. }\end{array}$ \\
\hline Calidad & $\begin{array}{l}\text { Contaremos con políticas } \\
\text { de calidad que se } \\
\text { plasmarán no sólo en el } \\
\text { producto final que se le } \\
\text { entregará al cliente, sino } \\
\text { también en el servicio } \\
\text { delivery y la atención post } \\
\text { venta. }\end{array}$ & $\begin{array}{l}\text { Presenta el producto } \\
\text { elaborado con insumos } \\
\text { de calidad básica. }\end{array}$ & $\begin{array}{l}\text { No se basa en generar } \\
\text { un producto final de } \\
\text { calidad, y los insumos } \\
\text { utilizados no son los } \\
\text { adecuados para generar } \\
\text { un buen rendimiento de } \\
\text { calidad. }\end{array}$ & $\begin{array}{l}\text { Cuenta con buena } \\
\text { sazón pero la calidad de } \\
\text { los insumos utilizados } \\
\text { es deficiente, lo que } \\
\text { genera un servicio no } \\
\text { óptimo para el cliente. }\end{array}$ \\
\hline $\begin{array}{l}\text { Puntualidad en } \\
\text { la entrega }\end{array}$ & $\begin{array}{l}\text { Generaremos los repartos } \\
\text { durante la hora promedio } \\
\text { de refrigerio, siguiendo una } \\
\text { ruta adecuada que nos } \\
\text { permita cumplir con todos } \\
\text { los pedidos. }\end{array}$ & $\begin{array}{l}\text { Reparte los alimentos } \\
\text { desde muy temprano, } \\
\text { fuera de la hora } \\
\text { promedio de refrigerio. }\end{array}$ & $\begin{array}{l}\text { Reparte los alimentos } \\
\text { desde muy temprano, } \\
\text { fuera de la hora } \\
\text { promedio de refrigerio. }\end{array}$ & $\begin{array}{l}\text { Realiza los repartos } \\
\text { muy tarde (pasando la } \\
\text { hora promedio de } \\
\text { refrigerio). }\end{array}$ \\
\hline $\begin{array}{l}\text { Envase del } \\
\text { producto }\end{array}$ & $\begin{array}{l}\text { Usaremos tupper con } \\
\text { separaciones acecuadas } \\
\text { para los alimentos, y a su } \\
\text { vez amigables con el } \\
\text { medio ambiente. }\end{array}$ & $\begin{array}{l}\text { Usa envases diferentes } \\
\text { para cada comida, pero } \\
\text { todos del mismo } \\
\text { modelo/ color. }\end{array}$ & $\begin{array}{l}\text { Usa envases diferentes } \\
\text { para cada comida, pero } \\
\text { todos del mismo } \\
\text { modelo/ color. }\end{array}$ & $\begin{array}{l}\text { Usa envases diferentes } \\
\text { para cada comida, no } \\
\text { guardando simetría } \\
\text { entre ellos, puesto que } \\
\text { son todos de distinto } \\
\text { material. }\end{array}$ \\
\hline $\begin{array}{l}\text { Compromiso de } \\
\text { entrega }\end{array}$ & $\begin{array}{l}\text { Estaremos comprom etidos } \\
\text { en realizar una entrega } \\
\text { eficiente (hora acordada) } \\
\text { manteniendo } \\
\text { características en el } \\
\text { producto(la temperatura y } \\
\text { buen estado del mismo). }\end{array}$ & $\begin{array}{l}\text { Muchas veces no llegan } \\
\text { a la totalidad del reparto } \\
\text { por una mala } \\
\text { organización y por } \\
\text { querer abarcar muchos } \\
\text { distritos. }\end{array}$ & $\begin{array}{l}\text { Llegan los alimentos en } \\
\text { malas condiciones en } \\
\text { cuanto a presentación. }\end{array}$ & $\begin{array}{l}\text { Reparten los alimentos } \\
\text { con demora, puesto que } \\
\text { poseen un restaurante } \\
\text { físico y centran su } \\
\text { atención primero en ello. }\end{array}$ \\
\hline $\begin{array}{l}\text { Atención al } \\
\text { cliente }\end{array}$ & $\begin{array}{l}\text { Abarcaremos el uso total } \\
\text { de las redes sociales y } \\
\text { llamadas telefónicas para } \\
\text { interactuar con los } \\
\text { clientes. }\end{array}$ & $\begin{array}{l}\text { Interactúa con el cliente } \\
\text { por llam adas y } \\
\text { mensajes. }\end{array}$ & $\begin{array}{l}\text { Interactúa con el cliente } \\
\text { por llamadas y } \\
\text { mensajes. }\end{array}$ & $\begin{array}{l}\text { Sólo interactúa con el } \\
\text { cliente mediante } \\
\text { Ilamada telefónica }\end{array}$ \\
\hline
\end{tabular}

Elaboración propia.

\subsection{Determinación de las ventajas competitivas críticas.}

Consideraremos las siguientes ventajas competitivas: 
- Estableceremos como nuestra ventaja competitiva la diferenciación a través de la calidad de nuestro producto, brindando al mercado características que hagan único nuestro servicio y/o producto y así generar un valor superior al de la competencia.

- Contaremos con personal altamente capacitado e instruido para poder realizar los objetivos como empresa, esto nos permitirá crear en nuestros clientes una relaciónidentidad con nuestra marca, que nos llevará a la fidelización de los mismos.

- Otra ventaja altamente competitiva, será el valor que le daremos a nuestro producto en cuanto al "tiempo de entrega", cumpliendo esta promesa con el cliente y realizando nuestro servicio de forma eficiente.

- Así mismo, nos preocuparemos por realizar el servicio de delivery en envases que no son dañinos para la salud y son eco-amigables con nuestro planeta.

\subsection{Diseño de la estructura organizacional deseada.}

Nuestro proyecto tiene una estructura organizacional simple, ya que al ser un servicio de delivery necesita de pocos colaboradores para cumplir con los requerimientos.

El organigrama estará constituido por personal con experiencia en el rubro culinario, el poder máximo gira alrededor del Gerente General- que a su vez será el Administrador- será el encargado de tomar las decisiones y sobre él recaerán las responsabilidades de las mismas, como parte del área operacionales tendremos un jefe de cocina, un cocinero y un asistente de cocina, quienes se encargarán de la elaboración el producto, y un repartidor para efectuar el servicio de delivery. Así mismo, tendremos la asesoría de una nutricionista que nos brindará las dietas balanceadas que se verán reflejadas en nuestro producto, 
también contaremos con un asesor contables quien se encargara del cumplimiento de nuestras obligaciones tributarias con el FISCO.

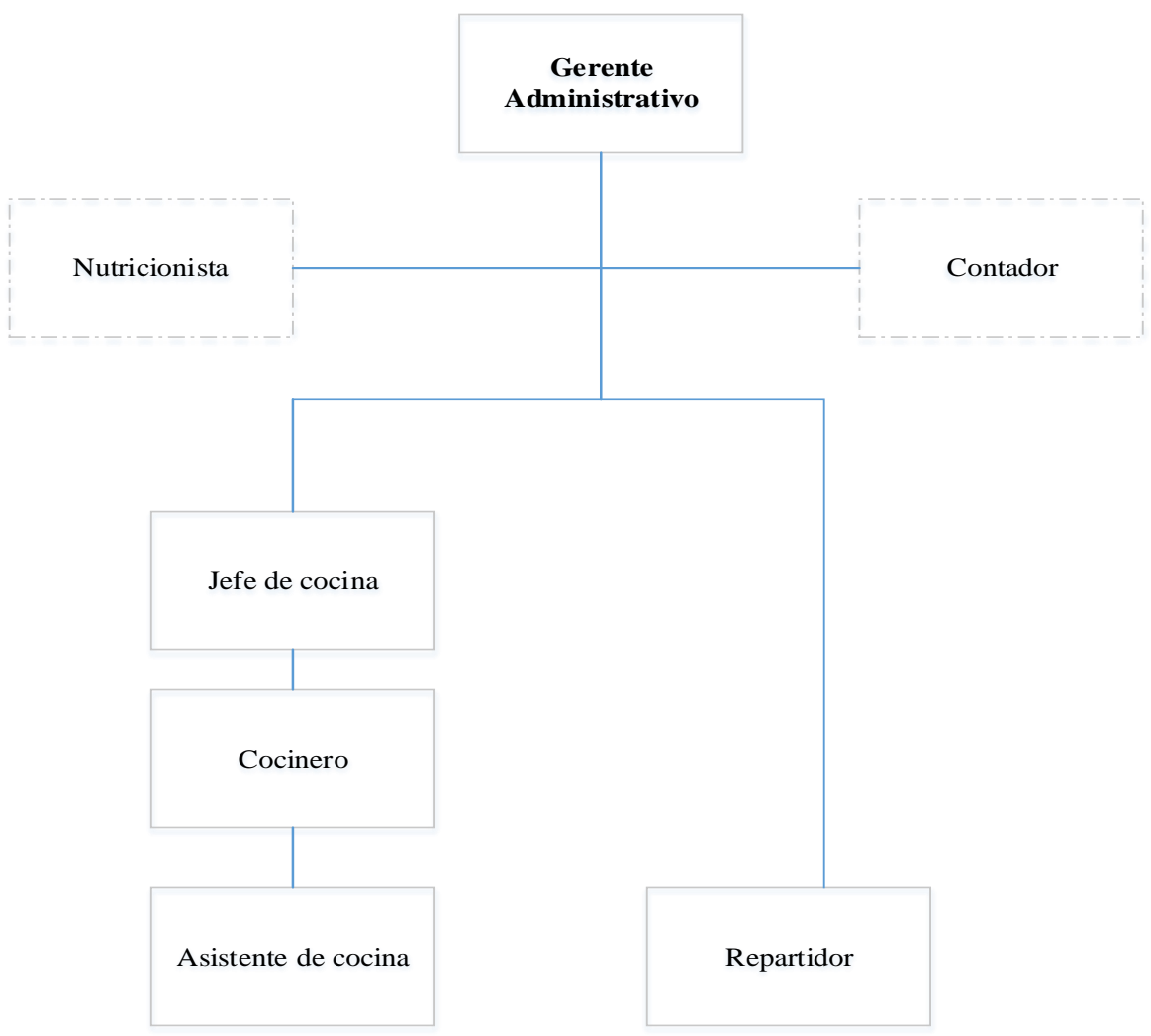

Figura 82 Estructura organizacional diseñada según las necesidades y tamaño de la organización

Fuente: Elaboración Propia.

\subsection{Diseño de los perfiles de puestos claves.}




\section{DESCRIPCIÓN Y PERFIL DE PUESTO}

\section{IDENTIFICACIÓN DEL PUESTO}

$$
\text { Área: }
$$

Categoría:

Nombre del puesto:

Dependencia Jerárquica Lineal:

Dependencia Jerárquica Funcional:

Puestos que supervisa:

\begin{tabular}{c}
\hline Administración \\
\hline Gerencia \\
\hline Gerente Administrativo \\
\hline Comité de Socios \\
\hline Comité de Socios \\
\hline Maestro de cocina, Repartidor
\end{tabular}

\section{OBJETIVO DEL PUESTO}

Planificar, organizar, dirigir, ejecutar y controlar la gestión institucional en concordancia con los planes, políticas, estrategias y presupuesto aprobados por el Comite de Socios. Tener visión y pensamiento estratégico para el desarrollo, que garanticen la operatividad de la organización.

III. FUNCIONES
\begin{tabular}{|c|l|}
\hline$N^{0}$ & \multicolumn{1}{|c|}{ FUNCIONES DEL PUESTO } \\
\hline 1 & Proponer, dirigir y gestionar el cumplimiento de las estrategias organizacionales para alcanzar los objetivos de la misma a corto y largo plazo. \\
\hline 2 & Realizar los actos de administración y gestión ordinaria de la sociedad \\
\hline 3 & $\begin{array}{l}\text { Representar a la organización y apersonarse en su nombre y representación ante las autoridades judiciales, administrativas, laborales, municipales, políticas y } \\
\text { policiales, en cualquier lugar de la República o en el extranjero }\end{array}$ \\
\hline 4 & Celebrar y firmar los contratos y obligaciones de la sociedad, dentro de los criterios autorizados por el Estatuto y el Comité Participacionista de la sociedad. \\
\hline 5 & $\begin{array}{l}\text { Realizar las negociaciones y representar los intereses de la organización ante los proveedores, clientes, grupos de presión, organismos gubernamentales y no } \\
\text { gubernamentales. }\end{array}$ \\
\hline 6 & $\begin{array}{l}\text { Evaluar permanentemente los cambios del entorno y sus probables efectos en la organización e informar de sus efectos, así como proponer las acciones } \\
\text { pertinentes cuando sea necesario. }\end{array}$ \\
\hline 7 & Presentar e informar al comité de socios los estados financieros y de gestión para su revisión y aprobación. \\
\hline 8 & Controla la contratación de personal. \\
\hline 9 & Llevar el registro y control de clientes y/o proveedores, asi como supervisar las cuentas por pagar y/o cobrar. \\
\hline 10 & Atender e informar a los proveedores, clientes y/o el público en general respecto de los servicios que brinda la empresa. \\
\hline 11 & Generar y enviar los comprobantes de pago a los clientes. \\
\hline 12 & Otras funciones establecidasque permitan lograr los objetivos de la organización y del puesto. \\
\hline
\end{tabular}

\begin{tabular}{|c|l|}
\hline IV. COORDINACIONES PRINCIPALES \\
\hline Coordinaciones Internas: & Comité Participacionista, Gerencias y Jefaturas. \\
\hline Coordinaciones Externas: & Proveedores, clientes, grupos de presión, organismos gubernamentales y no gubernamentales. \\
\hline
\end{tabular}

\begin{tabular}{|c|c|}
\hline V. REQUISITOS DE FORMACIÓN ACADÉMICA \\
\hline Formación Académica: & Universitaria Completa \\
\hline Grado Académico: & Titulado \\
\hline Carrera o Estudios requeridos: & Adminsitrador, Contador, Ingeniero Industrial carreras afines. \\
\hline Postgrados: & Especialización o Diplomados en Gestión Empresarial, Finanzas, Economía u otros similares graduado. \\
\hline Colegiatura: & $\mathrm{Si}$ \\
\hline Habilitación Profesional: & $\mathrm{Si}$ \\
\hline
\end{tabular}

\begin{tabular}{|c|c|c|c|c|c|}
\hline \multicolumn{6}{|l|}{ VI. REQUISITOS DE CONOCIMIENTOS } \\
\hline \begin{tabular}{|c|} 
Dirección Estratégica \\
\end{tabular} & Ofimática & No Aplica & Básico & Intermedio & Avanzado \\
\hline Gestión de Restaurantes & Word & & & $\mathrm{X}$ & \\
\hline Planeamiento Estratégico y Financiero & Excel & & & $\mathrm{X}$ & \\
\hline Capacidad de Negociación de conflictos & Power Point & & & $\mathrm{X}$ & \\
\hline \multirow[t]{4}{*}{ Manejo de Presupuesto e inversión } & Internet & & & $x$ & \\
\hline & Idioma & No Aplica & Básico & Intermedio & Avanzado \\
\hline & Inglés & & & $\mathrm{X}$ & \\
\hline & Otros & & & & \\
\hline
\end{tabular}

\begin{tabular}{|c|c|}
\hline VII. REQUISITOS DE EXPERIENCIA LABORAL \\
\hline Experiencia general: & 02 años de experiencia general en gestión empresarial y/o en servicios de restaurantes \\
\hline Experiencia especifica: & 01 años de experiencia específica en puestos gerenciales \\
\hline
\end{tabular}

\begin{tabular}{|c|c|c|c|c|}
\hline \multicolumn{5}{|c|}{ VIII. COMPETENCIAS } \\
\hline & \multirow{2}{*}{ DESCRIPCIÓN } & \multicolumn{3}{|c|}{ NIVEL } \\
\hline & & ALTO & MEDIO & BAJO \\
\hline \multicolumn{5}{|c|}{ GENERALES } \\
\hline 1 & Orientación al cliente & $\mathrm{X}$ & & \\
\hline 2 & Trabajo en Equipo & $\mathrm{X}$ & & \\
\hline 3 & Planificación & $\mathrm{X}$ & & \\
\hline 4 & Puntualidad & $x$ & & \\
\hline 5 & Calidad en el trabajo & $\bar{x}$ & & \\
\hline
\end{tabular}




\section{DESCRIPCIÓN Y PERFIL DE PUESTO}

\begin{tabular}{|c|c|}
\hline I. IDENTIFICACIÓN DEL PUESTO & \\
\hline Área: & Producción \\
\hline Categoría: & Jefatura \\
\hline Nombre del puesto: & Jefe de cocina \\
\hline Dependencia Jerárquica Lineal: & Gerencia \\
\hline Dependencia Jerárquica Funcional: & Gerencia \\
\hline Puestos que supervisa: & Cocinero \\
\hline
\end{tabular}

Gestionar el area de cocina, supervisar a los empleados, crear menús y con la asistencia del gerente del restaurante establecer la planificación de la compra de los insumos. Vigilar el consumo racional de materias primas, entrenar a los aprendices y supervisar la higiene de las áreas de preparación de alimentos.

III. FUNCIONES
\begin{tabular}{|c|l|}
\hline $\mathbf{N}^{\mathbf{O}}$ & \multicolumn{1}{|c|}{ FUNCIONES DEL PUESTO } \\
\hline 1 & Realizar de manera cualificada la planificación, organización y control de todas las tareas propias del departamento de cocina. \\
\hline 2 & Organizar, dirigir y coordinar el trabajo del personal a su cargo. \\
\hline 3 & Dirigir y planificar el conjunto de actividades de su área. \\
\hline 4 & Realizar inventarios, controles de materiales, mercancías, y demas insumos de uso en el departamento de su responsabilidad. \\
\hline 5 & Diseñar platos y participar en su preelaboración, preparación y distribución de los alimentos. \\
\hline 6 & Realizar propuestas de pedidos de mercancías y materias primas y gestionar su conservación, almacenamiento y rendimiento. \\
\hline 7 & $\begin{array}{l}\text { Supervisar y controlar el mantenimiento y uso de maquinaria, materiales, utillaje del departamento, realizando los correspondientes inventarios y propuestas de } \\
\text { reposición. }\end{array}$ \\
\hline 8 & Controlar que los pedidos salgan en las condiciones exigidas. \\
\hline 9 & $\begin{array}{l}\text { Filtrar candidatos para los puestos que van a ser parte de su equipo, proponer reconocimientos, progaramar horarios de trabajo, días libres, fechas de } \\
\text { vacaciones y vigilar horarios de entrada y salida. }\end{array}$ \\
\hline 10 & Aplicar normas y técnicas de manipulación e higiene de alimentos. \\
\hline 11 & Velar por el aseo, higiene y buen uso de utensilios y equipos de trabajo. \\
\hline 12 & Colaborar en la instrucción del personal a su cargo. \\
\hline 13 & Firma de facturas de mercancía que se adquiera. \\
\hline 14 & Realizar cualquier otra actividad, de índole similar a las anteriores, que su jefe le requiera. \\
\hline
\end{tabular}

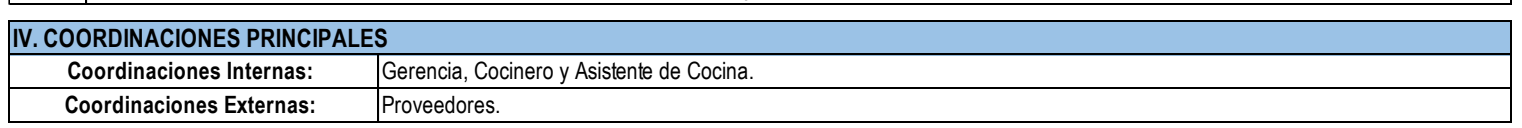

\begin{tabular}{|c|c|}
\hline V. REQUISITOS DE FORMACIÓN ACADÉMICA & \\
\hline Formación Académica: & Técnica Completa \\
\hline Grado Académico: & Titulado \\
\hline Carrera o Estudios requeridos: & Gastronomía \\
\hline Postgrados: & No Aplica \\
\hline Colegiatura: & No Aplica \\
\hline Habilitación Profesional: & Carnet de sanidad \\
\hline
\end{tabular}

\begin{tabular}{|c|c|c|c|c|c|}
\hline \multicolumn{6}{|l|}{ VI. REQUISITOS DE CONOCIMIENTOS } \\
\hline Conocimiento de reglamento de manipulación e higiene de alimentos & Ofimática & No Aplica & Básico & Intermedio & Avanzado \\
\hline Gestión de Restaurantes & Word & & $\mathrm{X}$ & & \\
\hline Capacidad de atención y organización & Excel & & $\mathrm{X}$ & & \\
\hline Alimentación saludable & Power Point & & $\mathrm{X}$ & & \\
\hline Solución de problemas & Internet & & & $X$ & \\
\hline Habilidades comunicativas & Idioma & No Aplica & Básico & Intermedio & Avanzado \\
\hline & Inglés & & $\mathrm{X}$ & & \\
\hline & Otros & & & & \\
\hline
\end{tabular}

\begin{tabular}{|c|c|}
\hline VII. REQUISITOS DE EXPERIENCIA LABORAL \\
\hline Experiencia general: & 02 años de experiencia general en cocina \\
\hline Experiencia específica: & 01 años de experiencia especíica en puestos de jefatura \\
\hline
\end{tabular}

\begin{tabular}{|c|c|c|c|c|}
\hline \multicolumn{5}{|c|}{ VIII. COMPETENCIAS } \\
\hline & \multirow{2}{*}{ DESCRIPCIÓN } & \multicolumn{3}{|c|}{ NIVEL } \\
\hline & & ALTO & MEDIO & BAJO \\
\hline \multicolumn{5}{|c|}{ GENERALES } \\
\hline 1 & Orientación al cliente & $X$ & & \\
\hline 2 & Trabajo en Equipo & $X$ & & \\
\hline 3 & Planificación & $x$ & & \\
\hline 4 & Puntualidad & $X$ & & \\
\hline 5 & Calidad en el trabajo & $\mathrm{x}$ & & \\
\hline
\end{tabular}




\section{DESCRIPCIÓN Y PERFIL DE PUESTO}

I. IDENTIFICACIÓN DEL PUESTO

Área:

Categoría:

Nombre del puesto:

Dependencia Jerárquica Lineal:

Dependencia Jerárquica Funcional:

Puestos que supervisa:
Producción

Supervisor

Cocinero

Jefe de cocina

Jefe de cocina

Asistente de cocina

\section{OBJETIVO DEL PUESTO}

Realizar las preparaciones culinarias conforme a las recetas indicadas, empleando las técnicas de calidad y cantidad de ingredientes requeridos, así como en el uso de los equipos y utensilios, con base en los estándares de calidad y procedimientos de la empresa, la reglamentación sanitaria vigente y los sistemas de gestión en higiene de los alimentos que marcan las normas nacionales e internacionales, a fin de contribuir al logro de los objetivos del servicio.

III. FUNCIONES
\begin{tabular}{|c|l|}
\hline $\mathbf{N}^{0}$ & \multicolumn{1}{|c|}{ FUNCIONES DEL PUESTO } \\
\hline 1 & Comunicarse directamente con el jefe de cocina. \\
\hline 2 & Elaborar y terminar los platos específicos de los que es responsable, poniendo esmero en la presentación y montaje de las piezas solicitadas. \\
\hline 3 & Verificar y solicitar insumos de acuerdo a los requerimientos del servicio, siguiendo el procedimiento establecido. \\
\hline 4 & Confeccionar, siempre que el jefe de cocina se lo pida, el inventario. \\
\hline 5 & $\begin{array}{l}\text { Repartir, organizar y dirigir el trabajo de sus ayudantes en la preparación de los platos de la partida o evento, supervisando de cerca el trabajo y aclarando e } \\
\text { informando sobre las dudas que puedan surgir. }\end{array}$ \\
\hline 6 & Colaborar en los pedidos y conservación de materias primas y productos de uso en la cocina. \\
\hline 7 & Revisar y controlar el material de uso en la cocina, comunicando cualquier incidencia al respecto. \\
\hline 8 & Controlar y cuidar de la conservación y aprovechamiento de los productos puestos a su disposición. \\
\hline 9 & Verificar que se cumpla las normas de higiene y que el personal a su cargo desempeñe correctamente sus funciones. \\
\hline 10 & Recorre el área de trabajo y revisa si hay acumulación de desperdicios. \\
\hline 11 & Colabora en conjunto con el personal de cocina a mantener todo limpio y ordenado. \\
\hline 12 & Firma de facturas de mercancía cuando el Supervisor se encuentran ausente \\
\hline 13 & Debe realizar otras tareas relacionadas con las funciones de su unidad. \\
\hline
\end{tabular}

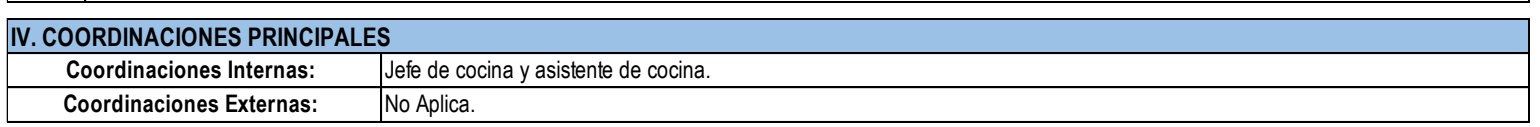

\begin{tabular}{|c|c|}
\hline V. REQUISITOS DE FORMACIÓN ACADÉMICA & \\
\hline Formación Académica: & Tecnica completa \\
\hline Grado Académico: & Egresado \\
\hline Carrera o Estudios requeridos: & Gastronomía \\
\hline Postgrados: & No Aplica \\
\hline Colegiatura: & No Aplica \\
\hline Habilitación Profesional: & Carnet de sanidad \\
\hline
\end{tabular}

\begin{tabular}{|c|c|c|c|c|c|}
\hline \multicolumn{6}{|l|}{ VI. REQUISITOS DE CONOCIMIENTOS } \\
\hline Jornadas gastronómicas & Ofimática & No Aplica & Básico & Intermedio & Avanzado \\
\hline Alimentación saludable & Word & & $\mathrm{X}$ & & \\
\hline \multirow[t]{6}{*}{ Conocimiento de reglamento de manipulación e higiene de alimentos } & Excel & & $\mathrm{X}$ & & \\
\hline & Power Point & $X$ & & & \\
\hline & Internet & & $\mathrm{X}$ & & \\
\hline & Idioma & No Aplica & Básico & Intermedio & Avanzado \\
\hline & Inglés & & $\mathrm{X}$ & & \\
\hline & Otros & & & & \\
\hline
\end{tabular}

\begin{tabular}{|c|c|}
\hline VII. REQUISITOS DE EXPERIENCIA LABORAL \\
\hline Experiencia general: & 01 año de experiencia en el sector restaurantes \\
\hline Experiencia específica: & No requiere \\
\hline
\end{tabular}

\begin{tabular}{|c|c|c|c|c|}
\hline \multicolumn{5}{|c|}{ VIII. COMPETENCIAS } \\
\hline & \multirow{2}{*}{ DESCRIPCIÓN } & \multicolumn{3}{|c|}{ NIVEL } \\
\hline & & ALTO & MEDIO & BAJO \\
\hline \multicolumn{5}{|c|}{ GENERALES } \\
\hline 1 & Orientación al cliente & & $x$ & \\
\hline 2 & Trabajo en Equipo & $\mathrm{X}$ & & \\
\hline 3 & Planificación & $\mathrm{X}$ & & \\
\hline 4 & Puntualidad & $\mathrm{X}$ & & \\
\hline 5 & Calidad en el trabajo & $x$ & & \\
\hline
\end{tabular}




\section{DESCRIPCIÓN Y PERFIL DE PUESTO}

\section{IDENTIFICACIÓN DEL PUESTO}

\section{Área: \\ Categoría: \\ Nombre del puesto: \\ Dependencia Jerárquica Lineal: \\ Dependencia Jerárquica Funcional: \\ Puestos que supervisa:}

\section{OBJETIVO DEL PUESTO}

Auxiliar al cocinero en la preparación y distribución de los alimentos, realizar trabajos sencillos y mecanicos de asistencia en el área, así como mantener el orden y la limpieza en la cocina.

\section{FUNCIONES}

\begin{tabular}{|c|l|}
\hline $\mathbf{N}^{\mathbf{0}}$ & \multicolumn{1}{|c|}{ FUNCIONES DEL PUESTO } \\
\hline 1 & Participa diariamente en la preparación de alimentos. \\
\hline 2 & Distribuir los alimentos en platos de acuerdo con los menús y las raciones indicadas en ellos. \\
\hline 3 & Seleccionar, lavar, cortar y picar los alimentos, posterormente colocarlos en recipientes adecuados. \\
\hline 4 & Llevar al fuego los alimentos. \\
\hline 5 & Preparar diariamente las ensaladas. \\
\hline 6 & Cumplir con las normas de higiene y seguridad necesarias para preservar la salud y evitar accidentes. \\
\hline 7 & Servir y recoger el servicio del comedor. \\
\hline 8 & Mantener en perfecta lim pieza y orden la cocina, equipo e instalaciones, incluyendo vajillas, cubiertos, platos de cocina y demas utensilios. \\
\hline 9 & Debe realizar otras tareas relacionadas con las funciones de su unidad. \\
\hline
\end{tabular}

\section{COORDINACIONES PRINCIPALES}

\begin{tabular}{l|l} 
Coordinaciones Internas: & Cocinero \\
Coordinaciones Externas: & No aplica
\end{tabular}

\begin{tabular}{|c|c|}
\hline \multicolumn{2}{|c|}{ V. REQUISITOS DE FORMACIÓN ACADÉMICA } \\
\hline Formación Académica: & Estudiantes de gastronomia \\
\hline Grado Académico: & Estudiante \\
\hline Carrera o Estudios requeridos: & Gastronomía \\
\hline Posgrados: & No Aplica \\
\hline Colegiatura: & No Aplica \\
\hline Habilitación Profesional: & Carnet de Sanidad \\
\hline
\end{tabular}

\section{REQUISITOS DE CONOCIMIENTOS}

\begin{tabular}{|c|c|c|c|c|c|}
\hline Curso de manipulación e higiene de alimentos & Ofimática & No Aplica & Básico & Intermedio & Avanzado \\
\hline Cuidado y uso de vajillas & Word & $\mathrm{X}$ & & & \\
\hline Preparación de alimentos sencillos & Excel & $X$ & & & \\
\hline \multirow[t]{5}{*}{ Manejo de equipos de cocina } & Power Point & $X$ & & & \\
\hline & Internet & & $X$ & & \\
\hline & Idioma & No Aplica & Básico & Intermedio & Avanzado \\
\hline & Inglés & $X$ & & & \\
\hline & Otros & & & & \\
\hline
\end{tabular}

\begin{tabular}{|c|c|}
\hline \multicolumn{2}{|c|}{ VII. REQUISITOS DE EXPERIENCIA LABORAL } \\
\hline Experiencia general: & No requiere \\
\hline Experiencia específica: & No requiere \\
\hline
\end{tabular}

\begin{tabular}{|c|c|c|c|c|}
\hline \multicolumn{5}{|c|}{ VIII. COMPETENCIAS } \\
\hline & \multirow{2}{*}{ DESCRIPCIÓN } & \multicolumn{3}{|c|}{ NIVEL } \\
\hline & & ALTO & MEDIO & BAJO \\
\hline \multicolumn{5}{|c|}{ GENERALES } \\
\hline 1 & Orientación al cliente & & $X$ & \\
\hline 2 & Trabajo en Equipo & $X$ & & \\
\hline 3 & Planificación & $X$ & & \\
\hline 4 & Puntualidad & $x$ & & \\
\hline 5 & Calidad en el trabajo & $\mathrm{X}$ & & \\
\hline
\end{tabular}




\section{DESCRIPCIÓN Y PERFIL DE PUESTO}

\begin{tabular}{|c|c|}
\hline I. IDENTIFICACIÓN DEL PUESTO & \\
Área: & Distribución \\
Categoría: & Asistente \\
\cline { 2 - 2 } Nombre del puesto: \\
\cline { 2 - 2 } $\begin{array}{c}\text { Dependencia Jerárquica Lineal: } \\
\text { Dependencia Jerárquica Funcional: } \\
\text { Puestos que supervisa: }\end{array}$ & Repartidor \\
\cline { 2 - 2 } & Gerencia \\
\cline { 2 - 2 } & Gerencia \\
\hline II. OBJETIVO DEL PUESTO & - \\
\hline
\end{tabular}

Transporte y distribución de platos preparados desde el lugar de elaboración hasta el domicilio de destino. Hacer llegar el pedido al consumidor final en unas condiciones de consumo óptimas, cumpliendo con los horarios establecidos de despacho de los productos y cobrando cuando corresponda.

III. FUNCIONES
\begin{tabular}{|c|l|}
\hline N$^{\circ}$ & \multicolumn{1}{|c|}{ FUNCIONES DEL PUESTO } \\
\hline 1 & Organizar la ruta de transporte en función del número de pedidos y la localización de los domicilios de entrega. \\
\hline 2 & Revisar las planillas de despacho, ruta y productos. \\
\hline 3 & Chequear canastas, cajas y contenedores en general. \\
\hline 4 & Llamar a los clientes cuando este cerca dirigiendose a su destino para verificar que se encuentre. \\
\hline 5 & Ayudar de ser necesario a ordenar los productos en las bolsas para su reparto. \\
\hline 6 & Ordenar la carga interior del movil. \\
\hline 7 & Conduce el vehículo desde el lugar de elaboración y envasado hasta el domicilio de entrega. \\
\hline 8 & Carga y descarga platos preparados, bebidas y contenedores. \\
\hline 9 & Entregar el pedido cuidando que la atención al cliente sea la correcta. \\
\hline 10 & Elaborar cobranza de los clientes que paguen contra-entrega y solicitar firma de recepción. \\
\hline 11 & Se responsabiliza del vehiculo de reparto y su documentación durante el servicio. \\
\hline 12 & Reportar opiniones, sugerencias y quejas, si es que hubieran, a la administración \\
\hline 13 & Otras funciones establecidasque permitan lograr los objetivos de la organización y del puesto. \\
\hline
\end{tabular}

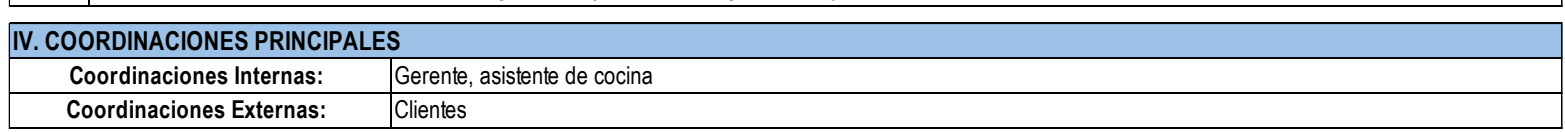

\begin{tabular}{|c|c|}
\hline V. REQUISITOS DE FORMACIÓN ACADÉMICA \\
\hline Formación Académica: & Secundaria completa \\
\hline Grado Académico: & Egresado \\
\hline Carrera o Estudios requeridos: & Adminsitrador, Contador, Ingeniero Industrial carreras afines. \\
\hline Posgrados: & No Aplica \\
\hline Colegiatura: & No Aplica \\
\hline Habilitación Profesional: & Brevette para manejo de moto \\
\hline
\end{tabular}

\begin{tabular}{|c|c|c|c|c|c|}
\hline VI. REQUISITOS DE CONOCIMIENTOS \\
\hline Conocimiento de normas de higiene y seguridad de alimentos & Ofimática & No Aplica & Básico & Intermedio & Avanzado \\
\hline Manejar moto & Word & & & $X$ & \\
\hline Preparar y despachar pedidos & Excel & & & $X$ & \\
\hline Conciliación de caja & Power Point & $X$ & & & \\
\hline Organización y distribución de recursos materiales & Internet & & & $X$ & \\
\hline Manejo de habilidades de comunicación, recepción y entrega de información & Idioma & No Aplica & Básico & Intermedio & Avanzado \\
\hline Capacitación en manejo seguro de vehiculos motorizados & Inglés & & $X$ & & \\
\hline Uso de equipo de protección personal & Otros & & & & \\
\hline
\end{tabular}

\begin{tabular}{|c|c|}
\hline VII. REQUISITOS DE EXPERIENCIA LABORAL \\
\hline Experiencia general: & 06 meses de experiencia general en reparto de alimentos \\
\hline Experiencia específica: & No requiere \\
\hline
\end{tabular}

\begin{tabular}{|c|c|c|c|c|}
\hline \multicolumn{5}{|c|}{ VIII. COMPETENCIAS } \\
\hline & \multirow{2}{*}{ DESCRIPCIÓN } & \multicolumn{3}{|c|}{ NIVEL } \\
\hline & & ALTO & MEDIO & BAJO \\
\hline \multicolumn{5}{|c|}{ GENERALES } \\
\hline 1 & Orientación al cliente & $X$ & & \\
\hline 2 & Trabajo en Equipo & $x$ & & \\
\hline 3 & Planificación & $x$ & & \\
\hline 4 & Puntualidad & $X$ & & \\
\hline 5 & Calidad en el trabajo & $X$ & & \\
\hline
\end{tabular}




\subsection{Remuneraciones, compensaciones e incentivos.}

Según Porret (2014), es la compensación económica que recibe el trabajador por parte de la empresa, por el esfuerzo físico e intelectual realizado, independientemente de los factores que se tuvieron en cuenta, método de cálculo y la modalidad de pago.

Según Chiavenato (2007), es el estímulo que el trabajador recibe a cambio de las tareas realizadas para la organización. Es esencialmente un intercambio, en el que el trabajador ofrece su trabajo por una compensación o remuneración económica y extraeconómica. La remuneración económica puede ser directa e indirecta; directa es el pago de salarios, bonos, comisiones, entre otros; indirecta se considera el plan de beneficios sociales que brinda la organización u otros similares. La compensación extraeconómica está compuesta por toda iniciativa por parte de la organización que, aunque no es económica, procura la satisfacción del trabajador.

La gestión moderna de compensaciones variables es una herramienta fundamental para una llevar una gestión eficaz y competitiva.

\subsubsection{Compensación total.}

Compensación es la suma de todos los mecanismos que la empresa utiliza para retribuir a sus colaboradores; por lo tanto, cuando hablamos del término compensación nos referimos a algo más que los pagos efectuados en forma de sueldos. 
Podemos referirnos a compensación total como el paquete integral que una organización otorga a sus empleados. Según las últimas tendencias mundiales este paquete se encuentra compuesto por:

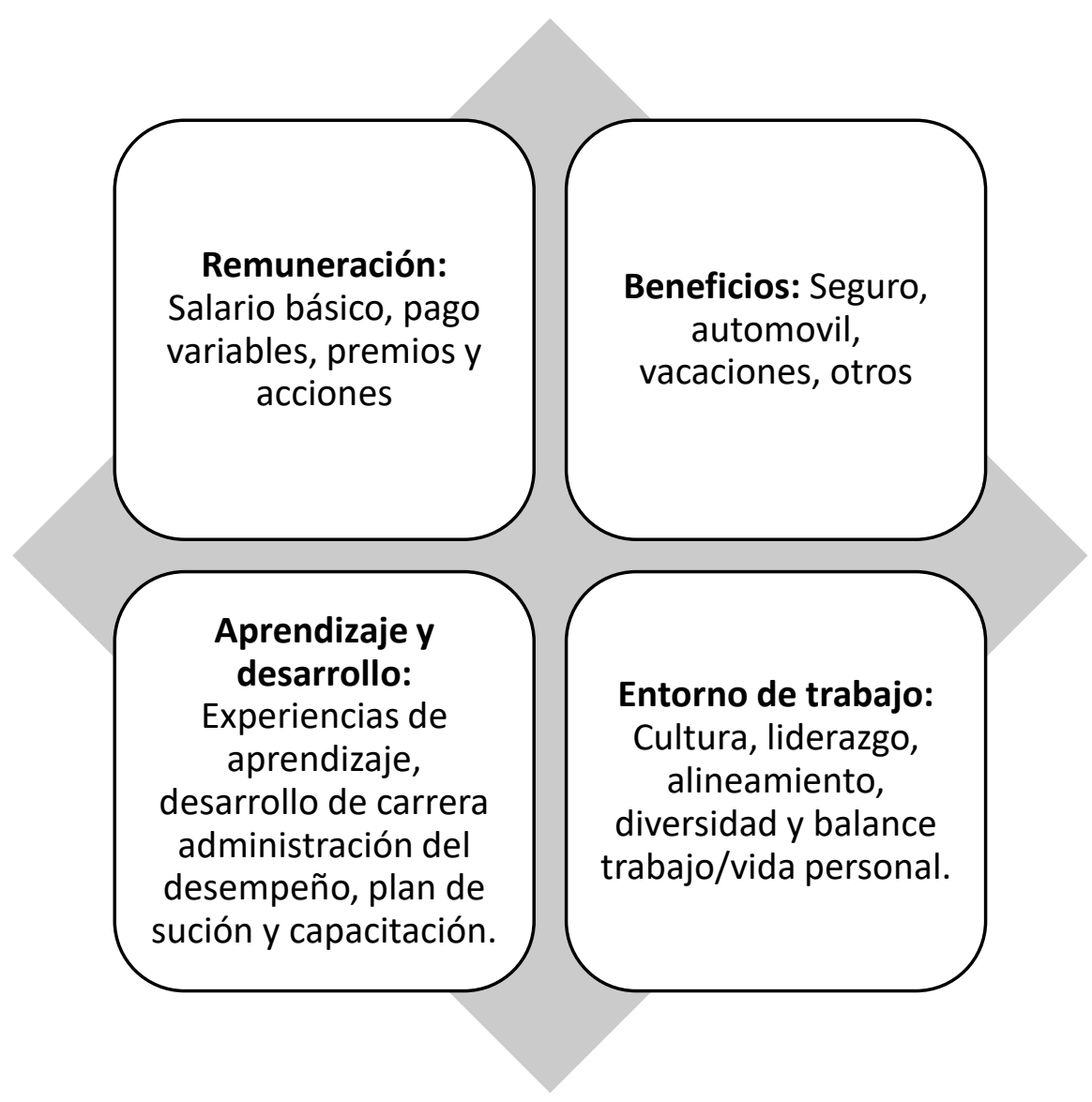

Figura 83 Paquete de compensación total a los empleados según las últimas tendencias.

Lograr armar una estructura de compensación adecuada requiere de dedicación, sin embargo, puede traernos múltiples beneficios, como:

- Atraer personal calificado: Hoy en día la competencia en el mercado laboral es muy alta por lo que las compensaciones deben ir de acuerdo a la oferta y demanda que se experimenta en el mercado. 
- Retener a los empleados actuales: Si tiene una alta tasa de rotación, se debe revisar el paquete de compensaciones, es muy probable que esa sea la razón.

- Garantizar la equidad: Debemos buscar mantener la equidad interna, esto quiere decir: "igual retribución a igual categoría de puesto". Igualmente debemos buscar mantener la competitividad externa, lo que significa: "cubrir a los miembros de la organización con una compensación similar al promedio (o referente que la organización decidida utilizar) que obtienen los empleados con funciones análogas en otras organizaciones comparables.

- Alentar el desempeño sobresaliente: Realizar un trabajo optimo es un resultado esperado, sin embargo, realizar un trabajo sobresaliente debe ser compensado, de forma que se sienta motivados a hacerlo cada vez mejor y contribuyan al logro de objetivos.

- Generar un valor agregado: La remuneración no debe ser tomada como un gasto sino como una inversión en las personas, quienes generan un valor agregado en las organizaciones y un retorno de la inversión en forma de resultados.

Debemos tener en cuenta que quien trabaja como empleado de una empresa grande, mediana o pequeña se pregunta si lo que se le paga es justo, además de cuestionarse si no estaría mejor haciendo lo mismo, pero como empleado de una empresa más grande.

\subsubsection{Salario emocional.}

La irrupción de los millennnials en el mercado laboral ha hecho que gran parte de los patrones de empleo más clásicos hayan evolucionado. Muchos de estos jóvenes apuestan por una conciliación real entre las vida personal y laboral, dejando atrás la 
idea que "el trabajo es lo más importante". Si bien la remuneración económica es fundamental, el salario emocional cumple un papel importante cuando hablamos de motivación y retención de talento. La clave para aplicar este sistema es la coherencia, es decir, la aplicación de técnicas de salario emocional implica tener una estrategia empresarial a largo plazo.

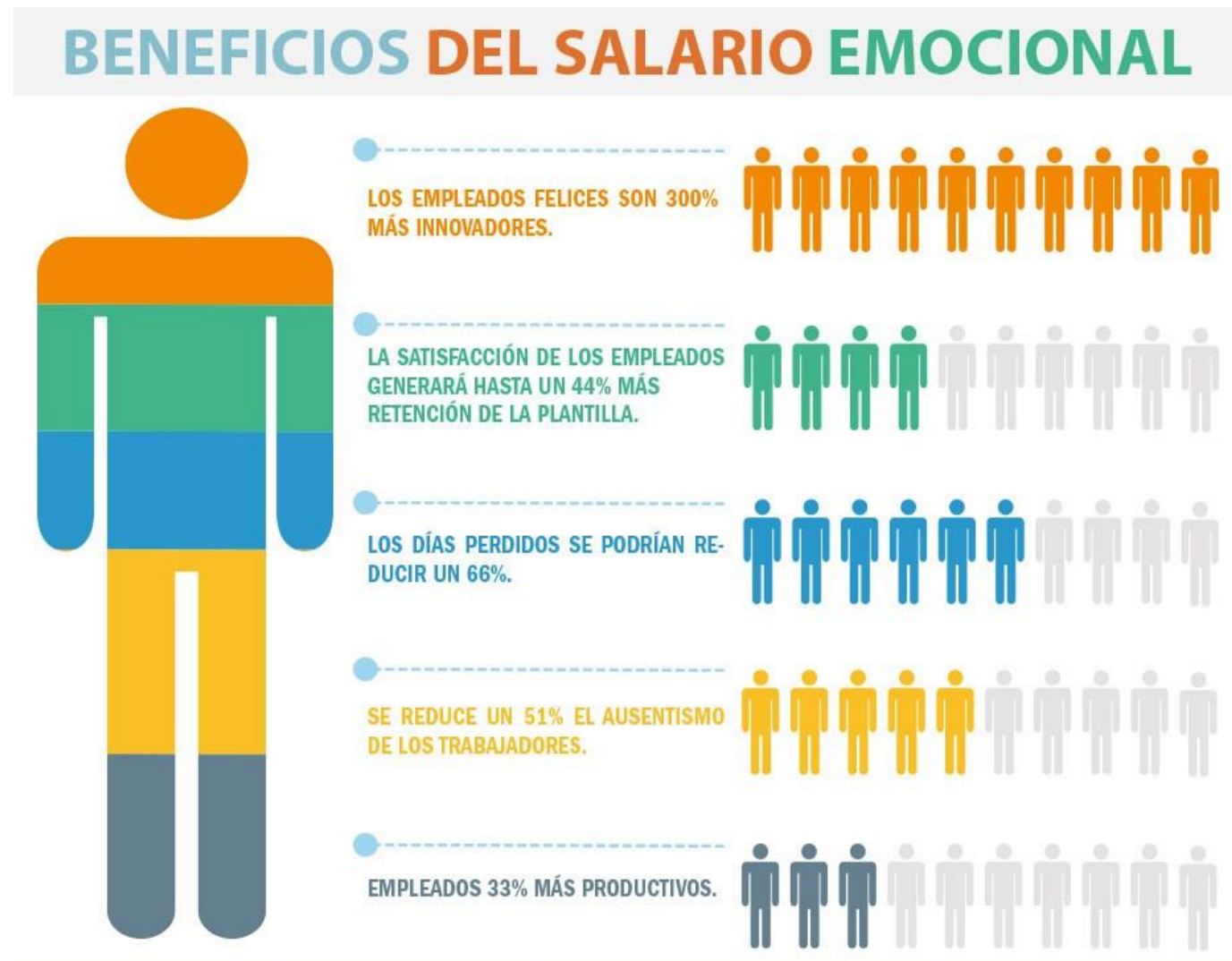

LOS COLABORADORES ESTARÁN MOTIVADOS EN OBTENER NUEVOS CONOCIMIENTOS QUE CONTRIBUYAN AL DESARROLLO DE SUS ACTIVIDADES DIARIAS.

MEJORA EN EL AMBIENTE LABORAL.

Figura 84 Beneficios del salario emocional. Recuperado de http://aevum.com.mx/

\subsubsection{Remuneración del personal}

El Ministerio de Trabajo y Promoción del Empleo se encarga de realizar anualmente la Encuesta de Demanda Ocupacional (EDO), en base a la cual se preparar el informe denominado Demanda de Ocupaciones a Nivel Nacional, dicho 
informe nos brinda información real acerca de las necesidades de mano de obra del sector empresarial, sobre todo de la demanda de ocupaciones y sus remuneraciones promedio, así como de las características de los trabajadores tales como edad, sexo, nivel educativo, capacitación específica requerida, entre otros. La población objetivo de la EDO está definida por el conjunto de empresas privadas formales con 20 a más trabajadores a nivel nacional, siendo nosotros una empresa que está considerada dentro de las MIPYME con menos de 10 trabajadores, debemos acudir a otras fuentes de información, ya que dicha información podría distorsionar nuestra evaluación.

El INEI, en base a los datos provenientes de la Encuesta Económica Anual 2017, elabora anualmente la publicación "Perú: Características Económicas y Financieras de las Empresas de Servicios", siendo la última publicación la que corresponde al periodo 2017, la cual nos brinda información clasificada por actividad económica sobre las características del sector empresarial del país, tales como: Ventas anuales, número de trabajadores, remuneraciones, egresos, inversión, volúmenes producidos, entre otros, clasificando la información según el segmento empresarial.

Según los datos brindados los trabajadores de las empresas de servicios recibieron un promedio de 2,900 soles mensuales en el año 2016. Por segmento empresarial dicha información va a tener ciertas variaciones, los trabajadores de las grandes empresas recibieron en promedio 3,317 soles, los de la mediana empresa 2,309 soles y los de la pequeña empresa 2,216 soles. 


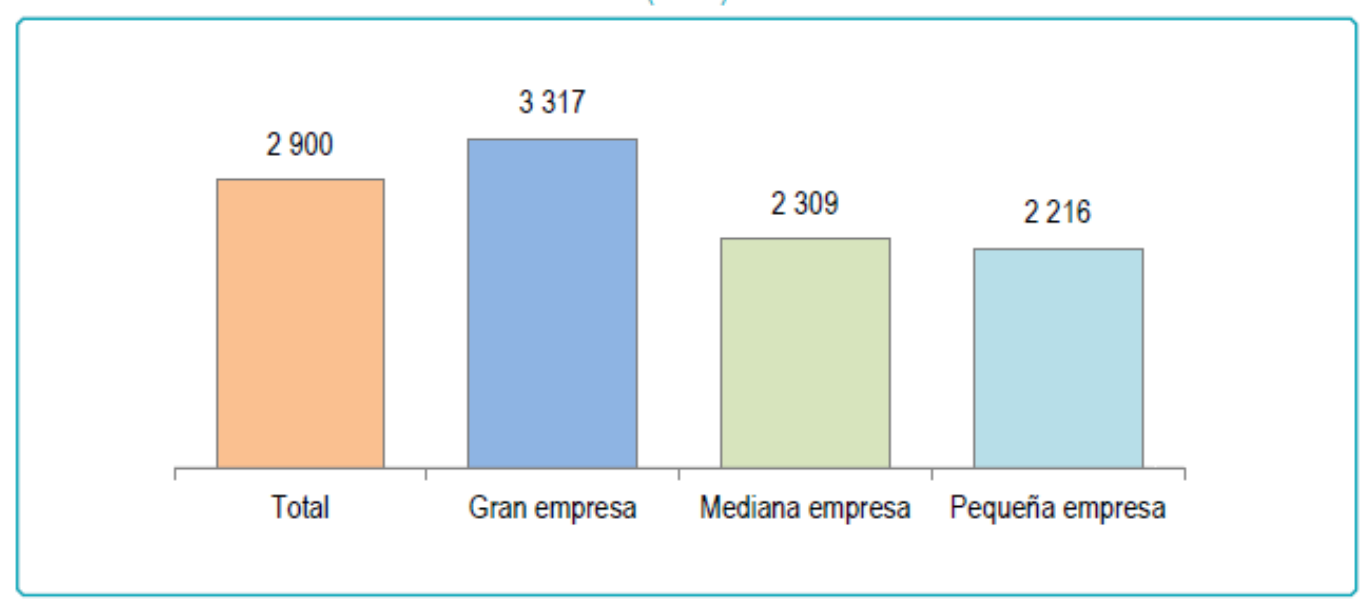

Figura 85 Perú: Remuneración promedio mensual de las empresas de servicios, según segmento empresarial, 2016. Datos tomados del Instituto Nacional de Estadística e Informática - INEI Encuesta Económica Anual 2017.

Según la actividad económica, durante el año 2016, la mayor remuneración promedio al recibieron los empleados de las empresas de servicios eléctricos con 11,619 soles y los de menor promedio mensual fueron los de servicios de comidas y bebidas con 1,346 soles. 


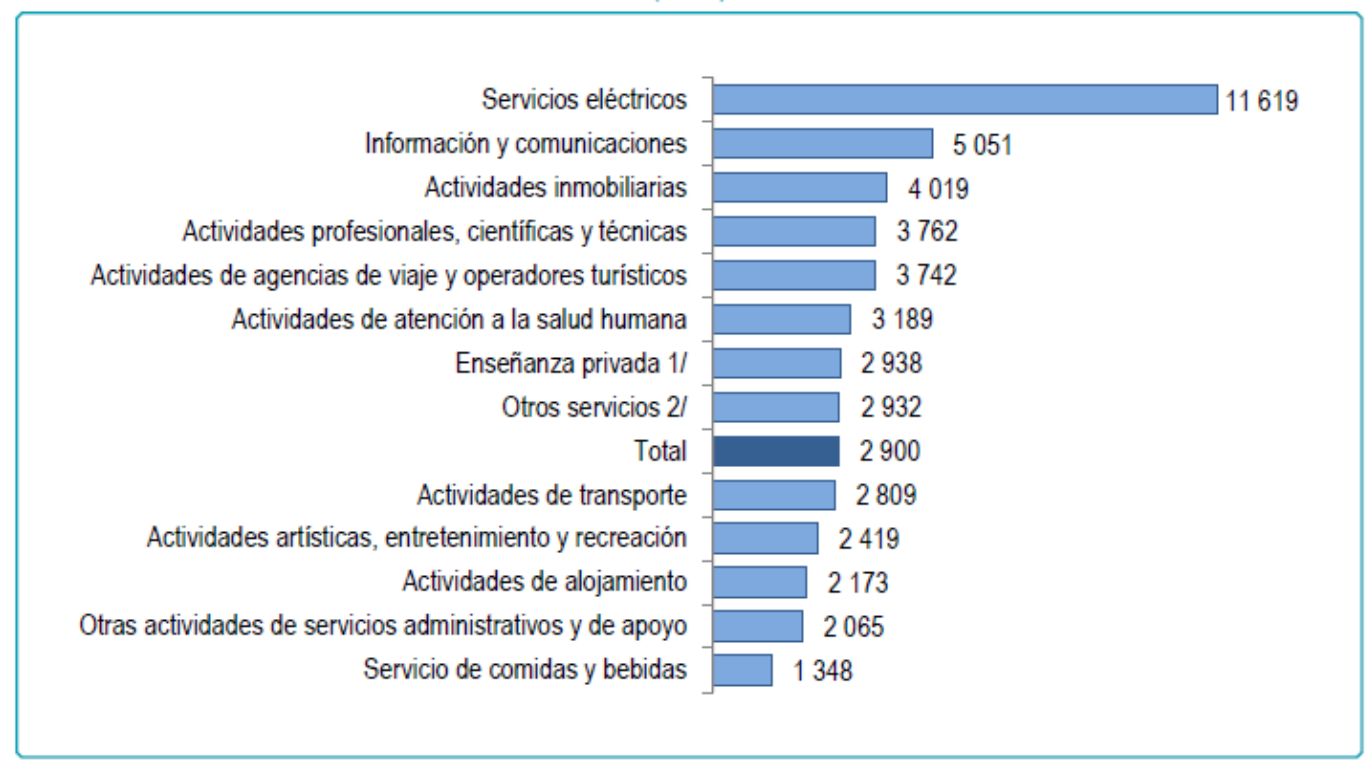

1/ Comprende los centros educativos privados y universidades privadas.

2/ Incluye actividades funerarias, servicios de lavanderia, reparación y mantenimiento de aparatos domésticos y equipos informáticos, suministro de agua, recuperación de materiales y otros.

Figura 86 Perú: Remuneración promedio mensual de las empresas de servicios, según actividad económica, 2016. Datos tomados del Instituto Nacional de Estadística e Informática - INEI Encuesta Económica Anual 2017.

Así mismo, tenemos información por segmento empresarial según la actividad económica, en la que observamos que, en la mediana empresa, aquellas que brindan servicios de información y comunicaciones se obtiene el mayor promedio mensual de 6,370 soles, siendo nuevamente los servicios de comidas y bebidas los de menor promedio mensual con 1,238 soles.

Por otro lado, en la pequeña empresa, son los servicios eléctricos los de mayor promedio con 5,027 soles y el servicio de comidas y bebidas el de menor promedio con 1,385 soles 
PERU: REMUNERACION PROMEDIO MENSUAL DE LAS EMPRESAS DE SERVICIOS, POR SEGMENTO EMPRESARIAL, SEGÚN ACTIVIDAD ECONÓMICA, 2016 (Soles)

\begin{tabular}{|c|c|c|c|c|}
\hline \multirow{2}{*}{ Actividad económica } & \multicolumn{4}{|c|}{ Remuneración promedio mensual } \\
\hline & Total & Gran empresa & Mediana empresa & Pequeña empresa \\
\hline Total & 2900 & 3317 & 2309 & 2216 \\
\hline Servicios eléctricos & 11619 & 11781 & 4359 & 5027 \\
\hline Actividades de transporte & 2809 & 3378 & 2049 & 2078 \\
\hline Actividades de alojamiento & 2173 & 2656 & 2415 & 1641 \\
\hline Servicio de comidas y bebidas & 1348 & 1346 & 1238 & 1385 \\
\hline Información y comunicaciones & 5051 & 6190 & 6370 & 2632 \\
\hline Actividades inmobiliarias & 4019 & 4816 & 4009 & 2805 \\
\hline Actividades profesionales, cientificas y técnicas & 3762 & 4236 & 4840 & 2978 \\
\hline Actividades de servicios administrativos y de apoyo & 2100 & 2149 & 1852 & 2031 \\
\hline Actividades de agencias de viaje y operadores turísticos & 3742 & 4555 & 5834 & 2820 \\
\hline Otras actividades de servicios administrativos y de apoyo & 2065 & 2109 & 1841 & 2003 \\
\hline Enseñanza privada $1 /$ & 2938 & 3368 & 2055 & 1806 \\
\hline Actividades de atención a la salud humana & 3189 & 3351 & 2691 & 2949 \\
\hline Actividades artisticas, entretenimiento y recreación & 2419 & 2531 & 2144 & 2302 \\
\hline Otros servicios $2 /$ & 2932 & 3505 & 1794 & 2208 \\
\hline
\end{tabular}

Figura 87 Perú: Remuneración promedio mensual de las empresas de servicios, por segmento empresarial, según actividad económica, 2016. Datos tomados del Instituto Nacional de Estadística e Informática - INEI Encuesta Económica Anual 2017.

Según PRODUCE, el ingreso que obtienen mensualmente los empleados de una microempresa representa cerca del $40 \%$ del ingreso obtenido por los empleados de empresas grandes, lo cual refleja la existencia de brechas significativas entre los ingresos de diferentes estratos empresariales (Cámara de Comercio e Industria de Arequipa, 2018). 


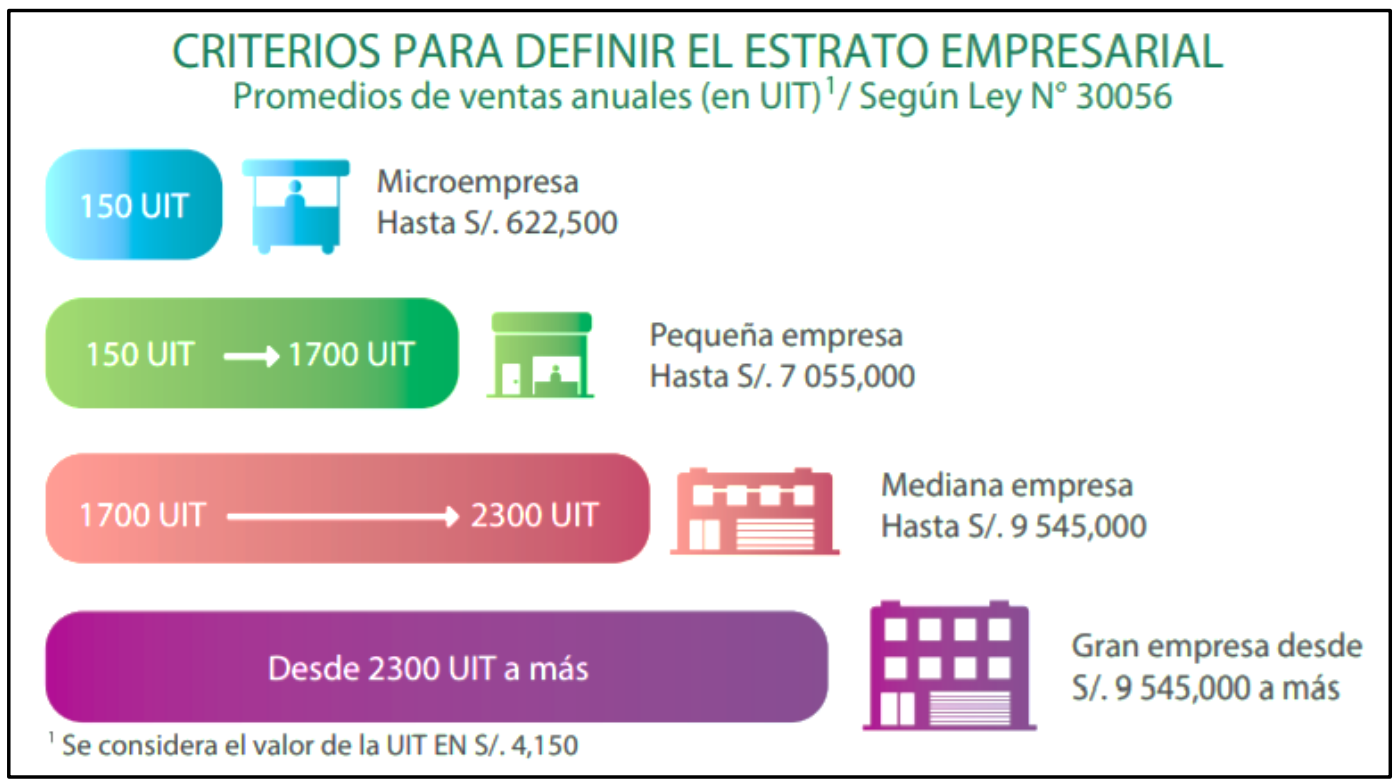

Figura 88 Criterios para definir el estrato empresarial. Recuperado de https://www.camara-arequipa.org.pe/

Considerando que, según nuestros ingresos proyectados, nos encontramos dentro del segmento empresarial de la Microempresa, requerimos de opiniones de expertos, como dueños de restaurantes que pertenecen a la pequeña empresa, en esta oportunidad pudimos contactarnos con la dueña de pollerías El Colorado, María Astorga de Ortiz, según la entrevista realizada nos dice que su personal labora la jornada máxima de 8 horas, con un día de descanso y las remuneraciones en sus restaurantes son como sigue:

Tabla 45

Escala remunerativa restaurantes El Colorado.

\begin{tabular}{lr}
\hline \multicolumn{1}{c}{ Cargo } & Remuneración \\
\hline Hornero & $\mathrm{S} / .1,000.00$ \\
Cocinero & $\mathrm{S} / .1,000.00$ \\
Asistente de Cocina & $\mathrm{S} / .930 .00$ \\
Mozo & $\mathrm{S} / .930 .00$ \\
Cajero & $\mathrm{S} / .1,150.00$ \\
\hline
\end{tabular}

Elaboración propia 
En este proyecto estamos considerando contar con cinco colaboradores

permanentes bajo la modalidad de contrato de inicio de actividades laborando menos de ocho horas diarias de lunes a viernes, un médico nutricionista y un contador contratado de manera externa.

Para tomar esta decisión fue necesario tener en cuenta el segmento empresarial en el que nos encontramos, evaluar diferentes aspectos internos como el tamaño de la empresa, la capacidad económica y financiera, el desempeño y la competitividad de la empresa y aspectos externos como la economía de la ciudad de Arequipa, la situación del mercado, los informes obtenidos respecto a la remuneración promedio mensual por segmentos y la legislación laboral peruana para micro y pequeñas empresas.

Tabla 46

Recurso humano - Mano de obra directa (expresado en soles).

\begin{tabular}{|c|c|c|c|c|c|c|c|c|c|c|c|c|c|}
\hline \multirow{2}{*}{$\begin{array}{l}\text { DESCRIPCION } \\
\text { Cocinero }\end{array}$} & \multirow{2}{*}{$\begin{array}{c}\text { TIPO DE } \\
\text { COSTO } \\
\text { Fijo }\end{array}$} & \multicolumn{2}{|c|}{$\begin{array}{c}\text { COSTO } \\
\text { MENSUAL }\end{array}$} & \multicolumn{2}{|c|}{ ESSALUD } & \multicolumn{2}{|c|}{ VACACIONS } & \multicolumn{2}{|c|}{$\begin{array}{c}\text { GRATIFICA } \\
\text { C }\end{array}$} & \multirow{2}{*}{\multicolumn{2}{|c|}{$\begin{array}{l}\text { CTS } \\
\text { / } 53.47\end{array}$}} & \multirow{2}{*}{$\begin{array}{c}\text { TOTAL } \\
\text { S/ } 1,398.63\end{array}$} & \multirow{2}{*}{$\begin{array}{c}\begin{array}{c}\text { TOTAL } \\
\text { ANUAL }\end{array} \\
\text { S/ } 16,783.62\end{array}$} \\
\hline & & $\mathrm{S} /$ & $1,100.00$ & $\mathrm{~S} /$ & & $\mathrm{S} /$ & & & 99.92 & & & & \\
\hline Cocinero 1 & Fijo & S/ & $1,100.00$ & $\mathrm{~S} /$ & 99.00 & $\mathrm{~S} /$ & 46.25 & & 99.92 & S/ & 53.47 & $\mathrm{~S} / 1,398.63$ & S/ $16,783.62$ \\
\hline Asistente de cocina & Fijo & S/ & 950.00 & $\mathrm{~S} /$ & 86.00 & $\mathrm{~S} /$ & 39.94 & $\mathrm{~S} /$ & 86.33 & S/ & 46.18 & S/ $1,208.45$ & S/ $14,501.44$ \\
\hline & Fijo & $\mathrm{S} /$ & 500.00 & $\mathrm{~S} /$ & 84.00 & $\mathrm{~S} /$ & - & $\mathrm{S} /$ & 48.67 & $\mathrm{~S} /$ & - & 632.67 & $7,592.00$ \\
\hline Asistente de cocina 1 & Fijo & S/ & 500.00 & S/ & 84.00 & $\mathrm{~S} /$ & - & $\mathrm{S} /$ & 48.67 & S/ & - & 632.67 & S/ $\quad 7,592.00$ \\
\hline
\end{tabular}

Elaboración propia

Tabla 47

Recurso humano - Administración (expresado en soles).

\begin{tabular}{|c|c|c|c|c|c|c|c|c|c|c|c|}
\hline DESCRIPCION & $\begin{array}{l}\text { TIPO DE } \\
\text { COSTO }\end{array}$ & $\begin{array}{c}\text { COSTO } \\
\text { MENSUAL }\end{array}$ & ES: & SALUD & & $\begin{array}{l}\text { CACIONE } \\
\quad S\end{array}$ & GR & $\begin{array}{l}\text { ATIFICA } \\
\text { C }\end{array}$ & CTS & TOTAL & $\begin{array}{l}\text { TOTAL } \\
\text { ANUAL }\end{array}$ \\
\hline Administrador & Fijo & S/ $\quad 1,100.00$ & S/ & 99.00 & $\mathrm{~S} /$ & 46.25 & $\mathrm{~S} /$ & 99.92 & S/ 53.47 & S/ 1,398.63 & S/ $16,783.62$ \\
\hline $\begin{array}{l}\text { Asistente administr } \\
\text { (tiempo parcial) }\end{array}$ & Fijo & 500.00 & $\mathrm{~S} /$ & 84.00 & $\mathrm{~S} /$ & - & $\mathrm{S} /$ & 48.67 & $\mathrm{~S} /$ & 632.67 & S/ $\quad 7,592.04$ \\
\hline
\end{tabular}

Elaboración propia 
Tabla 48

Recurso humano - Ventas (expresado en soles).

\begin{tabular}{|c|c|c|c|c|c|c|c|c|c|c|c|c|c|c|c|}
\hline \multirow{2}{*}{$\begin{array}{l}\text { DESCRIPCION } \\
\text { Repartidor } 1 \\
\text { (Tiempo Parcial) }\end{array}$} & \multirow{2}{*}{$\begin{array}{c}\text { TIPO DE } \\
\text { COSTO } \\
\text { Fijo }\end{array}$} & \multicolumn{2}{|c|}{$\begin{array}{c}\text { COSTO } \\
\text { MENSUAL }\end{array}$} & \multicolumn{2}{|c|}{ ESSALUD } & \multicolumn{2}{|c|}{$\begin{array}{c}\text { VACACIONE } \\
S \\
\end{array}$} & \multicolumn{2}{|c|}{$\begin{array}{c}\text { GRATIFICA } \\
\text { C } \\
\end{array}$} & \multicolumn{2}{|c|}{ CTS } & \multicolumn{2}{|c|}{ TOTAL } & \multirow{2}{*}{\multicolumn{2}{|c|}{$\begin{array}{c}\text { TOTAL } \\
\text { ANUAL } \\
\text { S/ } 7,592.00\end{array}$}} \\
\hline & & $\mathrm{S} /$ & 500.00 & S/ & 84.00 & $\mathrm{~S} /$ & - & S/ & 48.67 & $\mathrm{~S} /$ & - & $\mathrm{S} /$ & 632.67 & & \\
\hline $\begin{array}{l}\text { Repartidor } 2 \\
\text { (Tiempo Parcial) }\end{array}$ & Fijo & $\mathrm{S} /$ & 500.00 & $\mathrm{~S} /$ & 84.00 & $\mathrm{~S} /$ & - & $\mathrm{S} /$ & 48.67 & S/ & - & $\mathrm{S} /$ & 632.67 & $\mathrm{~S} /$ & $7,592.00$ \\
\hline $\begin{array}{l}\text { Repartidor } 3 \\
\text { (Tiempo Parcial) }\end{array}$ & Fijo & S/ & 500.00 & S/ & 84.00 & $\mathrm{~S} /$ & - & $\mathrm{S} /$ & 48.67 & S/ & - & $\mathrm{S} /$ & 632.67 & $\mathrm{~S} /$ & $7,592.00$ \\
\hline $\begin{array}{l}\text { Repartidor } 4 \\
\text { (Tiempo Parcial) }\end{array}$ & Fijo & S/ & 500.00 & S/ & 84.00 & $\mathrm{~S} /$ & - & S/ & 48.67 & S/ & - & S/ & 632.67 & $\mathrm{~S} /$ & $7,592.00$ \\
\hline
\end{tabular}

Elaboración propia

En el caso del repartidor, será requisito indispensable para contratarlo que, cuente con moto propia y con los documentos en regla.

Según el análisis realizado en las principales páginas de empleos, encontramos tres casos con respecto al personal de reparto que cuenta con moto propia:

1. Recibe una remuneración fija, y la empresa se encarga de pagar el combustible;

2. Pago de remuneración fija más gasto de movilidad que oscila entre 100 y 120 soles, dicho pago por movilidad no forma parte de la base de cálculo para beneficios sociales.

3. Pago de entre 3 y 4 soles solo por pedidos, sin percibir una remuneración fija ni beneficios sociales, similar al pago que realizan las aplicaciones de servicio delivery a sus socios repartidores.

Según la entrevista realizada al representante de pollerías El Colorado, experta en el rubro, nos dice que su empresa opta por la tercera opción, una persona que se encargue de realizar los repartos y gane en función a los pedidos repartidos, que es muy común últimamente porque genera menos costos a la empresa. 
En nuestro caso optaremos por la segunda opción, contratar a los repartidores con un sueldo fijo más un costo de uso del vehículo y beneficios según ley.

\subsection{Política de Recursos Humanos}

La forma en que la organización trata a sus miembros es fundamental para el logro de objetivos organizacionales, ya que les brinda apoyo para el logro de sus objetivos personales. "Las políticas varían enormemente de una organización a otra. Cada organización desarrolla la política de recursos humanos más adecuada a su filosofía y a sus necesidades (...)". (Chiavenato, 2007, p.121)

Así, si hablamos de una política de Recursos Humanos que cumpla con todo lo necesario, es decir, debe abarcar los objetivos organizacionales respecto de cinco aspectos principales (Chiavenato, 2007).

\begin{tabular}{|c|c|c|c|c|}
\hline Integración & Organización & Retención & Desarrollo & Auditoría \\
\hline $\begin{array}{l}\text { Quién trabajará } \\
\text { en la organización }\end{array}$ & $\begin{array}{l}\text { Qué harán las } \\
\text { personas en la } \\
\text { organización }\end{array}$ & $\begin{array}{l}\text { Cómo retener a } \\
\text { las personas que } \\
\text { trabajan en la } \\
\text { organización }\end{array}$ & $\begin{array}{l}\text { Cómo preparar } \\
\text { y desarrollar a las } \\
\text { personas dentro de } \\
\text { la organización }\end{array}$ & $\begin{array}{l}\text { Cómo saber lo } \\
\text { que hacen las } \\
\text { personas }\end{array}$ \\
\hline $\begin{array}{l}\text { - Investigación } \\
\text { de mercado } \\
\text { - Reclutamiento } \\
\text { - Selección }\end{array}$ & $\begin{array}{l}\text { - Programa } \\
\text { de inducción } \\
\text { - Diseño de } \\
\text { puestos } \\
\text { - Evaluación del } \\
\text { desempeño }\end{array}$ & $\begin{array}{l}\text { - Remuneración } \\
\text { - Prestaciones } \\
\text { sociales } \\
\text { - Higiene y } \\
\text { seguridad } \\
\text { - Relaciones } \\
\text { sindicales }\end{array}$ & $\begin{array}{l}\text { - Capacitación } \\
\text { - Desarrollo } \\
\text { organizacional }\end{array}$ & $\begin{array}{l}\text { - Sistema de } \\
\text { información } \\
\text { - Controles y } \\
\text { auditorías de } \\
\text { personal }\end{array}$ \\
\hline
\end{tabular}

Figura 89 Proceso global de la administración de recursos humanos. Tomada del libro Administración de recursos humanos (Chiavenato, 2007).

Para el proyecto que estamos desarrollando, y para cualquier organización, la persona es la base para el desarrollo del mismo y su trabajo alineado a la cultura organizacional de la empresa nos llevara al logro de los objetivos, es así que se plantearon las siguientes políticas: 


\subsubsection{Políticas de integración}

Las fuentes de reclutamiento de talento humano para iniciar actividades serán páginas web especializadas en búsqueda de empleo, redes sociales, bolsas de trabajo de institutos de gastronomía y por referencias.

El reclutamiento después de iniciadas las actividades, podrá ser fuera y dentro de la organización.

Los criterios de selección serán de acuerdo a las capacidades y competencias que se especificaron en el descriptivo de puesto, así como su predisposición para cumplir las funciones que le correspondería.

Se realizarán reuniones a inicio de semana, para tener un feedback de la semana anterior y planificación de la que está iniciando; así mismo, éstas tendrán el objetivo de integrar a los miembros de la organización procurando un clima laboral amigable.

\subsubsection{Políticas de organización}

Analizar cada puesto definiendo conocimientos, habilidades, requisitos, competencias y funciones, con el fin de diseñar su descriptivo o perfil y poder contratar a la persona adecuada para el puesto adecuado.

El personal de cocina podrá rotar o ser promovido según los resultados de sus evaluaciones de desempeño.

La evaluación de desempeño al personal será constante, se tomarán en cuenta las opiniones de sus superiores, subordinados (si es que lo tuvieran), pares y clientes. 


\subsubsection{Políticas de retención}

Las remuneraciones serán equitativas según el puesto y competitivas en el mercado, así mismo estarán alineadas a la regularización y normativa legal vigente

El desempeño sobresaliente, la iniciativa y la capacidad de ejecutar y contribuir serán reconocidos y recompensados.

Nuestro personal son parte fundamental de la organización, por lo que su opinión será siempre tomada en cuenta; así, se le comunicaran los objetivos y cualquier modificación planteada para que se sienta parte de ello.

Las labores se llevaran a cabo en un ambiente idóneo para ellos cumpliendo todas las normas de salud y seguridad, así como, contar con el espacio suficiente en donde se puedan instalar muebles y las herramientas de trabajo, permitiendo que el colaborador pueda moverse libremente y pueda evacuar fácilmente ante una emergencia, las áreas de trabajo deben contar con la ventilación e iluminación suficiente sea natural o artificial, de acuerdo a la necesidad, escritorios y sillas ergonómicos, limpieza y organización, pisos adecuados según la labor que realicen y mantener una temperatura confortable.

\subsubsection{Políticas de desarrollo}

Planificar capacitaciones periódicas específicas según el puesto, y como resultado de las evaluaciones realizadas.

Planificar talleres de integración y desarrollo de habilidades blandas para el personal en general. 


\subsubsection{Políticas de auditoria}

Evaluar periódicamente las políticas de recursos humanos de la organización, verificando que se ajusten a la realidad de la organización.

Evaluar los descriptivos de puestos, separando a las características del puesto a las de la persona que lo ocupa, para evitar errores al momento de seleccionar personal.

Mantener siempre la base de datos de información relacionada a recursos humanos actualizada. 


\section{CAPÍTULO IX}

\section{Planificación Financiera}

La planificación financiera marca las pautas y la forma en cómo se lograrán los objetivos estratégicos de la organización; así mismo, constituye la base de su actividad económica. Cuando hablamos de planificación, nos referimos a la acción de anticiparnos a las necesidades futuras y satisfacer las presentes; enfocándose también en aumentar la rentabilidad, establecer el capital de trabajo necesario, flujo de efectivo, financiamiento requerido, proyecciones de ventas y control de gastos. "La planeación financiera es un aspecto importante de las operaciones de la empresa porque brinda rutas que guían, coordinan y controlan las acciones de la empresa para lograr sus objetivos" (Gitman \& Zutter, 2012, p.117).

\subsection{La inversión.}

Cuando hablamos de inversión nos referimos al aporte de recursos que se hace en un proyecto con el objetivo de obtener rentabilidad, es decir, nos genere ganancia en el corto o largo plazo. Esta inversión se realizará en base a datos proyectados según el estudio realizado anteriormente; el monto requerido será básicamente para la adquisición de activos tangibles e intangibles y para el capital de trabajo requerido para el inicio de operaciones. "Una inversión es esencialmente cualquier instrumento en el que se depositan fondos con la expectativa de que genere ingresos positivos y/o conserve o aumente su valor" (Gitman, 2009, p.3).

\subsubsection{Inversión pre-operativa.}

La inversión pre-operativa engloba todo desembolso necesario que se realiza en el periodo cero antes de iniciar operaciones y sin los cuales no podría llevarse a cabo el 
proyecto. "El término inversión inicial se refiere a las salidas iniciales de efectivo necesarias para emprender una inversión de capital” (Gitman \& Zutter, 2012, p.400).

En este caso específico la inversión inicial será en gastos pre-operativos (trámites en general) y activo fijo tangible e intangible.

\subsubsection{Activo fijo tangible.}

El activo fijo está compuesto por todos los recursos o bienes necesarios para el proceso de producción del bien final y operación optima de la organización. Dentro de esta clasificación están:

- Equipos y utensilios de cocina: Adquisición de equipamiento y utensilios necesarios para el funcionamiento de la cocina según las ventas proyectadas.

- Habilitación local: Se alquilará un local adecuado para el funcionamiento del centro de servicios donde funcionara tanto el área de producción, como la de administración, es por ello que se tendrá que habilitar el espacio alquilado según la distribución ya diseñada anteriormente. Dentro de esta habilitación está considerado todos los ajustes de seguridad según lo solicitado por la municipalidad para obtener las licencias.

- Equipo y mobiliario de oficina: Forman parte de esta subdivisión los equipos y muebles necesarios para ambientar una oficina administrativa lo suficientemente cómoda y organizada.

- Mobiliario: Se incluye en esta sección el mobiliario diverso para asegurar la comodidad, seguridad y clima agradable para nuestros colaboradores.

El detalle del activo fijo tangibles se encuentra en el anexo V. 
La depreciación del activo fijo se realizará según los porcentajes

establecidos en el inciso b) del artículo $22^{\circ}$ del Reglamento del TUO de la Ley del Impuesto a la Renta.

Tabla 49

Tabla de porcentajes de depreciación

\begin{tabular}{lc}
\hline \multicolumn{1}{c}{ BIENES } & $\begin{array}{c}\text { PORCENTAJE ANUAL } \\
\text { MÁXIMO DE } \\
\text { DEPRECIACIÓN }\end{array}$ \\
\hline 1. Ganado de trabajo y reproducción; redes de pesca & $25 \%$ \\
2. Vehículos de transporte terrestre (excepto ferrocarriles); & $20 \%$ \\
hornos en general & \\
3. Maquinaria y equipo utilizados por las actividades minera, & $20 \%$ \\
petrolera y de construcción, excepto muebles, enseres y & \\
equipos de oficina & $25 \%$ \\
4. Equipos de procesamiento de datos & $10 \%$ \\
5. Maquinaria y equipo adquirido a partir del 1.1.1991 & $10 \%$ \\
6. Otros bienes del activo fijo &
\end{tabular}

Elaboración propia

Tabla 50

Activo fijo tangible (expresado en soles).

\begin{tabular}{lr}
\hline DESCRIPCION & \multicolumn{1}{c}{ TOTAL } \\
\hline VEHICULOS MOTORIZADOS & $3,500.00$ \\
MAQUINARIA Y EQUIPO & $10,340.00$ \\
MUEBLES Y ENSERES & $14,100.00$ \\
EQUIPOS DIVERSOS & $3,500.00$ \\
\hline TOTAL ACTIVO FIJO TANGIBLE & S/ $\mathbf{3 1 , 4 4 0 . 0 0}$ \\
\hline
\end{tabular}

Elaboración propia

\subsubsection{Activo fijo intangible.}

Se considera activo intangible a aquel que es identificable, pero no tiene apariencia física. En este caso se considerarán como tal aquellos servicios, investigaciones, derechos, registros y demás adquisiciones no tangibles que se 
realizaron para el funcionamiento normal de la empresa. Para nuestro proyecto serán los siguientes:

- Gastos pre-operacionales: Gastos para la constitución legal de la empresa, licencias y permisos especiales del rubro al que pertenecemos, registro del nombre en SUNARP y todo desembolso relacionado a trámites legales para el inicio de operaciones.

- Recursos informáticos: Se contará con una página web para la promoción del producto y con software de ventas para el control y facturación de las ventas realizadas.

- Gastos de investigación: Se incluye principalmente el desembolso realizado para el estudio de mercado, capacitaciones, diseño de logo, cartillas y publicidad inicial.

Tabla 51

Activo Fijo Intangible (expresado en soles).

\begin{tabular}{|c|c|}
\hline DESCRIPCION & TOTAL \\
\hline GASTOS PRE-OPERACIONALES & $10,078.00$ \\
\hline RECURSOS INFORMATICOS & $3,150.00$ \\
\hline GASTOS DE CAPACITACION E INVESTIGAC & $7,120.00$ \\
\hline TOTAL ACTIVO FIJO INTANGIBLE & S/ $20,348.00$ \\
\hline
\end{tabular}

Elaboración propia

\subsubsection{Inversión en capital de trabajo.}

Determinar la inversión en el capital de trabajo de forma correcta es fundamental para el éxito del negocio. Cuando se calcula el total de la inversión tomar en cuenta solo los activos fijos necesarios para su funcionamiento sería un gran error, determinar el capital de trabajo es igual de importante para financiar los desfases en 
la caja sobre todo durante el inicio de las operaciones, de lo contrario el proyecto podría fracasar.

Existen tres métodos para el cálculo del capital de trabajo: el método contable, el del periodo de desfase y el del déficit acumulado máximo.

El método usado en este proyecto será el déficit acumulado. Éste es considerado el más exacto de los tres métodos mencionados porque supone la ocurrencia de variación en la producción, venta o compras de insumos que influyan en las proyecciones; consiste en determinar cuál es el máximo déficit que se origina producto de la diferencia entre ingresos y egresos durante un periodo de 12 meses (Sapag, 2011). 
Tabla 52

Capital de Trabajo (expresado en soles).

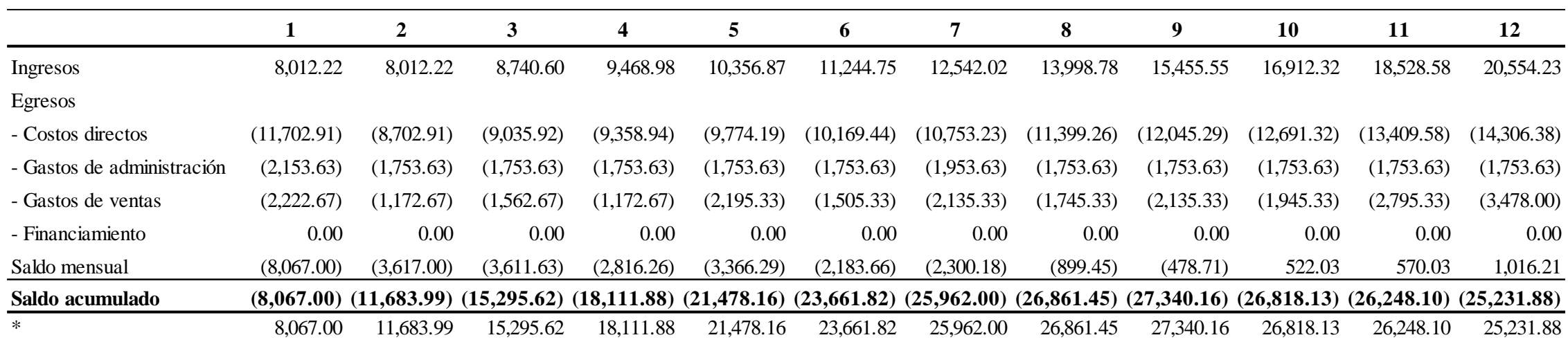

Elaboración propia

En el flujo de efectivo presentado, evaluando los doce primeros meses, para determinar el capital de trabajo inicial,

podemos observar que en el mes de mayo se da el máximo déficit acumulado de S/ 27,340.16, de esta forma fijamos este

valor como el capital de trabajo necesario para iniciar operaciones. El pago del servicio brindado es al contado por lo que

los ingresos a caja son iguales a las ventas. 


\subsubsection{Costo del proyecto.}

Considerando la inversión en activos tangibles e intangibles necesarios para la operación del negocio, e incluyendo el capital de trabajo que evite el fracaso del mismo, el monto requerido en calidad de inversión es S/ 79,128.16.

Tabla 53

Inversión total del proyecto (expresado en soles).

\begin{tabular}{|c|c|c|}
\hline DESCRIPCION & $\begin{array}{c}\text { MONTO } \\
\text { TOTAL } \\
\end{array}$ & $\begin{array}{c}\text { PORCENT } \\
\% \\
\end{array}$ \\
\hline INVERSION TANGIBLE & $31,440.00$ & $39.73 \%$ \\
\hline INVERSION INTANGIBLE & $20,348.00$ & $25.72 \%$ \\
\hline CAPITAL DE TRABAJO & $27,340.16$ & $34.55 \%$ \\
\hline INVERSION TOTAL & S/ $79,128.16$ & $100 \%$ \\
\hline
\end{tabular}

Elaboración propia

\subsubsection{Inversiones futuras.}

Las inversiones que se realicen una vez puesto en marcha el proyecto, se realizara de forma independiente a la inversión inicial y serán financiadas con las utilidades producto de las operaciones corrientes. Son básicamente inversiones en activos para su reemplazo o por crecimiento de operaciones; aquellas que son por reemplazo no siempre coinciden con la depreciación total del bien adquirido inicialmente, ya que el método utilizado es el reglamentado por Ley y no siempre coincide con el deterioro normal del mismo. Así mismo, están también aquellas que son productos del incremento de colaboradores por aumento de operaciones según las proyecciones realizadas. 
Tabla 54

Inversiones futuras en activos tangibles (expresado en soles).

\begin{tabular}{|c|c|c|c|c|c|}
\hline DESCRIPCION & AÑO 1 & AÑO 2 & AÑO 3 & AÑO 4 & AÑO 5 \\
\hline \multicolumn{6}{|c|}{ INVERSION TANGIBLE } \\
\hline Freidor electrico de aire & & & 800.00 & & \\
\hline Licuadora & & & 700.00 & & \\
\hline Procesador de alimentos & & & & 300.00 & \\
\hline Utensilios varios & 300.00 & 300.00 & 300.00 & 300.00 & 300.00 \\
\hline Balanza gramera & & & 90.00 & & \\
\hline Laptop & & & & $2,000.00$ & \\
\hline Equipo celular administración & & 100.00 & & 100.00 & \\
\hline Equipo celular ventas & & 100.00 & & 150.00 & \\
\hline Cajas de delivery para motos & & & 200.00 & & \\
\hline Sillas & & & 200.00 & & \\
\hline Sillas (vestidores) & & & 100.00 & & \\
\hline TOTAL & S/ 300.00 & 500.00 & $\mathrm{~S} / 2,390.00$ & $\mathrm{~S} / \mathbf{2 , 8 5 0 . 0 0}$ & $\mathrm{S} / \mathbf{3 0 0 . 0 0}$ \\
\hline
\end{tabular}

Elaboración propia

\subsection{Financiamiento.}

La inversión total en el proyecto es de S/ 79,128.16, siendo su elemento más importante los activos fijos por un valor de S/ 31,440.00 representando el 39.73\%, seguido por el activo fijo intangible por S/ 20,348.00 que representa el $25.72 \%$ y finalmente el capital de trabajo necesario para iniciar operaciones S/ 27,340.16 que significa el 34.55\%.

Teniendo ya determinado el monto total de la inversión para el proyecto, debemos definir cuál será la estructura del capital, en el mercado actual tenemos tres modelos: financiamiento propio, financiamiento externo y financiamiento mixto.

Al optar por un financiamiento externo total o mixto nos enfrentamos a una clara incertidumbre de pago como consecuencia del compromiso obtenido y eso es denominado también riesgo financiero. Conforme mayor sea la proporción de financiamiento externo, mayor será el riesgo financiero; tener en cuenta que la incapacidad para el pago de las obligaciones pueden ocasionar la quiebra de la organización. 
Muchas empresas en el mercado usan el financiamiento bancario como una fuente importante de financiamiento; sin embargo, esto ya no es tan recomendado por la inestabilidad en la economía y las consecuencias que podría traer el incumplimiento de sus obligaciones, de hecho muchas empresas grandes y de diferentes industrias prefieren reducir al mínimo sino es que eliminar la deuda, por ejemplo, Starbucks, Intel, Intuit, Coach, EMC y Symantec tienen menos de 3\% de deuda en sus estructuras de capital. Además, Centex, QLogic, Altera, Forest Labs, KLA-Tencor y Robert Half International tienen poca o ninguna deuda a largo plazo en absoluto (Gitman, 2009).

Teniendo la información necesaria y al ser una empresa que está iniciando operaciones, ofreciendo un producto y un servicio que está entrando recién al mercado es poco probable que una entidad financiera nos brinde financiamiento bancario y, sobre todo, no lo consideramos necesario para poder emprender el proyecto, es por ello que se consideró que el $100 \%$ de la estructura de capital corresponderá a aportes propios.

\section{Tabla 55}

Financiamiento (expresado en soles).

\begin{tabular}{lcr}
\hline \multicolumn{1}{c}{ FUENTE DE } & $\%$ & \multicolumn{1}{c}{ MONTO } \\
FINANCIAMIENTO & & \multicolumn{1}{c}{} \\
\hline Propio & $100 \%$ & $79,128.16$ \\
Externo & $0 \%$ & 0.00 \\
\hline \multicolumn{1}{c}{ TOTAL } & & S/ $\mathbf{7 9 , 1 2 8 . 1 6}$ \\
\hline
\end{tabular}

Elaboración propia

\subsubsection{Capital y costo de oportunidad.}

Un concepto importante cuando queremos evaluar un proyecto es el costo de oportunidad y lo definimos como la rentabilidad que está dejando de obtener el inversionista, producto de otras posibles inversiones, por destinarlo al proyecto 
evaluado. Teniendo claro a que nos referimos cuando hablamos de costo de oportunidad podemos pasar a definir el costo de capital como "aquel porcentaje que representa el costo del financiamiento de una compañía y es la tasa mínima de rendimiento que debe ganar un proyecto" (Gitman \& Zutter, 2012, p.333).

Cuando hablamos de tasa mínima de rendimiento nos referimos a la tasa de retorno exigida, que compensa el costo de oportunidad de los recursos invertidos en el proyecto y el riesgo que se asume. Con esta tasa se descuentan los flujos de efectivo proyectados para traerlos a valor presente y obtener el valor actual de éstos. Es importante que el proyecto evaluado tengo una tasa mayor a la del costo de capital, de lo contrario no convendría invertir en el mismo. El costo de capital obtenido muestra el costo promedio del total del fondo invertido, sin distinguir la fuente de procedencia.

Se determina una tasa que pueda ser considerada como el equivalente a una tasa libre de riesgo y que sea representativa de la mejor opción segura a la que podría acceder el inversionista, a la cual se le agrega una prima por cada tipo de riesgo asociado específicamente con el proyecto. (Sapag, 2011, p.372)

En nuestro caso el proyecto será financiado en su totalidad con capital propio, por lo que el total del activo es igual al total del patrimonio y el costo de capital del inversionista es igual al costo del capital desapalancado.

Debemos tener en cuenta que un inversionista estaría dispuesto a depositar sus recursos en un proyecto solo si éste le proporciona una rentabilidad mayor que la que obtendría invirtiendo en un activo financiero con un riego equivalente; sin embargo, 
es casi improbable que dos o más opciones de inversión tengan riesgos similares por lo que deberá realizarse un ajuste por riesgo.

El riesgo asociado con una inversión se define por su beta $(\beta)$, que es el factor de medida de riesgo metódico de invertir en la industria.

La rentabilidad esperada o costo de capital del proyecto se calculará mediante el modelo CAPM (Capital assets price model), que señala que la tasa exigida de rentabilidad es igual a la tasa libre de riesgo más una prima por riesgo

$$
K e=R_{F}+\beta_{\text {Sector }}\left(R_{M}-R_{F}\right)
$$

Dónde:

Ke: costo de capital del proyecto

Rf: activo libre de riesgo

$\beta u$ : beta al cual pertenece el proyecto

Rm: rendimiento promedio del mercado

En el Perú, como en varios países emergentes, no se desarrollan COK consistentes con un mercado eficiente, dado que no tenemos datos históricos ni confiables de rentabilidad en el mercado de acciones, y ha habido cambios considerables en la economía. Nuestro mercado de capitales tiene como índice el S\&P/GBVL, el cual corresponde a un índice de mercado pequeño (emergente), se recomienda recurrir a estimaciones internacionales como las de Estados Unidos. Sin embargo, el resultado que obtendríamos pueden no reflejar la realidad del proyecto ya que estamos usando 
datos de países con riesgo diferente al nuestro, es por esto que deberá hacerse un ajuste adicional adicionándole el valor del riesgo país y aplicar la fórmula para cambiar el resultado de dólares americanos a soles peruanos.

$$
K e=R_{F}+\beta_{\text {Sector }}\left(R_{M}-R_{F}\right)+R_{P}+\left[\left(\frac{1+\pi_{P E R u ́}}{1+\pi_{E E U U}}\right)-1\right]
$$

Donde

Rp: Riesgo país medido por el EMBI

Primero el activo libre de riesgo (Rf) la obtendremos del promedio del rendimiento de bonos emitidos por el Tesoro de los Estado Unidos de Norte América durante los últimos 10 años. Debemos tener en cuenta que, a mediados del año 2011 EEUU atravesó la denominada "Crisis del Techo de deuda", esto debido a que el país norteamericano llegó a su límite de endeudamiento acordado en el Congreso, por lo que debían decidir si se elevaba para hacer frente al vencimiento de las deudas pendientes o si se hacía real la suspensión de pagos de la deuda.

Tradicionalmente se considera que los bonos soberanos de este país, como los alemanes, son los más estables en época de turbulencias para los inversores, debido a que las probabilidades de que incurran en un impago son escazas. Pero esta circunstancia estuvo por cambiar y esto se vio reflejado en el rendimiento de los bonos durante ese periodo como podemos observar en el siguiente gráfico. 


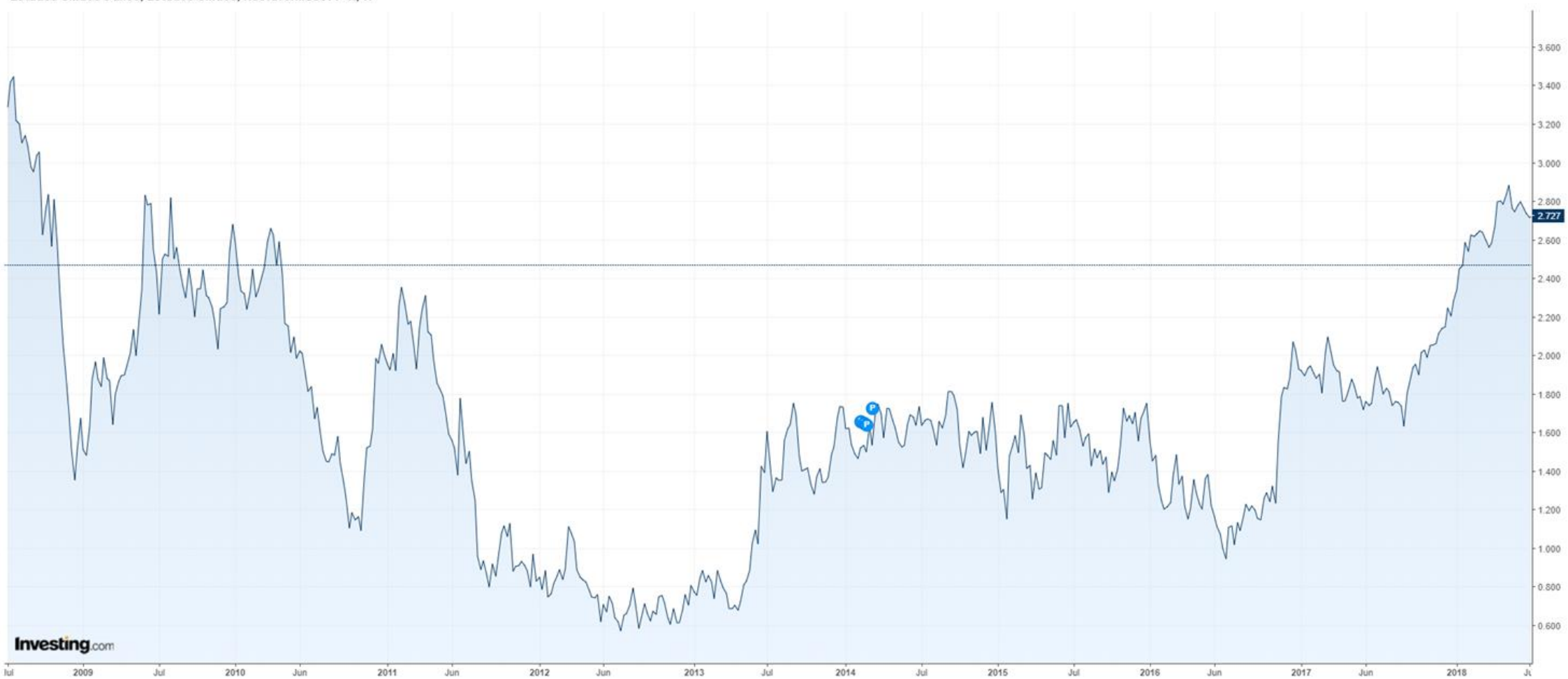

Figura 90 Gráfico de la rentabilidad del bono de Estados Unidos 5 años durante los últimos 10 años. Recuperado de https://es.investing.com/rates-bonds/u.s.-5-year-bond-yield-streaming-chart 
Tomando en cuenta esta información, procederemos a calcular el promedio de los rendimientos, dejando de lado los datos que van desde el periodo de julio del 2011 a abril del 2013, en los cuales se observaron las mayores variaciones porcentuales en los rendimientos. El promedio resultante según el Anexo VIII es 1.837 (www.es.investing.com/rates-bonds/u.s.-5-year-bond-yield-historical-data)

Segundo, el beta desapalancado ( $\beta \mathrm{u}$ ), tomado de los datos publicados por el profesor Aswath Damodaran en el Anexo XII (www.stern.nyu.edu/ adamodar), del sector restaurantes actualizada a Enero de 2018 es 0.85 .

Tercero, la tasa de retorno esperada para el mercado ( $\mathrm{Rm})$, decidimos tomar el rendimiento promedio del mercado norteamericano según el índice DJIA (Dow Jones Index Average). Para el cálculo del promedio debemos tomar en cuenta que EEUU atravesó en el 2008 una de sus peores crisis financieras, lo que entre otras cosas resulto en la debilitación del mercado bursátil, quiebra de bancos y grandes empresas de diferentes rubros, es en el 2010 que la situación de los mercados bursátiles empiezan a repuntar como podemos observar en la Figura 71, es por ello que para el cálculo del promedio del rendimiento del mercado solo tomaremos en cuenta los datos a partir del año 2010. El promedio resultante según el Anexo IX es 17.03 (www.investing.com/indices/us-30-historical-data) 


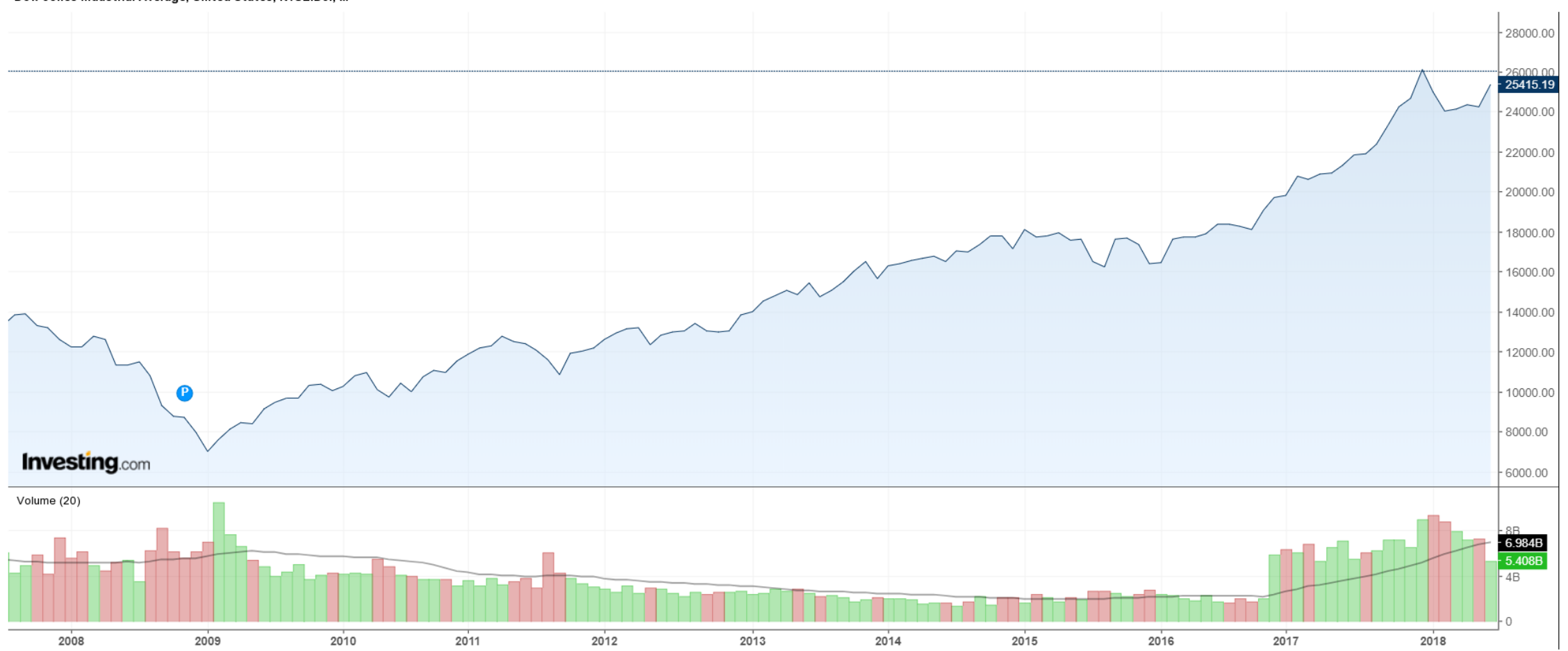

Figura 91 Promedio rendimiento de la industria según Dow Jones Industrial Average de los ultimos 10 años. Recuperado de https://www.investing.com/indices/us-30-chart 
Cuarto, prima por riesgo país (Rp), tomamos el promedio de la información de los últimos 10 años publicado por la empresa financiera JP Morgan. Tomando en cuenta que, la crisis financiera norteamericana del 2008 mencionada anteriormente, se vio reflejada en las economías de los países alrededor del mundo, los datos del riesgo país de este periodo se vieron afectados, por lo que los datos del cuarto trimestre del 2008 al tercer trimestre del 2009 no serán tomados en cuenta. El promedio calculado del riesgo país según el Anexo X es 1.708 (https://www.ambito.com/contenidos/riesgo-pais-peru.html).

Finalmente, debemos convertir a soles el resultado, ya que los valores utilizados corresponden a EEUU por lo que, se encuentran en dólares americanos. El valor promedio de la tasa de inflación de EEUU y de Perú de los últimos 10 años es $1.64 \%$ y $2.96 \%$, respectivamente según el Anexo XI.

Entonces, siguiendo con la aplicación del modelo CAPM según los datos obtenidos, aplicaremos la siguiente fórmula para hallar el COK nominal USA:

$$
C O K_{U S A}=R f+\beta u *(R m-R f)
$$

Dónde:

$$
\begin{gathered}
R f=1.8371 \\
\beta u=0.85 \\
R m=17.06 \\
\operatorname{COK}_{U S A}=1.8371+0.85 *(17.06-1.8371) \\
\operatorname{COK}_{U S A}=14.7783 \%
\end{gathered}
$$


Una vez que tenemos el COK nominal de USA, se procede a obtener el COK nominal de Perú, para lo cual hay que agregarle el riesgo país, aplicando la siguiente fórmula:

$$
C O K_{P E R U} U S \$=C O K_{U S A}+\text { Riesgo país }
$$

Dónde:

$$
\begin{gathered}
\text { Riesgo país }=1.708 \% \\
C O K_{R E A L}=14.7783 \% \\
C O K_{P E R U} U S \$=16.4863 \%
\end{gathered}
$$

El COK obtenido se encuentra en dólares, entonces para convertirlo de dólares USA a soles peruanos debemos aplicar la siguiente fórmula:

$$
\operatorname{COK}_{P E R U} S /=\operatorname{COK}_{P E R U} U S \$+[[1+\operatorname{Inf} . \text { Perú }) /(1+\operatorname{Inf} . U S A]-1]
$$

Dónde:

$$
\begin{gathered}
\text { Inflación Perú }=2.96 \% \\
\text { Inflación } U S A=1.64 \% \\
\text { COK }{ }_{P E R U} U S \$=16.4863 \% \\
\text { COK }_{P E R U} S /=16.4863 \%+\left[\frac{(1+2.96 \%)}{(1+1.64 \%)}-1\right] \\
\operatorname{COK}_{P E R U} S /=17.7760 \%
\end{gathered}
$$

Finalmente, habiendo obtenido el COK en soles, se le debe sumar un riesgo adicional por ser un proyecto nuevo, en este caso se le adicionara un riesgo del $2 \%$.

$$
C O K_{\text {Proyecto }}=C O K_{P E R U} S /+ \text { Riesgo Nuevo Proyecto }
$$

Dónde:

$$
\text { Riesgo Nuevo Proy. }=2 \%
$$




$$
\begin{gathered}
\operatorname{COK}_{P E R U} S /=17.7760 \% \\
\text { COK }_{\text {Proyecto }}=\text { COK }_{P E R U} S /+ \text { Riesgo Nuevo Proyecto } \\
\text { COK }_{\text {Proyecto }}=17.7760 \%+2 \% \\
\text { COK }_{\text {Proyecto }}=19.7760 \%
\end{gathered}
$$

La tasa obtenida para el costo de capital del proyecto es de $19.7760 \%$, la cual será empleada para la posterior evaluación de la rentabilidad económica - financiera del proyecto planteado, independientemente de quien lo haga.

\subsection{Presupuesto base.}

Según Burbano (2005) el presupuesto es la estimación proyectada de forma metódica, de las operaciones y resultados que se alcanzaran en un periodo determinado; así mismo, a través de éste se expresa cuantitativamente los objetivos planteados por la administración de la organización para el periodo evaluado, apoyándose en la ejecución de las estrategias adecuadas para lograrlos.

Esta proyección se trata básicamente de costear cada uno de los gastos y costos inevitables y proyectar los ingresos más acordes a la realidad, según los estudios de mercado, para que sea considerado factible en el tiempo y así obtener los estados financieros y resultados del proyecto. En este caso se está considerando un incremento en los precios del $4.20 \%$ anual a partir del año 2, basados en el crecimiento del PBI proyectado para el 2019. 


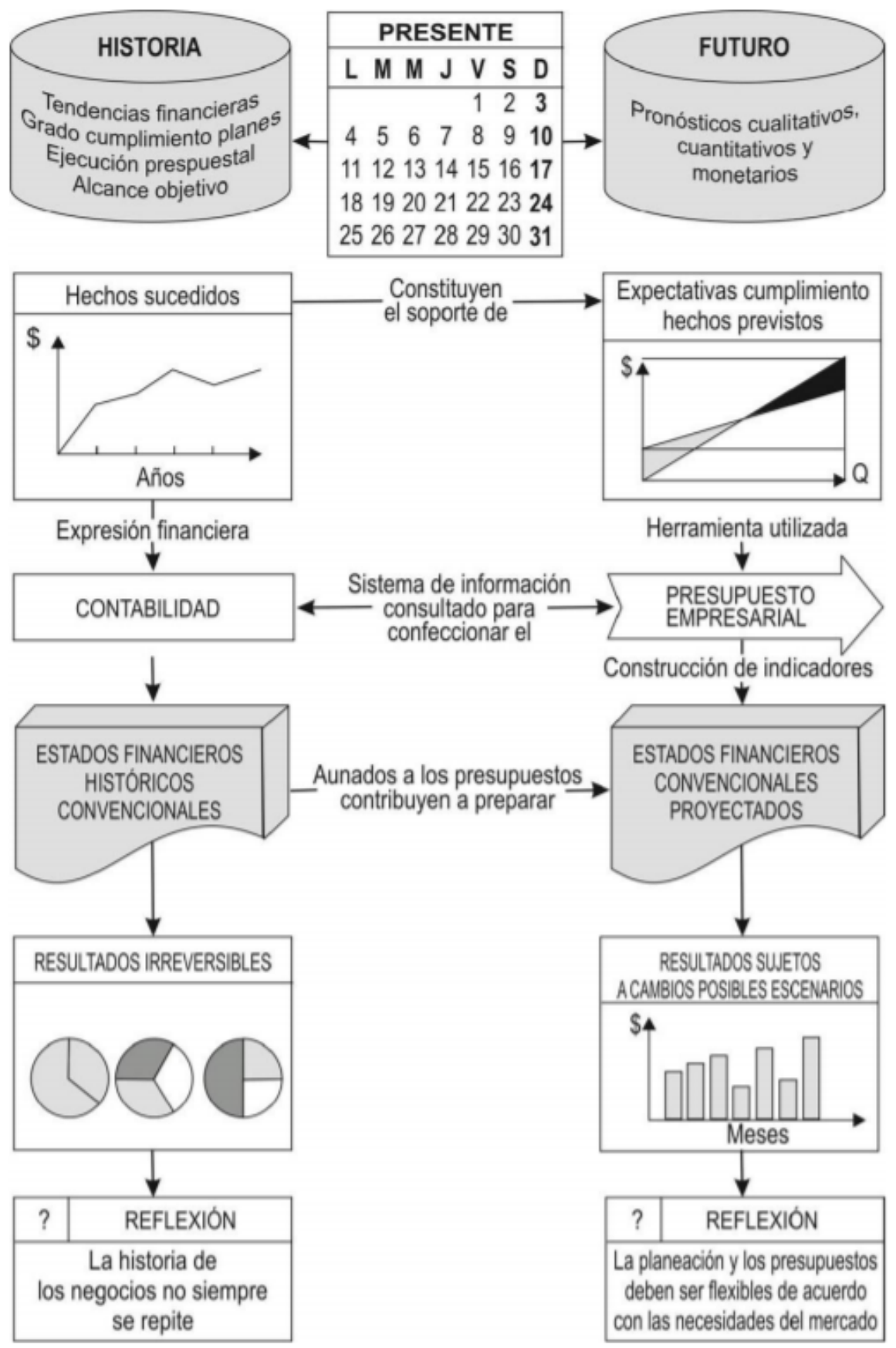

Figura 92 Diagrama comparativo del presupuesto a través del tiempo. Tomado de Presupuestos. Enfoque de gestión, planeación y control de recursos (Burbano, 2005).

En esta la figura 62 se muestra cual es la función que cumple el presupuesto empresarial, incorporando elementos básicos para su ejecución como: Expresión 
cuantitativa, planificación operativa, proyección de resultados, tiempo determinado y control de resultados.

Los elementos principales del presupuesto son:

Integrador: El presupuesto no se realiza solo para un área o ciertas actividades, sino que se toma todo como una unidad y se dirigen las estrategias hacia el logro del objetivo general de la organización.

Coordinador: Las actividades o planes para las áreas no son preparadas de forma aislada sino deben ser parte de un engranaje y desarrollarse en armonía.

En términos monetarios: debe ser expresado en unidades monetarias, en nuestro proyecto todo está expresado en la moneda oficial del país.

Operaciones: Una característica principal de los presupuestos es el cálculo, más exacto y detallado posible, de los gastos que se van a realizar e ingresos que nos proyectamos a obtener durante el periodo evaluado,

Recursos: Aun cuando ya hemos proyectado los ingresos y gastos, esto no es suficiente la empresa debe planificar aquellos recursos necesarios para su operación, lo cual se ha planteado en los presupuestos de inversión.

Ventajas de los presupuestos

Horngren (2012) refiere que los presupuestos tienen un rol importante en los sistemas de control administrativo y si son aplicados de la forma correcta pueden lograr:

- La coordinación entre las áreas y actividades que se realizan dentro de la organización, de la mejor forma posible para el logro de objetivos; así mismo, 
asegurarse de que todos los miembros de la organización conozcan los objetivos y se sientan parte de ellos.

- Medir el desempeño real contra el planeado. Desechando la práctica errónea de comparar resultados actuales con datos históricos, ya que estos traen consigo errores cometidos y condiciones sociales y económicas diferentes a las actuales.

- Motivar y mejorar el desempeño de todos los colaboradores de la organización, dado que ellos percibirán como un fracaso el hecho de no lograr las cifras presupuestadas.

\subsubsection{Presupuesto de ventas.}

Es la predicción de las ventas de la empresa durante un periodo determinado, basándose en información interna y externa; se considera información determinante para el proceso de planificación financiera (Gitman \& Zutter, 2012).

Las proyecciones de ventas realizadas se hicieron basándonos en el estudio de mercado realizado. El precio fue fijado, como ya se explicó anteriormente, en base al promedio existente en el mercado, todos los ingresos se consideran al contado por lo que las ventas son iguales a los ingresos en caja.

El presupuesto de ventas resumido para los cinco años que se está evaluando el proyecto es como sigue: 
Tabla 56

Presupuesto de ventas (expresado en soles).

\begin{tabular}{lccccc}
\hline \multicolumn{1}{c}{ INGRESOS } & AÑO 1 & AÑO 2 & AÑO 3 & AÑO 4 & AÑO 5 \\
\hline Demanda mensual almuerzos diarios (promedio) & 351 & 608 & 717 & 831 & 963 \\
Demanda mensual almuerzos coorporativos (promedio) & 140 & 243 & 287 & 332 & 385 \\
Demanda mensual almuerzos interdiarios (promedio) & 392 & 676 & 796 & 923 & 1,069 \\
Demanda anual almuerzos diarios & 4,598 & 7,965 & 9,390 & 10,880 & 12,606 \\
Demanda anual almuerzos coorporativos & 1,839 & 3,186 & 3,756 & 4,352 & 5,042 \\
Demanda anual almuerzos interdiarios & 5,136 & 8,844 & 10,427 & 12,081 & 13,997 \\
\hline Precio & $\mathbf{1 4 . 5 0}$ & $\mathbf{1 5 . 1 1}$ & $\mathbf{1 5 . 7 4}$ & $\mathbf{1 6 . 4 0}$ & $\mathbf{1 7 . 0 9}$ \\
Crecimiento de precio & & $4.20 \%$ & $4.20 \%$ & $4.20 \%$ & $4.20 \%$ \\
\hline Ingreso Almuerzos diarios & 61,115 & 110,323 & 135,483 & 163,559 & 197,481 \\
Ingreso Almuerzos coorporativos & 24,446 & 44,129 & 54,193 & 65,424 & 78,993 \\
Ingreso Almuerzos interdiarios & 68,266 & 122,502 & 150,439 & 181,615 & 219,281 \\
\hline Ventas (miles de soles) & $\mathbf{S / ~} \mathbf{1 5 3 , 8 2 7 . 1 2}$ & S/ $\mathbf{2 7 6 , 9 5 4 . 7 8}$ & S/ 340,114.55 & S/ 410,597.93 & S/ $\mathbf{4 9 5 , 7 5 5 . 3 3}$ \\
\hline
\end{tabular}

\section{Elaboración propia}


Tabla 57

Presupuesto de ventas mensual - Año 1 (expresado en soles).

\begin{tabular}{|c|c|c|c|c|c|c|c|c|c|c|c|c|}
\hline & 1 & 2 & 3 & 4 & 5 & 6 & 7 & 8 & 9 & 10 & 11 & 12 \\
\hline Cantidad clientes diarios & 11 & 11 & 12 & 13 & 14 & 15 & 17 & 19 & 21 & 23 & 25 & 28 \\
\hline Cantidad clientes coorporativos & 4 & 4 & 5 & 5 & 6 & 6 & 7 & 8 & 8 & 9 & 10 & 11 \\
\hline Cantidad clientes interdiarios & 22 & 22 & 24 & 26 & 29 & 32 & 35 & 39 & 43 & 47 & 52 & 57 \\
\hline Cantidad mensual diarios & 242 & 242 & 264 & 286 & 308 & 330 & 374 & 418 & 462 & 506 & 550 & 616 \\
\hline Cantidad mensual coorporativos & 97 & 97 & 106 & 114 & 123 & 132 & 150 & 167 & 185 & 202 & 220 & 246 \\
\hline Cantidad mensual interdiarios & 264 & 264 & 288 & 312 & 348 & 384 & 420 & 468 & 516 & 564 & 624 & 684 \\
\hline Proporc vacaciones clientes diarios & 20 & 20 & 22 & 24 & 26 & 28 & 31 & 35 & 39 & 42 & 46 & 51 \\
\hline Proporc vacaciones clientes coorpora & 8 & 8 & 9 & 10 & 10 & 11 & 12 & 14 & 15 & 17 & 18 & 21 \\
\hline Proporc vacaciones clientes interdiari & 22 & 22 & 24 & 26 & 29 & 32 & 35 & 39 & 43 & 47 & 52 & 57 \\
\hline Cantidad mensual diarios - vacac & 222 & 222 & 242 & 262 & 282 & 303 & 343 & 383 & 424 & 464 & 504 & 565 \\
\hline Cantidad mensual coorpor - vacac & 89 & 89 & 97 & 105 & 113 & 121 & 137 & 153 & 169 & 186 & 202 & 226 \\
\hline Cantidad mensual interdiarios - vacac & 242 & 242 & 264 & 286 & 319 & 352 & 385 & 429 & 473 & 517 & 572 & 627 \\
\hline
\end{tabular}

14.50

14.5

14.50

14.50

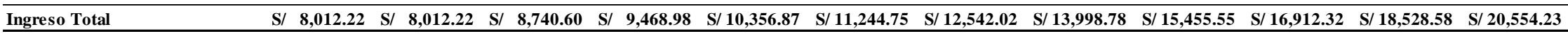

Elaboración propia

Tabla 58

Presupuesto de ventas mensual - Año 2 (expresado en soles).

\begin{tabular}{|c|c|c|c|c|c|c|c|c|c|c|c|c|}
\hline & 1 & 2 & 3 & 4 & 5 & 6 & 7 & 8 & 9 & 10 & 11 & 12 \\
\hline Cantidad diaria cliente comun & 28 & 28 & 28 & 29 & 29 & 29 & 31 & 31 & 31 & 32 & 32 & 32 \\
\hline Cantidad clientes coorporativos & 11 & 11 & 11 & 12 & 12 & 12 & 12 & 12 & 12 & 13 & 13 & 13 \\
\hline Cantidad clientes interdiarios & 57 & 57 & 57 & 60 & 60 & 60 & 63 & 63 & 63 & 66 & 66 & 66 \\
\hline Cantidad mensual diarios & 616 & 616 & 616 & 647 & 647 & 647 & 679 & 679 & 679 & 713 & 713 & 713 \\
\hline Cantidad mensual coorporativos & 246 & 246 & 246 & 259 & 259 & 259 & 272 & 272 & 272 & 285 & 285 & 285 \\
\hline Cantidad mensual interdiarios & 684 & 684 & 684 & 718 & 718 & 718 & 754 & 754 & 754 & 792 & 792 & 792 \\
\hline Proporc vacaciones clientes diarios & 51 & 51 & 51 & 54 & 54 & 54 & 57 & 57 & 57 & 59 & 59 & 59 \\
\hline Proporc vacaciones clientes coorpora & 21 & 21 & 21 & 22 & 22 & 22 & 23 & 23 & 23 & 24 & 24 & 24 \\
\hline Proporc vacaciones clientes interdiari & 57 & 57 & 57 & 60 & 60 & 60 & 63 & 63 & 63 & 66 & 66 & 66 \\
\hline Cantidad mensual diarios - vacac & 565 & 565 & 565 & 593 & 593 & 593 & 623 & 623 & 623 & 654 & 654 & 654 \\
\hline Cantidad mensual coorpor - vacac & 226 & 226 & 226 & 237 & 237 & 237 & 249 & 249 & 249 & 261 & 261 & 261 \\
\hline Cantidad mensual interdiarios - vacac & 627 & 627 & 627 & 658 & 658 & 658 & 691 & 691 & 691 & 726 & 726 & 726 \\
\hline Precio & 15.11 & 15.11 & 15.11 & 15.11 & 15.11 & 15.11 & 15.11 & 15.11 & 15.11 & 15.11 & 15.11 & 15.11 \\
\hline Ingreso Total & $\mathrm{S} / \mathbf{2 1 , 4 1 8 . 9 3}$ & $\mathrm{S} / \mathbf{2 1 , 4 1 8 . 9 3}$ & S/ 21,418.93 & S/ 22,489.88 & $\mathrm{S} / 22,489.88$ & S/ 22,489.88 & S/ 23,614.37 & S/ 23,614.37 & S/ 23,614.37 & $\mathrm{S} / 24,795.09$ & S/ 24,795.09 & S/ 24,795.09 \\
\hline
\end{tabular}

Elaboración propia 
Tabla 59

Presupuesto de ventas mensual - Año 3 (expresado en soles).

\begin{tabular}{|c|c|c|c|c|c|c|c|c|c|c|c|c|}
\hline & 1 & 2 & 3 & 4 & 5 & 6 & 7 & 8 & 9 & 10 & 11 & 12 \\
\hline Cantidad diaria cliente comun & 34 & 34 & 34 & 35 & 35 & 35 & 36 & 36 & 36 & 38 & 38 & 38 \\
\hline Cantidad clientes coorporativos & 13 & 13 & 13 & 14 & 14 & 14 & 14 & 14 & 14 & 15 & 15 & 15 \\
\hline Cantidad clientes interdiarios & 68 & 68 & 68 & 71 & 71 & 71 & 74 & 74 & 74 & 76 & 76 & 76 \\
\hline Cantidad mensual diarios & 740 & 740 & 740 & 768 & 768 & 768 & 796 & 796 & 796 & 826 & 826 & 826 \\
\hline Cantidad mensual coorporativos & 296 & 296 & 296 & 307 & 307 & 307 & 319 & 319 & 319 & 330 & 330 & 330 \\
\hline Cantidad mensual interdiarios & 822 & 822 & 822 & 852 & 852 & 852 & 884 & 884 & 884 & 917 & 917 & 917 \\
\hline Proporc vacaciones clientes diarios & 62 & 62 & 62 & 64 & 64 & 64 & 66 & 66 & 66 & 69 & 69 & 69 \\
\hline Proporc vacaciones clientes coorpora & 25 & 25 & 25 & 26 & 26 & 26 & 27 & 27 & 27 & 28 & 28 & 28 \\
\hline Proporc vacaciones clientes interdiari & 68 & 68 & 68 & 71 & 71 & 71 & 74 & 74 & 74 & 76 & 76 & 76 \\
\hline Cantidad mensual diarios - vacac & 678 & 678 & 678 & 704 & 704 & 704 & 730 & 730 & 730 & 757 & 757 & 757 \\
\hline Cantidad mensual coorpor - vacac & 271 & 271 & 271 & 281 & 281 & 281 & 292 & 292 & 292 & 303 & 303 & 303 \\
\hline Cantidad mensual interdiarios - vacac & 753 & 753 & 753 & 781 & 781 & 781 & 811 & 811 & 811 & 841 & 841 & 841 \\
\hline Precio & 15.74 & 15.74 & 15.74 & 15.74 & 15.74 & 15.74 & 15.74 & 15.74 & 15.74 & 15.74 & 15.74 & 15.74 \\
\hline
\end{tabular}

Precio

$\begin{array}{rrrrrrr}15,797.48 & \text { S/ 26,797.48 } & \text { S/ 26,797.48 } & \text { S/ 27,802.39 } & \text { S/ 27,802.39 } & \text { S/ 27,802.39 }\end{array}$

$15.74 \quad 15.74$

15.74

15.74

15.74

Ingreso Total

Elaboración propia

Tabla 60

Presupuesto de ventas mensual - Año 4 (expresado en soles).

\begin{tabular}{|c|c|c|c|c|c|c|c|c|c|c|c|c|}
\hline & 1 & 2 & 3 & 4 & 5 & 6 & 7 & 8 & 9 & 10 & 11 & 12 \\
\hline Cantidad diaria cliente comun & 39 & 39 & 39 & 40 & 40 & 40 & 42 & 42 & 42 & 44 & 44 & 44 \\
\hline Cantidad clientes coorporativos & 16 & 16 & 16 & 16 & 16 & 16 & 17 & 17 & 17 & 17 & 17 & 17 \\
\hline Cantidad clientes interdiarios & 79 & 79 & 79 & 82 & 82 & 82 & 85 & 85 & 85 & 89 & 89 & 89 \\
\hline Cantidad mensual diarios & 857 & 857 & 857 & 889 & 889 & 889 & 923 & 923 & 923 & 957 & 957 & 957 \\
\hline Cantidad mensual coorporativos & 343 & 343 & 343 & 356 & 356 & 356 & 369 & 369 & 369 & 383 & 383 & 383 \\
\hline Cantidad mensual interdiarios & 952 & 952 & 952 & 988 & 988 & 988 & 1,025 & 1,025 & 1,025 & 1,063 & 1,063 & 1,063 \\
\hline Proporc vacaciones clientes diarios & 71 & 71 & 71 & 74 & 74 & 74 & 77 & 77 & 77 & 80 & 80 & 80 \\
\hline Proporc vacaciones clientes coorpora & 29 & 29 & 29 & 30 & 30 & 30 & 31 & 31 & 31 & 32 & 32 & 32 \\
\hline Proporc vacaciones clientes interdiari & 79 & 79 & 79 & 82 & 82 & 82 & 85 & 85 & 85 & 89 & 89 & 89 \\
\hline Cantidad mensual diarios - vacac & 786 & 786 & 786 & 815 & 815 & 815 & 846 & 846 & 846 & 878 & 878 & 878 \\
\hline Cantidad mensual coorpor - vacac & 314 & 314 & 314 & 326 & 326 & 326 & 338 & 338 & 338 & 351 & 351 & 351 \\
\hline Cantidad mensual interdiarios - vacac & 873 & 873 & 873 & 905 & 905 & 905 & 939 & 939 & 939 & 974 & 974 & 974 \\
\hline Precio & 16.40 & 16.40 & 16.40 & 16.40 & 16.40 & 16.40 & 16.40 & 16.40 & 16.40 & 16.40 & 16.40 & 16.40 \\
\hline Ingreso Total & S/ 32,350.84 & $\mathrm{S} / \mathbf{3 2 , 3 5 0 . 8 4}$ & S/ 32,350.84 & S/ 33,564.00 & S/ 33,564.00 & S/ 33,564.00 & $\mathrm{S} / \mathbf{3 4 , 8 2 2 . 6 5}$ & S/ 34,822.65 & $\mathrm{S} / \mathbf{3 4 , 8 2 2 . 6 5}$ & S/ 36,128.49 & S/ 36,128.49 & S/ 36,128.49 \\
\hline
\end{tabular}

Elaboración propia 
Tabla 61

Presupuesto de ventas mensual - Año 5 (expresado en soles).

\begin{tabular}{|c|c|c|c|c|c|c|c|c|c|c|c|c|}
\hline & 1 & 2 & 3 & 4 & 5 & 6 & 7 & 8 & 9 & 10 & 11 & 12 \\
\hline Cantidad diaria cliente comun & 45 & 45 & 45 & 47 & 47 & 47 & 49 & 49 & 49 & 50 & 50 & 50 \\
\hline Cantidad clientes coorporativos & 18 & 18 & 18 & 19 & 19 & 19 & 19 & 19 & 19 & 20 & 20 & 20 \\
\hline Cantidad clientes interdiarios & 92 & 92 & 92 & 95 & 95 & 95 & 99 & 99 & 99 & 103 & 103 & 103 \\
\hline Cantidad mensual diarios & 993 & 993 & 993 & 1,030 & 1,030 & 1,030 & 1,069 & 1,069 & 1,069 & 1,109 & 1,109 & 1,109 \\
\hline Cantidad mensual coorporativos & 397 & 397 & 397 & 412 & 412 & 412 & 428 & 428 & 428 & 444 & 444 & 444 \\
\hline Cantidad mensual interdiarios & 1,103 & 1,103 & 1,103 & 1,144 & 1,144 & 1,144 & 1,187 & 1,187 & 1,187 & 1,232 & 1,232 & 1,232 \\
\hline Proporc vacaciones clientes diarios & 83 & 83 & 83 & 86 & 86 & 86 & 89 & 89 & 89 & 92 & 92 & 92 \\
\hline Proporc vacaciones clientes coorpora & 33 & 33 & 33 & 34 & 34 & 34 & 36 & 36 & 36 & 37 & 37 & 37 \\
\hline Proporc vacaciones clientes interdiari & 92 & 92 & 92 & 95 & 95 & 95 & 99 & 99 & 99 & 103 & 103 & 103 \\
\hline Cantidad mensual diarios - vacac & 910 & 910 & 910 & 945 & 945 & 945 & 980 & 980 & 980 & 1,017 & 1,017 & 1,017 \\
\hline Cantidad mensual coorpor - vacac & 364 & 364 & 364 & 378 & 378 & 378 & 392 & 392 & 392 & 407 & 407 & 407 \\
\hline Cantidad mensual interdiarios - vacac & 1,011 & 1,011 & 1,011 & 1,049 & 1,049 & 1,049 & 1,088 & 1,088 & 1,088 & 1,129 & 1,129 & 1,129 \\
\hline Precio & 17.09 & 17.09 & 17.09 & 17.09 & 17.09 & 17.09 & 17.09 & 17.09 & 17.09 & 17.09 & 17.09 & 17.09 \\
\hline Ingreso Total & S/ 39,060.36 & S/ 39,060.36 & S/ 39,060.36 & S/ 40,525.12 & S/ 40,525.12 & S/ 40,525.12 & S/ 42,044.81 & S/ 42,044.81 & S/ 42,044.81 & S/ 43,621.49 & S/ 43,621.49 & S/ 43,621.49 \\
\hline
\end{tabular}

Elaboración propia 


\subsubsection{Presupuesto de costo de producción.}

El presupuesto de producción está relacionado directamente con el presupuesto de ventas, pues convierte el volumen de ventas en unidades producidas en un periodo específico.

El proceso de producción se refiere a la consecución de actividades necesarias para crear o fabricar un bien, en un periodo presupuestado y en condiciones determinadas, a través de la transformación de materia prima en productos finales.

La fórmula general para llevar a cabo el presupuesto de producción es: Presupuesto de producción (unidades) = Presupuesto de ventas + Inventario final planificado - Inventario inicial. En nuestro caso no se maneja inventario final ni inicial de productos terminados, por lo que nuestro presupuesto de producción es igual a nuestro presupuesto de ventas.

El presupuesto de producción debe incluir varios elementos: presupuestos de materiales, compras, mano de obra, gastos de fabricación y los costes operativos de la empresa.

\subsubsection{Presupuesto de materiales.}

La información que se incluye en el presupuesto de materias primas es todo lo relacionado con la compra de los insumos necesarios para la preparación de los almuerzos según lo proyectado. Es útil para determinar la cantidad y costo de los insumos; así como, asegurar la calidad de los mismos.

Según el presupuesto de ventas y la carta planificada para la semana podemos saber qué insumos y en qué cantidad deben adquirirse, tener en 
cuenta también, que la cantidad exacta de pedidos no la sabemos hasta la noche anterior al servicio.

Para determinar el costo de los insumos necesarios para un almuerzo saludable, se ha costeado una receta estándar, detallada en el anexo VI Costeo de insumos, la que se tomara como costo promedio.

Tabla 62

Presupuesto estimado de materia prima, envases y materiales (expresado en soles)

\begin{tabular}{|c|c|c|c|c|c|c|c|}
\hline DESCRIPCION & $\begin{array}{c}\text { TIPO DE } \\
\text { COSTO }\end{array}$ & costo & AÑO 1 & AÑO 2 & AÑO 3 & AÑO 4 & AÑO 5 \\
\hline Materia Prima & Variable & 4.66 & 4.66 & 4.86 & 5.06 & 5.27 & 5.50 \\
\hline Envases & Variable & 1.60 & 1.60 & 1.67 & 1.74 & 1.81 & 1.89 \\
\hline Total Costo Unitario Variable & & 6.2615 & 6.2615 & 6.5245 & 6.7985 & 7.0840 & 7.3816 \\
\hline Unidades vendidas & & & $10,608.77$ & $18,329.24$ & $21,608.29$ & $25,036.46$ & $29,008.50$ \\
\hline \multicolumn{3}{|c|}{ TOTAL } & S/ 66,426.72 & S/ 119,588.67 & S/ $146,904.08$ & S/ $177,359.31$ & S/ 214,128.33 \\
\hline \multicolumn{3}{|c|}{$\%$ rendimiento } & $43.18 \%$ & $43.18 \%$ & $43.19 \%$ & $43.20 \%$ & $43.19 \%$ \\
\hline
\end{tabular}

Elaboración propia

\subsubsection{Presupuesto de mano de obra}

Se refiere al personal necesario para ejecutar la producción presupuestada, este tipo de costo es considerado un costo fijo, ya que la remuneración de los colaboradores no depende de cuantos almuerzos preparen o se vendan; peor aún, es casi imposible asignar el costo correspondiente por la preparación de cada plato.

Dentro del costo de mano se incluye las cargas de personal de acuerdo a ley y según el tipo de contrato, tales como ESSALUD, Vacaciones, Gratificaciones y CTS, las que mensualmente representan el $27.49 \%$ de la remuneración por estar afiliados al REMYPE, en caso de las medianas y grandes empresas estos conceptos representan el $45.97 \%$ de la remuneración. 
Tabla 63

Presupuesto de mano de obra (expresado en soles)

\begin{tabular}{|c|c|c|c|c|c|c|c|c|c|c|c|c|c|}
\hline DESCRIPCION & $\begin{array}{c}\text { TIPO DE } \\
\text { COSTO }\end{array}$ & $\begin{array}{c}\text { COSTO } \\
\text { MENSUAL } \\
\end{array}$ & ESSALUD & VACACIONES & GRATIFICAC & CTS & TOTAL & $\begin{array}{l}\text { TOTAL } \\
\text { ANUAL } \\
\end{array}$ & AÑO 1 & AÑO 2 & AÑO 3 & AÑO 4 & AÑO 5 \\
\hline Cocinero & Fijo & $1,100.00$ & 99.00 & 46.25 & 99.92 & 53.47 & $1,398.63$ & $16,783.62$ & $16,783.62$ & $17,488.53$ & $18,223.05$ & $18,988.41$ & $19,785.93$ \\
\hline Cocinero 1 & Fijo & $1,100.00$ & 99.00 & 46.25 & 99.92 & 53.47 & $1,398.63$ & $16,783.62$ & 0.00 & 0.00 & 0.00 & $18,988.41$ & $19,785.93$ \\
\hline Asistente de cocina & Fijo & 950.00 & 86.00 & 39.94 & 86.33 & 46.18 & $1,208.45$ & $14,501.44$ & $14,501.44$ & $15,110.50$ & $15,745.14$ & $16,406.44$ & $17,095.51$ \\
\hline Asistente de cocina 1 & Fijo & 500.00 & 84.00 & 0.00 & 48.67 & 0.00 & 632.67 & $7,592.00$ & $7,592.00$ & $8,243.12$ & $8,950.08$ & $9,325.99$ & $9,717.68$ \\
\hline \multirow[t]{2}{*}{ Asistente de cocina 1} & Fijo & 500.00 & 84.00 & 0.00 & 48.67 & 0.00 & 632.67 & $7,592.00$ & 0.00 & 0.00 & 0.00 & 0.00 & $8,950.08$ \\
\hline & TOTAL & & & 132.43 & 383.50 & $\mathrm{~S} / \mathbf{1 5 3 . 1 3}$ & S/ 5,271.06 & S/ $63,252.68$ & S/ 38,877.06 & S/ $40,842.15$ & S/ $42,918.27$ & S/ $63,709.26$ & S/ $75,335.13$ \\
\hline
\end{tabular}

Elaboración propia

Se está considerando terminar el año 6 con cinco colaboradores, incrementándolos conforme las ventas aumenten,

el año 1 se inicia con dos colaboradores, en el cuarto trimestre ingresa un practicante como apoyo, en el año 2

ingresa un jefe de cocina por medio tiempo, dado que a comparación del inicio de operaciones las ventas se habían

casi cuadruplicado, en el año 3 ingresa un asistente de cocina como practicante, en el año 4 un segundo cocinero y en

el año 5 un segundo practicante. 


\subsubsection{Presupuesto de gastos indirectos de fabricación.}

En este concepto se incluyen tanto los gastos indirectos como los directos, que pasan a formar parte del costo del producto. Se consideran gastos indirectos a aquellos que no pueden asignarse directamente al costo de producción o que no forman parte exclusiva de éste, sino de varios productos o áreas de la organización por lo que es necesario proporcionar su valor.

Nuestros gastos indirectos de fabricación están compuestos por el servicio de la nutricionista que armara la carta de menús semanales, el alquiler del local, servicios básicos como son agua y luz, los que serán asignados en su totalidad al área de producción, y se costearon según el promedio de la industria con operaciones similares y el gas propano, considerado un gasto variable, se asignó un consumo de S/ 0.22 por almuerzo, los mismo que han sido reflejados en el siguiente cuadro:

Tabla 64

Gastos indirectos de fabricación (expresado en soles).

\begin{tabular}{|c|c|c|c|c|c|c|c|c|}
\hline DESCRIPCION & $\begin{array}{c}\text { TIPO DE } \\
\text { COSTO }\end{array}$ & $\begin{array}{c}\text { COSTO } \\
\text { UNITARIO }\end{array}$ & $\begin{array}{l}\text { TOTAL } \\
\text { ANUAL }\end{array}$ & Ã̃NO 1 & AÑNO 2 & Ã̃̃ 3 & AÑN 4 & AÑNO 5 \\
\hline Nutricionista & Fijo & 300.00 & $3,600.00$ & $3,600.00$ & $3,751.20$ & $3,908.75$ & $3,908.75$ & $3,908.75$ \\
\hline Alquiler & Fijo & $1,500.00$ & $18,000.00$ & $18,000.00$ & $18,756.00$ & $19,543.75$ & $20,364.59$ & $21,219.90$ \\
\hline Servicios basicos (agua+luz) & Fijo & 150.00 & $1,800.00$ & $1,640.00$ & $1,875.60$ & $1,954.38$ & $2,036.46$ & $2,121.99$ \\
\hline Gas propano & Variable & 0.22 & & $1,141.33$ & $1,844.37$ & $2,414.34$ & $2,519.27$ & $2,918.96$ \\
\hline \multicolumn{3}{|c|}{ TOTAL } & $\mathrm{S} / \mathbf{2 3 , 4 0 0 . 0 0}$ & S/ 24,381.33 & S/ 26,227.17 & S/ 27,821.22 & S/ 28,829.07 & S/ 30,169.60 \\
\hline
\end{tabular}

Elaboración propia

La depreciación de los activos adquiridos que participan en el proceso de producción pasa a formar de los gastos de fabricación. El cálculo de la depreciación inicia cuando el activo esté disponible para su uso, es decir, 
cuando se encuentre en la ubicación y cuente con las condiciones necesarias

para operar de forma adecuada.

En el cuadro siguiente se mostrarán los cálculos de depreciación anual y

valores acumulados según la norma tributaria, a una tasa lineal del 10\%, de

acuerdo a la tabla propuesta en el artículo 38 de la ley del impuesto a la renta.

Tabla 65

Depreciación Activo fijo - Producción (expresado en soles).

\begin{tabular}{|c|c|c|c|c|c|c|c|c|c|}
\hline DESCRIPCION & COSTO & $\begin{array}{c}\text { TIPO DE } \\
\text { COSTO }\end{array}$ & TASA & $\begin{array}{c}\text { DEPREC } \\
\text { ANUAL }\end{array}$ & AÑO 1 & AÑ̃ 2 & AÑ̃ 3 & AÑO 4 & AÑ̃ 5 \\
\hline \multicolumn{10}{|l|}{ VEHICULOS DE TRANSPORTE } \\
\hline Moto & $3,500.00$ & Fijo & $20 \%$ & 700.00 & 700.00 & 700.00 & 700.00 & 700.00 & 700.00 \\
\hline \multicolumn{10}{|l|}{ MAQUINARIA Y EQUIPO } \\
\hline Congelador vertical & $1,600.00$ & Fijo & $10 \%$ & 160.00 & 160.00 & 160.00 & 160.00 & 160.00 & 160.00 \\
\hline Congelador horizontal & $1,500.00$ & Fijo & $10 \%$ & 150.00 & 150.00 & 150.00 & 150.00 & 150.00 & 150.00 \\
\hline Cocina industrial & $1,700.00$ & Fijo & $10 \%$ & 170.00 & 170.00 & 170.00 & 170.00 & 170.00 & 340.00 \\
\hline Campana extractora & 550.00 & Fijo & $10 \%$ & 55.00 & 55.00 & 55.00 & 55.00 & 55.00 & 110.00 \\
\hline Horno eléctrico & $2,300.00$ & Fijo & $10 \%$ & 230.00 & 230.00 & 230.00 & 230.00 & 230.00 & 460.00 \\
\hline Freidor electrico de aire & 800.00 & Fijo & $10 \%$ & 80.00 & 80.00 & 80.00 & 80.00 & 80.00 & 160.00 \\
\hline Licuadora & 700.00 & Fijo & $10 \%$ & 70.00 & 70.00 & 70.00 & 70.00 & 70.00 & 140.00 \\
\hline Batidora de pedestal & 800.00 & Fijo & $10 \%$ & 80.00 & 80.00 & 80.00 & 80.00 & 80.00 & 160.00 \\
\hline Procesador de alimentos & 300.00 & Fijo & $10 \%$ & 30.00 & 30.00 & 30.00 & 30.00 & 30.00 & 60.00 \\
\hline Balanza gramera & 90.00 & Fijo & $10 \%$ & 9.00 & 9.00 & 9.00 & 9.00 & 9.00 & 9.00 \\
\hline Balanza gramera 2 & 90.00 & Fijo & $10 \%$ & & & & & 9.00 & 9.00 \\
\hline \multicolumn{10}{|l|}{ MUEBLES Y ENSERES } \\
\hline Habilitación del local & $5,000.00$ & Fijo & $10 \%$ & 500.00 & 500.00 & 500.00 & 500.00 & 500.00 & 500.00 \\
\hline Utensilios varios & $3,000.00$ & Fijo & $10 \%$ & 300.00 & 300.00 & 300.00 & 300.00 & 300.00 & 300.00 \\
\hline Mesa para preparación de alimentos & 600.00 & Fijo & $10 \%$ & 60.00 & 60.00 & 60.00 & 60.00 & 60.00 & 60.00 \\
\hline Mesa para empaque & 250.00 & Fijo & $10 \%$ & 25.00 & 25.00 & 25.00 & 25.00 & 25.00 & 25.00 \\
\hline Estante para cocina & $1,050.00$ & Fijo & $10 \%$ & 105.00 & 105.00 & 105.00 & 105.00 & 105.00 & 105.00 \\
\hline Estante para area empaque y despacho & 200.00 & Fijo & $10 \%$ & 20.00 & 20.00 & 20.00 & 20.00 & 20.00 & 20.00 \\
\hline Estante para almacen de MP e insumos & $1,200.00$ & Fijo & $10 \%$ & 120.00 & 120.00 & 120.00 & 120.00 & 120.00 & 120.00 \\
\hline Cajas organizadoras grandes & 200.00 & Fijo & $10 \%$ & 20.00 & 20.00 & 20.00 & 20.00 & 20.00 & 20.00 \\
\hline Cajas organizadoras medianas & 160.00 & Fijo & $10 \%$ & 16.00 & 16.00 & 16.00 & 16.00 & 16.00 & 16.00 \\
\hline Mesa + 4 sillas (vestidores) & 210.00 & Fijo & $10 \%$ & 21.00 & 21.00 & 21.00 & 21.00 & 21.00 & 21.00 \\
\hline Casilleros lockers & 800.00 & Fijo & $10 \%$ & 80.00 & 80.00 & 80.00 & 80.00 & 80.00 & 80.00 \\
\hline Utensilios varios (reemplazo) & 400.00 & Fijo & $10 \%$ & & & 40.00 & 80.00 & 120.00 & 160.00 \\
\hline Sillas (vestidores) & 100.00 & Fijo & $10 \%$ & & & & & 10.00 & 10.00 \\
\hline \multicolumn{4}{|c|}{ TOTAL ANUAL } & S/ 3,001.00 & S/ 3,001.00 & S/ 3,041.00 & S/ 3,081.00 & $\mathrm{S} / \quad \mathbf{3 , 1 4 0 . 0 0}$ & $\mathrm{S} / \quad \mathbf{3 , 8 9 5 . 0 0}$ \\
\hline \multicolumn{4}{|c|}{ TOTAL ACUMULADO } & & S/ 3,001.00 & S/ $6,042.00$ & S/ 9,123.00 & S/ 12,263.00 & S/ $16,158.00$ \\
\hline
\end{tabular}

Elaboración propia

\subsubsection{Presupuesto del costo de ventas.}

Para poder preparar el presupuesto de costo de ventas un punto de partida es el presupuesto de compra de materiales directos, el presupuesto de mano de obra 
directa, y el presupuesto de gastos indirectos de fabricación. Posteriormente el inventario final deseado y el inventario inicial estimado serán necesarios para que junto con esta información se pueda obtener el presupuesto de costo de ventas. La forma general es:

\begin{tabular}{l} 
Inventario Inicial \\
$(+)$ Compras Netas \\
$(-)$ Inventario Final \\
\hline Costo de ventas
\end{tabular}

En nuestro proyecto no manejaremos inventario inicial, ni inventario final ya que trabajamos bajo el supuesto de que nos abastecemos según los pedidos realizados, por lo que nuestro costo de ventas será igual a la suma de costo de materiales, manos de obra directa y otros costos indirectos de fabricación.

Tabla 66

Presupuesto de costo de ventas (expresado en soles).

\begin{tabular}{lrrrrr}
\hline \multicolumn{1}{c}{ DESCRIPCION } & AÑO 1 & \multicolumn{1}{c}{ AÑO 2 } & \multicolumn{1}{c}{ AÑO 3 } & \multicolumn{1}{c}{ AÑO 4 } & \multicolumn{1}{c}{ AÑO 5 } \\
\hline MATERIA PRIMA & $66,426.72$ & $119,588.67$ & $146,904.08$ & $177,359.31$ & $214,128.33$ \\
MANO DE OBRA DIRECTA & $38,877.06$ & $40,842.15$ & $42,918.27$ & $63,709.26$ & $75,335.13$ \\
OTROS GASTOS DE FABRICACION & $27,382.33$ & $29,268.17$ & $30,902.22$ & $31,969.07$ & $34,064.60$ \\
\hline \multicolumn{1}{c}{ TOTAL } & S/ 132,686.11 & S/ 189,698.99 & S/ 220,724.57 & S/ 273,037.64 & S/ 323,528.06 \\
\hline
\end{tabular}

Elaboración propia

\subsubsection{Presupuesto de gastos administrativos.}

Todos los gastos administrativos, aunque no están relacionados directamente con el proceso de producción, cumplen un rol importante. Si bien la actividad principal es la producción, ésta no lo es todo, sino que los movimientos y recursos de la empresa necesitan ser planificados, presupuestados, registrados, clasificados, y todas las 
acciones administrativas deben ser ejecutadas por alguien. Así mismo es en función de ello que se determinan los requerimientos de recursos humanos, materiales y financieros para su normal funcionamiento.

Las estructuras organizacionales van a depender directamente del proyecto que se esté tratando, no podemos generalizar, y esto se plantea de acuerdo a criterios y principios de administración, siendo un aspecto importante para dividir el trabajo, delegar funciones y dividir la organización en áreas o departamentos.

Tabla 67

Gastos de administración - Varios (expresado en soles).

\begin{tabular}{|c|c|c|c|c|c|c|c|c|c|}
\hline DESCRIPCION & $\begin{array}{c}\text { TIPO DE } \\
\text { COSTO }\end{array}$ & $\begin{array}{c}\text { COSTO } \\
\text { UNITARIO }\end{array}$ & $\begin{array}{c}\text { COSTO } \\
\text { MENSUAL }\end{array}$ & $\begin{array}{l}\text { TOTAL } \\
\text { ANUAL } \\
\end{array}$ & AÑNO 1 & AÑNO 2 & AÑ $\mathbf{3}$ & AÑO 4 & AÑO 5 \\
\hline Contador & Fijo & 200.00 & 200.00 & $2,400.00$ & $2,400.00$ & $2,500.80$ & $2,605.83$ & $2,715.28$ & $2,829.32$ \\
\hline Servicio de telefonía celular & Fijo & 80.00 & 80.00 & 960.00 & 960.00 & $1,000.32$ & $1,042.33$ & $1,086.11$ & $1,131.73$ \\
\hline Servicio de internet & Fijo & 75.00 & 75.00 & 900.00 & 900.00 & 937.80 & 977.19 & $1,018.23$ & $1,061.00$ \\
\hline Implementos de limpieza & Fijo & 200.00 & 0.00 & 0.00 & 200.00 & 208.40 & 217.15 & 226.27 & 235.78 \\
\hline Implementos de oficina & Fijo & 200.00 & 0.00 & 0.00 & 400.00 & 416.80 & 434.31 & 452.55 & 471.55 \\
\hline \multicolumn{3}{|c|}{ TOTAL } & 355.00 & $\mathrm{~S} / 4,260.00$ & $\mathrm{~S} / \mathbf{4 , 8 6 0 . 0 0}$ & S/ 5,064.12 & S/ 5,276.81 & S/ 5,498.44 & S/ 5,729.37 \\
\hline
\end{tabular}

Elaboración propia

Tabla 68

Depreciación Activo fijo - Administración (expresado en soles).

\begin{tabular}{|c|c|c|c|c|c|c|c|c|}
\hline DESCRIPCION & $\begin{array}{c}\text { TIPO DE } \\
\text { COSTO }\end{array}$ & TASA & $\begin{array}{c}\text { DEPREC } \\
\text { ANUAL }\end{array}$ & AÑNO 1 & AÑ̃ 2 & AÑO 3 & AÑO 4 & AÑNO 5 \\
\hline \multicolumn{9}{|l|}{ MUEB LES Y ENSERES } \\
\hline Escritorio & Fijo & $10 \%$ & 50.00 & 50.00 & 50.00 & 50.00 & 50.00 & 50.00 \\
\hline Sillon Gerencial & Fijo & $10 \%$ & 25.00 & 25.00 & 25.00 & 25.00 & 25.00 & 25.00 \\
\hline Sillas & Fijo & $10 \%$ & 48.00 & 48.00 & 48.00 & 48.00 & 48.00 & 48.00 \\
\hline Librero & Fijo & $10 \%$ & 20.00 & 20.00 & 20.00 & 20.00 & 20.00 & 20.00 \\
\hline Sillas 2 & Fijo & $10 \%$ & 20.00 & & & & 20.00 & 20.00 \\
\hline \multicolumn{9}{|l|}{ EQUIPOS DIVERSOS } \\
\hline Laptop & Fijo & $25 \%$ & 500.00 & 500.00 & 500.00 & 500.00 & 500.00 & \\
\hline Impresora & Fijo & $10 \%$ & 30.00 & 30.00 & 30.00 & 30.00 & 30.00 & 30.00 \\
\hline Equipo celular administración & Fijo & $25 \%$ & 100.00 & 100.00 & 100.00 & 100.00 & 100.00 & \\
\hline Laptop 2 & Fijo & $25 \%$ & 0.00 & & & & 0.00 & 0.00 \\
\hline Equipo celular administración & Fijo & $25 \%$ & 25.00 & & & 25.00 & 25.00 & 25.00 \\
\hline Equipo celular administración & Fijo & $25 \%$ & 25.00 & & & & & 25.00 \\
\hline \multicolumn{3}{|c|}{ TOTAL ANUAL } & 843.00 & 773.00 & S/ $\quad 773.00$ & S/ 798.00 & S/ 818.00 & S/ 243.00 \\
\hline \multicolumn{3}{|c|}{ TOTAL ACUMULADO } & & 773.00 & $\mathrm{S} / \mathbf{1 , 5 4 6 . 0 0}$ & S/ 2,344.00 & $\mathrm{S} / \mathbf{3 , 1 6 2 . 0 0}$ & $\mathrm{S} / \mathbf{3 , 4 0 5 . 0 0}$ \\
\hline
\end{tabular}

Elaboración propia 
Tabla 69

Gastos de administración - Planilla (expresado en soles).

\begin{tabular}{|c|c|c|c|c|c|c|c|c|c|c|c|c|c|}
\hline DESCRIPCION & $\begin{array}{c}\text { TIPO DE } \\
\text { COSTO }\end{array}$ & $\begin{array}{c}\text { REMUN } \\
\text { MENSUAL }\end{array}$ & ESSALUD & VACACIO & GRATIF & CTS & $\begin{array}{c}\text { TOTAL } \\
\text { MENSUAL }\end{array}$ & TOTAL & AÑ̃ 1 & AÑ̃ 2 & AÑ̃ 3 & AÑO 4 & AÑ̃ 5 \\
\hline Administrador & Fijo & $1,100.00$ & 99.00 & 46.25 & 99.92 & 53.47 & $1,398.63$ & $16,783.62$ & $16,783.62$ & $17,488.53$ & $18,223.05$ & $18,988.41$ & $19,785.93$ \\
\hline $\begin{array}{l}\text { Asistente administrativo } \\
\text { (medio tiempo) }\end{array}$ & Fijo & 500.00 & 84.00 & 0.00 & 48.67 & 0.00 & 632.67 & $7,592.00$ & 0.00 & $7,910.86$ & $8,243.12$ & $8,589.33$ & $8,950.08$ \\
\hline TOTAL & & & & 46.25 & S/ $\quad 99.92$ & S/ 53.47 & $\mathrm{~S} / \mathbf{1 , 3 9 8 . 6 3}$ & S/ 16,783.62 & S/ 16,783.62 & $\mathrm{S} / \mathbf{1 7 , 4 8 8 . 5 3}$ & S/ 18,223.05 & S/ 18,988.41 & S/ 19,785.93 \\
\hline
\end{tabular}

Elaboración propia.

Se han considerado dentro de los gastos de administración los desembolsos por los servicios externos de un contador, servicios de telefonía celular e internet para oficina y diversos suministros. Así mismo, la depreciación de los bienes asignados a dicha área y carga laboral del administrador. 


\subsubsection{Presupuesto de marketing y ventas}

Los gastos de venta están conformados por todos aquellos egresos, depreciaciones

y amortizaciones relacionados con el despacho y entrega de los bienes producidos

por la organización. Se incluyen también los gastos de promoción publicidad y

gastos del departamento de ventas y su personal.

Se refiere a todo aquello que tenga que ver con la labor de comunicarse con el cliente y atención post-venta, actividades que son diferentes de aquellas que se relacionan directamente con el proceso de producción y a la administración de la empresa.

Nuestros gastos de ventas están compuestos básicamente por marketing digital, publicidad externa y gastos de envió. Así mismo, se incluye la depreciación y gastos de personal relacionados.

Tabla 70

Gastos de ventas diversos (expresado en soles).

\begin{tabular}{|c|c|c|c|c|c|c|c|c|}
\hline DESCRIPCION & $\begin{array}{c}\text { TIPO DE } \\
\text { COSTO }\end{array}$ & $\begin{array}{c}\text { TOTAL } \\
\text { MENSUAL }\end{array}$ & $\begin{array}{l}\text { TOTAL } \\
\text { ANUAL }\end{array}$ & AÑ O 1 & AÑ $\mathbf{2}$ & AÑ̃ 3 & AÑO 4 & AÑ O 5 \\
\hline Asesoria externa en publicidad & Fijo & 300.00 & $3,600.00$ & $1,600.00$ & $3,751.20$ & $3,908.75$ & $4,072.92$ & $4,243.98$ \\
\hline Publicidad exterior & Fijo & 330.00 & $1,980.00$ & $1,980.00$ & $2,063.16$ & $2,149.81$ & $2,240.10$ & $2,334.19$ \\
\hline Publicidad en redes sociales (facebook) & Fijo & 100.00 & 600.00 & 600.00 & 625.20 & 651.46 & 678.82 & 707.33 \\
\hline Publicidad en redes sociales (instagram) & Fijo & 90.00 & 540.00 & 540.00 & 562.68 & 586.31 & 610.94 & 636.60 \\
\hline Dominio y hosting dirección web (anual) & Fijo & 150.00 & 150.00 & 0.00 & 156.30 & 162.86 & 169.70 & 176.83 \\
\hline Combustible 3 & Fijo & 100.00 & $1,200.00$ & 100.00 & $1,250.40$ & $1,302.92$ & $1,357.64$ & $1,414.66$ \\
\hline Combustible 4 & Fijo & 100.00 & $1,200.00$ & 0.00 & 0.00 & 0.00 & $1,357.64$ & $1,414.66$ \\
\hline Uso vehículo 1 & Fijo & 100.00 & $1,200.00$ & $1,200.00$ & $1,250.40$ & $1,302.92$ & $1,357.64$ & $1,414.66$ \\
\hline Uso vehículo 2 & Fijo & 100.00 & $1,200.00$ & 600.00 & $1,250.40$ & $1,302.92$ & $1,357.64$ & $1,414.66$ \\
\hline Uso vehículo 3 & Fijo & 100.00 & $1,200.00$ & 100.00 & $1,250.40$ & $1,302.92$ & $1,357.64$ & $1,414.66$ \\
\hline Uso vehículo 4 & Fijo & 100.00 & $1,200.00$ & 0.00 & 0.00 & 0.00 & $1,357.64$ & $1,414.66$ \\
\hline $\begin{array}{ll}\text { TOTAL } \\
\end{array}$ & & & S/ $19,890.00$ & $\mathrm{~S} / \mathbf{1 0 , 7 8 0 . 0 0}$ & S/ 15,701.26 & S/ $16,840.20$ & S/ 20,805.82 & S/ 21,679.67 \\
\hline
\end{tabular}

Elaboración propia 
Tabla 71

Gastos de ventas - Planilla (expresado en soles).

\begin{tabular}{|c|c|c|c|c|c|c|c|c|c|c|c|c|}
\hline DESCRIPCION & $\begin{array}{l}\text { TIPO DE } \\
\text { COSTO }\end{array}$ & $\begin{array}{c}\text { REMUN } \\
\text { MENSUAL }\end{array}$ & ESSALUD & GRATIFIC & TOTAL & $\begin{array}{l}\text { TOTAL } \\
\text { ANUAL }\end{array}$ & TOTAL & AÑO 1 & AÑO 2 & AÑO 3 & AÑO 4 & AÑO 5 \\
\hline Repartidor 1 (Tiempo Parcial) & Fijo & 500.00 & 84.00 & 48.67 & 632.67 & $7,592.00$ & $7,592.00$ & $7,592.00$ & $7,910.86$ & $8,243.12$ & $8,589.33$ & $8,950.08$ \\
\hline Repartidor 2 (Tiempo Parcial) & Fijo & 500.00 & 84.00 & 48.67 & 632.67 & $7,592.00$ & $7,592.00$ & $5,061.33$ & $7,910.86$ & $8,243.12$ & $8,589.33$ & $8,950.08$ \\
\hline Repartidor 3 (Tiempo Parcial) & Fijo & 500.00 & 84.00 & 48.67 & 632.67 & $7,592.00$ & $7,592.00$ & 632.67 & $7,910.86$ & $8,243.12$ & $8,589.33$ & $8,950.08$ \\
\hline Repartidor 4 (Tiempo Parcial) & Fijo & 500.00 & 84.00 & 48.67 & 632.67 & $7,592.00$ & $7,592.00$ & 0.00 & 0.00 & 0.00 & $8,589.33$ & $8,950.08$ \\
\hline \multicolumn{4}{|c|}{ TOTAL } & S/.146.00 & $\mathrm{S} / .1,898.00$ & $\mathrm{~S} / .22,776.00$ & $\mathrm{~S} / .22,776.00$ & $\mathrm{~S} / .13,286.00$ & $\mathrm{~S} / .23,732.59$ & $\mathrm{~S} / .24,729.36$ & $\mathrm{~S} / \mathbf{3 4 , 3 5 7 . 3 3}$ & $\mathrm{S} / .35,800.33$ \\
\hline
\end{tabular}

Elaboración propia

Tabla 72

Depreciación Activo fijo - Ventas (expresado en soles).

\begin{tabular}{|c|c|c|c|c|c|c|c|c|c|c|c|c|c|c|}
\hline DESCRIPCION & $\begin{array}{c}\text { TIPO DE } \\
\text { COSTO }\end{array}$ & TASA & & $\begin{array}{l}\text { PREC } \\
\text { NUAL }\end{array}$ & & AÑO 1 & & AÑO 2 & & IÑO 3 & & ÑNO 4 & \multicolumn{2}{|c|}{ AÑN 5} \\
\hline \multicolumn{15}{|l|}{ EQUIPOS DIVERSOS } \\
\hline Equipo celular ventas & Fijo & $25 \%$ & & 100.00 & & 100.00 & & 100.00 & & 100.00 & & 100.00 & & \\
\hline Cajas de delivery para motos & Fijo & $10 \%$ & & 40.00 & & 40.00 & & 40.00 & & 40.00 & & 40.00 & & 40.00 \\
\hline Equipo celular ventas & Fijo & $10 \%$ & & 20.00 & & & & & & 20.00 & & 20.00 & & 40.00 \\
\hline Cajas de delivery para motos & Fijo & $10 \%$ & & 20.00 & & & & & & & & 20.00 & & 20.00 \\
\hline \multicolumn{3}{|c|}{ TOTAL ANUAL } & $\mathbf{S} /$ & 180.00 & $\mathbf{S} /$ & 140.00 & $\mathbf{S} /$ & 140.00 & $\mathbf{S} /$ & 160.00 & $\mathbf{S} /$ & 180.00 & $\mathbf{S} /$ & 100.00 \\
\hline \multicolumn{3}{|c|}{ TOTAL ACUMULADO } & & & $\mathbf{S} /$ & 140.00 & $\mathbf{S} /$ & 280.00 & $\mathbf{S} /$ & 440.00 & $\mathbf{S} /$ & 620.00 & S/ & 720.00 \\
\hline
\end{tabular}

Elaboración propia 


\subsection{Presupuesto de Resultados.}

Se proyectarán tres estados financieros que reflejaran cifras futuras las cuales no se basan en datos históricos, sino que en lo que hemos trabajado en capítulos anteriores en referencia a inversión, estudios de mercado, proyecciones de ventas y presupuestos de gastos según métodos de evaluación económica y reglas de decisión empleadas. Nos presentan un escenario futuro de cómo nos pudiéramos encontrar en un periodo determinado.

Los Estados financieros proyectados contienen uno o varios supuestos con la finalidad de mostrar cual sería la situación financiera de la organización si estos ocurrieran. Muestran resultados en base a proyectos que se realicen como planes futuros o proyección de tendencias observadas, dándonos la confianza de que las decisiones que se tomen son las más idóneas para obtener la rentabilidad deseada.

\subsubsection{Estado de ganancias y pérdidas proyectado.}

"El estado de pérdidas y ganancias o estado de resultados proporciona un resumen financiero de los resultados de operación de la empresa durante un periodo específico" (Gitman \& Zutter, 2012, p.53).

Los Estados de Resultados se realizan para periodos específicos, generalmente los proyectados cubren 12 meses; sin embargo, en la práctica según las políticas de la empresa pueden realizarse desde periodos mensuales hasta anuales. Según la SMV (Superintendencia del Mercado de Valores) en el Reglamento de Información Financiera y Manual para la Preparación de Información Financiera en su artículo $25^{\circ}$ dice que en el estado de resultados debe incluirse todas las partidas que 
representen ingresos o ganancias y gastos o pérdidas originadas durante el periodo evaluado.

En el estado de resultados presentado se están proyectando los resultados para un horizonte de cinco años.

Tabla 73

Estado de Ganancias y Pérdidas Proyectado (expresado en soles).

\begin{tabular}{|c|c|c|c|c|c|c|c|c|c|c|}
\hline & \multicolumn{2}{|l|}{ AÑ̃ 1} & \multicolumn{2}{|l|}{ AÑO 2} & \multicolumn{2}{|l|}{ AÑO 3} & \multicolumn{2}{|l|}{ AÑO 4} & \multicolumn{2}{|l|}{ AÑO 5} \\
\hline Ingresos & $153,827.12$ & $100 \%$ & $276,954.78$ & $100 \%$ & $340,114.55$ & $100 \%$ & $410,597.93$ & $100 \%$ & $495,755.33$ & $100 \%$ \\
\hline Costos Variables & $(66,426.72)$ & $43 \%$ & $(119,588.67)$ & $43 \%$ & $(146,904.08)$ & $43 \%$ & $(177,359.31)$ & $43 \%$ & $(214,128.33)$ & $43 \%$ \\
\hline Costos Fijos & $(66,259.39)$ & $43 \%$ & $(70,110.32)$ & $25 \%$ & $(73,820.49)$ & $22 \%$ & $(95,678.33)$ & $23 \%$ & $(109,399.73)$ & $22 \%$ \\
\hline Utilidad Bruta & $21,141.00$ & $14 \%$ & $87,255.79$ & $32 \%$ & $119,389.98$ & $35 \%$ & $137,560.29$ & $34 \%$ & $172,227.26$ & $35 \%$ \\
\hline Gastos de Administración & $(22,416.62)$ & $15 \%$ & $(23,325.65)$ & $8 \%$ & $(24,297.86)$ & $7 \%$ & $(25,304.85)$ & $6 \%$ & $(25,758.30)$ & $5 \%$ \\
\hline Gastos de Ventas & $(24,206.00)$ & $16 \%$ & $(39,573.85)$ & $14 \%$ & $(41,729.56)$ & $12 \%$ & $(55,343.15)$ & $13 \%$ & $(57,580.00)$ & $12 \%$ \\
\hline Utilidad Operativa & $(25,481.61)$ & $17 \%$ & $24,356.29$ & $9 \%$ & $53,362.56$ & $16 \%$ & $56,912.28$ & $14 \%$ & $88,888.96$ & $18 \%$ \\
\hline Gastos Financieros & 0.00 & & 0.00 & & 0.00 & & 0.00 & & 0.00 & \\
\hline $\begin{array}{l}\text { UTILIDAD ANTES } \\
\text { DE IMPUESTOS }\end{array}$ & $(25,481.61)$ & $17 \%$ & $24,356.29$ & $9 \%$ & $53,362.56$ & $16 \%$ & $56,912.28$ & $14 \%$ & $\mathbf{8 8 , 8 8 8 . 9 6}$ & $18 \%$ \\
\hline Impuesto a la renta & 0.00 & & $(2,435.63)$ & $1 \%$ & $(5,336.26)$ & $2 \%$ & $(5,691.23)$ & $1 \%$ & $(14,083.49)$ & $3 \%$ \\
\hline UTILIDAD NETA & S/ -25,481.61 & $17 \%$ & S/ 21,920.66 & $8 \%$ & $\mathrm{~S} / 48,026.30$ & $14 \%$ & S/ 51,221.05 & $12 \%$ & S/ 74,805.47 & $15 \%$ \\
\hline
\end{tabular}

\section{Elaboración propia}

Podemos observar que el costo de ventas representa un $86 \%$ de los ingresos en el año 1, disminuyendo hasta un $65 \%$ en el año 5, esta disminución se dio básicamente en los costos fijos. Así mismo, en el año 1 tuvimos una pérdida de aproximadamente el $17 \%$ de los ingresos totales, podemos asumir que este resultado es por ser un producto nuevo que en un primer año está buscando ser reconocido y posicionarse en el mercado, revertiéndose esta situación a partir del segundo año obteniendo un \% de utilidad neta con respecto a los ingresos, llegando al $15 \%$ en el año 5.

\subsubsection{Balance general proyectado.}

“El balance general presenta un estado resumido de la situación financiera de la empresa en un momento específico. El estado sopesa los activos de la empresa (lo 
que posee) contra su financiamiento, que puede ser deuda o patrimonio" (Gitman \& Zutter, 2012, p.56).

El balance general o denominado estado de situación financiera según la versión revisada de la NIC 1 en el 2007, es realizado a un momento específico; así por ejemplo, si este fue elaborado al 31 de diciembre, significa que estos valores muestran la situación de la empresa a ese día, sin asumir que la situación podría ser la misma al día siguiente, es por esto que muchos lo definen como la foto de la empresa a un día o momento determinado.

Según la SMV (Superintendencia del Mercado de Valores) en el Reglamento de Información Financiera y Manual para la Preparación de Información Financiera en su artículo $21^{\circ}$ dice que el Balance General de las empresas comprende las cuentas del activo, pasivo y patrimonio neto a una fecha dada.

En el balance general presentado se están proyectando los resultados para un horizonte de cinco años. 
Tabla 74

Balance General Proyectado (expresado en soles).

\begin{tabular}{|c|c|c|c|c|c|c|c|c|}
\hline & AÑ̃O 0 & & AÑO 1 & & AÑ O 2 & AÑ̃ 3 & AÑO 4 & AÑ̃ 5 \\
\hline \multicolumn{9}{|l|}{ ACTIVO } \\
\hline \multicolumn{9}{|l|}{ Activo Corriente } \\
\hline Efectivo y equivalent de efectivo & $24,340.16$ & & $1,808.28$ & & $29,086.95$ & $81,389.72$ & $133,949.19$ & $220,717.24$ \\
\hline Depositos en garantía por alquiler & $3,000.00$ & & $3,000.00$ & & $3,000.00$ & $3,000.00$ & $3,000.00$ & $3,000.00$ \\
\hline Materiales (inventario) & & & 664.27 & & $1,195.89$ & $1,469.04$ & $1,773.59$ & $2,141.28$ \\
\hline \multicolumn{9}{|l|}{ Activo diferido } \\
\hline Total Activo Corriente & S/ $27,340.16$ & $\mathbf{S} /$ & $5,472.54$ & S/ & $33,282.83$ & S/ $\mathbf{8 5 , 8 5 8 . 7 6}$ & S/ $138,722.79$ & S/ 225,858.52 \\
\hline \multicolumn{9}{|l|}{ Activo No Corriente } \\
\hline Activo Fijo Tangible & $27,940.00$ & & $28,240.00$ & & $28,740.00$ & $31,130.00$ & $33,980.00$ & $34,280.00$ \\
\hline Activo Fijo Intangible & $12,505.00$ & & $12,505.00$ & & $12,505.00$ & $12,505.00$ & $12,505.00$ & $12,505.00$ \\
\hline Depreciac y amortizac & & & $(3,914.00)$ & & $(7,868.00)$ & $(11,907.00)$ & $(16,045.00)$ & $(20,283.00)$ \\
\hline Total Activo No Corriente & $\mathrm{S} / \mathrm{40,445.00}$ & S/ & $36,831.00$ & S/ & 33,377.00 & S/ $\quad 31,728.00$ & $\mathrm{~S} / \quad \mathbf{3 0 , 4 4 0 . 0 0}$ & S/ $\quad 26,502.00$ \\
\hline TOTAL ACTIVO & S/ 67,785.16 & S/ & $42,303.54$ & $\mathrm{~S} /$ & $66,659.83$ & S/ 117,586.76 & S/ 169,162.79 & S/ 252,360.52 \\
\hline \multicolumn{9}{|l|}{ PASIVO } \\
\hline \multicolumn{9}{|l|}{ Pasivo Corriente } \\
\hline Tributos por pagar & & & 0.00 & & $2,435.63$ & $5,336.26$ & $5,691.23$ & $14,083.49$ \\
\hline Parte corriente deuda LP & & & 0.00 & & & & & \\
\hline Total Pasivo Corriente & & & 0.00 & & $2,435.63$ & $5,336.26$ & $5,691.23$ & $14,083.49$ \\
\hline Pasivo No Corriente & & & 0.00 & & 0.00 & 0.00 & 0.00 & 0.00 \\
\hline TOTAL PASIVO & $\mathbf{S} /$ & $\mathbf{S} /$ & - & $\mathrm{S} /$ & $2,435.63$ & $5,336.26$ & $5,691.23$ & S/ $\quad 14,083.49$ \\
\hline \multicolumn{9}{|l|}{ PATRIMONIO } \\
\hline Capital & $79,128.16$ & & $79,128.16$ & & $79,128.16$ & $79,128.16$ & $79,128.16$ & $79,128.16$ \\
\hline Resultados Acumulados & & & & & $(25,481.61)$ & $(3,560.96)$ & $44,465.34$ & $95,686.40$ \\
\hline Resultado del ejercicio & & & $(25,481.61)$ & & $21,920.66$ & $48,026.30$ & $51,221.05$ & $74,805.47$ \\
\hline TOTAL PATRIMONIO & S/ 79,128.16 & $\mathbf{S} /$ & $53,646.54$ & $\mathrm{~S} /$ & $75,567.20$ & S/ 123,593.50 & S/ $174,814.56$ & $\mathrm{~S} / \mathbf{2 4 9 , 6 2 0 . 0 3}$ \\
\hline TOTAL PASIVO Y PATRIMONIO & S/ 79,128.16 & $\mathbf{S} /$ & $53,646.54$ & S/ & $78,002.83$ & S/ 128,929.76 & S/ $180,505.79$ & S/ 263,703.52 \\
\hline
\end{tabular}

Elaboración propia

Tabla 75

Variación de activo y pasivo corriente (expresado en soles).

\begin{tabular}{|c|c|c|c|c|c|c|}
\hline CONCEPTO & AÑO 0 & AÑO 1 & AÑO 2 & AÑO 3 & AÑO 4 & AÑO 5 \\
\hline Activo Corriente & $3,000.00$ & $3,664.27$ & $4,195.89$ & $4,469.04$ & $4,773.59$ & 5,1 \\
\hline Pasivo Corriente & 0.00 & 0.00 & $2,435.63$ & $5,336.26$ & $5,691.23$ & $14,083.49$ \\
\hline CAPITAL DE TRABAJO & $\mathrm{S} / \mathbf{3 , 0 0 0 . 0 0}$ & S/ 3,664.27 & S/ $1,760.26$ & -867.22 & -917.64 & $\mathrm{~S} / \mathbf{- 8 , 9 4 2 . 2 1}$ \\
\hline $\begin{array}{l}\text { VARIACION CAPITAL } \\
\text { DE TRABAJO }\end{array}$ & /3,000.00 & 664.27 & $-1,904.01$ & S/ -2,627.48 & -50.42 & S/ -8,024.57 \\
\hline
\end{tabular}

Elaboración propia 


\subsubsection{Flujo de caja proyectado.}

El Flujo de Caja muestra un resumen de los ingresos y egresos de dinero que se dan en una empresa en un periodo determinado, la diferencia que se obtiene se denomina saldo o flujo neto, convirtiéndose en un indicador importante de la liquidez de la empresa. Por lo tanto, si obtenemos un saldo positivo, quiere decir que nuestros ingresos fueron mayores a los egresos, de lo contrario los egresos fueron mayores.

La proyección del flujo de caja constituye uno de los elementos más importantes del estudio de un proyecto, ya que la evaluación del mismo se efectuará sobre los resultados que se determinen en ella. La información básica para realizar esta proyección está contenida tanto en los estudios de mercado, técnico y organizacional, como en el cálculo de los beneficios. (Sapag \& Sapag, 2008, p.291)

Los desembolsos que se toman en cuenta son los considerados anteriormente, en donde se detallaron los presupuestos de materiales, mano de obra y otros gastos indirectos de fabricación; así como gastos de administración y ventas. Se considerará el periodo anual para el cálculo del impuesto a la renta y dependerá de si hubo o no utilidad. Adicionalmente se aclara que para el flujo de caja no se consideran gastos que no representan salida de efectivo, por lo tanto, la depreciación y amortización no serán tomadas en cuenta.

En el flujo de caja presentado se están proyectando los resultados para un horizonte de cinco años. 
Tabla 76

Flujo de caja proyectado (expresado en soles).

\begin{tabular}{lrrrrrr}
\hline & AÑO 0 & \multicolumn{1}{c}{ AÑO 1 } & \multicolumn{1}{c}{ AÑO 2 } & AÑO 3 & AÑO 4 & AÑO 5 \\
\hline UTILIDAD NETA & & $(\mathbf{2 5 , 4 8 1 . 6 1 )}$ & $\mathbf{2 1 , 9 2 0 . 6 6}$ & $\mathbf{4 8 , 0 2 6 . 3 0}$ & $\mathbf{5 1 , 2 2 1 . 0 5}$ & $\mathbf{7 4 , 8 0 5 . 4 7}$ \\
Variación de efectivo & $(664.27)$ & $1,904.01$ & $2,627.48$ & 50.42 & $8,024.57$ \\
Depreciación operación & & $3,001.00$ & $3,041.00$ & $3,081.00$ & $3,140.00$ & $3,895.00$ \\
Depreciación administración & & 773.00 & 773.00 & 798.00 & 818.00 & 243.00 \\
Depreciación ventas & 140.00 & 140.00 & 160.00 & 180.00 & 100.00 \\
\hline FLUJO DE CAJA OPERATIVO & $\mathbf{( 2 2 , 2 3 1 . 8 8 )}$ & $\mathbf{2 7 , 7 7 8 . 6 7}$ & $\mathbf{5 4 , 6 9 2 . 7 8}$ & $\mathbf{5 5 , 4 0 9 . 4 7}$ & $\mathbf{8 7 , 0 6 8 . 0 4}$ \\
\hline Inversión Tangible & $(31,440.00)$ & $(300.00)$ & $(500.00)$ & $(2,390.00)$ & $(2,850.00)$ & $(300.00)$ \\
Inversión Intangible & $(20,348.00)$ & 0.00 & 0.00 & 0.00 & 0.00 & 0.00 \\
Capital de Trabajo & $(27,340.16)$ & 0.00 & 0.00 & 0.00 & 0.00 & 0.00 \\
\hline FLUJO DE CAJA DE CAP & $\mathbf{( 7 9 , 1 2 8 . 1 6 )}$ & $\mathbf{( 3 0 0 . 0 0 )}$ & $\mathbf{( 5 0 0 . 0 0 )}$ & $\mathbf{( 2 , 3 9 0 . 0 0 )}$ & $\mathbf{( 2 , 8 5 0 . 0 0 )}$ & $\mathbf{( 3 0 0 . 0 0 )}$ \\
\hline \hline FLUJO DE CAJA ECONO & $\mathbf{( 7 9 , 1 2 8 . 1 6 )}$ & $\mathbf{( 2 2 , 5 3 1 . 8 8 )}$ & $\mathbf{2 7 , 2 7 8 . 6 7}$ & $\mathbf{5 2 , 3 0 2 . 7 8}$ & $\mathbf{5 2 , 5 5 9 . 4 7}$ & $\mathbf{8 6 , 7 6 8 . 0 4}$ \\
\hline Efectivo y equivalente de efectivo al inicio de & $24,340.16$ & $1,808.28$ & $29,086.95$ & $81,389.72$ & $133,949.19$ \\
\hline Efectivo y equivalente de efectivo al final S/ & $\mathbf{1 , 8 0 8 . 2 8}$ & S/ 29,086.95 & S/ & $\mathbf{8 1 , 3 8 9 . 7 2}$ & S/ 133,949.19 & S/ 220,717.24 \\
\hline
\end{tabular}

Elaboración propia

En este caso hemos proyectado los flujos de caja de la empresa a cinco años, como si tuviera una vida definida de 5 años. Consideramos que la empresa no va a durar solo cinco años, sino que va a generar flujos de caja futuros por un periodo de tiempo indefinido, entonces procedemos a calcular el valor residual de la empresa, tomando el último flujo de caja proyectado. El valor residual lo que nos dice básicamente es que la empresa es capaz de generar caja desde el año 6 hasta el infinito, esta caja debería tenerse en cuenta cuando valorizamos la empresa sino estaríamos infravalorando la valoración si solo tomamos en cuenta la generación de caja hasta el año 5 .

El valor residual pasará a ser el valor de la empresa a perpetuidad, el cálculo de los flujos de caja al periodo n se realiza teniendo en cuenta dos variables: la tasa de actualización y el crecimiento de la compañía a perpetuidad. 


$$
V R=C F_{n} x \frac{(1+g)}{(k-g)}
$$

Dónde:

$\mathrm{CF}_{\mathrm{n}}=$ Flujo de caja para el periodo $\mathrm{n}$

$\mathrm{k}=$ tasa de actualización/ WACC / COK

$\mathrm{g}=$ tasa de crecimiento a perpetuidad

Entonces:

$$
\mathrm{g}=0 \% \quad ; \quad \mathrm{i}=19.78 \%
$$

$$
V R=86,768.042 \times \frac{(1+0)}{0.1978-0}
$$

$$
V R=438,753.21
$$

\begin{tabular}{|c|c|c|}
\hline PERIODO & $\begin{array}{c}\text { FLUJO DE } \\
\text { CAJA }\end{array}$ & $\begin{array}{c}\text { VALOR } \\
\text { ACTUAL }\end{array}$ \\
\hline $\mathrm{CF} 1$ & $(79,128.16)$ & $(79,128.16)$ \\
\hline $\mathrm{CF} 1$ & $(22,531.88)$ & $(18,811.68)$ \\
\hline $\mathrm{CF} 2$ & $27,278.67$ & $19,014.43$ \\
\hline $\mathrm{CF} 3$ & $52,302.78$ & $30,437.91$ \\
\hline CF4 & $52,559.47$ & $25,537.07$ \\
\hline CF5 & $86,768.04$ & $35,197.35$ \\
\hline VR & $438,753.21$ & $177,979.68$ \\
\hline EV & & / $269,354.75$ \\
\hline
\end{tabular}

Tabla 77

Valorización de la empresa por descuento de flujos (expresado en soles)

Elaboración propia 
Tabla 78

VAN y TIR de la perpetuidad

(expresado en soles).

\begin{tabular}{cc}
\hline VAN & S/ $269,354.75$ \\
\hline TIRP & $48 \%$ \\
\hline
\end{tabular}

Elaboración propia 


\section{Capítulo X}

\section{Evaluación Económica Financiera.}

Medir la rentabilidad económica y financiera de un proyecto no resulta fácil por el comportamiento tan diverso que pueden tener las variables que influyen en los resultados. Es por ello que es necesario tener la información suficiente para plantear el escenario más probable que podría llegar a enfrentar el proyecto.

Después de haber establecido cuáles serán los ingresos y egresos del proyecto, podemos aplicar los indicadores que nos ayudarán a analizar de manera objetiva cuan atractiva resulta la idea de negocio en términos monetarios. Debemos tener claro que determinar la rentabilidad en valores numéricos es producto de la aplicación correcta de una formula; sin embargo, es aún más importante la interpretación de dichos resultados.

\subsection{Evaluación financiera.}

La evaluación financiera se realiza con el fin de conocer si la inversión en la idea de negocio creara valor o tendrá la rentabilidad esperada. Como ya se mencionó anteriormente, esto implica ubicarse en el escenario más probable y evaluar los factores involucrados en su ejecución.

Para el análisis de la evaluación financiera se toman en cuenta los flujos económico y financiero del proyecto, distinguiendo entre el aporte propio y aquel que sea producto de un financiamiento. 


\subsubsection{Tasa Interna de Retorno (TIR).}

La TIR mide la rentabilidad del proyecto como porcentaje, es decir la tasa de rendimiento que tendrá el accionista si invierte en el proyecto y se materializan los flujos esperados. "Evalúa el proyecto en función de una única tasa de rendimiento por periodo, con la cual la totalidad de los beneficios actualizados son exactamente iguales a los desembolsos expresados en moneda actual” (Sapag \& Sapag, 2008, p.323).

Después de calculada la TIR debemos evaluar y tomar una decisión, si ésta es mayor al costo de capital el proyecto se acepta, de lo contrario se rechaza.

La TIR calculada es de $23.89 \%$, esta tasa es la que hace al VAN del proyecto igual a cero; resultando superior a la rentabilidad mínima exigida por los inversionistas como costo de capital de $19.78 \%$. Tenemos entonces que, por el primer criterio de evaluación financiera el proyecto debería ser aceptado.

Tabla 79

Tasa Interna de Retorno (expresado en soles).

\begin{tabular}{|c|c|c|c|c|c|c|}
\hline & INVERSION & AÑO 1 & AÑO 2 & AÑO3 & AÑO 4 & AÑO 5 \\
\hline FLUJ & & & & & & $86,768.04$ \\
\hline FCE VALOR ACTUAL & & & & & $22,309.83$ & $29,728.04$ \\
\hline FCE VALOR ACTUAL ACUMULADO & $(79,128.16)$ & $(97,315.06)$ & $(79,542.68)($ & $(52,037.87)$ & $(29,728.04)$ & 0.00 \\
\hline
\end{tabular}

Elaboración propia

\subsubsection{Valor Actual Neto (VAN).}

El valor actual neto es una técnica de evaluación de proyectos y se obtiene de la diferencia de la inversión inicial y sus flujos de efectivo, proyectados a partir del primer periodo de operación, traídos a valor presente descontados a una tasa equivalente al costo de capital de la empresa. 
El VAN “mide el excedente resultante después de obtener la rentabilidad deseada o exigida y después de recuperar toda la inversión” (Sapag, 2011, p.300).

El resultado que obtengamos nos puede situar en diferentes escenarios, cuando es mayor a 0 , nos indica cuanto se está ganando después de haber recuperado la inversión, superando el costo de capital o rendimiento exigido; si es igual a 0 hemos recuperado el capital y la tasa de rendimiento es exactamente la misma que se pedía; por último, si el resultado es menor que 0 o negativo, nos indica cuanto nos falta para alcanzar la tasa mínima exigida después de recuperar la inversión. El criterio de decisión sería que, si el VAN es mayor a 0 el proyecto se acepte de lo contrario se rechace.

Después de descontar los flujos anuales a valor presente a la tasa de costo de capital de $19.78 \%$, el VAN obtenido para nuestro proyecto es S/ 12,246.91, el cual representa alrededor del $15.48 \%$ de la inversión, resultado que nos lleva a aceptar el proyecto.

Tabla 80 Valor Actual Neto (expresado en soles).

\begin{tabular}{|c|c|c|c|c|c|c|}
\hline & INVERSION & AÑO 1 & AÑO 2 & AÑ̃ 3 & AÑO 4 & AÑO 5 \\
\hline FLUJO DE CAJA ECO & $(79,128.16)$ & $22,531.88)$ & $27,278.67$ & $52,302.78$ & $52,559.47$ & $86,768.04$ \\
\hline FCE V & & 68) & $19,014.43$ & $30,437.91$ & $25,537.07$ & $35,197.35$ \\
\hline FCE VALOR ACTUAL ACUMULADO & $(79,128.16)$ & $97,939.84)$ & $(78,925.41)$ & $48,487.50)$ & $(22,950.43)$ & $12,246.91$ \\
\hline
\end{tabular}

Elaboración propia

\subsubsection{Retorno sobre el patrimonio (ROE).}

Proviene de sus siglas en ingles Return On Equity, lo que significa rendimiento sobre el patrimonio o recursos propios. 
El ROE es un indicador que mide la rentabilidad del capital invertido, es decir cómo se están empleando los recursos propios que forman parte del patrimonio de la empresa, haciendo una comparación entre la utilidad neta obtenida y el patrimonio neto de la misma; cuanto mayor sea, más alta será la rentabilidad que puede lograr la empresa en función de sus recursos propios. "Muestra que tan rentable es la empresa con respecto a su patrimonio o capital" (Andrade, 2011, p.59).

La fórmula del ROE es:

$$
\text { ROE }=\frac{\text { Utilidad Neta }}{\text { Capitales Propios }}
$$

Tabla 81

Rentabilidad sobre el patrimonio (ROE)

\begin{tabular}{|c|c|c|c|c|c|}
\hline & AÑNO 1 & AÑO 2 & AÑO 3 & AÑO 4 & AÑO 5 \\
\hline $\begin{array}{l}\text { RENDIMIENTO SOBRE EL } \\
\text { PATRIMONIO }\end{array}$ & $-32 \%$ & $29 \%$ & $39 \%$ & $29 \%$ & $30 \%$ \\
\hline
\end{tabular}

Elaboración propia

Podemos observar que, aunque el primer año obtuvimos un valor negativo debido a la naturaleza del negocio, a partir del segundo año observamos que esto se revierte, indicándonos que nuestro patrimonio tiene un rendimiento que en promedio supera el $32 \%$, lo que resulta atractivo para cualquier inversionista.

\subsubsection{Ratios.}

Un ratio es definido como un cociente, una relación entre dos valores que por sí mismos no brindan información suficiente. Por lo tanto, una primera característica sería que permite relativizar información absoluta, es decir, si solo tenemos como 
dato la utilidad del periodo, en realidad lo que sabemos es poco, puede ser que sea suficiente o no, en cambio si la relacionamos con otro dato como, el capital propio ya podemos saber el origen de la utilidad, nos proporciona información completa no solo un número. Podemos usarlos también para comparar: información entre empresas del mismo rubro y conocer nuestra posición respecto a las demás; resultados de la empresa en diferentes periodos y situaciones; o con otros ratios para entender la estructura del negocio, todo ellos para comprender mejor la realidad de la empresa.

Tabla 82

Ratios de Rentabilidad

\begin{tabular}{|c|c|c|c|c|c|c|}
\hline RATIO & FORMULA & AÑNO 1 & AÑO 2 & AÑ̃ 3 & AÑO 4 & AÑ̃ 5 \\
\hline \multirow{2}{*}{$\begin{array}{l}\text { Rentabilidad del patrimonio } \\
\text { ROE }\end{array}$} & Utilidad Neta & \multirow{2}{*}{$-32.20 \%$} & \multirow{2}{*}{$29.01 \%$} & \multirow{2}{*}{$38.86 \%$} & \multirow{2}{*}{$29.30 \%$} & \multirow{2}{*}{$29.97 \%$} \\
\hline & Patrimonio & & & & & \\
\hline \multirow{2}{*}{$\begin{array}{c}\text { Rentabilidad del activo } \\
\text { ROA }\end{array}$} & Utilidad Neta & \multirow{2}{*}{$-50.00 \%$} & \multirow{2}{*}{$32.88 \%$} & \multirow{2}{*}{$40.84 \%$} & \multirow{2}{*}{$30.28 \%$} & \multirow{2}{*}{$29.64 \%$} \\
\hline & Activos Totales & & & & & \\
\hline \multirow{2}{*}{ Margen de utilidad neta } & Utilidad Neta & \multirow{2}{*}{$-16.57 \%$} & \multirow{2}{*}{$7.91 \%$} & \multirow{2}{*}{$14.12 \%$} & \multirow{2}{*}{$12.47 \%$} & \multirow{2}{*}{$15.09 \%$} \\
\hline & Ventas Netas & & & & & \\
\hline \multirow{2}{*}{ Margen de utilidad bruta } & Utilidad Brutas & \multirow{2}{*}{$13.74 \%$} & \multirow{2}{*}{$31.51 \%$} & \multirow{2}{*}{$35.10 \%$} & \multirow{2}{*}{$33.50 \%$} & \multirow{2}{*}{$34.74 \%$} \\
\hline & Ventas Netas & & & & & \\
\hline \multirow{2}{*}{ Rentabilidad del capital } & Utilidad Neta & \multirow{2}{*}{$-32.20 \%$} & \multirow{2}{*}{$27.70 \%$} & \multirow{2}{*}{$60.69 \%$} & \multirow{2}{*}{$64.73 \%$} & \multirow{2}{*}{$94.54 \%$} \\
\hline & Capital Social & & & & & \\
\hline \multirow{2}{*}{$\begin{array}{l}\text { Multiplicador de apalancam. } \\
\text { Financiero }\end{array}$} & Activos Totales & \multirow{2}{*}{0.79} & \multirow{2}{*}{0.88} & \multirow{2}{*}{0.95} & \multirow{2}{*}{0.97} & \multirow{2}{*}{1.01} \\
\hline & Patrimonio & & & & & \\
\hline
\end{tabular}

Elaboración propia.

El ROA nos muestra la relación entre la utilidad neta y las ventas, es decir a más beneficio por el mismo número de ventas, es mejor. Es decir, cuanta utilidad se queda en la empresa por cada sol de ventas o, es lo mismo decir, cuanto tienen a su disposición por cada sol invertido, en este caso el inversionista tiene alrededor del $30 \%$ disponible. 
El margen de utilidad neta nos presenta el rendimiento de los ingresos operacionales, es decir la utilidad por cada sol vendido, si bien no es nuestro caso, debería ponerse atención en este ratio cuando la empresa tiene ingresos de actividades que son propias del negocio, nuestro proyecto presenta un margen de utilidad neta aceptable.

El margen de utilidad bruta muestra un resultado más relacionado con la actividad principal de la empresa, ya que es el porcentaje que queda de los ingresos operacionales después de retirado el costo de ventas. Entre más alto sea este indicador, mayor será la posibilidad de la empresa de cubrir sus gastos operacionales, en nuestra evaluación podemos observar que este margen va a en ascenso.

La rentabilidad del capital expone el rendimiento de cada unidad monetaria invertida, refiriéndonos con esto específicamente al capital propio, a lo largo del proyecto.

Nuestro ratio de apalancamiento financiera nos indica que de ser necesario, sería rentable recurrir al financiamiento externo.

Observando los resultados de los ratios aplicados, podemos afirmar que la idea de negocio afirma su rentabilidad atractiva.

\subsection{Análisis del riesgo.}

Los resultados que obtenemos al evaluar un proyecto aplicando criterios predefinidos no nos muestran la rentabilidad exacta del proyecto, sino la que resultaría en el escenario más probable. El comportamiento de las variables casi siempre difiere de este escenario por lo que es imposible esperar que la rentabilidad calculada sea la del proyecto. Por ello, cuando 
se toma la decisión de aceptar o rechazar un proyecto, más allá de los resultados que nos da la evaluación debemos fijarnos en las variables determinantes que definen su rentabilidad y las consecuencias de la variación o no ocurrencia de algún supuesto.

Cuando el proyecto es muy rentable podemos tener reacciones diversas de nuestros competidores que intentaran imitar o sustituir el modelo, los proveedores incrementaran los precios en un intento de ser partícipe del éxito del negocio, e incluso los trabajadores quienes pueden exigir mejoras en sus remuneraciones por los buenos resultados. La posibilidad de ocurrencias de estos supuestos debe preverse mediante un análisis de sensibilidad de la rentabilidad a cambios, dentro de los rangos probables (Sapag, 2011).

\subsubsection{Punto de Equilibrio.}

Es aquel punto de actividad o volumen de ventas donde los ingresos totales son iguales a los costos totales, es decir, alcanza a cubrir sus costos, pero no se registra ni utilidad ni perdida.

Este punto es considerado una referencia importante, ya que nos muestra un dato importante para la planificación para áreas como ventas, producción, operaciones, finanzas, así como establecer precios. Es un límite que influye en el diseño actividades que conduzcan a estar siempre por encima de él, donde se puedan obtener mayores utilidades (Mazon, Villao, Nuñez y Serrano, 2017).

$$
P d E=\frac{\text { Costos Fijos }}{\text { Precio }- \text { Costo Variable Unitario }}
$$


Tabla 83

Punto de Equilibrio operativo

\begin{tabular}{lrrrrr}
\hline & \multicolumn{1}{c}{ Año 1 } & \multicolumn{1}{c}{ Año 2 } & \multicolumn{1}{c}{ Año 3 } & \multicolumn{1}{c}{ Año 4 } & \multicolumn{1}{c}{ Año 5 } \\
\hline Costo Fijo & $111,740.68$ & $131,165.45$ & $137,433.57$ & $173,807.06$ & $189,819.07$ \\
Costo Variable & $67,568.06$ & $121,433.04$ & $149,318.42$ & $179,878.59$ & $217,047.29$ \\
Precio & 14.50 & 15.11 & 15.74 & 16.40 & 17.09 \\
CVu & 7.5725 & 7.2241 & 7.5350 & 7.8342 & 8.1587 \\
\hline \hline PdE & $\mathbf{1 6 , 1 3 0}$ & $\mathbf{1 6 , 6 3 3}$ & $\mathbf{1 6 , 7 5 0}$ & $\mathbf{2 0 , 2 9 1}$ & $\mathbf{2 1 , 2 5 3}$ \\
\hline
\end{tabular}

Elaboración propia

Podemos observar que nuestros costos fijos superan los dos primeros años a los costos variables, lo que podría resultar contraproducente con respecto a la posibilidad de la reducción de unidades vendidas. El primer año, por ser considerado el periodo de introducción del producto, no se está considerando en el análisis, es a partir del año 2 nuestras ventas en unidades superan ampliamente el punto de equilibrio, por lo que consideramos que es un proyecto perfectamente viable.

\subsubsection{Análisis de sensibilidad.}

Como mencionamos anteriormente, si bien los resultados obtenidos de las evaluaciones resultan favorables a la aceptación del proyecto, debemos tener claro que éstos difieren de lo que podría suceder en un escenario real, es por ello que surgen diferentes modelos de sensibilización como una alternativa para incluir en el análisis información que nos permite tomar una decisión adecuada. Debemos tener identificadas aquellas variables que son consideradas más críticas o menos controlables como menor demanda del producto, incremento del costo de mano de obra directa e incremente en el costo de materia prima. 
Este tipo de análisis nos plantea la pregunta ¿Qué pasaría si ...?, analizando el impacto que tendría en los resultados la desviación de cada variable, de forma independiente.

El análisis de sensibilidad es un método conductual en el cual los analistas calculan el VAN de un proyecto considerando escenario o resultados diversos (Gitman \& Zutter, 2012, p.415).

Para poder realizar el análisis de sensibilidad, hemos aquellas variables que son difíciles de controlar y que son sensibles al cambio por cuestiones económicas, ambientales o simplemente por el tiempo, las que en caso de sufrir modificaciones, independientes de las demás, podrían afectar los resultados.

\subsubsection{Variable: Demanda}

Analizamos el proyecto en función a la variación de la demanda, ya sea su incremento de $5 \%$ hasta un $10 \%$ como su disminución en el mismo rango.

Tabla 84

Análisis de Sensibilidad: demanda (expresado en soles).

\begin{tabular}{|c|c|c|c|c|c|c|c|c|c|}
\hline $\begin{array}{c}\text { Porcentaje de } \\
\text { variación }\end{array}$ & Año 0 & Año 1 & Año 2 & Año 3 & Año 4 & & Año 5 & VAN & TIR \\
\hline$-10 \%$ & S/ -79,128.16 & $\mathrm{S} /-31,271.92$ & $\mathrm{~S} / 13,115.72$ & S/ 34,913.84 & $\mathrm{S} / 31,568.00$ & $\mathrm{~S} /$ & $66,616.20$ & $\mathrm{~S} /-33,415.55$ & $7.84 \%$ \\
\hline$-5 \%$ & $\mathrm{~S} / \mathrm{-79,128.16}$ & S/ -26,901.90 & S/ $20,197.19$ & S/ 43,608.31 & S/ 42,063.73 & $\mathrm{S} /$ & $76,840.68$ & S/ -10,524.06 & $16.14 \%$ \\
\hline $0 \%$ & $\mathrm{~S} /-79,128.16$ & $\mathrm{~S} /-22,531.88$ & S/ $27,278.67$ & S/ 52,302.78 & S/ 52,559.47 & $\mathrm{S} /$ & $86,768.04$ & $\mathrm{~S} / \quad 12,246.91$ & $23.89 \%$ \\
\hline $5 \%$ & S/ -79,128.16 & $S /-18,161.86$ & $\mathrm{~S} / 34,360.14$ & $\mathrm{~S} / 60,846.50$ & S/ 61,821.99 & $\mathrm{S} /$ & $96,695.39$ & $34,330.97$ & $31.06 \%$ \\
\hline $10 \%$ & $\mathrm{~S} /-79,128.16$ & S/ $-13,791.84$ & S/ 41,441.62 & S/ $67,657.17$ & S/ 70,043.65 & $\mathrm{S} /$ & $106,622.74$ & $54,900.75$ & $37.54 \%$ \\
\hline
\end{tabular}

Elaboración propia

Observamos que, nuestro proyecto es muy sensible a la variación de la demanda, lo que nos obliga a planificar acciones que eviten su disminución y promuevan su incremento por encima de lo planeado. 


\subsubsection{Variable: Costo Materia Prima (expresado en soles).}

El costo de materia prima es otra variable que consideramos debe ser evaluada, ya que es el insumo principal para poder obtener el producto final.

Tabla 85

Análisis de sensibilidad: costo materia prima

\begin{tabular}{ccccccccccc}
\hline $\begin{array}{c}\text { Porcentaje de } \\
\text { variación }\end{array}$ & Año 0 & Año 1 & Año 2 & Año 3 & Año 4 & Año 5 & VAN & TIR \\
\hline$-10 \%$ & $\mathrm{~S} /-79,128.16$ & $\mathrm{~S} /-29,174.55$ & $\mathrm{~S} / 16,515.69$ & $\mathrm{~S} / 39,081.41$ & $\mathrm{~S} / 36,597.13$ & $\mathrm{~S} /$ & $71,671.99$ & $\mathrm{~S} /-22,374.83$ & $11.92 \%$ \\
$-5 \%$ & $\mathrm{~S} /-79,128.16$ & $\mathrm{~S} /-25,853.22$ & $\mathrm{~S} / 21,897.17$ & $\mathrm{~S} / 45,692.09$ & $\mathrm{~S} / 44,578.31$ & $\mathrm{~S} /$ & $79,220.02$ & $\mathrm{~S} /$ & $-5,063.96$ & $18.04 \%$ \\
$0 \%$ & $\mathrm{~S} /-79,128.16$ & $\mathrm{~S} /-22,531.88$ & $\mathrm{~S} / 27,278.67$ & $\mathrm{~S} / 52,302.78$ & $\mathrm{~S} / 52,559.47$ & $\mathrm{~S} /$ & $86,768.04$ & $\mathrm{~S} /$ & $12,246.91$ & $23.89 \%$ \\
$5 \%$ & $\mathrm{~S} /-79,128.16$ & $\mathrm{~S} /-19,210.55$ & $\mathrm{~S} / 32,660.16$ & $\mathrm{~S} / 58,913.46$ & $\mathrm{~S} / 59,852.25$ & $\mathrm{~S} /$ & $94,316.06$ & $\mathrm{~S} /$ & $29,223.32$ & $29.43 \%$ \\
$10 \%$ & $\mathrm{~S} /-79,128.16$ & $\mathrm{~S} /-15,889.21$ & $\mathrm{~S} / 38,041.65$ & $\mathrm{~S} / 64,392.56$ & S/ $66,104.16$ & $\mathrm{~S} / 101,864.09$ & $\mathrm{~S} /$ & $45,035.46$ & $34.45 \%$ \\
\hline
\end{tabular}

Elaboración propia

De acuerdo a los resultados obtenidos podemos observar que, aunque nuestro proyecto es sensible a la variación del costo en la materia prima, no lo es tanto como a la demanda, ya que los valores disminuyen en menor proporción.

\subsubsection{Variable: costo mano de obra}

Finalmente, se evaluará la variación del costo de mano de obra ya que reconocemos que el recurso humano se convierte en parte fundamental para el funcionamiento de una empresa.

Tabla 86 Análisis de sensibilidad: costo mano de obra (expresado en soles).

\begin{tabular}{|c|c|c|c|c|c|c|c|c|}
\hline $\begin{array}{l}\text { Porcentaje de } \\
\text { variación }\end{array}$ & Año 0 & Año 1 & Año 2 & Año 3 & Año 4 & Año 5 & VAN & TIR \\
\hline$-10 \%$ & S/ - $79,128.16$ & $\mathrm{~S} /-18,644.18$ & S/ 30,954.46 & S/ 56,165.42 & S/ 58,091.83 & S/ 92,079.17 & S/ $25,145.26$ & $28.17 \%$ \\
\hline$-5 \%$ & S/ -79,128.16 & S/ - $20,588.03$ & S/ 29,116.57 & S/ 54,234.10 & S/ 55,426.39 & S/ 89,423.60 & S/ $18,745.04$ & $26.05 \%$ \\
\hline $0 \%$ & S/ -79,128.16 & S/ - $22,531.88$ & S/ 27,278.67 & S/ 52,302.78 & S/ 52,559.47 & S/ 86,768.04 & S/ 12,246.91 & $23.89 \%$ \\
\hline $5 \%$ & S/ - $79,128.16$ & S/ - $24,475.74$ & S/ $25,440.77$ & S/ 50,371.46 & S/ 49,692.56 & S/ 84,112.48 & S/ $\quad 5,748.80$ & $21.72 \%$ \\
\hline $10 \%$ & S/ $-79,128.16$ & S/ $-26,419.59$ & S/ $23,602.87$ & S/ $48,440.14$ & S/ 46,825.64 & S/ $81,456.91$ & -749.33 & $19.52 \%$ \\
\hline
\end{tabular}

Elaboración propia 
Identificamos que, la variación en el costo de mano de obra no tendrá gran impacto en los resultados de la evaluación ya que llegando a un incremento del $10 \%$ en el costo, los valores recién empiezan a reducir cambiando el resultado del proyecto en un mínimo porcentaje. Este resultado nos indica que el proyecto es poco sensible a la variación del costo de mano de obra.

\subsubsection{Análisis de escenarios.}

Se evaluará las distintas desviaciones que pueden experimentar un grupo de variables a lo largo de la vida del proyecto, dejando a las demás constantes. Lo habitual es analizar tres escenarios, además del escenario probable, dos escenarios adicionales, el escenario optimista y el pesimista.

El optimista, donde el VAN deberá ser superior al esperado, el pesimista con un VAN inferior al esperado y el más probable donde el VAN es igual al esperado. 


\subsubsection{Escenario pesimista}

Tabla 87

Flujo de caja proyectado: escenario pesimista (expresado en soles).

\begin{tabular}{|c|c|c|c|c|c|c|c|}
\hline & Variación & AÑ̃ 0 & AÑ O 1 & AÑ̃ 2 & AÑNO 3 & AÑ̃ 4 & AÑ̃ 5 \\
\hline Ingresos & $-5 \%$ & & $146,135.76$ & $263,107.04$ & $323,108.82$ & $390,068.03$ & $470,967.56$ \\
\hline Costos Variables & & & $(63,105.39)$ & $(113,609.24)$ & $(139,558.87)$ & $(168,491.35)$ & $(203,421.92)$ \\
\hline Costos Fijos & $5 \%$ & & $(69,422.31)$ & $(73,463.78)$ & $(77,357.47)$ & $(100,305.25)$ & $(114,674.97)$ \\
\hline \multicolumn{2}{|l|}{ Gastos de Administración } & & $(22,416.62)$ & $(23,325.65)$ & $(24,297.86)$ & $(25,304.85)$ & $(25,758.30)$ \\
\hline \multicolumn{2}{|l|}{ Gastos de Ventas } & & $(24,206.00)$ & $(39,573.85)$ & $(41,729.56)$ & $(55,343.15)$ & $(57,580.00)$ \\
\hline \multicolumn{2}{|l|}{ Utilidad Operativa } & & $(33,014.55)$ & $13,134.52$ & $40,165.06$ & $40,623.44$ & $69,532.38$ \\
\hline \multicolumn{2}{|c|}{ UTILIDAD ANTES DE IMPUESTOS } & & $(33,014.55)$ & $13,134.52$ & $40,165.06$ & $40,623.44$ & $69,532.38$ \\
\hline \multicolumn{2}{|c|}{ Impuesto a la renta } & & 0.00 & $(1,313.45)$ & $(4,016.51)$ & $(4,062.34)$ & $(8,373.30)$ \\
\hline \multicolumn{2}{|l|}{ UTILIDAD NETA } & & $(33,014.55)$ & $11,821.07$ & $36,148.55$ & $36,561.10$ & $61,159.08$ \\
\hline \multicolumn{2}{|c|}{ Variación neta activo y pasivo corriente } & & $(664.27)$ & $1,904.01$ & $2,627.48$ & 50.42 & $8,024.57$ \\
\hline \multicolumn{2}{|c|}{ Depreciación operación } & & $3,001.00$ & $3,041.00$ & $3,081.00$ & $3,140.00$ & $3,895.00$ \\
\hline \multicolumn{2}{|l|}{ Depreciación adminitración } & & 773.00 & 773.00 & 798.00 & 818.00 & 243.00 \\
\hline \multicolumn{2}{|l|}{ Depreciación ventas } & & 140.00 & 140.00 & 160.00 & 180.00 & 100.00 \\
\hline \multicolumn{2}{|c|}{ FLUJO DE CAJA OPERATIVO } & & S/ -29,764.82 & S/ $17,679.08$ & $\mathrm{~S} / \mathrm{42,815.03}$ & S/ 40,749.51 & S/ 73,421.65 \\
\hline \multicolumn{2}{|c|}{ Inversión Tangible } & $(31,440.00)$ & $(300.00)$ & $(500.00)$ & $(2,390.00)$ & $(2,850.00)$ & $(300.00)$ \\
\hline \multicolumn{2}{|l|}{ Inversión Intangible } & $(20,348.00)$ & 0.00 & 0.00 & 0.00 & 0.00 & 0.00 \\
\hline \multicolumn{2}{|l|}{ Capital de Trabajo } & $(27,340.16)$ & 0.00 & 0.00 & 0.00 & 0.00 & 0.00 \\
\hline \multicolumn{2}{|c|}{ FLUJO DE CAJA DE CAPITAL } & $(79,128.16)$ & $(300.00)$ & $(500.00)$ & $(2,390.00)$ & $(2,850.00)$ & $(300.00)$ \\
\hline
\end{tabular}

FLUJO DE CAJA ECONOMICO

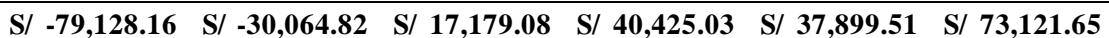

\begin{tabular}{cccc}
\hline COK & VANE & TIRE \\
\hline $19.78 \%$ & S/ & $-20,652.93$ & $12.60 \%$ \\
\hline
\end{tabular}

Elaboración propia 


\subsubsection{Escenario probable}

Tabla 88

Flujo de caja proyectado: escenario probable (expresado en soles).

\begin{tabular}{|c|c|c|c|c|c|c|}
\hline & AÑO 0 & AÑO 1 & AÑO 2 & AÑO 3 & AÑO 4 & AÑO 5 \\
\hline UTILIDAD NETA & & $(25,481.61)$ & $21,920.66$ & $48,026.30$ & $51,221.05$ & $74,805.47$ \\
\hline Variación de efectivo & & $(664.27)$ & $1,904.01$ & $2,627.48$ & 50.42 & $8,024.57$ \\
\hline Depreciación operación & & $3,001.00$ & $3,041.00$ & $3,081.00$ & $3,140.00$ & $3,895.00$ \\
\hline Depreciación administración & & 773.00 & 773.00 & 798.00 & 818.00 & 243.00 \\
\hline Depreciación ventas & & 140.00 & 140.00 & 160.00 & 180.00 & 100.00 \\
\hline FLUJO DE CAJA OPERAT & IIVO & $(22,231.88)$ & 27,778.67 & $54,692.78$ & $55,409.47$ & $87,068.04$ \\
\hline Inversión Tangible & $(31,440.00)$ & $(300.00)$ & $(500.00)$ & $(2,390.00)$ & $(2,850.00)$ & $(300.00)$ \\
\hline Inversión Intangible & $(20,348.00)$ & 0.00 & 0.00 & 0.00 & 0.00 & 0.00 \\
\hline Capital de Trabajo & $(27,340.16)$ & 0.00 & 0.00 & 0.00 & 0.00 & 0.00 \\
\hline FLUJO DE CAJA DE CAP & $(79,128.16)$ & $(300.00)$ & $(500.00)$ & $(2,390.00)$ & $(2,850.00)$ & $(300.00)$ \\
\hline FLUJO DE CAJA ECONO & $(79,128.16)$ & $(22,531.88)$ & 27,278.67 & $52,302.78$ & $52,559.47$ & $86,768.04$ \\
\hline Efectivo y equivalente de efecti & ivo al inicio de & $24,340.16$ & $1,808.28$ & $29,086.95$ & $81,389.72$ & $133,949.19$ \\
\hline \multicolumn{3}{|c|}{ Efectivo y equivalente de efectivo al final $S / \quad 1,808.28$} & S/ 29,086.95 & $\mathrm{S} / \mathrm{81,389.72}$ & S/ 133,949.19 & S/ 220,717.24 \\
\hline
\end{tabular}

\begin{tabular}{|c|c|c|}
\hline COK & VANE & TIRE \\
\hline $19.78 \%$ & S/ $12,246.91$ & $23.89 \%$ \\
\hline
\end{tabular}

Elaboración propia 


\subsubsection{Escenario optimista}

Tabla 89

Flujo de caja proyectado: escenario optimista (expresado en soles).

\begin{tabular}{|c|c|c|c|c|c|c|c|c|}
\hline & Variación & AÑ̃ 0 & & AÑ̃ 1 & AÑ O 2 & AÑ̃ 3 & AÑO 4 & AÑO 5 \\
\hline Ingresos & $5 \%$ & & & $161,518.47$ & $290,802.52$ & $357,120.28$ & $431,127.82$ & $520,543.09$ \\
\hline Costos Variables & & & & $(69,748.06)$ & $(125,568.11)$ & $(154,249.28)$ & $(186,227.28)$ & $(224,834.75)$ \\
\hline Costos Fijos & $-5 \%$ & & & $(63,096.47)$ & $(66,756.85)$ & $(70,283.52)$ & $(91,051.41)$ & $(104,124.49)$ \\
\hline Gastos de Administración & & & & $(22,416.62)$ & $(23,325.65)$ & $(24,297.86)$ & $(25,304.85)$ & $(25,758.30)$ \\
\hline Gastos de Ventas & & & & $(24,206.00)$ & $(39,573.85)$ & $(41,729.56)$ & $(55,343.15)$ & $(57,580.00)$ \\
\hline Utilidad Operativa & & & & $(17,948.68)$ & $35,578.06$ & $66,560.06$ & $73,201.13$ & $108,245.55$ \\
\hline$\overline{\text { UTILIDAD ANTES DE IMP }}$ & UESTOS & & & $(17,948.68)$ & $35,578.06$ & $66,560.06$ & $73,201.13$ & $108,245.55$ \\
\hline Impuesto a la renta & & & & 0.00 & $(3,557.81)$ & $(7,496.47)$ & $(9,455.58)$ & $(19,793.69)$ \\
\hline UTILIDAD NETA & & & & $(17,948.68)$ & $32,020.25$ & $59,063.59$ & $63,745.55$ & $88,451.86$ \\
\hline Variación neta activo y pasivo & corriente & & & $(664.27)$ & $1,904.01$ & $2,627.48$ & 50.42 & $8,024.57$ \\
\hline Depreciación operación & & & & $3,001.00$ & $3,041.00$ & $3,081.00$ & $3,140.00$ & $3,895.00$ \\
\hline Depreciación adminitración & & & & 773.00 & 773.00 & 798.00 & 818.00 & 243.00 \\
\hline Depreciación ventas & & & & 140.00 & 140.00 & 160.00 & 180.00 & 100.00 \\
\hline FLUJO DE CAJA OPERA & TIVO & & $\mathbf{S} /$ & $-14,698.94$ & S/ 37,878.26 & S/ $65,730.06$ & S/ 67,933.97 & S/ $100,714.43$ \\
\hline Inversión Tangible & & $(31,440.00)$ & & $(300.00)$ & $(500.00)$ & $(2,390.00)$ & $(2,850.00)$ & $(300.00)$ \\
\hline Inversión Intangible & & $(20,348.00)$ & & 0.00 & 0.00 & 0.00 & 0.00 & 0.00 \\
\hline Capital de Trabajo & & $(27,340.16)$ & & 0.00 & 0.00 & 0.00 & 0.00 & 0.00 \\
\hline FLUJO DE CAJA DE CAF & ITAL & $(79,128.16)$ & & $(300.00)$ & $(500.00)$ & $(2,390.00)$ & $(2,850.00)$ & $(300.00)$ \\
\hline \multirow{3}{*}{\multicolumn{2}{|c|}{ FLUJO DE CAJA ECONOMICO }} & S/ $-79,128.16$ & S/ & $-14,998.94$ & S/ 37,378.26 & S/ 63,340.06 & S/ 65,083.97 & S/ $100,414.43$ \\
\hline & & COK & & VANE & TIRE & & & \\
\hline & & $19.78 \%$ & $\mathrm{~S} /$ & $43,620.09$ & $34.11 \%$ & & & \\
\hline
\end{tabular}

Elaboración propia

Para el análisis de escenarios se ha considerado el posible cambio de dos variables: el precio del producto y costo de la mano de obra.

En el escenario pesimista se consideró una disminución en el precio de 5\% y un incremento en el costo de mano de obra del mismo porcentaje, en el que obtenemos un VAN negativo y una TIR por debajo del costo de oportunidad, lo que nos indica que el proyecto es muy sensible a estos dos factores y podría convertirse en inviable si se da este escenario

En el escenario optimista se incrementó el precio del producto en un 5\% y se disminuyó el costo de mano de obra en el mismo porcentaje, como es de suponerse 
los resultados fueron aún más rentables que en el escenario esperado, por lo que en estos dos casos el proyecto resulta atractivo para el inversionista. 


\section{Conclusiones y recomendaciones}

\section{Conclusiones}

a. El proyecto cuyo objetivo es la producción y delivery de almuerzos saludable en la ciudad de Arequipa es viable comercial, técnica y financieramente, sumado a que según los estudios de las tendencias de consumo de los últimos años, el mercado saludable está atravesando un crecimiento constante.

b. La producción y delivery de almuerzos saludable se realizará bajo procesos técnicos diseñados especialmente para el desarrollo óptimo del servicio y mitigación de riesgos.

c. El mercado objetivo determinado es mujeres de 24 a 44 años que viven y/o laboran en los distritos de Yanahuara, Cayma y Cercado de Arequipa, que se encuentren en un nivel socioeconómico A/ B y C, con necesidad de alimentarse con comida saludable; asi mismo, se ha identificado que la competencia es escaza, hay una cantidad considerable de proveedores que cumplen nuestras exigencias de calidad y el precio fijado se equipara al que ofrece la competencia.

d. Se desarrollara la estrategia de marketing mix analizando el comportamiento de los mercados y de los consumidores, y se planificaran acciones referentes al producto, precio, plaza y distribución, promoción y publicidad, personas y procesos, de esta forma retener y fidelizar a los clientes mediante la satisfacción de sus necesidades.

e. Los costos y presupuestos fueron realizados en base a los resultados de nuestro estudio de mercado, pronosticando nuestras ventas para mercados abiertos de frecuencia diaria e interdiaria y cerrados o coorporativos de frecuencia diaria; así mismo, los costos y gastos estarán establecidos según la capacidad instalada de equipos y recurso humano. 
f. El Valor Actual Neto (VAN) es de de S/ 12,246.91, lo que hace que el proyecto sea beneficioso para el o los inversionistas, será financiado por recursos propios, adicionándole a esto la Tasa Interna de Retorno (TIR) de $23.89 \%$, mayor que nuestro Costo de Oportunidad de Capital COK de $19.78 \%$, garantizando de esta manera la rentabilidad del proyecto.

\section{Recomendaciones}

a. Debido a la creciente tendencia hacia el consumo de lo saludable, la alimentación saludable se convertirá en un negocio rentable y se reflejará en un incremento de la competencia, se recomienda analizar la importancia de generar alianzas estratégicas con gimnasios, clínicas estéticas dedicadas al cuidado de la salud, centros de entrenamiento funcionales, etc; para generar posibilidades de incremento en la demanda.

b. Es importante monitorear los procesos, verificar su cumplimiento y mejorarlos constantemente, enfocándolos siempre en satisfacer las necesidades del cliente.

c. Es relevante para el proyecto, monitorear el nivel de crecimiento que pueda presentar el negocio en los primeros dos años, ya que esto permitirá determinar la expansión a otros distritos y/o zonas de la Ciudad de Arequipa.

d. Se recomienda implementar planes de capacitación a los colaboradores del proyecto, en temas como: Calidad del Producto, Servicio al Cliente, Coaching Empresarial y Organizacional, de la misma forma verificar que las estrategias de marketing se estén desarrollando óptimamente lo que permita afianzar la marca y lograr la fidelización de los clientes.

e. Del $100 \%$ de encuestados, el $56 \%$ prefiere realizar pedidos diarios y el $44 \%$ contratar planes mensuales o semanales, lo que nos sugiere analizar una mayor promoción de planes mensuales para asegurar ventas e incrementarlas. Se sugiere que para una segunda etapa del 
proyecto se implementen productos adicionales a los almuerzos, tales como postres, snacks, según los requerimientos de los clientes.

f. Se recomienda realizar un seguimiento continuo a la planificación financiera para lograr los resultados proyectados y los beneficios esperados. 


\section{Índice de Figuras}

Figura 1 Naciones con más hombres y mujeres obesos. Información tomada de los resultados del estudio publicado en la revista The Lancet en el 2016 Recuperado de https://www.bbc.com/.... 19

Figura 2 Tasas globales de sobrepeso al 2014. Según estudios realizados por la Organización Mundial de la Salud. Recuperado de https://cnnespanol.cnn.com/ 20

Figura 3 Tasas globales de obesidad al 2014. Según estudios realizados por la Organización Mundial de la Salud. Recuperado de https://cnnespanol.cnn.com/

Figura 4 Etiquetado propuesto por el MINSA. Octágonos de color rojo con marco negro y blanco, advierten sobre el contenido de azúcar, sodio, grasas saturadas y grasas trans.

Recuperado de https://elcomercio.pe/

Figura 5 Etiquetado propuesto y aprobado por el Congreso. Semáforo nutricional. Recuperado de https://elcomercio.pe/....

Figura 6 Producto Bruto Interno 2008-2019. Datos tomados del Banco Central de Reserva del Perú y elaborado por ProInversión. $\left(^{*}\right)$ Cifras estimadas.

Figura 7 Tasas de Crecimiento Económico: Proyecciones Latinoamérica 2017-2018. Datos tomados del Banco Central de Reserva para Perú y Fondo Monetario Internacional el resto de países latinoamericanos. Elaborado por ProInversión.

Figura 8 Acontecimiento que influenciaron en la economía 2017. Datos tomados de Andina y otras fuentes.

Figura 9 Región Arequipa: evolución del PBI real 2000-2016. Datos tomados de Instituto Nacional de Estadística e Informática (INEI), Ministerio de Energía y Minas (MINEM). Elaborado por Aurum Consultoría y Mercado.

Figura 10 Región Arequipa: evolución promedio anual del gasto mensual del hogar 2010-2016. Datos tomados de la Encuesta Nacional de Hogares Enaho-INEI. Elaborado por Aurum Consultoría y Mercado.

Figura 11 Inflación Mensual (Nacional-Arequipa) Datos tomados del Instituto Nacional de Estadística e Informática-INEI.

Figura 12 Inflación mensual (Nacional-Arequipa-Lima Metropolitana) Datos tomados del Instituto Nacional de Estadística e Informática-INEI.

Figura 13 Perú: Empresas según actividad económica 2016. Datos tomados del Instituto Nacional de Estadística e Informática-INEI y elaborado por el Dpto. de Estudios Económicos de la Cámara de Comercio e Industria de Arequipa. 
Figura 14 Evolución actual de la actividad de restaurantes: 2016-2018. Datos tomados del Instituto Nacional de Estadística e Informática - INEI Encuesta Mensual de Restaurantes.

Figura 15 Variación en el sector restaurantes por tipo de comida. Datos tomados del Instituto Nacional de Estadística e Informática - INEI Encuesta Mensual de Restaurantes 50

Figura 16 Principales establecimientos registrados en las municipalidades al 2015. Datos tomados del Instituto Nacional de Estadística e Informática-INEI Y Registro Nacional de Municipalidades del 2016

Figura 17 ¿Qué significa tener una vida saludable? Datos tomados de Estudio de Vida Saludable a nivel nacional dirigido por Gustavo Yrala - DATUM. Recuperado de https://www.mercadonegro.pe/datum-presenta-estudio-sobre-vida-saludable/..... 52

Figura 18 ¿Por qué es difícil llevar una vida saludable? Datos tomados de Estudio de Vida Saludable a nivel nacional dirigido por Gustavo Yrala - DATUM. Recuperado de https://www.mercadonegro.pe/datum-presenta-estudio-sobre-vida-saludable/. 53

Figura 19 Hábitos alimenticios. Datos tomados de Estudio de Vida Saludable a nivel nacional dirigido por Gustavo Yrala - DATUM. Recuperado de https://www.mercadonegro.pe/datumpresenta-estudio-sobre-vida-saludable/

Figura 20 Presentación y empaque del producto ofrecido por la empresa FIT LUNCH............ 61

Figura 21 Presentación y empaque del producto ofrecido por la empresa SANTE................... 61

Figura 22 Presentación y empaque del producto ofrecido por la empresa MANSANA. ........... 62

Figura 23 Diagrama de las cinco fuerzas de Porter - Clave para el éxito de una empresa. Tomado de http://www.5fuerzasdeporter.com/............................................................................. 70

Figura 24 Factores que generan la rivalidad entre competidores......................................... 73

Figura 25 Alternativas de comida saludable en la ciudad de Arequipa. .................................. 80

Figura 26 Esquema de generación de contactos................................................................... 84

Figura 27 Participación de mercado de la competencia. Datos obtenidos de la encuesta............ 87

Figura 28 Marcas de competidores directos en el mercado local. .......................................... 89

Figura 29 Factores de criticidad en la industria de los restaurantes...................................... 90

Figura 30 Población en edad de trabajar segmentado por edades. Información tomada del Instituto Nacional de Estadística e Informática INEI y elaborado por el Dpto. de Estudios

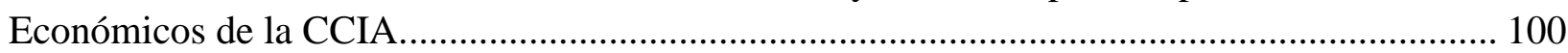


Figura 31 Resultados de Nivel de Ingresos de las personas encuestadas. Datos tomados de las encuestas realizadas.

Figura 32 Resultados de pregunta 1 ¿Consumes comida saludable? Datos tomados de las encuestas realizadas.

Figura 33 Resultados de pregunta 2 ¿Estarías dispuesto a consumir comida saludable? Datos tomados de las encuestas realizadas.

Figura 34 Resultados de pregunta 3 ¿Con qué elementos asocias la comida saludable? Datos tomados de las encuestas realizadas.

Figura 35 Resultados de pregunta 4 ¿Por qué consume comida saludable? Datos tomados de las encuestas realizadas.

Figura 36 Resultados de pregunta 5 ¿Con qué frecuencia consume comida saludable? Datos tomados de las encuestas realizadas.

Figura 37 Resultados de pregunta 6 ¿De dónde suele comer comida saludable? Datos tomados de las encuestas realizadas.

Figura 38 Resultados de pregunta 7 ¿Qué factores te orillarían a no consumir comida saludable en un restaurante o un servicio delivery? Datos tomados de las encuestas realizadas.

Figura 39 Resultados de pregunta 8 Restaurantes o servicios delivery de comida saludable que consume. Datos tomados de las encuestas realizadas.

Figura 40 Resultados de pregunta 9 ¿Qué es lo que más le llama la atención cuando acude a un restaurante o pide un servicio delivery. Datos tomados de las encuestas realizadas.

Figura 41 Resultados de pregunta 10. ¿Qué debe contener un almuerzo saludable? Datos tomados de las encuestas realizadas.

Figura 42 Resultados de pregunta 11 ¿Cuánto pagaría usted por un menú de comida saludable?

Datos tomados de las encuestas realizadas.

Figura 43 Resultados de pregunta 12 ¿A qué hora suele almorzar? Datos tomados de las encuestas realizadas.

Figura 44 Resultados de pregunta 13 ¿Es importante que los productos muestren información nutricional y valores calóricos? Datos tomados de las encuestas realizadas.

Figura 45 Resultados de pregunta 14 Si una empresa le ofrece el servicio delivery de comida saludable en su casa o trabajo a la hora que usted lo requiere, asegurándole puntualidad, buena presentación y variedad de platos. ¿Estarías dispuesto a contratar este servicio? Datos tomados de las encuestas realizadas. 
Figura 46 Resultados de pregunta 15 ¿Qué tipo de planes recomiendas? Datos tomados de las encuestas realizadas.

Figura 47 Resultados de pregunta 16 ¿En qué tipo de envase te gustaría recibir el producto ?

Datos tomados de las encuestas realizadas.

Figura 48 Resultados de pregunta 17 ¿De qué manera te gustaría comunicarte con el servicio?

Datos tomados de las encuestas realizadas.

Figura 49 Resultados de pregunta 18 ¿Qué consideras más relevante en este servicio? Datos tomados de las encuestas realizadas.

Figura 50 Resultados de pregunta 19 ¿A qué medio de comunicación acude usualmente? Datos tomados de las encuestas realizadas. 118

Figura 51 Resultados de pregunta 20 ¿Qué redes sociales frecuenta? Datos tomados de las encuestas realizadas.

Figura 52 : Estilos de vida proactivo y reactivo. Tomada de Arellano (2017) "LATIR: Los

Estilos de Vida de la Nueva Sociedad Peruana y Latinoamericana”.

Figura 53 Marca de envases ecológicos QAYA. Tomada de catálogo enviado por empresa.... 138

Figura 54 Imagotipo elegido para el proyecto de comida saludable.

Figura 55 Modelo 1 de imagen informativa. 145

Figura 56 Modelo 2 de imagen informativa. 145

Figura 57 Publicidad para enviar diariamente el menú 146

Figura 58 Modelo 3 de imagen informativa. 146

Figura 59 Ventajas de implementar el Branding. 150

Figura 60 Cuatro factores clave del Brand Equity. 151

Figura 61 Ubicación del proyecto según la Clasificación Internacional de Productos y Servicios.

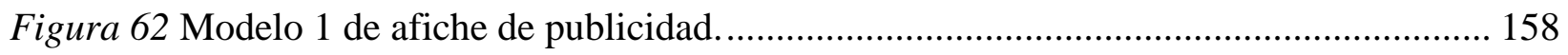

Figura 63 Modelo 2 de afiche de publicidad..................................................................... 158

Figura 64 Modelo cartilla de información nutricional de opción 1........................................ 159

Figura 65 Modelo de cartilla información nutricional de opción 2 ....................................... 160 
Figura 66 Mapa de ubicación de pedidos. 177

Figura 67 DOP-Flujo general del servicio. 183

Figura 68 DOP-Elaboración del menú. 184

Figura 69 DOP-Ventas. 185

Figura 70 DOP-Abastecimiento de materia prima e insumos. 186

Figura 71 DOP-Servicio al cliente. 187

Figura 72 DOP-Gestión de residuos. 188

Figura 73 Preparación del menú. 189

Figura 74 DOP-Delivery del producto. 190

Figura 75 Relación de maquinaria necesaria para la puesta en marcha. 192

Figura 76 Relación de equipos necesarios para la puesta en marcha. 193

Figura 77 Lay-out simple de planta. 194

Figura 78 Lay-out estructurado de planta. 196

Figura 79 Plan de delimitación de sectores - Distrito de Arequipa. Tomado de la Municipalidad Provincial de Arequipa. 204

Figura 80 Beneficios laborales de los trabajadores de una MICROEMPRESA. Datos tomados de la Ley MYPE. Recuperado de http://emprender.sunat.gob.pe/si-tengo-trabajadores-queobligaciones-y-beneficios-laborales-existen

Figura 81 Beneficios laborales de los trabajadores de una PEQUEÑA EMPRESA. Datos tomados de la Ley MYPE. Recuperado de http://emprender.sunat.gob.pe/si-tengo-trabajadoresque-obligaciones-y-beneficios-laborales-existen.

Figura 82 Estructura organizacional diseñada según las necesidades y tamaño de la organización 226

Figura 83 Paquete de compensación total a los empleados según las últimas tendencias. 233

Figura 84 Beneficios del salario emocional. Recuperado de http://aevum.com.mx/..... 235

Figura 85 Perú: Remuneración promedio mensual de las empresas de servicios, según segmento empresarial, 2016. Datos tomados del Instituto Nacional de Estadística e Informática - INEI Encuesta Económica Anual 2017. 
Figura 86 Perú: Remuneración promedio mensual de las empresas de servicios, según actividad económica, 2016. Datos tomados del Instituto Nacional de Estadística e Informática - INEI Encuesta Económica Anual 2017.

Figura 87 Perú: Remuneración promedio mensual de las empresas de servicios, por segmento empresarial, según actividad económica, 2016. Datos tomados del Instituto Nacional de Estadística e Informática - INEI Encuesta Económica Anual 2017.

Figura 88 Criterios para definir el estrato empresarial. Recuperado de https://www.camaraarequipa.org.pe/.

Figura 89 Proceso global de la administración de recursos humanos. Tomada del libro Administración de recursos humanos (Chiavenato, 2007).

Figura 90 Gráfico de la rentabilidad del bono de Estados Unidos 5 años durante los últimos 10 años. Recuperado de https://es.investing.com/rates-bonds/u.s.-5-year-bond-yield-streaming-chart

Figura 91 Promedio rendimiento de la industria según Dow Jones Industrial Average de los ultimos 10 años. Recuperado de https://www.investing.com/indices/us-30-chart .... 261

Figura 92 Diagrama comparativo del presupuesto a través del tiempo. Tomado de Presupuestos. Enfoque de gestión, planeación y control de recursos (Burbano, 2005). 265

Figura 93 Distribución de personas según NSE 2018 - Departamento Urbano. Datos tomados de APEIM: Niveles Socioeconómicos 2018.

Figura 94 Perfil de hogares segun NSE 2018. Perú Urbano. Datos tomados de APEIM: Niveles Socioeconómicos 2018.

Figura 95 Perfil de personas de 18 años a mas que usaron internet según NSE 2018. Datos tomados de APEIM: Niveles Socioeconómicos 2018.

Figura 96 Identidades coorporativas presentadas en el Focus Group.

Figura 97 Cartilla informativa de valores nutricionales presentada en el Focus Group. 344

Figura 98 Platos preparados para desarrollo de Focus Group. 345

Figura 99 Menú completo preparado para Focus Group.

Figura 100 Desarrollo de Focus Group. 346

Figura 101 Betas promedio por sector actualizado a enero 2018. Recuperado de http://pages.stern.nyu.edu/ adamodar/New_Home_Page/datafile/Betas.html..... 


\section{Índice de tablas}

Tabla 1 Resultados de indicadores: grupo etario de 5 a 9 años ............................................. 26

Tabla 2 Resultados de indicadores: grupo etario de 10 a 19 años ........................................... 26

Tabla 3 Resultados de indicadores: grupos etarios de 20 a 29 años y 30 a 59 años .................. 27

Tabla 4 Resultados de indicadores: grupo etarios mayor de 60 años....................................... 28

Tabla 5 Variaciones del sector alojamiento y restaurantes: diciembre 2017 (Año base 2007)... 47

Tabla 6 Análisis de las características del servicio de FIT LUNCH....................................... 58

Tabla 7 Análisis de las características del servicio de MANSANA. ........................................... 59

Tabla 8 Análisis de las características del servicio de SANTÉ. ............................................. 60

Tabla 9 Matriz de atractividad del mercado....................................................................... 76

Tabla 10 Análisis de características de competidores indirectos........................................... 81

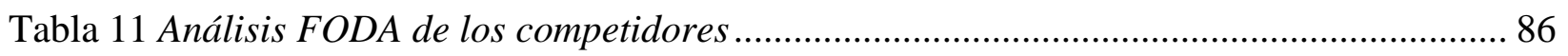

Tabla 12 Fortalezas y debilidades de la competencia. ........................................................... 88

Tabla 13 Análisis MPC de la Industria ............................................................................... 91

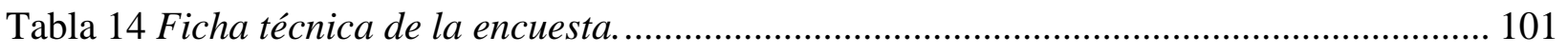

Tabla 15 Cantidad de mujeres de entre 14 y 44 años que trabajan en la zona urbana de los distritos de Arequipa, Cayma y Yanahuara al 2017............................................................ 103

Tabla 16 Tamaño de muestra........................................................................................ 104

Tabla 17 Cuadro de participación de cada estilo de vida LATIR en distintos países de América

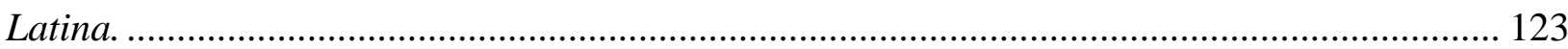

Tabla 18 Mercado potencial: Cantidad de mujeres de entre 14 y 44 años que trabajan en la zona urbana de los distritos de Arequipa, Cayma y Yanahuara al 2017. ................................ 127

Tabla 19 Mercado disponible ¿Consumes comida saludable? ............................................. 128

Tabla 20 Mercado efectivo: Intención de compra del producto o servicio .............................. 129 
Tabla 21 Intención de compra del producto o servicio. ..................................................... 130

Tabla 22 Calculo de mercado objetivo aplicando principio McDaniel. .................................. 131

Tabla 23 Frecuencia con la que se compra un menú saludable ............................................ 131

Tabla 24 Número de menús saludables al día. ..................................................................... 133

Tabla 25 Periodicidad de compra .................................................................................... 134

Tabla 26 Proyección de ventas según demanda diaria. ....................................................... 134

Tabla 27 Estructura de costos (expresado en soles) ........................................................... 140

Tabla 28 Precio almuerzo FIT FOOD (expresado en soles) ................................................. 140

Tabla 29 Presupuesto de creación de marca: Branding (expresado en soles)......................... 148

Tabla 30 Presupuesto registro de marca en Indecopi. ....................................................... 154

Tabla 31 Presupuesto de estrategias publicitarias (expresado en soles). ................................ 157

Tabla 32 Plan de Capacitación (expresado en soles).......................................................... 162

Tabla 33 Tiempo de demora en cocción por porción. ............................................................. 174

Tabla 34 Capacidad instalada de equipos principales ....................................................... 175

Tabla 35 Tiempo estimado de demora por porción.............................................................. 175

Tabla 36 Capacidad de producción por porción.................................................................... 176

Tabla 37 Capacidad instalada de cajas de reparto. ............................................................... 176

Tabla 38 Ubicación exacta de pedidos para analizar. .......................................................... 178

Tabla 39 Control de tiempos de reparto. ............................................................................... 179

Tabla 40 Cuadro comparativo de análisis de proveedores. ................................................. 180

Tabla 41 Tabla comparativa de requisitos, tiempos y costo de licencias de funcionamiento en los distritos de Arequipa, Cayma y Yanahuara.......................................................................... 205

Tabla 42 Requisitos para la inscripción al Régimen MYPE.................................................. 213

Tabla 43 Análisis MPC de las posibles ubicaciones de la planta de producción. .................... 219 
Tabla 44 Cuadro comparativo de aspectos diferenciadores en relación a nuestra competencia. 224

Tabla 45 Escala remunerativa restaurantes El Colorado. ....................................................... 240

Tabla 46 Recurso humano - Mano de obra directa (expresado en soles). ............................... 241

Tabla 47 Recurso humano - Administración (expresado en soles). ......................................... 241

Tabla 48 Recurso humano - Ventas (expresado en soles)................................................... 242

Tabla 49 Tabla de porcentajes de depreciación ....................................................................... 249

Tabla 50 Activo fijo tangible (expresado en soles). ............................................................. 249

Tabla 51 Activo Fijo Intangible (expresado en soles). ....................................................... 250

Tabla 52 Capital de Trabajo (expresado en soles)............................................................ 252

Tabla 53 Inversión total del proyecto (expresado en soles). ................................................... 253

Tabla 54 Inversiones futuras en activos tangibles (expresado en soles). ................................ 254

Tabla 55 Financiamiento (expresado en soles). ............................................................... 255

Tabla 56 Presupuesto de ventas (expresado en soles).......................................................... 268

Tabla 57 Presupuesto de ventas mensual - Año 1 (expresado en soles).................................... 269

Tabla 58 Presupuesto de ventas mensual - Año 2 (expresado en soles).................................. 269

Tabla 59 Presupuesto de ventas mensual - Año 3 (expresado en soles)................................... 270

Tabla 60 Presupuesto de ventas mensual - Año 4 (expresado en soles)................................... 270

Tabla 61 Presupuesto de ventas mensual - Año 5 (expresado en soles).................................. 271

Tabla 62 Presupuesto estimado de materia prima, envases y materiales (expresado en soles) 273

Tabla 63 Presupuesto de mano de obra (expresado en soles) ................................................. 274

Tabla 64 Gastos indirectos de fabricación (expresado en soles). ......................................... 275

Tabla 65 Depreciación Activo fijo - Producción (expresado en soles).................................... 276

Tabla 66 Presupuesto de costo de ventas (expresado en soles)............................................. 277

Tabla 67 Gastos de administración - Varios (expresado en soles).......................................... 278 
Tabla 68 Depreciación Activo fijo - Administración (expresado en soles)............................. 278

Tabla 69 Gastos de administración - Planilla (expresado en soles)..................................... 279

Tabla 70 Gastos de ventas diversos (expresado en soles). .................................................. 280

Tabla 71 Gastos de ventas - Planilla (expresado en soles).................................................. 281

Tabla 72 Depreciación Activo fijo - Ventas (expresado en soles). ......................................... 281

Tabla 73 Estado de Ganancias y Pérdidas Proyectado (expresado en soles).......................... 283

Tabla 74 Balance General Proyectado (expresado en soles). .............................................. 285

Tabla 75 Variación de activo y pasivo corriente (expresado en soles). ................................... 285

Tabla 76 Flujo de caja proyectado (expresado en soles). ................................................... 287

Tabla 77 Valorización de la empresa por descuento de flujos (expresado en soles) ................. 288

Tabla 78 VAN y TIR de la perpetuidad (expresado en soles). ............................................... 289

Tabla 79 Tasa Interna de Retorno (expresado en soles). ................................................... 291

Tabla 80 Valor Actual Neto (expresado en soles). ............................................................... 292

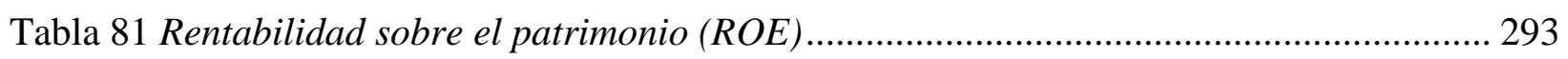

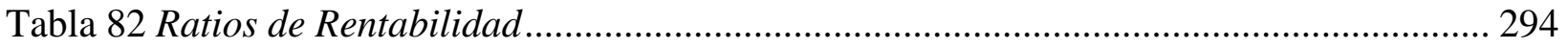

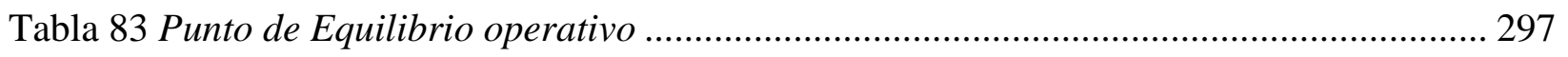

Tabla 84 Análisis de Sensibilidad: demanda (expresado en soles). ........................................ 298

Tabla 85 Análisis de sensibilidad: costo materia prima........................................................ 299

Tabla 86 Análisis de sensibilidad: costo mano de obra (expresado en soles).......................... 299

Tabla 87 Flujo de caja proyectado: escenario pesimista (expresado en soles). ....................... 301

Tabla 88 Flujo de caja proyectado: escenario probable (expresado en soles). ....................... 302

Tabla 89 Flujo de caja proyectado: escenario optimista (expresado en soles). ....................... 303

Tabla 90 Rentabilidad del bono de Estados Unidos 5 años. ................................................. 351

Tabla 91 Dow Jones rentabilidad promedio de la industria DJI. ......................................... 353 
Tabla 92 Información histórica riesgo país.

Tabla 93 Inflación promedio anual de EEUU

Tabla 94 Inflación promedio anual de Perú 356

Tabla 95 Tabla nutricional de opciones de entradas para el menú saludable. 358

Tabla 96 Tabla nutricional de opciones de platos de fondo para el menú saludable (Parte 1). 359

Tabla 97 Tabla nutricional de opciones de platos de fondo para el menú saludable (Parte 2). 360

Tabla 98 Tabla nutricional de opciones de platos de fondo para el menú saludable (Parte 3). 361 
Anexo I Resultados datos socioeconómicos APEIM - NSE 2018

DISTRIBUCIÓN DE PERSONAS SEGÚN NSE 2018 - DEPARTAMENTO URBANO

\begin{tabular}{|c|c|c|c|c|c|}
\hline \multirow{2}{*}{ DEPARTAMENTO } & \multicolumn{5}{|c|}{ PERSONAS - NIVEL SOCIOECONÓMICO - URBANO (\%) } \\
\hline & TOTAL & AB & C & D & $\mathbf{E}$ \\
\hline Amazonas & $100 \%$ & 3.8 & 23.8 & 35.3 & 37.1 \\
\hline Ancash & $100 \%$ & 7.8 & 39.9 & 36.6 & 15.7 \\
\hline Apurimac & $100 \%$ & 4.2 & 17.5 & 30.7 & 47.6 \\
\hline Arequipa & $100 \%$ & 17.7 & 40.9 & 32.7 & 8.7 \\
\hline Ayacucho & $100 \%$ & 4.0 & 13.2 & 31.6 & 51.2 \\
\hline Cajamarca & $100 \%$ & 6.6 & 22.4 & 41.0 & 30.0 \\
\hline Cusco & $100 \%$ & 8.4 & 17.9 & 26.1 & 47.6 \\
\hline Huancavelica & $100 \%$ & 1.4 & 15.3 & 28.7 & 54.6 \\
\hline Huanuco & $100 \%$ & 8.1 & 22.9 & 35.2 & 33.8 \\
\hline Ica & $100 \%$ & 10.7 & 43.2 & 40.5 & 5.6 \\
\hline Junin & $100 \%$ & 5.7 & 23.3 & 37.5 & 33.5 \\
\hline La Libertad & $100 \%$ & 10.8 & 33.4 & 34.7 & 21.1 \\
\hline
\end{tabular}

Figura 93 Distribución de personas según NSE 2018 - Departamento Urbano.

Datos tomados de APEIM: Niveles Socioeconómicos 2018.

\section{PERFIL DE HOGARES SEGÚN NSE 2018 - PERÚ URBANO}

\begin{tabular}{|l|c|c|c|c|c|c|c|c|}
\hline & Total & NSE A & NSE B & NSE C & NSE C1 & NSE C2 & NSE D & NSE E \\
\hline Servicio doméstico & $4.3 \%$ & $73.4 \%$ & $13.6 \%$ & $2.3 \%$ & $3.2 \%$ & $0.9 \%$ & $0.3 \%$ & $0.0 \%$ \\
\hline Auto & $11.1 \%$ & $87.0 \%$ & $39.4 \%$ & $9.7 \%$ & $11.6 \%$ & $6.9 \%$ & $2.0 \%$ & $0.2 \%$ \\
\hline Computadora & $42.4 \%$ & $97.5 \%$ & $88.8 \%$ & $63.5 \%$ & $72.6 \%$ & $49.0 \%$ & $20.6 \%$ & $4.2 \%$ \\
\hline Lavadora & $36.6 \%$ & $95.0 \%$ & $88.8 \%$ & $55.5 \%$ & $65.9 \%$ & $38.9 \%$ & $12.7 \%$ & $1.3 \%$ \\
\hline Refrigeradora & $64.9 \%$ & $99.0 \%$ & $97.4 \%$ & $88.5 \%$ & $92.9 \%$ & $81.5 \%$ & $54.8 \%$ & $15.5 \%$ \\
\hline Horno microondas & $26.1 \%$ & $94.5 \%$ & $73.5 \%$ & $36.2 \%$ & $44.3 \%$ & $23.3 \%$ & $6.5 \%$ & $0.9 \%$ \\
\hline Radio & $48.4 \%$ & $46.5 \%$ & $43.5 \%$ & $45.2 \%$ & $44.6 \%$ & $46.1 \%$ & $48.6 \%$ & $57.1 \%$ \\
\hline TV a color & $89.8 \%$ & $100.0 \%$ & $99.1 \%$ & $97.6 \%$ & $98.3 \%$ & $96.4 \%$ & $90.7 \%$ & $68.3 \%$ \\
\hline TV Blanco negro & $4.0 \%$ & $1.9 \%$ & $2.2 \%$ & $2.1 \%$ & $1.8 \%$ & $2.5 \%$ & $4.3 \%$ & $8.2 \%$ \\
\hline Equipo de sonido & $41.3 \%$ & $71.0 \%$ & $68.5 \%$ & $52.2 \%$ & $56.5 \%$ & $45.2 \%$ & $32.8 \%$ & $16.1 \%$ \\
\hline DVD & $49.0 \%$ & $65.6 \%$ & $64.2 \%$ & $56.2 \%$ & $58.4 \%$ & $52.6 \%$ & $45.4 \%$ & $31.0 \%$ \\
\hline Video grabadora & $0.9 \%$ & $6.8 \%$ & $2.8 \%$ & $0.9 \%$ & $1.2 \%$ & $0.5 \%$ & $0.3 \%$ & $0.1 \%$ \\
\hline Plancha & $69.8 \%$ & $96.4 \%$ & $95.0 \%$ & $87.2 \%$ & $90.2 \%$ & $82.5 \%$ & $62.1 \%$ & $33.7 \%$ \\
\hline Licuadora & $74.2 \%$ & $98.6 \%$ & $96.3 \%$ & $89.0 \%$ & $91.7 \%$ & $84.9 \%$ & $69.0 \%$ & $40.7 \%$ \\
\hline Cocina a gas & $93.8 \%$ & $95.8 \%$ & $97.7 \%$ & $97.5 \%$ & $97.8 \%$ & $97.1 \%$ & $94.1 \%$ & $84.3 \%$ \\
\hline Maquina de coser & $11.0 \%$ & $17.7 \%$ & $19.1 \%$ & $13.5 \%$ & $15.1 \%$ & $10.9 \%$ & $8.6 \%$ & $4.7 \%$ \\
\hline Bicicleta & $20.9 \%$ & $36.3 \%$ & $29.7 \%$ & $22.6 \%$ & $23.5 \%$ & $21.1 \%$ & $18.3 \%$ & $14.8 \%$ \\
\hline Motocicleta & $8.9 \%$ & $4.4 \%$ & $7.5 \%$ & $10.4 \%$ & $10.6 \%$ & $10.3 \%$ & $9.8 \%$ & $6.5 \%$ \\
\hline Mototaxi & $6.4 \%$ & $0.0 \%$ & $1.3 \%$ & $6.0 \%$ & $4.6 \%$ & $8.2 \%$ & $8.6 \%$ & $7.5 \%$ \\
\hline
\end{tabular}

Figura 94 Perfil de hogares segun NSE 2018. Perú Urbano. Datos tomados de APEIM: Niveles Socioeconómicos 2018. 
PERFIL DE PERSONAS DE 18 AÑOS A MÁS SEGÚN NSE 2018 - PERÚ URBANO

\begin{tabular}{|c|c|c|c|c|c|c|c|c|c|}
\hline & & Total & NSE A & NSE B & NSE C & NSE C1 & NSE C2 & NSE D & NSE E \\
\hline \multicolumn{2}{|c|}{ En el mes anterior, ¿ hizo uso del servicio de Internet? } & $53.0 \%$ & $88.6 \%$ & $81.6 \%$ & $62.7 \%$ & $67.1 \%$ & $55.2 \%$ & $40.4 \%$ & $23.4 \%$ \\
\hline \multirow{2}{*}{\multicolumn{2}{|c|}{$\begin{array}{c}\text { El hogar } \\
\text { En el mes anterior El trabajo }\end{array}$}} & $43.8 \%$ & $85.1 \%$ & $77.9 \%$ & $47.2 \%$ & $55.6 \%$ & $30.3 \%$ & $9.3 \%$ & $1.1 \%$ \\
\hline & r El trabajo & $18.9 \%$ & $50.7 \%$ & $31.2 \%$ & $17.1 \%$ & $19.0 \%$ & $13.1 \%$ & $8.7 \%$ & $4.6 \%$ \\
\hline \multirow{5}{*}{$\begin{array}{l}\text { Dónde usó } \\
\text { Internet? } \\
\text { (Respuesta } \\
\text { Múltiple) }\end{array}$} & Un establecimiento educativo & $4.1 \%$ & $3.2 \%$ & $5.0 \%$ & $4.2 \%$ & $4.6 \%$ & $3.5 \%$ & $3.4 \%$ & $2.9 \%$ \\
\hline & Una cabina pública & $12.4 \%$ & $1.3 \%$ & $2.3 \%$ & $9.2 \%$ & $6.9 \%$ & $13.7 \%$ & $23.2 \%$ & $34.8 \%$ \\
\hline & En casa de otra persona & $4.4 \%$ & $4.1 \%$ & $4.0 \%$ & $4.4 \%$ & $4.0 \%$ & $5.2 \%$ & $5.0 \%$ & $4.3 \%$ \\
\hline & Otro & $0.3 \%$ & $0.1 \%$ & $0.2 \%$ & $0.3 \%$ & $0.4 \%$ & $0.2 \%$ & $0.5 \%$ & $0.3 \%$ \\
\hline & Acceso móvil a internet & $80.5 \%$ & $88.3 \%$ & $83.4 \%$ & $78.8 \%$ & $78.8 \%$ & $79.0 \%$ & $80.7 \%$ & $76.0 \%$ \\
\hline \multirow{7}{*}{$\begin{array}{l}\text { En el mes anterio } \\
\text { ¿Donde lo usó } \\
\text { con mayor } \\
\text { frecuencia? }\end{array}$} & El hogar & $20.8 \%$ & $25.5 \%$ & $32.7 \%$ & $25.4 \%$ & $29.1 \%$ & $18.1 \%$ & $5.8 \%$ & $0.8 \%$ \\
\hline & El trabajo & $8.6 \%$ & $18.9 \%$ & $12.5 \%$ & $8.1 \%$ & $8.7 \%$ & $6.7 \%$ & $5.2 \%$ & $3.4 \%$ \\
\hline & 'Un establecimiento educativo & $0.9 \%$ & $0.3 \%$ & $0.7 \%$ & $0.9 \%$ & $0.8 \%$ & $1.0 \%$ & $1.1 \%$ & $1.6 \%$ \\
\hline & Una cabina pública & $7.2 \%$ & $0.2 \%$ & $0.5 \%$ & $4.4 \%$ & $2.8 \%$ & $7.5 \%$ & $14.9 \%$ & $24.5 \%$ \\
\hline & En casa de otra persona & $1.4 \%$ & $0.0 \%$ & $0.6 \%$ & $1.3 \%$ & $0.9 \%$ & $2.2 \%$ & $2.5 \%$ & $2.5 \%$ \\
\hline & Otro & $0.2 \%$ & $0.1 \%$ & $0.1 \%$ & $0.1 \%$ & $0.2 \%$ & $0.1 \%$ & $0.3 \%$ & $0.2 \%$ \\
\hline & Acceso móvil a internet & $60.9 \%$ & $55.0 \%$ & $52.9 \%$ & $59.8 \%$ & $57.5 \%$ & $64.4 \%$ & $70.2 \%$ & $67.0 \%$ \\
\hline \multirow{8}{*}{$\begin{array}{l}\text { Uso el Internet } \\
\text { para (Respuesta } \\
\text { Múltiple) }\end{array}$} & Obtener de información & $89.0 \%$ & $95.2 \%$ & $93.2 \%$ & $89.8 \%$ & $90.9 \%$ & $87.5 \%$ & $84.9 \%$ & $80.0 \%$ \\
\hline & Comunicarse (e-mail, chat, etc,) & $94.7 \%$ & $97.0 \%$ & $95.6 \%$ & $94.7 \%$ & $94.7 \%$ & $94.7 \%$ & $94.0 \%$ & $92.9 \%$ \\
\hline & Comprar productos y/o servicios & $9.0 \%$ & $36.4 \%$ & $17.4 \%$ & $6.5 \%$ & $7.6 \%$ & $4.4 \%$ & $2.8 \%$ & $1.9 \%$ \\
\hline & Operaciones de banca electrónica & $10.7 \%$ & $41.4 \%$ & $19.2 \%$ & $8.7 \%$ & $10.1 \%$ & $5.8 \%$ & $3.5 \%$ & $1.7 \%$ \\
\hline & Educación formal y actividades de capacitación & $8.8 \%$ & $20.4 \%$ & $12.3 \%$ & $8.4 \%$ & $9.5 \%$ & $6.2 \%$ & $5.5 \%$ & $3.2 \%$ \\
\hline & $\begin{array}{l}\text { Transacciones (interactuar) con organizaciones } \\
\text { estatales/autoridades públicas }\end{array}$ & $12.3 \%$ & $33.2 \%$ & $19.3 \%$ & $11.5 \%$ & $13.1 \%$ & $8.4 \%$ & $6.3 \%$ & $2.7 \%$ \\
\hline & Actividades de entretenimiento & $79.0 \%$ & $87.9 \%$ & $83.6 \%$ & $80.7 \%$ & $82.3 \%$ & $77.3 \%$ & $73.2 \%$ & $68.9 \%$ \\
\hline & Vender productos y/o servicios & $3.6 \%$ & $9.7 \%$ & $6.2 \%$ & $3.0 \%$ & $3.1 \%$ & $2.7 \%$ & $1.7 \%$ & $1.4 \%$ \\
\hline
\end{tabular}

Figura 95 Perfil de personas de 18 años a mas que usaron internet según NSE 2018. Datos tomados de APEIM: Niveles Socioeconómicos 2018.

\section{Anexo II Cuestionario aplicado en encuesta}

\section{CUESTIONARIO SOBRE COMIDA SALUDABLE}

Datos Generales:

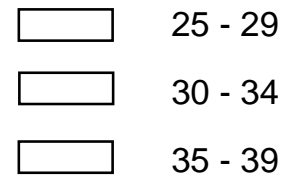

$35-39$
Estado Civil:

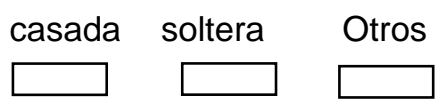

Nivel de ingresos:

No Trabajo

Menos de S/. 1000.00

Ocupación:

De S/. 1000.00 a S/. 2500.00

Más de S/. 2500.00

1. ¿Consumes Comida Saludable?

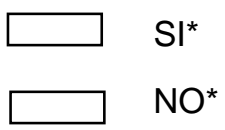


De ser $\mathrm{NO}^{*}$ en la pregunta $\mathrm{N}^{\circ} 1$ :

2. ¿Estarías dispuesta a consumir Comida Saludable?

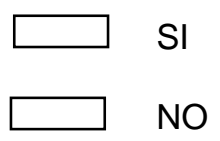

3. ¿Con qué elementos asocias la Comida Saludable?

De ser $\mathrm{SI}^{*}$ en la pregunta $\mathrm{N}^{\circ} 1$ :

4. ¿Por qué consume Comida Saludable?

\begin{tabular}{|l}
$\square \quad$ Me lo recomendó el medico \\
$\square \quad$ Me gusta \\
$\square \quad$ Consumo ocasionalmente \\
$\square \quad$ Para bajar de peso \\
$\square \quad$ Para tener mayor energía \\
$\square \quad$ Por obligación
\end{tabular}

5. ¿Con que frecuencia consume comida saludable?

$\square \quad$ Todos los días
$\square \quad$ Interdiario
$\square \quad$ Una vez a la semana

6. ¿De dónde sueles comer Comida Saludable?

Elaboración propia

Restaurantes

Servicio delivery

7. ¿Qué factores te orillarían a no consumir comida saludable en un restaurante o pedir servicio delivery? Explique brevemente 
8. De ser el caso, menciona nombres de los restaurantes o servicios delivery de comida saludable que consumes:

9. Si consume en restaurantes o servicios delivery, ¿Qué es lo que más le llama la atención?

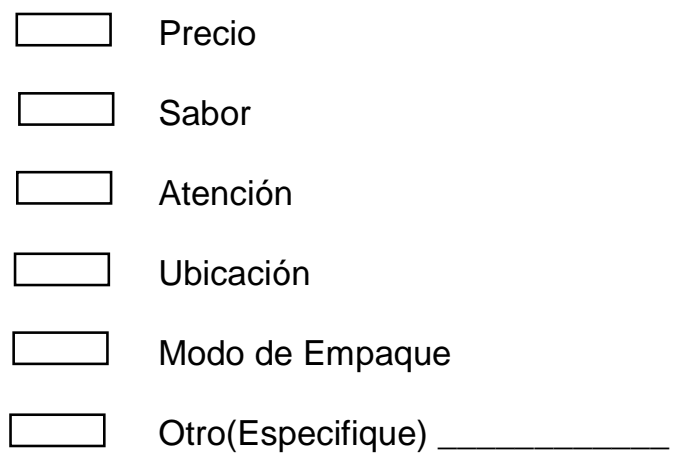

10. ¿Qué debe contener un almuerzo saludable? (marcar más de una opción)

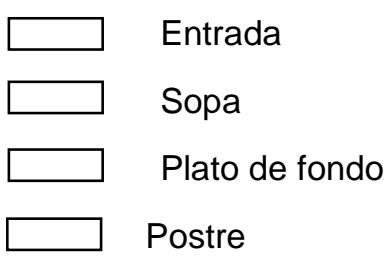

11. ¿Cuánto pagaría usted por un almuerzo saludable?

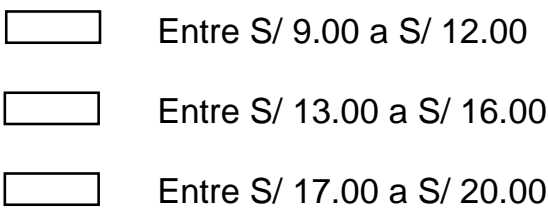

12. ¿A qué hora suele almorzar?

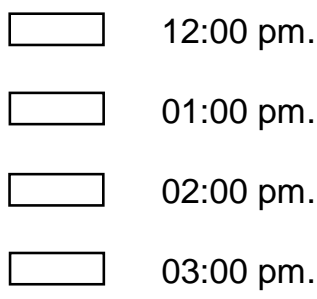

13. ¿Es importante que los productos muestren información nutricional y valores calóricos?

$\begin{array}{ll}\square & \text { Si } \\ \square & \text { No } \\ \square & \text { No leo esa información }\end{array}$


14. Si una empresa le ofrece el servicio delivery de comida saludable en su casa o trabajo a la hora que usted lo requiere, asegurándole puntualidad, buena presentación y variedad de platos. ¿Estarías dispuesto a contratar este servicio?

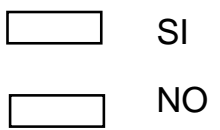

De ser su respuesta SI responda de la pregunta $\mathrm{N}^{\circ} 15$ a la $\mathrm{N}^{\circ} 20$

De ser su respuesta NO, por favor pase a la pregunta $\mathrm{N}^{\circ} 21$

15. ¿Por cuál plan optarías?

$\square$ Diario

$\square$ Semanal

Mensual

16. ¿En qué tipo de envase te gustaría recibir el producto?

$\square$ Tupper con separaciones

$\square$ Tupper para cada comida

$\square$ Tupper de cartón

17. ¿De qué manera te gustaría comunicarte con el servicio?

$\square$ Mediante una aplicación

Por redes sociales

Por teléfono

18. ¿Qué consideraría más relevante en este servicio? (marcar dos alternativas)

$\begin{array}{ll}\square & \text { Precio } \\ \square & \text { Puntualidad en la entrega } \\ \square & \text { Calidad de los insumos } \\ \square & \text { Envase adecuado } \\ \square & \text { Trato al cliente } \\ \square \quad \text { Variedad en las opciones diarias }\end{array}$


19. ¿A qué medios de comunicación acude usualmente?

\begin{tabular}{|ll}
\hline & Periódicos \\
$\square$ & Televisor \\
$\square$ & Radio \\
$\square$ & Celular \\
$\square$ & Internet \\
$\square$ & Otro
\end{tabular}

20. ¿Qué redes sociales frecuenta?

\begin{tabular}{|ll}
$\square$ & Facebook \\
$\square$ & Instagram \\
$\square$ & Twitter \\
$\square$ & Otro
\end{tabular}




\section{Anexo III Guía de preguntas Focus Group - comida saludable}

Nombre de cada una, a que se dedica.

1. ¿Qué es saludable?

2. Motivo por el cual Usted come comida saludable....

3. Revisa Usted las calorías de su comida

4. ¿Qué días pide delivery de comida saludable?

5. ¿Qué marcas de comida saludable consume?

6. ¿Qué piensa de los precios de comida saludable?

7. Además de alimentarse, cuál es el otro motivo por el que come comida saludable

8. ¿Cómo visualiza la presentación de los platos?

9. Considera que la decoración del palto va de acuerdo al beneficio de la marca.

10. ¿Alguna vez han tenido malas experiencias en deliverys?

11. Qué piensa de los servicios de delivery de comida saludable

12. ¿Qué opina de los colores del logotipo de comida saludable?

13. ¿Recomendaría la comida saludable a sus amigos?

14. ¿Cada cuánto tiempo consumiría comida saludable?

15. ¿Dónde compra comida saludable?

16. ¿Mientras el producto es orgánico tiene más beneficios?

17. ¿La comida que usted probó es variada? 
18. ¿Qué se debería de cambiar de la presentación del producto?

19. ¿Ustedes pagarían 13 soles por un almuerzo saludable?

20. ¿La cantidad que vieron fue suficiente para un (almuerzo)?

21. ¿Creen que debería existir presentaciones más pequeñas?

22. ¿Creen que se debería dar postres?

23. ¿Qué postres consideran saludables?

24. Relaciona la palabra saludable con un nombre de una comida

25. Relaciona la palabra saludable con un condimento

26. ¿Relaciona la palabra saludable con comida hecha en casa?

27. Cuáles de estos nombres: Green Power, Fit Food les gustaría para nuestro producto?

28. ¿Qué cantidad de comida saludable come al mes? 


\section{Anexo IV Desarrollo del Focus Group}

\section{FOCUS GROUP (transcripción)}

M: Muchas gracias por haber venido, les explico un poco de lo que se trata esto, de lo que se trata es sondear las necesidades del segmento, que en este caso son ustedes que lo convocamos por algunas razones de perfil. Lo que queremos es ver algunos insights que tengan como segmento, de acuerdo al negocio que estamos planteando. Este es un negocio de comida delivery, pero es comida saludable, ese es nuestro plus que estamos dando ahora, solamente va a ser delivery, no va a ser un restaurante, entonces nos estamos enfocando solamente a chicas que quieran comer saludable, no a gente que quiera comer saludable de una manera "profesional", por ejemplo que tengan algún problema de salud, pero si alguien que quiera cuidar la línea, o estar mejor físicamente. Ahora se trata de contestar las preguntas que voy a hacer y vamos a ir contando anécdotas como una conversación de amigos, ninguna pregunta está mal contestada, pero si me gustaría saber lo que ustedes quieren o ustedes esperan de un negocio de ese tipo.

Primero vamos a comenzar presentándonos, quisiera saber su nombre y a que se dedican.

P: Mi nombre es Pierina Piazze de profesión soy psicóloga y actualmente trabajo con niños con síndrome de down en la asociación Unamonos.

K: Soy Karin y tengo una pequeña empresa de desarrollo web.

L: Me llamo Liz Bernedo soy ingeniera informática y trabajo en un laboratorio de robótica.

F: Mi nombre es Flor y estoy terminando mis estudios de ingeniería metalúrgica.

J: Ximena Zolezzi soy psicóloga educativa y trabajo en el colegio Prescott

D: Daniela, trabajo como psicóloga 
M: Mi nombre se Maribel, soy contadora y trabajo en eso

Vamos a comenzar:

¿Qué es para ustedes comida saludable?

L: En comida saludable lo primero que se me ocurre son ensaladas y frutas. Es más que eso, pero es lo primero que me viene a la mente

P: Yo creo que es comida balanceada, que tiene que tener de todo pero en proporciones balanceadas, sin quitarse carbohidratos o grasas y que sean sanos porque hay carbohidratos que no son sanos como las harinas refinadas o las galletas. Por ejemplo te comer una papa es saludable, pero si la comes frita que es distinto. O el camote esas cosas.

¿Entonces que debería tener un plato de comida saludable?

P: Ensalada, proteína y un carbohidrato que sea bueno, como un camote o una papa, balanceado, pero más cantidad de ensalada que todo el resto de cosas.

D: Aparte que no tengan carbohidratos que no tengan nada de calorías, que creo que es lo que más puede afectar en las comidas.

J: Depende de la persona de tu edad, peso, sexo, por ejemplo mis esposo está haciendo dieta, y desayuna cosas, como por ejemplo un pescado grande, un filete de pescado con ensalada, el mide 1.90.

¿Cuál es el motivo por el que comen comida saludable?

J: Vivir más años 
P: Depende de la persona, porque si eres alguien que tiene problemas clínicos ya por obligación tienes que comenzar a comer bien, si eres una persona que gusta sentirte bien, porque además si comes algo muy pesado, muy grasoso o con mucha azúcar te sientes mal, si te comes un balde de KFC al otro vas a decir “¿Qué he comido?”, mientras con una ensalada, te sientes bien, te sientes alimentando, pero te sientes bien

¿Por qué decidirían optar por el servicio de comida saludable?

P: Yo creo que es el precio y la facilidad, cuando sales y tu trabajo queda en el centro, tienes cerca a KFC y MC Donalds, llévate tu hamburguesa y papas a S/5.00 pero no encuentras ensaladas, variedad de comida saludable, y esto aparece, es genial porque tengo esta opción, si es rentable para el bolsillo, me voy a alimentar bien sin necesidad de ir a un lugar donde me van a dar grasa y azúcar

J: Además yo creo que si vas a un restaurante es para ir un domingo o una vez a la semana, no vas a comer todos los días pollo a la brasa

L: Claro la grasa es rica, pero todos los días cansa, cuando buscas algo liviano que comer, está bien.

M: Y ustedes cuando ven productos que son orgánicos, vienen etiquetados con sus propiedades calóricas, vienen etiquetados con sus propiedades calóricas, ¿ustedes lo revisan?

J: si es orgánico, por ejemplo, me fijo en que no sea transgénico, porque sé que los transgénicos son malos, pero después no me fijo, además lo orgánico tiene un precio elevado.

M: Sí les ofrecieran un almuerzo orgánico, ¿pagarían porque fuera orgánico?

P: Yo no veo eso, veo solo calorías, pero no veo si es orgánico. 
$\mathrm{J}$ : Yo depende, si me convence lo que dice, puede ser.

L: SI me están invitando no puedo ver.

M: Claro, pero en este caso estamos hablando de ustedes, que piden el almuerzo. Es un almuerzo cuando están trabajando o en su casa.

P: Mientras sea un lugar higiénico y que sepas que tienen cuidado al preparar los alimentos, pero de que me vaya a fijar si es orgánico, no. Qué sea balanceado.

M: Ustedes alguna vez han pedido comida delivery pero de este tipo.

GRUPO: No. No hay.

G: ¿No conocen marcas de este tipo?

P: En Lima si hay. En Lima si he visto.

J: Por ejemplo en mi trabajo un profesor X, y su esposa cocina, entonces él dice ¿Quién quiere menú? Cocina en su casa, y dices es la esposa del profesor entonces confías. Pero comprar comida natural y baja en calorías, no.

P: Es que acá no hay. En Lima si.

L: Si hay restaurantes. Pero no sé si harán delivery.

P: Y hay otros que dicen no llegamos a esa zona, solo cuadras cerca. Y tu vives en un distrito alejado.

J: Sí y por ejemplo hay que vive en Sachaca y he escuchado que no llega nada.

P: No llega nada. 
M:¿No han escuchado restaurantes de comida saludable?

GRUPO: Si he escuchado, pero no de delivery, no sé si hacen delivery.

M: ¿Cómo cuales, que marcas conocen?

L: Pura Fruta o té verde.

D: Hay uno que se come sano, que está por Peruita (Pizzeria) por el centro.

P: Uno por la Católica (universidad) que se llama Nutri... algo.

M: ¿Han ido alguna vez a un restaurante?

GRUPO: El pura fruta sí.

M: ¿Pero vende almuerzos pura fruta?

$\mathrm{P}: \mathrm{Si}$, ensaladas, almuerzos como tal no, venden ensalada, como cuatro ingredientes y puedes escoger pechuga de pollo, pechuga de pavo.

L: $\mathrm{Y}$ en el capricho también venden ensaladas.

F: En día verde también venden menú vegetariano, te dan opciones para escoger, todo vegetariano.

M: ¿Es como un buffet?

F: Si.

¿Saben cuánto están los almuerzos?

P: El de pura fruta está S/14 y en el Capriccio está S/18

L: De $S / 18$ a S/24 
P: Y armar tu ensalada te cuesta S/16

M:¿Aparte de la nutrición que consideran que la nutrición aporta?

J: Prevenir enfermedades.

L: En la energía sobre todo, una cantidad de ensalada te da una cantidad de energía. Y por ejemplo en la décima parte de carbohidratos o azúcar te da la misma cantidad de energía, pero son diferente calidad de alimentos

P: Lo que pasa que comer un chocolate, te va a dar un montón de energía, pero no te va a llenar entonces vas a necesitar un más alimento, no como una ensalada te va a dar casi lo mismo de energía, pero te va a llenar sin necesidad que tengas que consumir más y más alimentos.

M: Si les presentan comida como la ven ahora, ¿Esta bien? ¿Lo consideran bonito? ¿Les falta algo?

J: Me llama la atención el papel. Eso te dice que estas cuidando el ambiente

P: Da esa sensación de saludable.

M: ¿Alguna vez han tenido una mala experiencia en deliverys, en general? Por ejemplo que hayan pedido y haya pasado algo con la comida.

P: El Pepe's (pollería), es muy grotesca su presentación, el tupper está con una liga y es muy grotesca la presentación

$\mathrm{J}$ : Las papas siempre tienen que ser crujientes.

P: Y salen sin textura, aguadas.

M: Y conforme al embace, ¿ha pasado algo con el producto al momento de llevarlo? 
J: que se rosee. El chifa que llega derramado.

P: El tupper de debajo del chifa tiene agua y termina toda la bolsa llena de agua.

L: y el adobo que se rosea.

M: Y aparte del embace ¿Han tenido algún problema con un delivery que nunca llegó?

L: Si demoró más de lo previsto y yo estaba que me moría de hambre.

M: ¿Les dieron algo, una disculpa aunque sea?

L: yo me pongo de mal humor cuando tengo hambre, y si demora ya no quiero. Simplemente ya no quiero

M: ¿no les ofrecieron un postre?

L: No sé si ofrecen, pero así lo hagan, yo como cliente ya no. Ya no vuelvo a pedir.

M: Como te solucionaría, por ejemplo que pasaría si te mando comida, pero la persona se accidenta y no te lo lleva. ¿Cómo se solucionaría el problema, para ti? ¿Qué te podría ofrecer la empresa para que te sintieras bien?

L: que de gratis la comida.

P: Un bono de descuento, para que puedas volver a llamar, un bono de $50 \%$ por ejemplo.

GURPO: Un descuento.

M: ¿Todos ven el logotipo en la bolsa? ¿les gusta? ¿les trasmite comida saludable?

$\mathrm{J}$ : Me gusta que sea sencilla.

P: Esta bonito 
M: ¿Les trasmite un restaurante o un delivery de comida saludable?

$\mathrm{J}$ : Parece un gimnasio

P: Suena como esos polos que te dan de publicidad de proteínas

M: ¿Digamos que el nombre está bien pero el logo les comunica saludable?

$\mathrm{J}: 100 \%$ y el nombre suena a gimnasio

M: ¿Por qué recomendaría consumir comida saludable? ¿La comen solo ustedes o es una costumbre familiar o de grupo de amigos?

L: A mí me gusta comer fruta, saludable, pero a mi hermano y familia no

P: Yo cocino para mí, no como lo mismo que en mi casa, yo cocino sola.

J: En mi casa es distinto desde que estoy casada, yo cocino, e improviso. Cuando vivía con mi familia, mi hermana es vegetariana, mi hermana cocinaba entonces comíamos vegetariano todo, bastante saludable.

M: ¿Si ustedes tendrían la oportunidad de consumir de este servicio, cada cuanto tiempo lo consumirían?

$\mathrm{J}$ : depende del precio

P: Si.

L: Bueno sin importar el precio lo consumiría tres o cuatro veces a la semana, porque igual necesito comer otra comida. 
P: Yo lo comería siempre, pero depende de cuál es el precio y que ofertas me pudieran dar. Por ejemplo ven y come variedad de almuerzos, como tipo Fridays que te dan variedad de almuerzos al mismo precio fijo, ya es más manejable.

P: Vas al Capriccio y solo tienes una variedad en el menú.

M: ¿Les gustaría que se les arme un plan por determinados días?

GRUPO: Por un mes mejor, si porque a veces aburre comer lo mismo. Y ahí es cuando comienzas a comer otras cosas que no son saludables.

M: ¿Y si se les arma un plan a cierto precio, ustedes podrían comerlo todo los días?

\section{GRUPO: SI}

D: También sería interesante un buffet, que te armen ensaladas de acuerdo a tus gustos, que sean saludables, o si estas enfermo, o quieres bajar de peso, o quieres tener un poco más de energía.

L: Es que es depende porque por ejemplo tú haces mercado para una semana, y si son 5 integrantes en la familia, tu gastas de acuerdo a los 5 , en el caso que tú me digas que me va a salir la suma que yo gastaría en la semana obviamente me convendría.

J: El hecho de pensar que ya no tendría que cocinar, yo si pagaría, odio cocinar.

P: Cuando llegas del trabajo llegas cansado, entonces el hecho de pensar que tengo que cocinar, dices ya no quiero comer.

D: Yo odio la cocina para mi es una parte de pasarte de frente y no existe, pero me encanta comer. Ahora salgo de mi casa, desayuno, pero como hasta la una entre agua y frutas, y llevo almuerzo y a veces no, si llego a mi casa y no hay almuerzo, agarro una fruta y nada mas 
L: Pero si todo el día trato de comer saludable, pero igual soy bien chatarrera.

M: ¿Cuánto pagarían por un menú delivery?

GRUPO: S/15

M: ¿Qué debería contener, entrada, segundo, postre?

J: A mí me gustaría un poquito de todo, no en mucha cantidad, por ejemplo el menú donde como en mi trabajo viene todo pero en porciones pequeñas. Un postrecito o un jugo de piña. No viene mucho, pero hay días que compensa. Algo así. Variado y completo.

P: Yo solo pediría un plato de fondo un postre que puede ser una ensalada de frutas o una fruta, o que tenga granola algo así y jugo. Entrada es demasiado y sopa también.

L: Cuando vivía con mis abuelos desayunaba quaker con panes, y de almuerzo era caldo, fondo, el postre y tu refresco. Entonces me acostumbre a eso, a comer mucho, cuando me mude igual, me acostumbré y me quedaba de hambre. Siempre busco, por mas chiquita que sea tomar algo, jugo de piña.

M: Podemos considerar un plato de fondo y agua, que no sea gaseosa.

P: Un jugo una infusión, un te.

M: ¿Le gustaría una entrada o una sopa?

GRUPO: La entrada tendría que ser opcional.

P: Hay gente que no come mucho, yo no como mucho, solo 1 plato y mi fruta. Algo mas sería forzar a mi estómago. Y el postre de todas maneras.

M: ¿Dónde compran insumos de comida saludable? 
GRUPO: Donde es fresca, donde queda cerca, a mercaditos

M: Actualmente si quieren comer comida saludable ¿A dónde van?

GRUPO: En casa.

L: Por un tema de higiene prefiero comer en casa, prepararlo sola porque comer verduras en la calle no me dan confianza.

P: No como en la calle porque el precio es elevado, no hay mucha variedad, al final voy a mi casa, me cocino la misma ensalada a mitad de precio, y tienes para servirte más.

M: ¿Qué es entonces lo que debe contener un producto de comida saludable para dejes de comer en casa?

P: Que sea bien servido, que tenga buenas porciones, no solo la mitad de un huevo si no, completo, o un tomate completo.

P: Hay ensaladas en el patio del Ekeko que cuestan S/36 soles pero son riquísimas. Y tú dices como las hacen porque el aliño es riquísimo.

GRUPO: El aliño es importante, muy importante.

GRUPO: Patio del Ekeko. Es buenísima. En chilis también

P: Algunos aliños llevan toda la grasa que no debería, la ensalada es saludable, pero el aliño no.

M: Procedemos a abrir la bolsa con la comida:

M: ¿Qué les parece la presentación del plato?

GRUPO: Preciosa, bonita. 
M: ¿Cómo valorarían esta presentación frente a otras?

GRUPO: No hay comparación.

M: ¿Eso sería importante para que ustedes lo consuman?

\section{GRUPO: SI}

M: ¿Es importante la cartilla de información?

GRUPO: Si es importante, es un plus, porque puedes ver cuánto estás consumiendo.

M: ¿Les importaría que el tapper no fuera liso?

L: En el caso de ensaladas si es importante porque pueden mezclarse los alimentos secos con los que tiene agua y pueden perder textura.

M: ¿Les molesta que el tapper sea negro?

GRUPO: No molesta.

J: Es que yo soy un poquito, no sé si decir TOC, el plástico, mi centro de trabajo todos comentan que no es bueno comer en plástico. El plástico no es bueno.

L: A mí lo que me da pena pedir delivery es el plástico, y la basura que genera.

GRUPO: Tener un cuidado ecológico.

P: o que hagan campañas de reciclaje. Donde te ganes una ensaladita.

M: Prueben el producto. ¿Les importa que los cubiertos vayan en bolsa?

L: en vez de que diga en la cartilla el contenido calórico me gustaría

J: podría ser en bolsas de papel, mantener la presentación. 
GRUPO: Es producto está muy bueno, diferente innovador.

GRUPO: La comida está muy buena muy rico todo.

GRUPO: en la cartilla debe decir los ingredientes, que contiene, al igual que el postre.

M: ¿ustedes creen que toda esta combinación es comida saludable?

GRUPO: Definitivamente que sí.

M: ¿Cuánto pagarían por un almuerzo así?

L: Si en un menú normal pagan entre 7 y 10 soles, este debería estar en el mismo rango, si no te van a decir que se lo des en tapper blanco.

P: por toda la presentación y todos los detalles 20 soles, 15 es muy poco para la presentación.

M: Si estuviera 15 soles si lo comprarían?

GRUPO: de todas maneras.

P: S/15 soles es muy barato para este producto.

GRUPO: A S/15 nadie compraría todos los días. Tendrías que ganar mucho. Por día pagaríamos S/10, pero si en el caso ocasional si podría ser S/15.

J: Pero igual como no hay un menú asi, no se puede comparar.

P: Los menús de aquí pagas poco, te dan mucho, pero no es saludable.

M: ¿Entonces les gustaría un plan?

GRUPO: Si sería mejor un plan.

M: ¿Sería importante que la empresa les de asesoría? 
GRUPO: Sería un plus. No es que sea importante. Hay gente que le gusta comer saludable y no le importa.

L: En una empresa en Lima, tú vas con tu dieta, entonces ellos te preparan en base a la dieta que tú les llevas o lo que prefieres comer. Son verduras específicas que cada quien pide.

M: ¿Si este menú estuviera S/15 cuantas veces a la semana lo consumirían?

GRUPO: 3 veces.

M: ¿Si este menú estuviera S/13 cuantas veces a la semana lo consumirían?

GRUPO: 4 veces

GRUPO: ya si esta S/10 toda la semana. Le das la plata que gastas a la semana y ya que te lo traigan.

M: ¿En el caso de los postres consideran que este postre es saludable?

\section{GRUPO: SI}

P: Esto se nota que es saludable porque no tiene azúcar, entonces inconscientemente la ansiedad de comer un chocolate porque dices esto es saludable.

M: ¿Con que palabra relacionan la comida saludable?

GRUPO: Albahaca, lechuga, tomate manzana, naranja

M: ¿Qué condimentos/Aliños debería llevar?

GRUPO: Sal, aceite de oliva, limón. Aliño aparte.

M: hay algunas personas que relacionan la comida de casa con comida saludable ¿Qué opinan? 
L: Pero si es saludable, porque saben cuanta cantidad darte. Pero si es saludable.

M: ¿Relacionan la comida de este tipo con la comida de casa?

GRUPO: Es comida de casa, es diferente a la comida saludable, no necesariamente tiene que ser saludable. Es rico pero no te hace bien. Depende de la casa también.

P: Hay casa donde desayunan mucho plato de almuerzo huevo frito, frejoles, pero no es necesariamente saludable.

M: ¿Cuál es la diferencia entre sano y saludable?

GRUPO: La comida de casa es sana mas no saludable. Depende también de la casa.

M: ¿Cuál es una comida que no es saludable?

GRUPO: KFC, gaseosa, chocolate, las pizzas de papa jones, las frituras, salchipapas.

M: ¿Esta cantidad es mucho o poco?

GRUPO: Suficiente, está perfecto. Por lo que es separado, pienso que es poco. Podrían comer el fondo y el postre.

J: Es que aquí en Arequipa las porciones son grandes, todos mis amigos que han venido me han dicho, aquí como comen. En verdad la gente come bastante.

P: Yo me he acostumbrado a comer poco, como 5 veces al día en porciones pequeñas, cuando como mucho no puedo.

P: Por eso yo pienso que es mucho, para mí es mucho; no podría terminar. 
M: Ya, está bien!.. Ahora conforme a los logos que enseñamos, quiero enfocarme a los nombres; FACTORY me queda claro que es una granja ... si fuera FACTORY FIT enfocándonos solo en el nombre? Transmite para una empresa de delivery?

GRUPO: FACTORY.. no! No suena a nada con comida.

M: Ya... y FIT FOOD?

P: Suena mucho mejor.

M: FIT si le queda claro a todos cual es el concepto no? Es fácil de entender esa palabra no? Que nombre les gustaría más?

GRUPO: Pensamos que FIT FOOD, suena a más gourmet

M: Con que logo creen que podría ir?

GRUPO: Con un logo que enfoque alimentos; cuando nosotros pensamos en algo saludable, imaginamos tomates o lechugas.

J: Yo creo que el logo debería de ser acompañado con una variedad de verduras, una ensalada de vegetales en un bowl... o algo así.

M: Tenemos diferentes slogans como propuestas... dentro de ellos está 100\% FIT.

GRUPO: Si ese nos gusta.. suena bien.

M: OK! ...Algo más que quieran agregar o comentar? Algo que les haya gustado o no gustado sobre el producto?.. Cómo lo calificarían?

GRUPO: Nos gustaría que sea un poco más líquido, pero todo estuvo rico. 
M: Muchas gracias por haber participado en el focus.. en realidad estamos haciendo un estudio de mercado para este producto, es totalmente anónimo así que esperemos todo haya sido contestado con sinceridad.

LOGOS: FOOD FIT en el logo 3 y con otro tipo de verduras, tomate, lechuga. Un Bowl con frutas. Y SLOGAN “Alimenta tu vida” 
1.

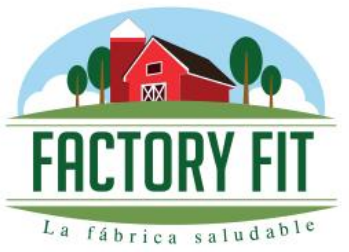

4.

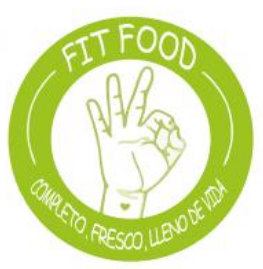

\section{3.}
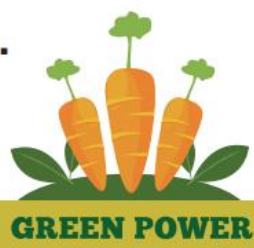

$100 \%$ FIT
2.

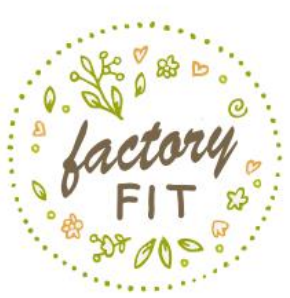

5.

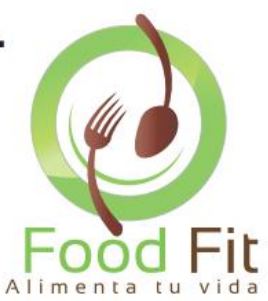

Figura 96 Identidades coorporativas presentadas en el Focus Group.

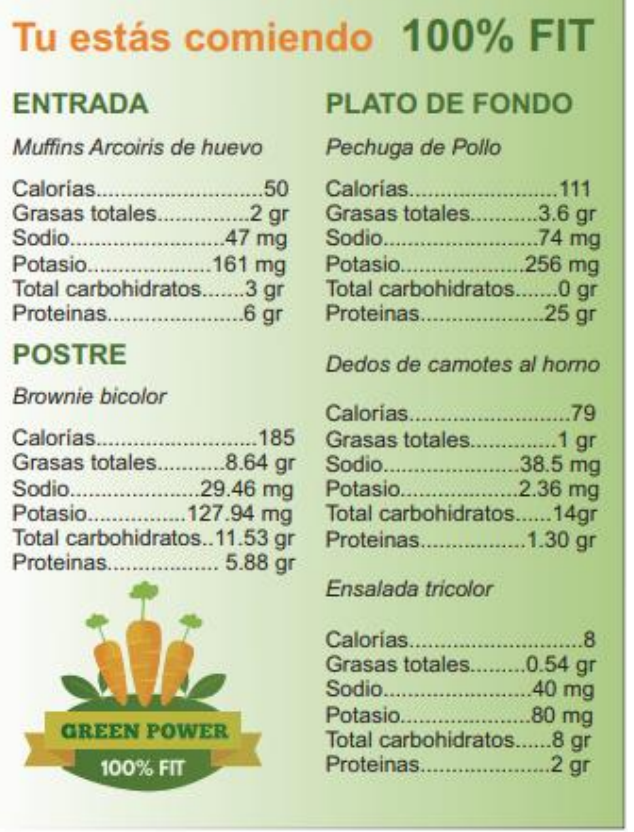

Figura 97 Cartilla informativa de valores nutricionales presentada en el Focus Group. 


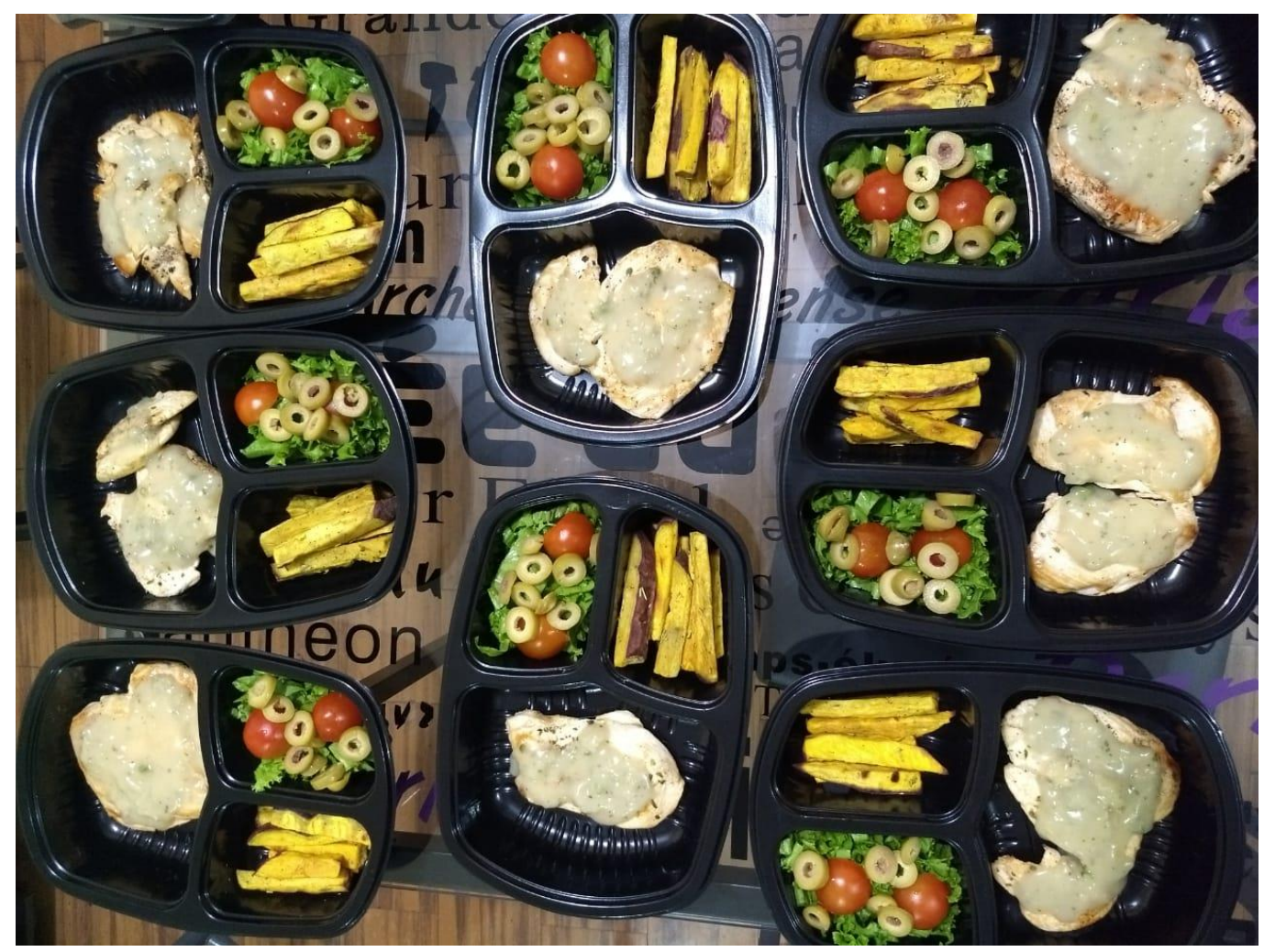

Figura 98 Platos preparados para desarrollo de Focus Group.

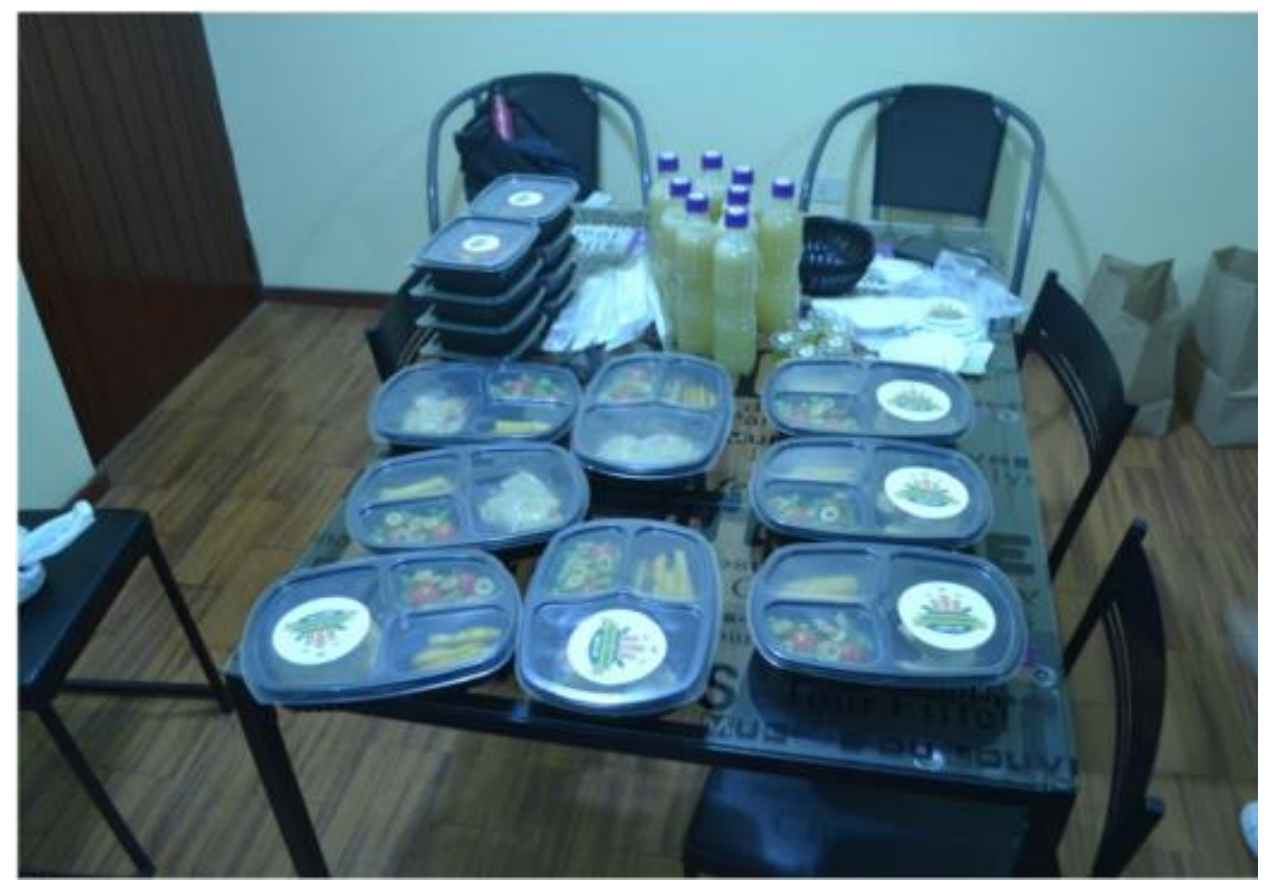

Figura 99 Menú completo preparado para Focus Group. 


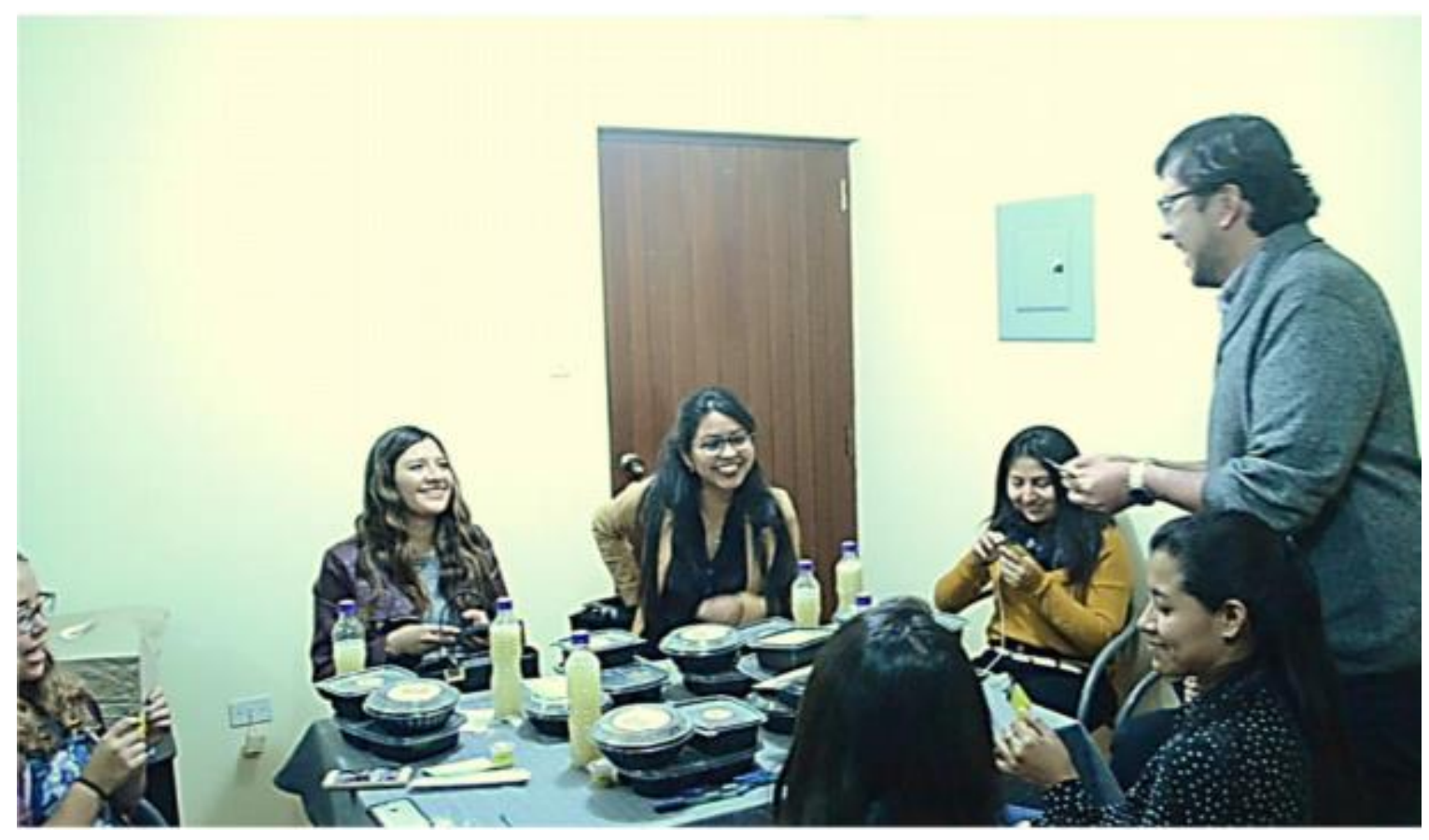

Figura 100 Desarrollo de Focus Group. 
Anexo VI Detalle de la inversión en activo fijo tangible

\begin{tabular}{|c|c|c|c|c|c|c|}
\hline DESCRIPCION & CANTIDAD & $\begin{array}{c}\text { COSTO } \\
\text { UNITARI } \\
\text { o } \\
\end{array}$ & $\begin{array}{l}\text { COSTO } \\
\text { TOTAL }\end{array}$ & $\begin{array}{l}\text { VIDA } \\
\text { UTIL }\end{array}$ & TASA & $\begin{array}{l}\text { DEPRECIA } \\
\text { CION }\end{array}$ \\
\hline \multicolumn{7}{|l|}{ MAQUINARIA Y EQUIPO } \\
\hline Congelador vertical & 1 & $1,600.00$ & $1,600.00$ & 10 & $10 \%$ & 160.00 \\
\hline Congelador horizontal & 1 & $1,500.00$ & $1,500.00$ & 10 & $10 \%$ & 150.00 \\
\hline Cocina industrial & 1 & $1,700.00$ & $1,700.00$ & 10 & $10 \%$ & 170.00 \\
\hline Campana extractora & 1 & 550.00 & 550.00 & 10 & $10 \%$ & 55.00 \\
\hline Horno eléctrico & 1 & $2,300.00$ & $2,300.00$ & 10 & $10 \%$ & 230.00 \\
\hline Horno microondas & 1 & 450.00 & 450.00 & 10 & $10 \%$ & 45.00 \\
\hline Freidor electrico de aire & 1 & 800.00 & 800.00 & 10 & $10 \%$ & 80.00 \\
\hline Licuadora & 1 & 700.00 & 700.00 & 10 & $10 \%$ & 70.00 \\
\hline Batidora de pedestal & 1 & $1,200.00$ & $1,200.00$ & 10 & $10 \%$ & 120.00 \\
\hline Procesador de alimentos & 1 & 300.00 & 300.00 & 10 & $10 \%$ & 30.00 \\
\hline Balanza gramera & 1 & 90.00 & 90.00 & 10 & $10 \%$ & 9.00 \\
\hline \multicolumn{7}{|l|}{ MUEB LES Y ENSERES } \\
\hline Habilitación del local & & & $7,000.00$ & 10 & $10 \%$ & 700.00 \\
\hline Utensilios varios & 1 & $4,000.00$ & $4,000.00$ & 10 & $10 \%$ & 400.00 \\
\hline Mesa para preparación de alim & 1 & 600.00 & 600.00 & 10 & $10 \%$ & 60.00 \\
\hline Mesa para empaque & 1 & 250.00 & 250.00 & 10 & $10 \%$ & 25.00 \\
\hline Estante para cocina & 3 & 350.00 & $1,050.00$ & 10 & $10 \%$ & 105.00 \\
\hline Estante para area empaque y $d_{\imath}$ & 1 & 200.00 & 200.00 & 10 & $10 \%$ & 20.00 \\
\hline Estante para almacen de MP e & 2 & 600.00 & $1,200.00$ & 10 & $10 \%$ & 120.00 \\
\hline Cajas organizadoras grandes & 10 & 20.00 & 200.00 & 10 & $10 \%$ & 20.00 \\
\hline Cajas organizadoras medianas & 10 & 16.00 & 160.00 & 10 & $10 \%$ & 16.00 \\
\hline Escritorio & 1 & 500.00 & 500.00 & 10 & $10 \%$ & 50.00 \\
\hline Sillon Gerencial & 1 & 250.00 & 250.00 & 10 & $10 \%$ & 25.00 \\
\hline Sillas & 6 & 80.00 & 480.00 & 10 & $10 \%$ & 48.00 \\
\hline Librero & 1 & 200.00 & 200.00 & 10 & $10 \%$ & 20.00 \\
\hline Mesa + 4 sillas (vestidores) & 1 & 210.00 & 210.00 & 10 & $10 \%$ & 21.00 \\
\hline Casilleros lockers & 2 & 400.00 & 800.00 & 10 & $10 \%$ & 80.00 \\
\hline \multicolumn{7}{|l|}{ EQUIPOS DIVERSOS } \\
\hline Laptop & 1 & $2,000.00$ & $2,000.00$ & 4 & $25 \%$ & 500.00 \\
\hline Impresora & 1 & 300.00 & 300.00 & 10 & $10 \%$ & 30.00 \\
\hline Equipo celular administración & 1 & 400.00 & 400.00 & 4 & $25 \%$ & 100.00 \\
\hline Equipo celular ventas & 2 & 200.00 & 400.00 & 4 & $25 \%$ & 100.00 \\
\hline Cajas de delivery para motos & 2 & 200.00 & 400.00 & 10 & $10 \%$ & 40.00 \\
\hline \multicolumn{3}{|c|}{ TOTAL ACTIVO FIJO TANGIBLE } & $\mathrm{S} / \mathbf{3 1 , 7 9 0 . 0 0}$ & & & $\mathrm{S} / . \mathbf{3 , 5 9 9 . 0 0}$ \\
\hline
\end{tabular}




\section{Anexo VII Costeo de materia prima y materiales varios para un menú saludable}

Entrada: Tortillas rellenas con jamon bajo en grasas, esparragos y ricota (3 porciones)

\begin{tabular}{|c|c|c|c|c|c|c|c|c|}
\hline Cant & UM & Insumo & Costo Total & $\begin{array}{l}\text { Cantidad } \\
\text { Utilizada } \\
\end{array}$ & $\%$ Merma & Merma & $\begin{array}{l}\text { Total } \\
\text { Bruto } \\
\end{array}$ & $\begin{array}{c}\text { Costo por } \\
\text { receta }(3 \text { porc })\end{array}$ \\
\hline 1 & $\mathrm{~kg}$ & clara de huevo & $\overline{7.00}$ & 0.150 & $15 \%$ & 0.0265 & 0.1765 & 1.2353 \\
\hline 1 & $\mathrm{~kg}$ & espinaca & 3.00 & 0.040 & $23 \%$ & 0.0119 & 0.0519 & 0.1558 \\
\hline 200 & $\mathrm{gr}$ & jamon bajo en grasas & 6.00 & 30.000 & $5 \%$ & 1.5789 & 31.5789 & 0.9474 \\
\hline 450 & gr & espárragos & 5.00 & 15.000 & $5 \%$ & 0.7895 & 15.7895 & 0.1754 \\
\hline 1.25 & $\mathrm{~kg}$ & ricota de almendras & 32.91 & 0.040 & $5 \%$ & 0.0021 & 0.0421 & 1.1085 \\
\hline 1 & $\mathrm{~kg}$ & sal & 1.50 & 0.005 & $5 \%$ & 0.0003 & 0.0053 & 0.0079 \\
\hline \multirow[t]{3}{*}{1} & \multirow[t]{3}{*}{$\mathrm{kg}$} & \multirow[t]{3}{*}{ pimienta } & \multirow[t]{3}{*}{42.00} & 0.005 & $5 \%$ & 0.0003 & 0.0053 & 0.2211 \\
\hline & & & & TOTAL & & & & S/.3.85 \\
\hline & & & & 1 PORCIOI & & & & S/.1.28 \\
\hline
\end{tabular}

Plato de Fondo: Croquetas de pollo con avena acompañado de quinoa

Croquetas de pollo con avena (1 porción)

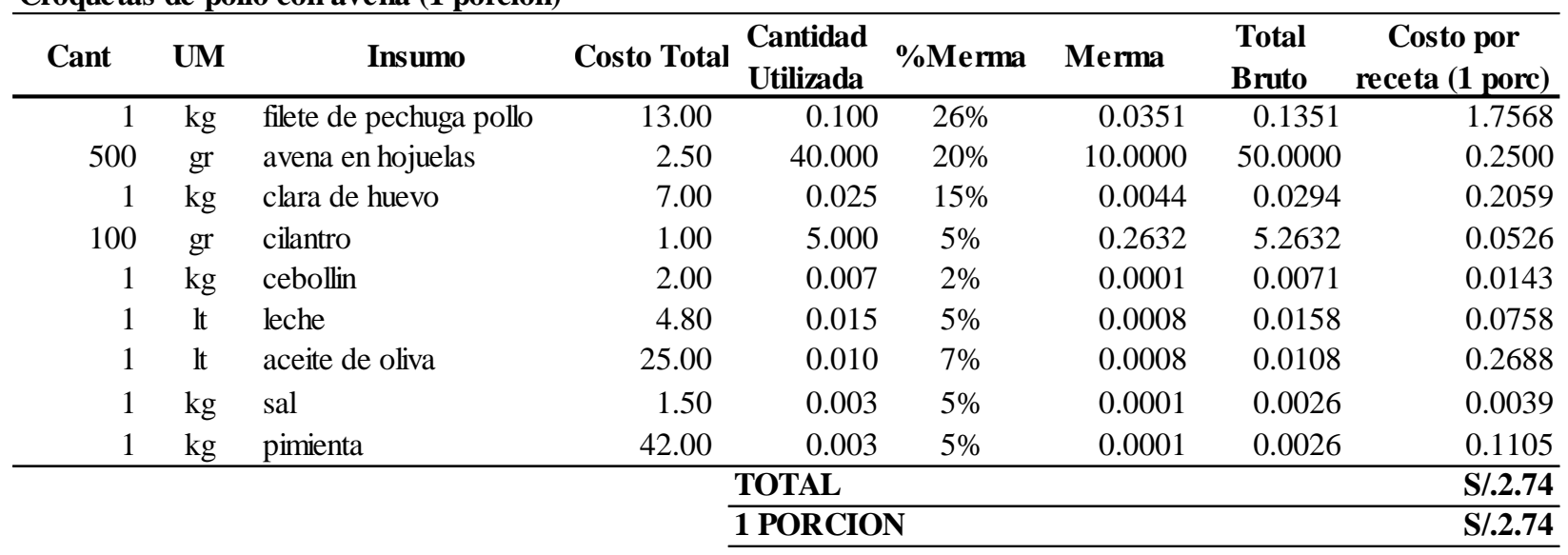

Quinoa graneada (5 porciones)

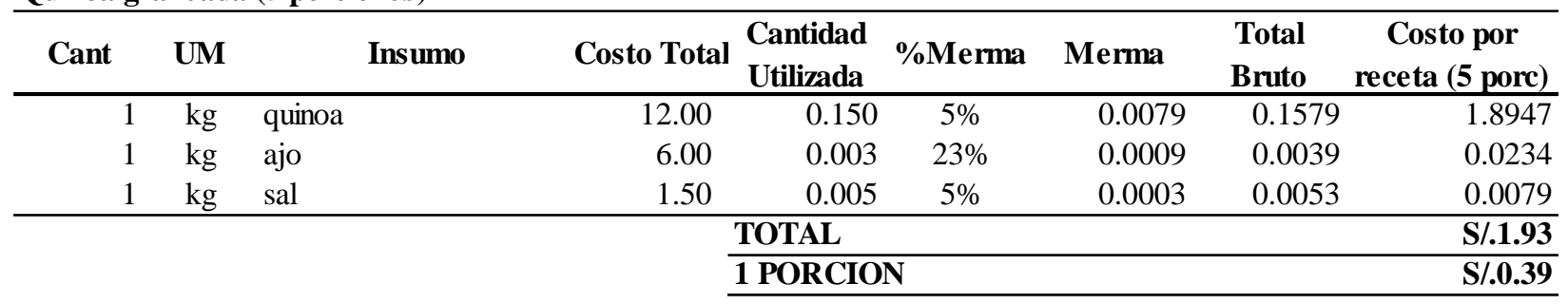


Refresco: Jugo de pera

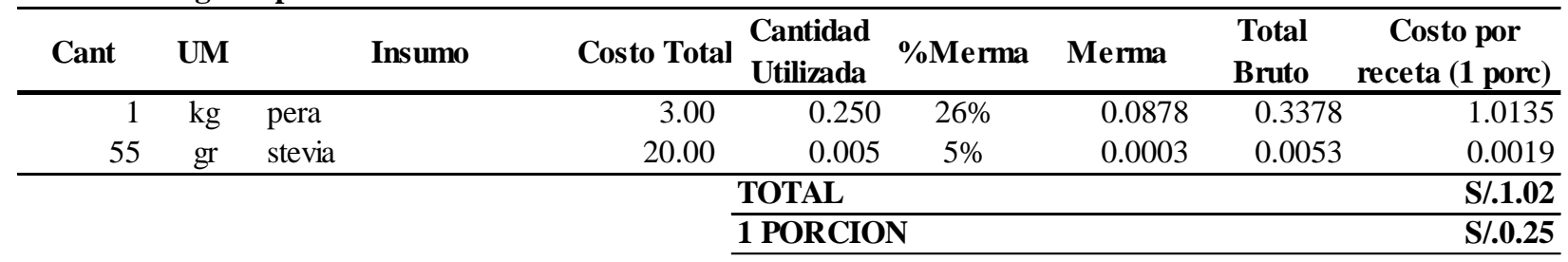

\section{COSTO UNITARIO}

\begin{tabular}{lrrrrr}
\hline Componentes del costo & \multicolumn{1}{c}{ AÑO 1 } & \multicolumn{1}{c}{ AÑO 2 } & \multicolumn{1}{c}{ AÑO 3 } & \multicolumn{1}{c}{ AÑO 4 } & \multicolumn{1}{c}{ AÑO 5 } \\
\hline Materia Prima & 4.661 & 4.857 & 5.061 & 5.274 & 5.495 \\
Mano de Obra & 1.801 & 1.877 & 1.956 & 2.038 & 2.123 \\
Materiales & 1.600 & 1.667 & 1.737 & 1.810 & 1.886 \\
\hline COSTO UNITARIO & S/.8.06 & S/.8.40 & S/.8.75 & S/.9.12 & S/.9.50 \\
\hline
\end{tabular}

Porcentaje de mermas recuperado de http://mermasydesperdicios.blogspot.com/2014/04/producto-porcentaje-abadejo-55.html 
Anexo VIII Diseños de envases ecológicos QAYA.

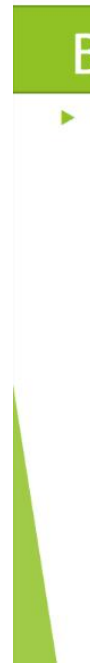

Bowls
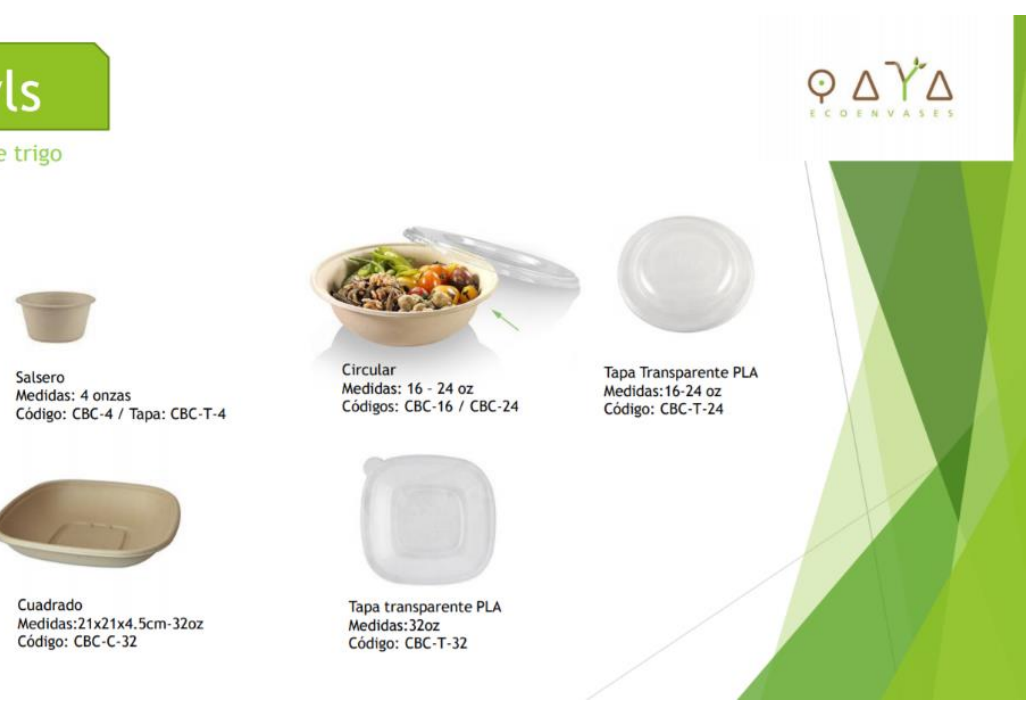

Medidas: 4 onzas
Código: CBC-4 / Tapa: CBC-T-4
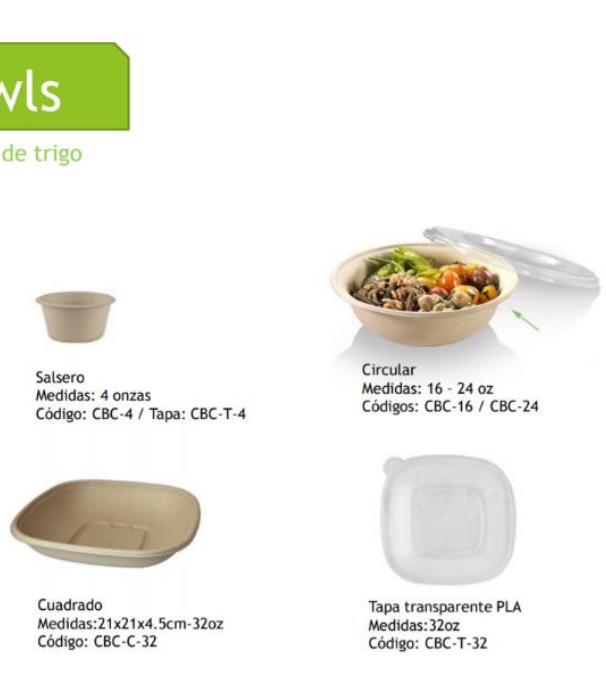

Módigo: CBC-C. 32
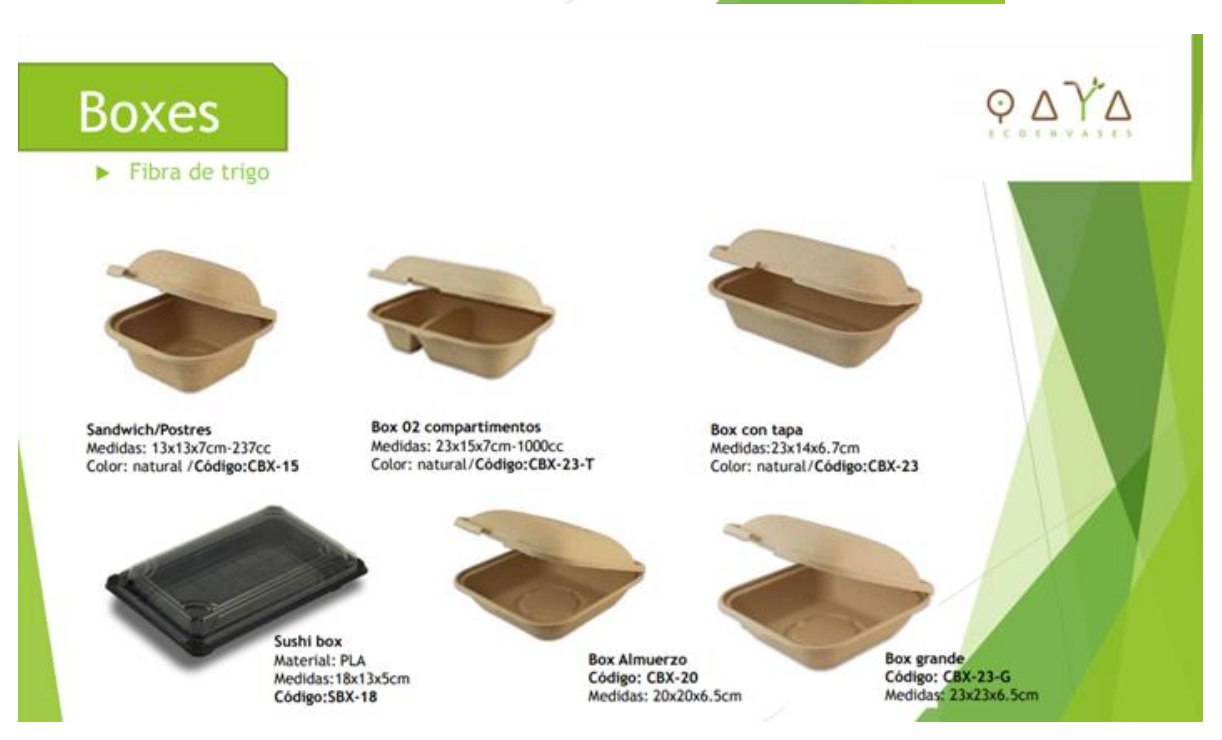

\section{Cubertería}

- CPLA/Bioplástico
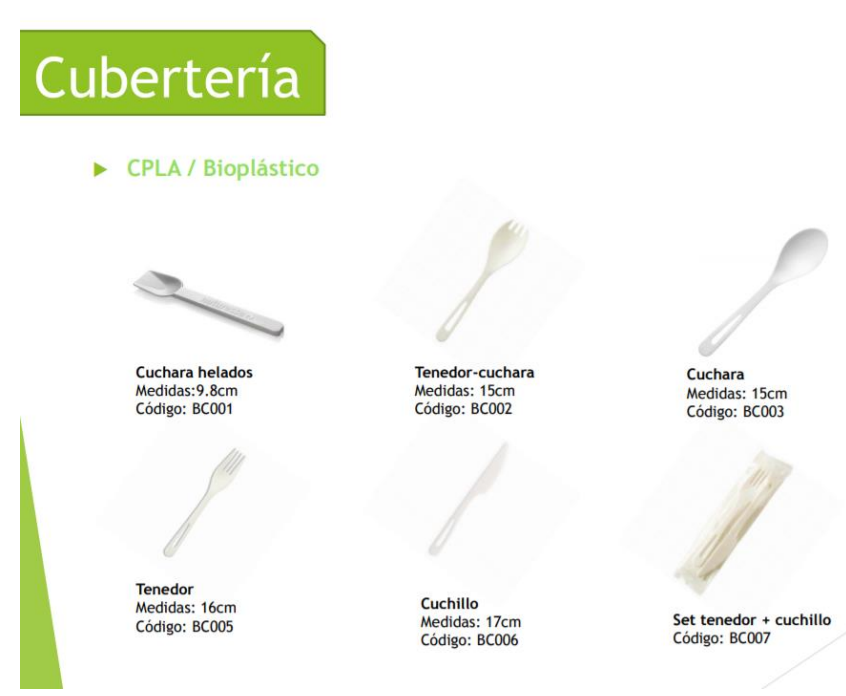
Anexo IX Rentabilidad del bono de Estados Unidos 5 años.

Tabla 90

Rentabilidad del bono de Estados Unidos 5 años.

\begin{tabular}{|c|c|c|c|c|c|}
\hline Fecha & Último & Apertura & Máximo & Mínimo & $\%$ Var. \\
\hline Jun-18 & 2.740 & 2.696 & 2.871 & 2.694 & $1.48 \%$ \\
\hline May-18 & 2.700 & 2.802 & 2.957 & 2.559 & $-3.61 \%$ \\
\hline Abr-18 & 2.801 & 2.580 & 2.854 & 2.535 & $9.33 \%$ \\
\hline Mar-18 & 2.562 & 2.645 & 2.735 & 2.540 & $-3.14 \%$ \\
\hline Feb-18 & 2.645 & 2.532 & 2.693 & 2.343 & $4.88 \%$ \\
\hline Ene-18 & 2.522 & 2.231 & 2.553 & 2.215 & $14.32 \%$ \\
\hline Dic-17 & 2.206 & 2.142 & 2.263 & 2.068 & $2.94 \%$ \\
\hline Nov-17 & 2.143 & 2.018 & 2.156 & 1.975 & $6.35 \%$ \\
\hline Oct-17 & 2.015 & 1.944 & 2.093 & 1.893 & $3.92 \%$ \\
\hline Set-17 & 1.939 & 1.710 & 1.954 & 1.599 & $13.72 \%$ \\
\hline Ago-17 & 1.705 & 1.844 & 1.857 & 1.669 & $-7.19 \%$ \\
\hline Jul-17 & 1.837 & 1.895 & 1.968 & 1.795 & $-2.65 \%$ \\
\hline Jun-17 & 1.887 & 1.762 & 1.893 & 1.673 & $7.64 \%$ \\
\hline May-17 & 1.753 & 1.814 & 1.951 & 1.713 & $-3.63 \%$ \\
\hline Abr-17 & 1.819 & 1.931 & 1.939 & 1.696 & $-5.51 \%$ \\
\hline Mar-17 & 1.925 & 1.959 & 2.148 & 1.883 & $-0.67 \%$ \\
\hline Feb-17 & 1.938 & 1.921 & 2.020 & 1.794 & $0.88 \%$ \\
\hline Ene-17 & 1.921 & 1.922 & 2.017 & 1.804 & $-0.67 \%$ \\
\hline Dic-16 & 1.934 & 1.855 & 2.124 & 1.788 & $4.60 \%$ \\
\hline Nov-16 & 1.849 & 1.320 & 1.906 & 1.153 & $41.69 \%$ \\
\hline Oct-16 & 1.305 & 1.157 & 1.368 & 1.148 & $13.58 \%$ \\
\hline Set-16 & 1.149 & 1.198 & 1.270 & 1.092 & $-3.77 \%$ \\
\hline Ago-16 & 1.194 & 1.035 & 1.241 & 0.996 & $16.83 \%$ \\
\hline Jul-16 & 1.022 & 0.997 & 1.181 & 0.900 & $2.10 \%$ \\
\hline Jun-16 & 1.001 & 1.373 & 1.390 & 0.940 & $-27.46 \%$ \\
\hline May-16 & 1.380 & 1.288 & 1.424 & 1.155 & $6.65 \%$ \\
\hline Abr-16 & 1.294 & 1.219 & 1.405 & 1.133 & $7.30 \%$ \\
\hline Mar-16 & 1.206 & 1.214 & 1.534 & 1.185 & $-0.90 \%$ \\
\hline Feb-16 & 1.217 & 1.344 & 1.385 & 0.976 & $-8.50 \%$ \\
\hline Ene-16 & 1.330 & 1.780 & 1.780 & 1.325 & $-24.35 \%$ \\
\hline Dic-15 & 1.758 & 1.653 & 1.829 & 1.553 & $6.80 \%$ \\
\hline Nov-15 & 1.646 & 1.517 & 1.779 & 1.512 & $8.15 \%$ \\
\hline Oct-15 & 1.522 & 1.364 & 1.558 & 1.213 & $12.32 \%$ \\
\hline Set-15 & 1.355 & 1.546 & 1.617 & 1.354 & $-12.47 \%$ \\
\hline Ago-15 & 1.548 & 1.543 & 1.671 & 1.292 & $0.91 \%$ \\
\hline Jul-15 & 1.534 & 1.651 & 1.752 & 1.473 & $-6.52 \%$ \\
\hline Jun-15 & 1.641 & 1.490 & 1.811 & 1.471 & $10.51 \%$ \\
\hline May-15 & 1.485 & 1.443 & 1.673 & 1.440 & $3.85 \%$ \\
\hline Abr-15 & 1.430 & 1.383 & 1.507 & 1.239 & $4.23 \%$ \\
\hline Mar-15 & 1.372 & 1.512 & 1.711 & 1.340 & $-8.53 \%$ \\
\hline Feb-15 & 1.500 & 1.173 & 1.646 & 1.164 & $30.10 \%$ \\
\hline Ene-15 & 1.153 & 1.689 & 1.705 & 1.152 & $-30.25 \%$ \\
\hline Dic-14 & 1.653 & 1.495 & 1.791 & 1.433 & $10.64 \%$ \\
\hline Nov-14 & 1.494 & 1.596 & 1.701 & 1.479 & $-7.15 \%$ \\
\hline Oct-14 & 1.609 & 1.771 & 1.775 & 1.115 & $-8.74 \%$ \\
\hline Set-14 & 1.763 & 1.638 & 1.879 & 1.628 & $8.36 \%$ \\
\hline Ago-14 & 1.627 & 1.758 & 1.789 & 1.495 & $-7.35 \%$ \\
\hline Jul-14 & 1.756 & 1.633 & 1.807 & 1.605 & $7.53 \%$ \\
\hline Jun-14 & 1.633 & 1.549 & 1.758 & 1.538 & $6.11 \%$ \\
\hline May-14 & 1.539 & 1.686 & 1.765 & 1.465 & $-8.23 \%$ \\
\hline Abr-14 & 1.677 & 1.728 & 1.811 & 1.546 & $-2.50 \%$ \\
\hline Mar-14 & 1.720 & 1.456 & 1.786 & 1.449 & $14.44 \%$ \\
\hline Feb-14 & 1.503 & 1.510 & 1.582 & 1.422 & $0.74 \%$ \\
\hline Ene-14 & 1.492 & 1.751 & 1.806 & 1.485 & $-14.65 \%$ \\
\hline Dic-13 & 1.748 & 1.375 & 1.759 & 1.372 & $27.41 \%$ \\
\hline Nov-13 & 1.372 & 1.333 & 1.461 & 1.270 & $3.47 \%$ \\
\hline Oct-13 & 1.326 & 1.386 & 1.473 & 1.250 & $-4.26 \%$ \\
\hline Set-13 & 1.385 & 1.698 & 1.864 & 1.360 & $-15.86 \%$ \\
\hline Ago-13 & 1.646 & 1.383 & 1.727 & 1.337 & $18.76 \%$ \\
\hline
\end{tabular}




\begin{tabular}{|c|c|c|c|c|c|}
\hline Fecha & Último & Apertura & Máximo & Mínimo & $\%$ Var. \\
\hline Jul-13 & 1.386 & 1.403 & 1.634 & 1.275 & $-0.72 \%$ \\
\hline Jun-13 & 1.396 & 1.043 & 1.558 & 0.947 & $36.33 \%$ \\
\hline May-13 & 1.024 & 0.674 & 1.090 & 0.639 & $51.03 \%$ \\
\hline Abr-13 & 0.678 & 0.788 & 0.792 & 0.65 & $-11.83 \%$ \\
\hline Mar-13 & 0.769 & 0.763 & 0.921 & 0.724 & $0.39 \%$ \\
\hline Feb-13 & 0.766 & 0.873 & 0.92 & 0.741 & $-12.95 \%$ \\
\hline Ene-13 & 0.88 & 0.725 & 0.918 & 0.725 & $21.38 \%$ \\
\hline Dic-12 & 0.725 & 0.617 & 0.795 & 0.591 & $17.12 \%$ \\
\hline Nov-12 & 0.619 & 0.729 & 0.774 & 0.598 & $-14.15 \%$ \\
\hline Oct-12 & 0.721 & 0.617 & 0.833 & 0.601 & $15.36 \%$ \\
\hline Set-12 & 0.625 & 0.592 & 0.741 & 0.587 & $6.29 \%$ \\
\hline Ago-12 & 0.588 & 0.581 & 0.839 & 0.581 & $0.34 \%$ \\
\hline Jul-12 & 0.586 & 0.729 & 0.732 & 0.536 & $-18.27 \%$ \\
\hline Jun-12 & 0.717 & 0.663 & 0.782 & 0.59 & $9.13 \%$ \\
\hline May-12 & 0.657 & 0.809 & 0.849 & 0.633 & $-19.19 \%$ \\
\hline Abr-12 & 0.813 & 1.068 & 1.120 & 0.784 & $-21.83 \%$ \\
\hline Mar-12 & 1.040 & 0.870 & 1.226 & 0.813 & $20.37 \%$ \\
\hline Feb-12 & 0.864 & 0.708 & 0.927 & 0.698 & $22.38 \%$ \\
\hline Ene-12 & 0.706 & 0.833 & 0.927 & 0.700 & $-15.25 \%$ \\
\hline Dic-11 & 0.833 & 0.959 & 1.020 & 0.796 & $-12.96 \%$ \\
\hline Nov-11 & 0.957 & 0.979 & 1.008 & 0.839 & $-0.93 \%$ \\
\hline Oct-11 & 0.966 & 0.961 & 1.221 & 0.843 & $1.15 \%$ \\
\hline Set-11 & 0.955 & 0.957 & 1.013 & 0.762 & $-1.55 \%$ \\
\hline Ago-11 & 0.97 & 1.383 & 1.422 & 0.792 & $-28.20 \%$ \\
\hline Jul-11 & 1.351 & 1.767 & 1.844 & 1.344 & $-23.41 \%$ \\
\hline Jun-11 & 1.764 & 1.709 & 1.815 & 1.355 & $3.89 \%$ \\
\hline May-11 & 1.698 & 1.979 & 2.010 & 1.678 & $-13.89 \%$ \\
\hline Abr-11 & 1.972 & 2.282 & 2.353 & 1.964 & $-13.20 \%$ \\
\hline Mar-11 & 2.272 & 2.155 & 2.345 & 1.802 & $6.32 \%$ \\
\hline Feb-11 & 2.137 & 1.942 & 2.424 & 1.942 & $9.82 \%$ \\
\hline Ene-11 & 1.946 & 2.014 & 2.168 & 1.859 & $-3.09 \%$ \\
\hline Dic-10 & 2.008 & 1.473 & 2.188 & 1.464 & $36.97 \%$ \\
\hline Nov-10 & 1.466 & 1.197 & 1.587 & 1.016 & $25.41 \%$ \\
\hline Oct-10 & 1.169 & 1.279 & 1.341 & 1.071 & $-8.17 \%$ \\
\hline Jul-10 & 1.273 & 1.346 & 1.627 & 1.225 & $-4.36 \%$ \\
\hline Set-10 & 1.331 & 1.613 & 1.645 & 1.278 & $-16.71 \%$ \\
\hline Jul-10 & 1.598 & 1.786 & 1.910 & 1.593 & $-10.12 \%$ \\
\hline Jun-10 & 1.778 & 2.118 & 2.211 & 1.747 & $-15.29 \%$ \\
\hline May-10 & 2.099 & 2.421 & 2.492 & 1.855 & $-13.19 \%$ \\
\hline Abr- 10 & 2.418 & 2.567 & 2.757 & 2.385 & $-5.32 \%$ \\
\hline Mar-10 & 2.554 & 2.317 & 2.693 & 2.240 & $10.80 \%$ \\
\hline Feb-10 & 2.305 & 2.343 & 2.507 & 2.197 & $-0.86 \%$ \\
\hline Ene-10 & 2.325 & 2.713 & 2.746 & 2.297 & $-13.38 \%$ \\
\hline Dic-09 & 2.684 & 2.006 & 2.760 & 1.991 & $34.00 \%$ \\
\hline Nov-09 & 2.003 & 2.322 & 2.422 & 1.949 & $-13.21 \%$ \\
\hline Oct-09 & 2.308 & 2.325 & 2.514 & 2.121 & $-0.30 \%$ \\
\hline Set-09 & 2.315 & 2.395 & 2.492 & 2.229 & $-3.02 \%$ \\
\hline Ago-09 & 2.387 & 2.545 & 2.871 & 2.354 & $-5.13 \%$ \\
\hline Jul-09 & 2.516 & 2.548 & 2.746 & 2.168 & $-1.72 \%$ \\
\hline Jun-09 & 2.560 & 2.367 & 2.993 & 2.357 & $9.31 \%$ \\
\hline May-09 & 2.342 & 2.010 & 2.540 & 1.936 & $16.29 \%$ \\
\hline Abr-09 & 2.014 & 1.668 & 2.080 & 1.641 & $20.74 \%$ \\
\hline Mar-09 & 1.668 & 1.992 & 2.049 & 1.500 & $-16.22 \%$ \\
\hline Feb-09 & 1.991 & 1.883 & 2.120 & 1.646 & $5.74 \%$ \\
\hline Ene-09 & 1.883 & 1.567 & 1.915 & 1.316 & $20.78 \%$ \\
\hline Dic-08 & 1.559 & 1.919 & 1.980 & 1.190 & $-18.76 \%$ \\
\hline Nov-08 & 1.919 & 2.806 & 2.840 & 1.872 & $-31.76 \%$ \\
\hline Oct-08 & 2.812 & 2.907 & 3.082 & 2.334 & $-5.92 \%$ \\
\hline Set-08 & 2.989 & 3.096 & 3.226 & 2.351 & $-3.39 \%$ \\
\hline Ago-08 & 3.094 & 3.249 & 3.380 & 2.981 & $-4.65 \%$ \\
\hline Jul-08 & 3.245 & 3.327 & 3.573 & 3.004 & $-2.76 \%$ \\
\hline \multirow[t]{2}{*}{ Máximo: } & 3.573 & Mínimo : & 0.639 & Diferencia: & 2.934 \\
\hline & Promedio: & 1.837 & Var \%: & -17.890 & \\
\hline
\end{tabular}

Recuperado de https://es.investing.com/rates-bonds/u.s.5-year-bond-yield-historical-data 
Anexo X Rendimiento promedio de la industria DJI.

Tabla 91

Dow Jones rentabilidad promedio de la industria DJI.

\begin{tabular}{|c|c|c|c|c|c|c|}
\hline Fecha & Último & Apertura & Máximo & Mínimo & Vol. & $\%$ Var. \\
\hline Jun-18 & $24,271.41$ & $24,542.09$ & $25,402.83$ & $23,997.21$ & $7.41 \mathrm{~B}$ & $-0.59 \%$ \\
\hline May-18 & $24,415.84$ & $24,117.29$ & $25,086.49$ & $23,531.31$ & $7.28 \mathrm{~B}$ & $1.05 \%$ \\
\hline Abr-18 & $24,163.15$ & $24,076.60$ & $24,858.97$ & $23,344.52$ & $8.06 \mathrm{~B}$ & $0.25 \%$ \\
\hline Mar-18 & $24,103.11$ & $25,024.04$ & $25,449.15$ & $23,509.06$ & $8.87 \mathrm{~B}$ & $-3.70 \%$ \\
\hline Feb-18 & $25,029.20$ & $26,083.04$ & $26,306.70$ & $23,360.29$ & $9.45 \mathrm{~B}$ & $-4.28 \%$ \\
\hline Ene-18 & $26,149.39$ & $24,809.35$ & $26,616.71$ & $24,741.70$ & $9.12 \mathrm{~B}$ & $5.79 \%$ \\
\hline Dic-17 & $24,719.22$ & $24,305.40$ & $24,876.07$ & $23,921.90$ & $6.59 \mathrm{~B}$ & $1.84 \%$ \\
\hline Nov-17 & $24,272.35$ & $23,442.90$ & $24,327.82$ & $23,242.75$ & $7.34 \mathrm{~B}$ & $3.83 \%$ \\
\hline Oct-17 & $23,377.24$ & $22,423.47$ & $23,485.25$ & $22,416.00$ & $7.30 \mathrm{~B}$ & $4.34 \%$ \\
\hline Set-17 & $22,405.09$ & $21,981.77$ & $22,419.51$ & $21,709.63$ & $6.34 \mathrm{~B}$ & $2.08 \%$ \\
\hline Ago-17 & $21,948.10$ & $21,961.42$ & $22,179.11$ & $21,600.34$ & $6.15 \mathrm{~B}$ & $0.26 \%$ \\
\hline Jul-17 & $21,891.12$ & $21,392.30$ & $21,929.80$ & $21,279.30$ & $5.57 \mathrm{~B}$ & $2.54 \%$ \\
\hline Jun-17 & $21,349.63$ & $21,030.55$ & $21,535.03$ & $20,994.22$ & $7.21 \mathrm{~B}$ & $1.62 \%$ \\
\hline May-17 & $21,008.65$ & $20,962.73$ & $21,112.32$ & $20,553.45$ & $6.61 \mathrm{~B}$ & $0.33 \%$ \\
\hline Abr-17 & $20,940.51$ & $20,665.17$ & $21,070.90$ & $20,379.55$ & $5.39 \mathrm{~B}$ & $1.34 \%$ \\
\hline Mar-17 & $20,663.22$ & $20,957.29$ & $21,169.11$ & $20,412.80$ & $6.94 \mathrm{~B}$ & $-0.72 \%$ \\
\hline Feb-17 & $20,812.24$ & $19,923.81$ & $20,851.33$ & $19,831.09$ & $6.19 \mathrm{~B}$ & $4.77 \%$ \\
\hline Ene-17 & $19,864.09$ & $19,872.86$ & $20,125.58$ & $19,677.94$ & $6.48 \mathrm{~B}$ & $0.51 \%$ \\
\hline Dic-16 & $19,762.60$ & $19,149.20$ & $19,987.63$ & $19,138.79$ & $5.95 \mathrm{~B}$ & $3.34 \%$ \\
\hline Nov-16 & $19,123.58$ & $18,158.24$ & $19,225.29$ & $17,883.56$ & $2.11 \mathrm{~B}$ & $5.41 \%$ \\
\hline Oct-16 & $18,142.42$ & $18,279.60$ & $18,399.96$ & $17,959.95$ & $1.79 \mathrm{~B}$ & $-0.91 \%$ \\
\hline Set-16 & $18,308.15$ & $18,396.57$ & $18,551.54$ & $17,992.21$ & $2.10 \mathrm{~B}$ & $-0.50 \%$ \\
\hline Ago-16 & $18,400.88$ & $18,434.50$ & $18,668.44$ & $18,247.79$ & $1.70 \mathrm{~B}$ & $-0.17 \%$ \\
\hline Jul-16 & $18,432.24$ & $17,924.24$ & $18,622.01$ & $17,713.45$ & $1.82 \mathrm{~B}$ & $2.80 \%$ \\
\hline Jun-16 & $17,929.99$ & $17,754.55$ & $18,016.00$ & $17,063.08$ & $2.35 \mathrm{~B}$ & $0.80 \%$ \\
\hline May-16 & $17,787.20$ & $17,783.78$ & $17,934.61$ & $17,331.07$ & $1.88 \mathrm{~B}$ & $0.08 \%$ \\
\hline Abr-16 & $17,773.64$ & $17,661.74$ & $18,167.63$ & $17,484.23$ & $2.10 \mathrm{~B}$ & $0.50 \%$ \\
\hline Mar-16 & $17,685.09$ & $16,545.67$ & $17,790.11$ & $16,545.67$ & $2.41 \mathrm{~B}$ & $7.08 \%$ \\
\hline Feb-16 & $16,516.50$ & $16,453.63$ & $16,795.98$ & $15,503.01$ & $2.49 \mathrm{~B}$ & $0.30 \%$ \\
\hline Ene-16 & $16,466.30$ & $17,405.48$ & $17,405.48$ & $15,450.56$ & 2.84B & $-5.50 \%$ \\
\hline Dic-15 & $17,425.03$ & $17,719.72$ & $17,901.58$ & $17,116.73$ & $2.52 \mathrm{~B}$ & $-1.66 \%$ \\
\hline Nov-15 & $17,719.92$ & $17,672.62$ & $17,977.85$ & $17,210.43$ & $2.30 \mathrm{~B}$ & $0.32 \%$ \\
\hline Oct-15 & $17,663.54$ & $16,278.62$ & $17,799.96$ & $16,013.66$ & $2.61 \mathrm{~B}$ & $8.47 \%$ \\
\hline Set-15 & $16,284.70$ & $16,528.03$ & $16,933.43$ & $15,942.37$ & $2.72 \mathrm{~B}$ & $-1.47 \%$ \\
\hline Ago-15 & $16,528.03$ & $17,696.74$ & $17,704.76$ & $15,370.33$ & $2.73 \mathrm{~B}$ & $-6.57 \%$ \\
\hline Jul-15 & $17,689.86$ & $17,638.12$ & $18,137.12$ & $17,399.17$ & $2.03 \mathrm{~B}$ & $0.40 \%$ \\
\hline Jun-15 & $17,619.51$ & $18,017.82$ & $18,188.81$ & $17,576.50$ & $2.22 \mathrm{~B}$ & $-2.17 \%$ \\
\hline May-15 & $18,010.68$ & $17,859.27$ & $18,351.36$ & $17,733.12$ & $1.83 \mathrm{~B}$ & $0.95 \%$ \\
\hline Abr-15 & $17,840.52$ & $17,778.52$ & $18,175.56$ & $17,585.01$ & $2.17 \mathrm{~B}$ & $0.36 \%$ \\
\hline Mar-15 & $17,776.12$ & $18,134.05$ & $18,288.63$ & $17,579.27$ & $2.47 \mathrm{~B}$ & $-1.97 \%$ \\
\hline Feb-15 & $18,132.70$ & $17,169.99$ & $18,244.38$ & $17,037.76$ & $1.75 \mathrm{~B}$ & $5.64 \%$ \\
\hline Ene-15 & $17,164.95$ & $17,823.07$ & $17,951.78$ & $17,136.30$ & $2.17 \mathrm{~B}$ & $-3.69 \%$ \\
\hline Dic-14 & $17,823.07$ & $17,827.27$ & $18,103.45$ & $17,067.59$ & $2.22 \mathrm{~B}$ & $-0.03 \%$ \\
\hline Nov-14 & $17,828.24$ & $17,390.90$ & $17,894.83$ & $17,278.36$ & $1.52 \mathrm{~B}$ & $2.52 \%$ \\
\hline Oct-14 & $17,390.52$ & $17,040.46$ & $17,395.54$ & $15,855.12$ & $2.31 \mathrm{~B}$ & $2.04 \%$ \\
\hline Set-14 & $17,042.90$ & $17,097.42$ & $17,350.64$ & $16,934.43$ & $1.87 \mathrm{~B}$ & $-0.32 \%$ \\
\hline Ago-14 & $17,098.45$ & $16,561.70$ & $17,153.80$ & $16,333.78$ & $1.48 \mathrm{~B}$ & $3.23 \%$ \\
\hline Jul-14 & $16,563.30$ & $16,828.53$ & $17,151.56$ & $16,563.30$ & $1.69 \mathrm{~B}$ & $-1.56 \%$ \\
\hline Jun-14 & $16,826.60$ & $16,716.85$ & $16,978.02$ & $16,673.65$ & $1.76 \mathrm{~B}$ & $0.65 \%$ \\
\hline May-14 & $16,717.17$ & $16,580.26$ & $16,735.51$ & $16,341.30$ & $1.64 \mathrm{~B}$ & $0.82 \%$ \\
\hline Abr-14 & $16,580.84$ & $16,458.05$ & $16,631.63$ & $16,015.32$ & $1.99 \mathrm{~B}$ & $0.75 \%$ \\
\hline Mar-14 & $16,457.66$ & $16,321.71$ & $16,505.70$ & $16,046.99$ & $2.10 \mathrm{~B}$ & $0.83 \%$ \\
\hline Feb-14 & $16,321.71$ & $15,697.69$ & $16,398.95$ & $15,340.69$ & $2.07 \mathrm{~B}$ & $3.97 \%$ \\
\hline Ene-14 & $15,698.85$ & $16,572.17$ & $16,573.07$ & $15,617.55$ & $2.18 \mathrm{~B}$ & $-5.30 \%$ \\
\hline Dic-13 & $16,576.66$ & $16,087.12$ & $16,588.25$ & $15,703.79$ & $2.06 \mathrm{~B}$ & $3.05 \%$ \\
\hline Nov-13 & $16,086.41$ & $15,558.01$ & $16,174.51$ & $15,522.18$ & $1.82 \mathrm{~B}$ & $3.48 \%$ \\
\hline Oct-13 & $15,545.75$ & $15,132.49$ & $15,721.00$ & $14,719.43$ & $2.21 \mathrm{~B}$ & $2.75 \%$ \\
\hline Jul-13 & $15,129.67$ & $14,801.55$ & $15,709.58$ & $14,777.48$ & $2.37 \mathrm{~B}$ & $2.16 \%$ \\
\hline Set-13 & $14,810.31$ & $15,503.85$ & $15,658.43$ & $14,760.41$ & $2.33 \mathrm{~B}$ & $-4.45 \%$ \\
\hline Jul-13 & $15,499.54$ & $14,911.60$ & $15,634.32$ & $14,858.93$ & $2.57 \mathrm{~B}$ & $3.96 \%$ \\
\hline
\end{tabular}




\begin{tabular}{|c|c|c|c|c|c|c|}
\hline Fecha & Último & Apertura & Máximo & Mínimo & Vol. & $\%$ Var. \\
\hline Jun-13 & $14,909.60$ & $15,123.55$ & $15,340.09$ & $14,551.27$ & $2.93 \mathrm{~B}$ & $-1.36 \%$ \\
\hline May-13 & $15,115.57$ & $14,839.80$ & $15,542.40$ & $14,687.05$ & $2.77 \mathrm{~B}$ & $1.86 \%$ \\
\hline Abr-13 & $14,839.80$ & $14,578.54$ & $14,887.51$ & $14,434.43$ & $2.92 \mathrm{~B}$ & $1.79 \%$ \\
\hline Mar-13 & $14,578.54$ & $14,054.49$ & $14,585.10$ & $13,937.60$ & $2.55 \mathrm{~B}$ & $3.73 \%$ \\
\hline Feb-13 & $14,054.49$ & $13,860.58$ & $14,149.15$ & $13,784.01$ & $2.49 \mathrm{~B}$ & $1.40 \%$ \\
\hline Ene-13 & $13,860.58$ & $13,104.30$ & $13,969.99$ & $13,104.30$ & $2.79 \mathrm{~B}$ & $5.77 \%$ \\
\hline Dic-12 & $13,104.14$ & $13,027.73$ & $13,365.86$ & $12,883.89$ & $2.67 \mathrm{~B}$ & $0.60 \%$ \\
\hline Nov-12 & $13,025.58$ & $13,099.19$ & $13,290.75$ & $12,471.49$ & $2.68 \mathrm{~B}$ & $-0.54 \%$ \\
\hline Oct-12 & $13,096.46$ & $13,437.66$ & $13,661.87$ & $13,039.86$ & $2.47 \mathrm{~B}$ & $-2.54 \%$ \\
\hline Set-12 & $13,437.13$ & $13,092.15$ & $13,653.24$ & $12,977.09$ & $2.70 \mathrm{~B}$ & $2.65 \%$ \\
\hline Ago-12 & $13,090.84$ & $13,007.47$ & $13,330.76$ & $12,778.90$ & $2.27 \mathrm{~B}$ & $0.63 \%$ \\
\hline Jul-12 & $13,008.68$ & $12,879.71$ & $13,128.64$ & $12,492.25$ & $2.58 \mathrm{~B}$ & $1.00 \%$ \\
\hline Jun-12 & $12,880.09$ & $12,391.56$ & $12,898.94$ & $12,035.09$ & $2.92 \mathrm{~B}$ & $3.93 \%$ \\
\hline May-12 & $12,393.45$ & $13,214.16$ & $13,338.66$ & $12,311.56$ & $3.05 \mathrm{~B}$ & $-6.21 \%$ \\
\hline Abr-12 & $13,213.63$ & $13,211.36$ & $13,297.11$ & $12,710.56$ & $2.57 \mathrm{~B}$ & $0.01 \%$ \\
\hline Mar-12 & $13,212.04$ & $12,952.29$ & $13,289.08$ & $12,734.86$ & $3.20 \mathrm{~B}$ & $2.01 \%$ \\
\hline Feb-12 & $12,952.07$ & $12,632.76$ & $13,055.75$ & $12,632.76$ & $2.71 \mathrm{~B}$ & $2.53 \%$ \\
\hline Ene-12 & $12,632.91$ & $12,221.19$ & $12,841.95$ & $12,221.19$ & $2.98 \mathrm{~B}$ & $3.40 \%$ \\
\hline Dic-11 & $12,217.56$ & $12,046.21$ & $12,328.47$ & $11,735.19$ & $3.15 \mathrm{~B}$ & $1.43 \%$ \\
\hline Nov-11 & $12,045.68$ & $11,951.53$ & $12,187.51$ & $11,231.56$ & $3.40 \mathrm{~B}$ & $0.76 \%$ \\
\hline Oct-11 & $11,955.01$ & $10,912.10$ & $12,284.31$ & $10,404.49$ & $3.91 \mathrm{~B}$ & $9.54 \%$ \\
\hline Set-11 & $10,913.38$ & $11,613.30$ & $11,716.84$ & $10,597.14$ & $4.40 \mathrm{~B}$ & $-6.03 \%$ \\
\hline Ago-11 & $11,613.53$ & $12,144.22$ & $12,282.42$ & $10,604.07$ & $6.20 \mathrm{~B}$ & $-4.36 \%$ \\
\hline Jul-11 & $12,143.24$ & $12,412.07$ & $12,753.89$ & $12,083.45$ & $3.09 \mathrm{~B}$ & $-2.18 \%$ \\
\hline Jun-11 & $12,414.34$ & $12,569.41$ & $12,569.49$ & $11,862.53$ & $3.88 \mathrm{~B}$ & $-1.24 \%$ \\
\hline May-11 & $12,569.79$ & $12,810.16$ & $12,876.00$ & $12,309.52$ & $3.58 \mathrm{~B}$ & $-1.88 \%$ \\
\hline Abr-11 & $12,810.54$ & $12,321.02$ & $12,832.83$ & $12,093.89$ & $3.32 \mathrm{~B}$ & $3.98 \%$ \\
\hline Mar-11 & $12,319.73$ & $12,226.49$ & $12,383.46$ & $11,555.48$ & $3.85 \mathrm{~B}$ & $0.76 \%$ \\
\hline Feb-11 & $12,226.34$ & $11,892.50$ & $12,391.29$ & $11,892.50$ & $3.22 \mathrm{~B}$ & $2.81 \%$ \\
\hline Ene-11 & $11,891.93$ & $11,577.43$ & $12,020.52$ & $11,573.87$ & $3.68 \mathrm{~B}$ & $2.72 \%$ \\
\hline Dic-10 & $11,577.51$ & $11,007.23$ & $11,625.00$ & $11,007.23$ & $3.25 \mathrm{~B}$ & $5.19 \%$ \\
\hline Nov-10 & $11,006.02$ & $11,120.30$ & $11,451.53$ & $10,929.28$ & $3.81 \mathrm{~B}$ & $-1.01 \%$ \\
\hline Oct-10 & $11,118.49$ & $10,789.72$ & $11,247.60$ & $10,711.12$ & $3.79 \mathrm{~B}$ & $3.06 \%$ \\
\hline Jul-10 & $10,788.05$ & $10,016.01$ & $10,948.88$ & $10,016.01$ & $3.76 \mathrm{~B}$ & $7.72 \%$ \\
\hline Set-10 & $10,014.72$ & $10,468.82$ & $10,719.94$ & $9,936.62$ & $4.12 \mathrm{~B}$ & $-4.31 \%$ \\
\hline Jul-10 & $10,465.94$ & $9,773.27$ & $10,584.99$ & $9,614.32$ & $4.20 \mathrm{~B}$ & $7.08 \%$ \\
\hline Jun-10 & $9,774.02$ & $10,133.94$ & $10,594.16$ & $9,753.84$ & $4.94 \mathrm{~B}$ & $-3.58 \%$ \\
\hline May-10 & $10,136.63$ & $11,009.60$ & $11,177.67$ & $9,774.48$ & $5.61 \mathrm{~B}$ & $-7.92 \%$ \\
\hline Abr-10 & $11,008.61$ & $10,857.31$ & $11,258.01$ & $10,844.09$ & $4.24 \mathrm{~B}$ & $1.40 \%$ \\
\hline Mar-10 & $10,856.63$ & $10,326.10$ & $10,955.48$ & $10,326.10$ & $4.39 \mathrm{~B}$ & $5.15 \%$ \\
\hline Feb-10 & $10,325.26$ & $10,068.99$ & $10,438.55$ & $9,835.09$ & $4.28 \mathrm{~B}$ & $2.56 \%$ \\
\hline Ene-10 & $10,067.33$ & $10,430.69$ & $10,729.89$ & $10,043.75$ & $4.39 \mathrm{~B}$ & $-3.46 \%$ \\
\hline Dic-09 & $10,428.05$ & $10,343.82$ & $10,580.33$ & $10,235.63$ & $4.17 \mathrm{~B}$ & $0.80 \%$ \\
\hline Nov-09 & $10,344.84$ & $9,712.13$ & $10,495.61$ & $9,678.95$ & $3.81 \mathrm{~B}$ & $6.51 \%$ \\
\hline Oct-09 & $9,712.73$ & $9,711.60$ & $10,119.47$ & $9,430.08$ & $5.15 \mathrm{~B}$ & $0.00 \%$ \\
\hline Set-09 & $9,712.28$ & $9,492.32$ & $9,917.99$ & $9,252.93$ & $4.48 \mathrm{~B}$ & $2.27 \%$ \\
\hline Ago-09 & $9,496.28$ & $9,173.65$ & $9,630.20$ & $9,116.52$ & $4.04 \mathrm{~B}$ & $3.54 \%$ \\
\hline Jul-09 & $9,171.61$ & $8,447.53$ & $9,246.43$ & $8,087.19$ & $4.90 \mathrm{~B}$ & $8.58 \%$ \\
\hline Jun-09 & $8,447.00$ & $8,501.53$ & $8,877.93$ & $8,259.43$ & $5.52 \mathrm{~B}$ & $-0.63 \%$ \\
\hline May-09 & $8,500.33$ & $8,167.41$ & $8,591.93$ & $8,099.31$ & $6.73 \mathrm{~B}$ & $4.07 \%$ \\
\hline Abr-09 & $8,168.12$ & $7,606.13$ & $8,307.51$ & $7,483.87$ & 7.80B & $7.35 \%$ \\
\hline Mar-09 & $7,608.92$ & $7,056.48$ & $7,931.33$ & $6,469.95$ & $10.56 \mathrm{~B}$ & $7.73 \%$ \\
\hline Feb-09 & $7,062.93$ & $8,000.62$ & $8,315.07$ & $7,033.62$ & $7.13 \mathrm{~B}$ & $-11.72 \%$ \\
\hline Ene-09 & $8,000.86$ & $8,772.25$ & $9,088.06$ & $7,909.03$ & $6.26 \mathrm{~B}$ & $-8.84 \%$ \\
\hline Dic-08 & $8,776.39$ & $8,826.89$ & $9,026.41$ & $8,118.50$ & $5.70 \mathrm{~B}$ & $-0.60 \%$ \\
\hline Nov-08 & $8,829.04$ & $9,326.04$ & $9,653.95$ & $7,449.38$ & $6.26 \mathrm{~B}$ & $-5.32 \%$ \\
\hline Oct-08 & $9,325.01$ & $10,847.40$ & $10,882.52$ & $7,882.51$ & $8.31 \mathrm{~B}$ & $-14.06 \%$ \\
\hline Set- 08 & $10,850.66$ & $11,545.63$ & $11,790.17$ & $10,365.45$ & $6.30 \mathrm{~B}$ & $-6.00 \%$ \\
\hline Ago-08 & $11,543.55$ & $11,379.89$ & $11,867.11$ & $11,221.53$ & $3.58 \mathrm{~B}$ & $1.45 \%$ \\
\hline Jul-08 & $11,378.02$ & $11,344.64$ & $11,698.17$ & $10,827.71$ & $5.52 \mathrm{~B}$ & $0.25 \%$ \\
\hline \multirow[t]{2}{*}{ Máximo : } & $26,616.710$ & Mínimo : & $6,469.950$ & Diferencia : & 20146.76 & \\
\hline & Promedio: & $17,062.030$ & Var \%: & 113.840 & & \\
\hline
\end{tabular}

Recuperado de https://www.investing.com/indices/us-30historical-data 


\section{Anexo XI Riesgo País}

Tabla 92

Información histórica riesgo país

\begin{tabular}{|c|c|}
\hline PERIODO & PUNTOS RIESGO PAIS \\
\hline \multicolumn{2}{|l|}{$\boxminus 2008$} \\
\hline$\boxplus$ Trim.3 & 216.197 \\
\hline$\boxminus$ Trim.4 & 503.032 \\
\hline Oct & 500.273 \\
\hline Nov & 482.316 \\
\hline Dic & 523.682 \\
\hline \multicolumn{2}{|l|}{$\boxminus 2009$} \\
\hline$\boxplus$ Trim.1 & 430.349 \\
\hline$\oplus$ Trim.2 & 301.750 \\
\hline$\oplus$ Trim.3 & 248.121 \\
\hline$\boxminus$ Trim.4 & 188.015 \\
\hline Oct & 194.955 \\
\hline Nov & 190.286 \\
\hline Dic & 178.909 \\
\hline$\boxplus \mathbf{2 0 1 0}$ & 171.740 \\
\hline$\boxplus 2011$ & 190.795 \\
\hline$\boxplus 2012$ & 157.166 \\
\hline$\boxplus 2013$ & 157.295 \\
\hline$\boxplus 2014$ & 159.988 \\
\hline$\boxplus 2015$ & 201.467 \\
\hline$\boxplus 2016$ & 204.405 \\
\hline$\boxplus 2017$ & 131.708 \\
\hline$\boxplus 2018$ & 121.055 \\
\hline Promedio : & 170.81 \\
\hline Máximo: & 653.00 \\
\hline Mínimo: & 11.00 \\
\hline
\end{tabular}

Elaborado por JP Morgan. Recuperado de https://www.ambito.com/contenidos/riesgopais-peru.html 


\section{Anexo XII Inflación promedio anual de Estados Unidos y Perú}

Tabla 93

Inflación promedio anual de EEUU

\begin{tabular}{lcccccccccccc}
\hline AÑO & $\mathbf{2 0 1 8}$ & $\mathbf{2 0 1 7}$ & $\mathbf{2 0 1 6}$ & $\mathbf{2 0 1 5}$ & $\mathbf{2 0 1 4}$ & $\mathbf{2 0 1 3}$ & $\mathbf{2 0 1 2}$ & $\mathbf{2 0 1 1}$ & $\mathbf{2 0 1 0}$ & $\mathbf{2 0 0 9}$ & 2008 & PROMEDIO \\
\hline INFLACION & $1.91 \%$ & $2.11 \%$ & $2.07 \%$ & $0.73 \%$ & $0.76 \%$ & $1.50 \%$ & $1.74 \%$ & $2.96 \%$ & $1.50 \%$ & $2.72 \%$ & $0.09 \%$ & $1.64 \%$ \\
\hline
\end{tabular}

Recuperado de https://es.global-rates.com/estadisticas-economicas/inflacion/indice-de-preciosal-consumo/ipc/estados-unidos.aspx

Tabla 94

Inflación promedio anual de Perú

\begin{tabular}{lcccccccccccc}
\hline AÑO & $\mathbf{2 0 1 8}$ & $\mathbf{2 0 1 7}$ & $\mathbf{2 0 1 6}$ & $\mathbf{2 0 1 5}$ & $\mathbf{2 0 1 4}$ & $\mathbf{2 0 1 3}$ & $\mathbf{2 0 1 2}$ & $\mathbf{2 0 1 1}$ & $\mathbf{2 0 1 0}$ & $\mathbf{2 0 0 9}$ & $\mathbf{2 0 0 8}$ & PROMEDIO \\
\hline INFLACION & $2.16 \%$ & $2.15 \%$ & $2.87 \%$ & $3.49 \%$ & $2.51 \%$ & $2.96 \%$ & $2.65 \%$ & $4.74 \%$ & $2.08 \%$ & $0.25 \%$ & $6.65 \%$ & $2.96 \%$ \\
\hline
\end{tabular}

Recuperado de http://www.bcrp.gob.pe/publicaciones/reporte-de-inflacion.html 


\section{Anexo XIII Betas promedio por sector}

\section{Betas by Sector (US)}

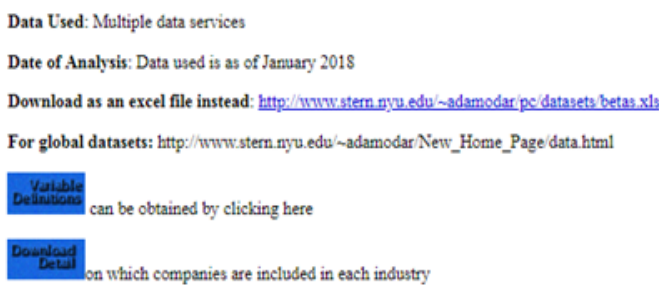

\begin{tabular}{|c|c|c|c|c|c|c|c|c|c|c|}
\hline Industry Name & Number of firms & Beta & D/E Ratio & $\begin{array}{l}\text { Effective } \\
\text { Tax rate }\end{array}$ & Unlevered beta & Cash/Firm value & Unlevered beta corrected for cash & Hilo Risk & Standard deviation of equity & $\begin{array}{c}\text { Standard deviation } \\
\text { in operating } \\
\text { income (last } 10 \\
\text { years) }\end{array}$ \\
\hline Advertising & 40 & 1.15 & $73.87 \%$ & $6.38 \%$ & 0.74 & \begin{tabular}{|l|l}
$5.80 \% 6$ \\
\end{tabular} & \begin{tabular}{|c|}
0.78 \\
\end{tabular} & 0.6310 & \begin{tabular}{|c|}
$80.95 \%$ \\
\end{tabular} & \begin{tabular}{|c|}
$15.30 \%$ \\
\end{tabular} \\
\hline Aerospace/Defense & 87 & 1.08 & $18.46 \%$ & $11.59 \%$ & 0.95 & $4.33 \%$ & 0.99 & 0.4893 & $49.06 \%$ & $12.87 \%$ \\
\hline Air Transport & 17 & 1.01 & $71.00 \%$ & $24.57 \%$ & 0.66 & $2.67 \%$ & 0.67 & 0.4148 & $40.20 \%$ & $92.29 \%$ \\
\hline Apparel & 51 & 1.02 & $34.18 \%$ & $10.35 \%$ & 0.81 & $5.16 \%$ & 0.85 & 0.4998 & $59.71 \%$ & $22.55 \%$ \\
\hline Auto \& Truck & 18 & 1.20 & $148.09 \%$ & $8.15 \%$ & 0.56 & $4.88 \%$ & 0.59 & 0.6051 & $38.59 \%$ & $209.62 \%$ \\
\hline Auto Parts & 62 & 1.04 & $28.30 \%$ & $7.71 \%$ & 0.85 & $7.19 \%$ & 0.92 & 0.5423 & $56.74 \%$ & $53.93 \%$ \\
\hline Bank (Money Center) & 11 & 0.64 & $157.26 \%$ & $27.31 \%$ & 0.29 & $9.94 \%$ & 0.32 & 0.1462 & $33.37 \%$ & NA \\
\hline Banks (Rezional) & 612 & 0.50 & $58.68 \%$ & $25.57 \%$ & 0.35 & $10.04 \%$ & 0.39 & 0.1809 & $32.03 \%$ & NA \\
\hline Beverage (Alcoholic) & 28 & 1.33 & $26.14 \%$ & $10.12 \%$ & 1.11 & $1.20 \%$ & 1.12 & 0.5387 & $50.14 \%$ & $32.58 \%$ \\
\hline Beverage (Soft) & 35 & 0.70 & $23.06 \%$ & $6.41 \%$ & 0.60 & $4.46 \%$ & 0.63 & 0.5850 & $45.33 \%$ & $13.03 \%$ \\
\hline Broadcasting & 27 & 1.12 & $112.17 \%$ & $17.18 \%$ & 0.60 & $7.16 \%$ & 0.65 & 0.4085 & $52.30 \%$ & $20.47 \%$ \\
\hline Brokerage \& Investment Banking & 42 & 1.24 & $219.92 \%$ & $14.56 \%$ & 0.46 & $14.84 \%$ & 0.54 & 0.4586 & $42.48 \%$ & $36.49 \%$ \\
\hline Bullding Materials & 39 & 1.11 & $21.46 \%$ & $23.34 \%$ & 0.95 & $3.30 \%$ & 0.99 & 0.3135 & $41.01 \%$ & $55.46 \%$ \\
\hline Business \& Consumer Services & 169 & 1.17 & $27.44 \%$ & $11.09 \%$ & 0.97 & $3.94 \%$ & 1.01 & 0.5442 & $49.45 \%$ & $19.49 \%$ \\
\hline Cable TV & 14 & 0.92 & $53.05 \%$ & $22.23 \%$ & 0.66 & $1.67 \%$ & 0.67 & 0.4154 & $36.33 \%$ & $35.61 \%$ \\
\hline Chemical (Basic) & 38 & 1.20 & $41.28 \%$ & $9.76 \%$ & 0.91 & $5.52 \%$ & 0.96 & 0.5297 & $59.39 \%$ & $40.60 \%$ \\
\hline Chemical (Diversified) & 7 & 2.03 & $27.19 \%$ & $11.66 \%$ & 1.69 & $6.07 \%$ & 1.79 & 0.3952 & $68.62 \%$ & $36.93 \%$ \\
\hline Chemical (Specialty) & 99 & 1.11 & $29.00 \%$ & $9.64 \%$ & 0.91 & $3.71 \%$ & 0.95 & 0.4598 & $59.69 \%$ & $20.92 \%$ \\
\hline Coal \& Related Energy & 30 & 1.25 & $45.41 \%$ & $4.94 \%$ & 0.93 & $10.94 \%$ & 1.04 & 0.5930 & $90.61 \%$ & $226.93 \%$ \\
\hline Computer Services & 111 & 1.10 & $30.83 \%$ & $9.40 \%$ & 0.89 & $5.49 \%$ & 0.94 & 0.5432 & $48.53 \%$ & $12.54 \%$ \\
\hline Computers/Peripherals & 58 & 1.01 & $18.17 \%$ & $5.03 \%$ & 0.89 & $4.44 \%$ & 0.93 & 0.5296 & $61.38 \%$ & $44.58 \%$ \\
\hline Office Equipment \& Services & 24 & 1.37 & $51.65 \%$ & $18.37 \%$ & 0.99 & $10.21 \%$ & 1.10 & 0.4977 & $49.66 \%$ & $18.32 \%$ \\
\hline Oil/Gas (Integrated) & 5 & 1.37 & $15.29 \%$ & $10.96 \%$ & 1.23 & $1.70 \%$ & 1.25 & 0.3307 & $20.21 \%$ & $61.70 \%$ \\
\hline Oil/Gas (Production and Exploration & 311 & 1.26 & $41.91 \%$ & $2.18 \%$ & 0.95 & $4.89 \%$ & 1.00 & 0.5978 & $78.88 \%$ & $109.36 \%$ \\
\hline Oil/Gas Distribution & 16 & 1.21 & $93.43 \%$ & $4.84 \%$ & 0.71 & $1.53 \%$ & 0.72 & 0.4481 & $62.79 \%$ & $30.48 \%$ \\
\hline Oliffield Sucs/Equip. & 130 & 1.23 & $30.98 \%$ & $5.27 \%$ & 0.99 & $5.93 \%$ & 1.06 & 0.5501 & $73.29 \%$ & $42.07 \%$ \\
\hline Packaging \& Container & 25 & 0.74 & $50.22 \%$ & $22.37 \%$ & 0.53 & $3.01 \%$ & 0.55 & 0.2952 & $27.67 \%$ & $17.89 \%$ \\
\hline Paper/Forest Products & 21 & 1.20 & $40.01 \%$ & $14.18 \%$ & 0.92 & $5.94 \%$ & 0.98 & 0.4787 & $56.81 \%$ & $34.50 \%$ \\
\hline Power & 61 & 0.50 & $76.36 \%$ & $20.31 \%$ & 0.32 & $1.75 \%$ & 0.32 & 0.2477 & $31.23 \%$ & $8.37 \%$ \\
\hline Precious Metals & 111 & 0.96 & $17.85 \%$ & $2.16 \%$ & 0.85 & $10.39 \%$ & 0.95 & 0.6903 & $91.35 \%$ & $72.71 \%$ \\
\hline Publishing \& Newspapers & 41 & 1.02 & $44.49 \%$ & $11.92 \%$ & 0.76 & $7.84 \%$ & 0.83 & 0.3562 & $54.14 \%$ & $13.55 \%$ \\
\hline R.E.IT. & 244 & 0.66 & $78.50 \%$ & $1.96 \%$ & 0.41 & $2.00 \%$ & 0.42 & 0.1817 & $32.14 \%$ & $30.62 \%$ \\
\hline Real Estate (Development) & 20 & 0.75 & $45.30 \%$ & $5.80 \%$ & 0.56 & $9.13 \%$ & 0.61 & 0.6155 & $44.27 \%$ & $136.76 \%$ \\
\hline Real Estate (General/Diversified) & 10 & 0.75 & $23.60 \%$ & $12.77 \%$ & 0.63 & $13.84 \%$ & 0.73 & 0.4356 & $41.07 \%$ & $204.05 \%$ \\
\hline Real Estate (Operations \& Services) & 60 & 1.02 & $46.71 \%$ & $8.82 \%$ & 0.75 & $5.89 \%$ & 0.80 & 0.5502 & $54.01 \%$ & $42.66 \%$ \\
\hline Recreation & 70 & 0.85 & $29.59 \%$ & $10.16 \%$ & 0.69 & $4.48 \%$ & 0.73 & 0.5329 & $50.85 \%$ & $47.63 \%$ \\
\hline Reingurance & 3 & 0.52 & $27.73 \%$ & $10.92 \%$ & 0.43 & $7.80 \%$ & 0.47 & 0.2463 & $18.99 \%$ & $52.13 \%$ \\
\hline Restaurant/Dining & 81 & 0.85 & $32.21 \%$ & $14.99 \%$ & 0.68 & $1.85 \%$ & 0.70 & 0.4220 & $48.41 \%$ & $18.74 \%$ \\
\hline Retail (Automotive) & 25 & 1.01 & $75.96 \%$ & $19.04 \%$ & 0.64 & $0.99 \%$ & 0.65 & 0.4279 & $42.62 \%$ & $35.82 \%$ \\
\hline Retail (Building Supply) & 8 & 0.86 & $17.86 \%$ & $15.36 \%$ & 0.75 & $1.21 \%$ & 0.76 & 0.4310 & $53.44 \%$ & $28.48 \%$ \\
\hline Retail (Distributors) & 92 & 1.15 & $45.58 \%$ & $14.20 \%$ & 0.85 & $2.07 \%$ & 0.87 & 0.4930 & $49.24 \%$ & $35.40 \%$ \\
\hline Retail (General) & 18 & 1.05 & $31.15 \%$ & $22.96 \%$ & 0.85 & $2.88 \%$ & 0.87 & 0.3620 & $49.94 \%$ & $6.34 \%$ \\
\hline Retail (Grocery and Food) & 14 & 0.71 & $83.68 \%$ & $21.04 \%$ & 0.43 & $1.61 \%$ & 0.44 & 0.4397 & $45.73 \%$ & $17.63 \%$ \\
\hline Retail (Online) & 61 & 1.18 & $11.41 \%$ & $7.57 \%$ & 1.09 & $3.21 \%$ & 1.12 & 0.5386 & $60.64 \%$ & $49.32 \%$ \\
\hline Retail (Special Lines) & 106 & 1.11 & $53.00 \%$ & $22.01 \%$ & 0.79 & $3.41 \%$ & 0.82 & 0.4805 & $59.68 \%$ & $22.09 \%$ \\
\hline Rubber\& Tires & 4 & 0.95 & $77.99 \%$ & $7.91 \%$ & 0.60 & $6.12 \%$ & 0.64 & 0.4488 & $56.24 \%$ & $42.44 \%$ \\
\hline Semiconductor & 72 & 1.17 & $13.10 \%$ & $8.04 \%$ & 1.07 & $7.82 \%$ & 1.16 & 0.3870 & $52.68 \%$ & $30.35 \%$ \\
\hline
\end{tabular}

Figura 101 Betas promedio por sector actualizado a enero 2018. Recuperado de http://pages.stern.nyu.edu/ adamodar/New_Home_Page/datafile/Betas.html 


\section{Anexo XIV Valores nutricionales de opciones de entradas para el menú saludable.}

Tabla 95

Tabla nutricional de opciones de entradas para el menú saludable.

\begin{tabular}{|c|c|c|c|c|c|c|c|c|c|c|}
\hline \multirow[b]{2}{*}{ Nro } & \multirow[b]{2}{*}{ Opción saludable de entradas } & \multirow[b]{2}{*}{ Porción } & \multicolumn{7}{|c|}{ Valores nutricionales por porción } & \multirow{2}{*}{$\begin{array}{l}\text { Porción } \\
\text { recomendada }\end{array}$} \\
\hline & & & Cal. & Prot. & Grasas & Carb. & Fibra & Col. (mg) & Sodio (mg) & \\
\hline 1 & $\begin{array}{l}\text { Omelette de claras de huevos, con } \\
\text { espinaca, jamon y champiñones }\end{array}$ & $130 \mathrm{gr}$ & 141.5 & 14.5 & 1.5 & 17.5 & 4.5 & 5 & 121.5 & 1 und. \\
\hline 2 & $\begin{array}{l}\text { Tortillas integrales de trigo rellenas de } \\
\text { pollo o carne }\end{array}$ & $150 \mathrm{gr}$. & 185 & 12.9 & 7.4 & 16.75 & 4 & 18.5 & 219.5 & 1 und. \\
\hline 3 & $\begin{array}{l}\text { Canastas de huevo rellenas de antipasto } \\
\text { de atun }\end{array}$ & $\begin{array}{l}40 \text { gr. clara de } \\
\text { huevo } \\
20 \text { gr antipasto }\end{array}$ & 58.6 & 4.2 & 4.3 & 0.8 & 0.2 & 1.6 & 84.1 & 2 und. \\
\hline 4 & $\begin{array}{l}\text { Crema de garbanzos con tallos de apio o } \\
\text { zanahoria }\end{array}$ & $\begin{array}{c}70 \text { gr. crema } \\
\text { de garbanzo } \\
4 \text { tallos de } \\
\text { zanahoria } \\
\end{array}$ & 130 & 5.2 & 9.8 & 27.5 & 5 & - & 95 & \\
\hline 5 & $\begin{array}{l}\text { Tortillas popeye rellenas de jamon bajo } \\
\text { en grasa, vainitas y ricota }\end{array}$ & $60 \mathrm{gr}$. & 105 & 10.15 & 6 & 2.65 & 1.6 & 5 & 125 & 2 und. \\
\hline 6 & Brochetas de pollo y cerdo a la parrilla & $70 \mathrm{gr}$. & 63.5 & 10.05 & 1.85 & 1.7 & 0.65 & 17.5 & 158.5 & 2 und. \\
\hline 7 & Ensalada griega con pollo & $150 \mathrm{gr}$. & 101 & 8 & 5.6 & 4.8 & 2 & 10 & 193.3 & 1 und. \\
\hline 8 & Lechugas rellenas de pollo coreano & $140 \mathrm{gr}$. & 208.6 & 19.6 & 6.5 & 17.9 & 2.7 & 35 & 259.8 & 1 und. \\
\hline 9 & $\begin{array}{l}\text { Ensalada tropical con vinagreta de } \\
\text { tamarindo }\end{array}$ & $150 \mathrm{gr}$. & 176 & 8.3 & 11.8 & 9.4 & 2.5 & 0 & 1.3 & 1 und. \\
\hline 10 & $\begin{array}{l}\text { Pimientos rellenos de ragú de carne o } \\
\text { pollo }\end{array}$ & $150 \mathrm{gr}$. & 117.2 & 16.6 & 3.6 & 8.5 & 4.1 & 33.8 & 81 & 1 und. \\
\hline 11 & Ensalada de atun ligera & $150 \mathrm{gr}$. & 330 & 23 & 10 & 35 & 6 & 12.2 & 214 & 1 und. \\
\hline 12 & Ceviche de pescado & $100 \mathrm{gr}$. & 99 & 13 & 0.6 & 103 & 0.56 & 25 & 0.42 & 1 und. \\
\hline 13 & Soltero de queso & $150 \mathrm{gr}$. & 257.5 & 8.03 & 7.36 & 39.5 & 6.2 & 0 & 250 & 1 und. \\
\hline 14 & $\begin{array}{l}\text { Ensalada de champiñones con vinagreta } \\
\text { de mostaza }\end{array}$ & $150 \mathrm{gr}$. & 215 & 9 & 11 & 20 & 10 & 0 & 30 & 1 und. \\
\hline 15 & Timbal de berenjenas y pollo & $140 \mathrm{gr}$. & 122.8 & 10.2 & 6.6 & 5.6 & 3.5 & 12.2 & 214 & 1 und. \\
\hline 16 & $\begin{array}{l}\text { Ensalada de pollo con calabacin con } \\
\text { vinagreta de maracuya }\end{array}$ & $150 \mathrm{gr}$. & 101 & 15 & 7 & 4 & 2 & 0 & 2.7 & 1 und. \\
\hline 17 & Tartar de pescado con palta & $100 \mathrm{gr}$. & 202.6 & 12.8 & 15.4 & 3.2 & 0.8 & 21 & 32 & \\
\hline 18 & $\begin{array}{l}\text { Ensalada de hortalizas con vinagreta de } \\
\text { mostaza }\end{array}$ & $150 \mathrm{gr}$. & 190 & 5 & 14 & 13 & 4 & 0 & 30 & 1 und. \\
\hline 19 & $\begin{array}{l}\text { Tequeños de avena rellenos de queso } \\
\text { blanco }\end{array}$ & $25 \mathrm{gr}$ & 83 & 4 & 3.8 & 8 & 1.3 & 10 & 120 & 2 und. \\
\hline 20 & $\begin{array}{l}\text { Ensalada de calabacin y zanahoria con } \\
\text { vinagreta thai }\end{array}$ & $150 \mathrm{gr}$. & 100 & 5 & 6 & 32 & 4 & 0 & 0 & 1 und. \\
\hline
\end{tabular}

Fuente: @SoySaludable en la cocina (Yorde, 2014) 


\section{Anexo XV Valores nutricionales de opciones de platos de fondo para el menú saludable.}

Tabla 96

Tabla nutricional de opciones de platos de fondo para el menú saludable (Parte 1).

\begin{tabular}{|c|c|c|c|c|c|c|c|c|c|c|}
\hline \multirow[b]{2}{*}{ Nro } & \multirow[b]{2}{*}{ Opción saludable de almuerzo } & \multirow[b]{2}{*}{ Porción } & \multicolumn{7}{|c|}{ Valores nutricionales por porción } & \multirow{2}{*}{$\begin{array}{l}\text { Porción } \\
\text { recomendad }\end{array}$} \\
\hline & & & Cal. & Prot. & Grasas & Carb. & Fibra & Col. (mg) & Sodio (mg) & \\
\hline \multirow{3}{*}{1} & $\begin{array}{l}\text { Croquetas de pollo o atun con avena } \\
\text { acompañado de quinua }\end{array}$ & & & & & & & & & \\
\hline & $\begin{array}{l}\text { - Croquetas de pollo o atun con } \\
\text { avena }\end{array}$ & $65 \mathrm{gr}$. & 117 & 11.4 & 2 & 13 & 2.2 & 20.2 & 42.3 & 3 und. \\
\hline & - Quinoa & $90 \mathrm{gr}$. & 136.8 & 4.9 & 2.1 & 24.5 & 2.5 & - & 5 & $1 / 2$ taza \\
\hline \multirow{3}{*}{2} & $\begin{array}{l}\text { Cordero marinado en yogurt } \\
\text { acompañado de lentejas }\end{array}$ & & & & & & & & & \\
\hline & - Cordero marinado en yogurt & $100 \mathrm{gr}$. & 180.6 & 31 & 5.4 & 1.6 & - & 105 & 141.1 & 1 und. \\
\hline & - Lentejas* & $120 \mathrm{gr}$. & 105.9 & 13.56 & 0.54 & 11.76 & 1.08 & - & 14.76 & 1 und. \\
\hline \multirow{3}{*}{3} & $\begin{array}{l}\text { Dados de pollo al curry acompañado } \\
\text { de arros integral }\end{array}$ & & & & & & & & & \\
\hline & - Pollo al curry & $120 \mathrm{gr}$. & 304.3 & 26.6 & 1.8 & 45.6 & 4.8 & 70.8 & 121.5 & 1 und. \\
\hline & - Arroz integral & $110 \mathrm{gr}$. & 166 & 3.4 & 0.6 & 30.5 & 104 & - & - & 1 und. \\
\hline \multirow{3}{*}{4} & $\begin{array}{l}\text { Filete de pescado a la mostaza } \\
\text { acompañado de vegetales grillados }\end{array}$ & & & & & & & & & \\
\hline & - Filete de pescado & $120 \mathrm{gr}$. & 227.5 & 29.5 & 8.7 & 7.6 & 4.4 & 72 & 285.6 & 1 und. \\
\hline & - Vegetales grillados & $200 \mathrm{gr}$. & 55 & 3.9 & 0.6 & 8.5 & 7.2 & - & 16.7 & 1 taza \\
\hline \multirow{4}{*}{5} & $\begin{array}{l}\text { Lomito al pistacho acompañado de } \\
\text { chips de camote y yuca }\end{array}$ & & & & & & & & & \\
\hline & - Lomito al pistacho & $150 \mathrm{gr}$. & 231 & 30 & 12 & 1.2 & 1.06 & 52.5 & - & 1 und. \\
\hline & - Chips de camote & $50 \mathrm{gr}$. & 67.9 & 0.8 & 0.3 & 15.5 & 3.8 & - & 2 & 1 und. \\
\hline & - Chips de yuca & $50 \mathrm{gr}$. & 71.5 & 0.6 & 0.1 & 17.1 & 1.3 & - & 7.5 & 1 und. \\
\hline \multirow{3}{*}{6} & $\begin{array}{l}\text { Linguini integrales de mariscos con } \\
\text { tomates y ají dulce }\end{array}$ & & & & & & & & & \\
\hline & - Salsa de mariscos & $120 \mathrm{gr}$. & 146.3 & 25 & 1.7 & 7.8 & 2.3 & 74.3 & 497 & 1 und. \\
\hline & - Pasta integral & $150 \mathrm{gr}$. & 156.6 & 6.8 & 0.6 & 31 & 5.4 & - & 192 & 1 und. \\
\hline \multirow{3}{*}{7} & $\begin{array}{l}\text { Lomo de cerdo al horno acompañado } \\
\text { de camotes horneadas }\end{array}$ & & & & & & & & & \\
\hline & - Lomo de cerdo & $150 \mathrm{gr}$. & 221 & 32.2 & 8.6 & 3.8 & 0.07 & 93 & 172 & 1 und. \\
\hline & - Camotes al horno & $100 \mathrm{gr}$. & 83 & 1.9 & 0.1 & 18.6 & 2.3 & - & 0.8 & 1 und. \\
\hline
\end{tabular}


Tabla 97

Tabla nutricional de opciones de platos de fondo para el menú saludable (Parte 2).

\begin{tabular}{|c|c|c|c|c|c|c|c|c|c|c|}
\hline \multirow[b]{2}{*}{ Nro } & \multirow[b]{2}{*}{ Opción saludable de almuerzo } & \multirow[b]{2}{*}{ Porción } & \multicolumn{7}{|c|}{ Valores nutricionales por porción } & \multirow{2}{*}{$\begin{array}{l}\text { Porción } \\
\text { recomendada }\end{array}$} \\
\hline & & & Cal. & Prot. & Grasas & Carb. & Fibra & Col. (mg) & Sodio (mg) & \\
\hline \multirow{3}{*}{8} & $\begin{array}{l}\text { Pollo horneado en costra de } \\
\text { especias sobre cama de quinoa }\end{array}$ & & & & & & & & & \\
\hline & - Pollo horneado & $165 \mathrm{gr}$. & 123.3 & 24.8 & 1.1 & 3.5 & - & 105.5 & 107.3 & 1 und. \\
\hline & - Quinoa & $90 \mathrm{gr}$. & 136.8 & 4.9 & 2.1 & 24.5 & 2.5 & - & 5 & $1 / 2$ taza \\
\hline \multirow{3}{*}{9} & $\begin{array}{l}\text { Pechugas de pollo relle nas de ricota } \\
\text { de almendras y espinaca } \\
\text { acompañado de ratatouille }\end{array}$ & & & & & & & & & \\
\hline & - Pechuga de pollo rellena & $175 \mathrm{gr}$. & 137 & 21.6 & 5.1 & 0.8 & 1.01 & 70.9 & 74.3 & 1 und. \\
\hline & - Ratatouille & $200 \mathrm{gr}$. & 48.6 & 3.3 & 0.6 & 7.5 & 4.8 & - & 5.4 & 1 und. \\
\hline 10 & $\begin{array}{l}\text { Pizza crocante de avena con } \\
\text { vegetales al grill, pechuga de pavo, } \\
\text { espinaca y tomates cherry }\end{array}$ & $190 \mathrm{gr}$. & 462.5 & 20.3 & 21.3 & 47.7 & 9.5 & 16.8 & 297 & 1 und. \\
\hline \multirow{3}{*}{11} & $\begin{array}{l}\text { Pescado glaseado en salsa de } \\
\text { naranja acompañado de pure de } \\
\text { coliflor }\end{array}$ & & & & & & & & & \\
\hline & - Pescado glaseado & $180 \mathrm{gr}$. & 390 & 34 & 25.2 & 6.9 & - & 63 & 92 & 1 und. \\
\hline & - Pure de coliflor & $150 \mathrm{gr}$. & 35.5 & 3.45 & 0.45 & 4.4 & 5.5 & - & 23.7 & 1 und. \\
\hline 12 & $\begin{array}{l}\text { Torta de platano rellena de pollo o } \\
\text { carne molida (se pue de sustituir el } \\
\text { platano por camote, colifor o papa) }\end{array}$ & $350 \mathrm{gr}$. & 327 & 21.8 & 5.6 & 47 & 4 & 29.3 & 370 & 1 und. \\
\hline \multirow{3}{*}{13} & $\begin{array}{l}\text { Guiso de pollo acompañado de } \\
\text { quinoa }\end{array}$ & & & & & & & & & \\
\hline & - Guiso de pollo & $200 \mathrm{gr}$. & 99 & 16 & 0.5 & 7.5 & 1.8 & 37 & 217 & 1 und. \\
\hline & - Quinoa & $90 \mathrm{gr}$. & 136.8 & 4.9 & 2.1 & 24.5 & 2.5 & - & 5 & $1 / 2$ taza \\
\hline \multirow{3}{*}{14} & $\begin{array}{l}\text { Hamburguesas de pollo y e spinaca } \\
\text { acompañado de arroz integral }\end{array}$ & & & & & & & & & \\
\hline & - Hamburguesas & $60 \mathrm{gr}$. & 105 & 12.2 & 5.4 & 1.4 & 0.8 & 77 & 92.6 & 3 und. \\
\hline & - Arroz integral & $110 \mathrm{gr}$. & 166 & 3.4 & 0.6 & 30.5 & 104 & - & - & 1 und. \\
\hline
\end{tabular}

Fuente: @SoySaludable en la cocina (Yorde, 2014) 
Tabla 98

Tabla nutricional de opciones de platos de fondo para el menú saludable (Parte 3).

\begin{tabular}{|c|c|c|c|c|c|c|c|c|c|c|}
\hline \multirow[b]{2}{*}{ Nro } & \multirow[b]{2}{*}{ Opción saludable de almuerzo } & \multirow[b]{2}{*}{ Porción } & \multicolumn{7}{|c|}{ Valores nutricionales por porción } & \multirow{2}{*}{$\begin{array}{c}\text { Porción } \\
\text { recomendada }\end{array}$} \\
\hline & & & Cal. & Prot. & Grasas & Carb. & Fibra & Col. (mg) & Sodio $(\mathrm{mg})$ & \\
\hline \multirow{3}{*}{15} & $\begin{array}{l}\text { Ensalada asiatica de mariscos } \\
\text { acompañada de croûtons }\end{array}$ & & & & & & & & & \\
\hline & - Ensalada asiática & $300 \mathrm{gr}$. & 230.6 & 27.6 & 6.1 & 14 & 6.6 & 47.5 & 488.7 & 1 und. \\
\hline & - Croûtons & $30 \mathrm{gr}$. & 122.1 & 3.6 & 2.1 & 22.2 & - & - & 209.4 & 1 und. \\
\hline \multirow{3}{*}{16} & $\begin{array}{l}\text { Canoas de calabacin rellenas de atun } \\
\text { acompañados de quinoa }\end{array}$ & & & & & & & & & \\
\hline & -Canoas de calabacin & $150 \mathrm{gr}$. & 63.8 & 10 & 0.5 & 4.8 & 1.4 & 18 & 107 & 2 und. \\
\hline & - Quinoa & $90 \mathrm{gr}$. & 136.8 & 4.9 & 2.1 & 24.5 & 2.5 & - & 5 & $1 / 2$ taza \\
\hline \multirow{3}{*}{17} & $\begin{array}{l}\text { Pechuga de pollo a la plancha } \\
\text { acompañada de bastones de camote }\end{array}$ & & & & & & & & & \\
\hline & - Pechuga de pollo & $150 \mathrm{gr}$. & 111 & 25 & 3.6 & 0 & 0 & 84.4 & 224 & 1 und. \\
\hline & - Bastones de camote & $100 \mathrm{gr}$. & 83 & 1.9 & 0.1 & 18.6 & 2.3 & - & 0.8 & 1 und. \\
\hline \multirow{3}{*}{18} & $\begin{array}{l}\text { Ensalada griega con pollo } \\
\text { acompañada de pan pita integral }\end{array}$ & & & & & & & & & \\
\hline & - Ensalada griega & $150 \mathrm{gr}$. & 101 & 8 & 5.6 & 4.8 & 2 & 10 & 193.3 & 1 und. \\
\hline & - Pan pita integral & $38 \mathrm{gr}$. & 96 & 4.6 & 0.8 & 18 & 2.8 & 0 & 150 & 2 und. \\
\hline \multirow{3}{*}{19} & $\begin{array}{l}\text { Pimientos rellenos de ragú de carne } \\
\text { o pollo acompañado de papitas } \\
\text { blancas horneadas (con cascara) }\end{array}$ & & & & & & & & & \\
\hline & - Pimientos rellenos & $150 \mathrm{gr}$. & 117.2 & 16.6 & 3.6 & 8.5 & 4.1 & 33.8 & 81 & 2 und. \\
\hline & - Papas horneadas & $100 \mathrm{gr}$. & 94 & 2.1 & 0.15 & 21.08 & 2.1 & - & 7 & 1 und. \\
\hline \multirow{3}{*}{20} & $\begin{array}{l}\text { Pollo al horno con limon y romero } \\
\text { acompañado de vegetales grillados }\end{array}$ & & & & & & & & & \\
\hline & - Pollo al horno & $300 \mathrm{gr}$. & 112.3 & 20 & 0.19 & 7.7 & 1 & 62 & 139.3 & 1 und. \\
\hline & - Vegetales grillados & $200 \mathrm{gr}$. & 55 & 3.9 & 0.6 & 8.5 & 7.2 & - & 16.7 & 1 taza \\
\hline
\end{tabular}

Fuente: @SoySaludable en la cocina (Yorde, 2014) 


\section{Referencias}

Agueda, E. T. (1997). Principios de Marketing. (1 ed.) Madrid, España: Esic Editorial

Andrade, A.M. (2da quincena - noviembre 2016). Análisis del ROA, ROE y ROI. Contadores y Empresas. (170), p. 59-61.

Arellano, R. (2017). Mucho más que tener: Latir 1 ed.). Lima, Perú: Grupo Planeta

Asociación Peruana de Empresas de Investigación de Mercados (APEIM). (2018). Niveles socioeconómicos 2018. Recuperado de http://www.apeim.com.pe/

Burbano, J. E. (2005). Presupuestos Enfoque de gestión, planeación y control de recursos (3 ed.). Cali, Colombia: McGraw-Hill.

Cámara de Comercio e Industria Arequipa (CCIA). (2018). Indicadores Económicos IV Trimestre 2017. Recuperado de http://www.camara-arequipa.org.pe/

Cámara de Comercio e Industria Arequipa (CCIA). (2018). Informe de Coyuntura - marzo 2018 Perú: panorama actual. Recuperado de http://www.camara-arequipa.org.pe/

Cámara de Comercio e Industria Arequipa (CCIA). (2018). Informe de Coyuntura - agosto 2018 MIPYMES en el Perú. Recuperado de http://www.camara-arequipa.org.pe/

Castro, C. (6 de abril de 2018). Mapamundi de la obesidad: así es el índice de masa corporal medio en cada país. Recuperado de https://www.elindependiente.com/vidasana/2018/04/06/mapamundi-de-la-obesidad/

Chiavenato, I. (2007). Administración de recursos humanos - El capital humano de las organizaciones (8 ed.). México D.F., México: McGraw-Hill Interamericana. 
Congreso de la República. (2013). Ley 30021. Recuperado de http://www4.congreso.gob.pe/ pvp/leyes/ley30021.pdf

David, F. R. (2013). Conceptos de administración estratégica (14 ed.). Juarez, México: Pearson Educación de México.

Eguren, F. (Agosto de 2015). ¿Los industriales vs. la alimentación saludable? La Revista Agraria (176), p.6-9.

En Arequipa 3 de cada 10 personas padecen de sobrepeso. (8 de octubre de 2016). Diario Sin Fronteras. Recuperado de http://www.diariosinfronteras.pe/2016 /10/08/en-arequipa-3-decada-10-personas-padecen-de-sobrepeso/

Entérate sobre el avance de la alimentación saludable en el Perú. (04 de agosto de 2017). El Comercio. Recuperado de https://elcomercio.pe/suplementos/comercial/educacionnutricion/enterate-sobre-avance-alimentacion-saludable-peru-1002916

Ezzati, M. (2016). Trends in adult body-mass index in 200 countries from 1975 to 2014: a pooled analysis of 1698 population-based measurement studies with 19.2 million participants. The Lancet, 387(10026), 1377-1396. doi: 10.1016/S0140-6736(16)30054-X

EY Perú. (2016). Guía de Negocios e Inversión en el Perú 2016/2017. Recuperado de https://www.ey.com/

Gitman L. J. (2009). Fundamentos de inversiones (10 ed.). Juarez, México: Pearson Educación de México.

Gitman, L. J. y Zutter, C. J. (2012). Principios de administración financiera (12 ed.). Juarez, México: Pearson Educación de México. 
Horngren, C.T. (2012). Contabilidad de costos. Un enfoque gerencial (14 ed.). Juarez, Mexico: Pearson Educación de México.

Huerta, E. (12 de marzo de 2018). Más de la mitad de los peruanos somos gordos o supergordos. El Comercio. Recuperado de https://elcomercio.pe/tecnologia/ciencias/salud-peru-tercerpais-obesos-region-noticia-503786

Instituto Nacional de Estadística e Informática (INEI). Metodología de Cálculo del Producto Bruto Interno Anual. Recuperado de https://www.inei.gob.pe/

Instituto Nacional de Estadística e Informática (INEI). (25 de julio de 2018). Negocios de restaurantes aumentó en 3,11\% y sumó 14 meses de crecimiento continuo. Recuperado de https://www.inei.gob.pe/

Instituto Nacional de Estadística e Informática (INEI). (21 de febrero de 2018). Negocios de restaurantes (servicios de comidas y bebidas) crecieron 1,94\% en diciembre de 2017. Recuperado de https://www.inei.gob.pe/

Instituto Nacional de Estadística e Informática (INEI). (2017). Perú: Características Económicas y Financieras de las Empresas de Servicios, 2016. Recuperado de https://www.inei.gob.pe/ Instituto Nacional de Estadística e Informática (INEI). (2018). Producción Nacional - diciembre 2017 (Informe Técnico No 02). Recuperado de https://www.inei.gob.pe/

Instituto Nacional de Estadística e Informática (INEI). (diciembre 2018). Arequipa - Resultados definitivos, Población económicamente activa, 2017.

Kotler, P. y Armstrong, G. (2013). Fundamento de Marketing (11 ed.). Juarez, México: Pearson Educación de México. 
Ley de alimentación saludable: ¿Por qué lleva 5 años sin ser implementada? (16 de junio de 2018). El Comercio. Recuperado https://elcomercio.pe/peru/ley-alimentacion-saludableley-lleva-5-anos-implementada-noticia-520185

Lima Orgánica: "el mercado de comida saludable ha evolucionado favorablemente por la demanda del público". (05 de abril de 2017). Gestión. Recuperado de https://gestion.pe/tendencias/lima-organica-mercado-comida-saludable-evolucionadofavorablemente-demanda-publico-132445

McDaniel C. Y Gates R. (2016). Investigación de Mercados (10 ed.). Mexico D.F., Mexico: Cengage Learning Editores.

Mazon, L., Villao, D., Núñez, W. y Serrano, M. (junio 2017). Análisis de punto de equilibrio en la toma de decisiones de un negocio: caso Grand Bazar Riobamba-Ecuador. Revista de Estrategias del Desarrollo Empresarial. Tres (8), p. 14-24.

German De B. (21 de Abril de 2014). Mermas y desperdicios gastronómicos [Mensaje en un blog]. Recuperado de http://mermasydesperdicios.blogspot.com/2014/04/productoporcentaje-abadejo-55.html

Ministerio de Salud - Centro Nacional de Alimentación y Nutrición. (2013). Informe Ejecutivo Arequipa - Situación Nutricional. Recuperado de www.ins.gob.pe/

Obesidad alcanza a más del 50\% de la población peruana. (06 de marzo de 2018). El Comercio. Recuperado de https://elcomercio.pe/peru/obesidad-alcanza-50-poblacion-peruana-noticia502266 
Octágonos se impusieron, pero $65 \%$ de los peruanos dice que semáforos eran más entendibles. (09 de julio de 2018). Gestión. Recuperado de https://gestion.pe/economia/octagonosimpusieron-65-peruanos-dice-semaforos-entendibles-237882

Organización Mundial de la Salud. (16 de febrero de 2018). Obesidad y sobrepeso. Recuperado de http://www.who.int/es/news-room/fact-sheets/detail/obesity-and-overweight

Senthilingam, M. (14 de julio de 2017). Estos son los países más obesos del mundo. Recuperado de https://cnnespanol.cnn.com/2017/07/14/estos-son-los-paises-mas-obesos-del-mundo/

Perú: niveles de sobrepeso y obesidad ya son un problema de salud pública. (20 de junio de 2017). La República. Recuperado de https://larepublica.pe/sociedad/ 1053729-peruniveles-de-sobrepeso-y-obesidad-ya-son-un-problema-de-salud-publica

Pickadeli, primer 'fast food' peruano de comida saludable. (26 de enero de 2017). El Comercio. Recuperado de https://elcomercio.pe/gastronomia/nutricion/pickadeli-primer-fast-foodperuano-comida-saludable-161192

Por una alimentación saludable. (25 de junio de 2017). El Peruano. Recuperado de https://elperuano.pe/noticia-por-una-alimentacion-saludable-57038.aspx

Porret, M. (2014). Gestión de personas: Manual para la gestión del capital humano en las organizaciones (6 ed.). Madrid, España: ESIC Editorial.

Porter, M. (2008). Estrategia competitiva: Técnicas para el análisis de los sectores industriales y de la competencia (1 ed. revisada). México DF, México: Grupo Editorial Patria SA.

ProInversión. (2017). Resultados macroeconómicos. Recuperado de https://www.investinperu.pe 
Rengifo, T. (29 de marzo de 2017). Tendencias del mercado de lo natural. La República. Recuperado de https://larepublica.pe/marketing/860310-tendencias-del-mercado-de-lonatural

Sapag, N. (2011) Proyectos de Inversión. Formulación y evaluación (2 ed.). Santiago de Chile, Chile: Pearson Educación de Chile.

Sapag, N. y Sapag, R. (2008). Preparación y evaluación de proyectos (5 ed.). Bogota, D.C., Colombia: McGraw-Hill Interamericana

Superintendencia Nacional de Administración Tributaria. (09 de marzo de 2017). Negocio en marcha - Si tengo trabajadores ¿Qué obligaciones y beneficios laborales existen? Recuperado de http://emprender.sunat.gob.pe/

Tendencia mundial: marcas al servicio del consumidor. (2018). COMEBIEN.PE. Recuperado de http://comebien.pe/tendencia-mundial-marcas-al-servicio-del-consumidor/

Yorde, S. (2015). @SoySaludable en la cocina (5 ed.). Caracas, Venezuela: Editorial Arte. 